Sous la direction de

Michel Espagne, Hamlet Isaxanli

et Shahin Mustafayev

\title{
LA MONTAGNE DES LANGUES ET DES PEUPLES
} Imbrications et transferts dans l'espace du Caucase

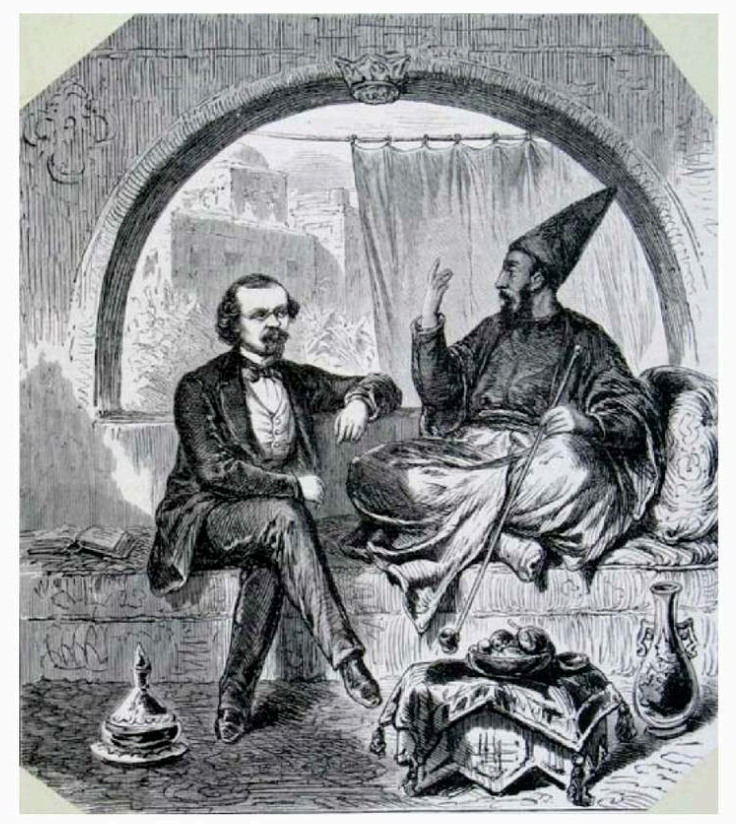




\section{La Montagne des langues et des peuples}

Imbrications et transferts culturels dans l'espace Caucase

Michel Espagne, Hamlet Isaxanli et Shalin Mustafayev (dir.)

DOI : 10.4000/books.demopolis.3182

Éditeur : Demopolis

Année d'édition : 2019

Date de mise en ligne : 1 octobre 2020

Collection : Quaero

ISBN électronique : 9782354571719

\section{Dronatition}

http://books.openedition.org

\section{Édition imprimée}

ISBN : 9782354571597

Nombre de pages : 496

\section{Référence électronique}

ESPAGNE, Michel (dir.) ; ISAXANLI, Hamlet (dir.) ; et MUSTAFAYEV, Shalin (dir.). La Montagne des langues et des peuples: Imbrications et transferts culturels dans l'espace Caucase. Nouvelle édition [en ligne]. Paris : Demopolis, 2019 (généré le 10 décembre 2020). Disponible sur Internet : <http:// books.openedition.org/demopolis/3182>. ISBN : 9782354571719 . DOI : https://doi.org/10.4000/ books.demopolis.3182. 


\section{Sous la direction de}

Michel Espagne, Hamlet Isaxanli

et Shahin Mustafayev

\section{LA MONTAGNE \\ DES LANGUES \\ ET DES PEUPLES}

Imbrications et transferts dans l'espace du Caucase

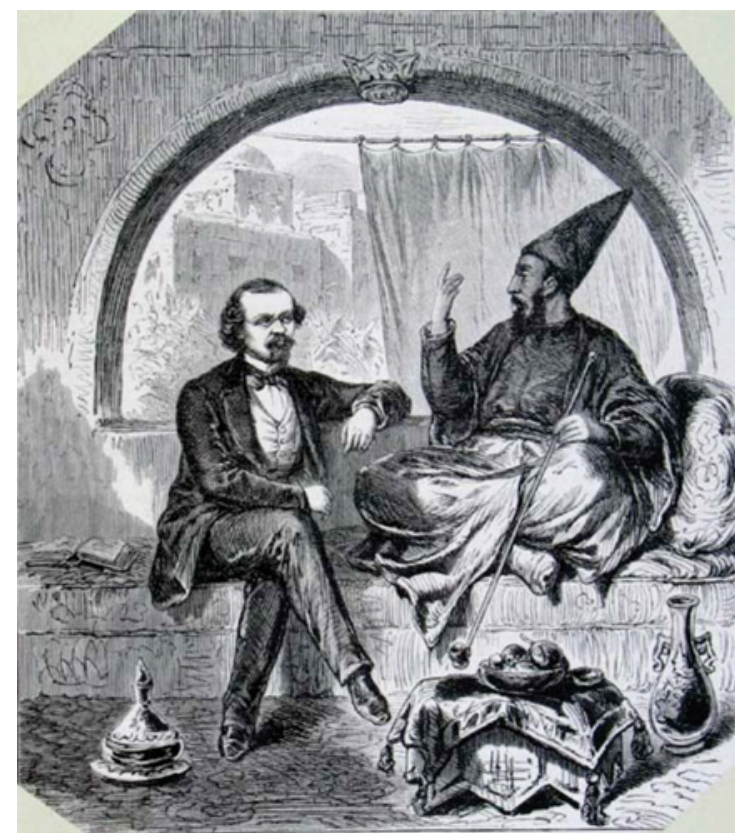






\section{LA MONTAGNE DES LANGUES ET DES PEUPLES}

Imbrications et transferts dans l'espace du Caucase 


\section{«QUAERO »}

Collection dirigée par Jean-Christophe Tamisier

\section{Voir aussi parmi nos parutions:}

Savoir traditionnel et pratiques magiques sur la route de la Soie, Yu Xin

Transferts culturels en Sibérie. De l'Altaï à la Iakoutie, Pavel Alexeiev, Ekaterina Dmitrieva, Michel Espagne (dir.)

Illustration de couverture:

Friedrich Bodenstedt et Mirza Schaffy

(c) Collections d'histoire théâtrale et musée Hebbel, musées du Schleswig-Holstein et de Hambourg.

(C) Éditions Demopolis, 2019

67, rue Saint-Jacques

75005 Paris

www.demopolis.fr

ISBN : 978-2-35457-159-7 


\section{sous la direction de \\ MICHEL ESPAGNE, HAMLET ISAXANLI, \\ SHAHIN MUSTAFAYEV}

\section{LA MONTAGNE DES LANGUES ET DES PEUPLES}

\section{Imbrications et transferts dans l'espace du Caucase}

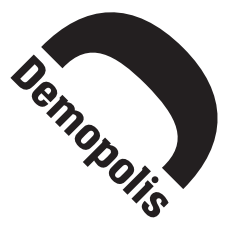


Cet ouvrage a été publié avec le soutien du laboratoire d'excellence TransferS (programme Investissements d'avenir ANR-10-IDEX-0001-02 PSL* et ANR-10-LABX-0099)

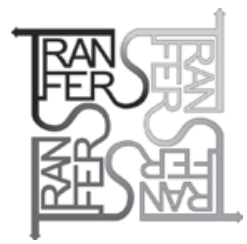




\section{Les auteurs}

FARDA ASADov - Directeur du Département d'histoire et d'économie des pays arabes, Institut d'études orientales Z.M. Buniyatov, Académie des sciences d'Azerbaïdjan.

IRADA BAGHIROva - Docteur en sciences historiques, Institut d'histoire A.A. Bakikhanov, Académie des sciences d'Azerbaïdjan.

SOPHIE BASch - Professeur de littérature française à l'université de Paris-Sorbonne.

Nino Chikovani - Professeur, directrice de l'Institut d'études culturelles auprès de la Faculté des humanités, université d’État Ivane Javakhishvili, de Tbilissi, Géorgie.

ANCA DAN - Chargée de recherche au CNRS, UMR Archéologie d'Orient et d'Occident, labex TransferS.

Georges DePeyrot - Directeur de recherche au CNRS, UMR Archéologie d'Orient et d'Occident, labex Transfers.

Haji Murad Donogo - Docteur en sciences historiques, directeur adjoint du musée national de la République du Daghestan.

Michel ESPAGNE - Directeur de recherche au CNRS, UMR Pays germaniques, transferts culturels, directeur du labex TransferS.

SVETLANA GoRSHENINA - Dr habil., maître de conférences associée au Collège de France.

RAfael Huseynov - Prof. Dr, Directeur du musée national de littérature d'Azerbaïdjan Nizami de Gandja, Académie des sciences d'Azerbaïdjan. 
HAMLET IsAXANLI - Fondateur de l'université Khazar de Bakou, comité des directeurs et membre fondateur de l'Académie eurasienne.

SERVANNE Jollivet - Chargée de recherche au CNRS, UMR Pays germaniques, transferts culturels, labex Transfers.

Boris Magomet-Gireevich Kharsiev - Directeur du Département d'ethnologie, Institut de recherche ingouche Chakh Ahriev, république d'Ingouchie.

BERTILLE LYONNET - Directrice de Recherches au CNRS, UMR 7192.

SAID MushahajIyev - Maître de conférences à l'université technologique de Maïkop, république d'Adyguée.

Shahin Mustafayev - Prof. Dr, directeur adjoint de l'institut d'études orientales Z.M. Buniyatov, Académie des sciences de l'Azerbaïdjan.

IRINA NATCHKEBIA - Directrice du Département d'histoire moderne et prémoderne du Moyen-Orient, Institut d'études orientales Tsérétéli, université d'État Ilia (Géorgie).

DANIEl PetiT - Prof. Dr., École normale supérieure \& École pratique des hautes études, Paris.

Nino Pirthskalava - Prof. Dr, Institut de littérature comparée auprès de l'université d'État Ilia (Géorgie).

HeATHER S. SonNTAG - Centre d'étude de la Russie, de l'Europe orientale et de l'Asie centrale, université Wisconsin-Madison, États-Unis. 


\section{Introduction}

Les cultures du Caucase sont trop souvent envisagées comme une juxtaposition de constructions identitaires, de nations et de langues. Les Géorgiens ne sont pas des Azerbaïdjanais ni des Ossètes. Les Arméniens ne sont pas des Tchétchènes. Mosaïque de langues et de nations attachées à leurs traditions, l'espace du Caucase peut aussi être abordé, dans la très longue durée, du point de vue des imbrications entre cultures créatrices de nouvelles formes. Même si l'état de la protohistoire n'autorise pas encore de réponse définitive, il est clair que des liens ont existé entre les cultures de la Mésopotamie et le Caucase. Une rencontre organisée à l'université Khazar de Bakou a servi de point de départ à l'étude des métissages caractéristiques de l'espace caucasien dans la longue durée, de l'Antiquité à la fin de la période soviétique. Le royaume de Géorgie a repris à l'administration persane ses catégories administratives. S'il n'est pas faux de dire que les Azerbaidjanais sont un peu héritiers de la culture persane, que les Arméniens et les Géorgiens ont eu longtemps une histoire commune et que beaucoup de cosaques ont une ascendance tcherkesse, tatare, caucasienne, que les peuples du Nord-Caucase ont été tantôt musulmans, tantôt chrétiens orthodoxes, tantôt adeptes de religions païennes, que des implantations de populations juives ou kurdes ont toujours joué aussi un rôle important, ces métissages ne peuvent-ils être l'objet d'une histoire spécifique, un biais pour aborder la complexité de la région? Si l'on observe chacune des nations du Caucase ou de façon plus réaliste un éventail de ces cultures, dont certaines, comme les Oubykhs chers à Georges Dumézil, ont disparu, on remarque qu'elles font toutes apparaître, même celles qui semblent avoir misé longtemps sur un isolement dans les montagnes comme les Tchétchènes ou les Ingouches, des relations structurantes avec leurs voisins ou avec les 
nations qui ont, des Byzantins aux Persans, des Grecs aux Mongols occupé un temps le Caucase. Le Caucase a été l'un des itinéraires empruntés par la "route de la Soie » et se trouve de ce fait marqué par cette voie d'échanges. Il a été en partie peuplé par les Khazars et les Seldjoukides puis par des populations venues d'Asie centrale, envoyées par Gengis Khan ou Tamerlan. Il a fait partie du mystérieux Empire khazar et a connu l'ordre de l'Empire mongol. Envahis par les Grecs, les Romains, les Byzantins, par des Mongols turcisés hésitant longtemps entre christianisme et islam, avec quelques épisodes bouddhistes moins importants, la région a combiné les nombreuses strates culturelles dont elle est héritière. Mais la patrie de Prométhée et de Médée, la Colchide dépositaire de la Toison d'or, a aussi été un domaine de pénétration de l'hellénisme et relève de ce que l'on peut désigner comme l'hellénisme pontique. Si l'étude du Caucase du point de vue des transferts diachroniques implique une relation à la mythologie antique, elle implique aussi de garder à l'esprit une strate zoroastrienne qui perdure jusqu'au XIX ${ }^{\mathrm{e}}$ siècle. Les simples dépôts de monnaies anciennes révèlent la complexité des échanges commerciaux dont le Caucase a été le théâtre depuis l'Antiquité.

Parler des transferts culturels dans le Caucase suppose bien sûr de prendre d'abord une perspective linguistique. La soixantaine de langues parlées dans ces montagnes correspondent à autant de groupes ethniques et se constituent notamment sur la base d'emprunts, de contaminations qui suggèrent des rapprochements tantôt avec les anciennes langues anatoliennes, tantôt avec la Mésopotamie, tantôt avec le monde persan. C'est en référence aux langues caucasiennes que le linguiste officiel de l'Union soviétique, originaire de Koutaïssi, Nicolas Marr, développa l'idée des «langues japhétiques » pré-indo-européennes. Ce musée linguistique a d'ailleurs fasciné des générations de savants, notamment allemands, et cette fascination peut elle-même devenir un objet d'étude. Il existe une strate antique voire préhistorique dans l'étude du Caucase qui oblige à sortir de son espace propre pour observer sa valeur de substrat possible. Le hatti, le urartéen, le hourrite sont des langues véhiculant des cultures dont on suit l'extension à travers l'Anatolie et jusqu'en Mésopotamie sans pouvoir exclure, même si la profon- 
deur historique doit inciter à une grande prudence, la possibilité d'un lien avec le Caucase.

Le Caucase est particulièrement important pour l'imaginaire littéraire russe de Lermontov à Pouchkine, ou de Griboïedov en passant par Tolstoï jusqu'à Mandelstam et à Tynianov ou à Sergueï Essenine, le poète qui a laissé son nom à l'un des sommets du Grand Caucase. Ses poètes comme le Géorgien Roustaveli ou l'Azerbaïdjanais écrivant en persan Nizami sont eux-mêmes au confluent de plusieurs littératures et Nizami a livré des modèles littéraires à la plupart des cultures de l'Eurasie. L'itinéraire de Lev Nussimbaum, alias Essad Bey, montre la persistance de l'internationalisme littéraire de Bakou au Xx ${ }^{\mathrm{e}}$ siècle.

Une histoire transculturelle du Caucase peut être envisagée du point de vue des lieux de mémoires croisées: ses villes cosmopolites comme Bakou, l'une des villes musulmanes où a vécu une forte minorité juive ou Tbilissi/Tiflis, la géorgienne, qui du califat abbasside aux Persans, des Séfévides aux Ottomans connut d'innombrables occupants avant de devenir sous l'Empire russe une capitale administrative et intellectuelle du Caucase. Nous ne proposons évidemment pas ici d'histoire générale du Caucase, elle exigerait entre autres d'aborder la question complexe des conflits récents qui, de l'Abkhazie à l'Ossétie en passant par le Karabagh ou la Tchétchénie, ont ensanglanté la région; il s'agit de se concentrer strictement sur les phénomènes de transferts historiques, littéraires, linguistiques, archéologiques et esthétiques comme principe de structuration de cet espace dans une histoire longue, antérieure à la disparition de l'URSS et à des conflits qui, en l'absence de distance historique, sont difficiles à traiter. Les limites de l'espace désigné par le terme de Caucase ne sont elles-mêmes pas du tout claires. L'Albanie du Caucase allait très loin vers le sud, l'Empire khazar très loin vers le nord. La région de Tabriz est une partie intégrante de l'espace culturel azéri. Le traité de San Stefano a rattaché à l'Empire russe et au Caucase une part importante de l'Anatolie orientale, perdue après le traité de Brest-Litovsk, et nous ne parlons même pas ici des diasporas de nations caucasiennes à Moscou, Jérusalem ou Paris.

L'enjeu est ici d'appliquer un mode nouveau d'approche d'une aire culturelle à la complexité paradigmatique, en utilisant, de l'his- 
toire des sciences humaines à la linguistique en passant par l'histoire des villes ou l'archéologie, les divers outils disponibles et les compétences de spécialistes reconnus issus aussi des régions concernées.

Tenter de parler des transferts culturels dans le Caucase oblige à relativiser la représentation de la périphérie en histoire. Croisement des cultures, le Caucase n'est pas à la périphérie du monde russe ou turc, de l'Europe ou du Proche-Orient. Il est lui-même un centre. Comment ne pas situer au centre du développement industriel de la Russie et d'une histoire européenne les puits de pétrole de Bakou, à l'origine aussi de l'enrichissement de la famille Nobel. Comment ne pas situer au centre des drames politiques du $\mathrm{xx}^{\mathrm{e}}$ siècle la région qui a été un lieu d'intense fermentation bolchevique, a vu naître Staline, Géorgien d'ascendance ossète et Beria, Mingrélien d'Abkhazie, ou encore le dernier ministre des Affaires étrangères de l'Union soviétique Édouard Chevardnadze? Et il ne faut pas oublier non plus l'Azerbaidjanais Nariman Narimanov, responsable du ProcheOrient au commissariat pour les Affaires étrangères, son adversaire le Géorgien Grigory Ordjonikidze, membre du Bureau politique, l'Arménien Anastase Mikoyan, qui devint président du Présidium du soviet suprême, Heydar Aliyev vice-Premier Ministre de l'URSS. Car Bakou et Tbilissi ont été très tôt des métropoles cosmopolites dont même Napoléon n'ignorait pas l'importance dans les stratégies qui le poussaient à imaginer la conquête de l'Inde.

Depuis le milieu du XviII ${ }^{\mathrm{e}}$ siècle, le Caucase a aussi fasciné les voyageurs et savants européens qui ont cherché à comprendre les mystères d'un territoire aussi complexe, la genèse de ses langues et de ses nationalités. Beaucoup étaient allemands comme Friedrich Bodenstedt, singulièrement oublié de nos jours, dont les traductions-réinventions des œuvres d'un poète azerbaïdjanais installé à Tiflis, Mirza Schaffy, ont rencontré un immense succès en Allemagne et dont les travaux ethnographiques ont contribué à éclairer la compréhension de la région. Comprendre le Caucase ce n'est pas seulement publier des récits de voyage ou des descriptions littéraires à la manière d'Alexandre Dumas dans son Voyage au Caucase ou d'Arthur de Gobineau dans sa " Danseuse de Shamakha ». Depuis le milieu du XIX ${ }^{\mathrm{e}}$ siècle on cherche à en fixer les images sur des photographies, qui servent tant à organiser les postes militaires dans un 
vaste ensemble russe incluant aussi l'Asie centrale qu'à reconnaître les spécificités des mœurs et modes de vie locaux.

Il est bien clair que cet ouvrage sur les transferts culturels dans le Caucase ne prétend à aucune forme d'exhaustivité. Toutes les nations composant le puzzle caucasien ne seront pas évoquées, et moins encore toutes les possibilités d'interactions souvent pacifiques, mais très souvent aussi belliqueuses qui jalonnent leur histoire. Nous souhaitions seulement rappeler l'intérêt pour presque toutes les disciplines des sciences humaines d'un champ de recherche dont on peut suivre les caractéristiques de la préhistoire jusqu'au $\mathrm{Xx}^{\mathrm{e}}$ siècle et tester la fiabilité d'un fil directeur, celui des transferts culturels, pour l'aborder.

Michel Espagne, Hamlet Isaxanli, Shahin Mustafayev 



\section{PREMIÈRE PARTIE}

\section{RENCONTRES ANCIENNES}





\title{
Transferts culturels entre le Caucase, le Proche-Orient ancien et les steppes eurasiennes
}

\author{
Du Néolithique au début de l'âge du bronze \\ (VI $I^{e}$ au $\mathrm{III}^{e}$ millénaire avant notre ère) \\ Bertille Lyonnet
}

Des mouvements de population et des échanges de matériaux, de biens et d'idées sont attestés partout depuis les temps les plus anciens. Ils constituent l'un des traits spécifiques de l'humanité et contribuent à son extraordinaire variété et complexité. Bien que les montagnes, comme le Grand Caucase, aient souvent été considérées comme des barrières ou des refuges pour des groupes locaux qui ont pu y conserver leur langue, il y a toujours des points de passage, défilés ou cols, qui ont permis de les traverser et d'ouvrir les horizons.

Cet article vise à présenter plusieurs témoignages de contacts culturels entre les régions du Caucase, le Proche-Orient ancien et les steppes eurasiennes à partir du Néolithique, au VI $\mathrm{VI}^{\mathrm{e}}$ millénaire, et jusqu'au bronze ancien, autour du milieu du $\mathrm{III}^{\mathrm{e}}$ millénaire. Comme nous le verrons, il est possible que ces relations aient été dues à des migrations, soit de petits groupes de marchands, soit de communautés plus importantes en nombre, mais il est encore impossible de le prouver en l'absence de recherches sur l'ADN des ossements retrouvés.

Les preuves de ces contacts et "transferts culturels " reposent essentiellement sur la culture matérielle, et surtout sur la pote- 
rie, l'un des matériaux les plus abondants trouvés lors des fouilles archéologiques. Les récipients, ou ce qu'ils contenaient, peuvent être facilement échangés et leur décoration peut être imitée, mais, en général, on considère la poterie comme un marqueur d'identité culturelle. Toutefois, il est très rare qu'il y ait une parfaite équation entre un type de poterie et une population, de la même manière que la langue ne peut se réduire à une ethnie ou à des gènes. De plus, même lorsque de grandes migrations ont lieu, ou que des changements climatiques très importants se produisent, la population locale et sa culture ne disparaissent jamais totalement et l'on voit généralement cette dernière reparaître plus tard sous diverses formes, y compris par une sorte d'hybridation. De ce fait, les interprétations que l'on peut formuler sur les raisons des transferts culturels observés sont difficiles à manier, d'autant qu'elles traitent de questions sensibles. Elles ne peuvent être qu'hypothétiques. Il est particulièrement important de le souligner dans le cas du Caucase, puisque cette région est considérée par certains comme la patrie des Indo-Européens ${ }^{1}$ et aussi celle des Hourrites connus par les textes mésopotamiens.

\section{ILL. 1. Caucase et Proche-Orient (ci-contre)}

Les principaux sites mentionnés dans le texte sont en gras:

1- Djurso; 2- Svobodnoe; 3- Jasenova Poljana; 4- Novosvobodnaya; 5- Meshoko; 6- Ust’Dzheguta； 7-Zamok； 8-Galjugaj; 9-Ginchi； 10-Chokh；11-Velikent ; 12- Darkveti；13- Berikldeebi；14- Kavtiskhevi; 15-Sioni; 16-Shulaveris-Gora; 17- Boyuk Kesik; 18-Shomu Tepe; 19- Ilanly; 20-Leilatepe; 21-Chalagan-Tepe; 22- Alikemek; 23- Kül'-Tepe; 24- Tekhut; 25- Aratashen et Aknashen; 26-Sos Höyük; 27- Arslantepe; 28- Norşuntepe; 29- Tepecik; 30- Tülintepe; 31- Tilki Tepe; 32- Kurban Höyük; 33- Oylum Höyük; 34- Hacinebi； 35- Kosak Shamali; 36- Sheikh Hassan; 37- Habuba Kabira; 38- Hammam et-Turkman; 39- Tell Halaf; 40- Tell Brak; 41- Tell Leilan; 42- Gray Resh ; 43- Tepe Gawra ; 44- Geoy Tepe ; 45- Haji Firuz/ Dalma Tepe; 46-Sé Girdan; 47-Tell Rubeidheh; 48-Uruk Warka; 49- Byblos; 50- Tell Beth Yerah.

1. T. V. Gamkrelidze and V. V. Ivanov, Indoevropejskij jazyk i Indoevropejtsy. Rekonstrucija i istoriko-tipologičeskij analiz prajazyka i protokul'tury. University of Tbilissi. Tbilissi, 1984. 
Transferts culturels entre le Caucase, le Proche-Orient ancien et les steppes eurasiennes

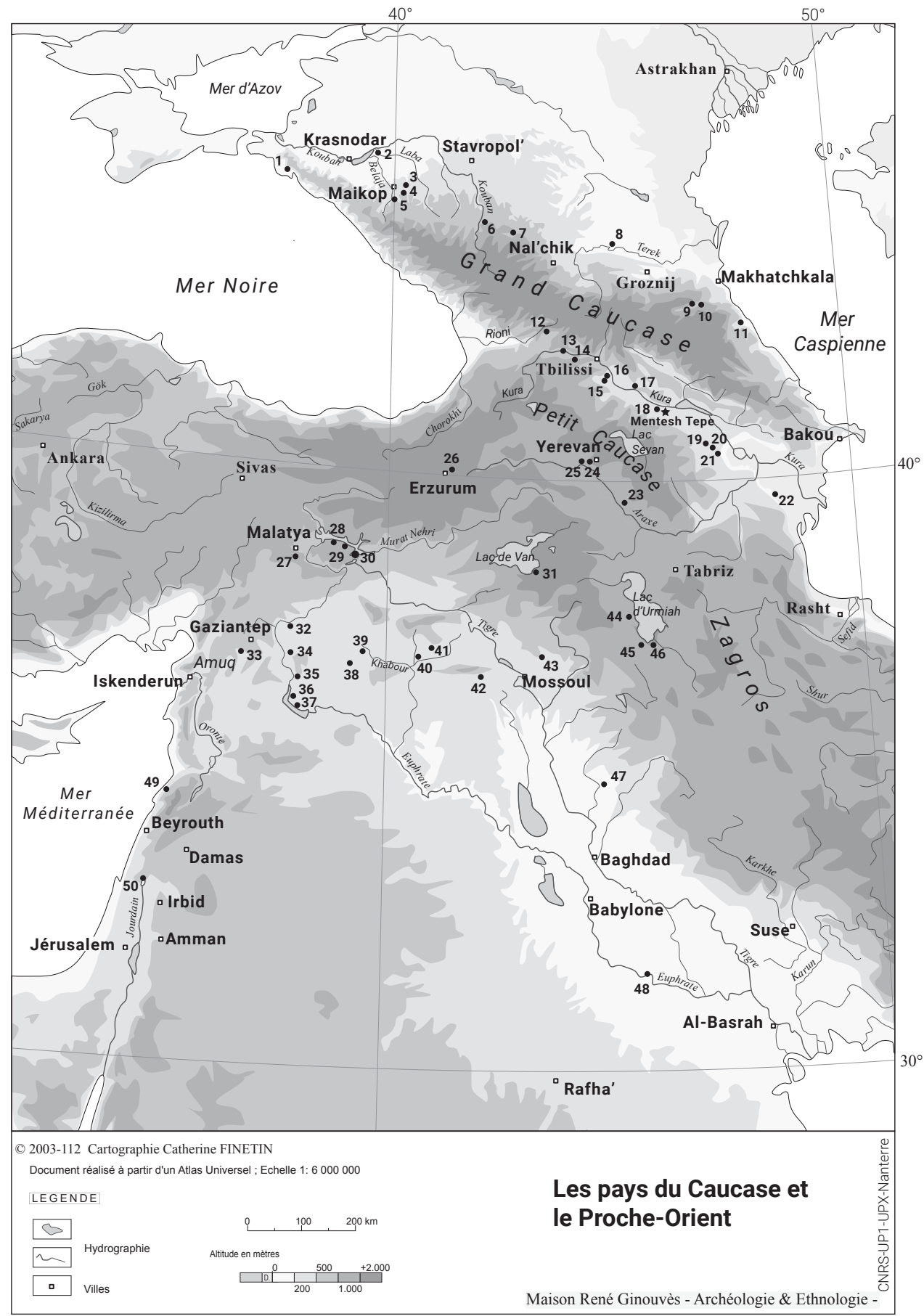




\section{Le Néolithique}

Par rapport à la Mésopotamie du Nord et à l'Anatolie orientale, les premières preuves de l'installation de communautés néolithiques au Caucase Sud sont assez tardives, les plus anciennes ne datant que du début du $\mathrm{VI}^{\mathrm{e}}$ millénaire. Elles apparaissent sous la forme d'un ensemble de cultures déjà développées, avec architecture circulaire de briques crues, céramique, céréales et faune domestiquées, dont l'une des principales est celle de Shomu-Shulaveri, d'après le nom des deux premiers sites fouillés, Shomu Tepe en Azerbaïdjan occidental et Shulaveris Gora au sud-est de la Géorgie (ill. 1). Les fouilles récentes de deux sites de cette culture, Aknashen dans la vallée de l'Araxe, en Arménie ${ }^{2}$ et Hacı Elamxanlı Tepe dans la moyenne vallée de la Kura, en Azerbaïdjan ${ }^{3}$ ont donné pour les niveaux les plus anciens des dates au radiocarbone situées autour de 6000 avant notre ère et de la céramique peinte dont l'argile n'est pas locale et dont le décor présente des similitudes avec les styles de Samarra et Halaf transitionnel connus en Mésopotamie centrale et du Nord. De plus, les recherches en cours sur les communautés qui vivaient auparavant dans la région, retrouvées uniquement dans des grottes et abris et vivant de chasse et de cueillette, montrent qu'il n'y a pas de relations directes entre elles et cette culture de Shomu-Shulaveri ${ }^{4}$.

Plusieurs indices tendent à indiquer que l'événement climatique abrupt maintenant bien connu de 8,2 kA (autour de 6200 avant notre ère.) a eu des conséquences sévères au Proche-Orient. Il semble qu'on puisse lui relier la fondation, deux siècles plus

2. Badalyan et Harutyunyan, "Aknashen - The Late Neolithic settlement of the Ararat Valley: main results and prospects of the research ", in B. Gasparyan and M. Arimura (eds.), Stone Age of Armenia, Center for Cultural Resource Studies, Kanazawa University, 2014, p. 161-176.

3. Y. Nishiaki, F. Guliyev, S. Kadowaki, Y. Arimatsu, Y. Hayakawa, K. Shimogama, T. Miki, C. Akashi, S. Arai and S. Salimbeyov, « Hacı Elamxanlı Tepe: Excavations of the earliest Pottery Neolithic occupations on the Middle Kura, Azerbaijan ", in Archäoligische Mitteilungen aus Iran und Turan 45, 2012,1-25.

4. Kh.A. Amirkhanov, Čohskoe poselenie: chelovek i ego kul'tura v Mezolite i Neolite gornogo Dagestana, Nauka, Moskva, 1987 - A. Petrosyan, M. Arimura, B. Gasparyan, S. Nahapetyan, C. Chataigner, « Early Holocene Sites of the Republic of Armenia: Questions of Cultural Distribution and Chrnonology ", in B. Gasparyan \& M. Arimura (eds.), op.cit. p. 135-159., 
tard, de la culture de Shomu-Shulaveri entre l'Araxe et la Kura ${ }^{5}$. La richesse de la flore et de la faune locales, tout comme l'importance des différentes matières premières présentes dans le Petit Caucase ont aussi été souvent avancées pour expliquer les relations entre ces régions. Des recherches sont en cours sur ces différents thèmes pour tenter de prouver ou réfuter toutes ces propositions. De plus, nous avons aussi lancé des recherches sur l'ADN ancien ${ }^{6}$ de squelettes trouvés dans une tombe collective, datée de 5700 avant notre ère, mise au jour sur le site de Mentesh Tepe dans la vallée de la Kura (Azerbaïdjan) afin de tenter de connaître l'origine de cette population.

À côté de l'architecture circulaire de briques crues, également connue dans la culture de Halaf en Mésopotamie du Nord (même si elle est, là, habituellement associée à une architecture rectangulaire), d'autres éléments mettent en évidence l'existence de relations avec cette région mésopotamienne au cours du développement de la culture de Shomu-Shulaveri: c'est le cas de pierres à rainure ${ }^{7}$, de la présence de motifs appliqués fréquents dans les cultures néolithiques de cette zone, ou de celle de tessons de pots Halaf dans la vallée de l'Araxe, tant à Aratashen en Arménie ${ }^{8}$ qu'à Kül'Tepe au Nakhchivan ${ }^{9}$. Ceci montre clairement que des relations se sont maintenues entre les deux régions pendant plusieurs siècles.

5. B. Lyonnet, F. Guliyev, L. Bouquet, G. Bruley-Chabot, A. Samzun, L. Pecqueur, E. Jovenet, E. Baudouin, M. Fontugne, P. Raymond, E. Degorre, L. Astruc, D. Guilbeau, G. Le Dosseur, N. Benecke, C. Hamon, M. Poulmarc'h, A. Courcier, « Mentesh Tepe, an early settlement of the Shomu-Shulaveri Culture in Azerbaijan ", in Quaternary International 395, 2016, p. 170-183.

6. Ces recherches sont effectuées sous la direction de C. Bon, Museum national d'histoire naturelle/CNRS, Paris.

7. M. Arimura, R. Badalyan, B. Gasparyan, C. Chataigner, "Current Neolithic research in Armenia ", in Neo-Lithics 1/10, 2010, p. 77-85.

8. G. Palumbi, «A preliminary analysis on the Prehistoric pottery from Aratashen, Armenia ", in B. Lyonnet (éd.). Les cultures du Caucase (VI ${ }^{e} I I I^{e}$ millénaires avant notre ère). Leurs relations avec le Proche-Orient. ERC, Paris, CNRS-Editions, 2007, p. 63-76.

9. O.A. Abibullaev, Eneolit i Bronza na territorii Nakhichevanskoj ASSR, Baku, Elm, 1982 
Néanmoins, malgré ces intrusions et la continuité des échanges, la culture de Shomu-Shulaveri a développé son propre caractère, et témoigne de particularités, comme dans le domaine des industries osseuse et lithique. Il semble aussi qu'elle ait établi des liens avec des cultures plus à l'est, aux confins du monde iranien ${ }^{10}$.

Pour des raisons qui ne sont pas encore claires, toute trace d'occupation sédentaire disparaît après 5300 avant notre ère et il semble que les communautés se soient alors tournées vers une vie au moins semi-mobile.

\section{Le Chalcolithique}

Les rares preuves d'occupation à notre disposition pour le millénaire qui suit consistent surtout en fosses et trous de poteaux associés à une architecture légère et à un matériel très réduit. Seul le site de Sioni, en Géorgie orientale sur le piémont du Petit Caucase présente une architecture circulaire de pierre. De ce fait, nous considérons que le mode de vie était plus mobile. Néanmoins, la plupart de ces découvertes ont été faites il y a longtemps et, peu d'analyses 14C ayant été effectuées, nous manquons de repères assurés. Les quelques dates obtenues récemment placent certains des sites entre 4800 et 4000 avant notre ère. La céramique montre, d'une part, des éléments de continuité avec celle de la culture de ShomuShulaveri et, d'autre part, l'apparition de formes nouvelles ${ }^{11}$. On a attribué à cette culture matérielle le nom de "Sioni » d'après celui du premier site qui a été fouillé. Pour cette époque, aucun signe de relations avec d'autres régions lointaines n'a été mis en évidence, sauf, probablement vers la fin, avec les régions situées au nord du

10. B. Lyonnet, « Mentesh Tepe, Concluding Remarks », in B. Helwing, T. Aliyev, B. Lyonnet, F. Guliyev, S. Hansen and G. Mirtskhulava (eds.), The Kura Projects: New Research on the Later Prehistory of the Southern Caucasus, Archäologie in Iran und Turan, 16, Berlin, Dietrich Reimer Verlag, 2017, p. 193-194.

11. B. Lyonnet, « Rethinking the 'Sioni Cultural Complex' in the South Caucasus (Chalcolithic Period): New data from Mentesh Tepe (Azerbaijan) ", in A. Batmaz, G. Bedianashvili, A. Michalewicz and A. Robinson (eds.), Context and Connection: Studies on the Archaeology of the Ancient Near East in Honour of Antonio Sagona. Leuven, Peeters, 2017, p. 547-567. 
Grand Caucase, par la découverte de poterie similaire sur le site de Zamok $^{12}$.

Toutefois, des découvertes récentes ont également montré que, pendant le dernier tiers du $V^{\mathrm{e}}$ millénaire (entre ca 4350 et 4100 avant notre ère), au même moment où ces sites "Sioni " sont attestés, au moins un établissement, Mentesh Tepe, est entièrement différent dans son architecture, rectangulaire en briques crues présentant un plan totalement inconnu auparavant dans la région et qui pourrait se rattacher à celui des bâtiments tripartites de Mésopotamie ${ }^{13}$. De plus, la très abondante poterie trouvée sur le site témoigne de certains traits connus en Mésopotamie du Nord tant dans ses formes que dans son décor, même s'il n'y a pas de similitude totale. La poterie dite "Sioni » connue sur les autres sites est également attestée, mais ne représente que la céramique de cuisine à Mentesh Tepe ${ }^{14}$. Enfin, le site témoigne d'activités métallurgiques importantes utilisant les ressources en cuivre du Petit Caucase situées à proximité ${ }^{15}$. Malgré ces éléments, nous n'avons pas été en mesure d'identifier précisément quelle population a pu fonder un tel établissement et pourquoi.

Quelques siècles plus tard, pendant la première moitié du $\mathrm{IV}^{\mathrm{e}}$ millénaire, d'autres établissements témoignent d'une influence nord-mésopotamienne encore plus évidente. C'est le cas de Leilatepe en Azerbaïdjan ${ }^{16}$ ou de Berikldeebi en Géorgie, comme le montrent

12. S. N. Korenevskij, "Poselenie 'Zamok' u goroda Kislovodska (nižnij sloj) », in A.B. Belinskij (éd.), Materialy po izučeniju istoriko-kul'turnogo nasledija severnogo Kavkaza, I, Arheologija, Stavropol',1998, p. 96-147.

13. B. Lyonnet \& F. Guliyev, in collaboration with L. Bouquet, G. Bruley-Chabot, M. Fontugne, P. Raymond and A. Samzun, Mentesh Tepe, in B. Lyonnet et al., "Ancient Kura 2010-2011: The First Two Seasons of joint field work in the Southern Caucasus ", in Archäologische Mitteilungen aus Iran und Turan 44, 2012, p. 86-97.

14. Ibid..

15. A. Courcier, B. Jelilov, I. Aliyev, F. Guliyev, M. Jantzen, B. Lyonnet, N. Mukhtarov, N. Museibli, " The ancient metallurgy in Azerbaijan from the end of the Neolithic to the Early Bronze Age (6th-3rd mill. BCE): an overview in the light of new discoveries and recent archaeometallurgical research ", in From Bright Ores to Shiny Metals, Festchrift Andreas Hauptmann, Der Anschnitt, 29, 2016, p. 25-36.

16. I. Narimanov, Kul'tura drevnejšego zemledel'česko-skotovodčeskogo naselenija Azerbajdžana (epoha Eneolita VI-IV tys. do n. e.), Baku, Elm, 1987 
l'architecture et la poterie, cette dernière étant désormais tout à fait identique à celle de sites de Syrie ou d'Iraq du Nord ${ }^{17}$. Là encore, la métallurgie semble avoir joué un rôle important. Toutefois, quelques sites contemporains, comme Boyuk Kesik, en Azerbaïdjan, présentent une architecture plus traditionnelle, avec des formes ovales $^{18}$, témoignant peut-être par là d'une cohabitation entre des populations d'origine différente sur le même territoire.

$\mathrm{Au}$ même moment, dans cette même zone géographique du Caucase Sud, les kourganes (tumulus recouvrant une tombe) font leur première apparition. Ce type de construction funéraire a commencé un peu plus tôt dans les steppes au nord du Grand Caucase; on le relie généralement à des populations mobiles ${ }^{19}$. Non loin de Boyuk Kesik, à Soyuq Bulaq, en Azerbaïdjan occidental, une tombe relativement riche sous un kourgane de pierre peu élevé contenait des perles en or, en alliage de cuivre et d'argent, en lapis-lazuli, cornaline et pâte ainsi qu'un poignard en cuivre et un sceptre de pierre à tête d'équidé ${ }^{20}$. La poterie trouvée dans les kourganes est proche de celle de la culture de Leilatepe. Aucun squelette humain entier n'a été mis au jour dans les kourganes fouillés et il est possible qu'un rituel d'exposition des corps ait déjà été pratiqué à cette époque lointaine $^{21}$. Des kourganes avec le même matériel et peut-être le même

17. T. Akhundov, "Sites de migrants venus du Proche-Orient en Transcaucasie ", in B. Lyonnet (éd.), Les Cultures du Caucase... op. cit, p. 95-121 - Z. Makharadze, " Nouvelles données sur le Chalcolithique en Géorgie orientale ", in B. Lyonnet (éd.), Les Cultures du Caucase... op. cit, p. 123-131.

18. N. Museibli, Böyük Kesik eneolit dövrü yaşayiş maskani. The Chalcolithic Settlement of Beyuk Kesik. Baku: Institute of Archaeology and Ethnology, 2007.

19. Y. Rassamakin, "The Eneolithic of the Black Sea Steppe: Dynamics of Cultural and Economic Development 4500-2300 BC ", in M. Levine, Y. Rassamakin, A. Kislenko and N. Tatarintseva (eds.), Late Prehistoric Exploitation of the Eurasian Steppe, Mc Donald Institute Monographs, Cambridge, 1999, p. 59-182.

20. B. Lyonnet, T. Akhundov, K. Almamedov, L. Bouquet, A. Courcier, B. Jellilov, F. Huseynov, S. Loute, Z. Makharadze, S. Reynard, "Late Chalcolithic Kurgans in Transcaucasia. The cemetery of Soyuq Bulaq (Azerbaijan) », in Archäoligische Mitteilungen aus Iran und Turan, 40, 2008, p. 27-44.

21. B. Lyonnet, " Périphérie de la Mésopotamie à la période d'Uruk (IV millénaire): le cas des régions du Caucase ", in J.-M. Durand et A. Jacquet (éds.), Centre et Périphérie: approches nouvelles des Orientalistes, CIPOA vol. I, Paris, Maisonneuve, 2009, p. 1-28. 
rituel ont été fouillés à Sé Girdan, au sud du lac d’Urmia en Iran ${ }^{22}$, ainsi qu'en Géorgie, non loin de Berikldeebi ${ }^{23}$.

C'est aussi à cette époque que la culture de Maïkop, surtout connue par ses riches kourganes, se développe au nord du Grand Caucase. On connaît très peu d'établissements de cette culture, et elle a été datée d'une période beaucoup plus tardive pendant longtemps ${ }^{24}$. Les parallèles très clairs qu'on peut faire entre sa culture matérielle et celle de la culture de Leilatepe ou de la Mésopotamie du Nord ont néanmoins permis de la dater désormais de la première moitié $d u \mathrm{IV}^{\mathrm{e}}$ millénaire ${ }^{25}$, ce que des dates radiocarbones annonçaient déjà ${ }^{26}$. Les kourganes de la culture de Maikop sont particulièrement célèbres pour leur étonnante profusion de perles, bractées et figurines en or, argent ou pierres semi-précieuses.

En résumé, pendant environ 800 ans, au cours du Chalcolithique récent, entre ca 4300 et 3500 avant notre ère, on observe des relations intenses entre la Mésopotamie du Nord et les régions du Caucase, jusque sur le flanc nord des montagnes. Bien que certains considèrent qu'il s'agisse là de migrations ${ }^{27}$, il est possible que ceci n'ait concerné que de petits groupes de marchands en relation avec la population locale, alors mobile pour au moins une partie d'entre elle, et qui pouvait avoir accès à des matériaux venus de très loin,

22. O.W. Muscarella, "The Chronology and Culture of Sé Girdan: Phase III ", in Ancient Civilizations from Scythia to Siberia, 2003, p. 9, 1-2, 117-131.

23. Z. Makharadze, " Nouvelles données sur le Chalcolithique en Géorgie orientale ", in B. Lyonnet (éd.), Les Cultures du Caucase... op. cit., p. 123-131.

24. M.V. Andreeva, « K voprosu o južnyh svjazah Majkopskoj Kul’tury », in Sovetskaja Arheologija, 1977, 1, 39-56.

25. B. Lyonnet, « La Mésopotamie et le Caucase du Nord au cours du IV millénaire av. n. è.: leurs rapports et les problèmes chronologiques de la culture de Maikop. État de la question et nouvelles propositions ", in C. Marro et H. Hauptmann (éds.), Chronologies des pays de l'Euphrate et du Caucase aux IV ${ }^{e}$ - III ${ }^{e}$ mill., Varia Anatolica XI, Paris, De Boccard, 2000, p. 299-320 - id., " La culture de Maikop, la Transcaucasie, l'Anatolie orientale et le Proche-Orient: relations et chronologie ", in B. Lyonnet (dir.), Les cultures du Caucase... op. cit. p. 132-161.

26. V.A.Trifonov, « Popravki k absoljutnoj hronologii kul'tur epohi eneolita-bronzy severnogo Kavkaza ", Meždu Aziej i Evropoj, Kavkaz v IV-I tys. do n.e. (K 100-letiju co dnja roždenija A. A. Iessena), Sankt-Petersburg, 1996, p. 43-49.

27. T. Akhundov, "Sites de migrants venus du Proche-Orient en Transcaucasie », in B. Lyonnet (éd.), Les Cultures du Caucase..., op. cit., p. 95-121. 
comme le montre la présence du lapis-lazuli venant d'Afghanistan du Nord-Est. Nous ne savons pas quelles étaient les ressources naturelles, brutes ou travaillées, que recherchaient ces étrangers du Sud, même si on peut supposer que le métal y a joué un grand rôle. Mais la laine ou le bois ont pu aussi être recherchés à cette époque.

\section{L’âge du bronze ancien}

Une longue période de repli par rapport aux autres régions commence ensuite. Elle correspond à l'époque de l'expansion urukéenne venue du sud de la Mésopotamie, au cours de la seconde moitié du IV ${ }^{\mathrm{e}}$ millénaire. Cette expansion, unanimement considérée comme purement économique, a suivi la route de l'Euphrate jusqu'à Arslantepe en Turquie orientale. Plusieurs colonies ont été fondées, et d'autres sites témoignent de très fortes influences ${ }^{28}$. Au contraire, au Sud Caucase, pendant plusieurs siècles on ne voit aucune évolution de la culture matérielle sur les quelques rares sites qui ont été fouillés et qui datent de cette période. C'est le cas de Godedzor, en Arménie, jusque vers 3350 avant notre ère ${ }^{29}$.

À partir de 3300 avant notre ère., toutefois, un changement culturel important voit le jour et de nouveaux établissements sont fondés, particulièrement dans les zones d'altitude modérée. La poterie est désormais très différente, brunâtre ou noir poli, et un peu plus tard apparaissent des foyers, portatifs ou non, très spécifiques (andirons). La nouvelle culture ainsi apparue porte le nom de KuroAraxe car elle est principalement répartie entre ces deux rivières. Ses origines restent obscures30, mais il est certain qu'elle résulte du phénomène urukéen, même s'il n’y a eu aucun contact direct entre les deux entités.

28. G. Algaze, The Uruk World System. The Dynamics of Expansion of Early Mesopotamian Civilization. Chicago and London, The University of Chicago Press, 1993.

29. G. Palumbi \& C. Chataigner, "The Kura-Araxes Culture from the Caucasus to Iran, Anatolia and the Levant: Between unity and diversity. A synthesis », in Paléorient 40.2,2014, p. 247-260.

30. A. Sagona, "Rethinking the Kura-Araxes Genesis ", in Paléorient 40.2, 2014, 23-46. 
Dans la mesure où la population locale n'a jamais disparu, il est normal de retrouver encore quelques éléments des cultures antérieures, mais on observe surtout des changements importants. $\mathrm{Au}$ départ, l'habitat est surtout circulaire, fait de matériaux légers. Les inhumations se font dans des types de tombes très variés: certaines sont collectives, sous kourganes, d'autres sont individuelles dans des fosses de formes variées. Plus tard, les maisons deviennent sur un large territoire majoritairement rectangulaires à angles arrondis. La population s'installait à différentes altitudes et pratiquait à la fois l'élevage et l'agriculture. La production semble être restée à une échelle domestique, sans aucune preuve d'échanges avec l'extérieur ni de hiérarchie interne. La métallurgie semble avoir continué à jouer un rôle important, comme le montrent les fouilles récentes autour de la mine d'or de Sakdrisi, à Dzedzvebi en Géorgie orientale $^{31}$. Au fur et à mesure du développement de la culture Kuro-Araxe, la régionalisation des styles dans le décor de la poterie, l'architecture ou les tombes se fait plus intense.

Pendant la première moitié du $\mathrm{III}^{\mathrm{e}}$ millénaire, à partir de 2900 avant notre ère, une partie de cette population a migré dans deux directions, d'une part vers le Zagros ${ }^{32}$, et d'autre part vers le Levant ${ }^{33}$, où elle a été identifié sur de nombreux sites. On peut même tracer certains éléments jusqu'en Turkménie au cours de la période Namazga IV.

À nouveau, les raisons de ces migrations, qui, dans ce cas, sont indubitables, restent inexpliquées; de nombreuses hypothèses ont été avancées (pastoralisme et recherches de nouveaux territoires, métallurgie, commerce, etc.) mais aucune preuve certaine n'est venue les étayer.

31. I. Gambashidze \& T. Stöllner eds, The Gold of Sakdrisi. Man's first gold mining enterprise, Rahden (Westf.), Verlag Marie Leidorf GmbH, 2016.

32. M.S. Rothman, " Migration and Resettlement: Godin Period IV », in H. Gopnik and M.S. Rothman, with contributions by R.C. Henrickson and V.R. Badler (eds.), On the High Road. The History of Godin Tepe, Iran. Royal Ontario Museum Press and Mazda Publishers, Toronto, 2011, p. 139-206.

33. R. Greenberg, Shimelmitz and M. Iserlis, " New evidence for the Anatolian origins of "Khirbet Kerak Ware People" at Tel Bet Yerah (Israel) ", ca 2800 BC, in Paléorient, 40.2, 2014, p. 183-201. 
Vers le milieu du III ${ }^{\mathrm{e}}$ millénaire, un nouveau petit groupe de population apparaît au Sud Caucase, surtout le long de la Kura, en Géorgie et en Azerbaïdjan. Il a vécu côte à côte avec la population locale et lui a emprunté certains de ses éléments culturels, en particulier la poterie. Les premiers vestiges qu'on peut lui attribuer sont ceux de riches kourganes surmontant des chambres funéraires en rondins de bois dans la plupart desquelles se trouvaient un ou deux chariots de bois à quatre roues ${ }^{34}$. Très peu d'établissements ont été fouillés que l'on puisse associer à cette population, au moins dans les premiers temps de leur arrivée. Bien que la plupart de ces kourganes aient été pillés, souvent dès l'origine, tous attestent de la présence d'objets de prestige venant d'horizons très lointains (perles d'ambre venues de la mer Baltique, coquillages conus venus des mers chaudes, perles indentées bien connues en Asie centrale, etc.). On peut attribuer ces constructions funéraires plus à des groupes de commerçants venus des steppes eurasiennes du Nord qu'à des guerriers, comme cela avait été initialement avancé. Un certain nombre de traits les relie aussi aux tombes fabuleuses du cimetière royal d'Ur ${ }^{35}$. Ces nouveaux arrivants et les changements qu'ils vont apporter vont peu à peu mettre un terme à la culture Kuro-Araxe.

Les régions du Caucase ont longtemps été considérées comme isolées, et elles ont aussi été oubliées par beaucoup de chercheurs du monde occidental en raison de leur appartenance au monde soviétique. La courte présentation que nous en avons faite ci-dessus

34. Z. Makharadze, N. Kalandadze and B. Murvanidze, Ananauri Big Kurgan 3, Georgian National Museum and Shota Rustaveli Foundation, Tbilissi, 2016 - L. Pecqueur, A. Decaix and B. Lyonnet, "Un kourgane de la phase Martkopi à Mentesh Tepe (Période des Premiers Kourganes, Bronze ancien) " in B. Helwing, T. Aliyev, B. Lyonnet, F. Guliyev, S. Hansen and G. Mirtskhulava (eds.), op. cit, p. 179-192.

35. B. Lyonnet, "A Grave with a Wooden Wagon in Transcaucasia (Azerbaijan). Its Relations with Central Asia ", in N.A. Dubova, P. M. Kozhin, M. F. Kosarev, M. A. Mamedov, R. G. Muradov, R. M. Sataev, A. A. Tishkin (eds). V. Sarianidi Memorial Volume, Transaction of Margiana arcaheological expedition, Vol. 6. Moscow, Staryj Sad, 2016, p. 191-198 and color plate. 
montre que, au contraire, elles furent un carrefour important pendant une très longue période au cours de la protohistoire.

Leur richesse en matières premières, leur ouverture sur la steppe eurasienne au nord et leur accès plus facile vers la plaine mésopotamienne au sud ont certainement constitué les fondements de la plupart des relations observées. Des échanges ou un commerce de différents matériaux (métaux, obsidienne) sont attestés et expliquent beaucoup des relations les plus visibles. Mais cela a également conduit à des transferts culturels à plus large spectre dans les deux sens et a conduit au développement important de ces régions.

Il reste, bien sûr, encore de nombreux points obscurs. L'absence d'écriture et notre ignorance des langues parlées à ces époques en sont un. Beaucoup de recherches sont en cours sur l'environnement, les paléo-faune et flore, la métallurgie, la génétique, etc.: on espère que les résultats permettront une meilleure compréhension des composants tant locaux qu'exogènes des cultures successives qui s'y sont développées au cours de la protohistoire. 



\title{
Galatée au pays des Amazones
}

\author{
Le plat d'argent doré de Yenikend \\ (Azerbaïdjan) et les transferts entre le \\ monde gréco-romain et le Caucase*
}

Anca Dan

" His ego nec metas rerum nec tempora pono:/imperium sine fine dedi...// Je ne mets point de limites à leur possessions et temps:/je leur ai donné un empire sans fin... » écrivait Virgile dans son Énéide (1.278-279). En vérité, Rome est la première - et la seule — puissance occidentale à avoir pu revendiquer, avec une certaine vraisemblance, une domination s'étendant jusqu'aux confins du monde connu (avant la Renaissance). Cette revendication n'était pas juste l'écho de la propagande augustéenne et de sa résonance jusque dans les reconstitutions nostalgiques de la fin de l'Antiquité. Le rayonnement de l'Empire romain à son apogée est perceptible sur ses marges, au moins grâce à deux types de sources: les références littéraires et épigraphiques aux relations établies avec des rois fidèles aux intérêts de l'Empire, au-delà des limites; les découvertes archéologiques, d'aujourd'hui et d'hier, qui reflètent les réseaux de circulation de personnes et de diffusion d'objets et de savoir-faire. Dans certains cas, ces informations se recoupent et nous permettent d'observer la tentation de la "romanisation » des Barbares, au-delà du limes et même d'obstacles naturels réputés insurmontables. Cette "romanisation " n'est pourtant pas une acculturation, mais le résultat des transferts culturels qui changent le sens, la perception et la fonction

* Les choix typographiques concernant notamment les noms de déités, les noms de lieux, etc., sont ceux de l'auteure. 
des objets entre contexte de production et contexte de réception. Ces mêmes informations nous permettent également d'expliquer la construction des savoirs concernant les périphéries et les Autres, au cœur même du monde civilisé. Elles nous rappellent enfin que ce que l'on peut tirer des textes et des objets anciens n'est pas une réalité absolue, qui puisse servir de preuve dans les débats modernes: les témoignages littéraires et iconographiques antiques relèvent d'un imaginaire qui n'est pas le nôtre et qu'on ne peut comprendre qu'en reconstituant le cadre intellectuel et les intérêts propres aux Anciens.

Nous prendrons comme point d'appui ce qui est, sans doute, la trouvaille archéologique antique la plus fameuse d'Azerbaïdjan: c'est un cas d'étude souvent mentionné dans les manuels d'histoire du Caucase, mais dont les implications possibles en termes de transferts culturels sont passées presque inaperçues ${ }^{1}$. Il s'agit d'un objet de luxe, à forte valeur " romaine » - par la technique de son exécution et par sa décoration. Nous tenterons d'expliquer sa présence dans une des régions les plus reculées de l'Eurasie antique par l'étendue des réseaux politico-militaires auxquels devaient appartenir certaines élites transcaucasiennes, sensibles aux raffinements du style de vie romain. Il rappelle que le Caucase fut une zone de frontière et donc de passages - difficiles, mais continus - entre les États urbanisés d'Europe et d'Asie au Sud et les steppes des nomades au Nord.

Dans la première partie de cet article, nous décrirons l'objet qui nous sert de référence. Dans la seconde partie, nous nous livrerons à une présentation critique des identifications possibles de sa décoration et donc de sa fonction originelle, en contexte romain impérial. Dans la troisième partie, nous formulerons des hypothèses sur son itinéraire des bords de la mer Intérieure et du limes nord-oriental jusqu'au nord du Taurus, sur les pentes du Caucase, à partir de ce que l'on sait par ailleurs des transferts dans ce que nous appelons aujourd'hui la Transcaucasie. Nous mettrons ces scénarios hypothétiques dans la perspective plus générale de nos connaissances

1. Pour une introduction à l'étude des transferts culturels dans l'Antiquité classique, voir M. Espagne, « Transferts culturels, comparatisme et sciences de l'Antiquité ", in A. Dan, F. Queyrel (éds), "Les concepts en sciences de l’Antiquité: mode d'emploi. Chronique 2014 - Les transferts culturels ", Dialogues d'histoire ancienne 40.1 (2014), p. 239-305 (p. 247-256). 
concernant les relations politico-militaires et économiques de Rome avec les royaumes dits " albanien " et « ibère ", et conclurons sur ce qu'un tel objet peut nous apprendre sur le Caucase comme middle ground entre nomades et sédentaires et contested ground entre Orient et Occident ${ }^{2}$.

\section{Un objet d'exception là où on ne l'attendait pas}

En 1893, près du village de Yenikend (Yenikənd), dans le district de Goychay/Geokchai (ainsi nommé d'après la rivière qui se déverse dans le Koura - ancien Kyros - , au centre de l'Azerbaïdjan, au sud du district de Qabala (Qəbələ) et au sud-ouest du district d'Ismailli (Ismaylllı) [ill. 1], on a découvert un des plus beaux plats d'argent doré de l'antiquité gréco-romaine. La trouvaille a été associée avec des armes en fer (une épée, un poignard, une armure envoyés en 1896 au musée de Tbilissi, que nous n'avons pu retrouver) et une monnaie en or, malheureusement jamais identifiée, car elle fut déclarée perdue dès $1894^{3}$. Après un passage assez obscur à Bakou entre les mains du négociant en tabac Egor Romanovich Mirzabekyants, le plat fut récupéré par la Commission impériale d’archéologie; il est conservé depuis 1898 au musée de l’Ermitage

2. Nous utilisons le concept de middle ground dans son sens original (R. White, The Middle Ground: Indians, empires, and republics in the Great Lakes region, 16501815, Cambridge, 1991): il s'agit de désigner un espace où deux groupes culturels échangent entre eux en vue d'un profit (économique mais aussi politique ou militaire). Chaque groupe emprunte les codes sociaux de l'autre, sans pour autant pouvoir imposer sa domination. L'expression contested ground fait référence aux disputes entre les puissances hégémoniques gréco-romaine et iranienne (arsacide et ensuite sassanide) concernant les espaces caucasiens, en particulier les régions situées au sud de notre Grand Caucase, désignées pendant l'Antiquité par les noms d'Albanie, d'Ibérie et d'Arménie. Ces appellations ont couvert des réalités différentes selon les époques et l'implication des grands empires - autant qu'on puisse en juger d'après nos sources fragmentaires, indirectes et anachroniques. Notre usage des noms des pays et peuples suit une vulgate historiographique remontant aux textes antiques, indépendamment des enjeux actuels.

3. Comme le montre la réponse du gouverneur de Bakou à la demande de la Commission archéologique impériale (№ 230/1894, conservée à l'Institut pour la culture matérielle de l'Académie russe des sciences de Saint-Pétersbourg), suivant R.V. Kinžalov, "Grustnaja Nereida », Kunstkamera ètnografičeskie tetradi 12 (1998), p. 293-307 (en ligne http://woman.upelsinka.com/history/antic_4.htm). 


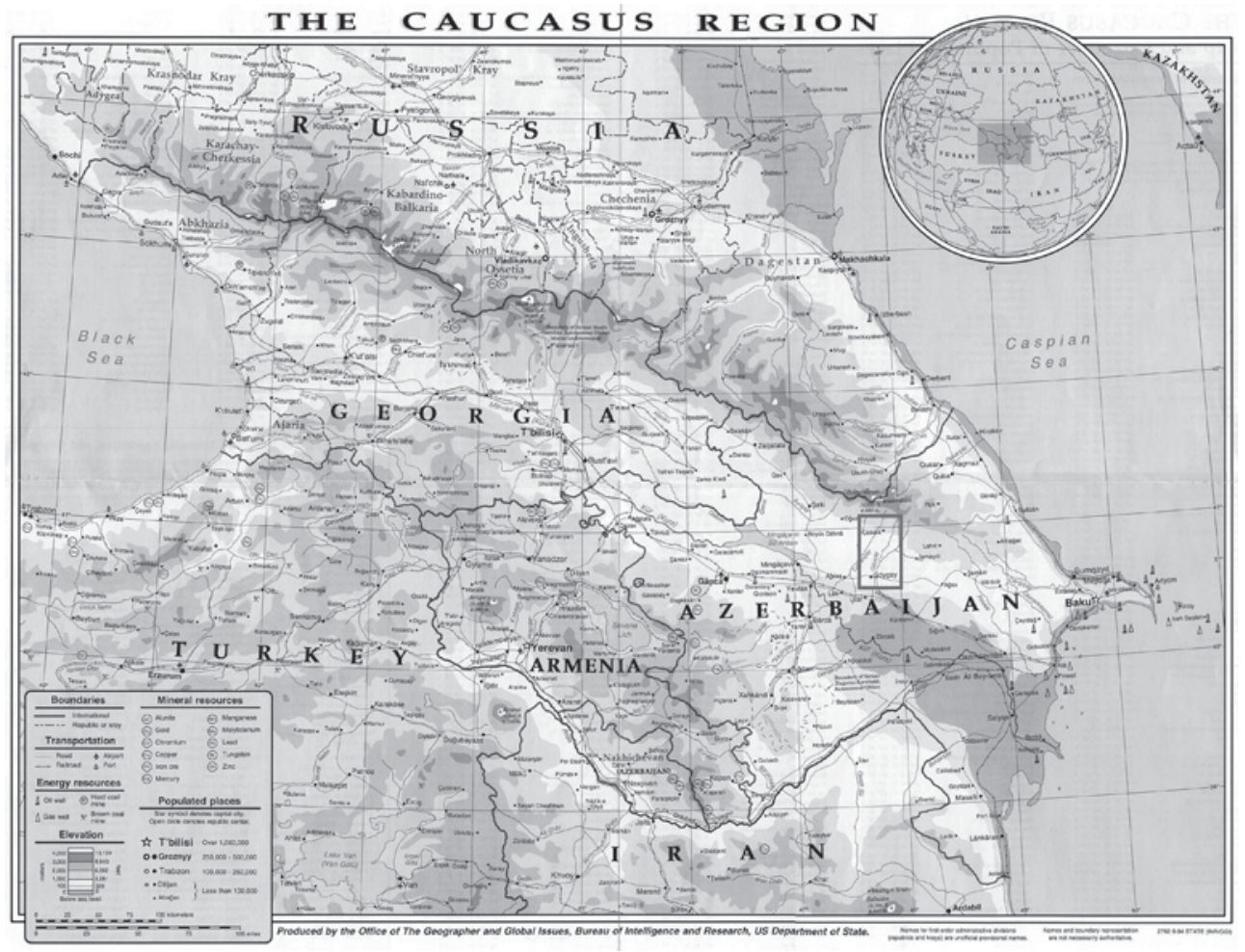

ILL. 1. Carte du Caucase produite par le Département d’État américain (2004), avec la zone de Goyçay et Qabala.

de Saint-Pétersbourg (Inv. no. K3 5308). Nous n'avons pas pu l'examiner directement, mais essaierons de donner ici quelques éléments de description, à partir des publications antérieures et des photos mises à disposition par l'Ermitage (ill. 2).

Le plat, rond, d'un diamètre de 24 centimètres, et d'un poids déclaré de 1030 grammes, s'appuie sur un pied circulaire d'un diamètre de 8,2 centimètres — c'est-à-dire trois fois plus petit que le diamètre total, comme cela semble avoir été la règle pour les plats gréco-romains de ce genre. Si ces valeurs sont exactes et si le plat n'a pas souffert de diminution depuis sa fabrication, son diamètre en unités de mesure romaines aurait été de dix onces (unciae). Son 


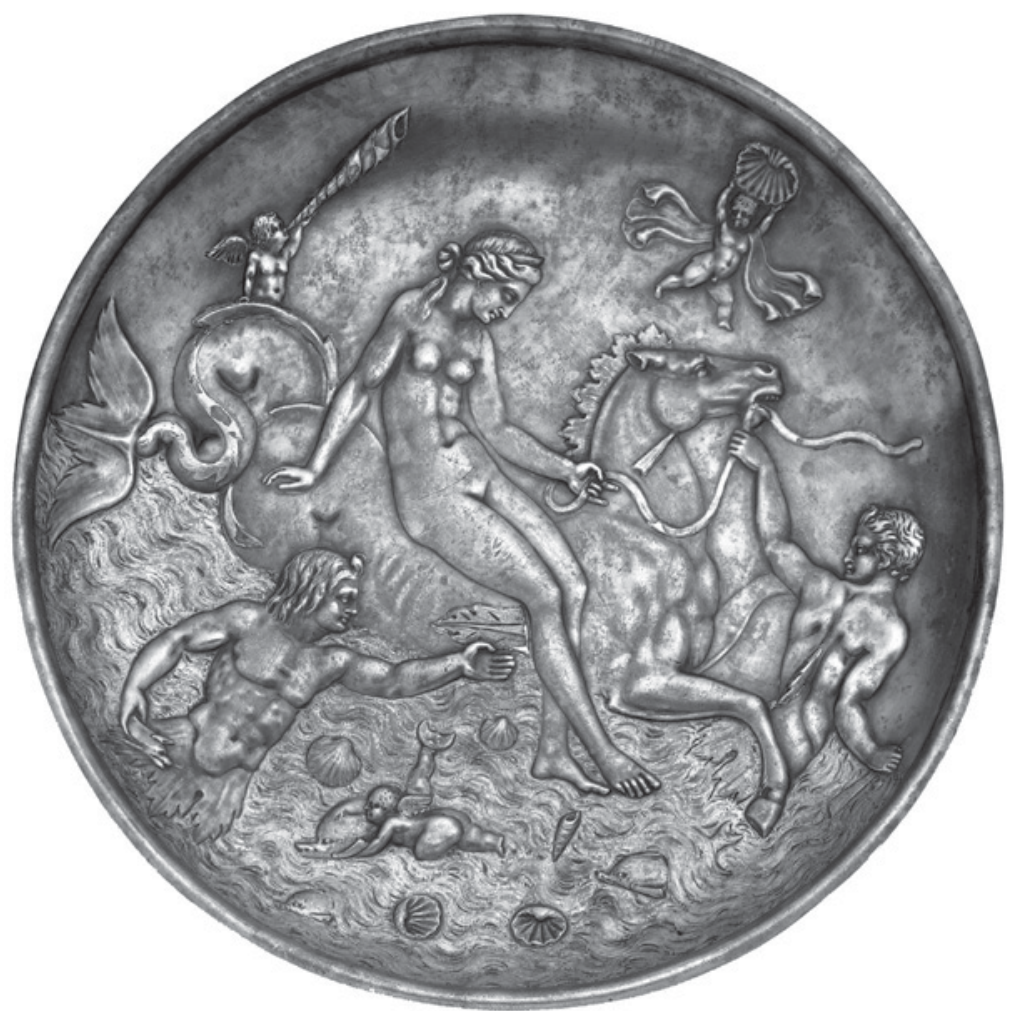

ILL. 2. Le plat de Yenikend. Musée de l’Ermitage, Inv. no. K3 5308. Photo Svetlana Suetova, reproduite avec la permission de l'Ermitage.

poids (d'environ trois livres) doit être apprécié en fonction du poids de l'argent dans le denier: il irait de quelque 300 deniers (pour un denier romain impérial de 3,4 grammes, sous les Julio-Claudiens) à 500 deniers (pour un dernier de 2,6 grammes d'argent, entre les derniers Antonins et les Sévères). En l'absence d'analyse de la composition de l'argent utilisé et devant le caractère assez approximatif des statistiques existantes sur le poids de l'argent dans les monnaies impériales, il est difficile de proposer une datation fiable sur la base de ces critères quantitatifs. Retenons, toutefois, que si l'argent du plat était assez pur, les 500 deniers auxquels aurait pu correspondre son poids entre les règnes de Marc-Aurèle (161-180 de notre 
ère) et Septime Sévère (193-211) - et tout particulièrement à partir de Commode (180-192) — équivaudraient à une somme ronde de 500 deniers, propre à servir de base de fabrication ${ }^{4}$. La valeur de la matière première (sans les frais d'artisanat) aurait correspondu à la solde d'une année (ou d'une année et demie) d'un légionnaire, avant déduction des frais de campagne ${ }^{5}$.

S'agissant de la technique de fabrication, le plat est composé de deux feuilles d'argent superposées et fixées ensemble au niveau de la lèvre, comme souvent à la haute époque. Le décor a sans doute été d'abord dessiné sur le dos de la feuille supérieure, qui est aujourd'hui entièrement recouvert par la seconde feuille d'argent, lisse, visible à l'extérieur et sous le pied du vase. Après avoir tracé les contours, l'artisan a probablement réalisé les formes décoratives par repoussé, à partir du dos, et par ciselure, à partir de la surface principale de la feuille supérieure; quelques raffinements ont pu être exécutés par incision. Finalement, certaines formes ont été couvertes par une dorure - ce qui pouvait se faire soit par l'impression d'une feuille d'or (peut-être sur la surface de la mer), soit par l'applica-

4. À titre de parallèle, le plat d'argent dit « Aulis ", pesant 1977 grammes, aurait pu correspondre à 500 deniers en Italie, au milieu du $\mathrm{I}^{\mathrm{er}}$ siècle avant notre ère: voir A. Dan, F. Grenet, Nicholas Sims-Williams, " Homeric Scenes in Bactria and India. Two Silver Plates with Bactrian and Middle Persian Inscriptions ", Bulletin of the Asia Institute 2014 [2018], p. 195-294. Pour le poids en argent du denier et les dévalorisations successives entre les derniers Antonins et les premiers Sévères, voir M. Corbier, " Dévaluations et fiscalité (161- 235) ", in Les " dévaluations " à Rome. Époque républicaine et impériale I. Actes du Colloque de Rome (1315 novembre 1975), Rome, 1978, p. 273-309; M. Corbier, " Coinage and Taxation: The State's point of view, A.D. 193-337 ", in A. K. Bowman, P. Garnsey, A. Cameron (éd.), The Cambridge Ancient History XII. The Crisis of Empire, A.D. 193-337, Cambridge, 20052, p. 327-392; A. Wassink, "Inflation and Financial Policy under the Roman Empire to the Price Edict of 301 A. D. ", Historia 40.4 (1991), p. 465-493; J. Hiernard, " Une source de l'histoire romaine: la monnaie impériale de Septime Sévère à Constantin », in Pallas. L'Empire romain de 192 à 325 (1997), p. 79-125; cf. J. France, « De Marc Aurèle à Constance II, le système financier de la paix romaine à l'épreuve de la guerre ", in J. Baechler, G.-H. Soutou (éd.), Guerre, économie et fiscalité: l'homme et la guerre, Paris, 2016, p. 71-84.

5. R. Alston, "Roman Military Pay from Caesar to Diocletian ", The Journal of Roman Studies 84 (1994), p. 113-123.; M. A. Speidel, « Roman Army Pay Scales Revisited: Responses and answers ", in M. Reddé (éd.), De l'or pour les braves! Soldes, armées et circulation monétaire dans le monde romain. Actes de la table ronde organisée par l'UMR 8210 à l'INHA (12 - 13 septembre 2013), Bordeaux, 2014, p. 53-62. 
tion d'un amalgame liquide d'or et mercure (probablement pour les détails plus fins). Dans tous les cas, cette dorure est encore en grande partie conservée. C'est une preuve de la fonction décorative, de prestige, du plat, qui n'a peut-être pas beaucoup servi comme vaisselle de table sur laquelle on aurait déposé des mets. Il semble avoir été bien préservé pour être, peut-être, exposé dans certaines occasions et finalement déposé dans une tombe, comme signe du rang social de son possesseur (voir infra). Nous disposons de plusieurs publications descriptives, proposant quelques parallèles iconographiques en phase avec le niveau des connaissances au milieu du $x^{e}$ siècle $^{6}$. Il n'y a pas encore, à notre connaissance, d'analyses scientifiques concernant l'origine de l'argent et les détails de fabrication.

Le décor représente une jeune femme nue, vue de trois quarts au milieu du vase, et chevauchant un des monstres marins les plus courants de l'iconographie gréco-romaine: l'hippocampe. Ce cheval de mer - sa partie antérieure est celle d'un cheval, la partie postérieure, derrière sa cavalière, se termine en queue de poisson ${ }^{7}-$

6. Otčet imperatorskoj arheologičeskoj komissii za 1896 god (1898), p. 113-114, ill. 410; L.A. Matzulewitsch, Byzantinische Antike: Studien auf Grund der Silbergefässe der Ermitage, Berlin-Leipzig, 1929, p. 35-36, 43 pl. 5; K.V. Trever, Očerki po istorii $i$ kul'ture Kavkazskoj Ajbanii: IV v. do n.è.- VII b. n.è., Moskva-Leningrad 1959, p. 24-25, 176-177 pl. 3; D.E. Strong, Greek and Roman Gold and Silver Plate, London, 1966, p. 198; K.V. Trever, « Bljudo serebrjanoe s izobraženiem nereidy: Rimskaja rabota IIIII vv. ", Sokroviša Ermitaža, Leningrad, 1969, nr.25; O. Ja. Neverov, Hudožestvennoe remeslo èpohi Rimskoj imperii (I v do n.è.- IV v.): katalog vystavki, Gosudarstvennyj Ermitaj, Leningrad, 1980, p. 46-47 n 127; J. M.C. Toynbee, K. S. Painter, « Silver Picture Plates from Late Antiquity: AD 300 to 700 », Archaeologia 108 (1986), p. 15-65 (p. 19, 36-37, nr. 37, pl. XVIc); N. Icard-Gianolio, A.-V. Szabados, « Nereides », in Lexicon Iconographicum Mythologiae Classicae 6 (1992), p. 785-824, nr. 208; R.V. Kinžalov, "Grustnaja Nereida ", art. cit; F. Althaus, M. Sutcliffe, The Road to Byzantium. Luxury arts of Antiquity, British Museum, London, 2006, p. 140 nr. 37.

7. Voir par ex. Pausanias 2.1.9; Philostrate l'Ancien, Images 1.8; Servius, Commentaire aux Géorgiques 4.387. Cf. B. Sauer, "Hippokamp ", in Roschers Lexikon der griechischen und römischen Mythologie $\mathrm{I}^{2}$ (1890), p. 2673-2677; H. Lamer, « Hippokampos ", in Paulys Real-Encyclopädie der classischen Altertumswissenschaft 16 (1913), col. 1748-1772; A. Rumpf, Die Meerwesen auf den antiken Sarkophagreliefs, Berlin, 1939 (réimpr. Roma, 1969; Die antiken Sakralrelief5.1), p. 114-117; S. Lattimore, The Marine Thiasos in Greek Sculpture, Los Angeles, 1976; Ch. Hünemörder, "Hippokampos ", in Der Neue Pauly, en ligne 2006 (http://dx.doi.org.janus.biu.sorbonne.fr/10.1163/15749347_dnp_e514510); C. Février, «De l'írлóкантоৎ à l'equus marinus. Le cheval de mer, ou les vicissitudes d'une figure double », Schedae 3.1 (2009), p. 33-46. 
galope vers la droite du spectateur. La femme, montant en amazone avec ses deux jambes sur le flanc droit de l'animal, se tient dans une position gracieuse, son corps épousant la forme d'un $\mathrm{S}$ qui fait écho aux bords ronds du vase. Sa tête est délicatement penchée en avant sur son épaule gauche, comme si elle tentait de compenser l'impulsion donnée par le saut de l'animal. En même temps, cette tête penchée pourrait être un signe de modestie et d'innocence, de mise pour une vierge issue des flots. Parfois, on y a vu l'expression d'une mélancolie, voire de la tristesse d'une vierge avant le mariage, puisque la candeur du personnage et le décor extérieur indiquent un lien avec l'amour (voir infra) . $^{8}$

Les détails du visage sont soigneusement dessinés: le personnage a les yeux en amande, avec les iris et les pupilles incisés, regardant vers l'avant, par-dessous les sourcils bien arqués. Le nez, bien marqué, est droit et long. Les lèvres, resserrées, sont assez charnues, signe de jeunesse et de sensualité; bien que la bouche reste fermée et n'esquisse pas de sourire, le visage dégage une sérénité juvénile certaine. Le menton légèrement en galoche et les pommettes saillantes complètent ce visage féminin quelque peu stéréotypé.

Les cheveux longs se séparent en mèches latérales, retournées autour d'un diadème dont on ne voit que la partie antérieure surélevée, triangulaire, avec quelques traces de dorure. Par-dessous la partie arrière, dissimulée, de cette couronne, les cheveux sont subtilement reliés derrière la nuque, d'où ils retombent sur les deux épaules. L'épaisseur des mèches ciselées diminue progressivement, jusqu'à se réduire à quelques incisions marquant des franges accolées à la peau. Sur le profil droit, on voit des accroche-cœurs incisés près du lobe délicat de l'oreille - signes de féminité mais également marques de la grande qualité du travail artisanal. Les trois mèches visibles sur le côté sont rehaussées et rattachées à la couronne, soulignant la fraîcheur de la jeune femme, peut-être même la sacralité du moment dans lequel on veut la représenter.

Les seins, exposés de face, sont parfaitement sphériques, comme le veut l'idéal gréco-romain de beauté d'une vierge. La musculature des bras, du torse et des jambes est ciselée et incisée avec grand

8. R.V. Kinžalov, « Grustnaja Nereida », art. cit. 
soin, pour évoquer à la fois la grâce féminine, la santé et la force de la jeunesse. La cavalière a les jambes légèrement croisées, le pied gauche sous le pied droit, tourné avec les orteils vers le spectateur. La longueur de ces orteils est supérieure à la proportion qu'on attendrait: cela s'explique sans doute par la volonté d'exprimer la grâce des jambes qui effleurent les flots. Le bras droit, doucement tendu, semble s'appuyer avec la paume ouverte sur la croupe de l'hippocampe. Le bras gauche est arqué vers la droite du spectateur, suivant la courbe du corps assis. Les doigts de la main gauche, que l'artiste a voulus parfaitement visibles, font un geste antinaturel pour quelqu'un qui voudrait vraiment tenir la rêne: l'index et le petit doigt sont tendus vers la droite, alors que le majeur et l'annulaire sont pliés, tenant la partie droite de la lanière, avec le pouce. La valeur apotropaïque de ce geste, bien attestée dans différentes cultures anciennes, de la Méditerranée à l'Iran et à l'Inde, persiste jusqu'à aujourd'hui: par un tel salut, on veut tenir loin le mal, la discorde, l'infidélité ${ }^{9}$. Puisque le personnage central fait ce signe en allant vers la droite, on peut supposer que le plat entier a été pensé comme un signe de bon augure pour le spectateur familier des superstitions romaines.

La posture de l'hippocampe est fortement dramatisée, comme souvent dans les scènes décoratives hellénistiques et romaines: l'artiste se plaît à insister sur les torsions des différentes parties de ce corps hybride. Il est saisi au galop, les deux membres antérieurs en l'air. La crinière, la queue et les nageoires de poisson (au niveau de la gorge, du passage de sangle et des fanons au-dessus des sabots) sont bien visibles au-dessus de l'eau. En ramenant la queue en écureuil devant le flanc visible de l'animal, l'artiste montre plus que sa virtuosité dans le trait des courbes: s'il connaît le langage corporel des chevaux, il veut sans doute exprimer l'excitation de l'animal. La tête est élevée, dressée vers l'avant; la mandibule tirée par la bride vers le bas laisse apparaître la dentition parfaite du maxillaire. L’oreille couchée vers l'arrière confirme l'impression de nervosité:

9. C.A. Bromberg, "An Iranian Gesture at Miran ", Bulletin of the Asia Institute 5 (1991), p. 45-58; voir aussi le geste de la nymphetria sur le plat indo-bactrien d'inspiration alexandrine, dit " des Grâces ", que nous avons publié dans A. Dan, F. Grenet, N. Sims-Williams, "Homeric Scenes... », art. cit. 
l'animal renâcle, refusant une soumission facile. Toutefois, malgré cette résistance, son corps reste stable au-dessus des flots, si bien que la jeune femme peut se tenir sans difficulté en équilibre. Un Triton imberbe - émergeant jusqu'à la ceinture d'écailles en forme de feuilles d'acanthe qui couvre son bas-ventre et marque l'articulation de son buste humain avec un corps de poisson totalement immergé ${ }^{10}$ - nage devant et contrôle l'hippocampe en tenant court la rêne de sa main gauche; la jeune femme retient la même du bout de ses deux doigts, sans la tendre, alors que de l'autre côté, l'autre bout de la lanière flotte dans les airs. Il y a un contraste saisissant, tout à fait irréaliste, entre la domination imposée à l'hippocampe par le jeune Triton mâle et la maîtrise gracieuse de la jeune femme.

L'artiste a fait preuve d'imagination et d'aisance dans la composition des formes, en intercalant le corps féminin, exposé en entier de face, entre les torses de deux Tritons qui se ressemblent sans être identiques. En effet, si le premier Triton, qui guide l'hippocampe, déploie de trois quarts son dos, laissant apparaître sa nageoire dorsale et des arêtes de sa nageoire caudale, le second nage parallèlement à l'hippocampe et affiche de face, également de trois quarts, la musculature de son vigoureux torse. Les deux se regardent, comme s'ils coordonnaient leurs mouvements sans se parler. Ils ont les bras gauches tendus vers la droite - le premier pour retenir l'hippocampe, le second pour secourir, en cas de besoin, la cavalière. Dans la main droite, repliée près du corps, le premier semble tenir une minuscule rame (gouvernail); le second tient un poisson monstrueux - sans doute un loup de mer ou un petit dauphin qui n'est pas bien dessiné11. Leurs sourcils très accentués et leurs mèches dont une ébouriffée en boucle au-dessus du front, rappelant l'aspect

10. A. Rumpf, Die Meerwesen..., op. cit., p. 101-107.

11. Cf. N. Icard-Gianolio, "Triton ", in Lexicon Iconographicum Mythologiae Classicae 8 (1997), p. 68-73, nr. 8, 11, 22 et 28 pour un poisson ou un dauphin; N. IcardGianolio, « Tritones ", in Lexicon Iconographicum... 8 (1997), p. 73-85, nr. 3, 7. Plus généralement sur l'évolution du Triton, K. Shepard, The Fish-tailed Monster in Greek and Etruscan Art, New York, 1940 (non uidi); N. Icard, A.-V. Szabados, "Cétacés et tritons, de la réalité à l'imaginaire ", in S. Llinares (éd.), Avec vue sur la mer. Actes du $132^{e}$ congrès national des sociétés historiques et scientifiques, Arles 2007, Paris, 2011, p. 9-23 (en ligne http://cths.fr/ed/edition.php?id=5686). 
hirsute des Satyres - soulignent leur nature monstrueuse d'amphibiens. Ainsi, comme dans la plupart des représentations romaines de grande qualité artistique, les deux Tritons forment un binôme générique et fonctionnel, tout en gardant chacun son identité ${ }^{12}$.

À travers les vagues dorées, qui couvrent la moitié inférieure du plat, trois dauphins de tailles variées nagent vers la gauche, à l'encontre de l'hippocampe. Les dauphins ont toujours séduit les Grecs et les Romains par leurs grâce, amitié et intelligence. Dans les textes et dans les représentations figurées de l'Antiquité, ils égaient souvent l'atmosphère d'une scène ${ }^{13}$. Comme sur d'autres images d'époque romaine impériale, un dauphin est attrapé par un putto ailé, bien charnu, dont il semble essayer de se défaire - à en juger d'après sa queue surélevée, qui échappe à l'étreinte du putto. Deux autres putti, à la surface de l'eau et dans les airs, complètent ce tableau dont on remarque l'harmonie des formes et des nombres ${ }^{14}$.

On pourrait croire que l'artiste a voulu mettre en avant la beauté et la vitalité de la nature marine, avec sa force, sa variété de formes, couleurs et sons, mais aussi avec ses curiosités, voire monstruosités. En réalité, il n’y a rien de naturel ni de naturaliste dans ce tableau: l'articulation des différents caractères et gestes bien connus de l'art gréco-romain suit des règles géométriques classiques. Ainsi, le disque intérieur du plat est décoré à moitié par des incisions et est couvert de la dorure - correspondant aux vagues de la mer; l'autre moitié, de fond lisse et couleur d'argent, correspond au ciel ouvert. Sur la ligne

12. N. Icard-Gianolio, " Tritones... ", art. cit., nr. 88 lorsqu'ils encadrent Aphrodite, mais aussi 31-34, 39, 50, 59, 72, 77-79, 92-93, 97. Voir, plus généralement, F. R. Dreßler, "Triton, Tritonen ", in Roschers Lexikon... 4 (1909-1915), col. 11501207; A. Boulanger, "Triton ", in Le dictionnaire des Antiquités grecques et romaines de Daremberg et Saglio 5 (1912) p. 483-486; A. Ambühl, W. Huß, Werner, "Triton ", in Der Neue Pauly, en ligne 2006 (http://dx.doi.org.janus.biu.sorbonne. fr/10.1163/1574-9347_dnp_e1221040); M.L. Neira Jiménez, « De Tritón a tritones. Su iconografía en los mosaicos romanos ", Tritão - Revista de História, Arte e Património (Revista de la Cámara de Sintra, Portugal), 2 (2014), p. 1-24.

13. Cf. J. Delorme, Ch. Roux, Guide illustré de la faune aquatique dans l'art grec, Juan-les-Pins 1987, p. 77-79, 152-155; pour l'histoire des différents types: B.S. Ridgway, « Dolphins and Dolphin-Riders ", Archaeology 23 (1970), p. 86-95.

14. Pour l'iconographie du putto, voir R. Stuveras, Le putto dans l'art roman, Bruxelles, 1969, p. 153-164 (en contexte marin); cf. aussi p. 127-135 (en association avec Vénus). 
médiane séparant les deux moitiés, il y a trois personnages - un putto, la jeune femme et le Triton précédant l'hippocampe; un putto complète un triangle formé par ces personnages dans le demi-cercle supérieur, alors que le second Triton complète un triangle analogue dans le demi-cercle marin, inférieur, du décor. Ces deux triangles sont d'ailleurs les deux moitiés d'un carré imaginaire, que l'artiste semble avoir inscrit dans le grand cercle (en marquant les quatre angles par les deux Tritons et les deux putti, suivant le schéma classique du «triomphe " ou " couronnement de Vénus ", voir infra). Cet emboîtement des formes géométriques peut être un simple artifice technique, pour mettre en ordre une composition qui devait intégrer certains repères formels et structurels facilement discernables par le public. Autrement, si l'on pense en termes philosophiques, le grand cercle comprenant un carré composé de triangles peut relever aussi d'une certaine vision platonicienne (et néopythagoricienne), banalisée, du monde. Cette interprétation n'est pas exagérée si l'on pense que la signification des nombres et des formes géométriques faisait, à l'époque impériale, partie de la "philosophie populaire », apprise par tous ceux qui auraient pu acheter ce plat ${ }^{15}$.

$\mathrm{Au}$ centre, la cavalière est une jeune beauté divine, liée à la mer dont elle vient de sortir, comme semblent l'indiquer ces cheveux encore humides. Outre ses serviteurs hybrides, issus d'une longue tradition iconographique, il y a des animaux marins - dauphins, mollusques et gastéropodes - tous dotés de significations mythiques et iconographiques qui devaient être bien connues du public romain ou romanisé à l'époque de la fabrication du vase. On compte cinq coquilles Saint-Jacques (pecten Jacobaeus ou le plus répandu pecten

15. La théorie platonicienne de la réduction des parties du monde à des formes géométriques (et donc à des nombres) apparaît dans le Timée (Th. K. Johansen, Plato's Natural Philosophy. A study of the Timaeus-Critias, Cambridge, 2004); elle est reprise à la fin de l'époque hellénistique et au début de l'époque romaine, entre autres, dans le traité du Pseudo-Timée (M. Baltes, Timaios Lokros. Über die Natur des Kosmos und der Seele, Leiden, 1972) et dans celui du Pseudo-Aristote, Sur le monde, un bon exemple de " philosophie populaire ", enseignée dans les écoles (A. Dan, K. Geus, "Weaving Landmarks in Common Sense Geography: Numbers in Pseudo-Aristotle's On the World ", in K. Geus, M. Thiering (éd.), Common Sense Geography II, à paraître). Sur la philosophie populaire hellénistique et romaine, voir J. C. Thom, « Popular Philosophy in the Hellenistic-Roman World », Early Christianity 3 (2012), p. 279-295. 
maximus), reconnaissables à leurs côtes en éventail: quatre coquilles sont représentées dans les vagues, deux vues de l'extérieur et deux autres, sectionnées à moitié, vues de l'intérieur; une autre valve est affichée, avec sa partie intérieure, au-dessus de toutes les têtes, en guise d'emblème ou de couronne (voir infra), par un putto flottant dans les airs, devant l'hippocampe ${ }^{16}$. Ces coquilles ne sont donc ni vivantes, ni dans leur milieu d'origine (les bas-fonds, où le courant est faible): c'est la forme de la coquille et sa signification qui justifient le soin avec lequel l'artiste les a représentées.

Cela est également le cas des gastéropodes: l'artiste s'est efforcé de marquer les différences entre un escargot marin utilisé comme instrument musical, tel une conque ou un buccin, par le putto assis sur la queue de l'hippocampe, et la coquille d'escargot qui flotte au milieu des vagues. Le premier, en haut à gauche quand on regarde le plat, est un escargot de mer de la superfamille des Cerithioidea - à laquelle appartiennent, entre autres, les Turritellidae. Bien qu'elles ne fussent pas les seuls gastéropodes en spirale - les Epitoniidae auraient pu également servir de modèle -, l'identification avec une des Turitellidae semble préférable, à cause de la forme convexe de la spirale et de son ouverture ronde. Ce coquillage apparaît donc comme une expression de la virtuosité, d'une part, de l'artiste et de l'artisan du plat, et, d'autre part, du putto qui l'utilise pour communiquer sur l'événement symbolisé par l'ensemble de la décoration ${ }^{17}$. Quant au gastéropode des flots, également spiralé mais de surface lisse, il semble appartenir plutôt à la famille des Neritidae, tout à fait remarquables par la beauté de leur forme et de leur coloris (voir infra).

Il ne fait donc pas de doute que tous les éléments ont été choisis avec soin, pour des raisons artistiques et symboliques. La reconstitution du contexte d'origine - dans les limites de la documentation préservée - nous permet d'espérer parvenir à apprécier le plat comme pouvait le faire le public cultivé (autrement dit, « hellénisé » et « romanisé »), auquel il était directement adressé.

16. Pour l'identification, voir J. Delorme, Ch. Roux, Guide..., op. cit., p. 21-22, 98-99 (fig. 3-4).

17. Voir A. Zucker, «Album mythique des coquillages voyageurs. De l'écume au labyrinthe ", Techniques et culture 59 (2012), p. 110-125 (en ligne https://journals. openedition.org/tc/6578): " De l'escargot de mer (et du génie du labyrinthe) ». 


\section{Charme et mystères de la mer, des Antonins aux Sévères}

Il n'est pas facile d'identifier le personnage central. Toutefois, son identité est essentielle pour écrire l'histoire du vase. Nous tenterons dans les pages suivantes d'expliquer les raisons et les enjeux des interprétations possibles, afin de comprendre au mieux la réception du plat dans son contexte de fabrication, à l'intérieur de l'Empire romain et ensuite sur ses marges, dans le Caucase.

\section{Une des nombreuses filles de Nérée?}

Pour nombre d'historiens et d'archéologues, l'identification ne pose pas vraiment de problème. Les monstres marins en général et les hippocampes en particulier servent de moyen de locomotion ou de compagnons de nage aux Néréides, depuis l'époque grecque archaïque, en peinture, sculpture ou mosaïque ${ }^{18}$. La beauté, la nudité et le lien de notre cavalière avec l'univers marin confortent cette thèse: les Néréides apparaissent comme des jeunes femmes partiellement dévêtues à partir de la fin de l'époque classique: elles commencent alors à être représentées selon les types iconographiques des Aphrodites dénudées ${ }^{19}$. Elles sont entièrement nues, le corps de plus en plus frontalement exposé à partir du $\mathrm{I}^{\mathrm{er}}$ siècle avant notre ère et du Ier siècle de notre ère. (ill. 3 et 4). Dans la seconde moitié du $\mathrm{II}^{\mathrm{e}}$ siècle, sous les règnes de Marc-Aurèle et de Commode, elles ont complètement perdu le voile qui leur servait d'accessoire vestimentaire et locomoteur (ill. 5). Cette perte du

18. Cf. supra n. 7.

19. En général, pour l'évolution des représentations littéraires et iconographiques des Néréides, voir surtout P. Weizsäcker, "Nereïden ", in Roschers Lexikon... 3 (1897-1902), col. 207-240; G. Herzog-Hauser, « Nereiden », in Real-Encyclopädie... 17.1 (1936), col. 1-23; N. Icard-Gianolio, A.-V. Szabados, " Nereides », in Lexicon Iconographicum..., 6 (1992), p. 785-824; S.-G. Miller, « Eros and the Arms of Achilles », American Journal of Archaeology 90 (1986), p. 159-170; M. L. Neira Jiménez, "Representaciones de nereidas. La pervivencia de algunas series tipológicas en los mosaicos romanos de la Antigüedad Tardía ", in La tradición en la Antigüedad Tardía. Antigüedad y cristianismo 14 (1997), p. 363-402. Cf. l'évolution analogue des représentations des Nymphes: M. Halm-Tisserant, G. Siebert, "Nymphai », in Lexicon Iconographicum... 8 (1997), p. 891-902; J.-L. Larson, Greek Nymphs: Myth, cult, lore, Oxford, 2001. 
voile reste toutefois assez rare et, autant que l'on puisse en juger à partir des documents publiés aujourd'hui, elle semble confinée à la période comprise entre la fin ${\mathrm{du} \mathrm{II}^{\mathrm{e}}}^{\mathrm{e}}$ et le $\mathrm{III}^{\mathrm{e}}$ siècle, avant la diffusion des auras ${ }^{20}$. Les représentations des Néréides peuvent donc être comparées à l'évolution du modèle des trois Charites/Grâces, compagnes d'Aphrodite/Vénus, qui exposaient leur nudité complète de face et de dos, en tant que divinités sanitaires des bains, depuis la haute époque romaine ${ }^{21}$. Issues des rêves des marins, qui se plaisent à personnifier l'attrait et les dangers de la mer sous la forme de l'Autre - jolie femme et/ou animal monstrueux —, les filles du dieu grec Nérée apparaissent comme des modèles de beauté féminine, au même titre qu'Aphrodite/Vénus et les autres déesses marines, et en contraste avec l'étrangeté des êtres fantastiques qui les portent sur les vagues. Favorables et agréables aux dieux, aux héros, aux humains et aux animaux en tout genre, les Néréides symbolisent l'attrait des multiples traversées, d'un rivage à l'autre sur une mer ou d'un bout à l'autre d'une vie ${ }^{22}$. On en fait donc des éléments de

20. Par ex. N. Icard-Gianolio, A.-V. Szabados, " Nereides... », art. cit., nr. 127 (mosaïque des thermes de Trajan à Acholla), 237 (plaque d'or égyptienne, musée du Louvre X.5340, $\mathrm{III}^{\mathrm{e}}$ siècle de notre ère). On pourrait y ajouter les mosaïques de la Maison de Neptune à Acholla, présentant des Néréides sans aucun voile $\left(\mathrm{n}^{0} 13\right.$, $18,19,21$ ) ou avec un voile qui n'a plus aucune fonction vestimentaire, ni de navigation. Les sondages archéologiques ont assuré une datation pendant la deuxième moitié du $\mathrm{II}^{\mathrm{e}}$ siècle de notre ère: voir S. Gozlan, A. Bourgeois, A. El Fourgi, F. Jannin, R. Prudhomme, La Maison du triomphe de Neptune à Acholla (Botria, Tunisie). I. Les mosaïques, Rome, 1992; cf. déjà S. Gozlan, « Les pavements en mosaïques de la Maison de Neptune à Acholla-Botria (Tunisie) ", in Monuments et mémoires de la Fondation Eugène Piot 59 (1974), p. 71-135. De même, la mosaïque de la naissance de Vénus à Cártama (Málaga) est datée de la fin du II $^{\mathrm{e}}$ siècle de notre ère: M.P. San Nicolás Pedraz, "Seres mitologicos y figuras alegóricas en los mosaicos romanos de Hispania en relación con el agua », Espacio, Tiempo y Forma. Serie II. Historia Antigua 17-18 (2004-2005), p. 301-333 (en ligne https://doi. org/10.5944/etfii.1718.2004.4429), p. 307 et fig. 5.

21. E.B. Harrison, "Charites ", in Lexicon Iconographicum... 3 (1986), p. 191-203; H. Sichtermann, "Gratiae », in Lexicon Iconographicum... 3 (1986), p. 203-210; D. Manacorda, «Per una lettura iconografica delle tre Grazie », in I. Colpo, G. Ghedini (éd.), Il gran poema delle passioni e delle meraviglio: Ovidio e il repertorio letterario e figurativo fra antico e risocerta dell'antico. Atti del convegno (Padova, 15-17 settembre 2011), Padova, 2012, p. 463-476.

22. Pour l'étymologie, voir F. Bader, "Autour de Thétis la Néréide ", in F. Jouan (éd.), Mort et fécondité dans les mythologies. Actes du colloque de Poitiers 13 au 

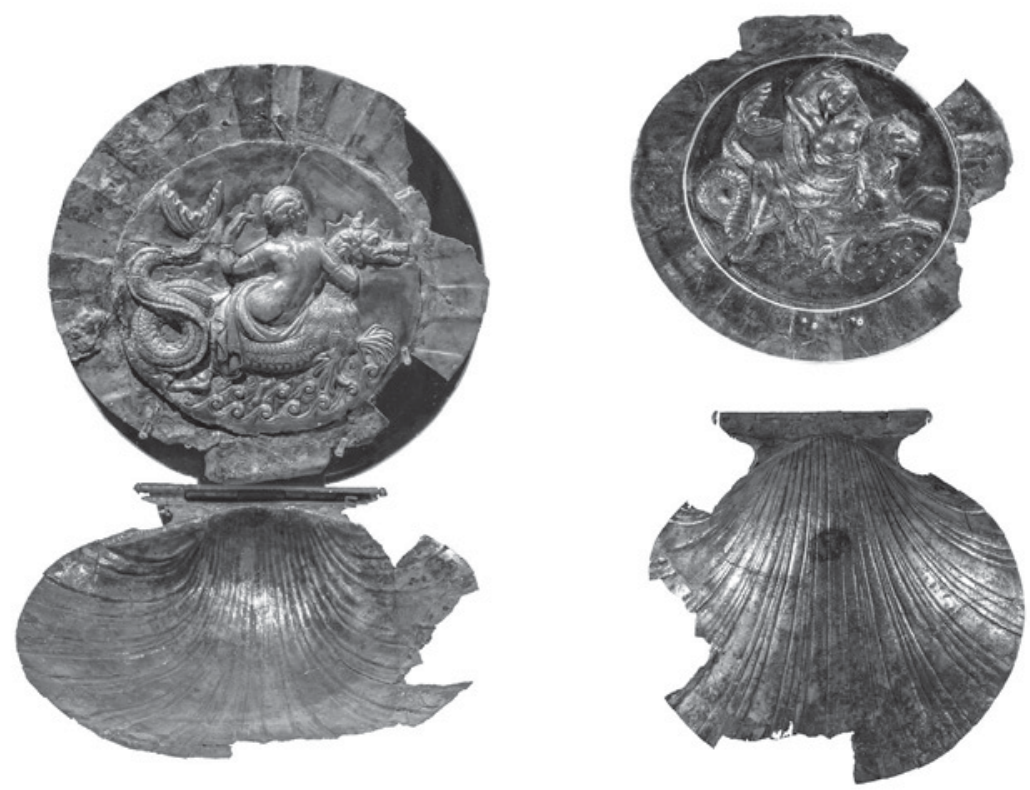

ILL. 3. Boîte de cosmétique en argent, en forme de coquille Saint-Jacques, seconde moitié du $\mathrm{III}^{\mathrm{e}}$ siècle avant notre ère. Museo archeologico nazionale di Taranto, inv. 22429-22430. Photo reproduite avec l’accord du musée.

décoration passe-partout, car adaptés d'égale façon aux espaces sacrés, publics ou privés, aux repas des hommes, aux loisirs des femmes et au repos des morts.

Depuis la haute époque hellénistique jusqu'à la fin de l'Antiquité, on se plaît à multiplier les angles de vue, leurs traits physiques ou les espèces des monstres qu'elles chevauchent, dans des poses plus ou moins acrobatiques. Ainsi, on observe le succès de la paire de

14 mai 1983, Paris, 1986, p. 19-37; plus généralement, L. M. Slatkin, The Power of Thetis: Allusion and interpretation in the Iliad, Berkeley, 1991, et J.-M. Barringer, Divine Escorts. Nereids in Archaic and Classical Greek art, Ann Arbor, 1995; dernièrement, A. Ambühl, « Nereiden », in Der Neue Pauly..., en ligne 2006 (http://dx.doi. org.janus.biu.sorbonne.fr/10.1163/1574-9347_dnp_e820480); sur la signification de la nudité, M.L. Neira Jiménez, « Desnudo y atracción en los mosaicos. Venus, Europa y las nereidas ", in M.L. Neira Jimenez (éd.), Desudo y Cultura. La construcción del cuerpo en los mosaicos romanos, Madrid, 2013, p. 32-47. 

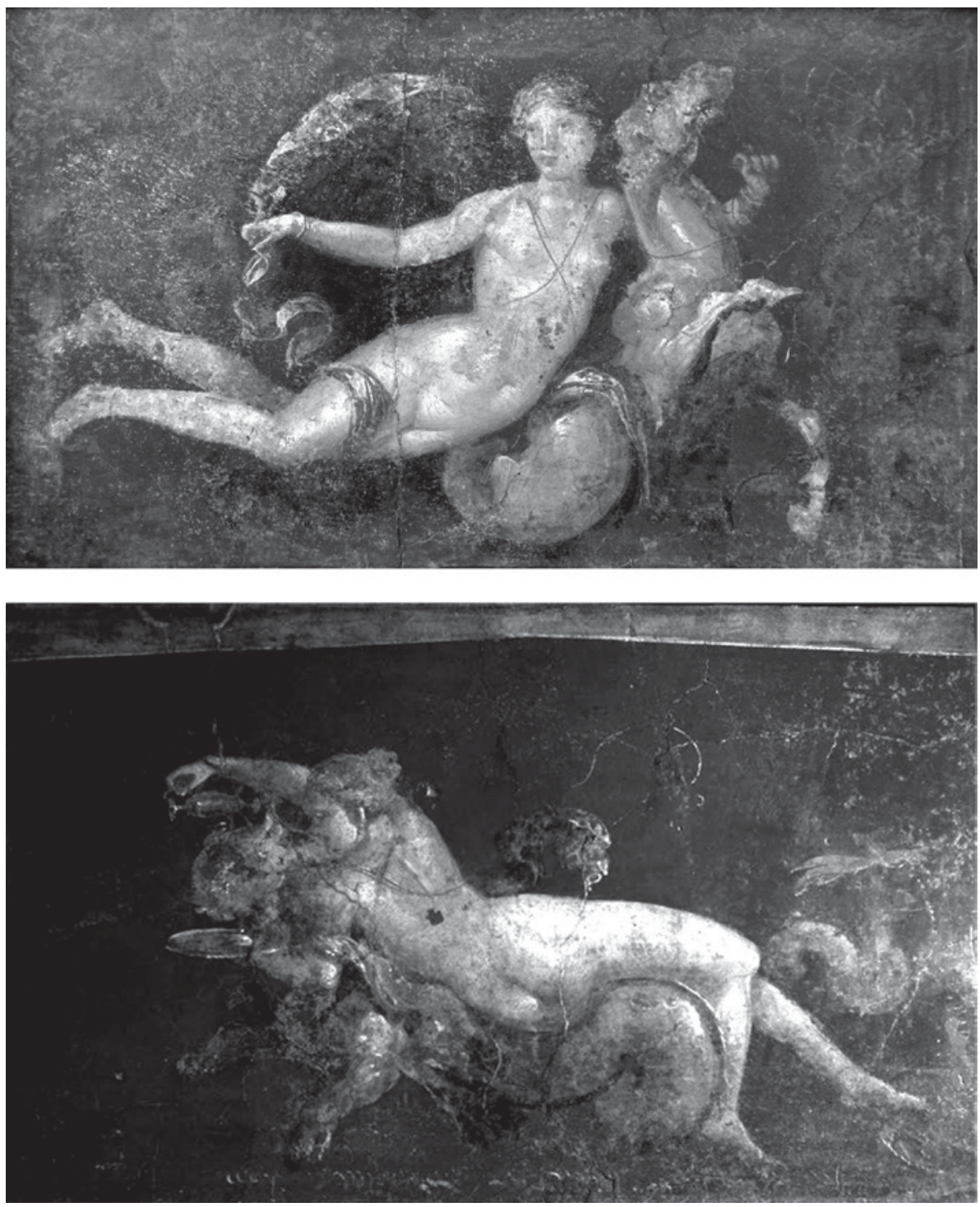

ILL. 4. Fresque de la Villa Arianna de Stabies, antichambre $8 ; 4^{\mathrm{e}}$ style, 54-68 de notre ère. Museo Archeologico Nazionale di Napoli, inv. 8859 and 8870. Photos @ Alix Barbet (Base " Décor antique " CNRS Paris). Su concessione del Ministero dei Beni e delle Attività Culturali-Museo Archeologico Nazionale di Napoli. 


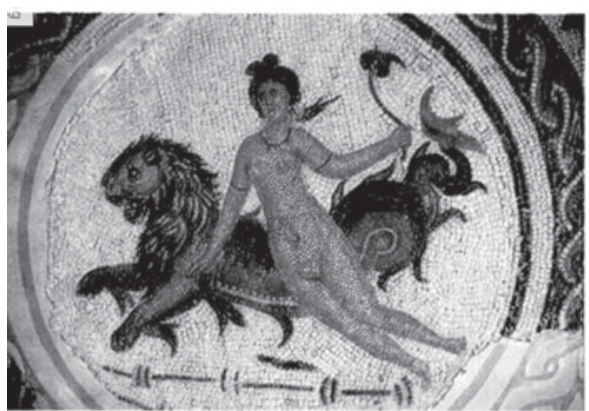

$1-\mathrm{N}$ - 53. Médaillon 19

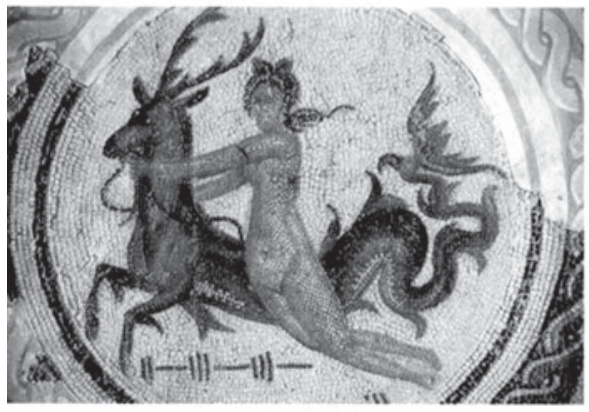

3- N-53. Medaillon 21

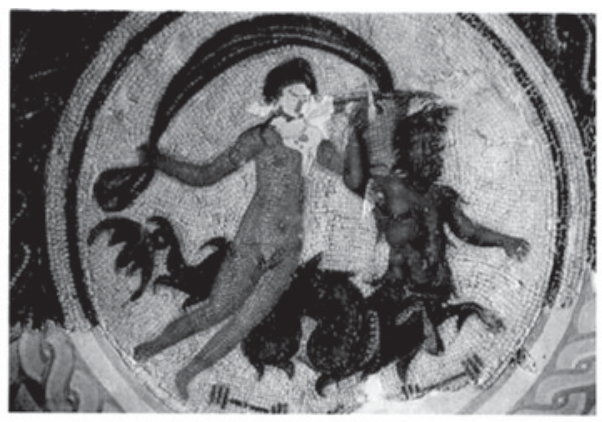

2 - N-53. Medaillon 20

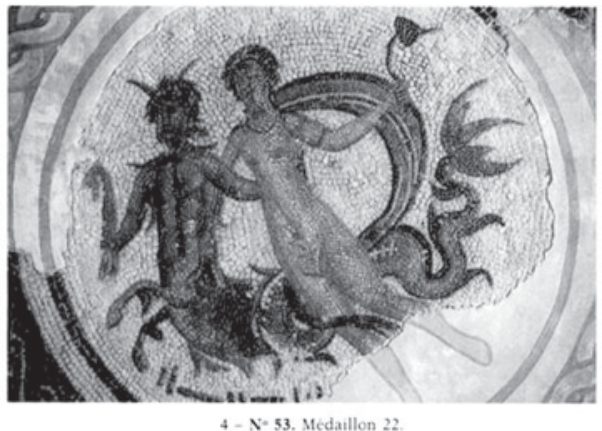

ILL. 5. Exemples de médaillons à Néréides à Acholla, d'après S. Gozlan, A. Bourgeois, A. El Fourgi, F. Jannin, R. Prudhomme, La Maison du triomphe de Neptune à Acholla (Botria, Tunisie). I. Les mosaïques, Rome, 1992, pl. LXXX.

Néréides cavalières, l'une vue de face, l'autre vue de dos, depuis la haute époque hellénistique, quand fut fabriquée la fameuse boîte à cosmétiques en forme de coquille Saint-Jacques, tournée et ciselée en argent doré et à incrustation de grenats, du musée de Tarente (ill. 3). La coque supérieure, qui sert de couvercle, a un double décor: sur la face extérieure, une Néréide, à moitié nue, dévoile ses seins en chevauchant une panthère marine; à l'intérieur, une autre Néréide, vue de dos, laisse apparaître sa cuisse alors qu'elle galope sur un hippocampe ${ }^{23}$. Au premier siècle de notre ère, sur les fresques de la Villa Arianna à Stabies (54-68 de notre ère, quatrième style pompéien), deux Néréides analogues révèlent leurs couleurs: l'une,

23. N. Icard-Gianolio, A.-V. Szabados, « Nereides... », art. cit., nr. 40. 

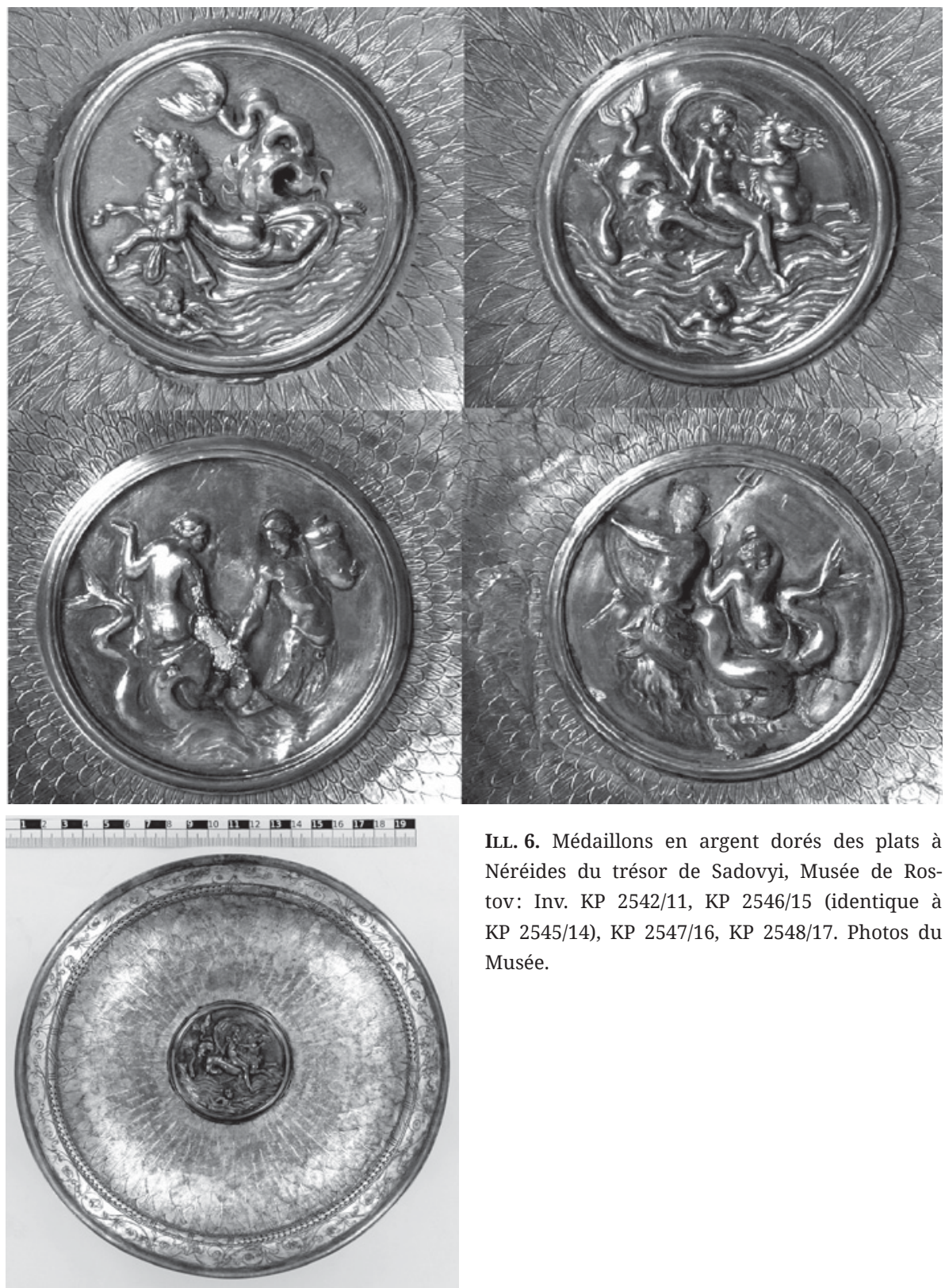

ILL. 6. Médaillons en argent dorés des plats à Néréides du trésor de Sadovyi, Musée de Rostov: Inv. KP 2542/11, KP 2546/15 (identique à KP 2545/14), KP 2547/16, KP 2548/17. Photos du Musée. 
cheveux bruns, vue de face, chevauche un hippocampe; l'autre, blonde, vue de dos, chevauche et abreuve une panthère marine $\left(\right.$ ill. 4) ${ }^{24}$. La même variation se retrouve sur la vaisselle de table, dans des séries thématiques comme celle du kourgane de Sadovyi (premier siècle de notre ère, ill. 6) ${ }^{25}$. Les huit coupes en argent doré découvertes avec un bassin en argent et deux chaudrons en bronze, sans doute pour rappeler le banquet funéraire, sont décorées de médaillons centraux à thématique ludique, bachique et érotique. Cinq médaillons comprennent des Néréides: trois (dont une vue de face et deux identiques vues de dos) chevauchent des hippocampes, en compagnie de putti ('Erôtes/Amours) nageurs; deux sont conduites par des Tritons portant des armes et une cuirasse. Avec les Amours, les Psychai et le Silène des autres médaillons, ces Néréides avec leurs monstres marins forment une véritable série de divinités liées aux plaisirs et aux ennuis de la vie humaine, qu'on peut résumer aux tumultes du banquet, de l'amour et de la guerre.

Jusqu'au $\mathrm{II}^{\mathrm{e}}$ siècle de notre ère, les artistes ont tant multiplié les poses des Néréides et les monstres auxquels elles pouvaient être attachées qu'on s'est mis à les représenter sur d'immenses mosaïques-inventaires. Ce sont de véritables exercices de virtuosité des artistes qui forcent leur imagination tout en restant à l'intérieur d'un canon iconographique relativement simple (ill. 7) ${ }^{26}$. De temps à l'autre, on peut leur associer des 'Erôtes, avec ou sans dauphins

24. O. Elia, Pitture di Stabia, Napoli, 1957, p. 65-69; A. Allroggen Bedel, « Die Wandmalereien aus der Villa in Campo Varano (Castellammare di Stabia) ", in Rheinisches Museum 84 (1977), p. 27-89; I. Bragantini, V. Sampaolo, L. Spina, La pittura pompeiana, Napoli, 2009, p. 449 nr. 238a-b (avec bibliographie).

25. V.M. Kossianenko, " Les phiales et phalères du kourgane Sadovyi ", in V. Schiltz (dir.), L'Or des Amazones. Peuples nomades entre Asie et l'Europe. $\mathrm{VI}^{e}$ siècle avant J.-C. - IV siècle après J.-C., musée Cernuschi, 16 mars-15 juillet 2001, Paris, 2001, p. 194-202, nr. 219-223.

26. J.-P. Laporte, H. Lavagne, "Sousse: la domus de Sorothus et ses mosaïques », Comptes-rendus de l'Académie des Inscriptions et Belles-Lettres 150.2 (2006), p. 1327-1392. De fait, le catalogue des Néréides est un motif littéraire homérique, remontant à l'Iliade 18.38-49. Pour la variation des poses des 'Erôtes, combinées à celle des Néréides, voir aussi la mosaïque du triomphe de Neptune à Utique (conservée au musée du Bardo et datée entre le $\mathrm{II}^{\mathrm{e}}$ et le $\mathrm{III}^{\mathrm{e}}$ siècle de notre ère): K.M.D. Dunbabin, The Mosaics of Roman North Africa: Studies in iconography and patronage, Oxford, 1978, p. 153-156. 
Galatée au pays des Amazones

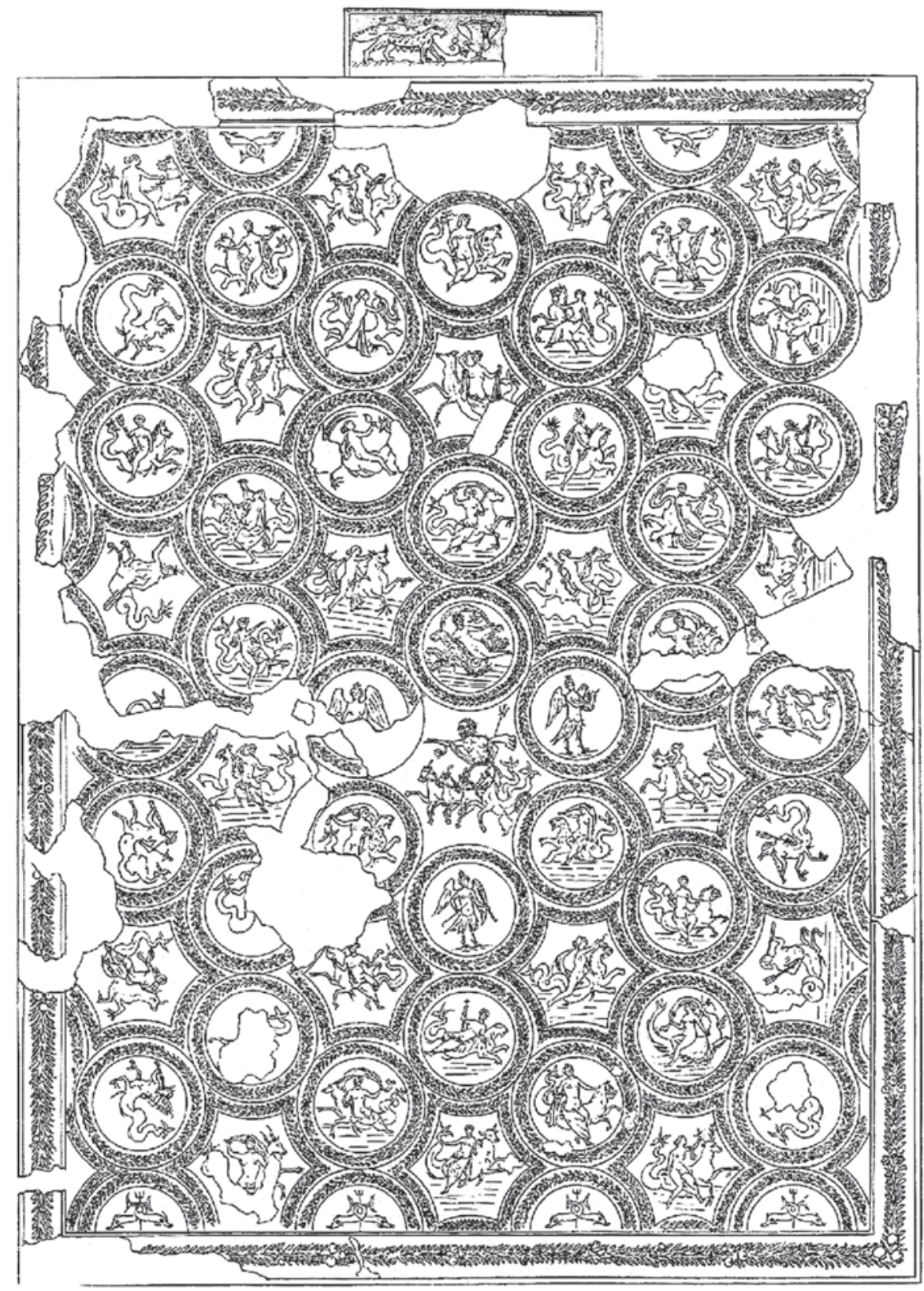

ILL. 7. Dessin d'après la mosaïque à Néréides de la domus de Sorothus à Sousse : d'après J.-P. Laporte, H. Lavagne, «Sousse: la domus de Sorothus et ses mosaïques ", Comptes-rendus de l'Académie des Inscriptions et Belles-Lettres 150.2 (2006), p. 1327-1392. 


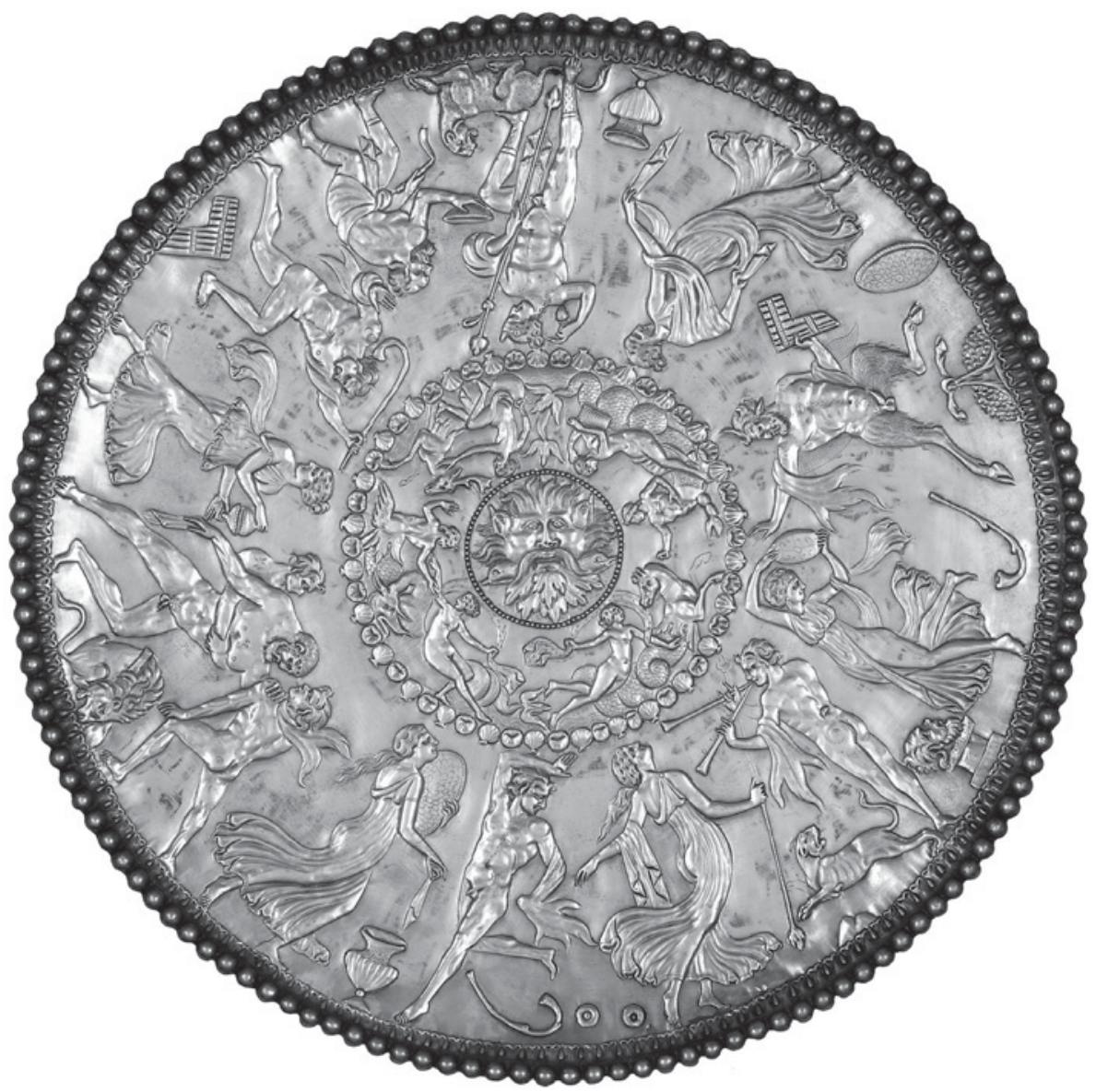

ILL. 8. Plat principal du trésor de Mildenhall, British Museum, Inv. 1946,1007.1. Photo @ British Museum.

et autres éléments de la faune marine, soit pour attirer l'attention sur leur pouvoir de séduction, soit pour évoquer les mythes relatant leurs unions transgressives avec des dieux, des monstres ou des hommes ${ }^{27}$. Ces traditions littéraires et iconographiques restent vivantes jusqu'à la fin de l'Antiquité, en contexte chrétien, comme en témoigne le grand plat dionysiaque du trésor de Mildenhall (en fait découvert à West Row, Suffolk, Royaume-Uni, en 1942, avec 34 autres

27. Cf. les inventaires de sources supra n. 19. 


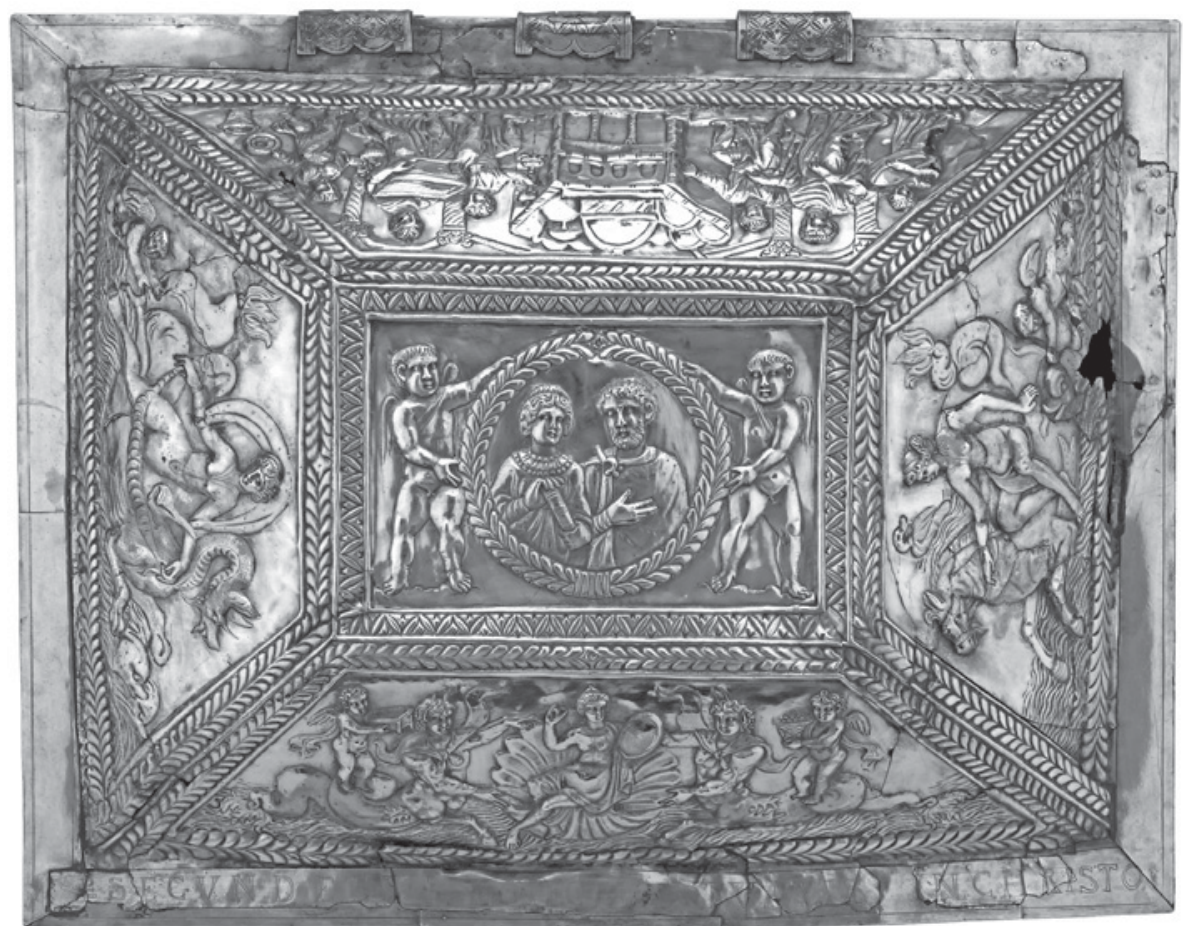

ILL. 9. Le coffret de Projecta du trésor de l’Esquilin, conservé au British Museum, Inv. 1866,1229.1. Photo (c) British Museum.

pièces de vaisselle romaine en argent, conservées au British Museum, ill. 8) ${ }^{28}$. Tout autour de la tête d'Océan - qu'il faudrait comprendre comme la rivière cosmique -, à l'intérieur d'un cercle marqué par des coquilles Saint-Jacques, il y a une série de quatre Néréides, dont deux chevauchent respectivement un hippocampe et un cerf-de-mer, vues de face et de dos, alors que, intercalées, deux autres Néréides s'entretiennent avec un Triton et un centaure marin. L'alternance de leurs positions finit par suggérer un retournement complet du corps nu de la belle déesse des profondeurs, comme dans une danse qui comprend toute la sphère des eaux, dans laquelle Dionysos/Bacchus

28. J.M. C. Toynbee, K. S. Painter, «Silver Picture Plates... », art. cit., p. 16-17, 22-24, nr. 1, pl. VIIa; dernièrement, R. Hobbs et al., The Mildenhall Treasure: Late Roman silver plate from East Anglia, London, 2016 (en ligne www.britishmuseum.org/ pdf/200_Mildenhall.pdf). 
a plongé pour échapper à Lycurgue et d'où il a ramené Ariane, alors qu'il étendait sa puissance autour de l'orbe terrestre. À la même époque, on a fabriqué le coffret en forme de tronc de pyramide et en argent doré du trésor de l'Esquilin (ill. 9). Le couvercle a cinq faces: sur la surface supérieure, rectangulaire, deux 'Erôtes/Amours présentent le portrait conjoint de deux époux chrétiens, pour le mariage desquels on a probablement réalisé cette œuvre. Des quatre panneaux trapézoïdaux latéraux, richement décorés, l'un représente la naissance et la toilette de Vénus marine au sein d'une coquille, soutenue par deux centaures marins sur lesquels se tiennent des Amours porteurs de dons. Sur la largeur opposée, six personnages divisés en deux groupes de trois se faisant face vont aux bains; l'un d'entre eux tient une boîte sans doute analogue à celle qui sert de support à ces représentations. Entre ces deux tableaux, sur les côtés courts du couvercle, deux Néréides chevauchent de face et de dos un hippocampe et un autre monstre marin (grec kêtos) ${ }^{29}$. Ici comme sur d'autres objets en métal, sur les fresques et les mosaïques, les Néréides relèvent d'un motif décoratif commun, qui permet de remplir l'espace de manière esthétique, harmonieuse, respectueuses des canons habituels. Parfois, on peut leur attribuer un sens fort, de divinités aquatiques de la beauté et de l'étrangeté, des jeux et des enjeux de la vie comme grand passage vers l'Au-Delà. Quel que soit le sens, faible ou fort, de ces représentations, aussi variées fussent-elles, l'iconographie de la Néréide reste facilement reconnaissable.

29. Pour le trésor en général, voir K.J. Shelton, The Esquiline Treasure, London, 1981; A. Cameron, "The Date and Owners of the Esquiline Treasure: The nature of the evidence ", American Journal of Archaeology 89.1 (1985), p. 135-145; K. Shelton, « The Esquiline Treasure: The nature of the evidence ", American Journal of Archaeology 89.1 (1985), p. 147-155; K. S. Painter, " Il tesoro dell'Esquilino ", in S. Ensoli, E. La Rocca (dir.), Aurea Roma. Dalla città pagana alla città cristiana, Roma, 2000, p. 140146; J. Elsner, Roman Eyes: Visuality and subjectivity in art and text, Princeton, 2007, p. 200-224. Pour l'iconographie du cortège marin de Vénus, K. M.D. Dunbabin, The Mosaics of Roman North Africa..., op. cit., p. 154-159; Sabina Toso, " Il "Trionfo di Venere”. Una nuova proposta di classificazione iconografica », in I. Bragantini, F. Guidobaldi (éd.), Atti del II Colloquio dell'Associazione italiana per lo studio e la conservazione del mosaico, Roma 5-7 dicembre 1994, Bordighera, 1995, p. 293-300; A. Papagiannaki, " Nereids and Hippocamps: the marine thiasos on Late Antique and Medieval Byzantine ivory and bone caskets ", in L. Kouneni (éd.), The Legacy of Antiquity: New perspectives in the reception of the Classical world, Cambridge, 2013, p. 71-103. 


\section{Une déesse marine: Thétis, Amphitrite, Béroé, Amymonè ou Leucothé?}

Toutefois, sur notre plat, plusieurs détails discordants par rapport aux normes iconographiques habituelles méritent l'attention: tout d'abord la jeune femme, nue et passive, est la seule de son espèce. Or, les Néréides sont généralement représentées à plusieurs, dans des hypostases actives, en rôle dirigeant, jouant ou interagissant avec d'autres personnages ou, du moins, avec leur monstre $\operatorname{marin}^{30}$. Ensuite, notre cavalière ne se déplace pas par ses propres moyens: c'est un Triton qui mène son hippocampe, un second Triton l'escortant par derrière. Ce tableau est, à notre connaissance, sans parallèle dans les représentations d'une Néréide sans identité forte. Sa position centrale sur le vase rend d'ailleurs une telle supposition peu probable - du moins si l'on ne suppose pas que le vase appartenait à une série, aujourd'hui perdue.

Il y a donc lieu de penser que cette Néréide » solitaire est connue, bien qu'elle ne présente aucun signe particulier. Il est donc impossible de reconnaître en elle Thétis, la plus célèbre des filles de Nérée ${ }^{31}$, quoi qu'il en soit de la forte récurrence de la déesse dans les arts visuels ${ }^{32}$. Seule la présence des armes commandées par la

30. Cf. supra, notes 19-20.

31. W. Roscher, « Thetis ", 4 (1909-1915), col. 785-799; M. Mayer, « Thetis », in RealEncyclopädie... II.11 (1936), col. 206-242; L. Séchan, « Légendes grecques de la mer ", Bulletin de l'Association Guillaume Budé 14 (1955), p. 3-47 (p. 37-43); R. Vollkommer, "Thetis ", in Lexicon Iconographicum... 8 (1997), p. 6-14; L. Slatkin, The Power of Thetis..., op. cit.

32. On aurait pu comparer la cavalière de notre plat avec les supposées représentations de Thétis, mère d'Achille, portée sur un centaure marin à trident sur les médaillons en or d'Aboukir, qu'on a datés du $\mathrm{III}^{\mathrm{e}}$ siècle de notre ère et interprétés comme expressions de l'imitatio Alexandri de la part des empereurs Caracalla (188-217) et Sévère Alexandre (222-235). Toutefois, malgré une bibliographie importante (notamment E. Carney, Olympias: Mother of Alexander the Great, London-New York, 2006, p. 63, 121, 192; K. Dahmen, The Legend of Alexander the Great on Greek and Roman Coins, London-New York, 2007, p. 37, 92-93, 166; K. Dahmen, " Alexander in Gold and Silver: Reassessing third century AD medaillons from Aboukir and Tarsos ", American Journal of Numismatics 20 [2008], p. 493-546), il semble bien que ces médaillons soient des faux de la fin du XIX ${ }^{\mathrm{e}}$ siècle. Voir A. Savio, "Intorno ai medaglioni talismanici di Tarso e di Aboukir ", Rivista italiana di numismatica e scienze affini 96 (1994-1995), p. 73-103; A. Savio, Veri o falsi? 
mère d'Achille à Héphaïstos/Vulcain nous obligerait à identifier une Néréide avec Thétis ou avec l'une de ses compagnes ${ }^{33}$. S'offre en deuxième candidate l'autre Néréide célèbre, Amphitrite, personnification de la mer même, épouse de Poséidon/Neptune et mère de Triton; la présence d'un Triton lors du mariage de ses parents est un anachronisme possible dans le temps mythique et fréquemment reproduit à l'époque romaine ${ }^{34}$. Dès la fin du $\mathrm{III}^{\mathrm{e}}$ siècle avant notre ère, Amphitrite (vraisemblablement) est représentée sur un hippocampe, en compagnie d'un 'Eros, sur le revers d'un drachme en or des Brettii, où la face est occupée par la tête et le trident de Poséidon $(\text { ill. 10 })^{35}$. Certes, l'hippocampe est lui-même un animal associé à Poséidon/Neptune mais, en l'absence du dieu lui-même, rien ne prouve que toutes les représentations de ce type correspondent à Amphitrite.

Aussi, on a pu penser en troisième lieu à Béroé-Amymonè, nymphe fille d'Aphrodite et d'Adonis promise à Poséidon, éponyme de la ville syrienne, qui a hérité d'une riche tradition mythique du fait de son homonymie avec une Danaïde - elle-aussi amante de

I medaglioni di Aboukir, Milano, 2011, avec le compte-rendu de F. de Callatay dans la Revue belge de numismatique, 157 (2011), p. 278-280.

33. Comme sur les plats du trésor de Sadovyi, mentionné supra, n. 25; voir aussi N. Icard-Gianolio, A.-V. Szabados, " Nereides... », art. cit., nr. 300-416.

34. Voir S. Kaempf-Dimitriadou, "Amphitrite », in Lexicon Iconographicum... 1 (1981), p. 724-735 (surtout nr. 67-74); N. Icard-Gianolio, " Tritones... », art. cit., nr. 70-72. Amphitrite partage sans doute une partie de son nom avec Triton; leurs noms semblent dérivés du frottement $(\tau \rho i ́ \zeta \omega)$ de la mer. Ils sont associés à partir d'Hésiode, Théogonie 930-931, dans les interprétations allégoriques de la nature (Cornutus, Sur la nature des dieux 43 Lang; Plutarque, Sur Isis et Osiris 381 ${ }^{\mathrm{e}}$; Proclus, Commentaires au Cratyle de Platon 151 Pasquali), dans des images textuelles et figurées (Lucien, Dialogues marins 15.3; Pausanias 2.1.7-8 = N. Icard-Gianolio, "Tritones... ", art. cit., nr. 72); dans les excursus mythologiques (Hygin, Fables. Préface; Ps.-Apollodore, Bibliothèque 1.28; Argonautiques Orphiques 338-339), et plus généralement dans les explications scolaires: J. Tzetzès, Scholies à Lycophron 34, 886; Eustathe, Commentaire à l'Iliade III p. 348 van der Valk. Plus généralement, voir H. W. Stoll, « Amphitrite ", Roschers Lexikon... 1 (1884-1890), col. 318321; K. Wernicke, " Amphitrite », in Real-Encyclopädie... 1 (1894), col. 1963-1967.

35. B. V. Head, Historia nummorum: A manual of Greek numismatics, Oxford, $1911^{2}$ (1 ${ }^{\text {re }}$ éd. 1887), p. 91; S. Kaempf-Dimitriadou, " Amphitrite... ", art. cit., nr. 6. D’autres ont préféré à y reconnaître Aphrodite: H. Riggauer, " Eros auf Münzen ", Zeitschrift für Numismatik 8 (1881), p. 71-99 (p. 74-75). 

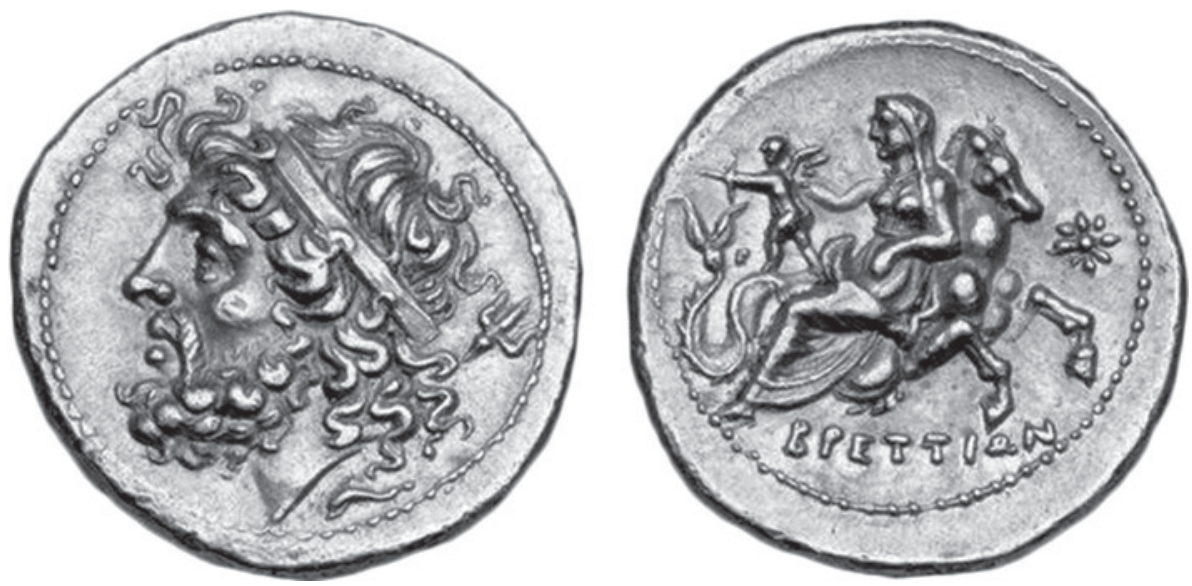

ILL. 10. Monnaie en or des Brettii, IV $v^{\mathrm{e}}$ siècle avant notre ère, représentant Poséidon et, de l'autre côté, Amphitrite, Aphrodite ou une Néréide: Michael Hewson Crawford, Coinage and Money Under the Roman Republic: Italy and the Mediterranean Economy, Berkeley-Los Angeles, 1985, p. 68.

Poséidon - mère de Nauplios et identifiée à une source de Lerne, en Argolide, dans le Péloponnèse. Le soin particulier qu'au moins un des deux Tritons semble prendre de notre cavalière nous fait d'ailleurs penser à cette autre Amymonè, que Triton avait amenée à Poséidon sur un dauphin ${ }^{36}$. Mais la jeune femme ne possède aucune hydrie (vase à eau) qui justifierait de l'identifier à une Danaïde ou, plus généralement à une nymphe de source, et le lien avec un des Tritons ou avec Poséidon n’est pas particulièrement mis en avant.

36. Le rapprochement avec Amymonè-Béroé fut proposé par R.V. Kinžalov, « Grustnaja Nereida ", art. cit. Les principaux textes sont Pausanias 2.37-38 et 4.35.2; Lucien, Dialogues marins 8; Pseudo-Apollodore, Bibliothèque 2.14; Philostrate, Images 1.8; cf. Nonnos de Panopolis 8.240-242, 42.464-474 et Rufin, Anthologie grecque 5.75 pour le développement plus tardif de son symbolisme érotique. Pour des inventaires plus complets d'occurrences, voir J. Escher, "Amymone 4 ", in Real-Encyclopädie... 1 (1894), col. 2002-2003; O. Waser, « Danaides », in Real-Encyclopädie... 4 (1901), col. 2087-2091; J. Ch. Balty, « Nouvelles mosaïques du Iv siècle sous la "Cathédrale de l'Est” ", in J. Balty, J. Ch. Balty (éd.), Apamée de Syrie. Bilan des recherches archéologiques 1969-1971. Actes du Colloque tenu à Bruxelles les 15, 17 et 18 avril 1972, Bruxelles, 1972, p. 163-185 (p. 174-177); E. Simon, « Amymone », in Lexicon Iconographicum... 1 (1891), p. 742-752. 
Certes, chacune de ces déesses pourraient être ici représentée avant ou précisément au moment de son mariage. Deux éléments servent d'appui à cette interprétation: d'abord, la jeune femme arbore une coiffure à trois mèches sur chaque côté (donc six mèches en tout), qui pourrait correspondre à la coiffure romaine des seni crines, spécifique des vestales et des jeunes mariées ${ }^{37}$. Ensuite, les nombreux attributs érotiques d'Aphrodite/Vénus (voir. infra) peuvent être interprétés aussi comme des éléments d'un décor érotique, donc nuptial. Toutefois, l'absence de toute référence au mari - qui devrait être présent en personne dans le décor, ou bien représenté par des émissaires ou du moins par son signe caractéristique, le trident - laisse cette explication à l'état de spéculation.

Puisque la femme n'est pas accompagnée, on pourrait penser à Leucothé, déesse marine en laquelle fut métamorphosée Inô, fille de Cadmos et d'Harmonie et épouse d'Athamas, qui se jeta dans les flots, frappée de folie par Héra pour avoir gardé Dionysos enfant ${ }^{38}$. Cela conviendrait parfaitement à une région du Caucase proche de la Colchide, puisque, selon Strabon (11.2.17), les indigènes Mosques adoraient tout particulièrement cette déesse. Plus généralement, on ne serait pas étonné de retrouver cette déesse sauveuse des naufragés sur un plat qu'on pouvait exposer dans une maison et qu'on a finalement déposé dans une tombe. Mais on peut nous répliquer, à juste titre, que la cavalière a l'air d'une vierge, qu'elle est dépourvue de voile et que la scène ne relève d'aucun des scénarios dans lesquels on reconnaît généralement Inô-Leucothé — c'est-à-dire au moment de son suicide et de sa métamorphose.

37. N. Boëls-Janssen, La vie religieuse des matrones dans la Rome archaïque, Rome, 1999, p. 103-126; K.K. Hersch, The Roman Wedding: Ritual and meaning in Antiquity, Cambridge, 2010, p. 69-134.

38. Voir les inventaires de H. Schirmer, "Leukothea ", in Rochers Lexikon... II. 2 (1894-1897), col. 2011-2017; S. Eitrem, « Leukothea 1 », in Real-Encyclopädie... 24 (1925), col. 2293-2306; A. Nercessian, «Ino », in Lexicon Iconographicum... 5 (1990), p. 657-661; aussi J.-P. Darmon, " Joueurs de dés et autres énigmes de la mosaïque aux chevaux de Carthage ", Bulletin de la Société nationale des Antiquaires de France 2000 [2004], p. 106-118; J. Hajji, « Le plongeon d'Ino dans la mer sur un emblema de Carthage », Africa 24 (2017), p. 135-146. 


\section{Aphrodite/Vénus des mers naissante et triomphante?}

Pour le spectateur moderne, habitué aux nombreuses représentations de la " naissance de Vénus " depuis Sandro Botticelli" ${ }^{39}$, le personnage central fait penser à Aphrodite Pontia/Vénus marine, transportée par un être marin immédiatement après sa naissance ${ }^{40}$. Bien qu'elle aille à l'encontre de la forte tradition iconographique et interprétative qui relie intimement les hippocampes aux Néréides et qui veut que Vénus soit portée seulement par une coquille, un dauphin ou des Tritons, plusieurs arguments pourraient appuyer une telle hypothèse ou, du moins, montrer la forte connotation sexuelle de la décoration.

39. Online https://artsandculture.google.com/asset/MQEeq50LABEBVg?hl=fr. Voir W.S. Heckscher, " The "Anadyomene " in the Mediaeval tradition: (Pelagia-Cleopatra-Aphrodite) a prelude to Botticelli's "Birth of Venus" ", Nederlands Kunsthistorisch Jaarboek 7 (1956), p. 1-38. Pour notre vase, la possibilité de l'identification avec Aphrodite a déjà été suggérée par S. Reinach, Répertoires de reliefs grecs et romains III, Paris, 1912, p. 482.

40. Outre les noms géographiques qui évoquent ses liens avec la mer (à Chypre, Cos), Aphrodite fut adorée en tant que déesse marine avec les épiclèses de " Pontia, Épipontia, Pelagia/marine ", "Euploia/Qui donne une heureuse navigation ", "Limènia/du port ", "Epilimênia/littorale ", "Naos/navale ", "Sôsineôs/qui sauve les bateaux ", "Ourios/qui envoie les vents favorables »); " Nauarkis/de la flotte ", "Limênarkhis/Qui commande le port ". À l'époque hellénistique et romaine, le type iconographique le plus commun pour sa naissance à partir de la mer est celui de l'Anadyomênè: Strabon 14.2.19; Pline l'Ancien 35.87, 91-92; Athénée de Naucratis 13.59 (590f). Voir D. M. Brinkerhoff, Hellenistic Statues of Aphrodite. Studies in the History of their Stylistic Development, New York-London, 1978, p. 56-69; A. Delivorrias, G. Berger-Doer, A. Kossatz-Deissmann, "Aphrodite ", in Lexicon Iconographicum... 2 (1984), p. 1-151 (nr. 423-455 pour l'Anadyomênè; nr. 977-986 sur un dauphin, nr. 1011-1017, dans la coquille, nr. 1158-1188 pour la naissance de la mer); M.-O. Jentel, " Aphrodite (in peripheria orientali) ", in Lexicon Iconographicum... 2 (1984), p. 154-166 (nr. 40-153); E. Schmidt, "Venus ", in Lexicon Iconographicum... 8 (1997), p. 192-230 (nr. 133-207 pour l'Anadyomênè, 307-311 pour la naissance, $\mathrm{nr}$. 312-319 pour le triomphe, nr. 322-323 pour le navire de Vénus, etc.). Plus récemment, K. Schoch, Die Doppelte Aphrodite: alt und neu bei griechischen Kultbildern, Göttingen, 2009; M.E. Wardle, Naked and Unashamed: A study of the Aphrodite anadyomene in the Greco-Roman world, PhD Duke University, 2010. Pour l'identification de l'Aphrodite Apatouros du Bosphore cimmérien en tant que déesse de l'eau, Y. Ustinova, " Aphrodite Ourania of the Bosporus: The Great Goddess of a frontier pantheon ", in Kernos 11 (1998), p. 209-226. Pour une synthèse sur ces cultes marins, voir maintenant A. Fenet, Les dieux olympiens et la mer, Rome, 2016, p. 105-136. 
Tout d'abord, l'image du chevauchement était une métaphore de l'acte sexuel: si les mouvements du dauphin qui se débat peuvent être interprétés comme une tentative d'échapper à l'emprise d'Éros, la jeune femme au cheval de mer correspond à un caractère qui domine par l'amour ${ }^{41}$. Sa nudité complète, clairement affichée, souligne la maîtrise sexuelle, inhabituelle pour une femme ${ }^{42}$. Ensuite, le point central du plat, à partir duquel l'artiste a pu tracer le cercle et ensuite y dessiner la scène, correspond précisément au sexe découvert de la jeune femme. Ce centre du cercle est une " origine du monde " qui évoque la fonction de Vénus Génitrix, déesse de l'amour mais aussi personnification de la force créatrice de la nature ${ }^{43}$. La figure correspondrait donc à un jeu de mots à partir de la formule latine Genitrix orbis, qui caractérise la déesse et les impératrices identifiées avec elle, à partir de Livie ${ }^{44}$ : c'est la déesse "qui donne naissance à l'orbe ", c'est-à-dire au cercle des terres entourées des mers sur le globe terrestre, au milieu du globe céleste, mais aussi... au cercle du plat au milieu duquel elle apparaît.

41. Voir B.S. Thornton, Eros. The myth of ancient Greek sexuality, Boulder Colorado, 1997, p. 38-40.

42. Cf. L. Bonfante, "Nudity as a Costume in Classical Art », American Journal of Archaeology 93.4 (1989), p. 543-570.

43. Cf. R. Schilling, La religion romaine de Vénus: depuis les origines jusqu'au temps d'Auguste, Paris, $1982^{2}$ (1 ${ }^{\mathrm{re}}$ éd. 1952); M. B. Skinner, Sexuality in Greek and Roman Culture, Chichester, $2014^{2}$ ( $1^{\text {re }}$ éd. 2005), p. 293-303. Pour la signification cosmique du cercle dans les arts figuratifs, I. Morand, "La structure des mosaïques romaines et ses rapports avec la pensée grecque », Revue des études anciennes 101 (1999), p. 143-159.

44. Cf. F. Chaves Tristán, "Livia como Venus en la amonedación de la Colonia Romula ", Acta Numismàtica 7 (1978), p. 89-96; M. B. Flory, "The Symbolism of Laurel in Cameo Portraits of Livia ", Memoirs of the American Academy in Rome 40 (1995), p. 43-68; R. Schilling, "L'évolution du culte de Vénus sous l'empire romain ", in Dans le sillage de Rome. Religion, poésie, humanisme, Paris, 1988, p. 152-183; R. Schilling, G. Freyburger, « La religion romaine de Vénus sous l'Empire ", in N. Belayche, Y. Lehmann (éd.), Religions de Rome. Dans le sillage des travaux de R. Schilling, Turnhout, 2017, p. 243-314. Plus généralement, sur l'adaptation des types iconographiques d'Aphrodite/Vénus aux représentations des mortelles, J.P. Salathe, Roman Women Portrayed as Venus: Political, social and religious contexts, PhD Baltimore 1997. 
Aussi, en tant que déesse née de la $\mathrm{mer}^{45}$, Aphrodite est une maîtresse qui apaise les flots, au moins à partir de l'époque hellénistique: l'absence du voile (et donc de tout souffle du vent) et l'équilibre gracieux dans lequel se tient la figure féminine sur le plat correspondent bien à une déesse Galènaiè (" qui apaise la mer ») ${ }^{46}$. La présence des dauphins confirmerait cette identification, même si ce n'est pas un argument décisif: outre leur intelligence et leur sens artistique, les dauphins étaient connus pour leur amour (envers leur propre progéniture mais aussi envers les humains), allant jusqu'à leur sacrifice au profit de l'être chéri. Au début du $\mathrm{II}^{\mathrm{e}}$ siècle de notre ère, Aulu-Gelle rappelait les histoires anciennes et nouvelles prouvant le lien entre ces animaux et la déesse, par leurs épithètes uenereos et amasios ${ }^{47}$. Dans les représentations sculpturales, un dauphin, parfois chevauché d'un 'Eros, accompagne plusieurs types d'Aphrodite/Vénus marine - comme l'Aphrodite de Médicis et l'Aphrodite de Doidalsas - intégrées dans la décoration de nymphées et autres fontaines ${ }^{48}$. Sans nul doute, les trois putti représentés

45. Hésiode, Théogonie 188-206; Homère, L'Hymne à Aphrodite (5); Platon, Cratyle 406c; Cornutus, Théologie grecque 24. Cf. V. Pirenne-Delforge, L'Aphrodite grecque, Liège, 1994; U. Bittrisch, Aphrodite und Eros in der antiken Tragödie mit Ausblicken auf motivgeschichtlich verwandte Dichtungen, Berlin-New York, 2005.

46. Callimaque, Épigramme 5 Pfeiffer, ap. Athénée de Naucratis 7.106 Kaibel 318bc (cf. H.W. Prescott, "Callimachus' Epigram on the Nautilus ", Classical Philology 16.4 [1921], p. 327-337; K. Gutzwiller, « The Nautilus, the Halycon, and Selenaia: Callimachus's "Epigram" 5 Pf. = 14 G. - P. ", Classical Antiquity 11.2 [1992], p. 194209 ; S. Barbantani, " Goddess of Love and Mistress of the Sea: Notes on a Hellenistic hymn to Arsinoe-Aphrodite [" P. Lit. Goodsp. 2 ", I-IV] ", Ancient Society 35 [2005], p. 135-165); Philodème de Gadara, Anthologie Palatine, 10.21. Voir aussi N. Icard-Gianolio, " Galene I ", in Lexicon iconographicum... 4 (1988), p. 151-153.

47. Nuits attiques 6.8.1; cf. les épigrammes érotiques hellénistiques et romaines: K.J. Gutzwiller, « Meleager as Erotic Dolphin: A reading of "AP” 12.52 », Hermathena 173/174. Studies in Hellenistic Poetry (2002-2003), p. 91-105. Pour un inventaire plus complet des références, voir R. Wagner, « Delphin », in Real-Encyclopädie... 4 (1901), col. 2504-2510; D’A. Wentworth Thompson, A Glossary of Greek Fishes, London, 1947, p. 52-56 s.v.

48. Voir G. Becatti, Ninfe e divinità marine. Ricerche mitologiche iconografiche e stilistiche, Roma, 1971, qui explique la large diffusion des types par l'interprétation en tant que nymphes, même s'il reconnaît, p. 27: «tipi di Afrodite chiaramente e intenzionalmente modificati in nuove creazioni con precisa funzione di statue decorative per fontana, per i quali non sappiamo più se fossero considerati ancora 
dans des positions variées, l'un en l'air, l'autre prenant appui sur l'hippocampe, le dernier nageant accroché sur un dauphin, sont des 'Erôtes/Amours: deux ont des ailes visibles alors qu'ils disposent de points d'appui. Le troisième flotte dans les airs grâce à une écharpe posée sur l'épaule gauche et déployée symétriquement devant et derrière, à droite et à gauche. Il expose de trois quarts son anatomie masculine d'enfant et lève de ses deux bras une coquille SaintJacques ${ }^{49}$. Cette présence n'est pas surprenante, vu la profusion des putti/'Erôtes dans les décorations romaines, et la nature d'Éros, qui n'est pas seulement chasseur à l'arc, mais aussi pêcheur - à la ligne, au filet ou même à main nue, comme dans le cas du dauphin sur notre plat ${ }^{50}$.

Aussi loin que l'on puisse remonter le temps, les hommes de différentes cultures ont établi une analogie entre certains coquillages et la vulve féminine ${ }^{51}$. Par ailleurs, à cause de leur caractère hermaphrodite, les mollusques étaient réputés relever de la génération spontanée (Aristote, Sur la génération des animaux 3.10 .8 761b): leur genèse correspondait donc à celle d'Aphrodite, née de l'écume marine - le sperme d'Ouranos (le Ciel) tombé dans l'eau ${ }^{52}$. Comme ces mollusques, la déesse grecque était parfois caractéri-

come immagini di Afrodite oppure di generiche Ninfe, nonostante la evidente ascendenza iconografica ".

49. Il n'est guère possible de trouver une explication unique à ces variations dans les représentations des putti ailés et aptères: R. Stuveras, Le putto..., op. cit., p. 165-181.

50. Cf. N. Blanc, F. Gury, "Eros/Amor ", in Lexicon Iconographicum... 3 (1986), p. 850-1049, nr. 301-331, 739-742. Plus généralement, pour l'image littéraire, voir encore F. Lasserre, La figure d'Éros dans la poésie grecque, Lausanne, 1946.

51. Cf. le mimographe Sophron de Syracuse ap. Athénée de Naucratis 3.32 86e; Fulgence, Mythologies 2.1. Ce symbole est clairement exprimé sur certaines fontaines en forme de Nymphe tenant une grande coquille devant leur bas-ventre: voir par ex. B. Kapossy, Brunnenfiguren der hellenistischen und römischen Zeit, Zürich, 1969, p. 12-14, Abb. 1-3. Pour le rapport avec Aphrodite, K. Tümpel, « Die Muschel der Aphrodite ", Philologus 51 (N.F. 5, 1892), p. 385-402; A. Zucker, " Album mythique... ", art. cit. Dans une perspective comparatiste, M. Eliade, "Remarques sur le symbolisme des coquillages ", in Images et symboles. Essais sur le symbolisme magico-religieux, Paris, 1952, p. 164-198.

52. Voir les sources chez F. Dümmler, "Aphrodite ", in Real-Encyclopädie... 1 (1894), 2729-2787 (col. 2772-2773); pour une critique moderne, S.L. Budin, The Origin of Aphrodite, Bethesda Maryland, 2003. 
sée par une sexualité dépourvue de fertilité, qui n’implique pas de couple uni par le mariage ${ }^{53}$. Or parmi les mollusques testacés, la belle coquille Saint-Jacques fut l'un des symboles les mieux connus de la déesse Aphrodite/Vénus, avant d'acquérir un renom chrétien, en tant qu'insigne protecteur des pèlerins ayant pris le chemin de Saint-Jacques-de-Compostelle pour honorer l'apôtre Jacques, ancien pêcheur de la mer de Tibériade.

Dès l'époque classique et hellénistique, les coquilles de Pectinidés sont largement attestées dans le mobilier domestique et funéraire en lien avec les soins de beauté féminins, comme emballages de cosmétiques ou comme modèle pour les boîtes et les miroirs en métal ${ }^{54}$. La confusion voulue avec les huîtres perlières a renforcé le lien entre coquillages et Aphrodite/Vénus: les deux étaient considérés comme nés de l'union du ciel et de la mer. D'abord matrice de la déesse - comme de la perle ${ }^{55}$ - la coquille est devenue son principal véhicule marin au plus tard à la fin de l'époque grecque classique - du moins si la fresque pompéienne de la déesse portée sur une coquille s'inspire de la peinture d'Apelle rapportée à Rome par Auguste (ill. 11) ${ }^{56}$. Toutefois, pendant l'Antiquité, la coque n’a pas été le moyen

53. Pour les fonctions de l'Aphrodite, originairement déesse grecque de la sexualité qui devient progressivement une déesse romaine des femmes mariées, voir, outre les travaux de R. Schilling (supra n. 43-44), G. Lloyd-Morgan, « Roman Venus: Public worship and private rites ", in M. Henig, A. King (éd.), Pagan Gods and Shrines of the Roman Empire, Oxford, 1986, p. 179-188; B. Lietz, La dea di Erice e la sua diffusione nel Mediterraneo. Un culto tra Fenici, Greci e Romani, Pisa, 2012.

54. Parmi les exemples d'époque romaine, on peut mentionner la coquille de Graincourt-lès-Havrincourt (Pas-de-Calais), L. $43 \mathrm{~cm}$, l. max. $41,5 \mathrm{~cm}$, h. $14,5 \mathrm{~cm}$, poids 1937 gr., ou les coquilles de moindre dimension du musée de Saint-Germain-en-Laye datant également du $\mathrm{II}^{\mathrm{e}}-\mathrm{III}^{\mathrm{e}}$ siècle de notre ère: F. Baratte (dir.), Trésors d'orfèvrerie gallo-romains. Musée du Luxembourg - Paris 8 février-23 avril 1989, Paris, 1989, p. 149 (nr. 95), 169-171 (nr. 115-116).

55. Pour l'association d'Aphrodite avec la perle: Properce 3.13.6 et Pline l'Ancien 9.80, avec M. B. Flory, " Pearls for Venus ", Historia 37.4 (1988), p. 498-504, et J.G.F. Hind, "Caligula and the Spoils of Ocean: a rush for riches in the far NorthWest? ", Britannia 34 (2003), p. 272-274.

56. Pour l'Anadyomène, voir supra n. 40. Dans l'iconographie grecque, Aphrodite sort d'une coquille (perlière) dès l'époque classique: M. Brickoff, "Afrodite nella conchiglia », Bollettino d'Arte 23 (1929-1930), p. 563-569; M. Bratschkova, " Die Muschel in der antiken Kunst ", Bulletin de l'Institut archéologique bulgare 12 (1938), p. 1-131. Dans les sources littéraires, l’image ne semble pourtant attestée 


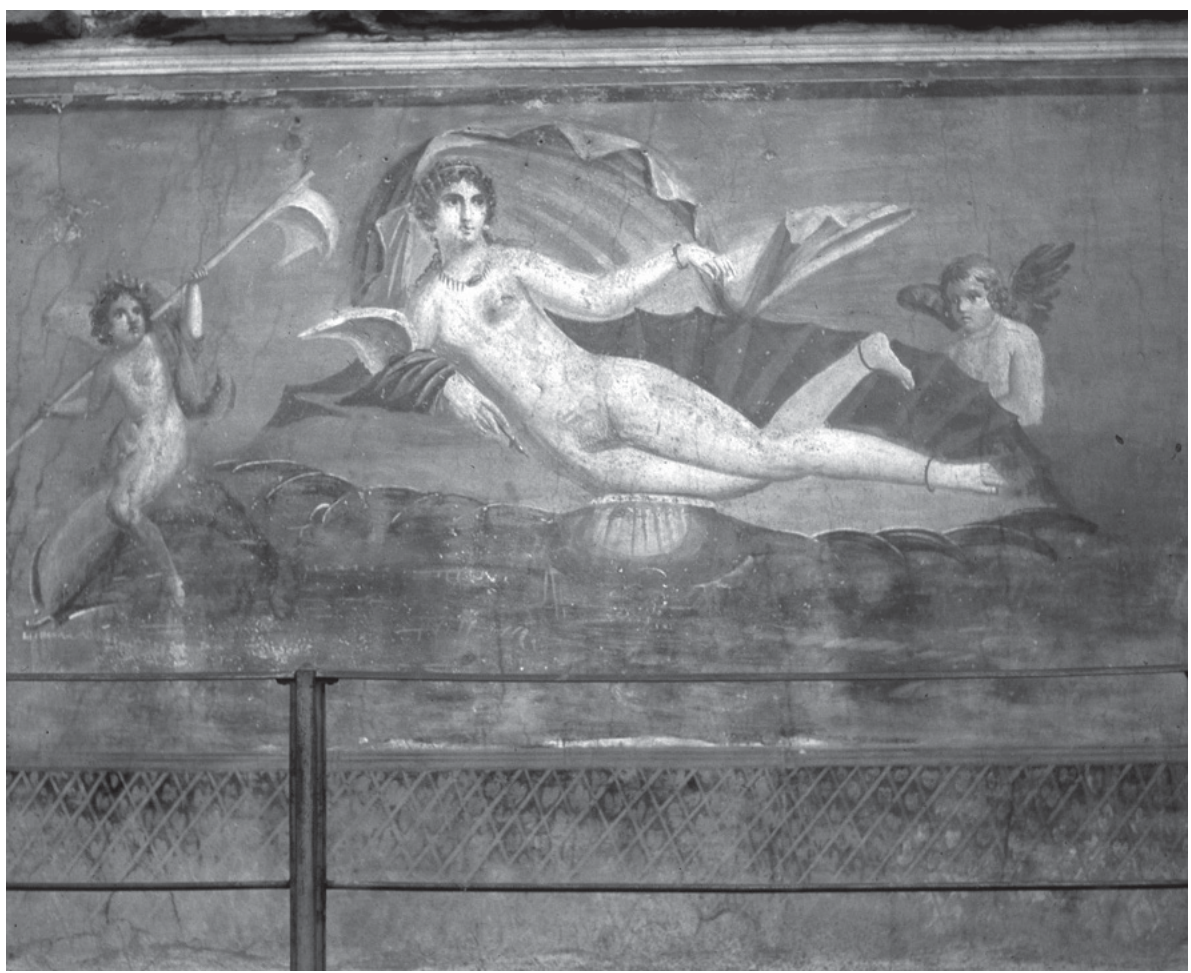

ILL. 11. Fresque de Pompéi II.3.3, maison de Vénus dans la coquille, le mur sud et le péristyle 8; $4^{\mathrm{e}}$ stèle, 62-79 après J.-C. Photo @Alix Barbet, dans la base « Décor antique » (POMP.00217).

de déplacement exclusif de la déesse à travers les mers: Aphrodite est aussi portée par des animaux (dauphins, poissons, oiseaux ${ }^{57}$ ) et par des monstres marins - en particulier par les Tritons, et, pourquoi pas, peut-être comme ici, par un hippocampe (ill. 12) ${ }^{58}$. Il faut toutefois souligner que cette association reste entièrement hypothé-

qu'à partir de Plaute, Rudens 704: E. W. Leach, « Plautus'Rudens: Venus born from a shell ", Texas Studies in Literature and Language 15.5. A Special Classics Issue on Myth and Interpretation (1974), p. 915-931; A. Zucker, " Album mythique... ", art. cit.

57. Anacreontea fr. 57.1-30.

58. E. Schmidt, «Venus... », art. cit., nr. 301. 


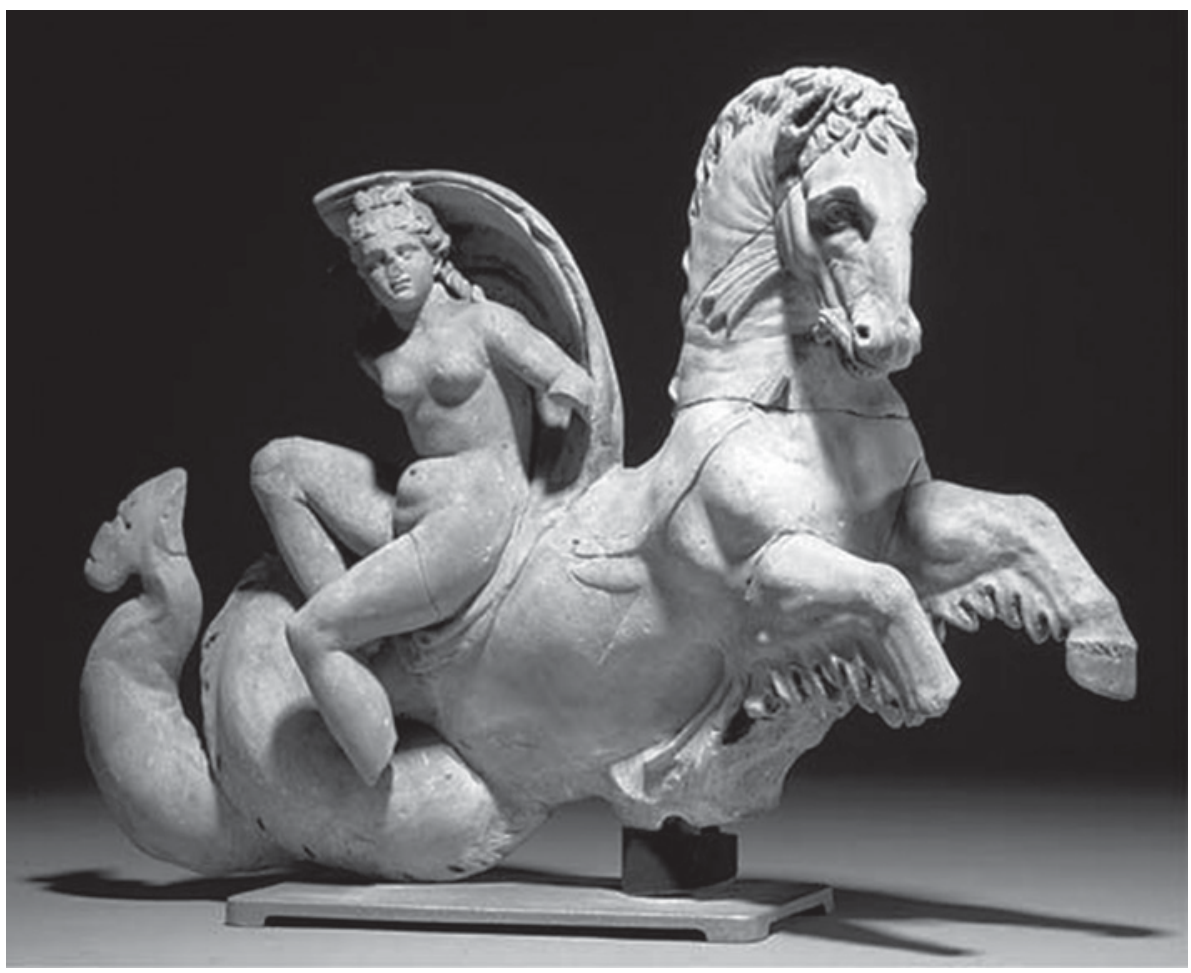

ILL. 12. Statuette en marbre dans une collection privée. Publiée par Schmidt 1997, nr. 301, comme étant localisée à Ehem/Lüttich.

tique et qu'elle n'est soutenue par aucun parallèle sûr, confirmé par un texte.

Un des plus beaux escargots de mer, le nêreitès - que nous continuons à identifier, faute de mieux, à des exemplaires de la famille des Neritidae -, était issu de la métamorphose d'un des amants d'Aphrodite/Vénus. C'est un de ces fascinants nérites - escargots de mer univalves et spiralés mais lisses ${ }^{59}$ - que nous proposons d'iden-

59. Si les Anciens s'accordent sur la beauté des couleurs et de la forme, ils se contredisent dans l'identification de l'espèce: cf., par ex., Élien, cité ici, et Aristote, Histoire des animaux 4.4.26 530a, avec D’A. Wentworth Thompson, A Glossary..., op. cit., p. 176 s.v.). Il est donc probable que plusieurs escargots marins ont été appelés « nérites ». Contre une identification précise, voir A. Zucker, « Album mythique... », art. cit. 
tifier sur le plat, précisément sous le pied gauche de la déesse (Élien, Sur la nature des animaux 14.28, traduction A. Zucker, légèrement modifiée):

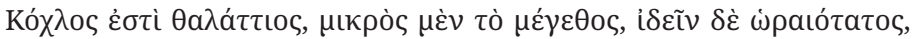

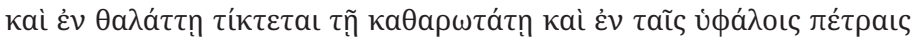

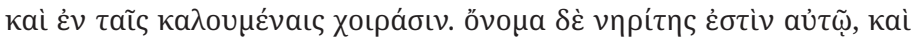

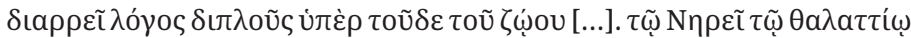

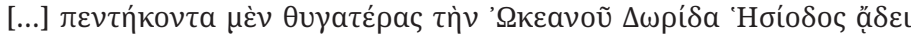

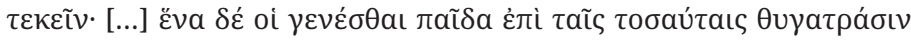

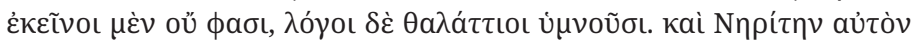

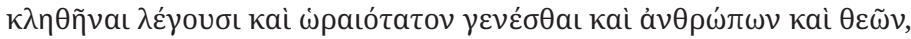

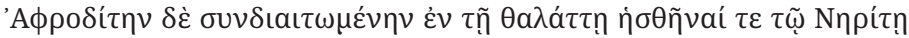

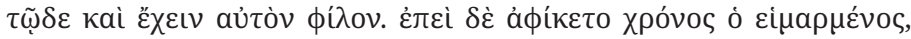

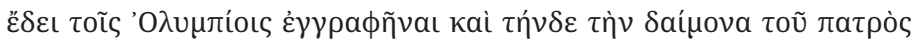

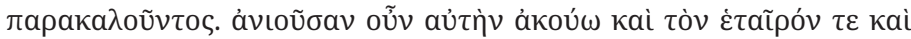

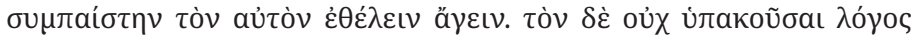

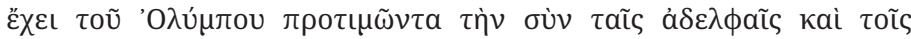

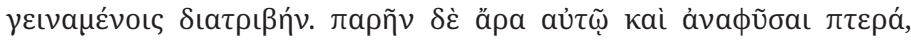

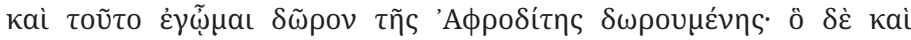

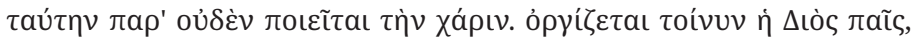

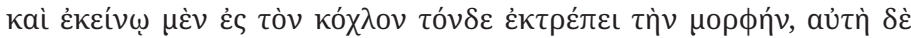

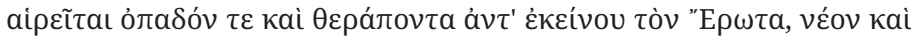

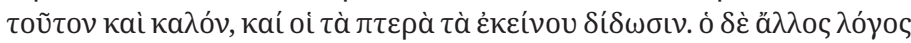

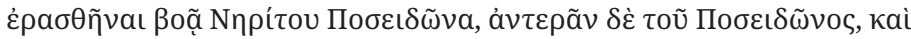

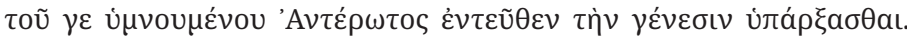

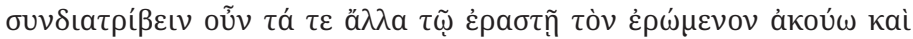

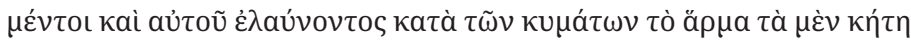
$\tau$

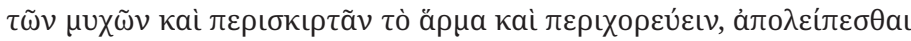

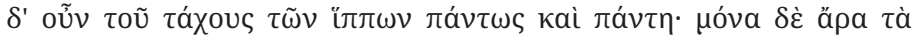

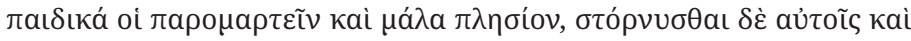

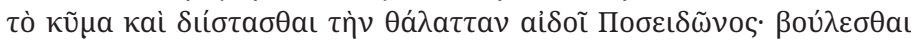

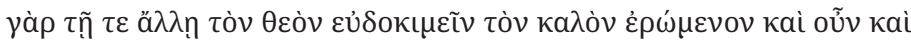

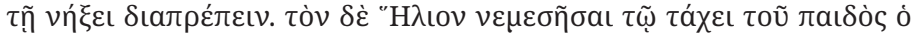

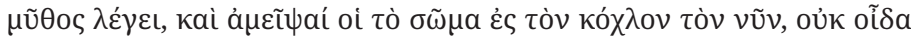

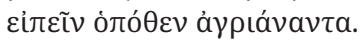

Il y a un coquillage marin en spirale qui est de petite taille et d'une très grande beauté; il naît dans les eaux les plus pures de la mer, sur les rochers immergés et dans ce que l'on appelle les "récifs ». Son nom est " nérite ". Il existe deux versions de l'histoire de cet animal [...]. Hésiode chante que Doris, fille d’Okéanos, donna cinquante filles 
à Nérée <le dieu> de la mer, [...] mais ce que ces auteurs ne disent pas et que célèbrent les histoires de marins c'est qu'à la suite de tant de filles il lui naquit un fils. Il s'appelait Nêritès et dépassait en beauté les hommes et les dieux ; Aphrodite prenait plaisir à partager son temps, dans la mer, avec ce Nêritès qui était son favori. Lorsqu'arriva le temps fixé par le destin où, sur les instances de son père, cette déesse devait être inscrite parmi les Olympiens, elle exprima le désir, d'après ce que j'ai entendu dire, d'emmener avec elle dans son ascension celui qui était à la fois son compagnon et son camarade de jeu. Et l'histoire veut que Nêritès ait refusé, préférant à l'Olympe la vie qu'il menait avec ses sœurs et ses parents. On lui aurait même offert d'avoir des ailes: c'était là, à mon avis, un cadeau personnel d'Aphrodite. Mais il n'accueillit pas cette faveur avec plus de grâce. Alors la fille de Zeus se mit en colère: elle le métamorphosa en ce coquillage et prit à sa place, comme page et comme servant, Éros (Amour), qui était lui aussi jeune et beau, et auquel elle donna les ailes destinées à Nêritès. L’autre version de l'histoire prétend que Poséidon était amoureux de Nêritès, qui lui rendait son amour, et que c'est là l'origine du célèbre Antéros [c'est-à-dire Amour-en-retour]. D'après ce que j'ai entendu dire l'aimé accompagnait son amant dans ses diverses occupations, et en particulier lorsque Poséidon conduisait son char à travers les vagues; les monstres marins, et parmi eux les dauphins mais aussi les Tritons, qui, surgissant des profondeurs, faisaient des cabrioles et une ronde autour du char, étaient alors très largement distancés par la vitesse des chevaux. Son mignon était le seul à rester à sa hauteur et il le serrait de près, tandis que les vagues se couchaient et que la mer s'entrouvrait sur leur passage par égard pour Poséidon. Car le dieu voulait que son bel aimé jouisse, à tous égards, d'une grande renommée, et qu'il brille en particulier par ses talents de nageur. Le mythe raconte qu'Hélios, énervé je ne sais pas pourquoi, considéra avec dépit la rapidité de l'enfant, et qu'il changea son corps en celui de ce coquillage, qui est désormais le sien.

Cette identification du gastéropode au milieu de la mer avec le nérite - quel qu'ait pu être concrètement ce nérite parmi les espèces de la famille moderne des Neritidae - est non seulement plausible du point de vue de la forme visible sur le vase, mais permet aussi d'expliquer sa position au milieu des flots, avec les Tritons, les dauphins et les 'Erôtes, autant de compagnons fidèles à la déesse de l'Amour.

Il faut toutefois reconnaître qu'il est difficile de distinguer entre Aphrodite/Vénus et une Néréide, et à plus forte raison de soutenir 
qu'Aphrodite chevauche l'hippocampe caractéristique des Néréides, parce que toute la tradition iconographique des déesses de l'eau Néréides, Nymphes ou Charites - à partir du Iv ${ }^{\mathrm{e}}$ siècle avant notre ère - s'inspire des modèles d'Aphrodite/Vénus dénudée, à peine née des flots ou allant au bain (qui préfigure la séduction et le mariage). Il y a, certes, des signes qui permettent la reconnaissance certaine d'Aphrodite - comme les gestes caractéristiques de l'Anadyomène sortant d'une coquille ou essorant ses cheveux, la pudica cachant son sexe ${ }^{60}$, la Pandemos et l'Epitragia, chevauchant un bouc ou une chèvre de mer, en particulier sur les répliques de la statue de culte d'Aphrodisias en Carie (dans la Turquie actuelle, ill. 13) ${ }^{61}$. Plus simplement, on reconnaît la déesse de l'Amour sur un plat lorsqu'elle y fait sa toilette aidée par des 'Erôtes (ill. 14). Mais aucun de ces signes caractéristiques ne se retrouve sur notre plat. Ainsi, comme pour d'autres identifications d'Aphrodite/Vénus en compagnie des putti, animaux ou monstres marins, il est difficile, sinon impossible de soutenir une telle identification, devant la profusion des images de Néréides et autres divinités marines sur les objets en tout genre. À titre d'exemple, au début du $\mathrm{III}^{\mathrm{e}}$ siècle avant notre ère, Aphrodite a pu être représentée chevauchant un dauphin à Thasos dans le temple de Poséidon — du moins selon l'interprétation des fouilleurs (ill. 15) ${ }^{62}$. Une Aphrodite souriante chevauche un hippocampe appartenant à un groupe de

60. Cf. A. Pasquier, La Vénus de Milo et les Aphrodites du Louvre, Paris, 1985, p. 55-59; C.M. Havelock, The Aphrodite of Knidos and Her Successors: A historical review of the female nude in Greek art, Ann Arbor, 1995; R. Kousser, "The Female Nude in Classical Art: Between voyeurism and power ", in Ch. Kondoleon, Ph. C. Segal (dir.), Aphrodite and the Gods of Love, Museum of Fine Arts Boston, 2012, p. 149-187.

61. R. Fleischer, "Aphrodite (Aphrodisias) ", in Lexicon Iconographicum... 2 (1984), p. 151-154; L.R. Brody, The Aphrodite of Aphrodisias, Mainz, 2007, p. 89-90.

62. "Chronique des fouilles et découvertes archéologiques dans l'Orient hellénique », Bulletin de correspondance hellénique 51 (1927), p. 469-501 (Thasos: p. 488490), repris dans A. Delivorrias, G. Berger-Doer, A. Kossatz-Deissmann, « Aphrodite... ", art. cit., nr. 978. L'identification doit être sujette à caution, car, la plupart du temps, ce sont les Néréides qui chevauchent des dauphins: voir B.S. Ridgway, "Dolphins... ", art. cit. Toutefois, à Thasos, Aphrodite aurait déjà été représentée chevauchant un dauphin sur un relief du début du $v^{\mathrm{e}}$ siècle avant notre ère: A. Delivorrias, G. Berger-Doer, A. Kossatz-Deissmann, « Aphrodite... », art. cit., nr. 977 (avec bibliographie). 


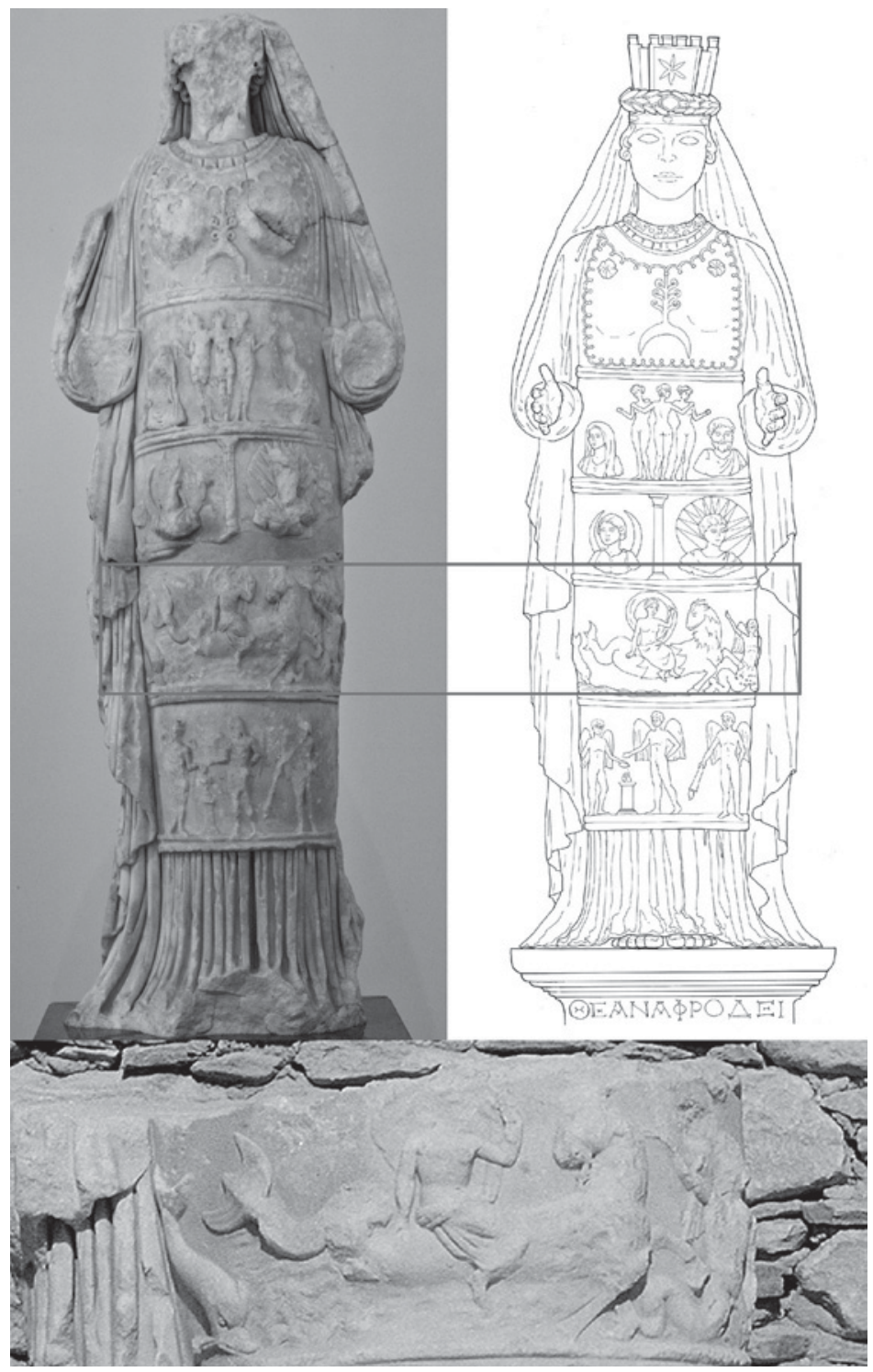

ILL. 13. Copie antique (trouvée dans le Bouleuterion d'Aphrodisias, II $^{\mathrm{e}}$ siècle de notre ère) et esquisse de reconstitution de la statue de culte d'Aphrodite, sur le costume de laquelle on voit une Aphrodite chevauchant un bouc de mer, accompagnée de Tritons. (@ 2017 Aphrodisias Excavations Project; http:// aphrodisias.classics.ox.ac.uk/aphrodite.html). 


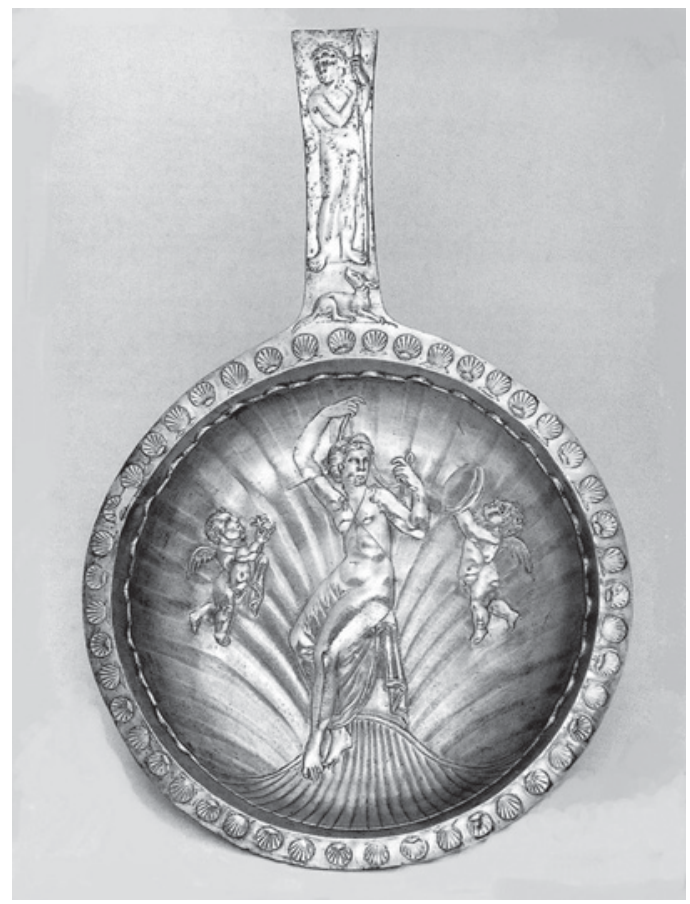

ILL. 14. Patère en argent découverte sur l'Esquilin, datant de la seconde moitié du $\mathrm{IV}^{\mathrm{e}}$ siècle de notre ère et conservée musée du Petit-Palais, inv. Dut. 171, à Paris (http://parismuseescollections.paris.fr/fr/ petit-palais/oeuvres/patere-de-l-esquilin\#infos-principales).

deux, sur un camée en sardonyx en provenance de l'Égypte ptolémaïque. Le voile enroulé autour de son bras gauche et de sa jambe droite est emporté par le vent au-dessus de sa tête, découvrant son corps (ill. 16) ${ }^{63}$. Cette identification a également été proposée pour une statue en marbre d'époque romaine, où la déesse - s'il s'agit bien d'elle et non d'une Néréide ou d'Amphitrite — chevauche un hippocampe (ill. 11). Enfin, Aphrodite/Vénus est aussi identifiée sur un dauphin et même sur un hippocampe, accompagnée d'Erôtes, sur des monnaies bithyniennes du début du III $^{\mathrm{e}}$ siècle de notre ère (ill. 17) ${ }^{64}$.

63. E. Babelon, Catalogue des camées antiques et modernes de la Bibliothèque nationale, Paris, 1897, nr. 54.

64. A. Delivorrias, G. Berger-Doer, A. Kossatz-Deissmann, « Aphrodite... », art. cit., nr. 973b. 


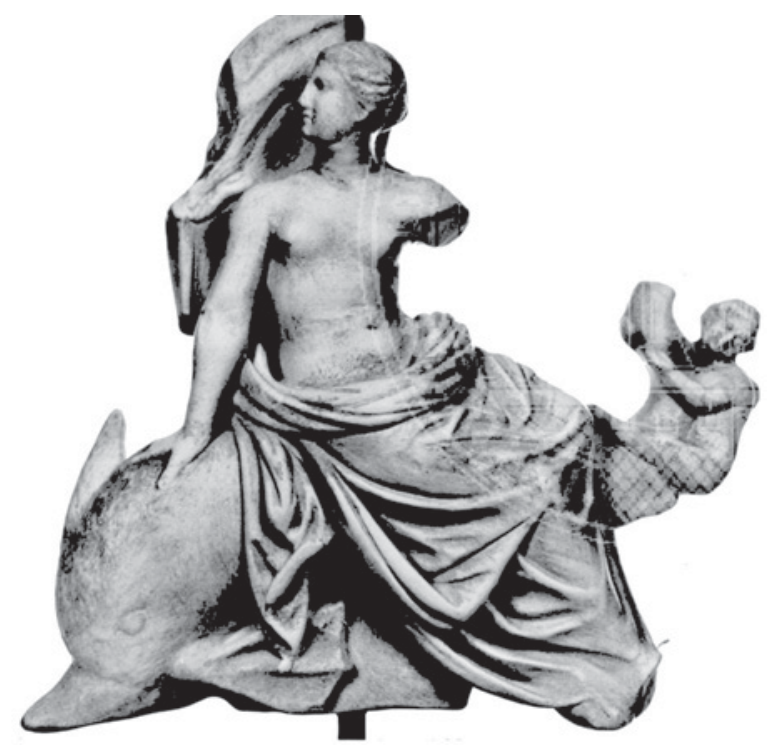

ILL. 15. Statue d'Aphrodite sur un dauphin découverte à Thasos. Photo DAI Rom d'après un gypse moderne de la FU Berlin (Abguss-Sammlung Antiker Plastik der freien Universität (Institut für klassische Archäologie) AAP345.17).

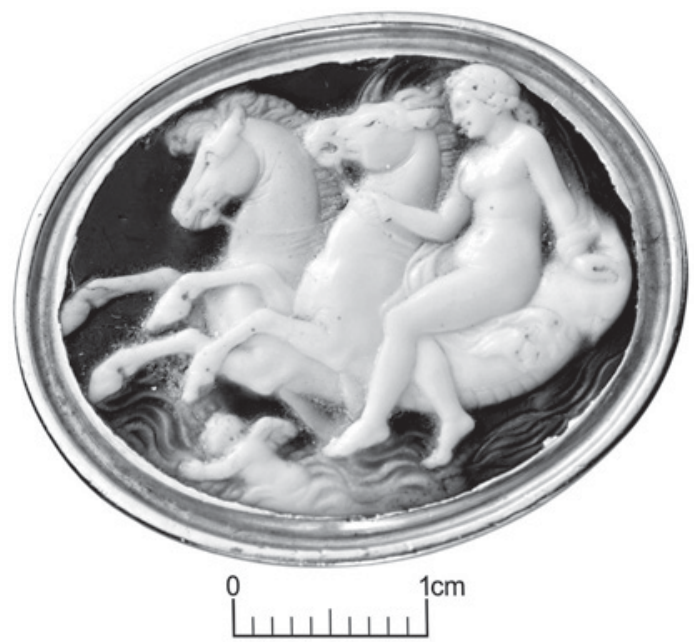

ILL. 16. Camée représentant sans doute Arsinoé IV en Aphrodite, BNF Cabinet des médailles Luynes.1 (inv.116), milieu du premier siècle avant notre ère. (http://medaillesetantiques.bnf.fr/ws/catalogue/app/collection/record/ark:/12148/c33gb1cs3p). Photo BNF. 

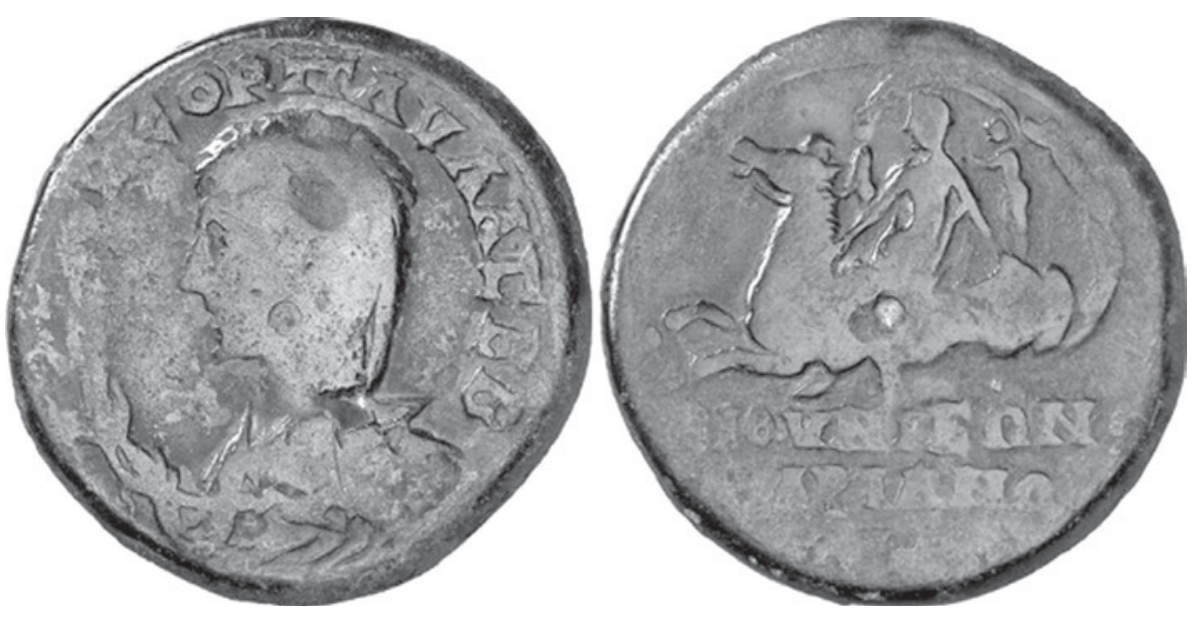

ILL. 17. Monnaie de Iulia Paula (218-222 de notre ère) frappée à Claudiopolis (Bithynie) (en ligne http:// eroscoin.blogspot.com/2011/03/type-38-eros-with-aphrodite-riding. html).

Toutefois, jusqu'à présent, aucun document écrit n'est venu confirmer ces hypothèses. Au contraire, textes et images incitent plutôt à la prudence, puisqu'ils montrent une large confusion des types iconographiques entre la déesse elle-même, ses compagnes les Charites et les Néréides.

Nous pouvons reconstituer ce processus de genèse iconographique des Néréides, parallèlement au déshabillage de l'Aphrodite marine/des bains (et donc du mariage) et à son implication accrue dans la vie politique, en comparant objets et textes de la haute époque hellénistique. En effet, nous avons déjà mentionné la célèbre boîte à cosmétiques en forme de coquille Saint-Jacques du musée de Tarente (ill. 3, supra). Cette découverte de la seconde moitié du III $^{\mathrm{e}}$ siècle avant notre ère offre une bonne illustration des objets originels en coquillages sculptés, auxquels avait pensé, quelques décennies auparavant, Posidippe de Pella écrivant son épigramme sur l'image d'Aglaé, la plus âgée des Charites compagnes d'Aphrodite, gravée dans une huitre perlière (11 Austin-Bastianini, traduction É. Prioux, légèrement modifiée) ${ }^{65}$ :

65. C. Austin, G. Bastianini, Posidippi Pellaei quae supersunt omnia, Milan, 2002; É. Prioux, Regards alexandrins. Histoire et théorie des arts dans l'épigramme hellé- 


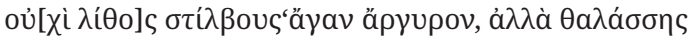

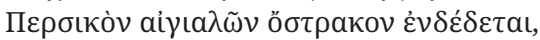

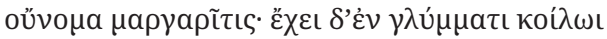

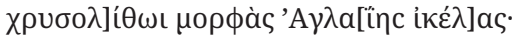

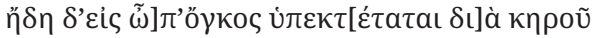

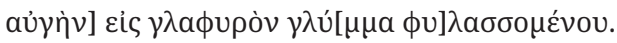

L'objet qu'on a serti n'est pas une gemme aux multiples reflets argentés, mais un coquillage perse qu'on a trouvé au bord de la mer et qu'on nomme huître perlière. Une gravure en creux y enferme les contours d'Aglaé, contours semblables à la topaze. Et voici qu'une enflure s'offre au regard, grâce à la cire qui préserve la lumière et l’oriente vers la délicate gravure.

Ce n'est pas un hasard si cette épigramme occupe une place centrale dans le recueil du papyrus de Milan (P. Mil. Vogl. 8: 309) que Posidippe semble avoir constitué à la cour de Ptolémée II Philadelphe. Sa femme et sœur, Arsinoé II, fut la première souveraine lagide à être identifiée de son vivant avec la déesse Aphrodite Zéphyritis de Canope (cf. Callimaque, Épigramme 5 Pfeiffer) ${ }^{66}$. Celle qui lui succéda, Bérénice, épouse de Ptolémée III Évergète, fut chantée comme une quatrième Charite/Grâce - ce qui lui permettait de marquer la cohérence dynastique par rapport à Arsinoé, tout en gardant son identité. En effet, une Charite était à la fois compagne et substitut de la déesse de la beauté féminine, avec laquelle elle partage une iconographie commune, à partir du Iv siècle avant notre ère. Or, au même titre qu'Aphrodite-Isis, une Charite, symbole de l'évergétisme grec, rappelait les attributs de la déesse égyptienne Hathor - dont Bérénice réclamait l'identité aussi à travers l'histoire de sa boucle de cheveux, qui se serait envolée du temple de Zéphyrion avant d'être transformée en constellation (Callimaque, Aitia fr. 110 Pfeiffer; Catulle 66). Les autres souveraines lagides ont continué à revendiquer l'identité d'Aphrodite-Isis-Hathor jusqu'à Cléopâtre VII Philopator, la première à se proclamer " Nouvelle

nistique, Louvain, 2007, p. 187, 190-243; É. Prioux, Petits musées en vers. Épigramme et discours sur les collections antiques, Paris, 2008, p. 163-164, 171, 178-179.

66. Voir A. Kuttner, "Cabinet Fit for a Queen: The $\Lambda$ เ $\theta$ เká as Posidippus'gem museum ", in K. Gutzwiller (dir.), The New Posidippus. A Hellenistic poetry book, Oxford, 2005, p. 141-163 (p. 148-151). 
Isis ", à se montrer et à se faire représenter sur des monnaies et des monuments comme la déesse même, avec son fils Césarion/ Éros-Harpocrate ${ }^{67}$.

Aphrodite/Vénus marine, ses Charites/Grâces, les Néréides et ensuite même les Nymphes en tout genre ont continué à partager certains types iconographiques communs et à s'influencer réciproquement pendant l'époque romaine. D’ailleurs, selon l'étymologie de R. Schilling, la Vénus latine n'aurait été à l'origine que Charis (grec pour "grâce"), puisque son théonyme vient de uenus/uenia, le mot latin signifiant " grâce " ${ }^{68}$ : c'est une bonne base pour ne pas différencier leur iconographie à l'époque hellénistique et romaine. Aphrodite/Vénus marine convenait parfaitement à l'expression des thalassocraties - lagide et ensuite romaine - s'étendant à la fois sur la mer de l'Inde, d'où l'on apportait les perles, et sur la mer Intérieure, centre du monde gréco-romain. Les hybridations réciproques avec les homologues orientales (Isis-Hathor, Inana-Ishtar-Atargatis-Dea Syria) n’ont jamais cessé à l'époque antique $^{69}$. La beauté, la force et la fécondité lui ont assuré le succès en contexte romain privé - où la déesse " Grâce ", adorée déjà comme Verticordia à l'époque républicaine, devient protectrice de la mariée, qui l'amène, par l'intermédiaire d'un eikon, dans son nouveau foyer ${ }^{70}$ - mais aussi en contexte public, où Aphrodite/Vénus

67. Voir W. A. Cheshire, "Aphrodite Cleopatra ", Journal of the American Research Center in Egypt 43 (2007), p. 151-191; S. Strano, L'immagine del potere nell'Egitto Tolemaico. Revisione critica dell'iconografia di Cleopatra VII Philopator, Oxford, 2015.

68.R. Schilling, "Les origines de la Vénus romaine ", Latomus 17.1 (1958), p. 3-26; R. Schilling, "Controverse à propos de la Vénus romaine (réponse aux observations de P. Boyancé) ", Revue des études anciennes (1959), p. 107-110; R. Schilling, " La relation Venus-Venia », Latomus 21.1 (1962), p. 3-7.

69. Pour ces rapports avec les divinités orientales, voir D.K. McDonald, J. Karageorghis, " Aphrodite's Ancestors », in Ch. Kondoleon, Ph. C. Segal (dir.), Aphrodite..., p. 17-40.

70. Comme l'attestent les papyri égyptiens (F. Burkhalter, "Les statuettes en bronze d'Aphrodite en Égypte romaine d'après les documents papyrologiques ", Revue archéologique 1 [1990], p. 51-60) et les découvertes archéologiques dans le monde grec (H.F. Sharpe, "Bronze Statuettes from the Athenian Agora: Evidence for Domestic Cults in Roman Greece ", Hesperia 83.1 [2014], p. 143-187). À Rome, Pétrone mentionne la statue parmi les Lares de Trimalchion: Satyricon 29.8. Cf. G. Lloyd-Morgan, « Roman Venus... ", art. cit.; A. Antal, Venus Cult in Roman Dacia, 
est génitrice, nourricière et finalement garante de l'équilibre du cosmos (cf. Lucrèce, Sur la nature 1.1-25).

Pour expliquer la large diffusion des décors et des images de la déesse, représentée en tant que telle ou pour prêter son corps à des déesses aquatiques, on pourrait ajouter ici le rôle important qu'elle joue dans la divinisation des femmes de la famille impériale. Vénus gagne continuellement en importance de Livie/les JulioClaudiens $^{71}$ jusque aux Flaviens (avec la fille de Titus) ${ }^{72}$ et surtout aux Antonins, après la restauration du temple de Vénus Genitrix par Trajan (marquée par une nouvelle dédicace le 12 mai 113 de notre ère), et la construction du temple de Vénus Felix et de Rome Aeterna par Hadrien (inauguré le 21 avril 121). D’ailleurs, Sabine, la femme d'Hadrien, et Faustine l'Ancienne, épouse d'Antonin le Pieux, furent représentées en Vénus, surtout Génitrix. Faustine la Jeune, fille d’Antonin le Pieux et épouse de Marc-Aurèle, franchit un pas de plus dans cette identification à la déesse, en tant que mère de César (Genitrix) et compagne dans les victoires de l'empereur (Victrix), garante de la prospérité de l'empire-monde (Felix $)^{73}$. Elle semble avoir été la première impératrice à s'être fait représenter en Vénus à moitié dénudée, sous la forme de la Vénus dite de Capoue, peut-être dans le

Cluj-Napoca, 2016, passim. Au $\mathrm{III}^{\mathrm{e}}$ siècle de notre ère, quelque part entre la Bactriane et l'Inde, un plat en argent illustrant le mariage de Pasithéa, une des trois Grâces, est offert (sans doute par son mari) à une jeune mariée: les Grâces, et en particulier Aglaïe, qui est déjà mariée parmi elles, est représentée selon l'iconographie d'Aphrodite-Isis de type Cléopâtre: A. Dan, F. Grenet, Nicholas Sims-Williams, " Homeric Scenes... ", art. cit. Au milieu du Iv siècle, la boîte en argent doré de Projecta, du trésor de l'Esquilin, est un autre exemple de la manière dont une Vénus pouvait accompagner la mariée.

71. Cf. R. Pera, « Venere sulle monete da Silla ad Augusto: aspetti storico-politici », in Contributi di storia antica in onore di Albino Garzetti, Genova, 1976, p. 241-268, et les travaux de R. Schilling mentionnés supra, n. 44-45.

72. Martial 6.13; cf. R. Pera, "Venere sulle monete da Vespasiano agli Antonini. Aspetti storico-politici », Rivista italiana di numismatica e scienze affini 80 (1978), p. 80-97.

73. J. Aymard, "Vénus et les impératrices sous les derniers Antonins ", Mélanges d'archéologie et d'histoire 51 (1934), p. 178-196; T. Mikocki, Sub specie deae. Les impératrices et princesses romaines assimilées à des déesses. Étude iconographique, Rome, 1995, p. 63-65, 112-115. 


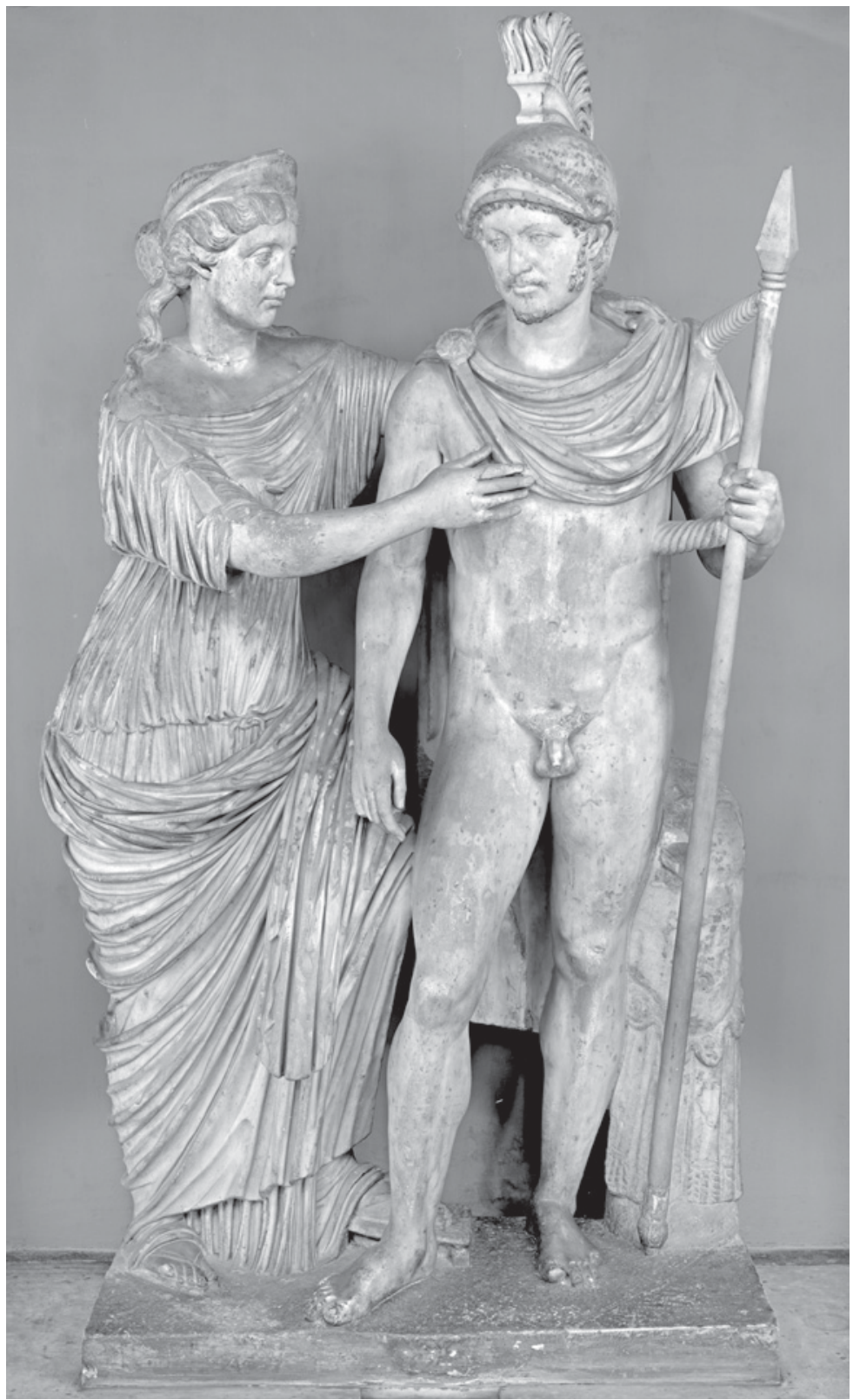

ILL. 18. Groupe statuaire de Vénus (de Capoue) et de Mars, avec les portraits de Faustine la Jeune et de Marc-Aurèle, conservé à Rome, Musei capitolini, Inv. 652. Photo DAI Rome (B. Malter Mal1384). 
groupe l'unissant à Mars-Marc-Aurèle (ill. 18) ${ }^{74}$, ou totalement nue et Felix, selon le modèle praxitélien de la Vénus dite Capitoline (ill. 19) ${ }^{75}$. Les raisons principales n'étaient ni son physique, ni même son style de vie dissolu, qui a valu tant de critiques à Marc-Aurèle et à son fils, l'empereur Commode ${ }^{76}$. On voulait mettre en avant son rôle exemplaire d'épouse et mère de César, continuateur des Iulii.

Faustine reproduisait la statue de Vénus Génitrix sur bon nombre de revers de ses monnaies (ill. 20), l'accompagnant parfois d'un gouvernail et d'un dauphin (ill. 21). Malgré cette profusion des représentations d'Aphrodite marine à partir de la seconde moitié $d u \mathrm{II}^{\mathrm{e}}$ siècle de notre ère, aucune représentation avérée de la déesse ne s'émancipe assez des types iconographiques figés pour se rapprocher de la figure de notre plat. Lors même que la déesse est représentée comme une Néréide, dans une pose similaire à celle de notre plat, elle apparaît à moitié couverte et portant, en plus, un

74. L'identification des portraits du couple impérial sur le groupe statuaire de la nécropole de l'Isola sacra d'Ostie (maintenant au Museo Capitolino Salone 34, inv. 652, datable de 145-147 de notre ère) reste débattue. Du moins, le groupe conservé dans temple de Mars Ultor sur le Forum d'Auguste apparaît sur les monnaies de Faustine. Cassius Dion (71.31) confirme ce lien avec Vénus. Sous les traits des dieux à l'origine du peuple romain, le couple impérial aurait symbolisé l'unité et la stabilité de l'empire. Voir E.E. Schmidt, « Die Mars-Venus-Gruppe im Museo Capitolino », Antike Plastik 8 (1968), p. 85-94, taf. 60-64; K. Fittschen, Die Bildnistypen der Faustina minor und die Fecunditas Augustae, Göttingen, 1982, p. 46; plus généralement, B. Levick, Faustina I and II: Imperial women of the Golden Age, Oxford, 2014. Contra, plaidant pour des portraits privés, R. Kousser, " Mythological Groupe Portraits in Antonine Rome: The performance of myth ", American Journal of Archaeology 111.4 (2007), p. 673-691. Plus généralement, pour les représentations de particulières sous les traits de Vénus, L.M. Gigante, " Roman Commemorative Portraits: Women with the attributes of Venus ", in W. Reinink, J. Stumpel (éd.), Memory and Oblivion. Proceedings of the XXIXth International Congress of the History of Art held in Amsterdam, 1-7 September 1996, Amstardam, 1999, p. 447-453. Pour les origines grecques du couple Aphrodite-Arès, G. Pironti, « Aphrodite dans le domaine d'Arès. Éléments pour un dialogue entre mythe et culte ", Kernos 18 (2005), p. 167-184.

75. H. Wrede, « Das Mausoleum der Claudia Semne und die bürgerliche Plastik der Kaiserzeit ", Mitteilungen des Deutschen Archäologischen Instituts. Römische Abteilung, 78 (1971), p. 125-166 (p. 155); D.E.E. Kleiner, « Second-Century Mythological Portraiture: Mars and Venus ", Latomus 40.3 (1981), p. 512-544.

76. Cf. A. Molinier Arbo, "La piété de Commode et les amants de Faustine: réflexions autour de Comm., 8, 1 dans l'Histoire Auguste ", in N. Belayche, Y. Lehmann (éd.), Religions de Rome..., p. 139-153. 


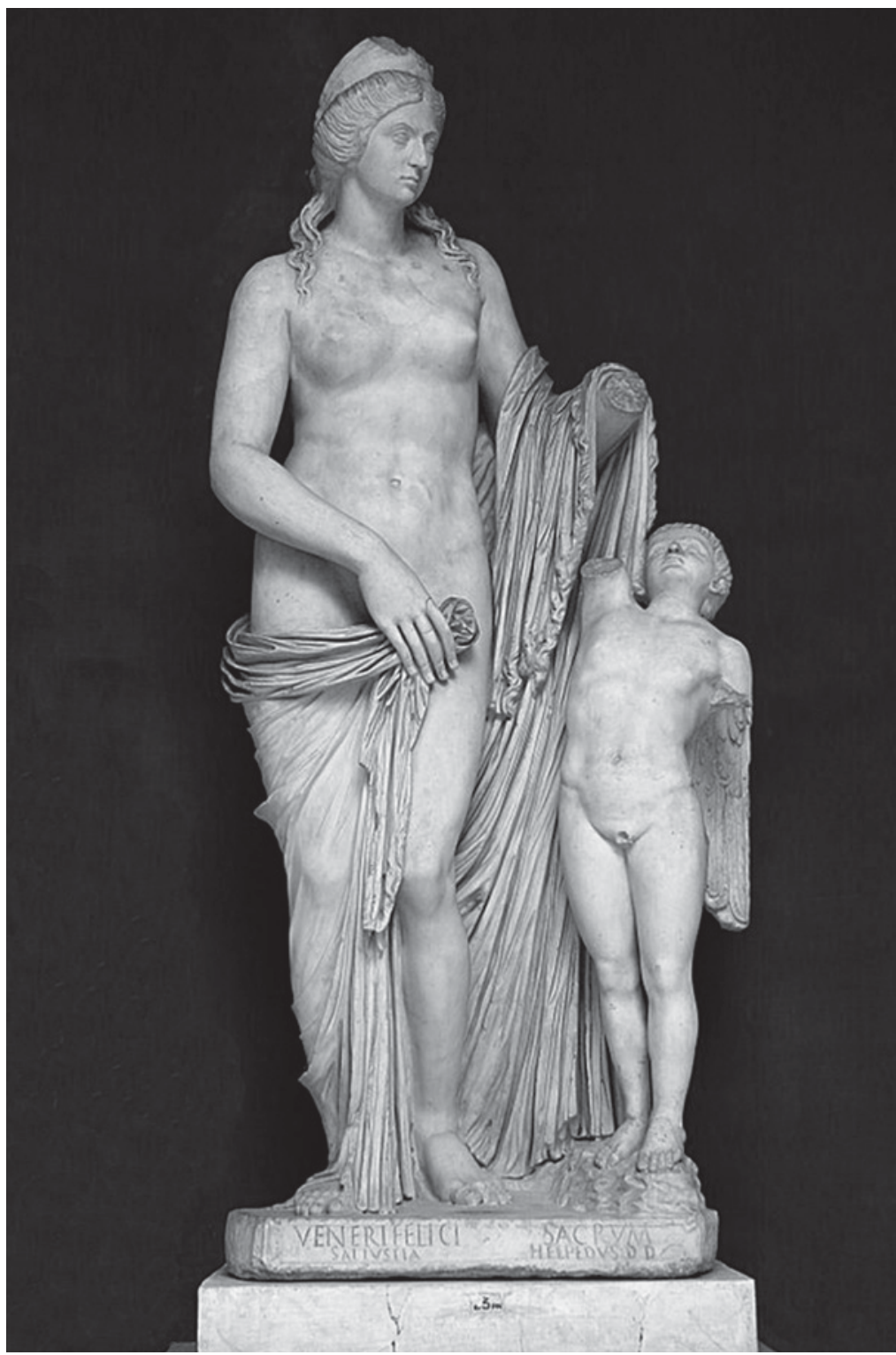

ILL. 19. Vénus Felix accompagnée d'un éros, avec un portrait de femme (Faustine la Jeune?) de la seconde moitié du $\mathrm{II}^{\mathrm{e}}$ siècle de notre ère, conservée à Musei Vaticani, Cortile del Belvedere. Inv. 936. Photo DAI Rome (D-DAI-ROM-1052R). 

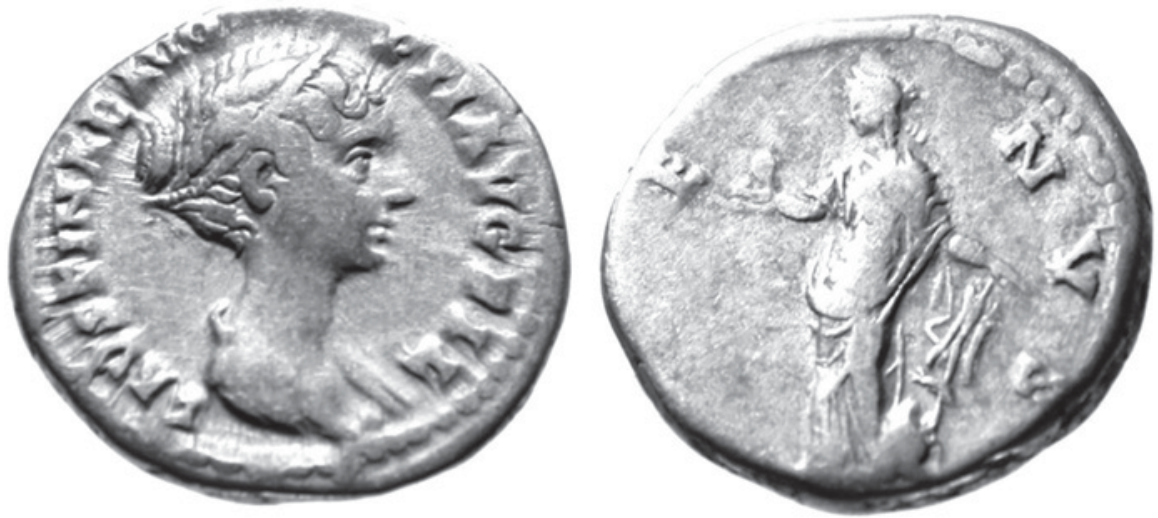

ILL. 20. Monnaie en argent de Faustine la Jeune, ayant sur le revers Vénus Génitrix, avec un dauphin et un gouvernail (https://www.vcoins.com/fr/stores/romae_aeternae_numismatics/136/product/faustina_ii_junior_ar_denarius_venus_rudder_dolphin_good_fine_nice_portrait/830172/Default. aspx).

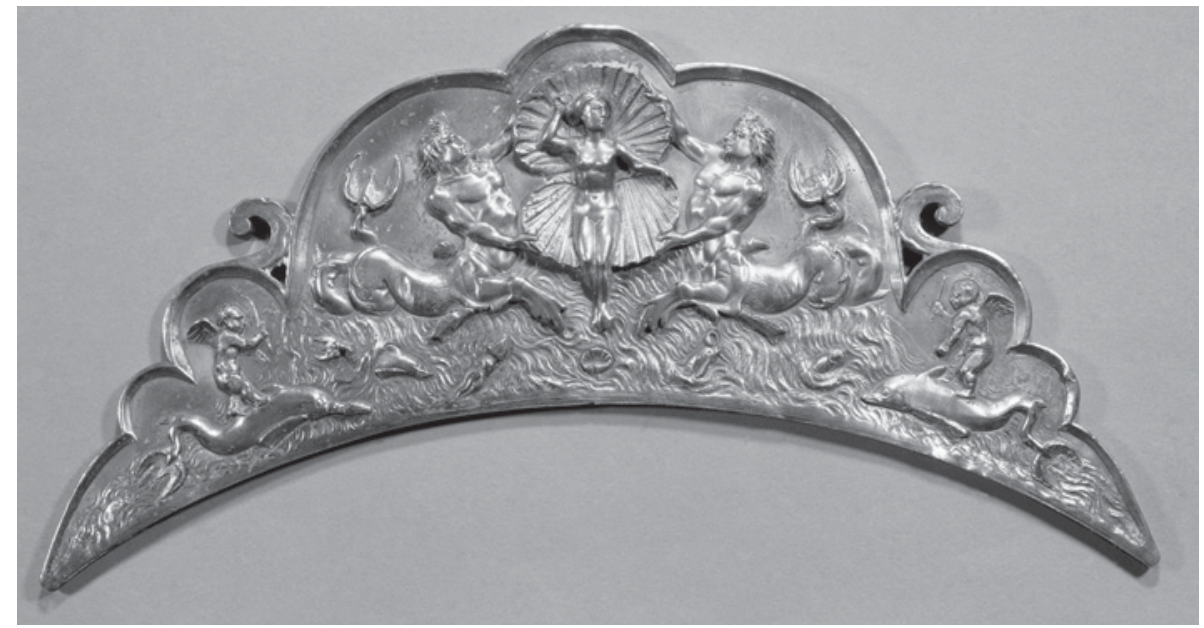

ILL. 21. Anse en argent d'un plat des $\mathrm{II}^{\mathrm{e}}-\mathrm{III}{ }^{\mathrm{e}}$ siècles de notre ère, découvert près de Montélimar et conservé au Louvre, Bj 2065 (https://www.louvre.fr/oeuvre-notices/anse-de-plat). Photo RMN. 
voile gonflé sur le dos. Elle n'est jamais portée par un hippocampe: le navire à la poupe duquel elle est parfois assise rappelle exclusivement la longue série des navigations dans la coquille ${ }^{77}$.

En conséquence, faute de pouvoir constituer des parallèles pour l'identification de la figure centrale, ces représentations servent à expliquer et à dater le décor aphrodisiaque dans lequel évolue notre personnage. Ainsi, la manière dont le putto volant présente une coquille Saint-Jacques ouverte rappelle le geste du couronnement de Vénus par deux putti qui l'encadrent, comme on le voit souvent à partir du II ${ }^{\mathrm{e}}$ siècle de notre ère sur les mosaïques dites de la naissance, du triomphe ou de la toilette de Vénus ${ }^{78}$. Dans notre cas, l'écharpe pleine de charmes d'Éros tient la place du voile alors que la coquille qu'il brandit rappelle la couronne. Le schéma des deux putti encadrant la déesse sortie de la mer apparaît déjà sur la fresque pompéienne supposée reproduire la peinture d'Apelle (cf. supra ill. 11). Ailleurs, ce rôle de guides-compagnons de la déesse juste née est tenu par deux Tritons (quand leurs corps humains finissent en queue de poissons, comme sur notre plat) ou par deux icthyocentaures, comme sur le coffret de Projecta, cf. supra ill. 9). Ils encadrent la déesse portée par une coque ou la transportent eux-mêmes en triomphe, voire lors d'un couronnement suivant de près sa sortie des eaux. Un exemple intéressant est l'anse du plat d'Allan (Montélimar, France, ill. 21) ${ }^{79}$ : Vénus surgit d'une coquille soutenue de part et d'autre par

77. Voir la mosaïque de la navigation de Vénus à Volubilis, datée entre Commode et Septime-Sévère: R. Thouvenot, " La mosaïque du "navigium Veneris" à Volubilis (Maroc) ", Revue archéologique 1 (1977), p. 37-52; E. Schmidt, "Venus... ", art. cit., nr. 322-323.

78. Cf. G. Charles-Picard, « Le couronnement de Vénus ", Mélanges d'archéologie et d'histoire 58 (1941), p. 43-108; J. Lassus, "Vénus marine », in G. Charles-Picard, H. Stern (éd.), La mosaïque gréco-romaine I. Actes du colloque international sur la mosaïque gréco-romaine Paris, du 29 août au 3 septembre 1963, Paris, 1965, p. 175190; J. Balty, Mosaïques antiques de Syrie, Bruxelles, 1977, p. 16-19 (à propos de la toilette de Vénus à Shahba-Philippopolis, au milieu du $\mathrm{III}^{\mathrm{e}}$ siècle de notre ère); J. Balty, La mosaïque de Sarrîn (Osrhoène), Paris, 1990, p. 50-53, 76-77 (à propos de la toilette de Vénus, au vi ${ }^{\mathrm{e}}$ siècle de notre ère); K. M.D. Dunbabin, Mosaics of the Greek and Roman World, Cambridge, 2001, p. 166-167. Pour un inventaire plus large, voir E. Schmidt, « Venus... ", nr. 312-319.

79. Conservée au musée du Louvre, Antiquités grecques, étrusques et romaines BJ 2065. Cf. F. Baratte (dir.), Trésors..., p. 229-230, op. cit., nr. 187. À comparer avec les 
deux Tritons distincts, alors que deux dauphins avec deux 'Erôtes et d'autres animaux marins l'entourent. Ainsi, on remarque presque le même nombre d'auxiliaires composant ce qui semble être un petit cortège stable à la fin du $\mathrm{II}^{\mathrm{e}}$ et au $\mathrm{III}^{\mathrm{e}}$ siècle de notre ère. Néanmoins, le moyen de transport et le geste qui permettent l'identification de la déesse ne sont pas les mêmes que sur notre plat. Cela nous fait conclure qu'un spectateur ancien n'aurait pas reconnu Aphrodite/ Vénus elle-même à Yenikend. Bien au contraire.

\section{Une solution par les textes: Galatée}

L’artiste a placé au milieu d'un décor marin une jeune déesse que la plupart des spectateurs romains, habitués au code iconographique, devaient interpréter spontanément comme une Néréide chevauchant un hippocampe. C'est sans doute un hasard dont ceux qui ont enterré le vase n'étaient pas conscients, mais la Néréide était une compagne appropriée pour celui qui faisait le voyage vers l'AuDelà. Originairement, les Néréides accompagnaient surtout Thétis, la Néréide par excellence, alors qu'elle portait les armes ou le corps de son fils, Achille (cf. ill. 6). L'étymologie de leur nom et leur présence sur des monuments comme le tombeau de Xanthos ou comme les sarcophages hellénistiques et romains confirment ce lien essentiel des Néréides avec les profondeurs dans lesquelles le soleil se couche et donc avec la mort ${ }^{80}$. C'est peut-être le sens qu'il faut attribuer à l'un des premiers groupes statuaires hellénistiques représentant une Néréide en extase, chevauchant un Triton aux côtés d'un putto, dans la décoration d'une fontaine: l'artiste a sans doute pensé à un cortège prêt à naviguer sur le fleuve Océan et à effectuer le voyage vers les îles des Bienheureux (ill. 22) ${ }^{81}$. Or, notre Transcaucasie, audelà des portes Caspiennes, n'était guère trop éloignée de l'Océan et

reliefs: A. Rumpf, Die Meerwesen..., op. cit., p. 36-38, 123-124.

80. Voir les références supra, n. 22 et A. Rumpf, Die Meerwesen..., op. cit.; S. Lattimore, The Marine Thiasos..., op. cit.; S. Muth, « Gegenwelt als Glückswelt - Glückswelt als Gegenwelt? Die Welt der Nereiden, Tritonen und Seemonster in der römischen Kunst », in T. Hölscher (éd.), Gegenwelten zu den Kulturen Griechenlands und Roms in der Antike, München-Leizpig, 2000, p. 467-498.

81. R. Stuveras, Le putto..., op. cit., p. 155, n. 5 et photo 3, selon G. Becatti, Arte e gusto negli scrittori latini, Firenze, 1951, pl. XXII, fig. 48. 


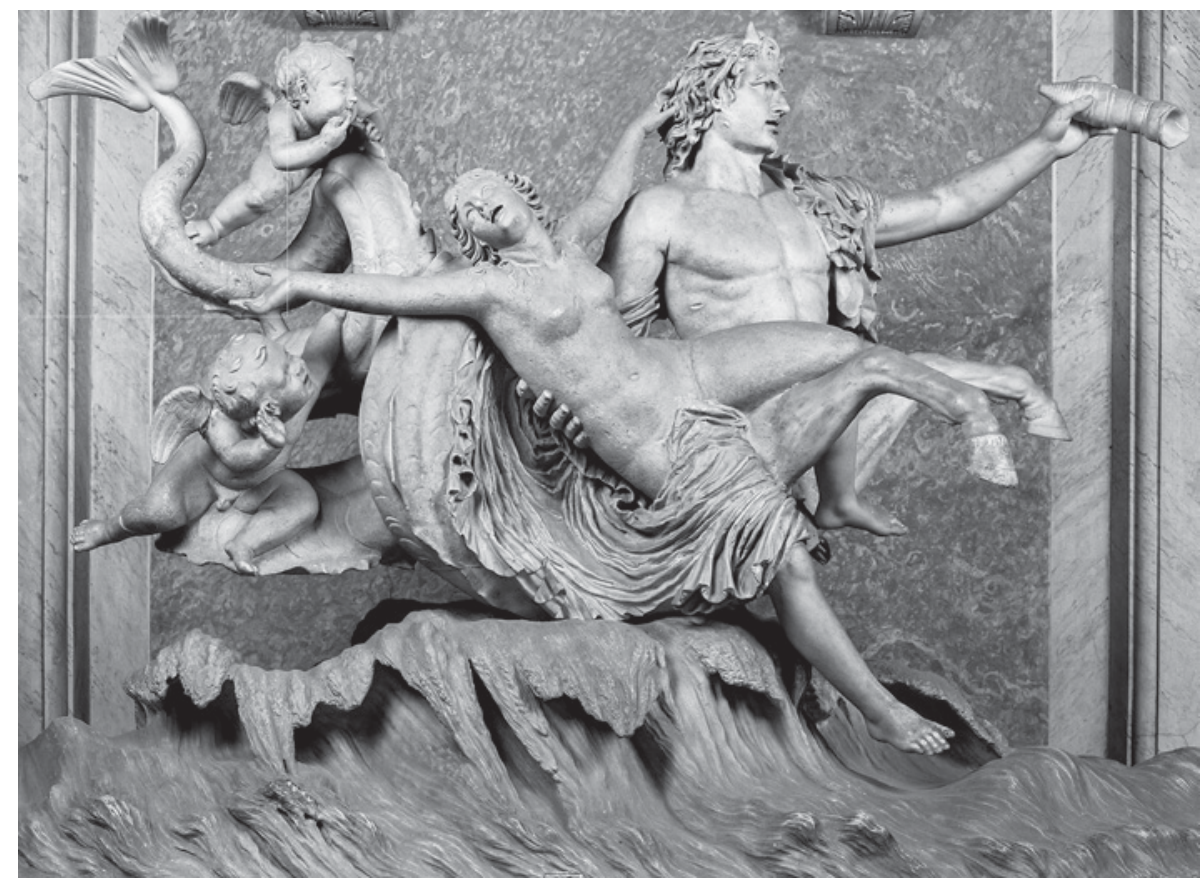

ILL. 22. Groupe statuaire hellénistique formé d'une Néréide, un Triton et deux 'Erôtes, conservé à Musei Vaticani, Museo Pio Clementino, Sala degli Animali, Inv. 464. Photo DAI Rome (D-DAI-ROM94Vat103).

donc de l'Au-Delà des Grecs et des Romains. Mais, une fois de plus, rien ne prouve que le dépôt du vase dans la tombe ait été motivé par cette interprétation mortuaire.

En même temps, le caractère particulier de la déesse ne fait pas de doute: si le plat était exposé lors d'un repas de gens instruits, il pouvait inspirer des contes et poèmes sur les unions mythiques de telle ou telle déesse marine, des étiologies sur différentes réalités géographiques ou historiques. L'aspect érotique est si fort que l'on a des raisons de croire que s'il ne s'agit pas d'Aphrodite/Vénus - en raison du véhicule employé -, il doit s'agir d'une déesse remarquable par l'amour qu'elle inspire, voire d'une autre Aphrodite.

Les candidates à une telle identification restent nombreuses. Dans la première moitié $d u v^{e}$ siècle de notre ère, Nonnos de 


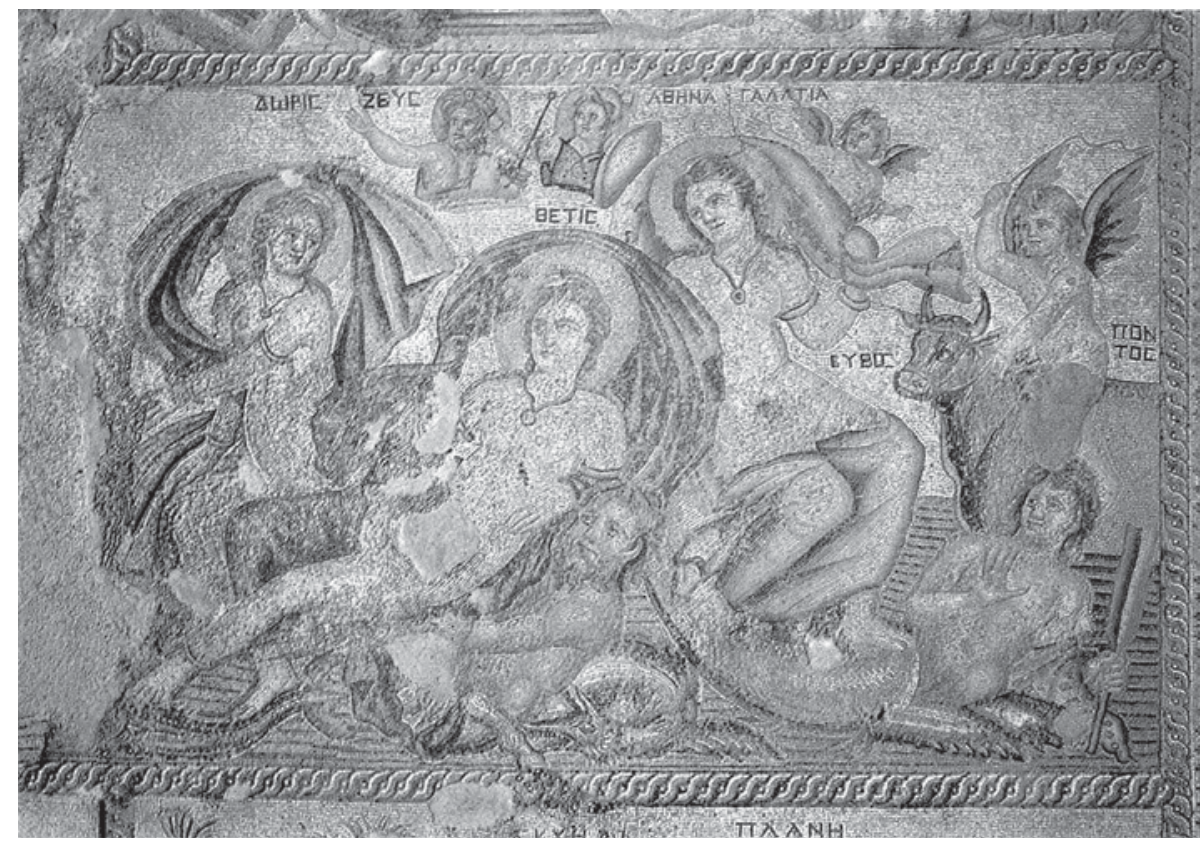

ILL. 23. Mosaïque dit " du jugement des Néréides ", IV $v^{\mathrm{e}}$ siècle de notre ère, dans la maison d'Aiôn, salle A, à Néa Paphos, Chypre (en ligne https://i.pinimg.com/originals/f0/98/38/f098386ea60b556d3c0db679445eda24.jpg).

Panopolis dresse un bref inventaire des déesses marines que ses lecteurs savants pouvaient reconnaître dans les variations iconographiques du motif de la belle vierge sortant de l'eau. Quand il raconte l'enlèvement de la nymphe Europè par Zeus sous forme de taureau, Nonnos la compare aux différentes déesses portées par des monstres et animaux sur la mer. Il obtient ainsi une image littéraire de groupe, que l'on peut comparer avec la mosaïque du concours de beauté entre Cassiopée et les Néréides Dôris, Thétis et Galatée, dans la maison d'Aiôn à Néa Paphos, datée du second quart du IV siècle de notre ère (ill. 23) ${ }^{82}$. Chez Nonnos, outre Europè reconnaissable

82. W.A. Daszewski, D. Michaelides, Guide des mosaïques de Paphos, Nicosie, 1989, p. 63-71; K. M.D. Dunbabin, Mosaics of the Greek and Roman World..., op. cit., p. 229-231. 
au taureau et une Néréide quelconque au dauphin, entrent dans la liste, sans distinctions particulières, Thétis, Galatée, Amphitrite ou Vénus portée par un Triton (Dionysiaques 1.55-83):

... ن்đદ̀

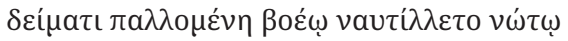

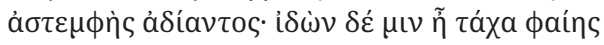

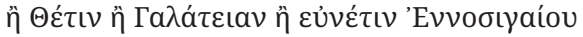

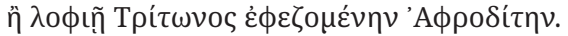

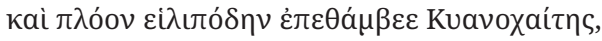

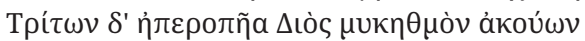

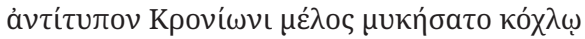

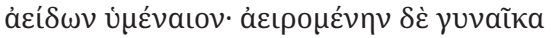

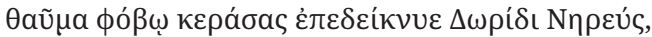

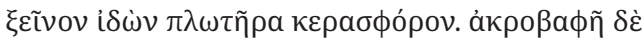

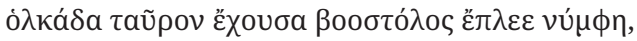

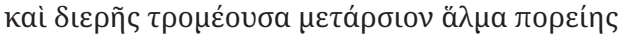

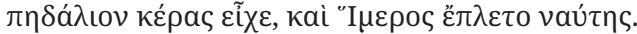

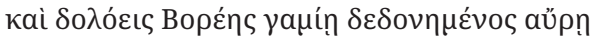

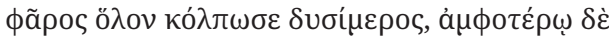

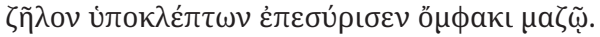

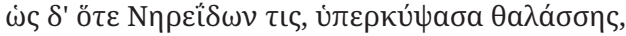

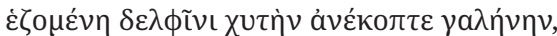

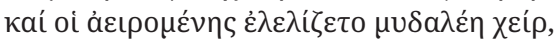

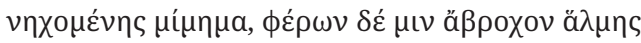

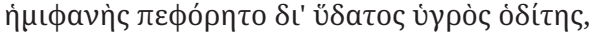

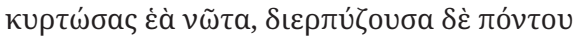

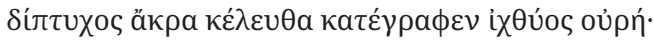

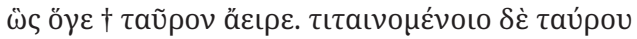

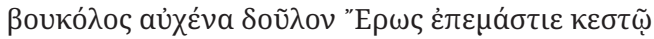

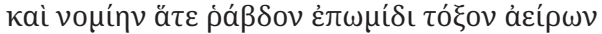

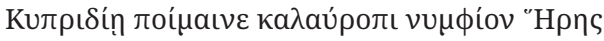

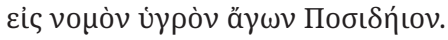

...au-dessus de la mer, la fille [c'est-à-dire Europè] saisie de terreur, naviguait sur le dos du taureau, immobile, hors de l'atteinte des vagues. En la voyant, on eût dit Thétis, ou Galatée, ou la compagne de lit de Celui-qui-fait-trembler-la-Terre [Amphitrite, épouse de Poséidon] ou Aphrodite assise sur l'aileron arrière d'un Triton. Chevelure-bleuemarine [Poséidon], cependant, s'étonnait de cette navigation au galop. En entendant les mugissements trompeurs de Zeus, Triton répondit au Cronide [Zeus] par le son de sa conque, en guise de chanson d'hyménée. Nérée montrait à Doris cette femme enlevée et ce nautonier cornu et étranger, objet d’admiration par crainte. De son côté la 
nymphe [c'est-à-dire la jeune mariée], naviguait en mouillant seulement les pointes de ses pieds et en chevauchant le taureau en guise de nef ; elle tenait la corne comme gouvernail, et tremblait pour son passage humide à travers la haute vague. Désir lui servait de pilote. Le rusé Borée enflait les plis de toute sa robe d'un air de mariage, et, lui-même épris de désir, sifflait sur la paire de seins non encore murs, en cachant sa jalousie. Ainsi quand une des Néréides s'élève furtivement au-dessus de la mer et, assise sur un dauphin, vient découper la calme surface, sa main humide pagaie, faisant semblant de nager et se tenir à la surface : le voyageur aquatique, à moitié visible, la porte en la préservant des vagues, la promène sur son dos recourbé, et tend sa queue qui fend les flots en y creusant un double sillon : tel s'avançait le divin taureau. Éros, devenu bouvier, fouette de son écharpe pleine de charme ce cou asservi du taureau tendu et, portant son arc sur son épaule comme un aiguillon pastoral, il dirige à l'aide de cette houlette de Cypris l'époux d’Héra vers les pâturages humides de Poséidon...

Selon quels critères Nonnos ou ses lecteurs pouvaient-ils reconnaître une de ces déesses sur les représentations qui les entouraient? À en juger d'après la mosaïque de Néa Paphos, où l'on a eu besoin d'inscriptions pour différencier les Néréides, elles n’avaient guère d'attribut spécifique ${ }^{83}$. C'était donc plutôt le contexte d'une représentation ou l'attente motivée par la culture générale du public qui dictait une identification.

Si nous avons pratiquement tout perdu sur le contexte de fabrication et de découverte du plat de Yenikend, nous avons la chance d'avoir conservé un écho de cette attente qu'un spectateur romain pouvait avoir en voyant un plat décoré avec une seule Néréide nue. Quatre épigrammes de l'Anthologie latine - recueil assemblé dans l'Afrique $d u v^{\mathrm{e}}$ siècle de notre ère mais mêlant des créations de différentes époques - évoquent Galatée. Les trois derniers, des ekphraseis de vases en argent, offrent, à notre sens, la juste clé de la décoration et de la fonction de notre plat (151-154 Riese $^{84}$ ):

83. Cf. aussi les inscriptions sur les mosaïques africaines: M. L. Neira Jiménez, "Inscripciones con nombres de nereidas y ninfas en los mosaicos romanos del Norte de Africa e Hispania ", L'Africa romana 9 (1992), p. 1013-1023.

84. Nous traduisons ici le texte d'A. Riese (Teubner, 1894), en acceptant certaines modifications de D. R. Shackleton Bailey, Towards a Text of Anthologia Latina, Cambridge 1979; D. R. Shackleton Bailey, Anthologia Latina I. Carmina in codicibus scripta 1. Libri Salmasiani aliorumque carmina, Stuttgardiae, 1982; cf. aussi 
151

Defugiens pontum siluas Galatea peragrat, Custodem ut pecorum cernere possit Acim. Nam eneros gressus infigit sentibus ardens Nec tamen alta pedum uulnera sentit amor. Ipsa Cupidineae laedunt tormenta pharetrae, Cuius et in mediis flamma suburit aquis.

En fuyant la mer, Galatée parcourt les forêts pour pouvoir apercevoir le gardien des troupeaux, Acis. Car en brûlant, elle se met des épines dans ses tendres plantes, mais l'Amour ne la laisse pas sentir les blessures profondes de ses pieds. Les éléments mêmes cèdent devant le carquois de Cupidon, dont la flamme brûle même au milieu des eaux.

152

De Galatea in uase

Fulget et in patinis ludens pulcherrima Nais, prandentum inflammans ora decore suo.

Congrua non tardus diffundat iura minister, ut lateat positis tecta libido cibis.

Galatée sur un vase.

La plus belle Naïade brille même en jouant dans les plats, en mettant en flammes les visages des participants aux repas, par son charme. Que le serveur ne tarde pas à verser les sauces appropriées, pour que l'objet de désir reste couvert par le dépôt des nourritures.

153

Ludere sueta uadis priuato nympha natatu

exornat mensas membra uenusta mouens.

Comptas nolo dapes; uacuum mihi pone boletar.

Quod placet aspiciam; renuo quod saturat.

La nymphe, habituée à s'amuser sur les bas-fonds, en nageant seule décore les tables en mouvant ses membres pleins de charme. Je ne

N.M. Kay, Epigrams from the Anthologia Latina: text, translation and commentary, London, 2006, ad loc; Loriano Zurli, Apographa Salmasiana II. Il secolo d'Or di " anthologia Salmasiana " (continuazione e fine), Hildesheim, 2010; Francisco Socas, Antología Latina. Repertorio de poemas extraído de códices y libros impresos, Madrid 2011; I. Bergasa, É. Wolff, Épigrammes latines de l'Afrique Vandale (Anthologie latine), Paris, 2016. Le texte repose sur une série de corrections: Bailey corrige les leçons suivantes de Riese : 151.3 teneros (à la place d'eneros) ; 151.5 cedunt elementa (pour laedunt tormenta), 152.2 ora (que nous gardons, en corda), 152.3 congrua (que nous gardons, en pinguia, diffundat en defundat) ; il écrit 154.4 ieiuno lumina tentet/ieiunus inguina tendat (pour ieiunus lumina tendat, que nous gardons). 
veux pas de mets exquis ; pose devant moi un plat vide, pour que je regarde ce que j'aime ; je rejette ce qui me rassasie...

154

In medio generata salo nunc arte magistra perueni

ad mensam; hic quoque nuda nato.

Si prandere cupis, differ spectare figuram,

ne tibi ieiunus lumina tendat amor.

Quae sim, ne dubites: ludens sine nomine lympha

quod Galatea uocer, lactea massa probat.

Née au milieu des eaux salées grâce à l'art d'un maître, je suis maintenant arrivée sur la table ; même ici je nage toute nue. Si tu veux manger, garde toi de regarder mon image, pour que l'amour affamé ne fasse bander tes yeux. Qui suis-je, n'aies pas de doute : une nymphe sans nom qui joue. Que mon nom soit Galatée, la matière couleur-delait du vase le montre.

Selon le poète anonyme, une Néréide bien individualisée sur un vase en argent, servant ou étant exposé lors d'un banquet romain, était la "très illustre " et " belle " Galatée. Pourquoi elle? Parce que seule parmi les Néréides, de manière analogue à Aphrodite/ Vénus marine, Galatée avait une nature aquatique, mais était devenue la protectrice des plantes et surtout des troupeaux terrestres ${ }^{85}$. Son nom, dérivé initialement de la mousse laiteuse des mers, a été

85. Après sa présence dans les catalogues épiques des Néréides (Homère, Iliade 18.45; Hésiode, Théogonie 250; Ps.-Apollodore, Bibliothèque 1.11), Galatée est surtout présente dans les récits étiologiques (Douris de Samos, BNJ 76 F58) et dans la poésie lyrique: Théocrite (Idyles 6, 11); Callimaque fr. 378-379 Pfeiffer; Properce 1.8.17-18, 3.2.7-8; Virgile, Bucoliques 1.30-31, 3.64-65, 72, 7.37, 9.39; Énéide 9.102-103; Ovide, Amours 2.11.34; Métamorphoses 13.738-968; Fastes 6.733-736; Valérius Flaccus, Argonautiques 1.134-136; Martial, Livre des spectacles 30.3-4; Silius Italicus, Puniques 14.221-226; Stace, Silves 1.4.76, 2.2.19-20; Lucien, Dialogues marins 1, Histoires vraies 2.3; Philostrate, Images 2.18, et infra n. 86; cf. P. Weizsäcker, "Galateia 1 ", in Roschers Lexikon... 1 (1884-1890), col. 1586-1589; G. Weicker, « Galateia 1 », in Real-Encyclopädie... 13 (1910), col. 517-519; L. Séchan, « Légendes... », art. cit., p. 34-37; S. Montón Subias, " Galateia », in Lexicon iconographicum... 5 (1990),-1005; A. R. Ghiotto, " Il mito di Polifemo e Galatea nella pittura della prima età imperiale ", Antenor 2 (2000), p. 29-51. Pour les épigrammes de l'Anthologie latine, voir S.T. Stevens, Image and Insight: Ekphrastic epigrams in the Latin Anthology, PhD University of Wisconsin-Madison, 1983, p. 132-169; W.J. Schneider, « Zu Tisch mit der Schönen Galatee. Zur missglückten Textkonstitution zweier Epigramme im Salmasianus », Classica et Mediaevalia, 50 (1999), p. 189-192; P. Paolucci, «Il ‘Ciclo di Galatea'(Anth. Latina 140143 S.B. = 151-154 R.) », Bollettino di Studi Latini 32 (2002), p. 111-127. 
associé au plus tard à l'époque grecque classique avec le lait des troupeaux - auxquelles elle fut attachée directement mais aussi par l'intermédiaire de ses amoureux, deux gardiens de troupeaux - le cyclope Polyphème et le jeune berger Acis (qui rappelle à certains égards Adonis, l'amant d'Aphrodite). Le nom de Galatée, la "laiteuse/Blanche-Lait », convenait bien à l'aspect brillant du corps d'une jeune femme, exposé nu au milieu d'un plat en argent. L'éclat du métal était donc une sorte de métonymie du théonyme. De plus, la sonorité gastronomique du nom la rendait tout à fait adaptée aux décorations des services de table. Par ailleurs, par le jeu de courbes, l'artiste pouvait suggérer la force tranquille de l'apaisement exercé sur les flots par la Néréide. Enfin, ses histoires d'amour à accents satyriques, tragiques ou comiques - rappelés incessamment dans les épigrammes cités par le verbe ludere, qui désigne à la fois le jeu innocent dans les vagues et les ébats sexuels - justifient bien la dimension érotique du décor de notre plat. La coquille Saint-Jacques dont l"Eros flottant dans les airs la couronne montre que toute la scène doit être lue sous le signe de la passion: c'est par l'amour que Galatée transcende sa condition marine pour rejoindre son berger. Le son du gastéropode, en guise de trompette, tenait lieu de chant d'hyménée, dans ce cortège nuptial aux allures triomphales, encadré par les deux Tritons. La présence du frère de la Néréide, métamorphosé en nérite, préfigure déjà les dangers de l'amour (voir supra). Quelle autre décoration pouvait être plus adaptée pour inspirer des propos de table, qu'une autre Aphrodite/ Vénus, une déesse symbolisant la beauté des mers, la prospérité de la nature terrestre, la force et les dangers de l'amour?

\section{Entre modèles grecs et grande distribution romaine}

Outre l'identification de la Néréide, la datation du plat est elle aussi restée, jusqu'à aujourd'hui, en suspens. En l'absence d'étude d'ensemble sur l'inventaire de la tombe de Yenikend, il est difficile d'être précis sur la date de fabrication et sur la durée de la vie antique du plat. C'est pourquoi les chercheurs sont généralement restés prudents, en proposant une datation large, entre le $\mathrm{II}^{\mathrm{e}}$ et le $\mathrm{IV}^{\mathrm{e}}$ siècle de notre ère, sans offrir d'arguments quant au choix de 
l'un et l'autre terminus ${ }^{86}$. Par une combinaison de spéculations iconographiques et historiques, on pourrait réduire cette période à la deuxième moitié du $\mathrm{II}^{\mathrm{e}}$ et à la première moitié du $\mathrm{III}^{\mathrm{e}}$ siècle, peutêtre même entre les derniers Antonins et les Sévères - du moins pour l'élaboration du modèle, qui a pu par la suite être utilisé par des artisans sur une période indéfinie. Certes, cet archétype s'appuie sur des figures tardo-hellénistiques et du début de l'époque romaine (entre le premier siècle avant notre ère et le premier siècle de notre ère), mais la composition de la scène ne semble pas pouvoir précéder les Antonins. Ce que l'on sait de la domination romaine dans le Caucase soutient la possibilité d'une telle diffusion, surtout jusqu'au milieu du $\mathrm{III}^{\mathrm{e}}$ siècle et aux conquêtes sassanides. Même si ces guerres n'ont certainement pas marqué l'arrêt des liens avec Rome, qui continue à être influente politiquement et à séduire par ses produits de luxe même au $\mathrm{IV}^{\mathrm{e}}$ siècle, il est certain que les élites albaniennes regardaient alors de plus en plus vers la Perse. C'est ce qui explique le mélange d'objets de luxe romains et sassanides dans certaines tombes ibères à partir du milieu du $\mathrm{III}^{\mathrm{e}}$ siècle — mais cela ne semble pas avoir été le cas de la tombe de Yenikend. De fait, si l'aureus perdu après la trouvaille de la tombe était romain, on s'attendrait à ce qu'il date d'entre les règnes de Néron et de Valérien, comme les autres monnaies en or trouvées en Albanie et surtout en Ibérie. Or, Valérien fut fait prisonnier par les Sassanides ${ }^{87}$ en 260. Par ailleurs, ce terminus ante quem correspond aussi à ce que l'on attend de la diffusion du christianisme au IV ${ }^{\mathrm{e}}$ siècle: même si les chrétiens ont utilisé l'imaginaire mythologique gréco-romain - comme en témoigne le coffret de Projecta, voir supra -, le choix d'un tel objet isolé aurait été moins judicieux après le baptême des rois caucasiens.

Hélas, nous ne disposons pas d'indice textuel pour préciser davantage cet intervalle. Nous ignorons la date de composition de la série épigrammatique consacrée à Galatée dans l'Anthologie latine: notre plat - avec un autre bien plus tardif (daté de 541), de

86. Cf. supra n. 6.

87. Voir désormais O. Coloru, L’imperatore prigionero: Valeriano, la Persia e la disfatta di Edessa, Bari, 2017. 
Carthage, sur lequel on a incisé une Néréide chevauchant une panthère marine, accompagnée d'un 'Eros ${ }^{88}$ - en offre aujourd'hui la seule illustration connue. Puisque les poèmes ont été composés en latin, que le mythe de Galatée concernait originairement la Sicile et que le peu de parallèles conservés pour la représentation de la déesse et des Tritons viennent surtout de la Méditerranée occidentale, on doit penser plutôt à une date à laquelle ce type d'objet et, plus généralement, la culture dont il relève, sont encore également partagés entre l'Occident et l'Orient de l'Empire romain. Une telle date, antérieure à l'Antiquité tardive, semble être suggérée aussi par la technique de fabrication à double coque - bien que nos connaissances actuelles sur l'histoire de la fabrication des plats romains ne rendent aucune certitude possible ${ }^{89}$.

$\mathrm{Du}$ point de vue iconographique, quelques détails semblent permettre un ancrage chronologique approximatif: tout d'abord, la nudité complète de la Néréide, sans trace de voile, est mieux attestée à partir de la fin du II ${ }^{\mathrm{e}}$ siècle (voir supra). Sa coiffure a des parallèles historiques surtout entre les règnes d'Hadrien et de MarcAurèle, et non sous les Sévères, mais l'hypothèse qu'il s'agisse ici de la reproduction d'un modèle antérieur ne peut, une fois encore, être écartée ${ }^{90}$. La présence du diadème doré, autour duquel sont retournés les cheveux d'au-dessus les tempes, correspond à une coiffure d'Aphrodite bien connue dès l'époque hellénistique (par exemple sur un denier de César, de 47-46 avant notre ère, ou sur une des sta-

88. J. M. C. Toynbee, K. S. Painter, « Silver Picture Plates... », art. cit., p. 19, pl. XVIIa; F. Baratte, "La vaisselle d'argent dans l'Afrique romaine et byzantine ", Antiquité tardive 5 (1997), p. 111-132, fig. 16.

89. Voir encore D.E. Strong, Greek..., op. cit.; cf., pour la période grecque, M. Yu Treister, The Role of Metals in Ancient Greek History, Leiden-New York-Köln, 1996.

90. Pour les coiffures à côtes de melon d'époque sévérienne, voir J. Meischner, Das Frauenporträt der Severerzeit. Inaugural-Dissertation..., Berlin, 1964. Mentionnons aussi le possible rapprochement avec la statue de Fortuna de Sainpuits (Yonne), au diadème surdimensionné, datée du début du $\mathrm{III}^{\mathrm{e}}$ siècle par F. Baratte (dir.), Trésors..., op. cit., p. 182-183 (nr. 129). Le plat d'Atalante et de Méléagre de l'Ermitage (Inv. W-1), daté par estampillage impérial du début du viI ${ }^{\mathrm{e}}$ siècle, est un bon exemple de la très longue durée de vie des modèles, puisque son archétype pourrait remonter aux I ${ }^{\mathrm{er}}$-II ${ }^{\mathrm{e}}$ siècles de notre ère: voir J. M. C. Toynbee, K. S. Painter, "Silver Picture Plates... », art. cit., p. 33 nr. 28 pl. XIIId. 
tuettes du type Sandalbinder), et revenue en vogue sur les copies romaines des $\mathrm{I}^{\mathrm{er}}-\mathrm{II}^{\mathrm{e}}$ siècles (quand on date la copie en marbre de l'Aphrodite de Capoue, dont le type a servi au groupe susmentionné avec Mars-Marc Aurèle, ill. 18, ou à la « Vénus marine " du Museo Ostiense inv. 110) ${ }^{91}$.

La jeunesse des Tritons imberbes, à mèches courtes, avec une ceinture d'écailles en forme de feuilles d'acanthe - tels qu'on les voit déjà à Pergame et qu'on les reproduit au premier siècle de notre ère (ill. 24) — s'accorderait également avec une date du HautEmpire: on n'avait pas encore généralisé à nouveau le type du Triton/ichthyocentaure barbu, proche d'un Vieux de la mer à capacités métamorphiques, ni la coiffure mêlée d'algues et crustacés des dieux marins à laquelle nous ont habitués les mosaïques hispaniques et africaines ${ }^{92}$. Les Tritons ne sont pas non plus couverts d'écailles - comme l'imaginait Pausanias (9.21) et comme on le voit parfois sur des monuments des $\mathrm{I}^{\mathrm{er}}-\mathrm{II}^{\mathrm{e}}$ siècles de notre ère - signe que l'artiste est resté proche du modèle tardo-classique (ill. 25) ${ }^{93}$.

La multiplication des putti, avec leurs attitudes variées, plus ou moins burlesques, et le scénario du triomphe marin, avec une scène de couronnement faisant allusion à Vénus, semblent possibles également plutôt à partir de la seconde moitié du $\mathrm{II}^{\mathrm{e}}$ siècle de notre ère. Le poids en argent équivalent à celui de 500 deniers, surtout à partir de Commode, si notre interprétation est juste, pourrait être un argument supplémentaire en faveur de cette date: à la fin des Antonins ou sous les Sévères.

91. G. Becatti, Ninfe..., op. cit., p. 17-18, I-VI. Remarquons aussi la coiffure de la tête d'Aphrodite sur la coupe d'Arras (publiée dès 1568 par Stephan Vinand Pighius), datant des $\mathrm{II}^{\mathrm{e}}$-III ${ }^{\mathrm{e}}$ siècle de notre ère: F. Baratte (dir.), Trésors..., op. cit., p. 156157. Plus généralement, pour le type de la Vénus de Milo, A. Pasquier, La Vénus de Milo... p. 66-78; dernièrement, F. Queyrel, La sculpture hellénistique. I. Formes, thèmes, fonctions, Paris, 2016, p. 57-69.

92. Cf. M.P. San Nicolás Pedraz, "Seres mitologicos... ", art. cit., p. 310-312, surtout fig. 8, le triton imberbe de la mosaïque de Conimbriga, datée entre le $\mathrm{II}^{\mathrm{e}}$ et le début du $\mathrm{III}^{\mathrm{e}}$ siècle de notre ère. Pour l'évolution du type, M.L. Neira Jiménez, « De Tritón a tritones..." ", art. cit.

93. Cf. A. Hekler, Die Sammlung antiker Skulpturen. Die antiken Skulpturen im Ungarischen Nationalmuseum und im Budapester Privatbesitz, Wien, 1929, nr. 101; N. Icard-Gianolio, « Tritones... », art. cit., $\mathrm{n}^{\circ}$ 22-24, 54-55, 62. 


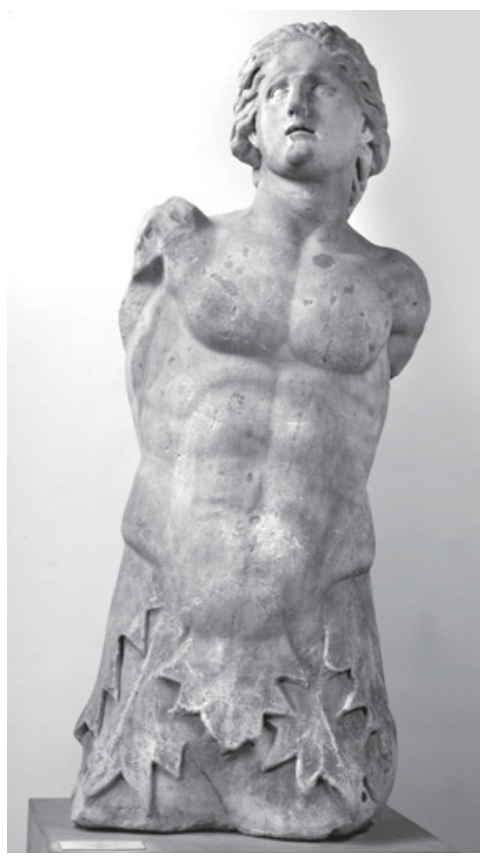

ILL. 24. Statue en marbre d'un Triton, copie du premier siècle de notre ère d'après un original hellénistique, conservée à Berlin, Staatliche Museen, Antikensammlung Berlin, Sk 286. Photo DAI Rome (FA-SPerg000495-01).

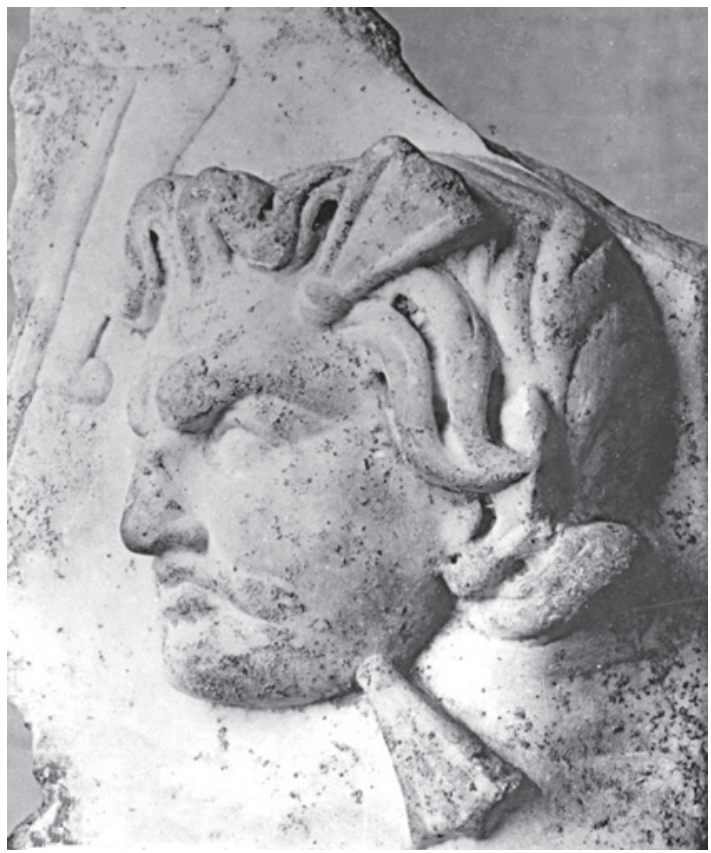

ILL. 25. Relief à double face, ayant, d'un côté, un masque de Triton, $\mathrm{II}^{\mathrm{e}}$ siècle de notre ère, conservé à Budapest, Szépmüvészéti Múzeum, Inv. 4830. Photo DAI Rome (D-DAIROM-72.3037).

La tâche de l'historien qui cherche à dater ces formes est compliquée par les reprises continues des modèles ainsi que par la longue vie des mythes et des traditions symposiastiques. Textes et images peuvent être mis en parallèle pour suivre le succès de Galatée amoureuse et de son cortège marin, depuis la fin de l'époque grecque classique et la haute époque hellénistique - quand Nicocharès et Alexis ont fait jouer la comédie de Galatée et quand Callimaque a composé le poème qui semble avoir servi de cadre pour bien des traditions postérieures. C'est à la suite de Praxitèle que l'on multiplie les représentations de déesses dénudées et à la suite de son contemporain, Skopas, que l'on fait des Tritons imberbes, qui ont connu un grand succès non seulement dans l'Orient hellénistique 


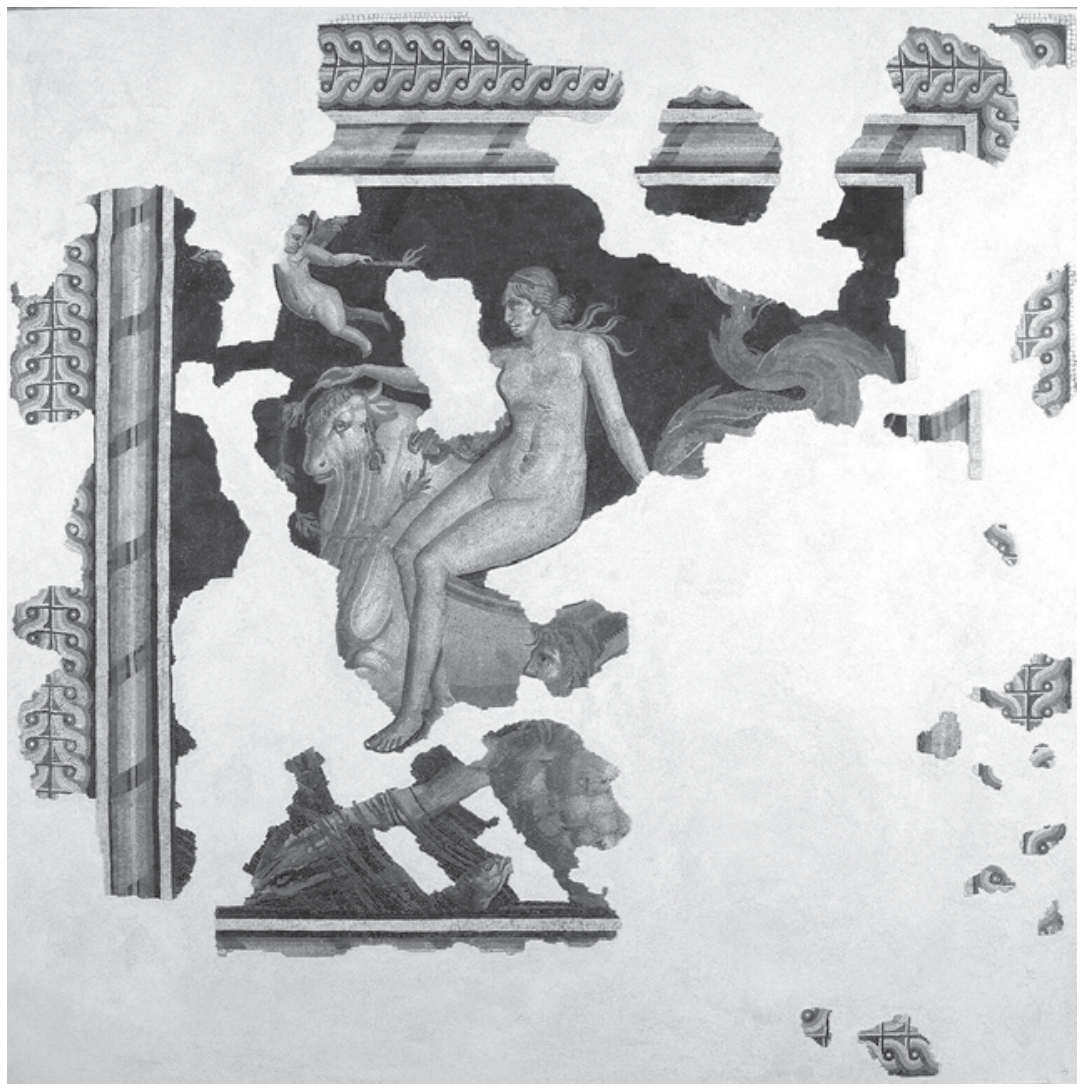

ILL. 26. Mosaïque dite de l'enlèvement d'Europè, Musée archéologique d'Aquilée, premier siècle de notre ère, restaurée (Photo Gruppo Mosaicisti Ravenna, su concessione del Ministero per i beni e le attività culturali, Polo Museale del Friuli Venezia Giulia.).

mais aussi à Rome, à partir de l'époque augustéenne. Pendant le premier siècle avant notre ère et le suivant, l'ébauche de notre cortège est déjà esquissée, sur la mosaïque dite de l'« Enlèvement d'Europè " à Aquilée (ill. 26) ${ }^{94}$ : la déesse qui chevauche un taureau de mer a

94. On met parfois en doute l'identification du personnage avec Europè, en raison de la queue marine que semble avoir le taureau sur cette mosaïque très abîmée et récemment restaurée: F. Ghedini, M. Bueno, M. Novello, F. Rinaldi, I pavimenti romani di Aquileia. Contesti, tecniche, repertorio decorativo, Padova, 2017. Il pourrait toutefois ne pas s'agir d'une queue de poisson mais bien du voile d'Europè: 

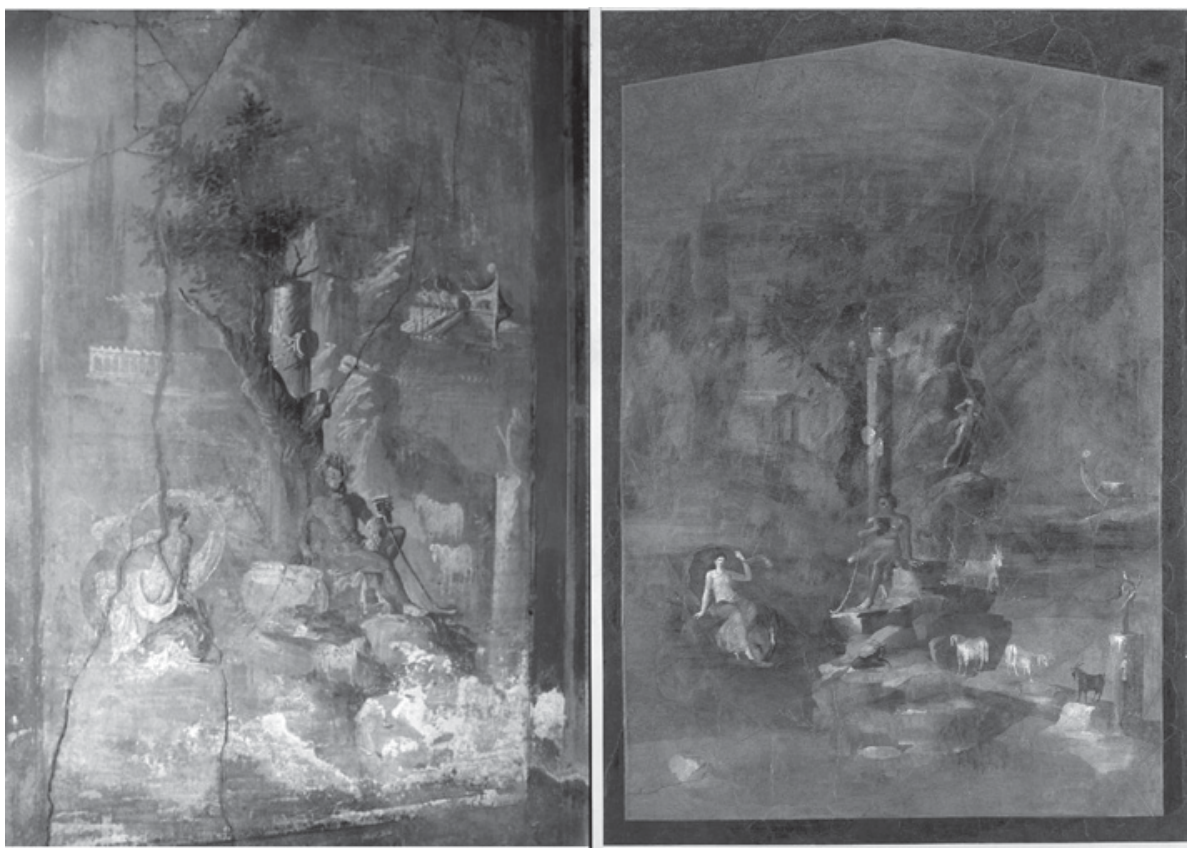

ILL. 27. Deux fresques du troisième style campanien, représentant les amours de Galatée et de Polyphème, l'une venant de Pompéi I, 7,7 maison du Prêtre Amandus, triclinium b, mur sud (photo @R. Huchin 2004, Base Décor Antique Paris, sous la direction d'A. Barbet), l'autre de la maison d'Agrippa Postumus à Boscotrecase, conservée au Metropolitan Museum of New York, Rogers Fund, 1920 (https://www.metmuseum.org/toah/works-of-art/20.192.17/).

son cortège limité à un 'Eros et d'un Triton, mais les formes et poses de ces derniers sont analogues à celles des personnages de notre plat. À la même époque, à en juger d'après les documents conservés aujourd'hui, les amours tragiques de Galatée et de Polyphème connaissent une diffusion sans précédent dans la sphère privée, avec la poésie d'Ovide et la peinture des deuxième et troisième styles (ill. 27): on y insiste sur le contraste entre la belle (blanche) et la bête (noire), sur l'impossibilité de la rencontre entre le monde aquatique,

voir A. Blanchard, compte-rendu de "Wattel-de Croizant (Odile). Les mosaïques représentant le mythe d'Europe ( $\mathrm{I}^{\mathrm{er}}-\mathrm{VI} \mathrm{I}^{\mathrm{e}}$ siècles). Évolution et interprétation des modèles grecs en milieu romain, Paris, De Boccard, 1995 ", Revue des études grecques 112 (1999), p. 274. 
divin, et celui des rudes montagnards monstrueux ou de fragiles humains. Au II ${ }^{\mathrm{e}}$ siècle de notre ère, la passion de Galatée est suffisamment célèbre pour ouvrir la série des Dialogues marins de Lucien: le public semble désormais prêt à entendre, comme la mère Dôris, des arguments en faveur d'une liaison entre la Néréide et le Cyclope. Aulu-Gelle (Nuits attiques 9.9.4-6) compare la provocation amoureuse du jet d'une pomme chez Théocrite (Idylles 5.88-89) et chez Virgile, qui mentionne Galatée (Bucoliques 3.64-65). Dans l'Égypte du III $^{\mathrm{e}}$ siècle de notre ère, au début du Banquet des sophistes d'Athénée de Naucratis (1.11 6e-7a), on sait l'histoire du mythe de Galatée et de Polyphème, dans laquelle la composition du poète Philoxène de Cythère, amoureux d'une certaine Galatée amante du tyran Denys de Syracuse, a joué un rôle important. Au v siècle, Nonnos n'est donc peut-être pas un témoin aussi isolé qu'on pourrait le penser, car dans les cercles cultivés, jusqu'à la fin de l'Antiquité, Galatée allait rester un symbole mondain et ensuite de plus en plus savant de la beauté et de l'érotisme féminin ${ }^{95}$.

Nous ignorons aussi tout du lieu de fabrication: on l'a généralement situé en Orient, en partant de la proximité géographique et de la présupposée importance des ateliers métallurgiques d'Asie Mineure, de Syrie, pourquoi pas d'Alexandrie - vu la diffusion d'autres vases métalliques dits syriens (antiochéens) ou alexandrins dans la steppe eurasiatique ${ }^{96}$. En réalité, sans analyses scientifiques extensives, il est impossible de se prononcer, d'autant plus que le mythe de Galatée est ancré en Sicile et, historiquement, lié à l'Adriatique. De plus, outre les épigrammes ekphrastiques qui nous ont permis l'identification, la majorité des références littéraires à Galatée sont bien latines. Certes, au moins jusqu'au III $^{\mathrm{e}}$ siècle de notre ère, le mythe semble avoir été

95. Par ex. Claudien 30.122-133, Sur l'enlèvement de Proserpine 3.335-356; Nonnos de Panopolis, Dionysiaques 1.57-59, 6.229-325, 9.80-81, 14.64-66, 34.79-80, 39.257291, 40.553-558, 43.266-267, 390-393; Sidoine Apollinaire 11; Paul le Silentiaire dans l'Anthologie Palatine 5.244, 256; Cassiodore, Variarum 2.40; Dracontius, Romulea 30-37; Théophylacte Simocatta, Lettres 33.

96. Pour la possible production syrienne, voir Ch. Kondoleon, Antioch: The lost ancient city, Princeton, 2000, nr. 71, 73, 75. Pour une possible influence de l'orfèvrerie alexandrine au $\mathrm{III}^{\mathrm{e}}$ siècle, voir A. Dan, F. Grenet, N. Sims-Williams, « Homeric Scenes... ", art. cit. 
bien connu des Grecs d'Orient. En même temps, les modèles iconographiques circulaient, sous forme de dessins ou de vases ${ }^{97}$. Mais nous ignorons presque tout de ces transferts entre Occident et Orient à l'intérieur du monde romain, alors même que la fonction du plat semble assurée: il était particulièrement adapté à l'atmosphère du banquet aristocratique, où l'on privilégiait la beauté des formes et les discussions, plus ou moins savantes, sur l'amour ${ }^{98}$.

Enfin, s'il n'était pas une banale décoration sur la table des riches, qu'on pouvait offrir ou vendre dans toute sorte d'occasion, un tel vase pouvait être offert lors d'un mariage, avec un vœu tel le refrain de la "Veillée de Vénus ", qu'il est possible de dater, selon R. Schilling, du II $^{\mathrm{e}}$ siècle de notre ère: "Cras amet qui numquam amauit quique amauit cras amet//Aimez demain, vous qui n'avez jamais aimé; vous qui avez aimé, aimez encore demain! $»^{99}$.

\section{De la mer Intérieure aux flancs du Caucase: jeux et enjeux des contacts entre Autres}

\section{Une approche des transferts par les gender studies}

Le plat de Galatée, façonné quelque part dans l'Empire romain vers la fin des Antonins (ou sous les Sévères), a pu être exporté au-delà du Taurus (notre Petit Caucase) et arriver dans le Grand Caucase (véritable Caucase occidental des Anciens) d'au moins trois manières. Primo, il a pu être vendu et acheté comme objet en argent à forte valeur ajoutée. Secundo, il a pu être apporté ou pillé lors d'une incursion armée dans les régions voisines ou dans l'Empire romain, par un raid «barbare » ou par l'engagement d'un soldat caucasien en tant que mercenaire. Tertio, il a pu être offert comme

97. Comme on peut le remarquer aussi pour la circulation des modèles de mosaïques: cf. M.L. Neira Jiménez, "The Sea Thiasos of Nereids and Tritons in the Roman Mosaics of Turkey ", in M. Şahin (éd.), Mosaics of Turkey and Parallel Developments in the Rest of the Ancient and Medieval World, Istanbul, 2012, p. 631-655.

98. Cf. K. M.D. Dunbabin, The Roman Banquet: Images of conviviality, Cambridge, 2003.

99. Peruigilium Veneris/« La veillée de Vénus » v. 1, 8, 12, 27, 36, 48, 57, 68, 75, 80, 93, éd. et trad. Robert Schilling, Paris, Les Belles Lettres, $1961^{2}$ ( $1^{\text {re }}$ éd. 1944). 
récompense ou cadeau, militaire ou diplomatique, à un membre de l'élite caucasienne. Bien que les objets de fabrication gréco-romaine soient plus rares en Albanie (correspondant en grande partie à l'Azerbaïdjan actuel) que dans l'Ibérie proche (Géorgie orientale) et malgré le témoignage de Strabon sur l'absence de monnayage et de tout système de mesures cohérent chez les Albaniens (Géographie 11.4.4), des monnaies et des objets en métal précieux frappés dans l'Empire romain entre le premier et le $\mathrm{III}^{\mathrm{e}}$ siècle de notre ère ont été retrouvés sur le territoire de l'Azerbaïdjan ${ }^{100}$. Ils ne sont vraisemblablement pas plus nombreux que les monnaies et les objets parthes, reflet d'une plus grande complicité, sur la très longue durée, entre Albaniens et Iraniens voisins. Mais il y a au moins un autre objet

100. Pour la manipulation politique romaine dans les sources de Strabon et chez Strabon lui-même, voir R. Nicolai, « Strabone e la campagna partica di Antonio. Critica delle fonti e critica del testo ", in G. Traina (éd.), Studi sull' XI libro dei Geographika di Strabone, Lecce, 2001, p. 95-126, et G. Traina, "Roman Representations of Caucasian Albania ", in A. K. Alikberov, M.S. Gadjiev (éd.), Albania Caucasica I, Moscow, 2015, p. 42-47; leur commentaire au livre XI de Strabon (2000) reste utile, malgré les adnotations plus récentes de S. Radt (2008) et D.W. Roller (2018). Pour les monnaies d'Azerbaïdjan, voir par ex. E.A. Pahomov, « Antičnye monety v Albanii (v predelah Azerbajdžanskoj SSR) ", in K. G. Aliev (éd.), Voprosy istorii Kavkazskoj Albanii, Baku, 1962, p. 48-51. Les principaux textes sur les Albaniens sont recueillis et traduits dans Z. Aleksidzé, J.-P. Mahé, « Découverte d'un texte albanien: une langue ancienne du Caucase retrouvée ", Comptes rendus des séances de l'Académie des Inscriptions et Belles-Lettres 141.2 (1997), p. 517-532; en russe, A. A. Akopjan, Albanija-Aluank v greko-latinskih i drevnearmjanskih istočnikah, Erevan, 1987. Pour l'histoire et l'archéologie du royaume albain, voir surtout K.V. Trever, Očerki po istorii i kul'ture kavkazskoj Albanii. IV v. do n. è. - VII v. n. è., Moskva-Leningrad, 1959; P.N. Tretiakov, A. L. Mongait, Contributions to the Ancient History of the USSR, Cambridge Ma, 1961, p. 72-106; Dž. A. Halilov, Material'naâ kul'tura Kavkazskoj Albanii (IV v. do n. è. - III v. n. è.), Baku, 1985; K. G. Aliev, Antičnaja Kavkazskaja Albanija, Baku, 1992; T.M. Mamedov, Kavkazskaja Albanija v IV-VII vv, Baku, 1993; F.L. Osmanov, Istorija i kul'tura Kavkazskoj Albanii IV v. do n.è. - III v. n.è.: (na osnovanii arheologičeskih materialov), Baku, 2006; M. M. Rasulova, Torgovoèkonomičeskie i kul'turnye svâzi Kavkazskoj Albanii s antičnym i èllinističeskim mirom: IV vek do n.è. - III vek n.è., Baku, 2008 (p. 177-178 concernant notre plat). Pour la géographie historique de l'Albanie, S.V. Murav'ev, « Ptolemeeva karta Kavkazskoj Albanii i uroven' Kaspija ", Vestnik drevnej istorii 1 (1983), p. 117-147; M.S. Gadžiev, « Kavkazskaja Albanija i Dagestan: istoriko-geografičeskij i administrativno - političeskij aspekty ", in A. K. Alikberov, M.S. Gadjiev (éd.), Albania Caucasica I..., p. 28-40. Pour l'Ibérie, voir surtout C. Toumanoff, « Chronology of the Early Kings of Iberia ", Traditio 25 (1969), p. 1-33, et D. Braund, Georgia in Antiquity. A history of Colchis and Transcaucasian Iberia 550 BC - AD 562, Oxford, 1994. 


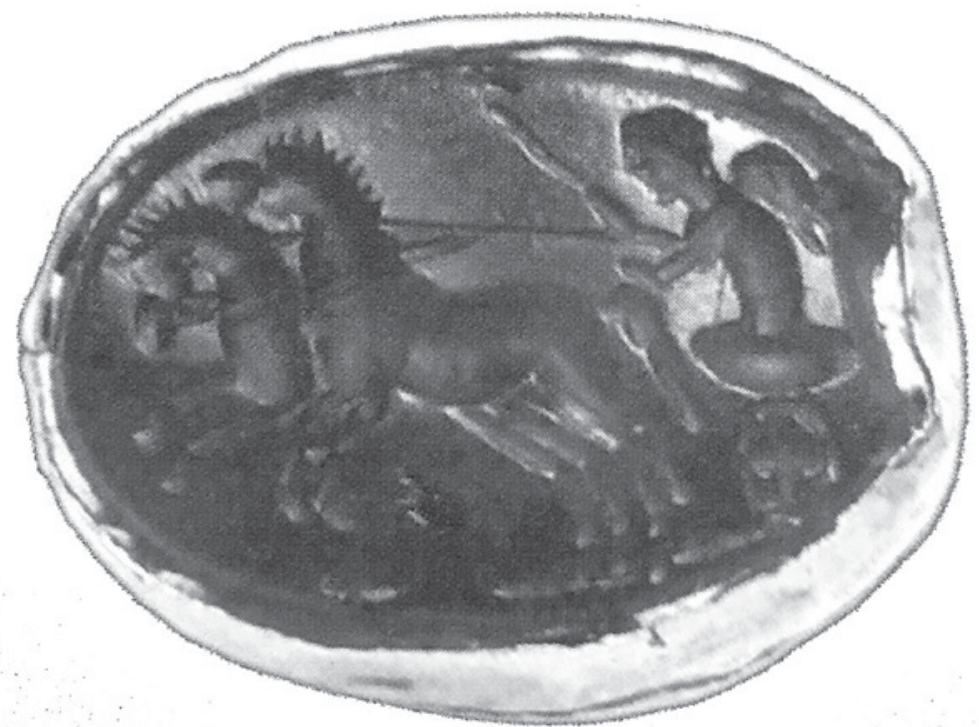

ILL. 28. Bague contenant une intaille avec Éros conduisant un char, $\mathrm{II}^{\mathrm{e}}-\mathrm{III} \mathrm{e}^{\mathrm{e}}$ siècle après J.-C., découverte dans la région d'Agjabedi, Uchtepe, conservée au Musée d'archéologie et d'ethnographie d'Azerbaidjan à Bakou, inv. XF 67; reproduite d'après N. Välixanll, Azərbaycanın arxeoloji quzıl və gümüş əşyaları..., nr. 112.

de luxe gréco-romain à thématique érotique: une bague en or avec Éros aurige, conservée actuellement au musée de Bakou (ill. 28) ${ }^{101}$. Néanmoins, comme le site archéologique de Yenikend et les détails concernant le reste de l'inventaire de la tombe restent méconnus, nous ne savons pas si le guerrier (ou la guerrière) avec lequel on a enterré le plat fut son premier propriétaire caucasien ou si le plat avait déjà eu une longue histoire avant son dépôt dans la tombe ${ }^{102}$.

101. Voir N. Välixanll, Azərbaycanın arxeoloji qızıl və gümüş aşyaları/Gold and Silver Archaeological Items of Azerbaijan, Baku, 2013. Nous n’avons pu consulter la publication antérieure de N. Välixanll, Milli Azärbaycan Tarixi Muzeyinin kolleksiyasinin inciläri/Gems from the collection of the National Museum of History of Azerbaijan, Baku, 2010. Elle peut être comparée avec certains exemplaires inventoriés par R. Vollkommer, " Eros ", in Lexicon Iconographicum... 3 (1986), p. 850-942, nr. 280-282; I. Bingöl, O. Bingöl, « Der Kameo aus Magnesia », Anadolu / Anatolia 25 (2003), p. 27-35..

102. Des objets d'origines et dates différentes ont été découverts dans les tombes ibères: par ex. A. Apakidze, V. Nikolaishvili, « An Aristocratic Tomb of the Roman Period from Mtskheta, Georgia », The Antiquaries Journal 74 (1994), p. 16-54. 
Dans l'état actuel des connaissances archéologiques sur la région de Yenikend, nous ne savons pas si le tombeau faisait partie d'une nécropole aristocratique - qui aurait été néanmoins assez éloignée de la capitale albanienne Kabalaka/Cabalaca, correspondant à la moderne Qabala, située plus au nord, dans la même vallée (cf. ill. 1) ${ }^{103}$. Deux raisons ont pu pousser ce membre des élites militaires et peutêtre aussi politiques à se faire enterrer avec ce plat, en pervertissant donc sa fonction originelle selon ses propres opinions et coutumes: tout d'abord, la valeur du métal. Selon Strabon (11.4.8), les Albaniens employaient le métal précieux surtout pour les mobiliers des tombes:

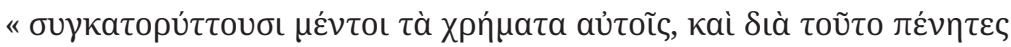

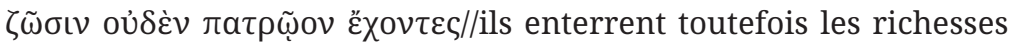
avec les défunts, raison pour laquelle ils vivent eux-mêmes très misérables, faute de patrimoine ». Dans une région où les échanges en métal précieux étaient peut-être assez rares et à une époque où la monnaie romaine d'argent perdait de sa valeur, on thésaurisait de l'or - d'où peut-être la monnaie d'or perdue après la fouille - et de la vaisselle en argent. C'est ce qui explique les grosses quantités de vaisselle romaine récupérées dans les tombes et trésors enfouis à partir du $\mathrm{III}^{\mathrm{e}}$ siècle de notre ère ${ }^{104}$. Ensuite, la personne décédée, ses proches ou du moins la personne qui a rapporté originairement cet objet en Transcaucasie mais dont on ne connaît pas le rapport avec la personne décédée, devaient avoir une certaine admiration pour le raffinement romain. Cela ne signifie pas qu'elle reconnaissait le mythe représenté; mais elle pouvait tout au moins reconnaître le prestige de l'artisanat romain. En même temps, si cette personne prêtait un peu d'attention au décor, même sans reconnaître Galatée, elle y distinguait la mer, une femme à cheval (marin), une figure érotique dominatrice: autant de contrastes avec les réalités environnantes des sociétés montagnardes, fortement polarisées entre la sphère sociale des hommes et des femmes, dans le Caucase ancien.

103. Pline l'Ancien 6.29; Ptolémée, Géographie 5.11-12, 8.19.7-9. Pour l'histoire et l'archéologie de la ville, I. A. Babaev, G. M. Ahmedov, Kabala, Baku, 1980 ; I. Aliev, F. Gadirov, Kabala, Baku, 1986.

104. Cf. l'inventaire de R. Hobbs, Late Roman Precious Metal Deposits, c. AD 200700: changes over time and space, PhD London, 1997, pour l'Occident romain. 
Ce contraste nous fait supposer que ce plat ne s'est peut-être retrouvé ni par hasard, ni à cause d'une trop grande profusion des décorations à Néréides - et surtout de Galatée la Sicilienne dans la Méditerranée orientale. Qu'il ait été un objet commercial ou de prestige, le transfert vers le Caucase, sillage mythique des Amazones, pourrait être dû à un subtil jeu d'esprit. On offrait ainsi, à un Albanien ou à une "Amazone " même - c'est-à-dire à une rude guerrière d'Albanie, telle celles que les Romains ont croisées sur les champs de bataille lors des campagnes de Pompée le Grand, en 66-65 avant notre ère ${ }^{105}$ - son altérité romaine: la belle Galatée, dépourvue de toute arme sauf de l'éclat argenté de son corps, qui chevauche un cheval en maîtresse des mers et de l'amour, et séduit les bergers. La délicate fille de Nérée, fameuse au-delà des mers, cherche à rejoindre les montagnes sauvages mais riches du Cyclope, Barbare par excellence (du point de vue de tout connaisseur de l'Odyssée). Un indice en faveur de cette hypothèse est le témoignage de Strabon sur ses sources romaines - dont sans doute Théophane de Mytilène (repris peut-être par Poséidonios d'Apamée), suite à la campagne de Pompée le Grand, et Q. Dellius, après la campagne parthe de Marc Antoine - , qui décrivaient les Albaniens comme des Cyclopes et leur pays, sur les marges de l'œkoumène, comme une utopie de l'âge d'or sauvage (Strabon 11.4.3):

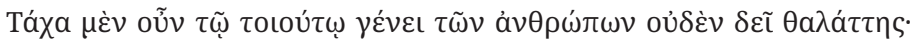

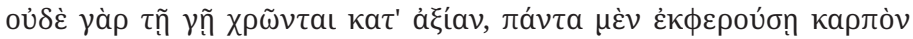

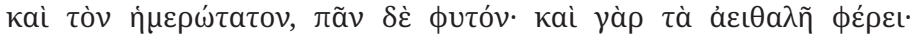

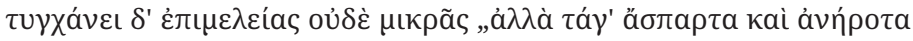

105. Plutarque, Vie de Pompée 35.5-6; Appien, Mithridatica 103; cf. Strabon 11.5 avec M. Dreher, " Pompeius und die kaukasischen Völker: Kolcher, Iberer, Albaner ", Historia 45 (1996), p. 188-207. Pour les Amazones, voir surtout J. Carlier, " Voyage en Amazonie grecque ", Acta antiqua Academiae Scientiarum Hungaricae 27.4 (1979), p. 381-405, repris dans " Les Amazones font la guerre et l'amour ", L'ethnographie 74 (1980), p. 11-33; F. Thélamon, « Amazones et Gargaréens: la disjonction des masculins et des féminins au Caucase ", in Mélanges Pierre Lévêque VII. Anthropologie et société, Besançon, 1993, p. 319-338. Plus récemment, les sources sur l'historicité des Amazones ont été reprises par I. Lebedynsky, Les Amazones: mythe et réalité des femmes guerrières chez les anciens nomades de la steppe, Paris, 2009, et A. Mayor, The Amazons: lives and legends of warrior women across the ancient world, Princeton-Oxford, 2014. 


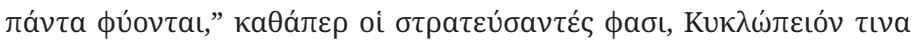

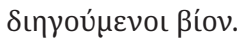

$\mathrm{Au}$ reste, ce genre d'hommes n'a nul besoin de la mer. Car ils ne savent même pas tirer de la terre un parti convenable, alors qu'elle produit tous les fruits, même les plus doux et tous les végétaux, car il y a même des arbres à feuillage persistant. Et cela arrive naturellement, sans le moindre soin. " Tout ici naît sans semailles, et sans labour " (Odyssée 9.109). C'est ce que disent ceux qui ont fait la guerre dans le pays : que les Albaniens mènent une vie de Cyclopes.

Telle qu'elle apparaît sur ce vase, Galatée est l'Autre de l'Amazone, elle-même l'Autre du modèle guerrier masculin méditerranéen. Galatée pourrait donc être la réponse supposée " civilisée " à tout ce que l'Amazone caucasienne-caspienne, guerrière monstrueuse issue de l'imaginaire grec, pouvait représenter pour les Romains éduqués, qui avaient affaire avec des Albaniens.

Bien plus que les textes littéraires, l'archéologie peut nourrir des réflexions sur l'origine et l'acheminement du plat vers le Caucase. Faute de pouvoir étudier le plat et le reste de l'inventaire, nous nous contentons de rappeler quelques parallèles possibles et les principaux moments de contact avec les Romains, connus des sources historiques, avant de conclure sur les difficultés mais aussi les enjeux de l'étude d'un middle ground.

\section{Les parallèles ibères de Mts'khet'a (II ${ }^{e}-I I I^{e}$ siècles de notre ère)}

Les meilleurs éléments de comparaison pour la tombe guerrière de Yenikend ont été découverts sur le haut cours du Kyros, dans ce que les Anciens appelaient l'Ibérie (Géorgie orientale). De nombreuses tombes, extrêmement riches en objets de luxe provenant aussi bien de l'Orient et du Proche-Orient que de l'Empire romain, selon les époques, ont été découvertes autour de la capitale d'Armaziskhevi près de la ville moderne de Mts'khet'a (à la confluence du Kyros et de son tributaire, Aragvi, au nord de Tbilissi, sur la route du passage de Dariali, suivie par l'actuelle route militaire géorgienne). Outre les objets en or et en argent qui ont pu être commandés ou achetés par la riche clientèle de la cour ibère, on y a trouvé des plats en argent romains dont la décoration ne laisse pas de doute: il 
s'agit de cadeaux offerts aux rois " clients " par l'empereur, les gouverneurs ou les chefs militaires, à des moments clé, confirmés par les textes - surtout pour les empereurs Antonins ${ }^{106}$. Les objets ont pu être acheminés à partir des régions proches du limes oriental (de l'Euphrate, à partir de la Syrie ou de la Cappadoce), suivant les voies de communication habituelles dans le Taurus (Arménie actuelle) ou à travers la Colchide (l'Ouest de la Géorgie actuelle).

Or, textes et archéologie s'accordent sur un certain contraste entre l'Albanie, plus proche des provinces romaines et du royaume client d'Arménie, et l'Ibérie sédentaire, agricole, peu guerrière et restée plus attachée à Rome. L'Albanie, voisine et concurrente de l'Ibérie, plus longtemps fragmentée en tribus montagnardes, fut moins urbanisée - ou, plutôt, resta dotée de petits centres urbains d'inspiration parthe. Les Albaniens apparaissaient aux Romains comme étant surtout des bergers, pratiquant la chasse, donc plus proches du style de vie des Nomades. Néanmoins, lors de l'invasion de Pompée le Grand, le royaume albanien fut capable de se défendre au moyen d'une infanterie de 60000 hommes et d'une cavalerie de 22000 ou, au moins, 12000 hommes (Strabon 11.4.4-5, cf. Plutarque, Vie de Pompée 35.3). Du point de vue grec, cette contradiction entre la capacité d'organiser une armée nombreuse et le lieu commun du manque de virilité des Nomades, asiatiques et septentrionaux, pouvait s'expliquer par l'éloignement de l'Albanie, par la sauvagerie et même la monstruosité des hautes montagnes du Caucase, car l'Albanie était la plus proche du pays caspio-caucasien des Amazones, compagnes des Gargaréens (Strabon 11.5). En réalité, ayant déjà appartenu à l'Empire achéménide (puisque les Albaniens sont attestés dans l'armée de Darius III à Gaugamèles, en 331 avant notre ère, cf. Arrien, Anabase 3.8.4, 3.11.4, 3.13.1), l'Albanie fut davantage tentée par la protection parthe, jusqu'à être pleinement intégrée dans l'Empire sassanide au milieu du $\mathrm{III}^{\mathrm{e}}$ siècle de notre ère, suite aux conquêtes de Šāpūr Ier (240-272) ${ }^{107}$. Outre les textes, la découverte

106. Pour ces relations « clientélaires ", voir encore D. Braund, Rome and the Friendly King: The character of the client kingship, London, 1984.

107. Res gestae diui Saporis (inscription datable vers 262 de notre ère) et l'inscription de Kirder 12-13 (datable entre 276-293); traductions dans M.H. Dodgeon, S. N.C. Lieu, The Roman Eastern Frontier and the Persian Wars AD 226-363. A docu- 


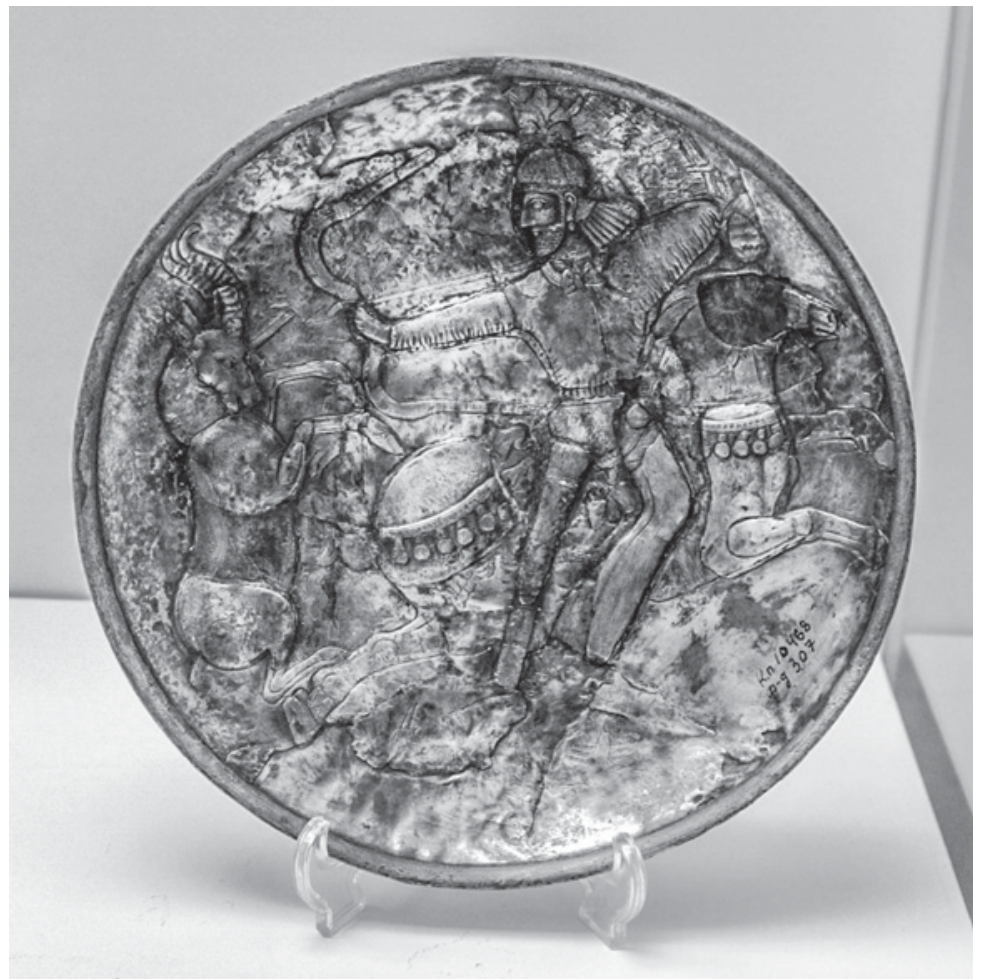

ILL. 29. Bol sassanide en argent doré, décoré d'une chasse royale, $\mathrm{III}^{\mathrm{e}}$ siècle de notre ère, découvert dans la région de Shamakhi/Şamaxı et conservé au Musée d'histoire de l'Azerbaïdjan à Bakou, inv. XF 307; cf. N. Välixanl, Azarbaycanın arxeoloji qızıl va gümüş aşyaları..., nr. 142.

d'un plat sassanide représentant une chasse royale a fourni un indice de cette emprise politique et militaire perse sur l'Albanie (ill. 29) ${ }^{108}$.

mented history, London-New York, 1991, p. 29-30, 56; pour la période postérieure, d'influence sassanide sur l'Albanie, G. Greatrex, S. N.C. Lieu, The Roman Eastern Frontier and the Persian Wars II. AD 363-630. A narrative sourcebook, LondonNew York, 2002. Pour les découvertes archéologiques, Sir J. Simpson, "Sasanian Glassware from Mesopotamia, Gilan, and the Caucasus ", Journal of Glass Studies 57 (2015), p. 77-96.

108. Dž. A. Halilov, «Serebrjanoe bljudo s pozolotoj iz drevnej šemahi », Vestnik drevnej istorii, 3 (1976), p. 146-149; P. O. Harper, P. Meyers, Silver Vessels of the Sasanian Period: Royal imagery, New York, 1981, p. 52, 56, pl. 8; K. O. Koškarly, Antičnaja I rannesrednevekovaja torevtika iz Azerbajdžana, Baku, 1985, p. 63-72. 
La différence avec l'Ibérie, où les élites restèrent sous la séduction de la culture gréco-romaine, est donc quelque peu saisissable, malgré les liens géographiques et historiques (dynastiques, diplomatiques, culturels) de ces deux royaumes caucasiens, entre eux ainsi qu'avec l'Arménie (royaume client ou province romaine) ${ }^{109}$. L'histoire complexe de ce voisinage, sur le détail de laquelle nous manquons de sources qui puissent répondre aux exigences des modernes, nous empêche de savoir si notre plat a pu être acquis directement auprès des Romains, ou s'il a été acheté ou importé d'une zone limitrophe, suite à des échanges ou à des conflits. Dans tous les cas, bien que rare, une telle découverte n'est pas surprenante, vu l'importance stratégique extraordinaire du Caucase et les nombreuses interventions directes de Rome dans la région.

\section{Au croisement de toutes les frontières: un pays plus que riche, par les contacts}

La zone entre le Caucase et le Taurus jouait un rôle essentiel dans la consolidation d'une frontière romano-parthe sur l'Euphrate et le Tigre, en ouvrant l'accès militaire à partir de la mer Noire (par les ports énumérés dans le Périple de la mer Noire d’Arrien, en 131/132 de notre ère) et en offrant un débouché sur la mer Caspienne, vers la Médie (cf. Élien, Sur la nature des animaux 17.32), la Syrie et la Mésopotamie, jusqu'à la mer Rouge ${ }^{110}$. Ainsi, les rois d’Ibérie et d'Alba-

Pour l'empreinte analogue en Ibérie, voir Ch. Amiranachvili, «Une coupe en argent du début de l'époque sassanide provenant des fouilles d'Armasiskhevi (Géorgie) ", Rivista degli studi orientali 34.3/4 (1959), p. 149-162, corrigé par Ch. J. Brunner, " Middle Persian Inscriptions on Sasanian Silverware ", Metropolitan Museum Journal 9 (1974), p. 109-121; cf. P. O. Harper, P. Meyers, Silver Vessels..., op. cit., p. 24-25.

109. Cf. l'importante découverte d'instruments d'écriture, prouvant la diffusion de la culture grecque, entre la fin du $\mathrm{III}^{\mathrm{e}}$ et le début du IV ${ }^{\mathrm{e}}$ siècle: A. Apakidze, G. Kipiani, V. Nikolaishvili, "A Rich Burial from Mtskheta (Caucasian Iberia) ", Ancient West \& East 3.1 (2004), p. 104-123.

110. Pour l'avènement de Rome dans la zone caucasienne, voir: M.-L. Chaumont, "L'Arménie entre Rome et l'Iran. I. De l'avènement d'Auguste à l'avènement de Dioclétien ", in Aufstieg und Niedergang der römischen Welt II. 9.1, Berlin-New-York, 1976, p. 71-194; M.L. Chaumont, « Albania », in Encyclopæedia Iranica I/8, p. 806-810, en ligne http://www.iranicaonline.org/articles/albania-iranian-aran-arm; A. Giardi- 
nie, de même que ceux d'Arménie ont joué un rôle très important dans la stratégie de défense des empires romain et parthe, s'agissant aussi bien de l'équilibre entre les deux puissances d'Occident et d'Orient, que de la confrontation avec les nomades septentrionaux, surtout Sarmates, Alains, et ensuite Huns, qui pouvaient emprunter les chemins de transhumance, par les portes Caucasiennes et Caspiennes, et menacer la sécurité de tous les sédentaires sud-caucasiens ${ }^{111}$.

Si le premier royaume albain comprenant les flancs méridionaux du Caucase, à partir des monts Cérauniens, et la basse vallée du Kyros-Araxes jusqu'à la Caspienne, n’a vraisemblablement été unifié qu'entre la fin du $\mathrm{II}^{\mathrm{e}}$ et le premier siècle avant notre ère, le premier contact avec Rome date de l'expédition de Pompée en Ibérie, jusqu'aux portes Caucasiennes, dites aussi Sarmates ou Alanes (passage de Dariali), pendant la dernière guerre mithridatique ${ }^{112}$. La présence de Rome a été rendue de plus en plus pressante par la mission en Albanie de P. Canidius Crassus qui a préparé l'expédi-

na, " Roma e il Caucaso ", in Il Caucaso: cerniera fra culture dal Mediterraneo alla Persia sec. IV-XI. Atti delle Settimane di Studio del centro italiano di studi sull'alto medioevo, Spoleto 20-26 aprile 1995. I. Spoleto, 1996, p. 85-141; E Dąbrowa, « Roman Policy in Transcaucasia from Pompey to Domitian ", in D. H. French, C.S. Lightfoot (éd.), The Eastern Frontier of the Roman Empire. Proceedings of a colloquium held at Ankara in September 1988, Ankara, 1989, p. 67-76; D. Braund, "Coping with the Caucasus: Roman responses to local conditions in Colchis ", ibidem, p. 31-43; D. Braund, "Hadrian and Pharasmanes ", Klio 73.1 (1991), p. 208-219; D. Braund, Georgia in Antiquity..., op. cit.; M. Bais, Albania Caucasica. Ethnos, storia, territorio attraverso le fonti greche, latine e armene, Milano, 2001; plus récemment, I. Gagoshidze, "Kartli in Hellenistic and Roman Times. General Aspects ", in A. Furtwängler, I. Gagoshidze, H. Löhr, N. Ludwig (dir.), Iberia and Rome: The excavations of the palace at Dedoplis Gora and the roman influence in the Caucasian kingdom of Iberia, Langenweissbach, 2008, p. 1-40; L. Zerbini, G. Gamkrelidze, T. Todua, I Romani nella Terra del Vello d'Oro. La Colchide e l'Iberia in età romana, Soveria Mannelli, 2012. Pour un essai de confrontation entre sources gréco-romaines et géorgiennes anciennes: G.L. Kavtaradze, "Caucasica II. The Georgian chronicles and the raison d'être of the Iberian kingdom ", Orbis Terrarum 6 (2000), p. 177-237.

111. Pour les sources sur les Alains, voir surtout A. Alemany, Sources on the Alans. A critical compilation, Leiden-Boston-Köln, 2000; A. B. Bosworth, " Arrian and the Alani », Harvard Studies in Classical Philology 81 (1977), p. 217-255; G. Gnoli, « Il nome degli Alani nelle iscrizioni sassanidi: considerazioni linguistiche e storiche sul tema dell'opposizione tra Iran esterno e Iran interno ", in Il Caucaso: cerniera..., p. 831-866.

112. Plutarque, Vie de Pompée 34-37; Cassius Dion 37.1-7, cf. 41.16; Appien, Mithridatica 477-496. 
tion parthe de Marc Antoine ${ }^{113}$, et, quelques années plus tard, par les missions de T. Claudius Néron, et ensuite par celle de C. Domitius Corbulon, sous Néron ${ }^{114}$. En 75, des soldats romains ont aidé à la construction de la fortification ibère de Harmozica/Harmastus, contrôlant le passage de Dariali115. En Albanie, sur la route du passage de Derbent, entre 84 et 96, la légion XII Fulminata a consolidé une forteresse à Bejuk Dash (dans la région de Gobustan), à $70 \mathrm{~km}$ au sud-ouest de Baku: l'implication de Domitien dans la protection des metuenda portae limina Caspiacae (" seuils de la porte Caspienne à craindre ») trouve un écho chez Stace (Silves 4.4.63-64). Ce n'est pas un cas isolé dans la poésie latine impériale, car, de manière plus générale, les Argonautiques de C. Valérius Flaccus répondent à l'attention des Flaviens pour la région pontico-caucasienne ${ }^{116}$. En 114, Trajan transforme l'Arménie en province romaine, donne un nouveau roi-client à l'Albanie et reçoit aussi bien la soumission des Sarmates du Nord du Caucase que celle des Ibères - l'empereur romain étant même accompagné par le prince ibère Amazaspus lors de son expédition parthe à Nisibis (IG XIV 1374 = IGR I 192) $)^{117}$.

Malgré un moment de tension entre l'empereur romain Hadrien et Pharasménès II d'Ibérie, qui refusa de renouveler sa soumission envers Rome à Satala en 129, les échanges de dons ont continué,

113. Strabon 11.3.5; Plutarque, Vie d'Antoine 34; Cassius Dion 49.24. Suivant les Res gestae Diui Augusti (5), le roi albanien reconnaissait la suzeraineté romaine.

114. Tacite, Annales 13.6-8, 30-41; 14.23-36; 15.24-31. Sur les plans de Néron, Pline l'Ancien 6.40; Tacite, Histoires 1.6; Suétone, Vie de Néron 19.2; Cassius Dion 63.8.1.

115. CIL III $6051=$ OGIS $379=$ ILS $8795=$ IGRR III $133=$ SEG 20112 (cf. Strabon 11.3.5 ; Pline l'Ancien 6.29-30); voir A.I. Boltunova, « Quelques notes sur l'inscription de Vespasien trouvée à Mtskheta ", Klio 53 (1971), p. 213-222; H. Halfmann, " Die Alanen und die römische Ostpolitik unter Vespasian », Epigraphica Anatolica 8 (1986), p. 39-50; aussi G. Migliorati, « L'incarico militare di M. Hirrius Fronto Neratius Pansa e gli interessi militari romani in area caucasica ", in A. Valvo-G. Manzoni (éd.), Analecta Brixiana. Contributi dell'Istituto di Filologia e storia dell'Università Cattolica del Sacro Cuore, Milano, 2004, p. 125-153.

116. AE 1951.263; F. Grosso, « Aspetti della politica orientale di Domiziano I. Albania, iberia caucasica e Armenia », Epigraphica 16 (1954), p. 117-179; R. Heindereich, «Zur östlichsten lateinischen Inschrift », Zeitschrift für Papyrologie und Epigraphik 52 (1983), p. 213-214.

117. Arrien, Périple du Pont-Euxin 11.2-3; Eutrope, Bréviaire 8.2-3; Rufus Festus, Bréviaire 20.2; Jérôme, Chronique (dans la $223^{\mathrm{e}}$ Olympiade). 
comme l'atteste l'Histoire Auguste et la découverte d'un plat avec le portrait d'Antinoüs dans la tombe supposé d'Aspaurukis, haut dignitaire ibère ${ }^{118}$. Vers 141 , sous Antonin le Pieux, probablement suite aux actions de Q. Iunius Rusticus, ce roi ibère s'est vu accorder de nouveaux territoires et une statue équestre dans le temple de Bellone. Signe de sa soumission, il vint à Rome avec sa famille, sacrifia sur le Capitole et organisa une démonstration militaire ${ }^{119}$. Suite à l'invasion parthe du royaume client d'Arménie et de la province de Syrie, pendant les guerres romano-parthes de 161-166, des troupes furent ramenées des fronts nord-occidentaux pour renforcer la présence romaine dans le Caucase. Sous les ordres de Statius Priscus, des éléments de la légion I Mineruia traversèrent les portes Caspiennes (à Derbent, CIL XIII 8213). Au cours des deux années suivantes, les Romains prirent Séleucie et Ctésiphon et entrèrent en Médie Atropatène. Sous le gouverneur Avidius Cassius, le limes fut fixé sur le Khabour et sur l'Euphrate; les Romains purent réinstaller leur protégé, Sohaemus, sur le trône d'Arménie, jusque dans les années 180 et au retour des Parthes sous Vologèse V. Expression directe des

118. Histoire Auguste, Hadrien, 13.8-9; 17.10-12 («... à beaucoup il a donné des dons, mais à personne plus que ceux des Ibères...//multis ingentia dedit munera, sed nulli maiora quam Hiberorum... »), 21.13. Le vase à médaillon illustrant Antinous doit être daté de la période suivant entre la mort accidentelle d'Antinoüs dans le Nil, mais avant la mort d'Hadrien (130/131-138). D’une tombe voisine, on a récupéré un médaillon à haut relief représentant la déesse Tychè/Fortuna avec une corne d'abondance et un vase avec un buste d'homme romain, peut-être sous les traits d'Héraclès - un personnage mythique lié au Caucase, par la libération de Prométhée. Parmi les nombreuses publications, voir K. Matchabeli, « Les coupes d'argent d'Armaziskhevi (Géorgie) », Bedi Kartlisa. Revue de kartvéologie 29 (1972), p. 291293; Th. Opper, "Hadrian's Diplomatic Gifts in Georgia », in Hadrian, Empire and Conflict, British Museum, London, 2008, p. 190-193; G. Gamkrelidze, Archaeology of the Roman Period of Georgia (Essay and Catalogue). Iberia-Colchis (The Journal of the Otar Lordkipanidze Centre of Archaeology of the Georgian National Museum) Supplement, 2014. Pour des découvertes comparables dans le Royaume du Bosphore, voir M. Ju Trejster, "Posuda i predmety utvaritra is serebra i bronzy ", in A. M. Butjagin (dir), Tajna zolotoj maski. Katalog vystavki [Sankt-Peterburg, 21 Aprelja- 3 sentjabrja 2009 g.], Sankt-Peterburg, 2009, p. 43-62; N.I. Vinokurov, M. Ju. Trejster, « Portretnye medal'ony krasnolakovyh čaš I v. do n.è. — I v. n.è. na poselenii Artezian v Krymskom Priazov'e ", in Bosporskij fenomen. Greki I varvary na Evrazijskom perekrëstke: Materialy meždunarodnoj naučnoj konferencii (Sankt-Peterburg 19-22 nojabrja 2013 g.) Sankt-Peterburg, 2013, p. 270-278.

119. Histoire Auguste, Antonin le Pieux 9.6; Cassius Dion 69.15. 
forts liens romains avec l'Ibérie, dans la nécropole de Mts'khet‘a, on retrouve un bol en argent avec un médaillon à l'effigie de MarcAurèle $^{120}$. Sous Commode, en 184-185, la légion XV Apollinaris est toujours en Arménie (CIL III 6052 = ILS 394). Faute de sources, on considère que la situation est restée relativement stable sous les Sévères, jusqu'aux conquêtes sassanides des années 250 (voir supra). Par la suite, bien que l'on ne puisse parler d'un arrêt complet des rapports avec Rome, ceux-ci deviennent moins soutenus - tout en étant temporairement renoués, par exemple, sous Aurélien (270-275) ${ }^{121}$ ou sous Domitien, suite à la paix de 298 de Nisibis, quand les Romains reprennent le contrôle de l'Ibérie. Si la diffusion du christianisme et la création des trois alphabets caucasiens furent des conséquences des liens historiques serrés avec l'Arménie et avec l'Occident, reste qu'au IV siècle la domination sassanide est de plus en plus enracinée en Albanie. Sur le plan militaire, elle se concrétise par la consolidation de la défense des passages par lesquels les Nomades du Nord pouvaient envahir l'Empire; sur le plan culturel, les conflits prennent également une dimension religieuse, les chrétiens cherchant appui en Arménie et dans l'Empire romain, lors des conflits avec les Barbares païens caucasiens et avec les Perses zoroastriens.

L'ancienne Albanie du Caucase nous apparaît ainsi comme une véritable zone tampon, de rencontres (middle ground) entre les deux grands empires, romain et iranien, qui aux $\mathrm{II}^{\mathrm{e}}$ et $\mathrm{III}^{\mathrm{e}}$ siècles maintenaient un fragile équilibre. Elle partage cette situation avec l'Ibérie et l'Arménie, à une différence près: si l'Arménie est l'enjeu principal du conflit, en raison de l'accès direct à la Syrie et à l'Asie Mineure, l'Ibérie est plus facilement attirée dans la sphère romaine - grâce à son voisinage avec la Colchide, la Cappadoce et le Pont —, alors que l'Albanie est, au contraire, proche de la Médie (l'Atropatène, l'Azerbaïdjan iranien des modernes). Les frontières entre ces trois États ont vraisemblablement bougé, en fonction des alliances et des oppositions de moment, aussi bien à l'intérieur de ces États qu'avec leurs voisins et avec les grands empires de Rome et de Perse, mais nous manquons

120. A. Miron, W. Orthmann (éd.), Unterwegs zum goldenen Vlies. Archäologische Funde aus Georgien, Saarbrücken, 1995, p. 313, n 325, Abb. 181.

121. Histoire Auguste, Aurélien 27.4-5, 33.4. 
de documents pour suivre leurs changements. Nous retiendrons que Romains et Parthes se disputaient l'espace intermédiaire de l'Ibérie et de l'Albanie pour verrouiller les passages du Caucase ${ }^{122}$ et pour favoriser leurs réseaux de contacts, d'une part, avec la mer Noire et, d'autre part, avec la Caspienne et la Haute-Asie du nord du Taurus.

Le royaume albanien, parfois rival du royaume ibère et arménien, avec l'aide des Nomades, des Parthes ou des Romains, contrôlait la principale traversée du Caucase proche de la Caspienne, par Derbent (ill. 1) ${ }^{123}$. Il pouvait tirer aussi profit de la traversée est-ouest entre la Caspienne et la mer Noire, le long des vallées du Kyros, de l'Araxe et du Phase, avec leurs affluents. C'était le dernier segment de ce que l'on imaginait être, à tort et à raison, une route de l'Inde et de la Bactriane jusqu'à l'extrémité orientale de la mer Noire ${ }^{124}$. Bien qu'incomplète, la Table de Peutinger est une preuve importante de l'existence d'un réseau routier qui rendait possible,

122. Ces deux cols majeurs sont plutôt des carrefours des routes de haute montagne, dans un véritable réseau de traversées du Caucase. Voir D. Braund, « Map 88. Caucasia ", in R. Talbert (dir.), Barrington Atlas of the Greek and Roman World, Princeton, 2000, et D. Braund, " Notes from the Black Sea and Caucasus: Arrian, Phlegon and Flavian Inscriptions ", Ancient Civilisations from Scythia to Siberia 9.3-4 (2003), p. 175-191.

123. Pour le système de fortification sassanide, voir D. Lawrence, T.J. Wilkinson, " The Northern and Western Borderlands of the Sasanian Empire: Contextualising the Roman/Byzantine and Sasanian frontier ", in E. W. Sauer (éd.), Sasanian Persia. Between Rome and the Steppes of Eurasia, Edinburgh, 2017, p. 99-125.

124. Les principales sources hellénistiques et romaines sont Ps.-Scymnos fr. 20 Marcotte (= 925-237 Diller) ap. Pseudo-Arrien, Périple de la mer Noire 45 Podossinov; Strabon 11.7.3; Pline l'Ancien 6.52; Procope, Guerres 2.25.1-3. Voir le débat entre les voix plus critiques, voire sceptiques, de D. Magie, "Roman Policy in Armenia and Transcaucasia, and its Significance ", American Historical Association Annual Report 1/1910, Washington 1923, p. 297-304, et D. Braund, " Indian Traders at Phasis: neglected texts on ancient Georgia ", in M. Faudot, A. Fraysse, É. Geny (éd.), Pont-Euxin et commerce. La genèse de la "route de la soie " (Actes du IX Symposium de Vani [Colchide] 1999), Besançon, 2002, p. 287-295, et Georgia in Antiquity..., op. cit., p. 40-41, et, d'autre part, ceux qui croient à cette voie: M. Wisseman, "Rom und das Kaspische Meer », Rheinisches Museum für Philologie 127.2 (1984), p. 166-173; P. Callieri, « La presunta via commerciale tra l'India e Roma attraverso l'Oxus e il Mar Caspio: nuovi dati di discussione ", Topoi 11.1 (2001), p. 537-546, et P. Schneider, « From India to the Black Sea: an overlooked trade route? ", publication préliminaire sur https://hal.archives-ouvertes.fr/hal01376630 (outre Procope, P. Schneider ajoute le témoignage de Perse 5.132-136). 


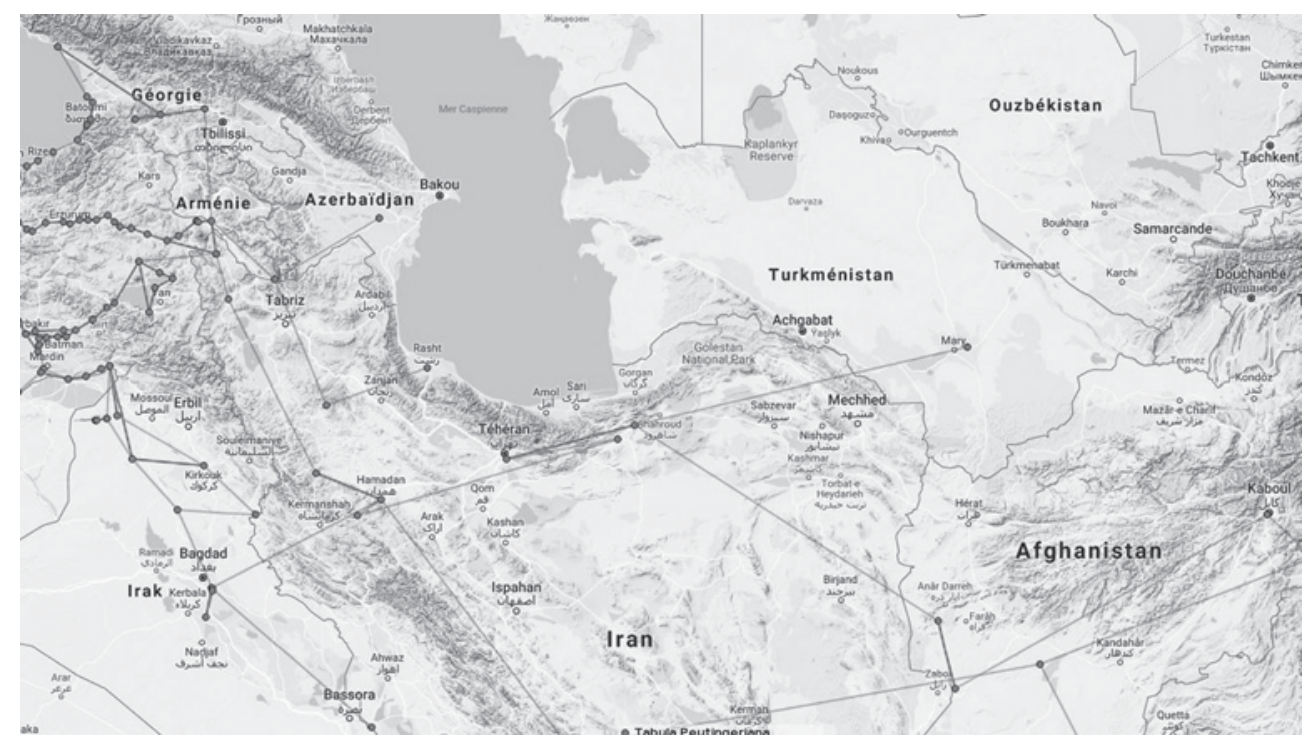

ILL. 30. Reconstitution du réseau routier de la Table de Peutinger ( $\mathrm{IV}^{\mathrm{e}}$ siècle de notre ère, suivant l'édition de R. Talbert, peutinger.atlantides.org/map-a/) sur fond de carte moderne, sur https://omnesviae.org, par René Voorburg.

du moins à certaines époques, l'acheminement indirect des produits exotiques par une longue route asiatique, transtaurique (ill. 30).

Mais cette position stratégique de contrôle de toutes les frontières et passages n'est qu'un des avantages de l'Albanie, qui s'ajoutait à des richesses assez exceptionnelles, naturelles et humaines, qui peuvent justifier à elles seules l'arrivée de notre plat à Yenikend. Enfermé entre ces hautes montagnes, grands fleuves et la mer, le territoire au cœur du royaume albanien était structuré surtout à partir des vallées des affluents du Kyros - comme le Goychay et son bassin hydrographique - le long desquelles on pouvait rejoindre plus facilement la plaine ou, au contraire, la montagne. Ces vallées ont été un facteur de fragmentation certaine - comme l'attestent les 26 langues tribales mentionnées par Strabon (11.4.6) et comme le montrent encore aujourd'hui les cartes des langues et dialectes caucasiens. Toutefois, leurs ressources propres, en terres, matières premières, animaux et hommes, étaient déjà exploitées et convoitées dans l'Antiquité. Elles forment l'argumentaire de l'éloge de 
l'Albanie caucasienne - une utopie de l'âge d'or, du point de vue gréco-romain (chez Strabon) et un paradeisos à la perse, sur la longue durée (chez Movsēs Dasxurançi, au milieu du $x^{\mathrm{e}}$ siècle).

Strabon 11.4.3-4:

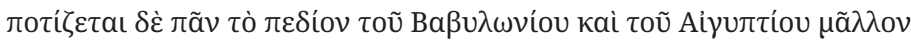

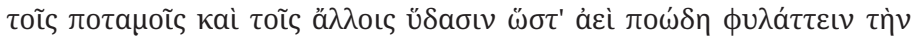

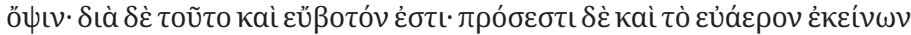

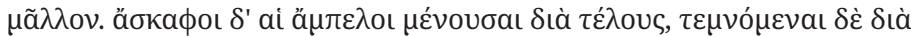

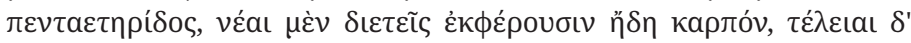

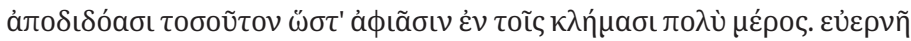

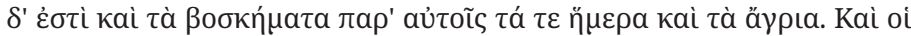

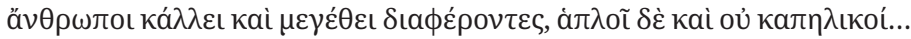

La plaine tout entière est mieux arrosée que les plaines babylonienne et égyptienne par ses rivières et ses autres cours d'eau et elle garde toujours l'aspect verdoyant. C'est pourquoi elle se prête bien au pâturage. À cela s'ajoute que le climat y est meilleur que dans ces pays-là. On ne bêche jamais les vignes, on se borne à les tailler de cinq en cinq ans. Les jeunes ceps donnent des fruits au bout de la deuxième année, les autres en donnent tellement qu'on en laisse une grande partie des raisins sur les branches. Leurs troupeaux se portent tout aussi bien, fussent-ils domestiques ou sauvages. Et les hommes excellent par la beauté et la grande taille, étant honnêtes et non pas des marchands...

Movsēs Dasxurançi, Histoire des Albaniens du Caucase, traduction d'après la version anglaise de C.J.F. Dowsett, Londres, 1961:

Chap. 5. La fertilité et l'abondance de l'Albanie et de ce qu'elle contient pour les besoins de l'homme

Située parmi les montagnes en forme de tours du Caucase, le pays albanien est agréable et séduisant, avec beaucoup d'avantages naturels. Le grand fleuve Kur court plaisamment à travers le pays, ayant des poissons grands et petits, et il se jette dans la mer Caspienne. Dans les plaines autour de l'embouchure, il y a beaucoup de nourriture et de vin, du naphte et du sel, de la soie et du coton et d'innombrables oliviers. L'or, l'argent, le cuivre et l'ocre se trouvent dans les montagnes. Parmi les animaux sauvages, il y a le lion, le léopard, la panthère, l'âne sauvage, et parmi les oiseaux, il y a l'aigle, le faucon etc. Et elle a la grande Partaw comme capitale. 


\section{Les transferts de lieux communs ou comment le mythe fait l'histoire}

Le plat en argent doré de Yenikend est un vestige du rayonnement de la civilisation gréco-romaine sur les marges de l'œkoumène, le plus probablement entre la seconde moitié du $\mathrm{II}^{\mathrm{e}}$ et la première moitié du $\mathrm{III}^{\mathrm{e}}$ siècle de notre ère. Sa décoration était assez commune dans l'Empire romain - peut-être surtout à l'Ouest -, mais son choix pour un transport dans le Caucase a dû être délibéré, donc réfléchi, motivé. Cette image permettait plusieurs niveaux de lecture - de l'admiration pour les belles formes d'une jeune femme dénudée jusqu'au plaisir d'y reconnaître une Néréide, l'emprise d'Aphrodite/Vénus (déesse des mers, de la beauté et de l'amour, de la nature, des unions et de la fécondité, des Romains) et finalement Galatée elle-même, pour les spectateurs les plus cultivés ou les plus familiers avec les pratiques du banquet gréco-romain.

Pour l'historien moderne du Taurus (Petit Caucase) et du Grand Caucase, une telle découverte archéologique, interprétée à la lumière des documents historiques, illustre la spécificité d'un middle ground, une zone de montagnes, frontière entre les grands empires territoriaux, urbanisés du Sud, et les steppes des nomades du Nord. La montagne fragmente, isole, protège tout en enrichissant les gens des vallées. En même temps, elle cristallise les traces des contacts le long des passages, même étroits, à travers lesquels on circule et qu'aucun obstacle historique ne peut obturer à jamais.

Le plat est un exemple de transfert culturel parce qu'il ne reflète pas seulement une possible acculturation des élites caucasiennes, attirées par le luxe romain. Notre analyse montre aussi que le plat a perdu sa fonction d'origine - de vaisselle décorative de table pour être utilisé selon la coutume locale, connue de Strabon et de ses sources. Malgré le peu d'informations que nous avons sur le plat lui-même et sur le contexte de sa découverte, on peut supposer que ce transfert est intervenu au moment où les contacts des Albaniens avec Rome avaient déjà plus d'un siècle d'ancienneté. Le plat a donc pu être acquis - du moins par le premier propriétaire du Caucase - non pas seulement par la vente, mais aussi (voire surtout) en tant que récompense politique ou militaire romaine, comme chez 
les élites ibères enterrées à la même époque près de la capitale de Mts'khet'a.

Si le plat a été choisi expressément pour honorer, récompenser ou dédommager un guerrier (ou une guerrière) indigène, il reflète nécessairement l'image que celui/celle qui a fait le choix se faisait de la personne et, plus généralement, du pays et du peuple où le plat pouvait être exposé. Or, vu de l'extérieur, un pays de montagnes, éloigné du centre civilisé, se prête facilement aux représentations les plus contrastées. Le territoire du royaume d'Albanie est à la fois une dystopie barbare, sauvage, abritant des monstres comme les Cyclopes et les Amazones, et une utopie prospère, habitée par des hommes justes, non corrompus. Si les deux représentations contiennent un noyau de réalités perçues à un certain moment par les quelques rares témoins qui s’y sont aventurés lors des guerres, elles ne sont pas moins le résultat de constructions intellectuelles, nourries des lieux communs de l'éducation classique ${ }^{125}$.

Strabon explique clairement comment, précisément dans le cas de l'Albanie, il est impossible de distinguer le mythe de l'histoire, puisque ceux qui ont vu le Caucase et y ont vécu l'histoire, l'ont fait sous le prisme du mythe des Amazones (Strabon 11.5.3):

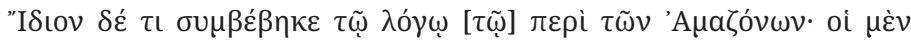

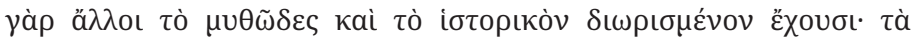

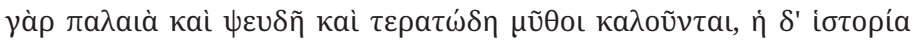

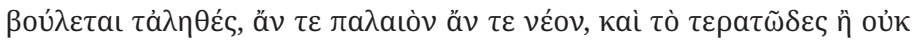

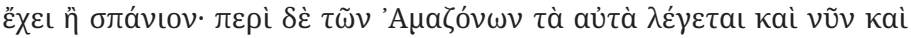

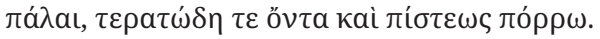

Ce qui arrive au discours sur les Amazones est particulier. Car les discours < sur les autres peuples $>$ se distinguent entre ceux qui tiennent du domaine mythique et ceux qui tiennent du domaine historique : on dénomme mythe tout ce qui est ancien, mensonger, prodigieux, alors que l'histoire s'attache à la vérité, fût-elle ancienne ou récente, et n'accueille pas le prodigieux, sauf exception. Mais quand il s'agit d'Amazones, on dit maintenant les mêmes choses monstrueuses et difficiles à croire que pour les temps anciens.

125. Cf. aussi G. Traina, " Due note sull'identità politica nel Caucaso antico », in C. Bearzot, F. Landucci, G. Zecchini (éd.), Gli stati territoriali nel mondo antico, Milano, 2003, p. 317-326; L. Fabian, Examining the Archaeology of 'Antik'-quity: the Eastern Caucasus beyond, Phd University of Pennsylvania, 2018. 
Nous proposons d'interpréter Galatée comme une réponse romaine au mythe, également gréco-romain, des Amazones: la cavalière sur l'hippocampe, sortie de la mer pour fouler les terres des bergers, n'a d'autre arme que la sensualité féminine. De la même manière, Rome, fondée et dirigée par les descendants d'Aphrodite/ Vénus, cherche à séduire les Cyclopes du Caucase, par le charme du mode de vie à la romaine. Si tel était le cas, le plat serait la réaction d'un connaisseur de la culture gréco-romaine à ce que la même culture lui a appris sur les Amazones du Caucase. Nous aurions affaire à un cas d'histoire façonnée par le mythe, à laquelle on réplique par un autre mythe.

Qu'elle soit vraie ou fausse, cette lecture historique montre ce que l'on peut espérer tirer des textes et images anciens. En effet, pendant les dernières décennies, l'histoire et surtout la géographie historique antique sont devenues des repères dans les débats actuels sur les frontières, les droits au sol et les identités ethniques du Caucase. Or, l'histoire de ce plat rappelle non seulement la spécificité d'un middle ground et la complexité des transferts à grande distance, mais aussi l'importance de l'imaginaire: textes et images anciennes n’offrent pas de morceaux bruts de réalités objectives, dans lesquelles nous puissions tailler des réponses à nos interrogations d'aujourd'hui. Il ne faut pas oublier que les histoires antiques sont des créations d'autres temps, par des auteurs qui utilisaient des sources insuffisantes et des méthodes " empiriques » (selon les critères modernes), pour répondre à des intérêts qui ne sont plus les nôtres. Aujourd'hui, il ne suffit pas de lire Strabon pour connaître le passé du Caucase, il faut aussi comprendre sa manière de travailler, ses concepts, la vision du monde et de son évolution que Strabon partageait avec ses contemporains. Cela implique un prisme homérique, par lequel les réalités du Caucase étaient explicables à travers les mythes des Cyclopes et des Amazones. L'histoire d'hier et d'aujourd'hui n'est finalement qu'interprétation subjective du passé, selon les contraintes et les aspirations d'un historien. 


\title{
L'Albanie du Caucase
}

\author{
Une zone de contact entre une population \\ sédentaire organisée en États et un peuple \\ nomade d'Eurasie ( $V^{e}$-VII siècle de notre ère)
}

Farda Asadov

\section{Histoire des conflits entre nomades et sédentaires}

L'émergence du nomadisme a toujours fait l'objet de vifs débats parmi les historiens. Précisons d'emblée que nous l'entendrons ici comme une forme d'élevage mobile, le nomadisme pouvant par ailleurs renvoyer aux conditions de vie d'individus et de larges groupes ethniques pratiquant d'autres types d'activités (artisanat, divination, jonglerie, musique, danse, etc.). Or donc, deux grands groupes n'ont cessé d'entretenir des relations conflictuelles dans l'histoire de l'humanité: les bergers nomades et les agriculteurs sédentaires. On a longtemps associé le nomadisme à une forme primitive d'organisation économique et sociale, mais il est désormais reconnu que le pastoralisme mobile, qui fut le fait de grands groupes, est apparu à une époque relativement tardive en comparaison de diverses activités de type artisanal: il a émergé de manière progressive dans l'histoire de la production, s'autonomisant sur fond d'une économie à la fois pastorale et agricole selon une logique d'extension et de productivité croissantes de l'élevage. La domestication de grandes hordes d'animaux - chevaux et chameaux —, dont l'élevage nécessite le développement de nouvelles ressources, a joué un rôle décisif dans son apparition. 
L'élevage de ces animaux requiert en effet de nouvelles compétences pour gérer la production et implique la vie nomade. Si l'on en croit les spécialistes de la question, le passage à ce nouveau mode de vie se serait effectué dans les steppes d'Eurasie et au Proche-Orient autour de la fin du $\mathrm{II}^{\mathrm{e}}$ et du début du $\mathrm{I}^{\mathrm{er}}$ millénaire avant notre ère ${ }^{1}$. Dès lors, le monde des nomades et celui des agriculteurs évoluèrent de manière séparée, même si, dans les faits, certains éléments de la tradition opposée survécurent dans l'économie de chacun de ces deux types de société. Un trait constitutif du nomadisme fut sa dimension militaire inédite: la vie nomade requiert le développement des compétences guerrières des hommes adultes, la quête de nouveaux pâturages et de butin impliquant de soutenir des conflits armés avec les peuples voisins, tant nomades que sédentaires.

Les relations entre peuples sédentaires et nomades prirent différentes formes. Les aspects militaro-politiques et économiques de ces interactions jouèrent bien évidemment un rôle fondamental. Ils expliquent la nature conflictuelle de ces rapports. L'économie des nomades des steppes eurasiennes apparaît fondée sur la transhumance et l'élevage extensif. Or, ces deux types de pastoralisme créent des tensions entre les communautés de fermiers sédentaires et les nomades. Les nomades pratiquant la transhumance ont en partie besoin d'occuper des terres arables. Quand il s'agit d'élevage extensif, la viabilité de l'économie nomade dépend en grande partie des conditions climatiques: un temps peu clément et le manque de fourrage obligent les nomades à aller chercher leur subsistance auprès des peuples d'agriculteurs, c'est-à-dire à mener des razzias ${ }^{2}$.

Les tensions s'aggravèrent encore avec l'apparition d'empires nomades, capables de mobiliser d'importantes ressources militaires dans les steppes eurasiennes. Le premier de ces empires fut celui des Xiongnu, apparu au $\mathrm{II}^{\mathrm{e}}$ siècle avant notre ère à la frontière avec la Chine. Dès lors, les conflits entre nomades et agriculteurs exer-

1. G.E. Markov, "Nekotorye problemi vozniknovenija i rannih etapov kočevničestva v Azii ", in Sovetskaja etnografija 1, 1973, p. 105.

2. N.N. Kradin, « Kočevniki, mir-imperii i socialnaja evolucija », in A.V. Korotajev, N. N. Kradin, D.M. Bondarenko, V.A. Lynša (éd.), Alternativnije puti k civilizacii, Moskva, Logos, 2000 [http://abuss.narod.ru/Biblio/AlterCiv/kradin.htm]. 
cèrent une influence décisive sur l'émergence et le développement des sociétés anciennes et médiévales dans la région.

Les sociétés nomades ne s'établissant pas, par définition, dans des lieux fixes ou des villes, leur mode de vie n'est pas consigné pour la postérité par les historiens, la mémoire n'en est pas conservée dans les archives ou les bibliothèques. Chez les nomades, la transmission d'une génération à l'autre de la mémoire et du savoir est orale. Mais les empires dont il est ici question laissèrent sur des pierres ou des roches des inscriptions très précieuses, qui survécurent aux aléas climatiques après que leurs auteurs eurent migré vers d'autres steppes. Ces sources ne permettent toutefois pas de connaître en détail la vie pastorale des peuples nomades et leurs interactions avec les sédentaires. Les inscriptions servaient surtout de déclarations politiques et proclamaient la légitimité des dynasties régnantes. On peut néanmoins y déceler quelques éléments illustrant la vie quotidienne et les préoccupations des masses d'éleveurs se déplaçant à travers de vastes déserts et steppes. Pour compléter ces maigres renseignements, les chercheurs travaillant sur les nomades sont souvent obligés de se tourner vers les sources écrites produites par les peuples sédentaires. Mais l'arrière-plan émotionnel de ces documents trahit la peur et la haine envers les peuples nomades, perçus comme des étrangers tant en raison de leur mode de vie que de leur culture.

\section{De longs murs}

La migration des nomades prend deux formes principales. À l'instar d'une boule de billard, une nation nomade peut en pousser une autre vers l'avant. Ou encore, les nomades peuvent traverser le territoire de nations voisines dans leur quête de nouvelles terres ${ }^{3}$. Les empires sédentaires réagissent à ces mouvements de différentes manières, en fonction des conditions géographiques et de la puissance militaire de leurs ennemis. La politique consistant à monter des nomades contre d'autres peuples se traduit parfois par le dépla-

3. Richard N. Fray \& B.A. Litvinskij, «Centralnaja Azija i kočevniki: 24.2. Severnije kočevniki, Sogdiana, Horezm », in J. Herrman et E. Zurcher (éd.), Istorija čelovečestva, Izdatelskij dom MAGISTR-PRESS, 2003, p. 471. 
cement vers les frontières de l'empire de groupes nomades, auxquels on confie la mission de garder ces dernières. Ainsi, les empereurs de Chine, ceux de l'Empire byzantin et le Shahanshah de l'Empire sassanide placent des nomades aux frontières de leur territoire, où ils font élever d'immenses fortifications. La muraille de Chine est le monument le plus impressionnant que nous a légué cette période.

La défaite du premier grand empire nomade, celui des Xiongnu, oblige les tribus des steppes eurasiennes à se déplacer. Vers 370, les derniers Xiongnu et d'autres nomades d'Eurasie triomphent des Alains dans le Caucase, marquant le début de l'ère de la domination turque, qui va désormais exercer une pression permanente sur les frontières du Moyen-Orient et de l'Europe de l'Est. Les Sassanides, qui vont devoir faire face à une puissance de plus en plus considérable des nomades dans le Caucase et en Asie centrale, élèvent des constructions grandioses pour protéger leurs frontières. Ils font notamment bâtir de longs murs au sud de la Caspienne, dans la province de Gorgan, ainsi que tout un ensemble de fortifications dans le Caucase.

La chaîne du nord du Caucase constitue une frontière naturelle entre les nomades et les populations sédentaires. Le jeune Empire sassanide tente de s'étendre jusqu'à cette limite naturelle et de la maintenir fermée. Il est notamment important de renforcer le col de Derbent, un passage très étroit entre les montagnes et la mer Caspienne. Lors de leurs raids, les nomades empruntent cette voie d'accès, ou alors la passe de Darial, au centre de la chaîne. La construction de forteresses débute vraisemblablement sous le règne

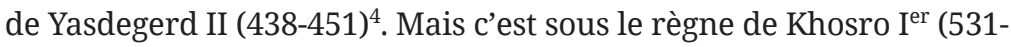
579) qu'est mis en place un vaste système de fortifications tout le long de la chaîne du Caucase, de Derbent jusqu'à l'extrémité ouest ${ }^{5}$. La lutte passionnée que mènent les Sassanides pour étendre leur empire jusqu'à cette frontière naturelle avec le monde nomade s'explique

4. Vladimir Minorsy et Ahmad ibn Lutf Allah Munajjim Bashi, A History of Sharvan and Darband in the $10^{\text {th }}-11^{\text {th }}$ Centuries, Cambridge, Heffer, 1958, p. 87, n. 2.

5. M.S. Gažijev, « K izučeniyu Limes Caspius », in « Severnij Kavkaz i kočevoj mir stepej Evrazii ». V "Minajevskije čteniya " po arheologii, etnografii i krajevedeniju Severnogo Kavkaza, Stavropol, Stavropolskij Gosudarstvennij Universitet, 2001, p. $80-81$. 
par des raisons militaires, stratégiques et économiques. L'historien arabe al-Tabari rapporte qu'après la fin de la construction des forteresses une grande campagne militaire menée par le khagan Sindjibu (sans doute Istämi, mort en 576) est facilement repoussée par une armée de quelque 5000 soldats sassanides seulement ${ }^{6}$.

\section{Les intérêts des États du Caucase du Sud}

Il faut souligner d'emblée que les intérêts des grandes puissances et ceux de leurs populations frontalières, en particulier des élites militaires et politiques, ne coïncidaient pas. L'Albanie caucasienne, qui borde le monde nomade du Caucase, a déjà une longue histoire quand les Sassanides progressent vers le nord de la région. Les Albanais possèdent en effet une armée puissante, qui a participé aux batailles d'Alexandre le Grand aux côtés des Achéménides, comme le rapportent des sources anciennes ${ }^{7}$.

Le fait d'intégrer le pays au sein d'une puissance plus grande ne peut résoudre qu'en partie le problème des raids nomades, puisque les frontières de l'empire ne sont pas d'elles-mêmes en mesure de protéger la population de ses voisins belliqueux. Il incombe à la population locale d'entretenir des troupes, en plus d'autres charges. Par ailleurs, leur soumission politique à la puissance impériale empêche la noblesse locale et les marchands albanais de tirer tous les profits possibles de leur commerce avec les nomades.

$\mathrm{Au}$ milieu du $\mathrm{IV}^{\mathrm{e}}$ siècle de notre ère, les rois albanais adoptent officiellement le christianisme. Dès lors, les attaques menées par les prêtres zoroastriens et les autorités contre les autres religions, en particulier contre les juifs et les chrétiens, renforcent le sentiment d'hostilité à l'égard des Sassanides. Ce n'est pas un hasard si la population vivant dans les régions proches des nomades avait tout intérêt à développer une coopération pacifique avec ses voisins du Nord. À de multiples reprises, les rois albanais font appel aux nomades du Caucase pour les aider à lutter contre le pouvoir sassanide. Durant

6. Abu Djafar Mohammad ibn Djarir At-Tabari, Tarikh at-Tabari: Tarikh al-Umam wa al-Muluk, 6 vol., Beyrouth, Dar Sadir, 2005, p. 251-252.

7. M.-L. Chaumont, « Albania », in Ehsan Yarshater (éd.), Encyclopcedia Iranica, vol. I, 1985, p. 807. 
la rébellion de 459-462, le roi Vatché II fait détruire les fortifications sassanides pour unir ses forces à celles de ses alliés Maskout ${ }^{8}$; il est imité par les souverains et les nobles des autres royaumes du sud du Caucase. Le roi géorgien Vakhtang Gorgosal compte quant à lui sur les Huns. Mais ces derniers n'envoient qu'une maigre troupe de trois cents cavaliers 9 . Peu avant l'arrivée des Arabes, les Naharars, des nobles arméniens, cherchent à établir une alliance avec les nomades Hons pour lutter contre l'Iran et Byzance, qui souhaitent étendre leur domination dans la région. L’historien arménien Sebeos (au $\mathrm{VII}^{\mathrm{e}}$ siècle) a livré un récit des négociations entre aristocrates arméniens et Huns qui se déroulèrent sur la rive gauche de la Koura ${ }^{10}$.

\section{L'Albanie caucasienne, une zone d'interaction et de commerce avec les nomades}

Le territoire de l'Albanie caucasienne représente donc une zone de contacts étroits avec les nomades. Le col de Derbent ne fait pas que permettre des mouvements de troupes, il constitue également une route commerciale pour les marchandises importées de Chine et des territoires du Nord. Strabon rapporte que le peuple nomade des Aorses faisait du commerce avec l'Inde et le Moyen-Orient tout le long de la côte ouest de la Caspienne, avec la participation des marchands locaux ${ }^{11}$. Un nombre important de pièces de monnaie romaines et parthes trouvées en Azerbaïdjan indiquent que les populations locales participaient déjà de manière active au commerce international ${ }^{12}$. Quant à la présence de larges quantités de

8. K. N. Juzbašjan, Armjanskaya Epopeja $V$ veka. Ot Avarajrskoj bitvi k soglašeniju v Nuarsake. Eliše. Slovo o vojne armjanskoj, Moskva, "XXI vek - Soglasije », 2001, p. 327; Farida Mamedova, Kavkazskaja Albaniia i albany, Bakou, Centr issledovanij Kavkazskoj Albanii, 2005, p. 354.

9. Leonti Mroveli, Žizn kartlijskih tsarej, Moskva, Nauka, 1976, p. 90.

10. Sebeos, The Armenian History Attributed to Sebeos, trad. Robert W. Thomson avec un commentaire de Tim Greenwood avec la collaboration de James HowardJohnston, Liverpool, Liverpool University Press, 1999, p. 32.

11. Strabon, Geografija v 17 knigah. Perevod, statja i kommentarii G. A. Stratanovskogo, Moskva, Nauka, 1964, p. 480.

12. Ilyas Babayev, « Kakie moneti upotreblialis’ na rinkah Azerbajdžana v I v. do n. e. - III v. n.e. ", Irs 1/25, 2007, p. 6; du même auteur, « Denežnoje obrašenije Kav- 
monnaies sassanides datant d'avant l'arrivée des Arabes, elle peut s'expliquer par l'existence d'une administration sassanide sur le territoire de l'Albanie caucasienne.

Les souverains albanais frappent une monnaie qui imite l'antique. On trouve de grandes quantités de ces monnaies, sans doute frappées à Gabala, la première capitale de l'Albanie caucasienne, dans des trésors de pièces. Elles témoignent de l'attitude des souverains albanais à l'égard du commerce international ${ }^{13}$. Celui-ci se déroule à une échelle si vaste qu'il requiert des masses monétaires importantes, mais il est clair qu'il concentre alors l'essentiel des opérations monétaires et des échanges commerciaux du pays. Quant à la circulation d'argent liée aux taxes et au marché des biens domestiques, elle était manifestement négligeable par comparaison avec le commerce international. Ce trait caractéristique de l'économie albanaise peut expliquer que la centralisation des autorités politiques ait été moins développée en Albanie que chez ses voisins du sud du Caucase. En d'autres termes, le principe de la confédération soustendant la formation de l'État albanais, qu'attestent de nombreuses sources écrites relatives à l'autonomie des régions albanaises et des tribus locales, peut se comprendre par la participation massive de la population albanaise au commerce international.

À la frontière nord du pays, les interactions avec les nomades prennent différentes formes. Les intrusions de ces derniers dans le territoire albanais s'effectuent à trois niveaux principaux: l'infiltration lente et graduelle de petits groupes ou clans; des campagnes militaires destinées à rafler butins et prisonniers; et la mise en place des structures administratives et politiques d'unions nomades dans les territoires conquis ${ }^{14}$. Quant à la population albanaise, Strabon remarque qu'elle pratique plutôt l'élevage, ce qui la rapproche des

kazskoj Albanii v ellenističeskuju epohu (konec IV - pervaja polovina I v. do n.e.) », in Muzej Istorii Azerbajdžana, Bakou, Nacionalnaja akademija nauk Azerbajdžana, 2002, p. 182.

13. Idem.

14. V.B. Kovalevskaja, « Noviie i tradicionniie podhodi k vzaimootnošenijam stepnogo mira i mestnogo naselenija Kavkaza », in "Severnij Kavkaz i kočevoy mir stepey Evrazii. V Minajevskiie čteniya po arkheologii, etnografii $i$ krajevedeniju Severnogo Kavkaza ", Stavropol, Stavropolskij gosudarstvennij Universitet, 2001, p. 3. 
nomades, sans toutefois partager leur penchant guerrier ${ }^{15}$. Cela indique sans doute la présence de masses considérables de nomades aux frontières de l'Albanie, ou alors un processus de sédentarisation progressive de populations albanaises à l'origine nomades, ces deux hypothèses n'étant d'ailleurs pas exclusives.

Les Sassanides ont pour coutume de sédentariser les groupes nomades qui se mettent à leur service, avec pour mission de garder les frontières de l'empire. On trouve des références directes à ce sujet dans les sources. Ibn al-Athir, notamment, rapporte qu'après la défaite d'Istämi dans le sud du Caucase, Khosro Ier fait installer dix mille Turcs en Azerbaïdjan ${ }^{16}$. Au même moment, quatre-vingts familles de guerriers nobles turcs sont déplacées de la région de Jurjan (Gorgan), au sud de la Caspienne, vers la frontière avec le Caucase, vraisemblablement pour défendre la forteresse de Derbent ${ }^{17}$.

L'intrusion et l'installation de nomades et de Khazars se déroulent principalement sur le territoire de l'Azerbaïdjan. Les descriptions des guerres entre les Arabes et les Khazars laissent penser que, dans de nombreuses villes, il existait des individus maîtrisant la langue khazar. Parmi les habitants, on trouve également des Khazars convertis à l'islam. Certains facilitèrent la progression des Arabes. Grâce à un guerrier khazar qui trahit son camp pour se convertir à l'islam, les Arabes parviennent ainsi à conquérir Derbent. Cependant, al-Kufi précise que dès le départ de Marwan, commandant des armées arabes, les Khazars reviennent et «s'installent dans la ville de al-Bab comme jadis ${ }^{18} "$.

Les nomades ont toujours aidé les souverains locaux à maintenir leur indépendance face à l'expansion des grandes puissances.

15. Strabon, Geografija v 17 knigah..., op. cit., p. 501.

16. Izz ad-Din Abi al-Hasan Ali b. Muhammad al-Jazari Ibn al-Athir, Al-Kamil Fi AlTarikh, 11 vol., Beyrouth, Dar al-Kutub al-ilmiyya, 2006, p. 337-338.

17. At-Tabari, Tarikh at-Tabari..., op. cit., p. 251.

18. Abu Muhammad Ahmad ibn Asam Al-Kufi, Kniga zavojevanij (Izvlečenija po istorii Azerbajdžana VII-IX vv.), Bakou, Elm, 1981, p. 14-15. 
L'installation de nomades dans le territoire de l'Albanie du Caucase est bien entendu ancienne et remonte à l'Antiquité, mais ce mouvement s'intensifie sous le règne des Sassanides. Les souverains iraniens déplacent de grands groupes de nomades turcs pour contrôler les frontières, où sont élevées d'importantes fortifications. La toponymie locale reflète ce processus, de nombreux noms dérivant d'ethnonymes turcs. Ces relations pacifiques avec les nomades ont un impact décisif sur les formes d'activités économiques et le développement du commerce international à travers toute l'Albanie.

(Traduit de l'anglais par Camille Joseph) 
La montagne des langues et des peuples 


\section{La monnaie dans le sud du Caucase Georges Depeyrot}

La Transcaucasie est un carrefour de toutes les voies de communication entre l'est et l'ouest, mais aussi entre le nord et le sud.

Depuis quelques années, un programme de coopération visait à inventorier les découvertes monétaires en Géorgie et en Arménie. Le résultat a été une série importante de publications qui donnent une vue complète des découvertes dans cette région.

Les trésors ont enregistré les principaux problèmes historiques, des combats entre Grecs et Perses à ceux entre les Russes et les Ottomans. La période la plus importante pour la thésaurisation était bien sûr les invasions mongoles et les guerres ilkhanides

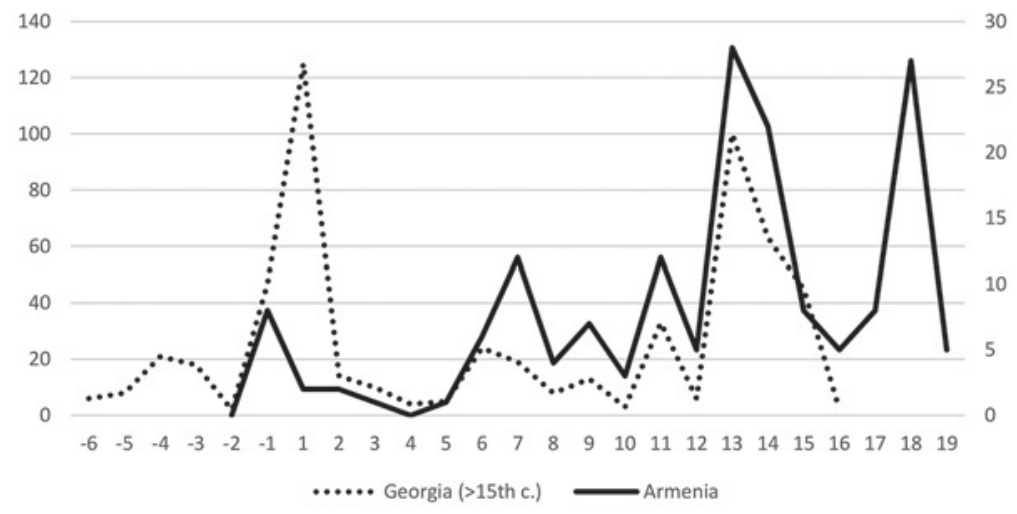

ILL. 1. Nombre de trésors par siècle.

Une des questions qui se posent dans l'étude des grands empires, est celle de savoir s'il faut étudier leur centre ou leurs périphéries. Bien 
sûr, le centre semble immédiatement être la partie la plus importante, la plus riche, le lieu où toutes les décisions ont été prises et immédiatement appliquées. Au contraire, les périphéries représentent les régions où n'arrivaient que les échos de ces mêmes décisions, où elles étaient plus ou moins appliquées, ou même plus ou moins comprises.

Si nous considérons l'Empire hellénistique, l'Empire romain, l'Empire chinois et, pour être bref, tous les empires, il est clair que l'étude de leur centre est rarement faite, et même que très peu de chercheurs ont tenté d'étudier les régions centrales. Par exemple, d'un point de vue monétaire, la ville de Rome est largement inconnue. La partie principale de la Rome antique est sous la ville actuelle; l'énorme quantité de pièces trouvées dans les fouilles et les constructions de bâtiments est encore inédite, même si elle est conservée ${ }^{1}$. Même cas de figure avec l'Empire hellénistique ${ }^{2}$, l'Empire chinois, etc. On peut penser que nous n'aurons jamais une vision complète de la circulation monétaire dans ces centres urbains, mis à part quelques catalogues de fouilles marginales.

Les choses étant ainsi, les sources principales proviennent des centres urbains secondaires, des frontières, et il en sera de même pendant les prochaines années et générations. Une pièce romaine trouvée en Pologne sera toujours plus discutée que les mêmes pièces trouvées en Italie. Un trésor italien ajoutera seulement quelques milliers de pièces de monnaie au flot des vestiges.

Une telle situation n'est pas vraiment un obstacle pour l'étude des grands empires. Après tout, il est plus aisé d'analyser l'industrialisation de l'Europe à partir de la glace des pôles que des terres européennes. Ce qui est plus facile pour la poussière de charbon est également plus facile pour les monnaies. Espérons que les générations futures seront plus efficaces que les nôtres et trouveront un moyen d'inventorier toutes les trouvailles.

En attendant, il est important de faire ce qui est possible, et en particulier d'analyser les découvertes sur place autant que possible.

1. Par exemple, les monnaies découvertes sous Mussolini ne sont toujours pas cataloguées.

2. Qu'en est-il des pièces trouvées à Athènes et dans les principales villes grecques autour de la mer Égée? 
Après la chute du mur de Berlin, les changements politiques en Europe de l'Est ont été si profonds que certains vestiges archéologiques et certains musées ont été pillés. Il avait été jusque alors impossible d'acheter et d'utiliser des détecteurs de métaux dans ces régions et les sites étaient restés parfaitement protégés. Les changements ouvrirent les frontières à l'importation de détecteurs de métaux et à l'exportation d'objets archéologiques, y compris les monnaies. Cette évolution s'est déroulée dans un cadre général de forte baisse des salaires et d'augmentation du chômage ${ }^{3}$.

\section{Go East !}

Dans les années 1990, alors que nous cherchions des sites comparatifs pour analyser les trouvailles de pièces faites à Zilil (Maroc $)^{4}$, nous avons eu l'occasion de rencontrer des collègues de Transcaucasie. Les publications de monnaies au Moyen-Orient sont rares et il est difficile de trouver des sites archéologiques importants à comparer avec les sites romains occidentaux. Nous avons décidé d'essayer d'inventorier les monnaies d'Arménie ${ }^{5}$ et de tout publier afin de promouvoir la recherche numismatique dans la région ${ }^{6}$.

3. Un salaire mensuel de 15-25 euros n'était pas rare pour les conservateurs de musées dans les années 1990.

4. G. Depeyrot, I. Zilil, Colonia Iulia Constantia Zilil, Étude du numéraire, collection de l'École française de Rome, 250, Rome, 1999.

5. La première visite eut lieu en septembre 1998 et a été suivie par d'autres, en avril 1999, octobre 1999; mai 2000, octobre 2000, septembre 2001, octobre 2001 et mai 2002.

6. A. Mousheghian, G. Depeyrot, Hellenistic and Roman Armenian, Coinage, (1st c. $B C-1 s t$ c. $A D$ ), Wetteren - A. Mousheghian, C. Bresc, G. Depeyrot, History and coin finds in Armenia, Antiquity, Wetteren, 1999 - A. Mousheghian, C. Bresc, G. Depeyrot, F. Gurnet, History and coin finds in Armenia, Coins from Duin, Capital of Armenia (4 - 13th c.), Inventory of Byzantine and Sasanian Coins in Armenia (6 - 7th c.), Wetteren, 2000 - A. Mousheghian, C. Bresc, G. Depeyrot, F. Gurnet, History and coin finds in Armenia, Coins from Garni (4th c. BC-19th c. AD), Wetteren, 2000 - A. Mousheghian, C. Bresc, G. Depeyrot, F. Gurnet, History and coin finds in Armenia; Coins from Ani (4th c. BC-19th c. AD), Wetteren, $2000-\mathrm{A}$. Mousheghian, C. Bresc, G. Depeyrot, F. Gurnet, History and coin finds in Armenia, Inventory of coins and hoards (7 - 19th c.), I, Wetteren, 2002 - A. Mousheghian, C. Bresc, G. Depeyrot, F. Gurnet, History and coin finds in Armenia, Inventory of coins and hoards (7 - 19th c.), II, Wetteren, 2003. 
Nous avons fait de même pour la Géorgie ${ }^{7}$. Ces publications ont été suivies par l'édition de livres similaires en Géorgie ${ }^{8}$ et par la publication des livres de base de Kropotkine sur les pièces de monnaie en URSS $^{9}$.

La documentation arménienne accessible était composée d'un grand nombre de notes sur papier, de frottis et de moulages en aluminium. Cette documentation avait été recueillie par Kh. Mousheghian, l'ancien directeur du cabinet des médailles d'Erevan ${ }^{10}$. Quand j'ai vu les archives, certains documents avaient déjà été mangés par des souris, y compris des parties des empreintes en aluminium. Nous avons décidé de préparer une publication de toutes les pièces afin de sauvegarder cette documentation. Clairement, sans les publications, toute la documentation aurait été perdue. La décision a été prise de ne pas limiter les publications aux monnaies antiques, mais d'inclure les pièces de monnaie sassanides et toutes les séries islamiques des Omeyyades aux dernières frappes $\mathrm{du} \mathrm{XIX}^{\mathrm{e}}$ siècle. Cela comprenait toutes les monnaies européennes

7. La première visite en octobre-novembre 2000 a été suivie par d'autres, en septembre 2001, novembre 2002, juillet 2009, juin 2010 et septembre 2010.

8. M. Tsotselia, History and coin finds in Georgia, coins from Tsitelitskaro ( $A D$ 641), collection "Moneta », 26, Wetteren, 2002 - M. Tsotselia, History and coin finds in Georgia, Sasanian coin finds and hoards, Wetteren, 2003 - I. Tsukhishvili, G. Depeyrot, History and coin finds in Georgia, Late Roman \& Byzantine hoards, collection "Moneta ", 34, Wetteren, 2003 - M. Sherozia, J.-M. Doyen, Les monnaies parthes du musée de Tbilissi (Géorgie), Wetteren - M. Tsotselia, Coin finds in Georgia (6th century $B C-15$ th century $A D$ ), with the collaboration of G. Depeyrot, Wetteren, 2007,. 2010.

9. V.I. Kropotkin, Les trouvailles de monnaies romaines en URSS, éd. par G. Depeyrot, Wetteren, 2005 - V.I. Kropotkin, Les trouvailles de monnaies byzantines en URSS, éd. par G. Depeyrot, Wetteren, 2006.

10. Khatchatour Artshesovich Mousheghian, 1919-1992, a été étudiant à Léningrad après la Seconde Guerre mondiale. Pendant ces années, il a travaillé au cabinet des Médailles. Après son retour à Erevan, il a travaillé avec E. Pakhomov, un influent auteur d'ouvrages sur la numismatique travaillant au cabinet des Médailles d'Azerbaïdjan, qui dans la période 1923-1960 a publié plusieurs volumes inventoriant les trouvailles monétaires de Transcaucasie. Ces volumes constituent la base essentielle de l'étude des monnaies en Géorgie, en Arménie et en Azerbaïdjan, mais aussi dans les républiques du Caucase (Daghestan, Ossétie, etc.). Dans de nombreux cas, ces livres sont les seules informations qui subsistent, maintenant que certains de ces trésors ont été dispersés. 
trouvées dans ces régions, comme les thalers et même les monnaies mongoles importées d'Asie ou les pièces d'argent frappées au Mexique. Cette décision nécessitait la formation d'une équipe alliant des chercheurs locaux et européens.

À cette documentation, nous avons ajouté des visites de musées pour voir, vérifier et analyser les trésors qui y sont conservés et les registres d'inventaire.

Pour cette documentation papier, il a été décidé d'ajouter tout ce que nous pouvions trouver dans les publications. La région a été très chanceuse à cet égard. $\mathrm{Au} \mathrm{Xx}^{\mathrm{e}}$ siècle, E. Pakhomov ${ }^{11}$ a publié un ensemble de livres inventoriant les découvertes monétaires faites dans les trois États du Caucase du Sud (Géorgie, Arménie et Azerbaïdjan), dans certaines régions du Caucase du Nord et dans certaines parties de l'Iran et de la Turquie. Il a publié huit volumes, le premier en $1926^{12}$.

Ce vaste programme de plusieurs années était placé sous les auspices de la Commission numismatique internationale ${ }^{13}$. Cet ensemble de publications donne un aperçu général des trouvailles monétaires faites dans la région.

11. Sur sa vie voir A.B. Akopjan, Evgenij Alexandrovič Pahomov (1880 - 1965), Èpigrafika vostoka, 2012, 30, p. 1-22.

12. Monetnye klady azerbajdžana, Vyp. I [trudy ooia. Vyp.3] Baku ooia, 1926 Klady azerbajdžana i drugih respublik, kraev i oblastej Kavkaza. Vyp. II. [trudy instituta istorii, jazyka i literatury. T. II/41]. -- - Baku izd- vo an azccr, 1938 Monetnye klady azerbajdžana i drugih respublik, kraev i oblastej Kavkaza. Vyp. III. - Baku, izd - vo azfan, 1940. — Monetnye klady azerbajdžana i drugih respublik, kraev i oblastej Kavkaza. Vyp.. IV. - - Baku izd- vo an azccr, 1949 - Monetnye klady azerbajdžana i drugih respublik, kraev i oblastej Kavkaza. Vyp.. V. -Bakou izd- vo an azccr, 1949 - Monetnye klady azerbajdžana i drugih respublik, kraev i oblastej Kavkaza. Vyp.. VI. - Bakou izd- vo an azccr, 1954 - Monetnye klady azerbajdžana i drugih respublik, kraev i oblastej Kavkaza. Vyp.. VII. - Baku izd- vo an azccr, 1957 - Monetnye klady azerbajdžana i drugih respublik, kraev i oblastej Kavkaza. Vyp.. VIII. - Baku izd- vo an azccr, 1959 - Monetnye klady azerbajdžana, i drugih respublik, kraev i oblastej Kavkaza. Vyp. IX - Baku izd- vo an azccr, 1966.

13. "Programme Transcaucasie ", Commission internationale de numismatique, Compte rendu 48, 2002, p. 22-24. Compte rendu 49, 2002, p. 88-89. Compte rendu 50, 2003, p. 34-36. Compte rendu 51, 2004, p. 73-74. Compte rendu 52, 2005, p. 75. Compte rendu 53, 2006, p. 73-74. Compte rendu 54, 2007, p. 55. 


\section{Une documentation importante}

L'importance de la documentation dans cette région est clairement liée à la situation géographique des pays et, en général, à la configuration du Caucase.

Sur la côte orientale du Caucase, la mer Caspienne ouvre la route vers le nord de l'Iran, l'Asie centrale, et via ces pays vers la Chine, l'Inde et le golfe Persique. C'est aussi la route vers la Russie centrale via la vallée de la Volga et vers le nord de la Russie et les pays baltes.

Sur le côté ouest, la mer Noire est la voie traditionnelle pour tous les voyages entre la Grèce et les nations du Nord, via la Crimée et la vallée du Dniepr. C'est le lien historique entre le Nord et le Sud, une route pour les commerçants venant avec de l'ambre, du fer, des esclaves ou des marchandises orientales; cette route est marquée par la diffusion de dirhams arabes le long des vallées.

Le Caucase lui-même est une région très montagneuse. La partie nord (le Grand Caucase) comprend les plus hautes montagnes d'Europe, culminant à plus de 5400 m, la partie sud (le Caucase inférieur) est moins élevée. Dans cette région se trouve le célèbre mont Ararat $(5100 \mathrm{~m})$. Entre ces deux chaînes de montagnes se situe la région transcaucasienne, une très longue et large vallée coupant la région d'est en ouest et permettant d'aller plus ou moins facilement de la mer Caspienne à la mer Noire.

La région est un carrefour parfait, reliant les voies de communication Nord/Sud et Est/Ouest.

Pour cette raison, la Transcaucasie a fait l'objet de conflits entre tous les empires, à commencer par les guerres de l'Antiquité entre Grecs et Perses. Les frontières et les zones d'influences coupent toujours la région. Depuis les temps les plus anciens, les villes grecques ont établi des colonies sur la côte géorgienne. Le mythe plaçait Toison d'or dans cette région, par allusion aux riches plaines de cette partie du Caucase. Le côté oriental de la Transcaucasie a quant à lui été principalement influencé par les empires orientaux, d'abord l'Empire perse puis, après lui, par tous les autres.

La frontière entre puissances d'Occident et puissances d'Orient coupant la région, celle-ci fut par excellence le lieu de batailles et d'actions militaires. Les armées ont été envoyées pour se battre et 
des forts ont été construits. L'axe de compétition est-ouest a été remplacé par un axe nord-sud créé par l'invasion arabe qui a tenté de conquérir le Caucase en remontant vers le nord. Cette tendance fut accentuée par l'invasion mongole (au XIII ${ }^{\mathrm{e}}$ siècle), venue d'Orient et traversant le Caucase du sud au nord. Après cette période, la région fut dominée par le long conflit entre la Russie et la Turquie.

\section{Les trouvailles monétaires}

Les premières monnaies ${ }^{14}$ venaient de Grèce, avec des oboles de Milet, et des dariques d'or ou d'argent étaient importés de Perse. Ce genre d'importation s'est poursuivi au cours des siècles suivants. La défaite de Darius face à Alexandre le Grand fit basculer la Transcaucasie dans la partie grecque du monde et changea la situation monétaire. Pillant les trésors de Darius, Alexandre ramena des tonnes d'or et d'argent dans les principaux ateliers monétaires de Grèce. Ce métal fut utilisé pour produire une quantité considérable de monnaies à son nom, utilisées pour financer ses armées et l'organisation de son empire. Il est maintenant possible d'estimer le butin ramené en Grèce à 200 tonnes d'or et 3000 tonnes d'argent ${ }^{15}$. Immédiatement, la monnaie grecque est devenue commune et la Transcaucasie a reçu des monnaies des principaux ateliers hellénistiques, y compris des pièces d'argent de Babylone.

La division de l'empire d'Alexandre a facilité la croissante influence de Rome. La Transcaucasie a alors bénéficié du développement du commerce entre l'Est et l'Ouest. Au-delà du mythe grec de la Toison d'or, les Romains avaient bien en vue les trésors des rois arméniens.

L'afflux de pièces grecques et romaines précéda certainement le premier siècle avant notre ère.

14. Je ne citerai pas encore les références aux divers livres. Toutes les trouvailles, trésors ou trouvailles isolées sont publiées dans les volumes cités ci-dessus.

15. G. Depeyrot, F. de Callataÿ, L. Villaronga, L’argent monnayé d'Alexandre le Grand à Auguste, travaux du Cercle d'études numismatiques, 13, 1993 - G. Depeyrot, Histoire de la monnaie des origines au XVIII siècle, Tome I, Introduction, de l’Antiquité au treizième siècle, Wetteren, 1995. 
Néanmoins, ce sont les conquêtes du roi arménien Tigrane II le Grand (v. 1211- v. 54 avant notre ère) qui déterminèrent le développement d'une économie monétaire en Arménie. Rassemblant diverses tribus et la noblesse locale, Tigrane entreprit d'annexer la Syrie et les régions voisines. Pour cette expédition, il augmenta son armée de mercenaires qui devaient être payés en espèces ${ }^{16}$. Tigrane fut ainsi le premier souverain d'Arménie à émettre de vastes quantités de monnaies. Toute l'économie arménienne se mit alors à utiliser la monnaie et les standards pondéraux d'Antioche.

En ce dernier siècle de la République romaine, le besoin de financement éprouvé par les principaux prétendants au pouvoir suprême poussa Pompée à envahir la région et à tenter de s'emparer du trésor des rois arméniens. La guerre se termina par la défaite de Tigrane, après la prise de sa capitale en 69; au versement de 6000 talents d'argent (200 tonnes) fut soumis le maintien du royaume arménien, devenu protectorat romain. Cette estimation de la quantité d'argent acquittée est donnée par les principaux historiens romains, mais nos études montrent qu'environ dix tonnes seulement furent transférées à Rome et émises comme deniers d'argent.

La défaite des armées de Tigrane n'aboutit pas à un retour à une économie prémonétaire. Mais l'occupation romaine apporta une modification des normes: les tétradrachmes d'étalon syrien furent remplacés par un tétradrachme dont le poids correspondait à celui de quatre deniers romain. Le pillage des réserves de Tigrane, de 69 à 66, réduisit les émissions de métaux précieux des rois arméniens. Par ce fait même, ce pillage facilita l'introduction de la monnaie grecque et romaine qui se mit alors à circuler en quantité. Liée à Rome, la circulation était largement dominée par les monnaies romaines, associées aux productions d'Antioche et d'autres royaumes hellénistiques. Les trésors étaient majoritairement constitutés de deniers frappés au premier siècle avant notre ère.

Le groupe principal des trésors du premier siècle avant notre ère est ainsi composé de monnaies émises après la conquête romaine. Ce n'est pas une surprise: la conquête a introduit un grand nombre

16. A. Mousheghian, G. Depeyrot, Hellenistic and Roman Armenian, Coinage, (1st c. $B C-1$ st c. $A D$ ), Wetteren, 1999. 
de monnaies romaines en Arménie. De plus, les guerres civiles de la fin du premier siècle avant notre ère favorisèrent la constitution de grands trésors. Les guerres entre les Parthes et les Romains au Moyen-Orient, contre Marc-Antoine en particulier, contribuèrent aussi à l'importation de nombreuses monnaies et facilitèrent cette constitution de trésors.

Cette période (du premier siècle avant notre ère au troisième siècle de notre ère) a été caractérisée par le développement de l'influence romaine en Transcaucasie. Pompée est allé en Azerbaïdjan. Quelques années après, les légions de Domitien se rendirent également en Azerbaïdjan: l'inscription de Qoboustan (75 après J.-C.) gravée par les soldats de la douzième légion le prouve. Le temple romain de Garni (Arménie) a été dédié en l'an 77, comme le mentionne l'inscription dédicatoire grecque. Un peu plus tard, une inscription trouvée en Arménie concerne un bâtiment construit par les soldats de la troisième légion ${ }^{17}$.

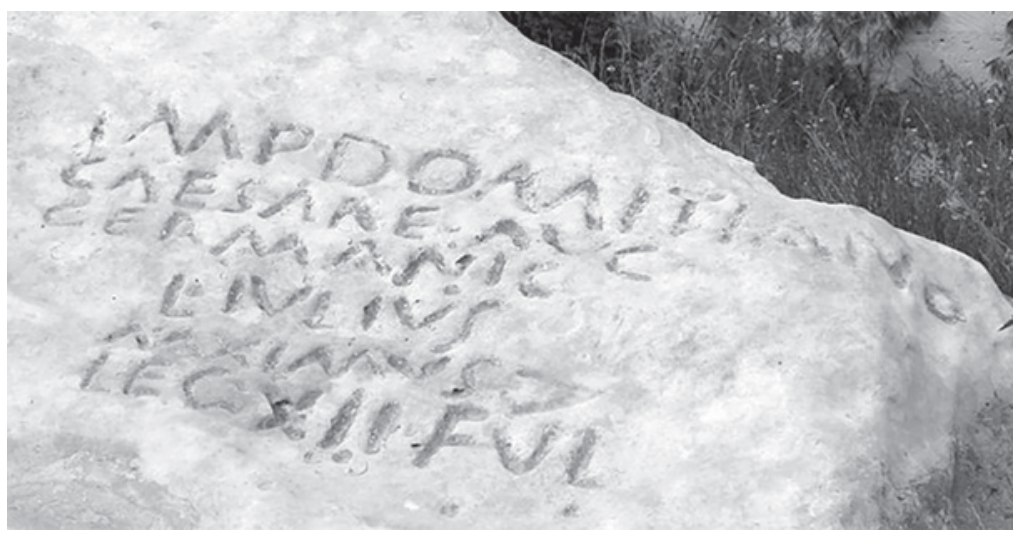

ILL. 2. Inscription de Qobustan.

$\mathrm{Au}$ cours du troisième siècle de notre ère et du développement de la crise de l'Empire romain, les Sassanides prirent le contrôle de la majeure partie de la région. Le grand royaume d'Arménie passa

17. Imp caesar divi nervae filius nerva traianus/optimus aug germ dacicus parthicus pon max/trib pot XX imp XIII cos VI per leg IIII sc fecit. 


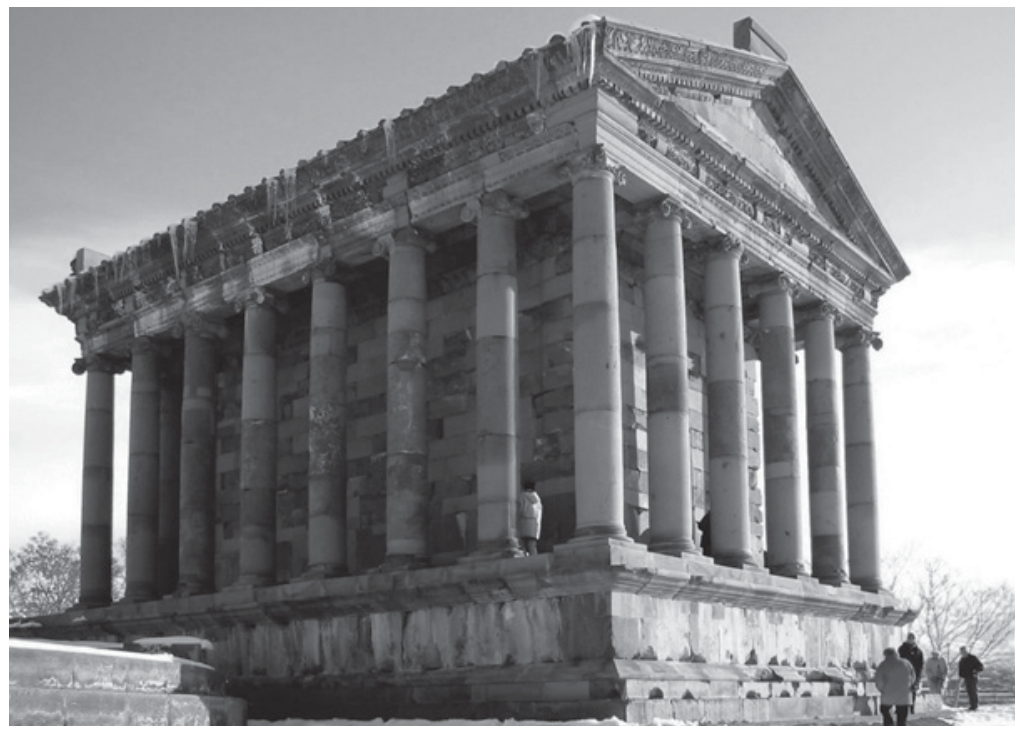

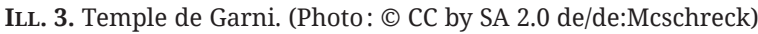

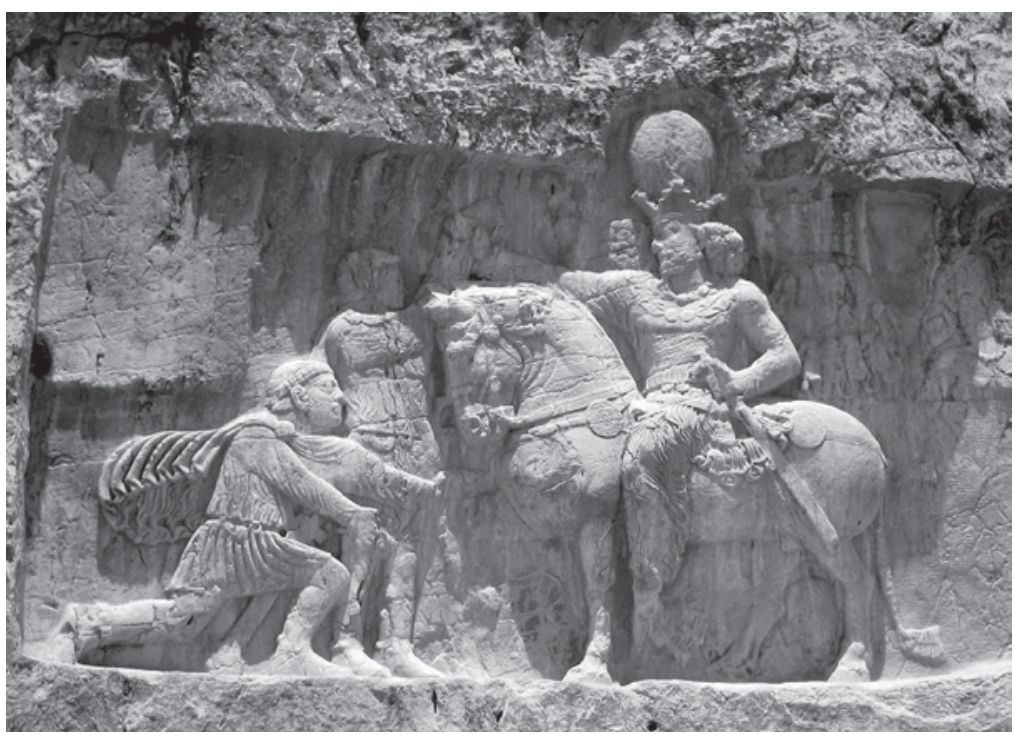

ILL. 4. Relief rocheux de Naqsh-e Rustam: Shapur I capture Valérien (260). 
sous le contrôle de Shapur $\mathrm{I}^{\mathrm{er}}$, qui régna de 240 à 272, puis la défaite et la capture de Valérien par Shapur $\mathrm{I}^{\mathrm{er}}$ mirent fin à la domination romaine sur la région. Après le troisième siècle, la circulation monétaire est dominée par les pièces sassanides, à l'exception de l'importation des monnaies byzantines apportées par les armées qui les combattaient. La pièce byzantine la plus spectaculaire était l'hexagramme, une grosse monnaie pesant environ six grammes spécialement produite pour payer les troupes. Les trésors d'hexagrammes se trouvent surtout le long des frontières, puisqu'ils ont été frappés pour les légions, le long du Danube et en Transcaucasie. La conquête arabe et les défaites des armées byzantines mirent fin à l'empire sassanide ${ }^{18}$.

\section{Un atelier temporaire romain en Transcaucasie?}

On sait que les deniers frappés par Auguste (avec le nom des deux Césars Caius et Lucius [C. L. CAESARES]) sont très communs en Transcaucasie. Les pièces authentiques que l'on croyait frappées en Gaule sont présentes dans tous les trésors romains et le type a été largement imité, au cours des siècles suivants. Selon les chronologies habituelles, les frappes n'ont pas duré longtemps et les monnaies ont été émises à Lyon. Mais en Transcaucasie, ces deniers sont très fréquents et répandus. Ils sont présents non seulement dans les grands centres urbains, mais aussi dans les sites ruraux ou dans des tombes isolées.

La proportion de deniers de type C. L. CAESARES est plus grande en Transcaucasie qu'en Europe centrale. Ce type est aussi courant en Transcaucasie que dans les zones proches de l'atelier qui est censé avoir produit ces monnaies.

Comme les proportions de ces deniers sont faibles en Europe centrale, on peut conclure que les deniers C. L CAESARES ont eu une distribution anormale en Transcaucasie. Deux hypothèses peuvent être avancées. Soit les pièces ont été envoyées directement de l'atelier de Lyon en Transcaucasie, soit les pièces ont été frappées dans une zone proche de la Transcaucasie. Nous nous rangeons à la

18. Voir les cartes dans P. Yannopoulos., 1978, L'hexagramme, Louvain-la-Neuve. 


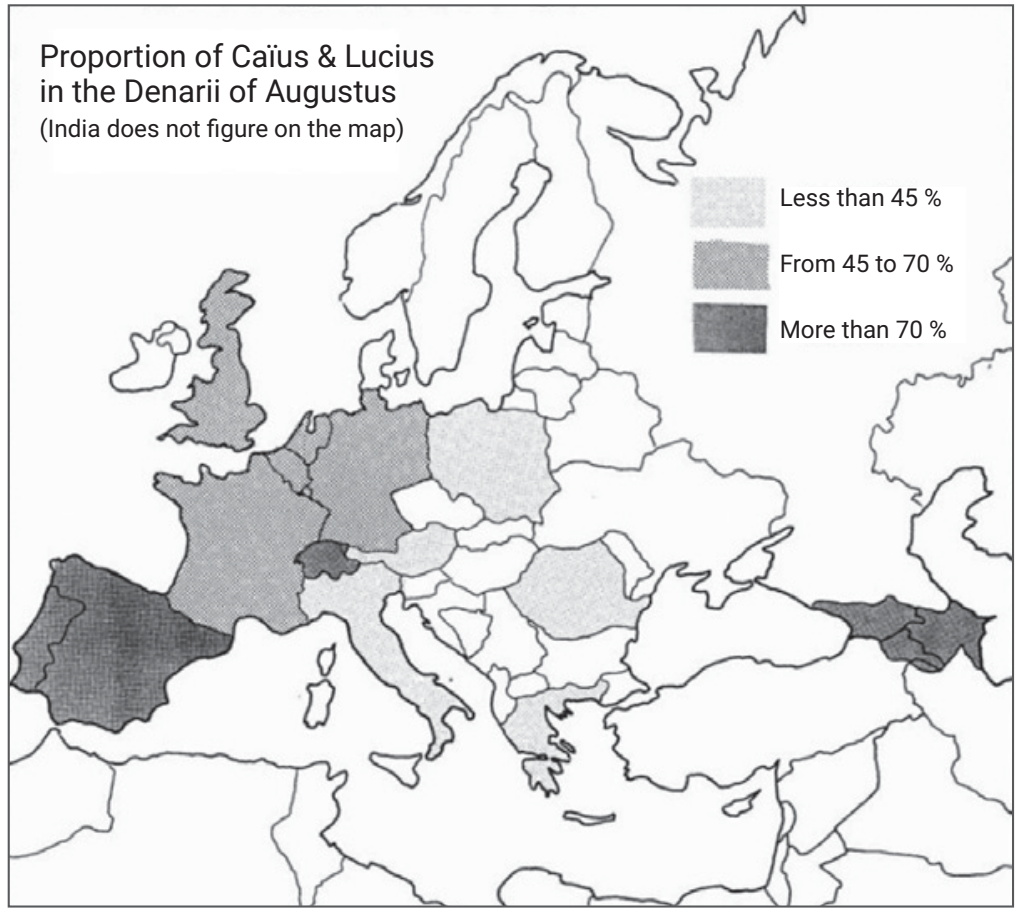

ILL. 5. Proportion des deniers Caius \& Lucius dans les frappes de deniers d'Auguste ${ }^{19}$.

seconde hypothèse. Voici ce qui, selon les éléments dont nous disposons, se passa.

Sous le règne d'Auguste, des légions restèrent stationnées dans cette région de l'Empire et combattirent les Parthes. Mais Lucius Caesar et Caius Caesar, ce dernier ayant participé aux opérations, moururent respectivement en 2 et 4 de notre ère. Il y a lieu de penser que, pendant ces années de guerre, un atelier itinérant fut actif dans la région, et que le retrait de Caius et des légions mirent fin aux activités de cet atelier. Ainsi, pendant un certain temps, la Transcaucasie a pu absorber ces pièces produites pendant la présence des légions et ayant constitué le stock monétaire local.

Mais la fermeture de l'atelier itinérant officiel produisant ces deniers C. L. CAESAR laissa insatisfait le besoin en nouvelles mon-

19. L'Inde, concernée, ne figure pas sur cette carte. 
naies. Des ateliers locaux réalisèrent des imitations. Ces dernières, typiques, ont été frappées tout au long du premier siècle et certainement au cours du deuxième siècle. Kropotkine a publié une pièce très convaincante où le revers classique CL CAESARES est associé à un buste typique de la seconde moitié du $\mathrm{II}^{\mathrm{e}}$ siècle $^{20}$.
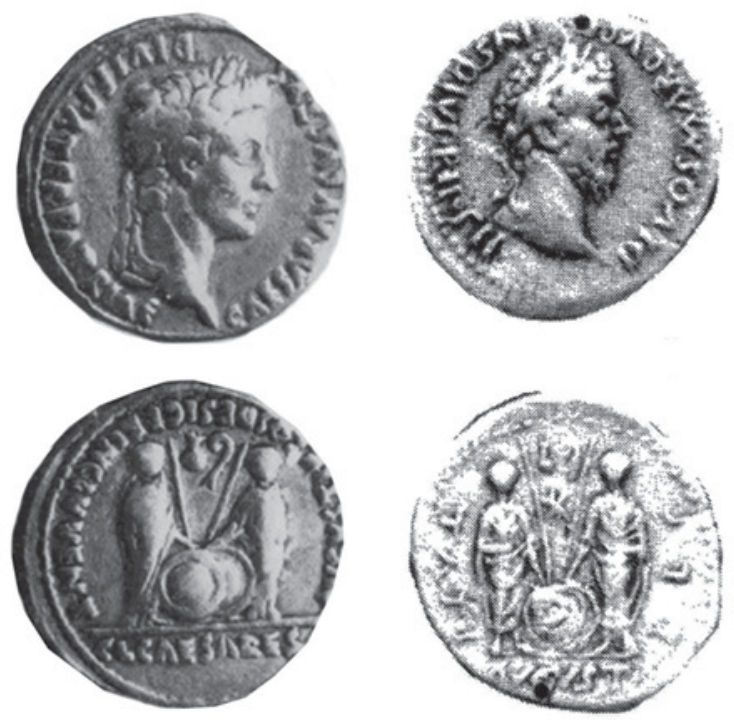

ILL. 6. Le prototype émis à Lyon et les frappes d'imitation du deuxième siècle.
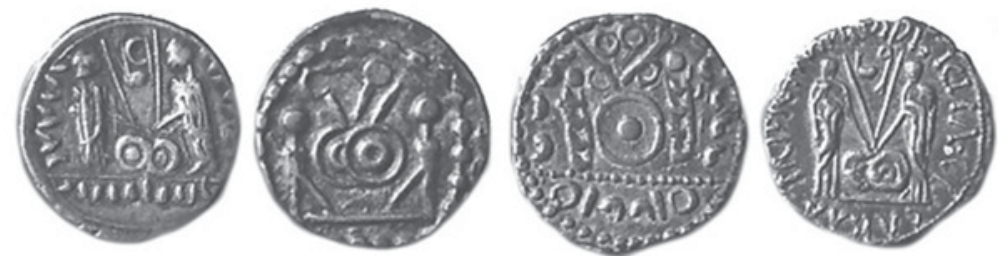

ILL. 7. Imitations transcaucasiennes de deniers C L CAESAR.

20. M. Sherozia "Spreading of denarii of Octavianus Augustus and so called drachms of Gotarzes on the territory of Kartli Kingdom (Georgia) », in Bulletin du Cercle d'Études Numismatiques, 2002, p. 173 - 180 


\section{Les périodes médiévales et modernes}

L'invasion arabe est liée à la chute du pouvoir sassanide. La crise politique n'eut aucun effet sur les besoins de l'économie monétaire. La fin des ateliers sassanides officiels et la pénurie de numéraire poussèrent donc à la production d'imitations plus ou moins illégales, comme c'était déjà le cas avec les deniers C.L. CAESAR.

La Transcaucasie commença à produire des monnaies "sassanides ", certaines utilisant des lettres sassanides (ce qui fut le cas avec la production locale de Duin en Arménie ${ }^{21}$ ), d'autres étant frappées avec les nouveaux alphabets géorgien et arménien.
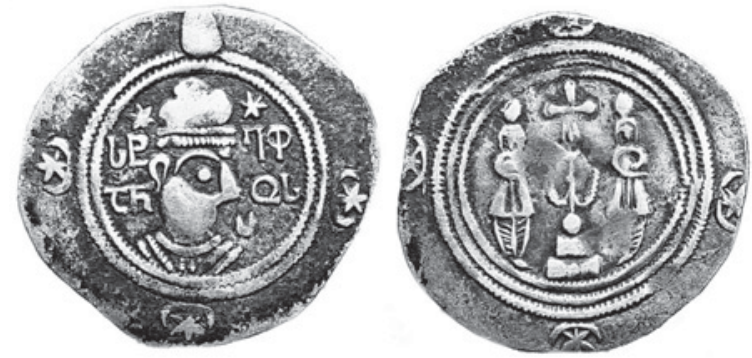

ILL. 8. La première frappe géorgienne de type sassanide avec une légende en géorgien.

Après l'installation des dynasties omeyyade et abbasside en Transcaucasie, l'atelier de Duin produisit un très grand nombre de dirhams d'argent qui furent principalement utilisés pour le commerce international. On en a retrouvé dans des trésors le long du Dniepr et de la Volga jusqu'aux pays Baltes et même en Écosse ${ }^{22}$.

Les premières crises du régime abbasside donnèrent aux dirigeants locaux l'occasion de se révolter contre l'administration centrale. Une nouvelle période de discorde et de division territoriale s'ouvrit avec cette crise politique. C'est à cette période qu'appartient

21. A. Mousheghian, C. Bresc, G. Depeyrot, F. Gurnet, History and coin finds in Armenia, Coins from Duin, Capital of Armenia (4 - 13th c.), Inventory of Byzantine and Sasanian Coins in Armenia (6 - 7th c.), Wetteren, 2000.

22. Ibid. 
le grand trésor de Sunik, composé de plus de 2000 pièces d'argent enterrées vers 815 de notre ère.

La déségrégation des principaux États ouvrit pour Byzance une nouvelle période de guerres. $\mathrm{Du} \mathrm{IX}{ }^{\mathrm{e}}$ aux XI $/ \mathrm{XII}^{\mathrm{e}}$ siècles, les empereurs se livrèrent à de nombreuses tentatives pour dominer à nouveau la Géorgie. Les armées montèrent en Arménie et assiégèrent Duin. Ces conflits furent financés par l'importation de nombreuses pièces d'or byzantines.

L'invasion mongole du Caucase, à partir de 1220, détruisit toutes les principales villes et contribua à la création d'une situation d'anarchie. Peu à peu, les entités féodales se transformèrent en de nouveaux États basés sur leur religion, alphabet et traditions respectifs, avec de nouvelles dynasties. La Transcaucasie se réorganisa autour du royaume géorgien. Circulèrent principalement alors les frappes de la reine Tamar (1160-1213) et de ses successeurs. Le système monétaire ainsi mis en place reposait sur de très grandes émissions de pièces de cuivre, peut-être une conséquence du vol des métaux précieux par les Mongols et de la présence de mines de cuivre dans la région. La production était si importante que certains morceaux de métal ne furent même pas transformés en flans mais furent frappés directement.

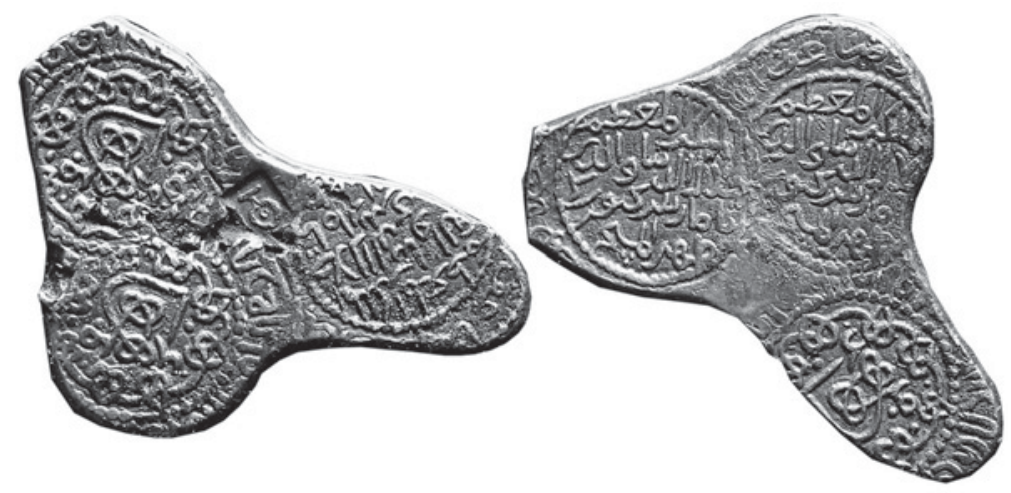

ILL. 9. Monnaie de la reine Tamar.

La période des invasions mongoles et celle qui suivit le passage des envahisseurs se distinguent par le très grand nombre de trésors 
parvenus jusqu'à nous se distinguent par le très grand nombre de trésors parvenus jusqu'à nous.

La stabilisation de la région après le $\mathrm{XvI}^{\mathrm{e}}$ siècle fut de nouveau suivie d'une importante période de thésaurisation, principalement liée à la pression russe sur les empires ottoman et perse au XVIII ${ }^{\mathrm{e}}$ siècle.

Les trois pays du Caucase du Sud ont toujours été une terre de transferts interculturels. Pour cette raison, ils ont reçu des monnaies frappées dans les diverses parties du monde, et les ont parfois frappées eux-mêmes dans des logiques d'imitation intéressée. Le nombre de trésors est un bon moyen de mesurer l'intensité des guerres, des invasions, des troubles et des peurs de la population, mais aussi le coût de ces événements, car ces pièces étaient surtout un moyen de financer la guerre.

Les programmes de coopération qui ont nourri le présent article ont contribué à une meilleure compréhension de l'histoire de la région. Nous espérons vivement que les historiens géorgiens, arméniens et azerbaïdjanais continueront ce travail.

\section{Trésors en Arménie ${ }^{23}$}

\section{Premier siècle avant J.-C.}

"Armenia »; Artashat $n^{0} 1$; Artashat n ${ }^{0} 2$; Artashat n ${ }^{0} 3$; Artik;

Gumri; Parakar; Sarnakounk.

\section{Premier siècle}

Vardenut-Aparan.

II $^{\mathrm{e}}$ siècle

Echmiadzin; Garni.

III $^{\mathrm{e}}$ siècle

Oshakan.

23. Liste établie sur la base de nos publications; tous les catalogues des trésors ont été publiés dans les divers volumes. L’orthographe des noms de lieux est celle retenue dans ces publications. 
$\mathrm{V}^{\mathrm{e}}$ siècle

Yerevan.

$\mathrm{VI}^{\mathrm{e}}$ siècle

Koghb; Lanjaghbyur; Oshakan; Sisian; Yerevan.

VII $^{\mathrm{e}}$ siècle

Armenia; Artsvaberd; Duin $n^{0} 1$; Duin $n^{0} 2$; Duin $n^{0} 3$; Duin

$n^{0} 4$; Durtchi; Echmiadzin $n^{0} 1$; Echmiadzin $n^{0} 2$; Gumri; Kosh;

Stepanavan.

VIII ${ }^{\mathrm{e}}$ siècle

Dilidjan; Shenavan; Verin Getashen $n^{0} 1$; Verin Getashen $n^{0} 2$.

$\mathrm{IX}^{\mathrm{e}}$ siècle

Duin $n^{0} 5$; Duin $n^{0} 6$; Nerkin Getashen; Paravakar; Sunik.

$\mathrm{x}^{\mathrm{e}}$ siècle

Duin $n^{0} 7$; Duin $n^{0} 8$.

$\mathrm{XI}^{\mathrm{e}}$ siècle

Artashat; Duin $n^{0} 10$; Duin $n^{0} 11$; Duin $n^{0}$ 9; Gavar; Hrazdan;

Ohanavank; Vardenis; Yerevan $n^{0} 1$; Yerevan $n^{0} 2$; Yerevan $n^{0} 3$;

Yerevan $n^{\circ} 4$.

$\mathrm{XII}^{\mathrm{e}}$ siècle

Armavir; Masis?; Ptghni; Vardenut; Demirgian.

XIII ${ }^{\mathrm{e}}$ siècle

Abovian; Abovian; Achajur; Aghavnatoun; Armenia 1225;

Artashat; Arzni; Ashnak; Duin $n^{0} 12$; Duin $n^{0} 13$; Duin $n^{0} 14$; Duin

$n^{0} 15$; Echmiadzin; Garni $n^{0} 3$; Garni no 4; Garni ${ }^{0} 5$; Goght; Gort;

Haykavan; Karbi; Karbi; Kartchaghbyur; Stepanavan; Ttujur;

Yeghegnadzor; Yeghvard; Yerevan $n^{0} 5$.

$\mathrm{XIV}^{\mathrm{e}}$ siècle

Armenia; Artik; Changar of Ardahan; Garni n ${ }^{0}$ 6; Garni $n^{0} 7$; Garni n 8; Gavar; Goght; Gumri; Haykashen; Meghri; Mets Parni; Panik; Penzashen; Shenavan; Yerevan $n^{0} 6$; Yerevan $n^{0} 7$; Yerevan $n^{0} 8$; Yerevan $n^{0}$ 9; Yerevan $n^{0} 10$; Yerevan $n^{0} 11$; Yerevan $n^{0} 12$.

$\mathrm{XV}^{\mathrm{e}}$ siècle

Ashtarak; Kosh; Kosh; Saragyugh; Yerevan $n^{0} 13$; Yerevan $n^{0} 14$;

Yerevan $n^{0} 15$; Yerevan $n^{0} 16$. 
$\mathrm{XVI}^{\mathrm{e}}$ siècle

Ashtarak; Gusanagyugh; Ohanavank; Sisian; Yerevan nº 17.

XVII $^{\mathrm{e}}$ siècle

Irind; Nerkin Getashen; Nerkin Getashen; Dilijan; Meghri; Gorayk; Yerevan $n^{0} 18$; Yerevan $n^{0} 19$.

\section{$\mathrm{XVIII}^{\mathrm{e}}$ siècle}

Armenia; Artsvanik; Eranos; Ferik; Gavar nº 1; Gavar n² 2; Goris;

Lernatap; Meghri; Meghri; Noragavit; Nouratus; Saragyugh;

Sisian; Vardenut; Yerevan Kort; Yerevan $n^{\circ} 20$; Yerevan $n^{0} 21$;

Yerevan $n^{0} 22$; Yerevan $n^{0} 23$; Yerevan $n^{0} 24$; Yerevan $n^{0} 25$;

Yerevan $n^{0} 26$; Yerevan $n^{0} 27$; Yerevan $n^{0} 28$; Yerevan $n^{0} 29$;

Yerevan $n^{0} 30$.

$\mathrm{XIX}^{\mathrm{e}}$ siècle

Aygezard; Gumri; Harich; Vardenut; Yerevan nº 31.

\section{Trésors en Géorgie}

Colchis $\mathrm{VI}^{\mathrm{e}}-\mathrm{II}^{\mathrm{e}}$ siècle avant $\mathrm{J}$.-C.

Akhali Abastumani; Akhalsopeli; Anaklia; Bargebi; Batumi;

Chitatskali; Chometi; Dablagomi $n^{0} 1$; Dablagomi $n^{0} 2$; Dapnari;

Dgnorisi; Djagira; Ergeta; Gergeta; Gumistavi; Jumati; Khoni;

Kobuleti $n^{0} 1$; Kobuleti $n^{0} 2$; Kukhi; Kutaisi $n^{0} 1$; Kutaisi $n^{0} 2$;

Kutaisi $n^{0} 3$; Kvirila; Lower Svaneti; Meskheti; Nabakhevi

$\mathrm{n}^{0} 1$; Nokalakevi $\mathrm{n}^{0} 2$; Norio; Obcha; Partskhanakanevi $\mathrm{n}^{0} 1$;

Partskhanakanevi ${ }^{\circ} 2$; Pichvnari; Poti; Potsko; Racha; Rukh;

Saberio; Sajavakho $n^{0} 1$; Sajavakho $n^{0} 2$; Satsulukidzo; Sokha;

Sukhumi; Takhtisdziri; Tsnisi; Vani $n^{0} 1$; Vani $n^{0} 2$; Vani $n^{0} 3$; Vani

$n^{0} 4$; Vani $n^{0} 5$; Zarati; Zemo Chibati; Zugdidi $n^{0} 1$; Zugdidi $n^{0} 2$;

Zugdidi $n^{0} 3$; Zvaragula.

$\mathrm{v}^{\mathrm{e}}$ siècle avant $\mathrm{J}$.-C.

Pichvnari; Suluri.

IV $^{\mathrm{e}}$ siècle avant $\mathrm{J}$.-C.

Colchis; Gebi; Larilari; Lechkhumi; Pichvnari; Surami; Svaneti

$n^{0} 1$; Svaneti $n^{0} 2$; Svaneti $n^{0} 3$; Svaneti $n^{0} 4$; Sviri; Vachevi; Vani. 
III ${ }^{\mathrm{e}}$ siècle avant $\mathrm{J}$.-C.

Agaiani; Ajara; Gori; Koroglistskali river; Makriala; Reke; Svaneti; Tsebelda; Vani; Zemo Markhi.

$\mathrm{II}^{\mathrm{e}}$ siècle avant $\mathrm{J}$.-C.

Gerzeul; Gori.

\section{Premier siècle avant J.-C.}

Abisi; Abkhazia; Agaiani $n^{0} 1$; Agaiani $n^{0} 2$; Agaiani $n^{0} 3$; Agaiani $n^{0} 4$; Agaiani $n^{0} 5$; Agaiani $n^{0} 6$; Agaiani $n^{0} 7$; Agaiani $n^{0} 8$; Agaiani $\mathrm{n}^{0}$ 9; Arkneti; Gori; Gumurishi; Karsniskhevi $\mathrm{n}^{0} 1$; Kavtiskhevi $\mathrm{n}^{0} 2$; Kodistskaro $\mathrm{n}^{0} 1$; Kodistskaro $\mathrm{n}^{0} 2$; Mokhisi; Mtskheta $\mathrm{n}^{0} 1$; Mtskheta $n^{0} 2$; Mtskheta $n^{0} 3$; Mtskheta $n^{0} 4$; Mtskheta $n^{0} 8$; Mtskheta $n^{0} 9$; Mtskheta-Samtavro $n^{0} 1$; Mtskheta-Samtavro $\mathrm{n}^{0} 2$; Mtskheta-Svetitskhoveli; Mtskheta-Tsitsamuri; Nastakisi; Natakhtari; Pakhulani; Sazodelavo; Sukhumi; Svetitskhoveli; Takhtisdziri; Tbilissi; Uplistsikhe; Vani $n^{0} 1$; Vani $n^{0} 2$; Vartsikhe; Zhinvali $n^{0} 1$; Zhinvali $n^{0} 2$; Zhinvali $n^{0} 3$; Zhinvali $n^{0} 4$; ZhinvaliBagichala; Zugdidi.

$\mathrm{VI}^{\mathrm{e}}-\mathrm{I}^{\mathrm{er}}$ siècle avant $\mathrm{J}$.-C.

Batumi; Kelasuri River; Pichvnari $n^{0} 1$; Pichvnari $n^{0} 2$; Pichvnari $\mathrm{n}^{0} 3$; Pichvnari $\mathrm{n}^{0} 4$.

\section{Vers 1-50}

Agaiani $n^{0} 1$; Agaiani $n^{0} 2$; Agaiani $n^{0} 3$; Agaiani $n^{0} 4$; Agaiani $n^{0} 5$; Agaiani $n^{0} 6$; Aranisi; Avchala; Bagichala; Batumi; Bori $n^{0} 1$; Bori $n^{0} 2$; Bori $n^{0} 3$; Cheremi; Digomi $n^{0} 1$; Digomi $^{0} 2$; Gori $n^{0} 1$; Gori n ${ }^{0}$; ; Gori $n^{0} 3$; Gori n ${ }^{0} 4$; Gori n ${ }^{0}$ 5; Gremi Monastery; Grmagele; Gumurishi; Karagadji; Kitskhi; Kldeeti $n^{0} 1$; Kldeeti $n^{0} 2$; Kldeeti $n^{0} 3$; Kvirila; Magraneti $n^{0} 1$; Magraneti $n^{0} 2$; Mtskheta $n^{0} 1$; Mtskheta $n^{0} 2$; Mtskheta $n^{0} 3$; Mtskheta $n^{0} 4$; Mtskheta $n^{0} 5$; Mtskheta $n^{0} 6$; Mtskheta $n^{0} 7$; Mtskheta $\mathrm{n}^{0}$ 8; Mtskheta-Armaziskhevi $\mathrm{n}^{0} 1$; Mtskheta-Armaziskhevi $\mathrm{n}^{0} 2$; Mtskheta-Armaziskhevi $n^{0} 3$; Mtskheta-Bagineti $n^{0} 1$; MtskhetaBagineti $n^{0} 2$; Mtskheta-Bagineti $n^{0} 3$; Mtskheta-Bagineti $n^{0} 4$; Mtskheta-Karniskhevi; Mtskheta-Mogvtakari; MtskhetaSamtavro $n^{0} 1$; Mtskheta-Samtavro $n^{0} 2$; Mtskheta-Samtavro $n^{0} 3$; Mtskheta-Samtavro $n^{0} 4$; Mtskheta-Samtavro $n^{0} 5$; MtskhetaSamtavro $n^{0} 6$; Mtskheta-Samtavro $n^{0} 7$; Mtskheta-Samtavro $n^{0} 8$; 
Mtskheta-Samtavro $n^{0} 9$; Mtskheta-Samtavro $\mathrm{n}^{0} 10$; MtskhetaSamtavro $\mathrm{n}^{0} 11$; Mtskheta-Samtavro $\mathrm{n}^{0} 12$; Mtskheta-Samtavro $\mathrm{n}^{0} 13$; Mtskheta-Samtavro $\mathrm{n}^{0} 14$; Mtskheta-Svetitskhoveli; Nastakisi $\mathrm{n}^{0} 1$; Nastakisi $\mathrm{n}^{0} 2$; Nastakisi $\mathrm{n}^{0} 3$; Nastakisi $\mathrm{n}^{0} 4$; Nastakisi $\mathrm{n}^{0} 5$; Nazodelavo; Nichbisi $n^{0} 1$; Nichbisi $n^{0} 2$; Stirpazi; Sukhumi; Tbilissi; Trani $\mathrm{n}^{0}$; Trani $\mathrm{n}^{0}$; Tsageri; Tsintskaro; Tsitsamuri Mtskheta; Urbnisi $\mathrm{n}^{0} 1$; Urbnisi ${ }^{0} 2$; Urbnisi $\mathrm{n}^{0} 3$; Urbnisi $\mathrm{n}^{0} 4$; Urbnisi $n^{0} 5$; Vaziani; Zemo Avchala $n^{0} 1$; Zemo Avchala $n^{0} 2$;

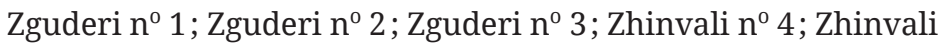
$\mathrm{n}^{0}$ 5; Zhinvali $\mathrm{n}^{0} 6$; Zhinvali ${ }^{0} 7$; Zhinvali $\mathrm{n}^{0} 8$.

\section{Vers 51-100}

Agaiani; Didi Lilo; Digomi ${ }^{0} 1$; Digomi $\mathrm{n}^{0} 2$; Ilemi; Khovle; Kldeeti; Mtskheta $\mathrm{n}^{0} 1$; Mtskheta $\mathrm{n}^{0} 2$; Mtskheta $\mathrm{n}^{0} 3$; Mtskheta $\mathrm{n}^{0} 4$; Mtskheta-Samtavro $\mathrm{n}^{0} 1$; Mtskheta-Samtavro $\mathrm{n}^{0} 2$; Naoza; Nastakisi; Nichbisi; Stiphraz; Tskhinvali; Vardisubani.

\section{Vers 101-150}

Bori; Chkorotsku; Kldeeti; Mtskheta; Mtskheta-Bagineti; MtskhetaSamtavro; Takhulani; West Georgia.

\section{Vers 151-200}

Gerzeul Gulripshi; Gerzeuli; Nobakevi; Nosiri; Pichvnari; Tsebelda.

\section{Vers 201-250}

Bori; Sepieti; Mtskheta-Samtavro; Sukhumi; Pitsunda ${ }^{0} 1$;

Pitsunda $\mathrm{n}^{\circ} 2$; Gonio.

\section{Vers 251-300}

Mtskheta; Tskhinvali; Ureki.

\section{Vers 301-350}

Agaiani; Modinakhe; Sukhumi.

Vers 351-400

Pitsunda.

Vers 401-450 - .

Vers 451-500

Andriatsminda; Archiloskalo; Bolnisi; Zhinvali nº 1 ; Zhinvali ${ }^{0} 2$. 


\section{Vers 501-550}

Kvemo Alevi; Mtskheta-Samtavro; Tbilissi-Krtsanisi; Tsitsamuri $\mathrm{n}^{0} 1$; Tskhumari $\mathrm{n}^{0} 2$; Zaridzeebi.

\section{Vers 551-600}

Baisubani; Chkhorotsku; Dedoplistskaro; Dusheti; Gamarjveba; Mtskheta $\mathrm{n}^{0} 1$; Mtskheta $\mathrm{n}^{0} 2$; Mtskheta $\mathrm{n}^{0}$ 3; Mtskheta-Mtakartli; Nedzikhi; Nekresi; Nokalakevi; Smekalovka; Tolenji; Tsikhisdziri; Tskhinvali; Urbnisi $\mathrm{n}^{0} 1$; Urbnisi $\mathrm{n}^{0} 2$.

\section{Vers 601-650}

Alevi; Chibati; Dedoplistskaro $\mathrm{n}^{0} 1$; Dedoplistskaro $\mathrm{n}^{0} 2$; Kvirila; Marganeti; Mtskheta ${ }^{0} 1$; Mtskheta ${ }^{0} 2$; Nekresi; Nokalakevi; Odishi; Sarachilo; Svaneti; Tbilissi $n^{0} 1$; Tbilissi $n^{0} 2$; TbilissiSololaki; Urbnisi.

\section{Vers 651-700}

Magraneti.

\section{Vers 701-750}

Mataani; monastère de Pitsunda.

\section{Vers 751-800}

Chikaani; Mtisdziri; Pitsunda; Savane; tour de Tsebelda; Zemo Alvani.

\section{Vers 801-850}

Apeni; Avhcala; rivière Chorokhi; Dilipi; Kavshiri; Leliani;

Mtisdziri; Pshaveli; Savane; Tbilissi; rivière Tergi.

\section{Vers 851-900}

Géorgie orientale; Pichkhovani.

Trésors islamiques $\mathrm{du}_{\mathrm{IX}}^{\mathrm{e}}$ siècle

Arkabi.

Vers 901-950

- .

Vers 951-1000

Borchalo; Tbilissi $\mathrm{n}^{0} 1$; Tbilissi $\mathrm{n}^{0} 2$.

Abbassid fals $\mathbf{8}$ th $\mathbf{- 9}$ th $\mathbf{- 1 0}$ th $\mathrm{c}$

Mtskheta-Samtavro; Tbilissi $n^{0} 1$; Tbilissi $n^{0} 2$. 
Vers 1001-1050

Akhaltsikhe; Kvakhvreli; Tbilissi $n^{0} 1$; Tbilissi $n^{0} 2$; Tbilissi $n^{0} 3$; Tbilissi $\mathrm{n}^{0} 4$; Tbilissi $\mathrm{n}^{0} 5$; Tsikhisdziri; Tskorda.

\section{Vers 1051-1100}

Bobokvati $\mathrm{n}^{0} 1$; Bobokvati $\mathrm{n}^{0} 2$; Dviri; Gelati; Gubi; Idumala; Kobuleti; Kolkheti; Likhnigold; Meskheti; Ochamchira; Ozurgeti; Racha; cloître de Saphara; monastère de Saphara; Tsikhesulori; Tsikhisdziri $\mathrm{n}^{0} 1$; Tsikhisdziri $\mathrm{n}^{0} 2$; Tsintskaro; Tskordza; inconnu; Vani; Vardisubani $n^{0} 1$; Vardisubani $n^{0} 2$.

\section{Vers 1101-1150}

Dmanisi; Gurjaani; Sukhumi (Abkhazie); Tsebelda.

\section{Vers 1151-1200}

Djandara; Tbilissi.

\section{Pièces de cuivre anonymes de Byzance du XI ${ }^{\mathrm{e}}$-XII ${ }^{\mathrm{e}}$ siècle}

Borchalo; Dmanisi n ${ }^{0} 1$; Dmanisi n ${ }^{\circ} 2$; Gelati; Gonio-Apsarosi; Keda; Nokalakevi; Tbilissi; Tsikhisdziri.

\section{Vers 1201-1250}

Abanoeti; Abulbog; Agaiani; Anaga; Atotsi; Bolnisi; Dedoplistskaro; Digomi (Tbilissi); Dmanisi n ${ }^{0} 1$; Dmanisi ${ }^{0} 2$; Dmanisi n ${ }^{\circ} 3$; Dmanisi $\mathrm{n}^{0} 4$; Dmanisi $\mathrm{n}^{0}$ 5; Georgia-Racha; Gorana et Kojbaani; Gudarekhi; ravin de Khrami; Kojbaani et Gorana; Krtsanisi; Kutaisi $n^{0} 1$; Kutaisi $\mathrm{n}^{0} 2$; Martkopi; Mashavera; Mataani; Mtskheta $\mathrm{n}^{0} 1$; Mtskheta $\mathrm{n}^{0} 2$; Nichbisi ${ }^{0} 1$; Nichbisi $n^{0} 2$; Patara Dmanisi; Patara Lilo; Pitsunda; église de Pitsunda; lit de la rivière Rioni; Rodionovka; Rustavi; Rustavi; Samshvilde; Signagi; Sukhumi; Svaneti $\mathrm{n}^{0} 1$; Svaneti $n^{0} 2$; Tbilissi $n^{0} 1$; Tbilissi $n^{0} 2$; Tbilissi $n^{0} 3$; Tbilissi $n^{0} 4$; Tbilissi $n^{0} 5$; Tbilissi $n^{0} 6$; Tbilissi $n^{0} 7$; Tbilissi $n^{0} 8$; Tbilissi $n^{0} 9$; Tbilissi $n^{0} 10$; Tbilissi $n^{0} 11$; Tbilissi $n^{0} 12$; Tbilissi $n^{0} 13$; Tbilissi $n^{0} 14$; Tbilissi $\mathrm{n}^{0} 15$; Tbilissi-Avlabari $\mathrm{n}^{0} 1$; Tbilissi-Avlabari $\mathrm{n}^{0} 2$; TbilissiGanjiskari $n^{0} 1$; Tbilissi-Ganjiskari $n^{0} 2$; Tbilissi Metekhi bridge; Tbilissi Ortachala; Tsalka; Tsikhisdziri; Tskhneti; Ujarma; Vedjini; Zhinvali $\mathrm{n}^{0} 1$; Zhinvali $\mathrm{n}^{0} 2$.

\section{Vers 1251-1300}

Akhaldaba; Arukhlo; Boslebi; Dmanisi; rivière Iori; Kardanakhi; Kheoba $\mathrm{n}^{0} 1$; Kheoba $\mathrm{n}^{0} 2$; Korbouli $\mathrm{n}^{0} 1$; Korbouli $\mathrm{n}^{0} 1$; rivière 
Kura; rivière Kura à proximité de Tbilissi; Kutaisi $\mathrm{n}^{0} 1$; Kutaisi $\mathrm{n}^{0}$ 2; Manavi; Nojiskhevi; Rekhi; Shalauri; Suzi et Zeda Sazano;

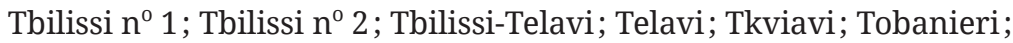
Ujarma; Zhinvali; Zhinvali-Khertvisi.

Pièces concaves en or $\mathrm{XI}^{\mathrm{e}}$ à XIII ${ }^{\mathrm{e}}$ siècle

Dzansul; Gubi; Ozurgeti; Racha.

\section{Vers 1301-1350}

Avchala; Borjomi; Darchieti; Dedoplistskaro; Djandara; Dmanisi; Grigolati; Kheiti $\mathrm{n}^{0} 1$; Kheiti $\mathrm{n}^{0} 2$; Kodala; Korbouli; Leliani; Pantiani; Patara Gomarteli; Phoka; Signagi; Skhlata; Tbilissi $\mathrm{n}^{0} 1$; Tbilissi $n^{0} 2$; Tbilissi ${ }^{0} 3$; Tbilissi ${ }^{0} 4$; Uraveli; Vazisubani.

\section{Vers 1351-1400}

Bodbe; Bolnisi; Gjukutau; Karagach $n^{0} 1$; Karagach $n^{0} 2$; Karagaji; Kvemo Machkhaani; Podaani; Sukhumi; Tbilissi $n^{0} 1$; Tbilissi $n^{0} 2$; Tbilissi $\mathrm{n}^{0}$ 3; Tobanieri; Tolo.

\section{Hulaguides-Ilkanides-Mongols XIII ${ }^{\mathrm{e}}$-XIV ${ }^{\mathrm{e}}$ siècles}

Chachari; Dzegvi; Jandara; Kakabeti; Lagodekhi; Sabatlo; Sartichala; Tbilissi; Tsintskaro; Vashlovani.

\section{Monnaies géorgiennes "Kirmaneuli tetri " XIII ${ }^{\mathrm{e}}$-XXIV ${ }^{\mathrm{e}}$ siècles}

Akhaltsikhe; Ali; Ambrolauri; Besleti; Chkhikvta; Cholevi; Dusheti; Gogasheni; Gori; Kobuleti; Kopitnari; Koreti $\mathrm{n}^{0} 1$; Koreti $\mathrm{n}^{0} 2$; Krasnaya Besletka; Kutaisi $n^{0} 1$; Kutaisi $n^{0} 2$; Kutaisi $n^{0} 3$; Kutaisi $\mathrm{n}^{0} 4$; Kutaisi $\mathrm{n}^{0} 4$; Kvitiri $\mathrm{n}^{0} 1$; Kvitiri $\mathrm{n}^{0} 2$; forteresse de Lori; Manea; Nojiskhevi $\mathrm{n}^{0} 1$; Nojiskhevi $\mathrm{n}^{0} 2$; Ochamchira; Patara Jikhaishi; Poti; Sairme; Sukhumi $n^{0} 1$; Sukhumi ${ }^{0} 2$; Sukhumi $n^{0} 3$; Sukhumi $n^{0} 4$; Sukhumi ${ }^{0} 5$; Tamishi $n^{0} 1$; Tamishi $n^{0} 2$; Tbilissi; Tobanieri; Tsebelda and Kraevich; Tsikhisdziri; Vardzia; Zugdidi.

\section{Vers 1401-1450}

Akhaldaba $n^{0} 1$; Akhaldaba $n^{0} 2$; Ali; Almati; Borchalo; Boshura; Chailuri; Dmanisi; Kakheti; Kopitnari; Patara Dmanisi; Patskhiskhevi; Tbilissi $\mathrm{n}^{0} 1$; Tbilissi $\mathrm{n}^{0} 2$; Uraveli; Varkhana and Abastumani.

\section{Vers 1451-1500}

Didgori; Sakobo; Tamarasheni; Tbilissi.

\section{Vers 1501-1550}


Gori; Mna. 


\section{Les grands traits de la suprématie mongole en Azerbaïdjan et en Transcaucasie} Shahin Mustafayev

Dans l'histoire du Moyen-Orient et du Caucase, la période des invasions puis de la domination mongoles, qui a duré environ deux cents ans, continue d'alimenter les débats et les appréciations contradictoires. Ce n'est pas un hasard. Gengis Khan et la pax mongolica, l'empire universel qu'il a instauré, constituent l'un des phénomènes clés de l'histoire mondiale. Après ces conquêtes, le monde ne pouvait plus revenir à son état antérieur, les Mongols ayant bouleversé le destin historique de quantité de régions et de peuples; il y a aussi la soudaineté avec laquelle ils sont apparus sur la scène historique. Surgis des profondeurs de l'Asie centrale, ils ont conquis en un rien de temps les empires les plus puissants de l'Eurasie, dont les habitants, sauf exception, ignoraient auparavant jusqu'à leur existence. Pour bien des nations conquises, y compris celles du Caucase, les Mongols étaient si mal connus, si exotiques, si différents par leur culture, leur mode de vie et leur apparence, qu'ils ont donné naissance à une foule de mythes et de légendes ${ }^{1}$.

1. De fait, la première rencontre avec les Mongols a été un choc pour les peuples chrétiens et musulmans de la région. Le moine arménien Grigor Aknertsi, dans l'ouvrage qu'il leur a consacré, les désigne comme " la nation des Archers ». Il dresse d'eux le portrait suivant: "Les premiers à attaquer notre pays n'avaient pas forme humaine. Ils étaient affreux à voir et impossibles à décrire. Ils avaient la tête énorme d'un buffle, les yeux fendus d'un poussin, le nez camus d'un chat, la mâchoire saillante d'un chien, la taille fine d'une fourmi et les pattes courtes d'un porc. Ce sont des êtres entièrement glabres, forts comme des lions, et dont la voix 
À ce titre, les conséquences ethniques, culturelles et religieuses des conquêtes mongoles en Azerbaïdjan et en Transcaucasie présentent nombre d'aspects intéressants.

$\mathrm{Au}$ Moyen-Orient et dans le Caucase, ces conquêtes interviennent au plus fort de la confrontation régionale entre islam et christianisme. Les sanglantes croisades entre chevaliers venus d'Europe occidentale et souverains musulmans qui se disputent la Terre sainte durent alors depuis plus d'un siècle. Les peuples caucasiens, si éloignés qu'ils soient de la Palestine, y sont également impliqués, dans un camp comme dans l'autre. Les rois chrétiens de Géorgie et les souverains arméniens de Cilicie apportent régulièrement leur soutien aux principautés latines du Levant, tandis que les atabegs turciques d'Azerbaïdjan s'allient aux grands adversaires des croisés - les atabegs d'Alep et de Mossoul, et les sultans seldjoukides d'Asie Mineure. Quant aux peuples de Ciscaucasie, on en trouve des représentants dans les rangs de l'armée mamelouk qui, en Syrie et en Égypte, se bat contre les principautés latines. Pendant ces années de confrontation exacerbée entre l'islam et le christianisme, un événement imprévu vient donc faire basculer toute l'histoire du Moyen-Orient et du Caucase. Il s'agit des terribles Mongols surgis des steppes d'Asie centrale qui, dans la première moitié du XIII ${ }^{\mathrm{e}}$ siècle, viennent asservir une multitude de peuples et de tribus et, au sein du grand espace eurasien, créent l'empire le plus vaste de toute l'histoire de l'humanité, un empire qui s'étend de la Chine jusqu'à l'Europe orientale.

La chronologie de la conquête mongole du Caucase est très bien connue. Après avoir vaincu l'État le plus puissant du monde musulman - l'empire des Khorezm-shahs - , le corps expéditionnaire mongol commandé par les lieutenants Djebé et Soubotaï part à la poursuite du dernier Khorezm-shah, envahissent l'Iran, attaquent l'Azerbaïdjan et la Transcaucasie en 1220. On ne saurait contester les conséquences dévastatrices de ces premières conquêtes mongoles pour les peuples locaux, conséquences dont témoignent de nombreuses sources primaires, y compris chez les Mongols eux-

est aussi perçante que celle de l'aigle. Ils ne connaissent pas la mort et peuvent vivre trois cents ans. " (Grigor Aknerts'i, History of the Nation of Archers, New Jersey, Long Branch, 2003, p. 3.) 
mêmes. Rachid al-Din, grand-vizir et historien des Ilkhanides, admet que, depuis les débuts de l'humanité, " aucun souverain n’avait pu conquérir autant de pays que Gengis Khan et sa famille, ni fait autant de morts qu'eux ${ }^{2}$ ». Ce sort n’a pas été épargné au territoire caucasien. Parmi les villes d'Azerbaïdjan dont la popula-

2. Rachid al-Din, Jami at-Tawarikh (texte persan et traduction russe), vol. 3, Bakou, Izdatel'stvo Akademii Nauk Azerbaijanskoi SSR, 1957, pp. 556-557 du texte persan. Pour une meilleure compréhension du volume, voici une liste d'autres translittérations trouvées dans des sources françaises et qui pourraient être préférées à celles choisies ici:

Abaga: Abaka, Apagha, Abaqa

Abchéron: Apsheron

al-Din ou al-Daoula (en fin de nom): ad-Din, ad-Daoula

Arbil: Erbil, Irbil

Ardabil: Ardebil, Artavil

Beïlagan: Baïlaqan, Beïlékân, Baïlagan, Béloucoum

Derbent: Derbend, Daruband

Djebé: Djebe

Dokouz-Khatoun: Dôkhouz-Khathoun, Doquz Qatun

Erevan: Erivan

Ghaïkhatu: Ghaykhatou

Gandja (ville d'Azerbaïdjan): Gandja, Gendge

Gantzac (ville d'Arménie): Gandzak, Ganjak,

Güyük: Gouyouk

Héthoum: Hethoum, Hethum

Hatchen: Khatchen

Houlagou: Hulagu, Hülegü, Houlavou

Kartli: Karthli, Karthlie, Kartalinie

Khan Baliq: Khanbalik, Cambaluc

Khorezm: Kharezm, Kwarezm

Kirakos Gandzaketsi: Kiragos, Kiracos de Gantzac

Kubilaï: Koubilaï, Khubilaï

Lascha: Lasha, Lacha

Mar Yaballaha: Mar Yahbalaha

Mengu Timur: Mengü Temür

Möngke: Mongke, Mongka, Mangu, Mancou

Nauruz: Nowruz, Nevrouz, Naûroûz

noïon: noyon, noyan

Ögödei: Ögedey, Ögödeï

Rousoudan: Roussoudane

Sembat: Smbat, Sempad

Soubotaï: Süböteï

Tchormagan: Tchormaghan

Teküder: Taghudar

Vartan: Vardan, Vardan Areveltsi 
tion est exterminée par les Mongols lors de la campagne de Djebé et de Soubotaï, les sources mentionnent Zendjan, Qazvin, Maragha, Ardabil, Beïlagan, Barda, Gandja ${ }^{3}$.

Ayant ravagé le territoire de l'Azerbaïdjan par le feu et par le glaive, les Mongols prennent leurs quartiers d'hiver dans la steppe du Moughan. Selon Kirakos Gandzaketsi, ils y entreposent tout leur butin dans une zone marécageuse située entre Barda et Beïlagan, très probablement à la confluence de la Koura et de l'Araxe, d'où ils lancent des raids sur diverses zones du pays à des fins de pillage ${ }^{4}$. Au début de l'année 1221, Djebé et Soubotaï passent en Géorgie, ayant apparemment appris qu'une offensive commune était ourdie contre eux par Özbeg, l'atabeg d'Azerbaïdjan, par Malik Ashraf, souverain ayyoubide d'Akhlat, et par le roi Georges Lascha de Géorgie ${ }^{5}$. Selon Vartan,

des hordes à l'aspect étrange, au langage inconnu, sortirent de la contrée de Tchïn et Matchïn. Leur nom était Mongol (Mough'al) et Tartare (Thathar). Elles pénétrèrent par les vallées de la contrée de Koukark', du côté des Agh'ouans, au nombre d'environ vingt mille hommes. Elles massacrèrent tout ce qu'elles rencontrèrent d'êtres vivants et s'en revinrent avec rapidité. Lascha, s'étant mis sur leurs traces avec toutes ses troupes, les atteignit près du fleuve Guesdman; mais il eut le dessous et il dut chercher son salut dans la fuite ${ }^{6}[\ldots]$.

En janvier ou février 1221, une féroce bataille oppose les Mongols à l'armée géorgienne menée par Georges Lascha. Vaincus, les détachements géorgien et arménien doivent se replier ${ }^{7}$. Ensuite les

3. Selon A.A. Alizade, Gandja n'a pas souffert pendant la première campagne de Djebé et de Soubotaï, à qui les habitants avaient versé une rançon, et n’a été détruite que pendant la " seconde invasion mongole " menée par Tchormagan en 1231 (A. A. Alizade, Social’no-ekonomičeskaja i političeskaja istorija Azerbajdžana XIII-XIV vv., Bakou, Izdatel'skij dom Kavkaz, 2012, pp. 102-103).

4. Kirakos Gandzaketsi, Histoire d'Arménie, in M. Brosset, Deux historiens arméniens: Kiracos de Gantzac et Oukthanès d'Ourha, Saint-Pétersbourg, Académie impériale des sciences, 1870, p. 100.

5. A. A. Alizade. op. cit., p. 98-99.

6. Vartan, in E. Dulaurier, «Les Mongols d'après les historiens arméniens. Extrait de l'histoire universelle de Vartan ", Journal asiatique (oct.-nov. 1860), p. 273-322, ici p. 278.

7. Notons que, de façon générale, les événements des conquêtes mongoles en Transcaucasie sont présentés de façon très contradictoire dans les sources locales. Même les chroniques géorgiennes de la Kartlis Tskhovreba ne s'accordent pas 
Mongols reviennent vers Tabriz, dont les habitants leur versent une rançon, prennent et détruisent Maragha vers la fin du mois de mars, marchent sur Diyarbakir et Erbil. Ils passent le printemps à Hamadan où, dit-on, ils répriment un soulèvement des citadins, puis retournent en Azerbaïdjan où ils s'emparent de nouvelles terres et multiplient les massacres ${ }^{8}$. Djebé et Soubotaï écrivent alors à Gengis Khan pour savoir s'il juge bon qu'ils poursuivent leurs conquêtes pendant un an ou deux, avant de retraverser le Caucase pour rentrer en Mongolie ${ }^{9}$.

De fait, les Mongols prennent et pillent alors Ardabil, Nakhitchevan, Khoï, Salmas, Beïlagan, puis traversent le territoire du Chirvan pour atteindre Derbent, dévastant tout sur leur passage, y compris Chamakha, la capitale du Chirvan, et tuant les habitants qui ne se sont pas enfuis ${ }^{10}$. Ils échouent à faire tomber Derbent

entre elles sur l'issue de la bataille entre Géorgiens et Mongols. Ainsi l'auteur de la Chronique des cinq règnes, sans nommer les Mongols et en se bornant à les désigner comme des "troupes étrangères ", mentionne deux victoires du roi Georges Lascha sur eux - d'abord à la bataille de Somkhiti et d'Hereti, où il reçut sa première blessure mais put mettre en fuite l'ennemi, " et ceux qui tentaient de s'échapper furent exterminés »; l'année suivante, quand les ennemis "revinrent dresser leurs tentes sur les rivages de Bardavi ", c'est-à-dire de Barda, dans la région de la Koura, il les mit à nouveau en déroute et « ils se replièrent en traversant Daruband [Derbent] " (cf. Kartlis Tskhovreba. A History of Georgia, Tbilissi, Artanuji, 2014, pp. 204-205). D'après le contexte, il est évident qu'il s'agit du premier raid de Djebé et de Soubotaï. Chose importante, l'auteur de la chronique est un contemporain des événements décrits, puisqu'il prie pour la santé de la reine Rousoudan qui a alors succédé à Georges Lascha son frère (ibid.). La Chronique de cent ans, en revanche, mentionne une défaite cuisante de l'armée géorgienne lors d'une bataille près de la rivière "Berdudji, aujourd'hui appelée Sagimi " (très probablement la Zegamtchaï en Azerbaïdjan). D'après l'auteur, "la colère du Très-Haut s'abattit sur nous pour tous nos péchés et notre peu de foi, et les Géorgiens prirent la fuite, de même que leurs soldats et le roi Lascha. Bien des âmes chrétiennes périrent ce jour-là. » (ibid., p. 321) Après quoi les Mongols atteignirent Samchvildé, "puis rebroussèrent chemin et firent une chose merveilleuse: ils prirent la route de Daruband ", passèrent les " portes " de la ville et pénétrèrent dans la "Qivtchakia », les steppes ciscaucasiennes qui, à l'époque, appartenaient aux Qiptchaqs (ibid.).

8. Alizade, op. cit., p. 100.

9. J. A. Boyle (éd.), The Cambridge History of Iran, Cambridge, Cambridge University Press, 1968, vol. 5, p. 311.

10. Rachid al-Din, Jami at-Tawarikh, op. cit., p. 557-558 du texte persan; Alizade, op. cit., $p$. 102-103. 
et doivent franchir la crête du Caucase par des sentiers de montagne, occasion de nombreuses batailles contre des tribus locales. Ils parviennent néanmoins à gagner les steppes ciscaucasiennes, où ils affrontent l'armée réunie des Alains et du peuple turcique des Qiptchaqs. Ayant conclu un accord avec les Qiptchaqs, Djebé et Soubotaï infligent une lourde défaite aux forces des Alains, mettant fin à l'existence du royaume alain en Ciscaucasie. Beaucoup d'Alains sont tués, d'autres se cachent dans des zones montagneuses et inaccessibles. Alors les Mongols ravagent les camps des Qiptchaqs, qu'ils chassent des steppes ciscaucasiennes vers celles situées au nord de la mer Noire. Djebé et Soubotaï traversent ensuite la région de la Volga pour regagner la Mongolie, où ils rapportent à Gengis Khan leurs victoires et l'ouverture de nouvelles terres de conquête.

Contemporain de ces événements, Ibn al-Athir a dressé un tableau haut en couleur des ravages provoqués par le corps expéditionnaire mongol dans sa rapide traversée du Caucase en direction du nord. Lorsque les " Tartares ", comme il les appelle,

n'eurent plus à s'occuper des possessions des musulmans dans l'Azerbéidjân et l'Arrân, ayant fait la conquête d'une portion et ayant conclu la paix avec le reste, ils marchèrent vers le pays des Géorgiens, situé également de ce côté. Les Géorgiens s'étaient préparés d'avance à leur résister. Ils firent marcher une armée considérable vers les frontières de leur pays, afin d'en repousser les Tartares. Mais ceux-ci les ayant rencontrés et attaqués, ils ne tinrent pas ferme et prirent la fuite; les Tartares en firent un grand carnage, et il n'en échappa qu'un petit nombre qui se virent réduits à errer çà et là. [...] Les Kifdjaks [Qiptchaqs] et les Russes essuyèrent une déroute complète, après que les Tartares eurent fait parmi eux un grand carnage. Beaucoup de fuyards furent massacrés; et un très petit nombre d'entre eux parvinrent à s'échapper. Tout ce qu'ils avaient avec eux fut pillé. [...] Les Tartares les poursuivirent, tuant, pillant et dévastant, de sorte que la plus grande partie du pays fut abandonnée de ses habitants ${ }^{11}$.

L'étape suivante de la conquête mongole du Caucase est liée à la figure du général Tchormagan-noïon, bras droit de Gengis Khan, que Kirakos Gandzaketsi décrit comme un "grand chef, commandant

11. Ibn al-Athir, Kamel-Altevarykh, in Recueil des historiens des Croisades. Historiens orientaux, t. II, ${ }^{\text {re }}$ partie, Paris, Imprimerie nationale, 1887, p. 161. 
l'armée, se distinguant par son amour de la justice ${ }^{12}$ ». Son expédition vers l'est est entreprise sur l'ordre du Grand Khan Ögödei contre Djalal al-Din, dernier représentant de la dynastie anushtiginide des Khorezm-shahs, qui a fui le Khorezm devant la menace mongole mais est parvenu à recréer son royaume au Moyen-Orient, avec l'Azerbaïdjan pour centre. En 1231, Djalal al-Din est cependant vaincu par une alliance des Seldjoukides d'Asie Mineure et des Ayyoubides, puis tué peu après. Tchormagan ne rencontre donc pas de résistance sérieuse à l'est, ce qui aurait été le cas du vivant de Djalal al-Din, car ce dernier et son armée " formaient une digue entre l'islam et les Tartares. Une brèche ayant été ouverte dans ce rempart, ni les Ayyoubides et les Seldjoukides n'étaient à même de contenir le déferlement ${ }^{13}$."

Après la prise du Khorassan, de Rey et d'Ispahan, les Mongols envahissent l'Arran (également nommé " Aghovanie » ou "Agvank » - l'Albanie caucasienne, comme on la désigne dans les sources en langue arménienne) et plantent leurs tentes dans la steppe fertile du Moughan, dont ils font leur base d'hiver et une tête de pont pour leurs conquêtes dans toute la Transcaucasie. "Aux approches de l'hiver, ils s'en allèrent dans la plaine du Moughan, au pays d'Aghovanie, où ils passaient la saison des frimas, puis se dispersaient de tous côtés au printemps ${ }^{14}$. " Bientôt sont prises Gandja, Chamkhor, Lori, Doumanis, Tiflis, Ani, Kars et autres villes, où les Mongols dépouillent les habitants "de leurs biens et propriétés, massacrent, dévastent, détruisent les beautés de la ville, réduisent le peuple en esclavage ${ }^{15}$ ". Les zones conquises, selon Vartan, sont partagées entre généraux mongols. Tchormagan notamment s'empare des régions d'Ani et de Kars, Tchaghata reçoit le district de Lori, Dolat reçoit la forteresse de Kaen, Gataga met la main sur les zones septentrionales du Haut-Karabagh et sur

12. Kirakos Gandzaketsi, Histoire d'Arménie, op. cit., p. 137.

13. J.A. Boyle (éd.), The Cambridge History of Iran, op. cit., vol. 5, p. 335.

14. Kirakos Gandzaketsi, Histoire d'Arménie, op. cit., p. 129.

15. Ibid., p. 128 (traduction adaptée). 
Kédabag, Molar prend en partage la forteresse de Chamkhor et son district ${ }^{16}$.

La Transcaucasie finit par devenir une partie du territoire mongol lors de son rattachement à l'Empire ilkhanide instauré en 1256 par Houlagou Khan, petit-fils de Gengis Khan.

Le principe fondamental des Mongols dans les pays conquis consiste à établir un rapport de forces qui garantisse leur hégémonie politique. En règle générale, ils détruisent résolument toute trace des institutions antérieures et créent leur propre système de contrôle dans les pays qu'ils gouvernent directement. Les conséquences d'une telle politique s'observent bien en Azerbaïdjan, où cette gouvernance directe a peu à peu gommé tous les vestiges du système politique remontant à l'ère seldjoukide. L'Azerbaïdjan représente par ailleurs le cœur de l'Empire ilkhanide, et les vastes possessions de l'Empire mongol au Moyen-Orient sont administrées depuis Maragha, puis Tabriz. Dans les régions devenues vassales et tributaires, les Mongols sapent lentement mais sûrement le système politique antérieur en créant une dualité de pouvoir, ou en mettant en rivalité les souverains locaux. Cette bonne vieille méthode est mise en pratique dans bien des pays subordonnés, par exemple dans le sultanat seldjoukide d'Asie Mineure, dont elle finira par provoquer l'effondrement. Dans le Caucase, elle est appliquée au Chirvan et en Géorgie. Les Mongols s'abstiennent ainsi de détruire entièrement les structures de l’État géorgien et maintiennent au pouvoir la dynastie locale des Bagratides. Mais dans les années 1240, deux rois différents montent sur le trône, tous deux nommés David. L'un, fils de la reine Rousoudan, reçoit le surnom de David Oulou (" l'Aîné "), l'autre, neveu de la reine et fils de son frère Georges Lascha, celui de David Narin ( "le Cadet »). Cette dualité de pouvoir provoque à terme le démembrement de la Géorgie en une partie orientale (le Kartli),

16. Vartan, in E. Dulaurier, « Les Mongols d'après les historiens arméniens. Extrait de l'histoire universelle de Vartan », op. cit., p. 283. Grigor Aknertsi, lui, écrit que les Mongols « tinrent sur l'ordre de Tchormagan un quriltaï, c'est-à-dire une grande assemblée, et répartirent les terres entre leur cent dix chefs. Notre pays fut divisé en trois parties: l'une au nord, l'autre au sud, et une dernière au centre du pays, laquelle reste encore en leur possession. " (Grigor Aknerts'i, History of the Nation of Archers, op. cit., p. 5) 
avec David l'Aîné pour roi, et en une partie occidentale, l'Imérétie, sur laquelle règne David le Cadet. Selon les usages politiques mongols, le droit de gouverner ne peut cependant être conféré que par le chef suprême de l'Empire: le Grand Khan tant que cet empire reste encore indivis, ce qui oblige les candidats au trône à se rendre personnellement à Karakorum, ou plus tard auprès des Ilkhans de Tabriz, après la partition de l'Empire en plusieurs ulus.

L'existence politique arménienne, à l'époque, est incarnée par le royaume de Cilicie, situé dans le sud de l'Anatolie. Il est aux mains des dynasties rubénide puis héthoumide. Le souverain cilicien Héthoum $\mathrm{I}^{\mathrm{er}}$ s'est vite rendu compte que seule une alliance avec les Mongols pouvait le préserver de la menace qu'ils représentaient. En 1247, il envoie donc son frère Sempad à la cour du Grand Khan Güyük, à Karakorum. En 1253 il se rend lui-même en Mongolie, où il est reçu par le Grand Khan Möngke, successeur de Güyük. Möngke lui garantit l'intégrité du royaume cilicien, et lui promet aussi d'exempter d'impôt églises et monastères arméniens sur tout le territoire mongol ${ }^{17}$.

Dans l'ensemble, la noblesse chrétienne du Caucase et de l'Anatolie, représentée par les rois géorgiens, les souverains arméniens de Cilicie et les princes de l'ancienne Albanie caucasienne, ou principauté de Hatchen, se soumettent bien vite à la suzeraineté mongole, se montrent loyaux à son égard, et tentent d'exploiter la protection de l'aristocratie mongole chrétienne pour renforcer leurs propres positions politiques, ainsi que celles de l'Église. Un autre souverain chrétien, Hasan Djalal al-Daoula, qui est un de ces princes chrétiens du Hatchen dans le Haut-Karabagh, doit lui aussi faire acte de vassalité. Vers 1257, il accompagne Sartak, fils du khan de la Horde d'or Batou, jusqu'à la cour de ce dernier. Les Mongols entérinent son pouvoir sur le Hatchen et accordent «à Ter Nersès, catholicos d'Aghovanie, un diplôme de franchise, pour tous ses biens et propriétés ${ }^{18} »$. Hasan Djalal al-Daoula et son épouse Mama

17. K. M. Setton (éditeur général), A History of Crusades, vol. II: The Later Crusades, 1189-1311, éd. R.L. Wolff et H.W. Hazard, Madison (Milwaukee) et Londres, The University of Wisconsin Press, 1969, p. 652-653.

18. Kirakos Gandzaketsi, Histoire d'Arménie, op. cit., p. 173. 
Khatoun sont également connus pour avoir fait construire l'église du monastère de Sandzasar au Karabagh, remarquable exemple d'architecture chrétienne locale dans la période mongole. Elle est consacrée en 1240, en présence de nombreux prêtres dont Nersès, catholicos d'Albanie. Le monastère restera la résidence et le sépulcre de la famille de Hasan Djalal al-Daoula, ainsi que la demeure des catholicos d'Albanie.

La noblesse chrétienne de Transcaucasie cherche également à renforcer son alliance avec les Mongols par l'établissement de liens matrimoniaux. Les mariages sont nombreux entre membres des dynasties chrétiennes et aristocrates mongols. La fille de Hasan Djalal, par exemple, Rouzoukan, épouse Bora, fils de Tchormagan; le roi David fils de Georges Lascha épouse la noble Esougan-Khavand, une parente de Tchormagan; Tamar, sœur du roi géorgien Démétré, est mariée au fils de l'émir mongol Arghoun; Rousoudan fille de Démétré, au fils de l'émir Bougha; le roi Vakhtang épouse la sœur d'Arghoun Khan, Oldjat, qui se remariera ensuite avec le roi David successeur de Vakhtang, etc ${ }^{19}$.

La Transcaucasie et en particulier l'Azerbaïdjan occupent une position centrale au sein de l'Empire ilkhanide, dont ils forment le cœur métropolitain. Houlagou, fondateur de l'empire, avait choisi Maragha puis Tabriz pour capitales, et pour quartier d'hiver l'Arran en Azerbaïdjan du nord, le "Karabagh d'Arran " comme on l'appelle dans les sources persanes. Y ont également lieu plusieurs intronisations de khans suprêmes selon la coutume des steppes turco-mongoles. C'est par exemple au Karabagh que Ghazan Khan monte sur le trône ilkhanide en novembre 1295. D'après Rachid al-Din,

toutes les dames de la cour (khavatin), les princes, les seigneurs de guerre (oumara), les piliers du pouvoir et hauts courtisans se rassem-

19. R.G. Bedrosian, The Turco-Mongol Invasions and the Lords of Armenia in the 13-14th Centuries, Columbia University, 1979, p. 189-190. Ces alliances matrimoniales, cependant, ne garantissent pas toujours la sécurité des souverains chrétiens ou musulmans ni leur maintien au pouvoir. Le même Hasan Djalal al-Daoula, par exemple, sera victime de l'hostilité de l'émir mongol Arghoun: arrêté, il est cruellement torturé et mis à mort à Qazvin en 1260. Le même sort frappe plusieurs autres souverains chrétiens du Caucase qui avaient fait allégeance aux Ilkhanides. 
blèrent au Karabagh d'Arran et, sans faux-semblants ni hypocrisie, saluèrent le règne du souverain de l'islam [Ghazan Khan] et s'engagèrent à le respecter ${ }^{20}$.

De toutes les régions de la Transcaucasie, les Mongols préfèrent en effet l'Azerbaïdjan, ou plutôt le territoire de l'Arran et du Karabagh, ainsi que le Chirvan où ils passent l'essentiel des mois d'hiver. Ils y trouvent leurs distractions habituelles, parmi lesquelles la chasse. Ghazan Khan passe ainsi l'hiver 1301-1302 au Karabagh mais, au lieu de s'y attarder, il se rend ensuite dans les montagnes du Chirvan et du Daghestan méridional, où il chasse pendant plusieurs jours. Après quoi il gagne le district de Gavbari, près de Derbent, pour s'adonner à la chasse aux oiseaux, essentiellement des cygnes, et à la pêche. Car la côte forme à cet endroit une baie que les Mongols appellent en turcique Koush-koïoun, et les oiseaux migrateurs y sont à l'époque nombreux. Les chefs des tribus montagnardes du Daghestan voisin viennent y rejoindre Ghazan Khan et lui prêter allégeance. Ils reçoivent l'ordre de capturer et d'exécuter les fuyards d'Azerbaïdjan qui sont allés se cacher des Mongols dans les hauteurs inaccessibles de la Transcaucasie, ce qui est fait. Ayant fini de chasser des oiseaux et de pêcher, Ghazan Khan se rend à Bilassouvar puis dans la région de Talish et d'Ispahbad, où a également lieu une partie de chasse grandiose. Il fait fabriquer une immense barrière de poteaux et de broussailles (divar ez chub ve khashak), coudée en son milieu et longue d'une journée de marche, vers laquelle ses guerriers rabattent ensuite le gibier — buffles des montagnes, chèvres et ânes sauvages, chacals, loups, ours et autres prédateurs - , qui se trouve pris au piège dans le renfoncement. Assis sur une estrade, Ghazan Khan et son épouse bien-aimée Boulghan Khatoun admirent ce spectacle d'un gigantesque « zoo ». Après quoi certains animaux sont tués, les autres relâchés ${ }^{21}$.

La Transcaucasie conservera son attrait pour l'élite mongole jusqu'après la période ilkhanide. L'émir Tchoban en particulier, célèbre régent du dernier grand Ilkhan Abou Saïd, choisit ses herbages d'été dans la région du Göktche-deniz (l'actuel lac Sevan),

20. Rachid al-Din, Jami at-Tawarikh, op. cit., p. 301-302 du texte persan.

21. Ibid., p. 344-345 du texte persan. 
« qui à la belle saison était vraiment un lieu de toute beauté22 ». On sait qu'après la chute de la dynastie houlagide, les grands clans mongols commencent à se disputer le pouvoir dans l'ancien territoire ilkhanide; ils s'affrontent entre autres dans le nord de l'Azerbaïdjan. En 1344 a ainsi lieu dans la steppe d'Akhstabad une bataille sanglante entre les troupes du tchobanide Malik Ashraf et celles de ses rivaux, les émirs Yagibasty et Sourgan. Malik Ashraf en sort vainqueur, asseyant sa suprématie en Azerbaïdjan pour treize années de suite. Selon la coutume des souverains mongols, il continue de faire du Karabagh son séjour préféré pour les quartiers d'hiver. Les chroniqueurs nous apprennent en effet que, dès l'hiver 1344-1345, il se trouve avec sa suite dans le Karabagh où Kavous, souverain du Chirvan, vient lui prêter allégeance. Malik Ashraf le reçoit avec de grands honneurs. Mais son caractère ombrageux et sa cruauté effraient tellement le Chirvan-shah que ce dernier prend secrètement la fuite. Comme l'hiver touche à sa fin et qu'il est temps de quitter le Karabagh, Malik Ashraf ne se risque pas à lancer une opération militaire contre lui, et retourne à Tabriz. Mais en 1346-1347, la ville est frappée par une terrible épidémie, écho de la " peste noire " qui ravage alors l'Europe. Elle fait une multitude de morts en Azerbaïdjan, et la cour mongole se réfugie dans les montagnes. Avant l'hiver, Malik Ashraf est de retour au Karabagh, d'où il décide d'attaquer le Chirvan et de punir le félon Kavous. Ce dernier a toutefois le temps de traverser la Koura avec ses troupes, ce qui oblige Malik Ashraf à conclure une trêve et à se replier. Pendant l'hiver 1347-1348, le tchobanide atteint enfin son but. Depuis le Karabagh où il se trouve à nouveau, il envoie au Chirvan une armée commandée par son vizir. Incapable de mettre sur pied une résistance, Kavous s'enferme dans une place forte avec sa suite, pendant que les troupes mongoles mettent le pays à feu et à sang ${ }^{23}$.

Parmi les conséquences des conquêtes mongoles en Azerbaïdjan et en Transcaucasie, il faut relever en premier lieu une modification significative de la situation ethnique. À la veille de l'expansion

22. Zayn ad-Din ibn Hamdallah Qazwini, Zail-i tarikh-i guzida, tr. russe de M.D. Kazimov, Bakou, Elm, 1990, p. 96.

23. Ibid., p. 96-102 
mongole, la population turcique était prédominante dans les plaines de l'Arran et du Moughan, comme il ressort de plusieurs sources primaires, notamment l'ouvrage de géographie persan Adjaïb aldouniya et la chronique d'al Nazawi. On trouvait une population plus mélangée dans certaines zones du Chirvan et à Derbent, avec une importante composante caucasienne et iranophone, ainsi que dans le Haut-Karabagh et surtout dans la principauté de Hatchen, où les chrétiens étaient majoritaires. Pendant les campagnes de Houlagou puis sous le règne des Ilkhanides, de nouvelles tribus (aymaks) de Mongols et de Turcs venus d'Asie centrale affluent dans ces territoires où, pour la plupart, elles vont s'établir et faire souche. Les sources révèlent un bouleversement de la composition ethnique dans le Caucase à la suite des conquêtes. Il tient d'abord, nous l'avons vu, à la réduction massive de la population locale à l'arrivée des Mongols, quand des villes et des régions entières sont dévastées et que leurs habitants soit périssent, soit prennent la fuite. Dans le même temps, on constate une augmentation considérable de la population turcique et mongole qui, constituant le parti vainqueur, se voit attribuer de nouveaux lieux de résidence. Pour renforcer les frontières nord de l'Empire contre la Horde d'or, par exemple, Houlagou Khan envoie les Qiptchaqs, ancienne garde turcique du califat, s'installer dans la région de Derbent et du Chirvan. Ils quittent alors Bagdad et se dirigent avec leurs familles vers le Caucase. Mais après avoir franchi l'Euphrate, ils obliquent vers la Syrie pour rejoindre les mamelouks, turciques eux aussi et ennemis des Mongols ${ }^{24}$. On sait aussi que le premier gouverneur ilkhanide de l'Arran et du Chirvan, Iaschmout fils de Houlagou Khan, s'est établi dans ces régions avec des troupes subordonnées ${ }^{25}$.

Ces processus, dans leur ensemble, ont contribué à un renforcement significatif de l'élément turcique en Azerbaïdjan et dans d'autres zones de la Transcaucasie, étant donné que la plupart des Mongols, comme on sait, se turcisent rapidement et s'intègrent aux milieux turciques locaux après leur conversion à l'islam. Pendant

24. Rachid al-Din, Histoire des Mongols de la Perse, tr. E. Quatremère, t. I, Paris, Imprimerie royale, 1836, p. 411-415.

25. Ibid., p. 403. 
son voyage du Kouhistan au Caucase, début 1281, le poète Nizari observe ainsi une forte concentration de troupes mongoles sur la route des caravanes. Entre Sarai et Bakou, la voie est barrée pendant dix jours par une armée mongole menée par Abaga Khan parti en campagne contre Mengu Timur, khan de la Horde d'or. Les vallées de l'Arran, note Nizari, fourmillent d'hommes de "l'armée des Turcs " (il s'agit des guerriers ilkhanides), qui à eux tous mettent un mois à franchir la Koura ${ }^{26}$. Les sources montrent amplement que les généraux mongols (noïons) nommés dans la région prennent leur service accompagnés de troupes à eux, souvent constituées de guerriers tribaux et de leurs vastes familles. Selon les chercheurs, une vingtaine de grandes tribus mongoles se seraient installées sur le territoire de l'Azerbaïdjan aux XIII ${ }^{\mathrm{e}}$ et XIV ${ }^{\mathrm{e}}$ siècles, parmi lesquelles les Süldüs et les Djalaïr ${ }^{27}$.

Aujourd'hui encore, de nombreux toponymes mongols rappellent la présence de ces tribus en Azerbaïdjan et leur rôle dans la formation ethnique de la nation azerbaïdjanaise moderne. Sans même quitter la petite péninsule d'Abchéron sur laquelle est implantée la capitale Bakou, on constate combien l'élément mongol a pénétré en profondeur les couches ethniques et culturelles de l'Azerbaïdjan ${ }^{28}$. Ainsi Soumgaït, l'une des principales villes du pays, tire son nom des Sugaut (Sagait), une de ces tribus mongoles. Et la ville n'est qu'à trente kilomètres de Bakou. Près de Soumgaït, on trouve le village de Djorat (du nom de la tribu des Djoïrat). Citons aussi, dans les environs, le village de Sarai (qu'on rapprochera de Sarai Berke, capitale de la Horde d'or, pour ne citer qu'un exemple). Au sud de Bakou, la ville d'Alat, qui devient aujourd'hui un site portuaire et industriel

26. Cité dans S. Ashurbeyli, Gosudarstvo širvanshahov (VI-XVI- vv.), Bakou, Elm, 1983, p. 159.

27. V. Piriev, Azarbaycan XIII-XIV asrlarda, Bakou, Nurlan, 2003, p. 261.

28. On notera que la péninsule d'Abchéron était l'un des herbages d'hiver choisis par les souverains ilkhanides. Ghazan Khan par exemple passe l'hiver 1297-1298 à Bakou. Venu de Tabriz avec son camp, il y arrive le 7 novembre 1297. En chemin, il a envoyé l'émir Kutlugshah en Géorgie, où des rumeurs faisaient état de troubles, et bientôt Kutlugshah ramène avec lui Vakhtang, frère du roi David de Géorgie. Vakhtang reçoit une récompense de l'ilkhan et est renvoyé chez lui. Ghazan Khan reste environ quatre mois à Bakou et, en avril, repart pour Tabriz via Bilassouvar (Rachid al-Din, Jami at-Tawarikh, op. cit., p. 324-325 du texte persan). 
majeur, est également nommée d'après la tribu mongole des Alat. Une telle concentration de toponymes mongols sur le territoire d'Abchéron n'est pas accidentelle: nombre de tribus y trouvaient leurs herbages d'hiver et ont fini par s'y implanter.

L'apparition de nouveaux noms de lieu n'est pas seulement due aux tribus mongoles qui se sont établies en Azerbaïdjan et y ont fait souche: c'est toute une strate toponymique qui a recouvert le territoire dans son ensemble. Très souvent, les anciens toponymes ont été soit abandonnés, soit utilisés en concurrence avec les nouveaux. Rachid al-Din évoque par exemple la bataille entre l'Ilkhanide et les armées de la Horde d'or dans le territoire de l'Arran, sur les rives de l'Aksu, dont le nom mongol était Tchagan Mouran. En fait, ce nom est un calque du toponyme turcique signifiant " eau blanche " ou « rivière blanche ${ }^{29}$. L'historien cite aussi, dans le sud de l'Azerbaïdjan, la Zerineh-roud « qui, chez les Mongols, porte le nom de Tchagatou-Nagatou ${ }^{30}$ ». Ce toponyme s'emploie encore dans la région d'Ourmia.

Il faut également noter que, après les dévastations accompagnant l'expansion mongole dans sa phase initiale, une œuvre de construction grandiose est ensuite entreprise dans la région sous les Ilkhanides. On trouve notamment une abondante documentation sur l'essor de Maragha, de Tabriz, et sur la fondation de la nouvelle capitale de l'Empire - Sultaniye. Ce sont très probablement aussi les Mongols qui ont fondé dans l'Arran une ville neuve, SaraiMansouriye. En tout cas, les ilkhans y passaient souvent l'hiver. Il est possible qu'ils aient simplement modernisé le village plus haut cité de Sarai, près de Soumgaït. Le fait que Sarai ne se trouve pas sur le territoire de l'Arran historique mais sur la péninsule d'Abchéron ne doit pas nous troubler, car les Mongols considéraient souvent le Chirvan comme faisant partie de l'Arran. Mais l'hypothèse reste à étayer. Quoi qu'il en soit, la ville de Sarai-Mansouriye était très prisée des souverains ilkhanides, qui s’y rendaient souvent. Les Mongols ont encore fondé d'autres agglomérations dans ce qui est aujourd'hui le nord de l'Azerbaïdjan. Le 31 mars 1294, nous apprend

29. Ibid., p. 104 du texte persan.

30. Rachid al-Din, Histoire des Mongols de la Perse, op. cit., p. 401. 
Rachid al-Din, Ghaïkhatu Khan a fondé sur les rives de la Koura une grande ville à laquelle il a donné le nom de Kutlugh-Balygh, ce qui signifie en turc "Ville heureuse (ou bénie) ${ }^{31}$ ». Il faudrait sans aucun doute que des historiens et archéologues modernes s'attachent sérieusement à rechercher des traces de cette ville.

Si les Mongols ont contribué à façonner l'image actuelle du peuple azerbaïdjanais, ce n'est pas seulement grâce à l'influence profonde exercée pendant la période ilkhanide sur les processus politiques et économiques locaux, mais aussi grâce à l'évolution qu'ils ont provoquée dans les traditions ethniques et culturelles des Azerbaïdjanais. Il n'est peut-être pas exagéré de dire que, sans cette période mongole dans l'histoire du Moyen-Orient et du Caucase, le panorama ethnique et culturel ne serait pas ce qu'il est aujourd'hui dans la région, et plus particulièrement en Azerbaïdjan. Il suffit de mentionner que l'essor et la diffusion rapides d'une littérature en langue turcique d'Azerbaïdjan ont justement été le fruit de cette période mongole. La conscience ethnique et la culture turciques ont prospéré sous les Ilkhanides et dans les États postmongols qui hériteront de leurs traditions.

La domination mongole a eu des effets tout aussi profonds sur la vie spirituelle et religieuse des peuples locaux. De façon générale, toute la conquête du Moyen-Orient a entraîné des conséquences mélangées pour les communautés musulmanes et chrétiennes, au Caucase comme ailleurs. Pour l'islam, la prise de Bagdad par les Mongols en 1258, l'assassinat du dernier calife et la destruction du califat ont été une catastrophe d'ampleur universelle. Elle a désintégré non seulement le système politique régissant le monde musulman depuis l'époque du Prophète, mais aussi toute sa structure idéologique et spirituelle. Les musulmans restaient atterrés et accablés par la perte de ce centre légitime du pouvoir islamique que représentait le calife. Cette catastrophe a eu des effets extrêmement durables sur le sort du monde musulman, qui ne retrouvera sa puissance et son intégrité qu'avec l'essor de l'Empire ottoman au début du XvI ${ }^{\mathrm{e}}$ siècle. En même temps, la fermentation idéologique et spirituelle qui a suivi la chute du califat a ouvert la voie à la diffusion de

31. Id., Jami at-Tawarikh, op. cit., p. 238 du texte persan. 
courants hétérodoxes au sein de l'islam, à la progression du chiisme et, au bout du compte, à la formation de l'État chiite safavide dans les territoires musulmans centraux.

Pour les chrétiens du Moyen-Orient, la période mongole a d'abord été une époque d'enthousiasme et d'espoir, suivie d'une cruelle déception. La plupart des Mongols, tel Gengis Khan luimême, étaient des païens adeptes du chamanisme turco-mongol ${ }^{32}$. Beaucoup d'entre eux avaient également adhéré au bouddhisme répandu par les Ouïghours, les Tibétains, les Chinois, les Indiens. Toutefois, un certain nombre de tribus comme les Kerait, les Naiman, les Merkit, les Öngüt, ainsi qu'une part importante des Khara-Khitaï, étaient de confession nestorienne, et l'on trouvait parmi ces nestoriens quantité de personnalités influentes ${ }^{33}$. Dans la période immédiatement postérieure à la conquête du Moyen-Orient et du Caucase, les Mongols, par politique, s'appuient sur l'élément chrétien et plus généralement non musulman pour administrer les pays conquis, ces populations ayant été pendant longtemps soumises à la domination musulmane, ce qui les porte à soutenir le nouveau pouvoir. Les Arméniens de Cilicie, les Géorgiens et les chrétiens nestoriens d'Azerbaïdjan et de Perse sont donc pro-mongols ${ }^{34}$.

On ne s'étonnera pas qu'à leur première apparition dans le Caucase, les Mongols, jusque-là inconnus des peuples autochtones, aient suscité une foule de rumeurs contradictoires qui ont semé le trouble et l'indécision dans les milieux chrétiens locaux ${ }^{35}$. La rapide

32. Cf. J.A. Boyle, "Turkish and Mongol Shamanism in the Middle Ages ", in Folklore, vol. 83, $\mathrm{n}^{0} 3$ (automne 1972).

33. A.Š. Kadyrbajev, «Vo Imja very hristovoj ", in Transcaucasica Vypusk 1 (2013), p. 57-68, ici p. 57.

34. K. M. Setton (éd.), A History of Crusades, op. cit., vol. II, p. 720. De l'aveu de Stéphannos Orbélian, Houlagou Khan qui instaura l'Empire ilkhanide montrait « tant d'affection pour les chrétiens, que tous les peuples fidèles se soumirent avec plaisir et lui prêtèrent l'assistance la plus active » (Stéphannos Orbélian, Histoire de la Siounie, tr. M. Brosset, Saint-Pétersbourg, Académie impériale des sciences, 1864, p. 227).

35. Sur la dynamique historique de la perception des Mongols et des autorités mongoles par les chrétiens du Caucase, voir Z. Pogossian, « Armenians, Mongols and the End of the Times ", in J. Tubach, S. G. Vashalomidze et M. Zimmer (éd.), Caucasus during the Mongol Period - Der Kaukasus in der Mongolenzeit, Wiesbaden, Reichert Verlag, 2012, p. 169-198. 
victoire des Mongols, non musulmans, sur les Khorezm-shahs, qui étaient à l'époque les souverains les plus puissants du monde islamique, avait insufflé aux chrétiens l'espoir qu'ils trouveraient en eux des alliés dans leur lutte contre les "Sarrasins ». Dans les chroniques tant arméniennes que géorgiennes, on constate une certaine bienveillance à l'égard des Mongols. Un historien arménien les décrit par exemple comme " connaissant la foi chrétienne et chérissant singulièrement ses sectateurs ${ }^{36}$ ". La Chronique de cent ans, une source géorgienne, affirme quant à elle:

Ils étaient riches de sagesse en tout genre, pleins de raison et de retenue. Il n'y avait pas place chez eux pour le mensonge; ils ne pliaient devant aucun homme, qu'il fût grand ou petit, ni devant aucune institution; ils s'en remettaient au bon ordre fondé par Gengis Khan ${ }^{37}$.

En outre, selon Kirakos Gandzaketsi, le bruit courait " qu'ils étaient mages ou chrétiens de religion, qu'ils faisaient des miracles et venaient pour venger les chrétiens de la tyrannie des musulmans ». Désarmés par ces rumeurs, les chrétiens ne prenaient pas de mesures sérieuses pour se protéger, si bien que, « un prêtre de village étant sorti au-devant [des Mongols] avec ses ouailles, la croix en tête, ils mirent le sabre au poing et massacrèrent tout ${ }^{38}$ ".

Les Mongols eux-mêmes, malgré leur puissance et l'émoi qu'ils provoquaient chez les peuples du Moyen-Orient et du Caucase, n'étaient qu'un énorme grumeau dans le moulin de la confrontation historique entre les deux civilisations présentes sur place - le christianisme et l'islam. Tôt ou tard, ils devaient être «moulus ». Restait seulement à savoir dans quel camp ils se rangeraient. La rivalité acharnée entre chrétiens et musulmans locaux pour convertir les Mongols à leur religion allait finalement déterminer le destin historique de la région. Les écrits des auteurs chrétiens et musulmans témoignent amplement de cette rivalité. L'apparition en Europe de la légende de Jean le Presbytérien, par exemple, ne fait que refléter l'ardent désir des chrétiens de trouver dans les Mongols des alliés

36. Stéphannos Orbélian, Histoire de la Siounie, op. cit., p. 226.

37. Kartlis Tskhovreba. A History of Georgia, Tbilissi, Artanuji, 2014, p. 318.

38. Kirakos Gandzaketsi, Histoire d'Arménie, op. cit., p. 100. 
inattendus mais providentiels, qui porteraient la mission des croisades à son terme logique et replanteraient la croix en Terre sainte.

Il faut donc prendre en compte la politique religieuse des Mongols et leurs relations avec les diverses confessions du MoyenOrient si l'on veut bien comprendre le rôle qu'a joué la suprématie mongole dans l'histoire du Caucase aux XIII ${ }^{\mathrm{e}}$ et XIv ${ }^{\mathrm{e}}$ siècles. Comme l'écrit Bartold:

Dans tous les territoires mongols, chrétiens, bouddhistes et musulmans luttaient pour gagner les khans à leur cause; mais l'hostilité entre chrétiens et bouddhistes n'était rien à côté de leur haine commune de l'islam, qu'ils combattaient souvent ensemble. Les premiers khans, encore adeptes du chamanisme, restaient neutres dans cette lutte, n'intervenant que si elle troublait trop gravement la paix publique; seuls certains d'entre eux, sous l'influence de leurs conseillers chrétiens et bouddhistes, prenaient des mesures à l'encontre des musulmans. Dès qu'un khan mongol se montrait hostile aux musulmans (comme Djaghataï, Güyük, Kubilaï, Baïdu), le bruit courait qu'il était chrétien; de même pour les khans qui (comme Möngke) accordaient équitablement leur protection à toutes les religions $\mathrm{s}^{39}$.

Ainsi Stéphannos Orbélian rapporte que le Grand Khan Möngke était un authentique chrétien, qui "avait dans son palais une grande pièce où était une église, avec des prêtres, célébrant sans interruption la liturgie et le saint sacrifice "; il aimait beaucoup les chrétiens, " et tout le pays professait le christianisme ${ }^{40}$ ".

La formation de l'Empire ilkhanide en 1256 ne modifie pas immédiatement l'attitude du gouvernement mongol face aux chrétiens locaux. Ces derniers continuent d'espérer qu'ils vont y gagner un puissant protecteur dans leur lutte contre les musulmans. La bienveillance des premiers Ilkhanides à leur égard s'observe dès le règne de Houlagou Khan. Beaucoup d'auteurs l'attribuent à l'influence de Dokouz-Khatoun, son épouse et aînée. Selon Rachid al-Din, DokouzKhatoun serait la petite-fille de Ong Khan, chef des Kerait. C'est une femme ambitieuse et puissante qui, étant nestorienne, soutient activement les chrétiens et leur permet d'atteindre des positions

39. V.V. Bartold, " Musul'manskije izvestija o čingizidah-khristianah », in id., Sočinenija, tome II, 2, Moskva, Nauka, 1964, p. 263.

40. Stéphannos Orbélian, Histoire de la Siounie, op. cit., p. 230. 
influentes dans l'Empire ilkhanide ${ }^{41}$. L'un des dignitaires chrétiens ainsi parvenu à une haute position grâce à la protection des Ilkhanides est le prince siounide Sembat. Vassal du roi David de Géorgie, il « le servit très fidèlement ", nous dit Stéphannos Orbélian, " et lui rendit auprès d'Houlavou-Ghan [Houlagou Khan], de ses grands et surtout du grand divan, les services les plus signalés ", car " il jouissait d'un tel crédit auprès d'Houlavou, qu'il faisait mourir ceux qu'il voulait et accordait grâce de la vie à d'autres ${ }^{42}$ ». Houlagou suit le conseil de Dokouz-Khatoun et bâtit des églises sur tous ses territoires; une chapelle ambulante suit partout le camp de sa femme et l'on y sonne les cloches ${ }^{43}$. Ce témoignage de Rachid al-Din est confirmé par Vartan. Selon l'historien arménien, Dokouz-Khatoun était une chrétienne syriaque ou nestorienne. Sans connaître toutes les subtilités de la doctrine chrétienne, elle vouait comme Houlagou un amour sincère à tous les chrétiens, leur montrait de la considération et sollicitait leurs prières. La cour transportait en permanence " une tente en toile, ayant la forme d'une église ", des prêtres et des diacres célébraient chaque jour les offices et la messe au son des cloches et des chants; il y avait aussi

des écoles et des instructions pour les enfants, qui s’y rendaient en toute liberté. Là vivaient tranquillement des ecclésiastiques accourus de tous les pays, de chez les chrétiens de toute langue. Venus pour demander la paix, ils l'obtenaient, et puis s'en retournaient satisfaits et avec des présents ${ }^{44}$.

Le même auteur note qu'après la prise de Bagdad par les Mongols, la population chrétienne de la capitale du califat est épargnée grâce à l'intercession " de la grande reine Dôkhouz ${ }^{45}$ ». Celle-ci ne survit que trois mois à son mari, et sa mort est amèrement pleurée par les sujets chrétiens de l’Empire ilkhanide. Car elle « espérait

41. Rachid al-Din, Histoire des Mongols de la Perse, op. cit., p. 93.

42. Stéphannos Orbélian, Histoire de la Siounie, op. cit., p. 236.

43. Rachid al-Din, Histoire des Mongols de la Perse, op. cit., p. 95.

44. Vartan, in E. Dulaurier, « Les Mongols d'après les historiens arméniens. Extrait de l'histoire universelle de Vartan ", op. cit., p. 290-291.

45. Ibid., p. 291. 
voir le christianisme prendre de plus en plus d'éclat ", et " tous les progrès qu'il fit, c'est à elle qu'il faut les attribuer ${ }^{46}$ ".

Quant à Abaga Khan (1265-1282) qui monte sur le trône après son père Houlagou, Stéphannos Orbélian le décrit comme un être plein de bonté et de douceur, épris de paix et ami des chrétiens ${ }^{47}$. De fait, cet ilkhan leur accorde lui aussi sa protection. Tarsaïdj notamment, frère et successeur du prince siounide Sembat, a toute sa confiance. C'est du moins ce qu'affirme le même Stéphannos Orbélian qui, Tarsaïdj étant de sa famille, cherche à le mettre en valeur et verse visiblement dans l'exagération: Abaga Khan, d'après lui, "le considérait tellement que plus d'une fois il se dépouilla des insignes du trône pour l'en revêtir de la tête aux pieds, et le fit ceindre de sa ceinture toute d'or, enrichie de pierreries précieuses et de perles ${ }^{48}$ ".

Le bref règne de l'ilkhan Teküder (1282-1284) déconcerte la population chrétienne de Transcaucasie qui y voit un mauvais signe, Teküder étant le premier Ilkhanide à se convertir à l'islam sous le nouveau nom d'Ahmad. Il faut croire que ses croyances religieuses sont assez éloignées de l'islam orthodoxe car, d'après Rachid alDin, il révère les cheikhs soufis, en particulier Abd al-Rahman qu'il appelle "père ", et place tout près de lui Ishan Mengli, disciple de Baba Yaqub d'Arran, un autre cheikh soufi. Mengli habite à proximité du camp de Teküder qui vient souvent le voir, l'appelle " frère " (karyndash) et, avec les derviches, s'adonne à la musique et à la danse (sema') ${ }^{49}$. Mais, à la suite de querelles intestines, Teküder est renversé et Arghoun (1284-1291), fils d'Abaga Khan, monte sur le trône ilkhanide à Tabriz. Les historiens arméniens sont unanimes à chanter les louanges de cet « homme doux, bon et pacifique, aimant aussi les chrétiens ${ }^{50}$ ".

L'un des exemples les plus frappants d'interpénétration culturelle, au cours de cette période, est sans doute l'histoire de deux

46. Ibid., p. 309.

47. Stéphannos Orbélian, Histoire de la Siounie, op. cit., p. 235.

48. Ibid., p. 236.

49. Rachid al-Din, Jami at-Tawarikh, op. cit., p. 173 du texte persan.

50. Stéphannos Orbélian, Histoire de la Siounie, op. cit., p. 235. 
moines nestoriens venus d'Extrême-Orient au Moyen-Orient dans la seconde moitié du XIII ${ }^{\mathrm{e}}$ siècle. Il s'agit de Rabban Bar Çauma et de Rabban Marcus. Selon Bar Hebraeus, ils étaient tous deux d'origine ouïghour ${ }^{51}$, même si la tradition chinoise laisse plutôt penser qu'ils auraient pu être des Öngüt chrétiens, tribu turcique ralliée aux Mongols ${ }^{52}$. En pèlerinage vers les lieux saints, Bar Çauma et son jeune disciple Marcus sont chaleureusement reçus à Maragha, en Azerbaïdjan, par Mar Denha Ier, patriarche de l'Église nestorienne. Bientôt Marcus est ordonné évêque et, après la mort de Mar Denha $\mathrm{I}^{\mathrm{er}}$ en 1281, il reprend ses fonctions sous le nom de Mar Yaballaha III. La vraie raison de cette ascension rapide n'est pas tant son ardente et sincère dévotion que son origine ouïghour ou turco-mongoles, et le fait qu'il arrive de Khan Baliq (l'actuel Pékin), capitale de l'Empire mongol (des Yuan). Patriarche nestorien plein d'expérience, Mar Denha a dû se dire que les affinités ethnoculturelles du jeune moine avec les Mongols pouvaient grandement bénéficier à l'Église nestorienne et à la propagation du christianisme parmi eux. De fait, Bar Çauma et Marcus sont bien accueillis à Maragha par l'ilkhan Arghoun, qui approuve le choix de Marcus comme nouveau patriarche. Quant à Bar Çauma, en 1287 il est envoyé en ambassade en Europe pour conclure une alliance francomongole contre les mamelouks. Là, il négocie avec le pape Nicolas IV, Philippe le Bel, Édouard Ir d'Angleterre et autres monarques européens. Les premiers Ilkhanides montrent donc tant de bienveillance à leurs sujets chrétiens, et surtout nestoriens, que les années 1258-1295 seront considérées comme une période faste pour l'Église nestorienne ${ }^{53}$.

L'orientation plutôt antimusulmane de la politique mongole, dans la première période qui suit la conquête, promeut l'élévation d'autres éléments non musulmans dans l'Empire ilkhanide, juifs compris. Un exemple illustre en serait Saad al-Daoula, de confes-

51. Th. Nöldeke, Sketches from Eastern History, tr. John Sutherland Black, LondresÉdimbourg, Adam et Charles Black, 1892, p. 249-250.

52.J.R.S. Phillips, The Medieval Expansion of Europe, $2^{\mathrm{e}}$ éd. Oxford, Clarendon Press, 1998, p. 82.

53. Ibid., p. 79. 
sion juive, qui devient ministre des Finances puis grand-vizir d'Arghoun Khan. Dans le nouvel appareil d'État ilkhanide auquel il donne forme, un nombre significatif de dignitaires sont des juifs ou des chrétiens. Ainsi ses frères Fahr al-Daoula et Amin al-Daoula sont nommés gouverneurs (hakim) des principales villes de l'Empire - Bagdad et Diyarbakir - et son cousin, grand inspecteur des Finances (mushrif) à Tabriz. Mais cela ne peut que susciter le rejet et les protestations de la bureaucratie musulmane. Lorsqu'Arghoun tombe subitement malade et meurt, Saad al-Daoula est accusé d'avoir empoisonné l'ilkhan, et exécuté. Tous ses protégés sont éliminés en même temps que lui ${ }^{54}$.

Cependant, la supériorité numérique des musulmans au MoyenOrient et en particulier en Azerbaïdjan, cœur de l'Empire ilkhanide, devait tôt ou tard faire pencher la balance en leur faveur dans cette rivalité entre l'islam et les autres religions. Les Ilkhanides n'allaient pas échapper longtemps à l'influence de la culture musulmane. Cette tendance de fond dans l'évolution culturelle des Mongols au Moyen-Orient est bien illustrée par le parcours de l'ilkhan Baïdu qui, à la suite de nouvelles querelles intestines, succède à Ghaïkhatu. Chrétien à l'origine, il se convertit à l'islam. À la fin du XIII siècle, note à juste titre Stéphannos Orbélian, tous les Mongols ou presque auront «abandonné leurs institutions nationales et embrassé la religion musulmane ${ }^{55}$ ". Le règne de Ghazan Khan (1295-1304) marque la conversion définitive à l'islam des Mongols du MoyenOrient et du Caucase, qui aura une influence décisive sur toute l'évolution culturelle et politique de la région.

De façon générale, la conquête mongole a suscité dans cette région l'émergence d'un panorama ethnique, culturel et religieux étonnamment varié. Les mosquées y avoisinent couramment des églises chrétiennes de diverses obédiences, et des synagogues. Mais les Mongols ont ajouté à ce panorama un élément entièrement nouveau qui, jusque-là, n'était pas caractéristique de la vie religieuse des peuples locaux: des temples bouddhistes. On en construit alors en grand nombre, comme en témoignent les sources. Rachid al-

54. Rachid al-Din, Jami at-Tawarikh, op. cit., p. 217-226 du texte persan.

55. Stéphannos Orbélian, Histoire de la Siounie, op. cit., p. 261. 
Din évoque ainsi la construction par Houlagou Khan de " temples d'idoles " (butkhane), c'est-à-dire de temples bouddhistes, à Khoï dans le sud de l'Azerbaïdjan ${ }^{56}$. Il est également question d'un temple bouddhiste à Maragha. Lors de la cérémonie religieuse qui y est tenue en présence de toute la cour mongole, Abaga Khan y annonce des décisions publiques majeures ${ }^{57}$. On peut supposer que d'autres temples de ce genre sont érigés dans l'Arran, où la cour ilkhanide prend ses longs quartiers d'hiver. Le bouddhisme, nous le savons, n'a pourtant pas fait souche en Azerbaïdjan ni ailleurs dans le Caucase, et est seulement resté la religion d'une partie des conquérants mongols. Sous le règne de Ghazan Khan puis d'Oldjaïtu, fin $\mathrm{XIII}^{\mathrm{e}}$-début XIV ${ }^{\mathrm{e}}$, l'islam reprend ses positions, et tous les temples bouddhistes sont brûlés au feu de la " revanche " musulmane.

Les moines bouddhistes ont néanmoins exercé une très forte influence sur les premiers ilkhans. Selon le témoignage de Vartan, Houlagou lui-même accordait une foi aveugle à " ceux que les Tartares appelaient Touïn ", et qui étaient en fait des lamas tibétains arrivés en Azerbaïdjan avec les Mongols; " leurs oracles décidaient s'il devait ou non marcher au combat ${ }^{58}$ ". Vartan a personnellement rencontré Houlagou Khan qui l'a chaleureusement reçu pendant le quriltaï, "mois de fêtes ", explique l'historien arménien, où se tiennent diverses assemblées. Il observe que, tout en traitant les chrétiens avec respect et affection, Houlagou lui-même n'était pas chrétien. Bien au contraire, il s'en remettait beaucoup trop aux moines bouddhistes - les Touïn, ces « astrologues » et « faux prêtres " d'une idole appelée Schagmonia qui, assure l'historien, ont trompé le Grand Khan en lui serinant: " Tu vivras longtemps dans le corps que tu animes; et, lorsque tu seras parvenu à une extrême vieillesse, tu revêtiras un corps nouveau ${ }^{59}$ ". On sent bien ici l'aversion du moine chrétien pour l'un des concepts fondamentaux du bouddhisme tibétain - la doctrine de la renaissance ou de

56. Rachid al-Din, Histoire des Mongols de la Perse, op. cit., p. 401.

57. Id., Jami at-Tawarikh, op. cit., p. 160 du texte persan.

58. Vartan, in E. Dulaurier, « Les Mongols d'après les historiens arméniens. Extrait de l'histoire universelle de Vartan ", op. cit., p. 306.

59. Ibid. 
la réincarnation. Vartan ne peut toutefois s'empêcher de reconnaître " la force " des lamas bouddhistes qui, experts en divination et en tromperie, prétendaient pouvoir « faire parler des idoles de feutre et des chevaux ", mais étaient par ailleurs " tempérants dans leur nourriture, modestes dans leurs vêtements, partisans de la chasteté, réglés dans le mariage ${ }^{60} »$.

Arghoun Khan respecte le bouddhisme autant que son grandpère Houlagou. Selon Rachid al-Din, il accorde beaucoup de confiance aux moines bouddhistes (appelés bakshis dans la tradition musulmane) et à leurs règles, les protège et les soutient avec constance. Rachid al-Din attribue même la mort de son souverain à cette confiance excessive. Un jour, écrit-il, un certain bakshi venu d'Inde est arrivé en Azerbaïdjan et, présenté à Arghoun, lui a assuré pouvoir vivre très vieux grâce à la prise d'une drogue spéciale. Arghoun lui a alors demandé de lui préparer cette drogue, qui contenait une grande quantité de soufre et de mercure, et en a pris pendant huit mois. Elle a provoqué en lui une grave maladie dont il est mort un peu plus tard ${ }^{61}$.

Sous les premiers khans, le bouddhisme se propage vite dans les terres ilkhanides et surtout, bien sûr, parmi les Mongols eux-mêmes. Si le bouddhisme connaît un tel succès, explique Rachid al-Din, c'est parce qu'il était la croyance des ancêtres des Ilkhans. Beaucoup de moines bouddhistes venus d'Inde, du Cachemire, de Chine, du Turkestan oriental et du Tibet sont invités dans le pays et se font les prédicateurs de cet enseignement au Moyen-Orient ${ }^{62}$. Les bouddhistes forment un contingent important jusqu'à la réforme religieuse de Ghazan, à en croire ce qu'écrit Rachid al-Din sur les «idolâtres (butperestan), les infidèles (kuffar) et les Mongols, qui étaient plus nombreux que des grains de sable ${ }^{63}$ ". Musulmans et chrétiens locaux ne perçoivent en effet les bouddhistes que comme des idolâtres, dont la foi n'a rien à voir avec le monothéisme. Kirakos Gandzaketsi, qui se réfère aux récits de voyage du roi Héthoum de Cilicie, parle

60. Ibid., p. 306-307.

61. Rachid al-din, Histoire des Mongols de la Perse, op. cit., p. 194.

62. Id., Jami at-Tawarikh, p. 373 du texte persan.

63. Ibid., p. 377 du texte persan. 
d'un pays où «il y a quantité d'idolâtres, adorant de très grandes idoles en terre, nommées chakmounia-chakiamouni ${ }^{64}$ ".

L'éducation des princes ilkhanides est elle aussi entre les mains des bakshis bouddhistes. À l'âge de cinq ans, nous apprend Rachid al-Din, le futur ilkhan Ghazan est confié par son grand-père Abaga au bakshi Yaruka, un Chinois (ou un Ouïghour) qui l'instruit, lui apprend les lettres, les sciences et les « bonnes méthodes » mongoles et ouïghours ${ }^{65}$. Certaines sources indiquent que Ghazan a commencé par être un bouddhiste zélé. Au Khorassan, qu'il a gouverné dans sa jeunesse, il a fait bâtir de "magnifiques maisons d'idoles ", c'està-dire des temples bouddhistes. Il met tant de zèle à observer les préceptes de cette religion, à pratiquer la mortification de la chair et l'ascétisme religieux qu'il impressionne les moines eux-mêmes. Après sa conversion à l'islam en juin 1295, pourtant, Ghazan se met à autoriser la construction de centres religieux musulmans mosquées, madrassas et khanakas. À l'automne de la même année, il ordonne par décret que soient "détruits à Tabriz la capitale, à Bagdad et dans d'autres villes de l'islam tous les temples des bakshis (ma'abed-e bakhshiyan), les maisons d'idoles, les églises et les synagogues $^{66}$ ». Dans un premier temps, tous les moines bouddhistes doivent se convertir à l'islam, mais il apparaît bientôt que beaucoup, l'ayant fait sous la contrainte, n'adhèrent pas aux prescriptions de leur nouvelle foi et continuent en secret de pratiquer l'ancienne. À ceux qui refusent de devenir de loyaux musulmans, Ghazan Khan permet alors de quitter les frontières de l'Empire ilkhanide pour regagner leur terre natale - Inde, Cachemire, Tibet; les autres, sous peine de mort, devront renoncer à toute pratique clandestine du bouddhisme et professer sincèrement l'islam ${ }^{67}$.

Même après la conversion en masse des Mongols à l'islam sous Ghazan Khan, il semble qu'une partie de la haute noblesse, les épouses d'ilkhans (qu'on appelle les khatouns) et les grands généraux (émirs), très influents dans les affaires publiques, soient

64. Kirakos Gandzaketsi, Histoire d'Arménie, op. cit., p. 180.

65. Rachid al-Din, Jami at-Tawarikh, op. cit., p. 252 du texte persan.

66. Ibid., p. $300 \mathrm{du}$ texte persan.

67. Ibid., p. $397 \mathrm{du}$ texte persan. 
mécontents de ce changement radical d'orientation religieuse et culturelle. En tout cas, on observe des tentatives pour préserver ne serait-ce qu'une petite partie des monuments et édifices bouddhistes. Le fait est que même le temple bouddhiste bâti par Arghoun, père de Ghazan, est alors détruit. Ses parois intérieures étaient décorées de fresques représentant Arghoun en personne. Après la démolition du toit et de plusieurs murs, elles se trouvent exposées aux intempéries. Des représentants de la plus haute noblesse soumettent une requête à Ghazan Khan pour qu'il fasse restaurer le bâtiment: la neige et la pluie n'endommageront plus ces portraits, et l'esprit de son père en sera apaisé. Ghazan refuse. Alors ses courtisans lui demandent de faire au moins transformer l'ancien temple en palais, ce qu'il refuse avec autant de fermeté. Si ce temple est reconverti en palais, ces représentations humaines sur les murs le feront toujours ressembler à un temple, ce qui n'est pas bienséant. Si l'ilkhan a besoin d'un nouveau palais, ce dernier peut être construit ailleurs ${ }^{68}$.

On peut pourtant supposer que la conversion de Ghazan à l'islam n'a pas effacé de son âme toute trace du bouddhisme pratiqué avec tant de ferveur dans sa jeunesse. Dans ses dernières années du moins, surtout après la perte de sa jeune épouse Kérémoun Khatoun, il s'interroge sur le sens de la vie et le sacrement de la mort, et affirme à ses proches que

le salut de l'âme " implique qu'on se libère " de l'étroite nature ", car « il n'est pas de chaînes, de prisons, d'enfer ni de douleur pires que l'ignorance et l'attachement au monde, ne serait-ce que parce que le monde est un enfer pour le peuple de Dieu, et l'au-delà, un paradis ${ }^{69}$.

Ne reconnaît-on pas là les idées fondamentales de la philosophie bouddhiste, et en particulier la doctrine du refus de la mâyâ comme expression de la vie matérielle condamnant l'homme au cycle éternel de la souffrance, auquel il ne peut échapper qu'en se détachant des choses terrestres et en atteignant le nirvâna? Ce n'est sans doute pas pour rien que Rachid al-Din juge nécessaire de souligner que

68. Ibid.

69. Ibid., p. 366. 
" la soumission à Dieu et la foi du souverain de l'islam Ghazan Khan étaient sincères, libres et pures de la souillure du faux-semblant ${ }^{70}$ ".

Sa conversion à l'islam, et son ardeur de néophyte mise à observer les prescriptions de la nouvelle religion, n'ont cependant pas réussi à couper complètement Ghazan Khan de ses racines ethnoculturelles, des croyances et coutumes spirituelles des steppes mongoles. Il reste fidèle à d'anciens cultes païens turco-mongols et n'y voit pas de contradiction avec les exigences de l'islam. Certains de ces cultes ont d'ailleurs survécu jusqu'à nos jours dans les milieux turciques du Caucase et de l'Asie centrale, et l'on peut encore voir dans ces régions des "arbres sacrés ", aux branches ornées de rubans multicolores. Lors de la rébellion de l'émir Nauruz, rapporte Rachid al-Din, Ghazan Khan dut un jour camper en pleine nature, sans tente, avec quelques autres personnes, et s'installa au pied d'un grand arbre aux branches fournies. Pour chasser les angoisses spirituelles que lui causaient les événements, il s'absorba dans ses pensées à l'ombre de cet arbre, et une joie venue de l'autre monde ('alem-e gheyb) envahit son âme. Longtemps après, revenu au même endroit avec sa suite, il se souvint de l'incident et retourna près de l'arbre. Là, il relata son expérience aux siens et, touché, éclata en sanglots, tout en priant le Tout-Puissant et en lui promettant d'accomplir des bienfaits. Après quoi, lui-même et tous les présents nouèrent des rubans aux branches de l'arbre, qui allait par la suite devenir l'objet d'un culte sacré et un but de pèlerinage. Il convient de noter qu'après l'accomplissement de ce rituel, des « bouffons " firent de la musique et que les émirs se livrèrent à des danses. Danses et musique auxquelles Ghazan participa lui aussi. Il est évident que ce rituel relevait de l'ancienne tradition du chamanisme turco-mongol. L'émir Pulad Tchingsang qui, récemment arrivé de Mongolie, assistait à la scène, rapporte un cas similaire à propos de Kubilaï Khan. Pendant la campagne contre les Merkit, ce dernier s'approcha d'un arbre, descendit de cheval et récita une prière à l'" ancien dieu " (khoda-ye qadim) pour lui demander son aide et son intercession. Une fois l'ennemi vaincu, sur la route du retour, il retourna près de cet arbre qu'il décora, comme promis, de "robes colorées ", et dont

70. Ibid., p. 296. 
il fit également un lieu de pèlerinage. Puis il récita une prière d'action de grâce au Tout-Puissant et, avec ses guerriers, se livra à une danse rituelle. Pulad Tchingsang précise qu'ils tapaient si fort du pied que la terre en dessous de l'arbre était toute creusée ${ }^{71}$.

Quoi qu'il en soit, l'instauration de l'islam comme religion officielle de l'Empire ilkhanide à la fin du XIII ${ }^{\mathrm{e}}$ siècle a été un tournant dans l'histoire des Mongols au Moyen-Orient et dans le Caucase, à la suite duquel ils se sont peu à peu assimilés aux milieux turciques d'Azerbaïdjan et d'Anatolie, tandis que la culture musulmane retrouvait ses positions dans la région, y compris en Transcaucasie.

La domination mongole a néanmoins laissé une trace profonde et indélébile dans l'histoire de l'Azerbaïdjan et des peuples de Transcaucasie. Elle a mis fin à la structure politique du monde islamique, dont l'institution du califat formait le centre réel ou officiel. En fait, ces innovations ont transformé toute la philosophie politique de l'islam et l'évolution de ses formes étatiques pendant la fin du Moyen Âge. Par la suite, toutes les entités étatiques musulmanes ayant pour centre l'Azerbaïdjan, qui dominera l'histoire du MoyenOrient pendant encore deux siècles après la chute de l'Empire ilkhanide - avec les Djalaïrides, les Kara Koyunlu, les Ak Koyunlu, les premiers Safavides - , s'inscriront dans la lignée politique des Ilkhanides. Elles se développeront sans beaucoup se soucier des traditions politiques musulmanes qui avaient eu cours avant les Mongols. Dans les principautés chrétiennes de la Transcaucasie et de l'Anatolie orientale, la domination mongole a commencé par susciter de faux espoirs: ces nouveaux venus allaient les venger des musulmans, ressusciter l'Église chrétienne et favoriser son essor dans la région. Originaires eux-mêmes d'Asie centrale, très influencés par la culture extrême-orientale et les traditions des steppes, les Mongols ont globalement apporté au panorama religieux et culturel de la région des éléments nouveaux et jusque-là inconnus des peuples locaux. Le bref épanouissement du bouddhisme sous leur égide, en

71. Ibid., p. 350-351 du texte persan. 
Azerbaïdjan et en Iran, l'utilisation et la diffusion de l'alphabet ouïghour dans l'État pendant près de deux siècles, la pénétration des traditions picturales chinoises dans l'art et l'artisanat des peuples musulmans et chrétiens locaux, tout cela a contribué à introduire un plus grand pluralisme culturel en Azerbaïdjan et en Transcaucasie.

(Traduit de l'anglais par Diane Meur) 


\section{DEUXIÈME PARTIE}

\section{CROISEMENT DES LANGUES ET NATIONS DU CAUCASE}





\title{
Classification génétique et aréale des langues en Anatolie et dans le Caucase
}

\author{
Daniel Petit
}

La classification des langues a toujours posé un problème redoutable aux linguistes, tout particulièrement pour les langues qui ne sont qu'insuffisamment documentées ou pour lesquelles nous ne pouvons que spéculer sur leur localisation à date préhistorique ou parfois même historique. Pour l'Antiquité, nous avons des informations étendues sur les cultures grecque et latine et des sources relativement détaillées sur les cultures bordant la mer Méditerranée ainsi que sur le Proche-Orient et l'Anatolie ancienne, mais notre degré d'information sur des aires plus éloignées, comme le Caucase ancien, sont beaucoup plus limitées. Intuitivement, nous avons tendance à localiser les langues là où elles sont parlées aujourd'hui, à moins de disposer d'informations sur des migrations dans leur passé, et à transposer notre vision des langues modernes sur les périodes antérieures de l'histoire. Par ailleurs, si nous savons que différentes langues appartiennent à la même famille linguistique, nous construisons souvent un scénario pré-écrit à partir de ce que nous pouvons appréhender de la diffusion de l'ensemble de la famille. L'objet de cet article est de discuter des éléments qui nous permettent de comprendre la diffusion des langues dans l'Anatolie et le Caucase anciens. Mon domaine de recherche à proprement parler est celui des langues indo-européennes, mais je m'efforcerai d'aborder le problème dans une perspective plus large.

Tout d'abord, il convient d'attirer l'attention sur une difficulté préliminaire quand on étudie les proximités linguistiques, celle de 
déterminer la part relative à attribuer aux héritages communs en termes de classification génétique et la part qui est à attribuer aux convergences intensives en termes de contact linguistique. Ce défi est particulièrement difficile à affronter pour l'Anatolie et pour le Caucase dans la mesure où l'on a souvent admis que chacune de ces deux régions appartenait à une " aire linguistique " distincte. La notion d'" aire linguistique " (en allemand Sprachbund) renvoie au fait que des langues voisines, mais sans parenté linguistique présentent des traits phonologiques, morphologiques et syntaxiques comparables. L'idée d'un Sprachbund caucasique a été défendue par différents savants et fait toujours l'objet de discussions actuellement. D’un autre côté, la découverte des archives de l'Empire hittite au début du $x^{\mathrm{e}}$ siècle nous a rendu plus familières les langues de l'Anatolie ancienne, et l'on a vite noté des ressemblances frappantes entre le hittite, langue indo-européenne ancienne, et les autres langues de son environnement. D’une manière plus hypothétique, des tentatives ont été faites de reconstruire un lien organique entre les aires linguistiques du Caucase, d'une part, et de l'Anatolie, d'autre part. Plusieurs savants ont ainsi soutenu que certains des traits qui caractérisent la langue arménienne actuelle dérivent de l'impact de traits anatoliens anciens, la langue ourartéenne ayant servi de châ̂non intermédiaire. On a aussi prétendu qu'il existait des liens entre le hourrite et le hatti, deux langues parlées dans l'Anatolie ancienne, d'une part, et les familles caucasique de l'Est ou kartvélienne, d'autre part. La question que posent ces hypothèses est celle de l'extension des contacts linguistiques entre l'Anatolie et le Caucase et plus généralement celle de l'évolution des langues attestées dans les régions du Caucase au sens large.

L'Anatolie ancienne a une histoire complexe évoluant autour de trois cultures dominantes dans l'Antiquité. Au second millénaire avant notre ère, nous avons d'abord l'Empire hittite avec sa capitale Hattušaš. La langue hittite était une langue indo-européenne appartenant à la sous-famille appelée " anatolienne "; elle ne survécut pas à l'effondrement de l'Empire hittite autour du XIII siècle avant notre ère. Une langue apparentée était le louvite, parlé pour l'essentiel sur les marges occidentales et méridionales de l'Anatolie en tant que tel ou à travers ses représentants plus récents jusqu'au 
$\mathrm{I}^{\mathrm{er}}$ millénaire avant notre ère (lycien, lydien, carien, pisidien et sidétique). Une autre langue indo-européenne parlée en Anatolie, mais extérieure à la famille anatolienne, le phrygien, nous est connue sous deux formes et à deux époques différentes (paléophrygien et néophrygien) en Anatolie occidentale. Aucune de ces langues n'a survécu après les premiers siècles de l'ère chrétienne. D'autres langues parlées dans l'Anatolie ancienne n'appartiennent pas à la famille indo-européenne. Ce sont (a) le hatti, langue isolée d'affiliation incertaine, parlée dans les mêmes zones que le hittite et qui n'est documentée que par quelques mots et phrases dispersés dans les textes hittites; (b) le hourrite, parlé au sud-est de l'Anatolie et au nord de la Mésopotamie (principalement dans la région du Mitanni) et qui a été rapproché par certains savants du protocaucasique de l'est; et (c) l'ourartéen, qui paraît appartenir à la même famille que le hourrite (au sein d'une famille hourro-ourartéenne) et qui était parlé dans la région du lac de Van, en Anatolie orientale. Au sud de l'Anatolie, nous rencontrons des langues sémitiques, l'ougaritique, l'assyrien et l'éblaïte, ainsi que le sumérien, une langue isolée sans apparentement connu, parlée en Irak du sud. Ce panorama pourrait être complété par d'autres langues qui n'ont eu qu'une présence plus limitée en Anatolie, le grec ancien (sur les côtes de l'Asie Mineure et en Pamphylie) ainsi que l'indien ancien (sporadiquement attesté dans la région du Mitanni). Partant de ce panorama ancien, nous arrivons à l'Anatolie actuelle à travers deux événements linguistiques et culturels majeurs. Tout d'abord, il faut mentionner l'arrivée de populations iraniennes, probablement à partir d'Asie centrale, durant le second millénaire avant notre ère et la création d'empires iraniens étendus, en particulier de l'Empire perse, qui culmina durant la période achéménide (550-330 avant notre ère) dans ce qui forme aujourd'hui la Turquie et l'Iran, puis sur des territoires plus vastes. Le second événement majeur a été l'apparition des langues turques: originaires d'Asie centrale (voire de plus loin encore), elles conquirent une large partie de l'Anatolie au cours du Moyen Âge (entre les $\mathrm{VI}^{\mathrm{e}}$ et XI $\mathrm{XI}^{\mathrm{e}}$ siècles de notre ère).

Nous disposons de beaucoup moins d'informations sur la situation linguistique dans le Caucase ancien. La langue ancienne du

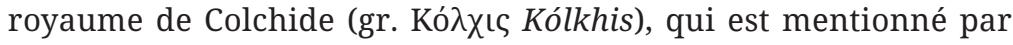


plusieurs auteurs grecs à partir du v $v^{e}$ siècle avant notre ère en rapport avec la légende de la Toison d'or, nous est inconnue, mais plusieurs auteurs ont supposé qu'elle devait appartenir à la famille kartvélienne, voire représenter une forme précoce de géorgien. Nous avons de nombreuses mentions des Arméniens durant l'Antiquité, notamment autour de la dynastie des Orontides ( $\mathrm{VI}^{\mathrm{e}}-\mathrm{II}^{\mathrm{e}}$ siècles avant notre ère), mais la langue arménienne elle-même ne nous est connue que plus tardivement, à partir du $\mathrm{v}^{\mathrm{e}}$ siècle de notre ère. Diverses sources anciennes remontant au premier millénaire avant notre ère nous renseignent sur d'autres peuples et langues, les Albaniens du Caucase, ancêtres linguistiques de la langue oudi moderne dans l'Azerbaïdjan actuel (ils sont appelés Ardhan dans les sources parthes), les Ibériens du Caucase dans la Géorgie actuelle (ils parlaient probablement une forme ancienne de géorgien). Enfin, il faut mentionner les Cimmériens, une population de langue iranienne, située autour de la mer Noire; leur localisation précise est mal définie, allant jusqu'à l'Ukraine actuelle et incluant différentes régions du Caucase.

Si l'on se tourne maintenant vers le Caucase moderne, il convient d'abord de rappeler que cette région est célèbre pour être un cas d'école de diversité linguistique. Dès le $\mathrm{x}^{\mathrm{e}}$ siècle de notre ère, un voyageur arabe, Ibn Haukal, signalait l'existence de 360 langues dans le Caucase, ce qui est très certainement une exagération, mais donne malgré tout l'idée d'une réelle diversité linguistique ${ }^{1}$.

Il existe dans le Caucase au moins cinq familles linguistiques: (a) le kartvélien (géorgien, laze, mingrélien et svane); (b) le caucasique du nord-est ou nakho-daghestanien (nakh, tchétchène, avar-andique, tsézique, lak, dargi, lezgi et khinalugh); (c) le caucasique du nord-ouest ou abkhazo-adyghéen (abkhaze, abaza, circassien et la langue oubykh, maintenant éteinte); (d) les langues turques (azéri, kumik); (e) les langues indo-européennes (arménien et différentes variétés d'iranien comme l'ossète, le kurde ou le tat). D’autres familles de langues sont également représentées de

1. J. Catford, "The classification of Caucasian languages ", in S. M. Lamb, E. D. Mitchell (ed.). Sprung from Some Common Source: Investigations into the Prehistory of Languages, Stanford, Stanford University Press, 1991, p. 232-268, ici p. 233. 
manière plus sporadique, comme les langues sémitiques (néo-araméen) et les langues mongoles (kalmyk). Des langues de superstrat dans certaines régions sont le turc, le persan, et plus récemment le russe. Tout cela est bien connu et je n'ai répété ces données que pour que chacune ait une vision claire de la diversité linguistique de cette région.

Ce qui résulte de cette présentation est la grande diversité linguistique de l'Anatolie ancienne, à quoi s'ajoutent des langues d'implantation plus récente (principalement iraniennes ou turques), et la diversité linguistique encore plus grande du Caucase moderne.

À la fois pour l'Anatolie ancienne et pour le Caucase moderne, de manière distincte, l'existence d'une aire linguistique a été postulée et l'attention s'est portée sur un nombre important de particularités linguistiques partagées par les langues de ces aires en dépit de leur affiliation génétique différente. La notion de Sprachbund, qui fut d'abord formulée dans les années 1930 pour l'aire balkanique, a été transposée par certains savants aux deux aires qui nous occupent ici. L’hypothèse d'un Sprachbund anatolien a été développée en particulier par Calvert Watkins (2008) ${ }^{2}$. Parmi les particularités partagées par le hittite et d'autres langues non-indo-européennes parlées dans l'Anatolie ancienne on peut relever les faits suivants:

1. Désonorisation des consonnes en position initiale absolue de mot: l'opposition des consonnes sourdes et sonores (par ex. T/D), probablement réalisée comme une opposition entre consonnes tendues et consonnes relâchées (par ex. TT ou DD/T ou D), a été éliminée au début du mot au profit du membre fort ou sourd (T-, ni *TT-, ni *D-, ni *DD-). Ce trait apparaît en hittite et en louvite (deux langues indo-européennes) ainsi qu'en hourrite (langue non-indo-européenne). En hittite ${ }^{3}$, les occlusives sourdes de l'indo-européen sont notées par des occlusives sourdes géminées, les occlusives sonores de l’indo-européen par

2. Calvert Watkins, "An Indo-European linguistic area and its characteristics: Ancient Anatolia. Areal diffusion as a challenge to the comparative method? ». in A.Y. Aikhenvald, R. M. W. Dixon (ed.). Areal Diffusion and Genetic Inheritance, Problems in Comparative Linguistics. Oxford, Oxford University Press, 2008, p. 43-63.

3. M. Pozza, La grafia delle occlusive intervocaliche in Ittito. Verso una Riformulazione della Lex Sturtevant, Roma, Il Calamo, 2011. 
des occlusives sourdes non-géminées (loi de Sturtevant), c'est-àdire qu'on a $t t[d]$, mais $t$ [t]; cependant, en début de mot, nous n'avons que $t$, et cela ne résulte pas seulement d'une convention graphique du syllabaire cunéiforme, mais d'une authentique distribution phonétique, comme le montre le lycien, qui utilise un alphabet dérivé du grec (lyc. tideimi « fils, enfant " < indoeuropéen *dhi-dheh ${ }_{1}^{-}$, cf. hittite têta- " poitrine, sein », louvite cunéiforme tìtan- " poitrine, sein ", titaimma/i- « tétant »). Nous avons exactement la même distribution en hourrite ${ }^{4}$; la situation en hatti et en ourartéen n'est pas claire.

2. Consonnes laryngales: la conservation de l'une des consonnes laryngales de l'indo-européen en hittite (consonne tendue hh ou relâchée $h$ < indo-européen ${ }^{*} h_{2}$ ) trouve un parallèle dans l'existence d'un type de consonnes comparables en hatti (par ex. hukur- " observer, voir ", šahaw " dieu »), en hourrite (par ex. ḩaš- " entendre ", paḩi « tête ») et en ourartéen (par ex. hini" fils ", nahu " apporter ").

3. Lien entre quantité vocalique et accent: il existe une corrélation forte entre quantité vocalique et accent, partagée par le hittite, le hourrite et le hatti: les voyelles accentuées sont allongées, les voyelles inaccentuées sont abrégées. L'écriture cunéiforme du hittite, suivant une convention akkadienne, note la quantité vocalique et l'accent au moyen de ce qu'on appelle la scriptio plena " écriture pleine ", à savoir l'usage d'un signe vocalique distinct, alors même que la voyelle est déjà indiquée par le signe syllabique précédent, cf. hitt. ne-e-pi-iš "ciel " [nébis] à partir de l'indo-européen *neb ${ }^{h}$-es-. Le même lien entre quantité vocalique et accent s'observe en hourrite ${ }^{5}$ et en hatti; il en allait probablement de même en ourartéen.

4. Ergativité: le sujet des verbes transitifs est marqué différemment du sujet des verbes intransitifs, qui, pour sa part, est

4. E. A. Speiser, Introduction to Hurrian, Eugene (Oregon), The American Schools of Oriental Research, 1940-1941, p. 35-36.

5. H.-J. Thiel, « Phonematik und grammatische Struktur des Hurrischen ", in W. Haas (ed.). Das hurritologische Archiv des Altorientalischen Seminars der Freien Universität Berlin. Berlin, Altorientalistisches Seminar, 1975, p. 98-239, ici p. 99. 
marqué de la même manière que l'objet des verbes transitifs. Le hourrite, l'ourartéen et le hatti sont des langues ergatives. Les langues anatoliennes (hittite, louvite) sont des langues à ergativité dite "scindée " (en anglais split-ergative languages) en fonction du genre grammatical: les noms de genre commun (non-neutre) ont un alignement syntaxique de type nominatif-accusatif (qui prédomine dans les autres langues indo-européennes), tandis que les noms de genre neutre ont une forme ergative spéciale qui reçoit le genre commun (hittite -anza, louvite-antis) et fonctionne comme sujet des verbes transitifs.

5. Développement de chaînes de particules enclitiques en seconde position de phrase: la seconde position dans la phrase est généralement remplie par des chaînes de particules enclitiques; ce trait est prédominant en hittite, en hatti et en hourrite. Par ailleurs, en hatti, le verbe occupe la position initiale, mais on peut également utiliser une particule de phrase de position initiale pala/bala, qui fournit un parallèle fonctionnel frappant avec la particule hittite $n u$.

6. Constructions possessives et copie casuelle (en anglais case copying $)^{6}$ : dans les groupes nominaux à fonction possessive, il existe une tendance forte à copier la finale du mot-tête sur la forme au génitif, ce qui a pour effet de la transformer en adjectif possessif. Cette tendance s'est imposée en louvite cunéiforme, par ex. zaššin ${ }^{\mathrm{DuMU}}$-aššaššin annin « la mère de cet enfant » (où le nom renvoyant au possesseur « cet enfant » a adopté la finale du mot-tête "mère "); la copie casuelle est également régulière en hourrite et en ourartéen.

7. Vocabulaire: l'existence de relations d'emprunt lexical entre le hittite, le hatti, le hourrite et l'ourartéen est indiscutable. Le hittite présente ainsi de nombreux emprunts au hatti (par ex.

6. S. Luraghi, "Possessive constructions in Anatolian, Hurrian, Urartian and Armenian as evidence for language contact ", in B. J. Collins, M. R. Bachvarova, I. C. Rutherford (ed.), Anatolian Interfaces, Hittites, Greeks and their Neighbours. Proceedins of an International Conference on Cross-Cultural Interaction, September, 17-19, 2004. Emory University, Atlanta, GA., Oxford, Oxbow Books, 2008, p. 143-151. 
dahanga- "sanctuaire ", tabarna- " chef ", purulli- " terre ») et au hourrite (par ex. zurki- " sang [offert] ", huprushi- " ustensile, sorte de vaisselle ", et puhugari- "substitut ", dont la source ultime est l'akkadien $p \bar{u} h u)^{7}$. Noter qu'il existe entre le hourrite et l'ourartéen un stock important de mots communs apparentés, remontant à la période hourro-ourartéen (par ex. hourrite $a r$ = ourartéen $a r$ - « donner », hourrite pab(a)ni = ourartéen babani " montagne ").

Ces convergences linguistiques ont été exploitées comme un appui à l'hypothèse d'interactions linguistiques intensives entre les différentes langues de l'Anatolie ancienne, mais elles soulèvent un problème fondamental. Comme on l'observe avec d'autres cas d'école tels que l'aire balkanique ou l'aire méso-américaine, l'hypothèse d'une aire linguistique se fonde en général sur du matériel de nature positive en termes de traits partagés, mais les divergences entre les langues considérées sont le plus souvent laissées de côté et passées sous silence. Or, on ne peut nier que les langues parlées dans l'Anatolie ancienne présentent par ailleurs des structures typologiques nettement différentes: pour ne prendre qu'un exemple, le hittite est une langue à suffixes, alors qu'une bonne partie de la morphologie hatti s'appuie sur des préfixes. Cette différence de perspective, privilégiant les convergences positives au détriment des divergences négatives, doit toujours être prise en compte.

Revenons au Caucase. La reconstruction d'une " aire linguistique caucasique " est ancienne, mais demeure controversée. Dès le XIX ${ }^{\mathrm{e}}$ siècle, le caucasologue russe Peter von Uslar (1816-1875) relevait des similarités frappantes entre les différentes langues de la région caucasique ${ }^{8}$ et l'hypothèse d'un Sprachbund caucasique fut clairement proposée au cours du $\mathrm{xx}^{\mathrm{e}}$ siècle par différent savants, par exemple par Polák $k^{9}$, mais elle fut rejetée tout aussi clairement

7. G. Wilhelm, "Suffixaufnahme in Hurrian and Urartian ", in F. Plank (ed.), Double Case, Oxford, Oxford University Press, 1995, p. 113-135.

8. Op. cit, p. 241.

9. V. Polák, « La position linguistique des langues caucasiennes », in Studia Linguistica, 4, 1950, p. 94-107. 
par d'autres savants, par exemple par Tuite $(1999)^{10}$. Le matériel cité à l'appui d'une aire linguistique caucasique a été rassemblé par Klimov (1978) $)^{11}$, Catford (1991) ${ }^{12}$ et Chiribka (2008) ${ }^{13}$; il pourrait rassembler les traits suivants:

1. Système extrêmement riche de consonnes, caractérisé en particulier par l'existence de consonnes glottaliques ${ }^{14}$ : il existe 29 consonnes en géorgien et jusqu'à 80 consonnes dans la langue oubhyk, qui est maintenant éteinte, voire 110 consonnes en abkhaze de Sadz ${ }^{15}$. Chiribka (2008) ${ }^{16}$ parle de langues à type consonantique (consonant-type languages). À côté des consonnes attendues de la série des occlusives labiales, dentales, vélaires et uvulaires (par ex. $p, t, k, q$ ) et de deux affriquées ( $t s$ et $t$ ) il existe dans l'aire linguistique caucasique un nombre impressionnant de fricatives alvéolaires, postalvéolaires et uvulaires, ainsi que des nasales bilabiales et dentales, des approximantes bilabiales ou labiodentales, des semi-voyelles palatales, des approximantes latérales. Ce qui frappe en particulier est l'existence de consonnes occlusives glottaliques (par ex. $t^{\prime}$ ) opposées à des occlusives sonores et sourdes: des occlusives glottalisées sont partagées par les langues indigènes du Caucase ainsi que par l'arménien oriental, l'ossète (langues indo-européennes), quelques dialectes de l'azéri, le kumyk (langues turques) et même les dialectes néo-araméens du Caucase (sémitique).

10. K. Tuite, " The myth of the Caucasian Sprachbund: the case of ergativity ", in Lingua, 108,1999 p. 1-29.

11. G.A. Klimov (ed.), Strukturnye obščenosti kavkazskih jazykov. Moskva, Akademia Nauk, 1978.

12. J. Catford, op. cit., p. 241 et suiv.

13. J. Chiribka, «The problem of the Caucasian Sprachbund », in P. Muysken (ed.), From Linguistic Areas to Areal Linguistics, Amsterdam \& Philadelphia, Benjamins, 2008, p. 25-94.

14. J. Catford, op. cit, p. 242-248.

15. Ibid., p. 242-243 et J. Chiribka, "The problem of the Caucasian Sprachbund' ", in P. Muysken (ed.), From Linguistic Areas to Areal Linguistics. Amsterdam \& Philadelphia, Benjamins, 2008, p. 25-94, ici p. 43.

16. J. Chiribka, ibid. 
2. Morphologie agglutinante: prédominante dans les langues turques, avec extension vers l'arménien oriental et l'ossète (langues indo-européennes à l'origine flexionnelles).

3. Flexion de groupe: dans des groupes de mots syntaxiquement associés, seul l'un d'entre eux est marqué morphologiquement, par ex. laze didi žal-epe-s " aux grands arbres" (" grand arbresPL-DAT' $)^{17}$. La même caractéristique apparaît en ossète et en arménien moderne, alors qu'elle est à l'origine étrangère à la morphologie indo-européenne, cf. ossète mœe zœrond fyd « mon vieux père " (nominatif singulier) et mœe zœrond fyd-cen « à mon vieux père " (datif singulier, avec la marque de datif -cen exprimée seulement une fois à la fin du groupe ${ }^{18}$.

4. Ordre des marques morphologiques: les marques du nombre précèdent les marques du cas, par ex. lezgi ruš-ar-iz "aux filles » (" fille-PL-DAT»), turc köy-ler-in " des villages » (" villagePL-GEN »). Cet ordre s'est implanté en ossète et en arménien moderne, en contraste avec l'ordre inverse normal dans les langues indo-européennes (cas + nombre). Comparer sur ce point l'arménien ancien (ban-iw- $k^{\iota}$ " par les choses " < « choseINSTR-PL ») et l'arménien moderne (ban-er-ow " par les choses " $<$ « chose-PL-INSTR »).

5. Haut degré de polysynthétisme: un trait frappant des langues du Caucase est leur richesse en " cas " (ou " morphèmes liés »). On a par exemple proposé que le tabassaran possédait plus de 50 cas et que le tsez (caucasique du nord-est) monte jusqu'au nombre extrême de 126 cas. Toutefois, ces nombres élevés peuvent être contestés, d'une part parce qu'ils incluent un système riche de cas locatifs postpositionnels et, d'autre part, parce que les différentes marques casuelles peuvent être combinées les unes aux autres, ce qui augmente considérablement le nombre des formes possibles; Comrie \& Polkinski (1998) ${ }^{19}$

17. Ibid., p. 55.

18. V.I. Abaev, A Grammatical Sketch of Ossetic, Bloomington, Indiana University, 1964, p. 124.

19. B. Comrie, M. Polkinski, « The great Daghestanian case hoax », in A. Siewierska \& J.J. Song (ed.), Case, Typology and Grammar: In Honor of Barry J. Blake, Amster- 
n'attribuent au tabassaran que 14 ou 15 cas et au tzez que 18 cas. Quoi qu'il en soit, il reste que la morphologie liée est particulièrement riche dans la région du Caucase. À titre de comparaison, le géorgien a 7 cas, le svane 6 cas, le mingrélien 9 cas (langues kartvéliennes); l'azéri (langue turque) a 6 cas, comme le turc. Il est frappant que les langues indo-européennes du Caucase soient précisément celles qui ont le mieux gardé la richesse du système casuel indo-européen ( 7 cas en arménien moderne) ou même ont développé de nouveaux cas ( 9 cas en ossète, certains d'origine postpositionnelle). Noter, cependant, qu'il n'existe que 3 cas en oubykh et 2 cas en abkhaze (langues caucasiques du nord-ouest).

6. Catégorie de l'évidentialité: un marquage morphologique de l'évidentialité, exprimant l'attitude du locuteur vis-à-vis de l'information ou donnant une indication sur sa source, est attesté dans presque toutes les langues du Caucase (caucasique du nord-est, caucasique du nord-ouest, kartvélien); on le trouve également en arménien moderne, mais pas en ossète. Comparer

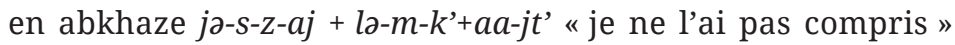
et jo-s-z-aj + la-m-k'+aa-zaap' "apparemment je ne l'ai pas compris $»^{20}$. On suppose souvent que le développement de l'évidentialité dans la zone caucasique est dû à une influence turque, mais le phénomène est attribuable au proto-abkhaze, donc à une époque où il n'y avait aucun contact avec les langues turques ${ }^{21}$. À la fois en géorgien et en arménien, l'évidentialité est limitée au temps du parfait (évidentialité scindée, en anglais split evidentiality), ce qui n'est pas le cas en svane, en mingrélien ou en laze.

7. Verbes potentiels: l'existence de formes verbales spéciales pour exprimer la capacité de produire une action, par ex. abkhaze $d \partial-z t^{w} a-w a-m$ "il (elle) ne peut pas s'asseoir ", tchétchène kxossa-vala « être capable de sauter » ou mingrélien $a$-čar-e $(-n)$

dam \& Philadelphia, Benjamins, 1998, p. 95-114, ici p. 105.

20. Exemple emprunté à V. Chiribka, Abkhaz, München, Lincom, 2003, p. 252.

21. Voir V. Chiribka, " Evidential category and evidential strategy in Abkhaz ", in A.Y. Aikhenvald, R. M. W. Dixon (ed.), Studies in Evidentiality, Amsterdam \& Philadelphia, Benjamins, 2003, p. 243-272, ici p. 266. 
" il (elle) peut l'écrire ${ }^{22}$. En archi (caucasique du nord-est), la forme potentielle du verbe est dérivée de la forme évidentielle suivie de $\chi o q i$.

8. Ergativité: presque toutes les langues du Caucase sont ergatives, ou présentent des traits ergatifs, à l'exception du dialecte mingrélien de Zan. En kartvélien, l'ergativité apparaît contextuellement limitée et réalisée comme une ergativité scindée.

9. Marquage synthétique de la causativité: des causatifs synthétiques apparaissent dans beaucoup de langues caucasiques. En lezgi (caucasique du nord-est), par exemple, la causativité peut être marquée par une formation suffixale spécifique (par ex. kwaxûn "être perdu " $\rightarrow$ kwadarun " perdre ") ${ }^{23}$; de manière comparable, le tchétchène (caucasique du nord-est) a un causatif suffixal (par ex. dada " courir, fuir » $\rightarrow$ daduo " voler, dérober " < «faire courir »). En géorgien (kartvélien), les causatifs de verbes intransitifs sont formés par l'ajout d'un préfixe $a$ - et d'un suffixe -eb- (par ex. duy-s «il boud" $\rightarrow a-d u \gamma-e b-s$ " il fait bouillir »), les causatifs de verbes transitifs par l'ajout d'un préfixe $a$ - et d'un suffixe -in-eb- (par ex. cer-s " il écrit » $\rightarrow$ $a$-çer-in-eb-s "il fait écrire »). Cf. aussi azéri ye "manger" $\rightarrow$ ye-dir "nourrir, faire manger" (avec un causatif secondaire $y e$-dir-t " faire nourrir »). Un marquage synthétique de la causativité se rencontre également en arménien oriental moderne: jeral « bouillir» (intrans.) $\rightarrow$ jerac'nel « bouillir, faire bouillir (trans.) ». Noter, cependant, que l'ossète a un causatif non synthétique, mais périphrastique, qui recourt à un auxiliaire kənın « faire » (+ inf.).

10. Usage de préverbes directionnels et orientationnels: des préverbes locatifs sont abondamment attestés dans presque toutes les familles de langues dans le Caucase. Ils sont prolifiques en lezgi (caucasique du nord-est), par ex. aq̃-udun « sortir quelque

22. V. Chiribka, «The problem of the Caucasian Sprachbund », op. cit., p. 52. Sur les causatifs du Caucase, voir plus d'informations chez B.G. Hewitt, « The causative: Daghestanian variations on a theme ", in B. Comrie (ed.), Studies in the Languages of the USSR, Edmonton, Linguistic Research, p. 173-204.

23. M. Haspelmath, A Grammar of Lezgian, Berlin, New York, De Gruyter, 1993, p. 165. 
chose ", ag-udun " approcher ", al-udun " enlever ", ak-udun " emporter ", xk-udun "emporter ", k-udun " commencer", g-udun "scinder ", gal-udun "détacher », kak-udun "placer dessous ", q̃aq̃-udun " enlever ", hal-udun " couvrir ", agaludun "appuyer», acal-udun "remplir ${ }^{24}$. Cf. aussi géorgien (kartvélien): mi-di-is « il va ", mi-mo-di-s 'il va et vient ", mo-di$s$ « il vient ", $a$-di-s " il va en montant ", a-mo-di-s " il vient en montant ", ga-di-s " il va en sortant ", ga-mo-di-s « il vient en sortant ", gada-di-s « il va en traversant ", gad-mo-di-s « il vient en traversant ", še-di-s " il va en entrant ", še-mo-di-s " il vient en entrant ", ča-di-s « il va en descendant à l'intérieur ", ča-mo$d i-s$ « il vient en descendant à l'intérieur ", $d a-d i-s$ « il va/descend régulièrement $»^{25}$. Il y a cependant des langues avec un groupe minimal de préverbes (par ex. oubykh) ou pratiquement sans aucun préverbe (arménien).

11. Postpositions: par ex. géorgien mta-ze "sur la montagne" (< « montagne $=$ à $)^{26}$, abkhaze (caucasique du nord-ouest) s-qanț «de moi » (< « moi = de »), ya-qanț « de lui " (< « lui $=\mathrm{de} "{ }^{27}$. L'arménien et l'ossète, langues à l'origine prépositionnelles, ont perdu un grand nombre de leurs prépositions et les ont remplacées par des postpositions, cf. arménien moderne jerrk'i meǰ "dans la main " (< « main dans ") ${ }^{28}$, im ènkeroj het "avec mon ami " (< « mon ami avec ") ${ }^{29}$, ossète xœzar-y sœr " sur le toit» (< « toit sur »). Dans certains des cas rencontrés, la préférence pour des postpositions peut être due à leur origine nominale (par ex. arm. het "pas ", oss. scer " tête "), mais une influence aréale n'est jamais à exclure.

12. Double coordination: coordination attachée aux deux membres de la structure coordonnée, par ex. lezgi zi buba-ni bubadin

24. Ibid., p. 167 et 171.

25. B. G. Hewitt, Georgian. A Structural Reference Grammar. Amsterdam \& Philadelphia, Benjamins, 1995, p. 148-149.

26. V. Chiribka, "The problem of the Caucasian Sprachbund », op. cit., ici p. 53.

27. B. G. Hewitt, Abkhaz: A Descriptive Grammar, London, Routledge, 2000.

28.V. Chiribka, « The problem of the Caucasian Sprachbund ", op. cit., p. 53.

29. J. Dum-Tragut, Modern Eastern Armenian, Amsterdam, Benjamins, 2009, p. 300. 
buba-ni " mon père et le père de mon père " (" mon père = et du père le père $=$ et " $)^{30}$, abkhaze war-g’ sar-g’ə " toi et moi " (< « toi = et moi = et »), tchétchène vaša a jiša $a$ " frère et sœur " ( $<$ « frère = et sœur = et »), svane $m-i s-i$ « toi et moi » $(<$ « moi = et toi $=$ et $»)^{31}$.

13. Ordre des mots SOV (sujet-objet-verbe): attesté de manière prédominante dans toutes les langues du Caucase.

Cette liste, fondée sur Chiribka (2008) $)^{32}$, ne donne qu'une collection représentative de traits considérés par certains savants comme significatifs pour la reconstruction d'un Sprachbund pancaucasique. Il va sans dire qu'une présentation à large spectre comme celle qui vient d'être faite prête le flanc à la critique, pour au moins trois raisons. La première raison est qu'elle ignore les différences fines qui existent entre les langues en se concentrant sur des paramètres définis de manière trop large sans prendre en compte la diversité de leurs réalisations individuelles. La seconde raison est qu'une vue panoramique d'une aire linguistique ne donne pas une image claire des multiples interactions culturelles qui existent, à échelle plus réduite, entre les langues. Par exemple, on sait que les langues du groupe tsez ont été influencées par leur contact avec le géorgien. Il existe des relations spéciales entre le géorgien et l'arménien. Il existe un substrat caucasique du nord-ouest en ossète, et probablement en kartvélien occidental (mingrélien, laze); etc. Le degré de polylinguisme a toujours été très élevé dans la région du Caucase au sens large. Tous ces contacts linguistiques particuliers, réalisés à différentes époques et selon des contextes différents, sont négligés par les présentations générales de l'aire linguistique caucasique. La troisième raison qui fait douter de la pertinence de cette présentation est que les traits sélectionnés sont de valeur inégale, certains étant trop élémentaires pour pouvoir être exploités utilement dans le cadre de la reconstruction d'une aire linguistique.

30. M. Haspelmath, op. cit., p. 327.

31. V. Chiribka, " The problem of the Caucasian Sprachbund ", op cit., ici p. 53.

32. Ibid. 
À ce point, j'ai présenté ce qui a été reconstruit comme deux aires linguistiques distinctes, l'aire linguistique anatolienne, d'une part, et l'aire linguistique caucasique, de l'autre. Sans surprise, étant donnée leur proximité géographique, des tentatives ont été faites de reconstruire un lien organique entre ces deux aires linguistiques. Ces tentatives sont d'emblée confrontées à de sérieux problèmes. Un premier problème est dû au décalage chronologique important qui sépare les données de chacune de ces aires. L’aire linguistique anatolienne est reconstruite sur la base de langues anciennes du second ou du premier millénaire avant notre ère, alors que l'aire linguistique caucasique est attestée beaucoup plus récemment: le géorgien et l'arménien sont documentés à partir du $v^{\mathrm{e}}$ siècle de notre ère, et nous disposons de textes albaniens de la même période; nous avons des textes azéris depuis le $\mathrm{XvI}^{\mathrm{e}}$ siècle; mais la majorité des langues du Caucase n'est connue que depuis une époque très récente (XIX ${ }^{\mathrm{e}}$, voire $\mathrm{xx}^{\mathrm{e}}$ siècle). Toute comparaison entre l'Anatolie et le Caucase doit prendre en considération cette différence chronologique. En outre, certaines des langues parlées maintenant dans la région du Caucase s'y sont implantées de manière récente et n'ont été affectées par les traits aréaux que dans une moindre mesure. Une seconde difficulté provient de la formation des linguistes qui ont proposé ces comparaisons. En fonction de leur degré de compétence dans les différentes familles de langues, ils peuvent être tentés de survaloriser la position de la famille de langues qu'ils connaissent le mieux ou, pis encore, de déformer les données des langues qu'ils connaissent le moins. Un troisième problème est que les contacts linguistiques impliquent souvent des hypothèses plus ou moins explicites sur l'extension territoriale ou la migration des populations, ce qui ouvre la porte à toutes sortes de déformations idéologiques. Les conflits politiques entre pays du Caucase peuvent conduire à minimiser la présence des "langues ennemies " sur un territoire disputé ou à exagérer l'implantation de sa propre langue sur des zones plus larges qu'elles n'occupent en réalité. Cela est peut-être compréhensible d'un point de vue psychologique, mais la linguistique n'a rien à voir avec la psychologie.

Un dernier problème est la distinction entre relations génétiques et relations aréales. Les deux types de relations ont été invoquées 
dans la bibliographie secondaire entre l'Anatolie ancienne et le Caucase moderne. Un premier pas dans cette direction est fait par les savants qui ont supposé l'unité originelle de toutes les familles de langues indigènes du Caucase (kartvélien, caucasique du nordouest, caucasique du nord-est) - une supposition qui est difficile à prouver avec certitude. Même l'hypothèse d'une origine commune de la famille caucasique du nord-ouest et de la famille caucasique du nord-est demeure controversée, en dépit de sa cristallisation dans le North Caucasian Etymological Dictionary de Nikolayev et Starostin $(1994)^{33}$. Un exemple extrême de cette perspective a été donné par Nikolaï Marr (1864-1934) avec sa théorie "japhétique ", qui postule une origine commune pour le "caucasique " défini comme un ensemble unique, le sémitique et le basque. Plus modestement, on a parfois supposé que le hourrite et l'ourartéen, deux membres de l'aire linguistique anatolienne ancienne, sont liés, d'une manière ou d'une autre, avec les langues caucasiques du nord-est; cette opinion a été soutenue récemment par Diakonoff et Starostin (1986) ${ }^{34}$. Tout cela est très incertain. À titre d'illustration, comparons le système des numéraux dans quelques langues de l'Anatolie ancienne et dans quelques langues modernes du Caucase ${ }^{35}$ :

33. S. L. Nikolayev, S. A. Starostin, A North Caucasian Etymological Dictionary, Moskva, Asterisk Publishers, 1994.

34. I. M. Diakonoff, S. A. Starostin, Hurro-Urartian as an Eastern Caucasian language. Münchener Studien zur Sprachwissenschaft, Beiheft 12,1986, Dettelbach.

35. Sources: pour le hourrite, voir E. A. Speiser, Introduction to Hurrian, Eugene (Oregon), The American Schools of Oriental Research, 1940-1941, p. 82.; G. Wilhelm, "Hurrian ", in R.D. Woodard (ed.), The Cambridge Encyclopedia of the World's Ancient Languages, Cambridge, Cambridge University Press, 2004, p. 95-118, ici p. 115.; V. Blažek, " Hurrian numerals ", in T. M. Nikolaeva (ed.), Issledovanija po lingvistike i semiotike. Sbornik stateï k jubilejo V. V. Ivanova, Moskva, Akademia Nauk, 2010, p. 117-123, ici p. 118. Pour le lezgi, voir M. Haspelmath, A Grammar of Lezgian, Berlin \& New York, De Gruyter, 1993, ici p. 230. Pour l'abkhaze, voir V. Chiribka, Abkhaz, München, Lincom, 2003, p. 34. Pour le géorgien, voir B. G. Hewitt, Georgian. A Structural Reference Grammar, Amsterdam \& Philadelphia, Benjamins, 1995, p. 29-30. Voir aussi H. Van den Berg, « The East Caucasian language family », in Lingua, 115, 2005 p. 147-190, ici p. 166. Noter la distinction en abkhaze entre numéraux non humains et humains. 


\begin{tabular}{|c|c|c|c|c|c|c|}
\hline & Hourrite & Ourartéen & Lezgi & Avar & Abkhaze & Géorgien \\
\hline 1 & $\begin{array}{l}\text { šukki, } \\
\text { šuga? }\end{array}$ & šusi-ni & $s a(d)$ & co & $\begin{array}{l}a k^{\prime} \partial ́, \\
a z^{\circ} \partial ́\end{array}$ & ert-i \\
\hline 2 & $\sin (a)$ & šl-šə? & q'we(d) & k’i.go & $j^{0}-b a, j^{0} \partial_{-} \check{z ̆}^{\prime} a$ & or $-i$ \\
\hline 3 & $\operatorname{kig}(a)$ & $?$ & pud & łab. go & $x-p a, x-j^{o} \partial ́\left(-k^{\prime}\right)$ & sam-i \\
\hline 4 & tumni & $?$ & q'ud & unq'.go & $p \check{s}^{\prime}-b a, p \check{s}^{\prime}-j^{o} \partial ́\left(-k^{\prime}\right)$ & $o t x-i$ \\
\hline 5 & $\operatorname{nariy}(a)$ & $?$ & wad & šu.go & $x^{o}-b a, x^{0}-j^{0} \partial\left(-k^{\prime}\right)$ & $x u t-i$ \\
\hline 6 & šeže & ? & rugud & ant.go & $f-b a, f-j^{o} \partial ́\left(-k^{\prime}\right)$ & $e k s v-i$ \\
\hline 7 & šindi & $?$ & irid & antt.go & $b \partial \check{2}-b a ́, b \partial \check{-}-j^{0} \partial ́\left(-k^{\prime}\right)$ & švid-i \\
\hline 8 & kira/i & $?$ & müžüd & mitt.go & $a a-b a ́, a a-j^{o} \partial\left(-k^{\prime}\right)$ & $R v a$ \\
\hline 9 & tamri/a & $?$ & k'üd & $i c ̌ ' . g o$ & $\check{Z}^{o}-b a, \check{z}^{o}-j^{o} \partial ́\left(-k^{\prime}\right)$ & Cxra \\
\hline 10 & eman & $?$ & c'ud & anc'.go & $\check{z}^{o} a-b a ́, \check{z}^{o} a-j^{o} \partial ́\left(-k^{\prime}\right)$ & $a t-i$ \\
\hline
\end{tabular}

Dès le premier regard, on voit qu'il n'y a apparemment rien de commun entre les numéraux de ces différentes langues. Toutefois, une telle comparaison n'a pas beaucoup de sens, car elle se fonde sur une sélection de langues particulières et non pas sur les protolangues intermédiaires de chacun des groupes, comme cela devrait être le cas. En conséquence, on ne peut rien faire d'autre que s'appuyer sur des ressemblances superficielles, et non sur des correspondances régulières; ce n'est pas de cette façon qu'on pratique efficacement la méthode comparative. Afin d'illustrer les problèmes posés par les comparaisons lexicales incontrôlées de ce type, on peut examiner un exemple extrême, à savoir la manière dont Blažek $(2010)^{36}$ explique l'origine des numéraux de ces langues. Cet auteur opère dans le cadre de l'hypothèse d'une unité caucasique du nord et propose la comparaison suivante entre le hourrite et d'autres langues, comprenant des langues caucasiques:

(1) Hourro-ourartéen *šu-, vs. caucasique du nord * $c H$.

36. V. Blažek, " Hurrian numerals’», in T. M. Nikolaeva (ed.), Issledovanija po lingvistike i semiotike. Sbornik statej k jubileju V.V. Ivanova, Moskva, Akademia Nauk, 2010, p. 117-123. 
(2) Hourrite šin(a), vs. caucasique du nord *šina-. Mais cf. aussi éblaïte (sémitique) šina.

(3) Hourrite ki-, vs. nakh’*qo-, obl. tchétchène qara-, bats qay-. Blažek ajoute l'étrusque $c i$.

(4) Hourrite tumni <*tamu(-)ni-. Une relation est proposée avec le sémitique *tamānáy- « 8 » (cf. ougaritique tmn, syriaque təmāne)

(5) Hourrite nariy(a), vs. caucasique du nord * pränגE '6' (d'un composé * prän- « 5 » + * $\chi E$ d'un verbe *äð $\ddot{E} w$ « poser, mettre », avec le sens " six » = " (un) placé sur cinq »)

(6) Hourrite šeže, emprunt à l'akkadien (šeššet)

(7) Hourrite šindi de *šin- et *na- « 2+5 »

(8) Hourrite kira/i de *ki- et *nariy(a) « 3+5 »

(9) Hourrite tamri/a de *tum- (<*tamu-?) et *nariy (a) « 4+5 »

(10) Hourrite eman. Blažek compare le basque hamar « 10 » ou, alternativement, spécule sur un nom signifiant " main », qui apparaît en caucasique du nord *mēhwV (lak $k^{w}$ i-jama " poignée ", akusha meh " creux de la main, poignée ", oudi aIm « bras, aile », abkhaze *ma

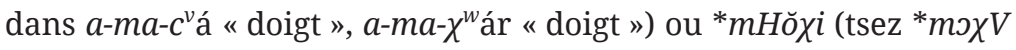
" poignée », lezgi * $\chi$ :am « main, poignée, paume de la main »)

Comme le souligne lui-même Blažek ${ }^{37}$, la relation hourroourartéo-caucasique ne serait visible que dans quelques-uns de ces numéraux; la plupart auraient une étymologie différente, soit interne, soit externe. Il est clair, je crois, que des étymologies à large spectre comme celles-ci sont complètement invalidées par leur recours précipité à du matériel linguistique incontrôlé et par l'absence dont elles témoignent de méthode comparative précise.

De la même manière que le hourro-ourartéen a parfois été rapproché du caucasique du nord-est, le hatti a parfois été rapproché, voire considéré comme un ancêtre, du caucasique du nord-ouest. Plusieurs savants se sont ralliés à cette hypothèse, Ardzinba (1974) ${ }^{38}$,

37. Ibid., p. 122.

38. V.G. Ardzinba, "Some notes on the typological affinity between Hattian and North-West Caucasian (Abkhazo-Adygian) languages ", in Internationale Tagung der Keilschriftforscher der sozialistischen Länder, Budapest, 23.-25. April 1974, Zusammenfassung der Vorträge, Budapest, ELTE, 1974, p. 10-15. 
Ivanov (1985) ${ }^{39}$ et, avant eux, Mészáros $(1934)^{40}$, mais elle ne repose que sur un petit nombre de convergences lexicales de valeur douteuse. La langue hattie est trop mal connue pour pouvoir se prêter à une macrocomparaison étymologique; nous ne disposons même pas d'un dictionnaire descriptif fiable de la langue ${ }^{41}$. Des préfixes parallèles ont été attribués au hatti et au caucasique du nord-ouest - par ex. hatti $a$ - (démonstratif) vs. abkhaze $a$ - (article) - mais leur forme est trop banale pour posséder la moindre valeur. Un exemple souvent mis en avant pour appuyer l'hypothèse d'un rapport entre le hatti et le caucasique du nord-ouest est le nom de "Dieu », hatti $w a$-šhaw comparé au circassien (tcherkesse) uas‘ho "Dieu " (mot archaïque), mais en réalité on a pu montrer que cette équation est fausse: le mot hatti est un collectif de $a$-šhab et doit avoir signifié à l'origine " tonnerre " (d'où " dieu du tonnerre, dieu »), alors que le circassien uas'ho a dû avoir comme sens premier " ciel » et donc remonter à une préhistoire différente ${ }^{42}$. D'autres équations proposées par Ivanov (1985) ${ }^{43}$ sont les suivantes ${ }^{44}$ :

- Hatti herta « cacher », vs. oubykh qarda «id. »

- Hatti kuwa « saisir ", vs. oubykh $q^{\circ} a$ «id. »

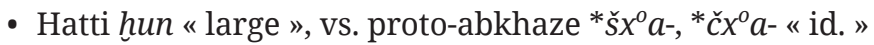

- Hatti šepšep " chaussures », vs. proto-abkhaze *c':ā qa «id. » (en fait $a-c^{o} a ́$ « cuir »)

- Hatti bu- « faire », vs. abkhaze (a-)u-ra «id. »

- Hatti štib « porte », vs. abkhaze $a$-šə « id. »

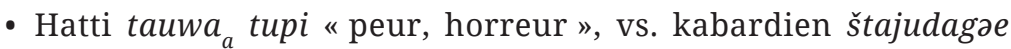
" peur »

39. V.V. Ivanov, " On the relationship of Hattic to the Northwest Caucasian languages ", in B. B. Piotrovskij, V.V. Ivanov, V.G. Ardzinba (ed.), Drevnjaja Anatolija, Ancient Anatolia. Moskva, Akademia Nauk, 1985, p. 26-59.

40. H. Mészáros, Die Päkhy-Sprache, Chicago, Chicago University Press, 1934.

41. Voir Z. Simon, Untersuchungen zur hattischen Grammatik, dissertation, Budapest, University of Budapest, 2015, p. 212.

42. Cf. Z. Simon Untersuchungen..., op.cit., p. 224.

43. V.V. Ivanov, "On the relationship... », op. cit.

44. Voir la discussion par Z. Simon Untersuchungen..., op. cit., p. 228-229. 
- Hatti izzi- « bon », vs. kabardien fIy, adyghe šIu « id. »

Ces comparaisons sont plus qu'incertaines: elles ne reposent pas sur des correspondances phonétiques régulières, mais sur des ressemblances superficielles. En outre, certaines des données produites à l'appui de cette hypothèse se révèlent peu fiables, voire complètement fausses. Il n'y a aucune preuve solide en faveur d'une parenté entre le hatti et le caucasique du nord-ouest.

D'un autre côté, l'idée d'une relation entre le hatti et le kartvélien a aussi été évoquée dans la littérature ${ }^{45}$. L'un des premiers à l'avoir proposée fut Deeters $(1963)^{46}$, se fondant sur la comparaison entre deux préfixes pluralisants du hatti le- et še- et des préfixes correspondants du géorgien ( $s a-)$ et du svane (la-, le-), mais on a montré, depuis lors, que ces préfixes ont des valeurs sémantiques différentes. Girbal (1986) ${ }^{47}$ et Gabeskiria $(1998)^{48}$ ont défendu la même hypothèse en produisant une liste de mots supposés apparentés ${ }^{49}$ :

- Hatti tette " grand », vs. géorgien didi « id. »

- Hatti tuhhukuru « voir ", vs. géorgien q'ur «id. "

- Hatti šama « entendre », vs. protokartvélien *sm- «id. »

- Hatti tumail « pluie », vs. géorgien c'vima «id. »

- Hatti šawaat " pommier ", vs. géorgien vašli " arbre "

- Hatti karam « vin », vs. géorgien kvevri « cuve pour faire fermenter le vin»

Cependant, Simon (2015) ${ }^{50}$ a montré que ces comparaisons souffraient de défauts irrémédiables, soit du côté hatti, soit du

45. Cf. Z. Simon, Untersuchungen..., op. cit., p. 249 et suiv.

46. G. Deeters, "Die kaukasischen Sprachen », in G. R. Solta, V. Inglisian (ed.), Armenisch und kaukasische Sprachen, Leiden, Köln, Brill, 1963, p. 1-79.

47. C. Girbal, Beiträge zur Grammatik des Hattischen, Frankfurt-am-Main, Bern, New York, Peter Lang, 1986.

48. S. Gabeskiria, "Hattiler, Hatti ve Hitit Dilleri Bazı Düşünceler ", in S. Alp, A. Süel (ed.), III. Uluslararası Hititoloji Kongresi Bildirileri. Çorum 16-22 Eylül 1996. Acts of the III In International Congress of Hittitology. Çorum, September 16-22, 1996, Ankara, Uyum Ajans, 1998, p. 223-231.

49. Cf. Z. Simon, Untersuchungen..., op. cit., p. 251-252.

50. Z. Simon, Untersuchungen..., op. cit. 
côté kartvélien, soit des deux. Il n’y a pas de preuve décisive d'une parenté entre le hatti et le kartvélien.

Indépendamment de la question de la parenté génétique, l'hypothèse de contacts linguistiques entre les aires linguistiques de l'Anatolie et du Caucase a souvent été formulée et cette hypothèse s'est le plus souvent concentrée sur les emprunts lexicaux potentiels. On a parfois défendu l'idée que la langue arménienne possédait un certain nombre de mots empruntés au hittite, au hatti ou au hourro-ourartéen. Historiquement, c'est d'abord l'hypothèse d'emprunts hittites en arménien qui a été proposée, d'abord par Austin $(1942)^{51}$, vite contredit par Kerns et Schwartz (1942) ${ }^{52}$; plus récemment, la même idée a été répétée à de nombreuses reprises par John A.C. Greppin (1980) ${ }^{53}$. Les exemples censés soutenir cette idée sont les suivants:

- Arménien targal « cuillère " < hittite taru-āli- " pilon »

- Arménien ołot- « inondation " < hittite $\operatorname{alalam}(m) a$ - « courant (d'une rivière) "

- Arménien hasteay "sorte de pâte " < hittite ḩaz(z)ita- "sorte de gâteau »

- Arménien brut « potier » < hittite purut- « argile »

- Arménien hazar « laitue » < hittite ḩašuššara- « légume potager »

- Arménien towp “ "boîte, coffre " < hittite tuppi- " arche, récipient »

Les données ont été récemment soumises à un examen critique par Simon $(2013)^{54}$, qui n'a reconnu qu'un nombre limité d'emprunts anatoliens en arménien, et seulement d'origine louvite. Le dossier est très fragile. Des ressemblances ont été aussi signalées

51. W.M. Austin, "Is Armenian an Anatolian language? ", in Language, 18, 1942, p. 22-25.

52. A. Kerns, B. Schwartz, " On the placing of Armenian ", in Language, 18, 1942, p. 226-228.

53. J.A.C. Greppin, « Hittite loan words in Armenian (synopsis) », in M. Mayrhofer, M. Peters, O.E. Pfeiffer (ed.), Lautgeschichte und Etymologie: Akten der VI. Fachtagung der Indogermanischen Gesellschaft, Wiesbaden, Reichelt, 1980, p. 203-207.

54. Z. Simon, « Die These der hethitisch-luwischen Lehnwörter im Armenischen: eine kritische Neubetrachtung ", in International Journal of Diachronic Linguistics and Linguistic Reconstruction, 10 février 2013, p. 97-135. 
dans le domaine phonétique entre l'anatolien et l'arménien, comme la préservation de la seconde laryngale indo-européenne comme $h$ à la fois en hittite (hanna- " grand-mère ", huhhha- " grand-père ») et en arménien (han " grand-mère ", haw " grand-père "); mais le statut du $h$ - initial de l'arménien est disputé et certainement pas comparable sans réserves avec celui du hittite $h$-. L'hypothèse de relations d'emprunt entre le hourro-ourartéen et l'arménien paraît plus prometteuse; elle se fonde souvent sur l'idée d'un lien de continuité entre l'ourartéen et l'arménien, parlés dans la même zone. Un des défenseurs de cette thèse a été Diakonoff $(1985)^{55}$, qui donne les exemples suivants d'emprunts hourro-ourartéens en arménien:

- Arménien astem " révéler sa famille » < hourrite ašte " épouse »

- Arménien caray " esclave" < hourrite sarre "prisonniers de guerre, captifs »

- Arménien owtt « chameau de Bactriane » < ourartéen ulțu

- Arménien xnjor «pomme (pommier)»< hourrite hinz-ora "pomme"

- Arménien car " arbre » < hourrite sar-me « bois », ourartéen șâra « verger"

- Arménien cov « mer » < ourartéen șûə « mer (intérieure)"

- Arménien xarxarem "je détruis " < ourartéen harhar- "être détruit"

Diakonoff a aussi postulé des emprunts dans la direction inverse, de l'arménien vers l'ourartéen, ce qui paraît très surprenant si l'on songe à la date précoce des données ourartéennes:

- Ourartéen Arșibə, nom d'un cheval, peut-être 'aigle’< arménien arcowi « aigle "

- Ourartéen burg-ana- " colonne (?) " < arménien burgn " tour » (< indo-européen *bhrĝh -)

- Ourartéen ulguša " santé, vie » < arménien oly « tout, complet »

55. I.M. Diakonoff, " Hurro-Urartian borrowings in Old Armenian », in Journal of the American Oriental Society, 105/4 1985, p. 597-603. 
- Ourartéen me(i) négation < arménien mi négation prohibitive (< indo-européen * meh ) $^{2}$

Certaines des convergences proposées pourraient avoir des apparentements ultérieurs dans des langues du Caucase ${ }^{56}$ :

- Arménien art "champ ", vs. hourrite arde, ourartéen ardi-ne "ville ", vs. tchétchène urd "parcelle de terrain d'un paysan ", ingouche urd " district"

- Arménien kowt "grain ", vs. hourrite kade « orge ", vs. lezgi gad " grain », lak č:ati "nourriture faite de semences de lin », andi, tindi ç̣̣̂ețu- «lin»

- Arménien maxr, dial. marx " conifère résineux, pin ", vs. hourrite mahri "sapin, genévrier ", vs. tchétchène max "tremble ", ingouche mixa "tremble", avar maxx "bouleau ", dargwa maq «bouleau ", tabassaran murx " bouleau », budukh märx «bouleau»

Reste la question épineuse des liens entre arménien et hatti. L'identification du nom indigène des Arméniens, Hayk', avec le nom des Hattis, a donné lieu à un débat purement émotionnel et peut difficilement passer pour généralement accepté. Une poignée de mots hattis ont été supposés en arménien, mais leur plausibilité n’est pas très élevée: l'un d'entre eux serait l'arménien kamowrǰ "pont", rapproché du hatti hamuru (wa) "voûte ", mais la comparaison est faible et l'on pourrait préférer de rapprocher le mot arménien avec

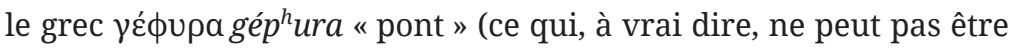
admis sans difficultés non plus).

Le mieux que l'on puisse dire à propos de ces comparaisons est qu'elles peuvent contenir un peu de vérité, mais le problème est que nous ne pouvons les évaluer correctement dans la mesure où nous ne savons pour ainsi dire rien sur les relations entre l'Anatolie ancienne et l'Arménie. Les comparaisons suggérées entre toutes ces langues sont souvent dénuées de tout sens critique, éloignées de la méthode comparative habituelle, parfois même du bon sens tout

56. Exemples venant de J.A.C. Greppin et I.M. Diakonoff, "Some effects of the Hurro-Urartian people and their languages upon the earliest Armenians ", in Journal of the American Oriental Society, 111/4, 1991 p. 720-730, ici p. 724. 
simplement. Un problème qui se pose est que ces comparaisons sont en général limitées à du matériel lexical, qui se révèle peu approprié dans la mesure où les lexèmes partagés peuvent refléter ou bien des héritages communs (en termes d'affiliation génétique), ou bien des relations d'emprunt linguistique (en termes de proximité géographique et culturelle). Il s'ensuit que, si nous trouvons entre le hatti et le caucasique du nord-ouest par exemple des convergences lexicales, nous ne sommes pas capables de déterminer si ces convergences sont dues à une origine commune de ces langues ou à des contacts linguistiques entre deux langues non apparentées. De surcroît, nous ne sommes même pas sûrs que les contacts linguistiques, s'il y en a eu, ont réellement eu lieu directement entre les deux langues considérées et non pas à travers l'intermédiaire d'une troisième langue, inconnue. Dans mon champ de recherche, le domaine des langues indo-européennes, des progrès n'ont pu avoir lieu qu'après que l'attention s'est tournée vers la comparaison du matériel grammatical, moins sujet à l'emprunt et donc plus utile pour la comparaison génétique.

Une dernière question est celle de savoir s'il peut exister un lien organique entre l'aire linguistique anatolienne et l'aire linguistique caucasique. Dans la linguistique génétique, on peut observer de nombreuses tentatives d'établir des formes distantes de parenté entre des familles linguistiques clairement définies, comme entre l'indo-européen et l'ouralique (conduisant à la reconstruction de macrofamilles), bien évidemment avec une part d'incertitude d'autant plus élevée que la date de la langue commune supposée doit avoir été très ancienne. Il est, en tout cas, bien plus difficile de procéder de la sorte avec les aires linguistiques et, d'une manière générale, il n’y a aucune possibilité de reconstruire des macro-aires linguistiques réunissant deux aires linguistiques bien délimitées. La raison en est probablement qu'une aire linguistique est un réseau de traits partagés qui se sont formés à une époque particulière de l'histoire et dans un lieu particulier, en raison d'un environnement culturel spécifique, ce qui exclut l'existence d'aires linguistiques étendues (macro-aires). Ce qui frappe ici, c'est que les traits considérés comme probants pour l'établissement des aires anatolienne et caucasique sont complétement différents et qu'il n’y pas de trait 
général partagé par les deux aires. Les seules particularités potentiellement partagées sont l'ergativité et l'existence de postpositions, mais elles sont banales et ne peuvent en tout cas fournir d'arguments en faveur d'un lien entre les aires linguistiques de l'Anatolie et du Caucase. Pis encore, il y a dans chacune de ces deux aires linguistiques des traits qui sont complètement absents de l'autre: par exemple, la catégorie de l'évidentialité, qui est répandue à travers tout le Caucase et se trouve également en turc, n'apparaît nulle part dans l'Anatolie ancienne. Il a pu exister des interactions culturelles entre l'Anatolie ancienne et le Caucase, sources de proximités linguistiques, mais nous ne pouvons pas établir la moindre connexion entre les aires linguistiques de l'Anatolie et du Caucase sur la base de traits partagés, et par ailleurs, dans l'état actuel de nos connaissances, l'existence de relations linguistiques entre ces deux régions, en termes de parenté ou de contact linguistique, ne peut être affirmée sans le moindre doute. Ce qui doit être fait à l'avenir est d'établir aussi précisément que possible la préhistoire linguistique de chacun des sous-groupes attestés dans les deux régions, et cela implique une stricte application de la méthode comparative et une bonne dose d'esprit critique. Ensuite, nous devons étudier toutes les formes de contact linguistique réellement observables à date historique. Pour cette tâche, la linguistique historique ne suffit pas, mais elle doit s'appuyer sur d'autres sciences comme l'archéologie et l'histoire: seule une approche transversale fondée sur toutes les données disponibles peut apporter une perspective nouvelle sur la préhistoire linguistique de l'Anatolie ancienne et du Caucase. 



\title{
De Julius Klaproth à Friedrich Bodenstedt
}

\author{
Des savants allemands des \\ XVIII ${ }^{e}$-XIX $X^{e}$ siècles découvrent le Caucase \\ Michel Espagne
}

Quand la science européenne commence à explorer l'espace du Caucase au début du XIX ${ }^{\mathrm{e}}$ siècle, elle est confrontée à un ensemble extraordinairement diversifié de langues et d'ethnies entre lesquelles elle s'efforce de répertorier des distinctions et des ressemblances pour reconnaître un système cohérent. Ces cohérences sont des constructions visant à comprendre et donc à fonder la domination russe. Paradoxalement, ce travail est toutefois majoritairement accompli par des Allemands au service de la Russie. Le travail de ces voyageurs généralement orientalistes a consisté à établir des typologies, mais aussi à les inscrire dans un devenir historique partant de l'Antiquité pour aller jusqu'à l'occupation russe. Aux échanges et passages d'une culture caucasienne à l'autre se superposent les transferts dans le temps, entre les ethnies ou religions dominantes qui ont marqué l'espace du Caucase. Soucieux de légitimer l'appartenance du Caucase à l'Empire russe, les voyageurs allemands vont aussi présenter les Russes comme des héritiers des cultures caucasiennes. De même que les Géorgiens sont un peu des Tatars, les Cosaques sont aussi un peu des Tcherkesses. Plus qu'une typologie, les récits de voyageurs mettent en évidence une dynamique de circulation. 


\section{Les explorateurs allemands du Caucase}

Lorsque Catherine de Russie décida en 1767 d'envoyer à travers toutes les parties de son Empire des membres de l'Académie des sciences qui décriraient les habitants, les caractéristiques et les productions de chaque région, le Caucase et la Géorgie échurent en partage au professeur Johann Anton Güldenstädt (1745-1781) originaire de Riga, qui parcourut le pays entre 1769 et 1775 . La mort l'empêcha de publier les résultats de son travail dont une première version fut éditée par Pierre Simon Pallas (1741-1811) en 1787 et 1791, une seconde édition complétée étant assurée par Julius Klaproth (1783-1835) en 1734. L'entreprise de Güldenstädt, qui sera régulièrement cité par tous ses successeurs, correspond à un mode traditionnel d'exploration de l'Orient russe grâce à des savants allemands au service de l'État russe. Après Güldenstädt, c'est un aventurier allemand, Jacob Reineggs (1744-1793), qui parcourt plusieurs fois le Caucase dans les années 1780, peut avoir des contacts privilégiés grâce à sa conversion à l'islam, et rassemble des notes qu'il n'éditera pas lui-même mais qui seront publiées après sa mort. L'étape suivante est représentée par le grand explorateur de la Russie, Simon Pallas, qui voyage dans les régions méridionales de l'Empire en 1793 et 1794, passe par le Caucase, mais se concentre sur une ligne au nord du Caucase qui correspond au cordon militaire de surveillance de la région. Après Simon Pallas, Jan Potocki (17611815), connu dans l'histoire littéraire pour son Manuscrit trouvé à Saragosse, voyage au Caucase en 1797-1798 et rassemble des notes. Le récit de son voyage a été publié après sa mort par l'orientaliste Julius Klaproth, qui devait à Potocki de l'avoir protégé et de l'avoir encouragé à s'installer à Paris pour suivre ses travaux sur l'Orient. On en vient à Julius Klaproth lui-même, qui parcourt le Caucase en 1807-1808. Il utilise les publications de ses prédécesseurs pour nourrir ses propres remarques, entre autres les documents sur l'histoire de la Russie de Christian Anton Lehrberg, de l'Académie des sciences de Russie. On doit mentionner le voyage au Caucase du professeur

1. Julius von Klaproth, Reise in den Kaukasus und nach Georgien unternommen in den Jahren 1807 und 1808, Halle und Berlin, In den Buchhandlungen des Hallischen Waisenhauses, p. 2. 
de Dorpat/Tartu Friedrich Parrot (1792-1841), qui va en 1829 escalader avec le poète arménien Khatchatour Abovian (1809-1848) le mont Ararat. Ou encore, en 1826, le voyage vers la Caspienne et dans le Caucase du professeur de Vilnius Eduard Eichwald (1795-1875), qui relate les épisodes de la guerre russo-persane.

Friedrich Bodenstedt (1819-1892), qui a été précepteur en Russie en 1840 dans la famille Galitzin avant d'arriver au Caucase en 1843 pour enseigner au lycée de Tiflis, s'inscrit ainsi dans une longue tradition d'Allemands de Russie curieux de ce monde mystérieux qu'est le Caucase $^{2}$. Il s'inspire volontiers de ce genre de la littérature de voyage et de la littérature scientifique allemande qui atteint avec ses propres contributions son stade classique. Il consacre au moins quatre ouvrages ("Les peuples du Caucase " [Die Völker des Kaukasus], " Mille et un jours en Orient " [Tausend und ein Tag im Orient], « Souvenirs de ma vie " [Erinnerungen aus meinem Leben], Mirza Schaffy) à cette région qui le fascine et qu'il aborde moins en explorateur qu'en élève désireux d'apprendre les langues - il connaît le russe et s'efforce d'acquérir le tatar, le géorgien et le persan - et d'enrichir la poésie allemande de la poésie qu'il a découverte au Caucase. Il se veut moins explorateur que traducteur, notamment des œuvres de Mirza Schaffy (1796-1852), mais aussi de la poésie allemande dans les langues du Caucase. Les Allemands de Russie développent au profit de l'Empire une science du Caucase qui, sur une cinquantaine d'années, se structure et correspond tant à des intérêts russes qu'à des intérêts allemands.

Arrivant à Tiflis, Friedrich Bodenstedt qui va tenter plus que quiconque de s'immerger dans les cultures du Caucase n'en est pas moins très attentif à la présence d'une colonie allemande de Géorgie, établie dans le quartier d'Awlabar. Il s'agit de Souabes, et Bodenstedt s'enthousiasme pour ces argonautes du Neckar aux larges épaules et aux poings puissants qui ont parcouru l'Hellespont et ont traversé les forêts de Colchide avant de s'établir dans ces vignobles lointains de Géorgie ${ }^{3}$. Ces Souabes ont leur propre auberge - l'au-

2. Friedrich Bodenstedt, Die Völker des Kaukasus und ihre Freiheitskämpfe gegen die Russen, Frankfurt am Mai, Verlag Hermann Johann Keßler 1848, p. VII.

3. Friedrich Bodenstedt, Gesammelte Schriften I, Tausend und ein Tag im Orient, Berlin, Verlag der königlichen Hofbuchdruckerei, 1865, p. 114. 
berge Salzmann - dans cette ville de Tiflis dont Bodenstedt évalue la population à 35000 habitants mais où il compte une quinzaine de nationalités. La colonie allemande qui porte le nom de "der Sand" comprend selon lui les meilleurs vignerons de Géorgie. Mais il y a d'autres groupes allemands comme la colonie d'Helenendorf dans le khanat de Gandja ou celle de Katharinenfeld qu'il rejoint avec un officier allemand de l'armée russe. On lui raconte de tristes histoires comme celle de la fille du maire de Katharinenfeld qui, enlevée par les Persans, a rejoint un harem de Tabriz. Des missionnaires envoyés par la maison des missions de Bâle essaient de convertir les Tatars au protestantisme ${ }^{4}$. La production du vin est un mode d'interaction entre les cultures ou plutôt les religions du Caucase, comme l'observe Klaproth: "Les possesseurs des vignobles étant musulmans, ne veulent pas s'occuper de la fabrication du vin, et vendent leur récolte en nature aux juifs et aux chrétiens. Ceux-ci font le vin, puis le revendent aux sectateurs de l'islam, dont la conscience s'effarouche de l'idée de presser le raisin et d'en faire fermenter euxmêmes le jus 5 . » Katharinenfeld ressemble à un village souabe, sans rien qui rappelle l'environnement asiatique ${ }^{6}$. Bodenstedt a le sentiment d'être le seul Allemand de Tiflis soucieux des échanges entre les communautés: "J'étais à cette époque le seul Allemand de Tiflis qui s'occupait des langues orientales et je commençai par la langue tatare parce qu'elle était la plus importante dans les échanges avec la population du pays et ses nombreuses langues. On pouvait avec le tatar se faire partout comprendre lorsque le russe n'y suffisait pas. Le tatar était familier à tous les Persans et les Arméniens et la plupart des Géorgiens le comprenaient au moins un peu ${ }^{7}$. "

À côté des Souabes, Bodenstedt rencontre à Tiflis une tout autre catégorie d'Allemands, les officiers de l'armée russe, généralement issus de la noblesse balte et directement impliqués dans la conquête russe du Caucase et de l'Asie centrale. Ils ont nom Grabbe, Neidhart,

4. Id., Erinnerungen aus meinem Leben, Berlin, Allgemeiner Verein für deutsche Litteratur, 1888 p. 281.

5. Julius Klaproth, Tableau du Caucase, Paris, Ponthieu et C lie libraires, 1827, p. 139.

6. Ibid.., p. 283.

7. Ibid., p. 290. 
Kotzebue, Krusenstern et quoiqu'Allemands sont de véritables sujets de l'Empire russe ${ }^{8}$. À Tiflis Bodenstedt a, d'ailleurs, fait même la connaissance du général Kaufmann qui deviendra le premier gouverneur de l'Asie centrale russe mais aussi, à sa manière, un promoteur des cultures locales.

Bodenstedt insiste dans ses souvenirs sur la présence allemande dans l'Empire russe en général. Les Allemands de Moscou ne sont pas même coupés de la vie littéraire et culturelle allemande mais peuvent suivre les dernières parutions à la "severinsche Buchhandlung ${ }^{9}$ ". Mais cette présence allemande est particulièrement visible dans les universités, qui ont toutes été fondées dans la première moitié du XIX ${ }^{e}$ siècle selon un modèle allemand. C'est tout particulièrement vrai pour l'université des Allemands de la Baltique, à Dorpat, devenue plus tard Tartu, où l'intégralité du corps enseignant est allemand. On trouve dans cette université un grand nombre d'explorateurs de l'Orient russe, du Caucase à la Sibérie. L'un des plus importants pour le Caucase est Friedrich Parrot, dont les voyages au Caucase sont centrés sur l'Arménie et le mont Ararat. Ce n'est d'ailleurs pas une pure curiosité scientifique qui guide Parrot et les professeurs de Dorpat, mais une loyauté particulière vis-à-vis des stratégies politiques de la Russie. Gravir le mont Ararat avait une valeur symbolique et Bodenstedt, même s'il ne va pas jusqu'au sommet, marche sur les traces de Parrot quand il visite l'Arménie qui sort à peine à peine de la domination persane et se présente comme une juxtaposition de nationalités diverses. Il rencontre à Erevan un ancien moine d'Etchmiadzin, Abovian, qui avait étudié à Dorpat ${ }^{10}$, en avait retiré une bonne connaissance de l'allemand et du français, et avait connu Parrot durant le voyage au Caucase. Cet Abovian est désormais enseignant d'allemand dans le Caucase. Il est le seul Arménien d'Erevan connaissant l'allemand, et le seul interlocuteur local qu'il peut avoir pour parler cette langue est le commandant d'Erevan, un certain colonel von Kiel, un

8. Friedrich Bodenstedt, Die Völker des Kaukasus, op. cit., p. 564.

9. Id., Erinnerungen..., op. cit., p. 135.

10. Id., Tausend und ein Tag im Orient, op. cit., I, p. 153. 
Allemand de la Baltique ${ }^{11}$. De la Baltique au Caucase, Bodenstedt met en évidence une sorte de forte composante allemande dans l'expansion coloniale russe ou plutôt dans ses dimensions scientifique et militaire.

\section{Classifier les peuples}

Lorsque des savants et voyageurs allemands sont mandatés pour étudier le Caucase, ils sont d'abord confrontés à un problème de classification. On observe cette perplexité dès les notes prises par Güldenstädt qui en Géorgie note la présence de Turcs, d'Arméniens, d'Ossètes et de Juifs et remarque que ces quatre nationalités prises ensemble pourraient dépasser le nombre des Géorgiens ${ }^{12}$. Mais surtout, les langues et les peuples sont perçus comme un inextricable mélange de groupes entre lesquels il est difficile de définir des frontières stables, d'opposer les langues mères à des dialectes. De nombreux groupes relèvent de mélanges ethnolinguistiques évidents. Güldenstädt, pour tenter de dominer cette complexité, énumère les districts et les caractéristiques, établit des registres de vocabulaire: "Une collection de mots mingréliens faite en vue de comparaisons m'a montré que la langue est un grossier dialecte géorgien mêlé à beaucoup de mots étrangers. Elle est dans la même relation au géorgien oriental que le hollandais à l'allemand ${ }^{13}$." La langue abkhaze et la langue tcherkesse lui semblent avoir une même origine, mais celle-ci est très difficile à percevoir ${ }^{14}$. Les supputations hasardeuses se multiplient. Pour Güldenstädt, les Ossètes seraient les restes des populations polovtsiennes battues par les Russes sur le Don au $\mathrm{xI}^{\mathrm{e}}$ siècle $^{15}$. Les langues lesghiennes comme le tchétchène seraient des isolats ${ }^{16}$, tandis que les Karabulaks seraient

11. Id., Erinnerungen..., op. cit., p. 298.

12. Johann Anton Güldenstädt, Beschreibung der kaukasischen Länder aus seinen Papieren gänzlich umgearbeitet von Julius Klaproth, Berlin, im Verlage der Stuhrschen Buchhandlung, 1834, p. 4.

13. Ibid., p. 105.

14. Ibid., p. 131.

15. Ibid., p. 139.

16. Ibid, p. 148 et 154. 
des peuples migrateurs sans assignation ${ }^{17}$ territoriale claire. La perplexité domine aussi chez Jacob Reineggs qui se demande si les Kabardes ne seraient pas les descendants de Tziganes ${ }^{18}$, et si les Tcherkesses ne sont pas un peuple trop mélangé pour qu'on puisse définir sa physionomie propre ${ }^{19}$. Les Lazes parleraient un dialecte grec pontique très corrompu ${ }^{20}$ et les Juifs ne se distinguent guère des Géorgiens au milieu desquels ils vivent. ${ }^{21}$ Simon Pallas suppose que les Kabardes qui se perçoivent comme des Arabes sont les restes des armées envoyées vers les monts Caucase par les anciens califes ${ }^{22}$ et que les Abkhazes auraient été une population originaire du nordouest repoussée dans les montagnes par les Tcherkesses. Potocki propose des classifications plus simples: "Je comprends dans la classe caucasienne quatre familles de peuples habitant le Caucase 1 les Lesghi, 2 les Misdjeghi 3 les Tcherkesses, 4 les Abazes ${ }^{23}$.". Klaproth pense en retenir six, les Lesghi, les Midsdjeghi ou Kistes, les Ossètes, les Abazo-Tcherkesses, les peuples d'origine géorgienne, les tribus turques ${ }^{24}$. Les classifications ne se sont pas vraiment opérées à l'époque de Bodenstedt qui observe que les Kurdes du Caucase sont en partie chrétiens, en partie musulmans et que les Tziganes parlent selon lui un arménien corrompu ${ }^{25}$. Mais il observe avec beaucoup plus d'attention les mouvements de peuples contemporains

17. Ibid., p. 154.

18. Jacob Reineggs, Allgemeine historisch-topographische Beschreibung des Kaukasus, hrsg. Von Friedrich Enoch Schröder, 1. Teil, Gotha und Sankt Petersburg bei Gerstenberg und Dittmar, 1796, p. 239.

19. Ibid., p. 241

20. Jacob Reineggs, Allgemeine historisch-topographische Beschreibung des Kaukasus, hrsg. Von Friedrich Enoch Schröder, 2. Teil Hildesheim und Sankt-Petersburg bei Gerstenberg und Dittmar, 1797, p. 14

21. Ibid., p. 76.

22. Peter Simon Pallas, Voyages entrepris dans les gouvernements méridionaux de l'Empire de Russie dans les années 1793 et 1794, traduit de l'allemand, t.1, Paris Deterville et à la librairie économique, 1805, p. 427.

23. Jean Potocki, Voyage dans les steppes d'Astrakhan et du Caucase. Histoire primitive des peuples qui ont habité antérieurement ces contrées. Nouveau périple du Pont-Euxin, t. 1, Paris, Merlin, 1829, p. 18.

24. Julius Klaproth, Tableau..., op. cit., p. 55.

25. Friedrich Bodenstedt, Die Völker des Kaukasus, op. cit., p. 163. 
dans un Caucase où la ville de Tiflis est un exemple de cosmopolitisme: "Après la conquête du pachalik d'Achalzig par le général Paskievitch presque tous les habitants turcs quittèrent la capitale et déménagèrent en Anatolie pour ne pas rester sous la domination des Russes. Les émigrants turcs furent en grande partie remplacés par des immigrants arméniens qui en tant que chrétiens préféraient la domination du tsar blanc à celle du représentant de Mahomet ${ }^{26}$. "

L'attention se focalise sur certains peuples comme, par exemple, les Ossètes. Güldenstädt voit en eux les descendants des Turcs polovtsiens ${ }^{27}$, Potocki reconnaît en eux des descendants des Mèdes et des Alains qui auraient été refoulés vers le Caucase depuis les bords du Don où ils étaient primitivement implantés ${ }^{28}$. Klaproth reprend très volontiers cette explication qui dans un contexte où se développe l'indo-européanisme reconnaît au moins dans les Ossètes une population susceptible d'être rattachée à l'arbre indo-européen et au groupe des langues iraniennes, une filiation rassurante dans la complexité indéchiffrable du Caucase: « Les Ossètes s'appellent Ir ou Iron, ce qui dans leur langue n'a pas de signification particulière, mais leur pays s'appelle Iron-sag ou Ironistan. Cette désignation prouve qu'ils sont d'origine mède, car selon Hérodote les Mèdes s'appelaient eux-mêmes Arianoi et aujourd'hui encore leur pays et la partie de la Perse sur laquelle ils s'étaient répandus est nommée en néopersan $\operatorname{Iran}^{29}$. " Bodenstedt reprend volontiers les analyses de Klaproth sur la parenté des Ossètes et des Alains, mais dénie à ce peuple qu'il considère comme peu cultivé, soumis aux Russes, dépourvu de tradition littéraire un intérêt particulier dans la mosaïque des peuples du Caucase. En particulier les Ossètes, se soumettant toujours aux tendances dominantes, seraient facilement passés de l'islam au christianisme tout en conservant des éléments de paganisme encore largement sensibles ${ }^{30}$.

26. Id., Tausend und ein Tag im Orient, op. cit., II, p. 30.

27. Johann Anton Güldenstädt, Beschreibung, op. cit., p. 138.

28. Jean Potocki, Voyage..., op. cit., p. 111-112.

29. Julius Klaproth, Reise in den Kaukasus, op. cit., p. 586.

30. Friedrich Bodenstedt, Die Völker des Kaukasus, op. cit., p. 236. 
À côté des Ossètes, les Tchétchènes retiennent aussi souvent l'attention, non seulement parce qu'ils font partie des nations caucasiennes belliqueuses correspondant à une image traditionnelle des montagnes du Caucase, mais aussi en raison des difficultés à les ranger dans le tableau que les voyageurs allemands s'efforcent d'obtenir. Güldenstädt fait partie des premiers à s'en émouvoir: "La langue kiste, misdjeghienne ou comme elle s'appelle d'habitude d'après l'un des plus nobles districts la langue tchétchène n'est d'ailleurs, comme le montrent mes échantillons linguistiques, apparentée à aucune langue caucasienne et en général à aucune langue connue de moi, donc une langue tout à fait particulière ${ }^{31}$. " Potocki propose de rapprocher les Tchétchènes des Ingouches et des Karabulaks mais note qu'ils sont musulmans, alors que les deux autres peuples sont restés païens ${ }^{32}$. Klaproth, quant à lui, considère que l'on prend trop souvent les Tchétchènes pour une entité autonome alors qu'ils ne sont qu'un rameau de la famille caucasienne des Misdjeghi, mais il voit aussi en eux les plus anciens habitants connus du Caucase et récuse les hypothèses de certains prédécesseurs, Pallas et Potocki, qui ont cru discerner en eux des descendants des Alains ${ }^{33}$.

Malgré la mosaïque ethnique du Caucase, les plus présents, ceux qui constituent un lien, fournissent une langue de large communication sont les Tatars, un terme qui désigne les populations turcophones du Caucase sans distinction de leurs différents dialectes. Bodenstedt considère que cette population est plus cultivée que celle des Russes. Certes, ils sont arrivés plus tard que d'autres et lorsque, accompagnés des Mongols, ils se sont répandus sur le Caucase en 1262, ils ont notamment repoussé des populations arméniennes vers la région d'Astrakhan ${ }^{34}$. Le niveau de développement culturel de certains peuples du Caucase remet en cause les représentations d'une conquête de terres peu développées liées à l'histoire du colonialisme. Au fond, le voyage dans le Caucase et notamment

31. Johann Anton Güldenstädt, Beschreibung..., op. cit., p. 148.

32. Jean Potocki, Voyage..., op. cit., p. 122.

33. Julius Klaproth, Reise in den Kaukasus, op.. cit., II, p. 143.

34. Friedrich Bodenstedt, Die Völker des Kaukasus, op. cit., p. 157. 
la confrontation avec les musulmans du Caucase est une occasion d'envisager la genèse de l'histoire culturelle russe elle-même, de s'interroger sur ses racines orientales.

Bakou est certainement la ville où les Tatars sont le plus présents, mais c'est aussi une ville qui, comme l'ensemble des villes du Caucase, comme Tiflis, reproduit sur un espace restreint la complexité des imbrications culturelles qui caractérisent le Caucase dans son ensemble. C'est précisément à Bakou que s'observe le mieux la connexion entre la culture turque et la culture persane. Klaproth observe que dans la vieille ville, où les Persans lui semblent être les plus nombreux, les maisons sont toutes pétries avec du naphte ${ }^{35}$. Dès les années 1820, la région de Bakou est perçue comme un lieu d'exploitation du pétrole: " On estime à quatre-vingt mille quintaux la récolte annuelle de naphte noir; sur cette quantité, la Perse seule en prend plus des sept huitièmes ${ }^{36}$. " Si les voyageurs allemands remarquent bien la citadelle construite par Shah Abbas, c'est en général le pétrole qui les fascine le plus. Il est lié à la secte des adorateurs du feu qui ont fait de Bakou une ville sacrée que Reineggs considère aussi comme un lieu sacré des brahmanes indiens ${ }^{37}$. Bodenstedt établit un lien entre le zoroastrisme et le culte du feu: "Derrière la ville tatare de Bakou sur la presqu'île d'Abchéron en forme de bec se trouve le célèbre feu éternel grâce aux flammes duquel les prières des derniers disciples de Zoroastre s'élèvent dans ce pays vers le $\mathrm{ciel}^{38}$. " Mais surtout, Bakou est avec Derbend la principale ville des musulmans du Caucase, et au milieu de la dispersion des ethnies la référence à l'islam, à un islam proche des traditions du soufisme, est un facteur d'unification culturelle qui explique, aux yeux de Bodenstedt, le phénomène de l'imam Chamil, à la fois prêtre, législateur et chef de guerre: "Le peuple à la tête duquel il se trouve n'est devenu un peuple que grâce à lui et cette fusion des éléments les plus hétérogènes en une seule masse indissoluble, ce rassemblement d'une foule grâce aux mœurs, aux traditions et à la haine

35. Friedrich Klaproth, Tableau..., op. cit., p. 148.

36. Ibid., p. 150.

37. Jacob Reineggs, Allgemeine Beschreibung, op. cit., p. 144.

38. Friedrich Bodenstedt, Tausend und ein Tag im Orient, I, p. 173-174. 
héritée de tribus séparées n'était pas moins difficile à diriger qu'il ne le serait de créer une Allemagne unie ${ }^{39}$. " Non seulement le moment turc dans les ethnies du Caucase opère une certaine unification sur la base de l'islam et d'un lien privilégié à la culture persane, mais cette unification pourrait servir de modèle à l'Allemagne, encore loin de s'être unifiée. Et s'il s'agit d'un espace d'expansion militaire, il s'agit tout autant, ce que le terme " tatar » en lui-même implique, d'un retour à l'une des composantes de l'histoire culturelle russe.

\section{Les références antiques}

Le Caucase apparaît aux savants allemands chargés d'en dresser le tableau comme un ensemble de stratifications qui suggèrent chacune des découpages particuliers. S'il y a des interférences entre les groupes ethniques, les voyageurs s'efforcent généralement de trouver une explication dans le passé, voire dans l'Antiquité. Pour Güldenstädt, le Caucase doit être analysé comme un ensemble de peuples résiduels qui lors des grandes invasions débordant sur l'Europe, se réfugièrent dans les montagnes. Certains sont d'ailleurs venus d'Europe, et on pourrait retrouver la présence de Génois dont l'implantation sur les côtes de la mer Noire date du XII siècle. Au niveau de chaque district on peut rencontrer une pluralité de langues et de peuples, mais aussi de formes politiques, certains habitants se concevant comme les sujets d'un despote local, d'autres vivant sans aucune forme d'autorité ${ }^{40}$. Klaproth recherche chez les Tcherkesses une tradition concernant les amazones. Alexandre le Grand aurait aussi laissé des traces, certains de ses adversaires, refoulés dans les montagnes, conservant leur mode de vie et leur religion ${ }^{41}$. On ne compte pas de façon générale les hypothèses concernant les tribus évoquées par les auteurs antiques, comme Arrien dans sa présentation du Pont-Euxin ${ }^{42}$. Car le nom même de Caucase apparaît pour la première fois dans le théâtre d'Eschyle; le supplice de Prométhée

39. Id., Die Völker des Kaukasus, op. cit., p. 469.

40. Johann Anton Güldenstädt, Allgemeine Beschreibung, op. cit., p. 125.

41. Julius Klaproth, Reise in den Kaukasus, op. cit., p. 295

42. Ibid., 226. 
est une des grandes légendes grecques liées au Caucase et dès le $\mathrm{VII}^{\mathrm{e}}$ siècle avant notre ère les Milésiens ont envoyé des colonies sur les côtes orientales de la mer Noire, fondant notamment Tanaïs à l'embouchure du Don ${ }^{43}$. Sans apporter de théorie pour expliquer l'origine de l'Ibérie du Caucase, Reineggs rapporte des récits selon lesquels les descendants de Noé auraient occupé le Caucase juste après le Déluge, ou encore selon laquelle des immigrants antiques venus de la péninsule ibérique auraient apporté la technique métallurgique au Caucase ${ }^{44}$. Potocki se fait l'écho d'une légende selon laquelle les Arméniens seraient les lointains descendants d'un peuple de l'Anatolie antique, les Phrygiens ${ }^{45}$. Pour Bodenstedt, ce sont les Phéniciens qui ouvrirent pour la première fois des voies maritimes vers le Caucase et la ville de Koutaïssi, sur les bords du Phasis, devenu Rioni, aurait été le lieu de la Toison d'or: «Les ruines de la forteresse de Koutaïssi célèbre depuis les anciens temps offrent une vue particulièrement splendide, des ruines qui sur la rive droite du Phasis couronnent une montagne escarpée qui domine la ville et sur laquelle se serait élevé le palais du légendaire roi Eétès qui reçut de façon si hospitalière Jason et ses compagnons quand ils débarquèrent dans l'ancienne capitale de la Colchide Kytaia ${ }^{46}$. » Les Mingréliens seraient ainsi les descendants des compagnons de Jason ${ }^{47}$. La référence à l'Antiquité est un auxiliaire indispensable aux premières approches du Caucase où Grecs et Perses, Romains et Parthes ont été les acteurs de conflits permanents.

\section{Croisements de peuples}

Les stratifications qui composent la population du Caucase conduisent les voyageurs allemands à observer les traces d'un groupe dans le groupe voisin. Pour Bodenstedt, la population dominante est celle des Tatars: "Les tribus turco-tatares qui sous

43. Julius Klaproth, Tableau..., op. cit., p. 10.

44. Jacob Reineggs, Allgemeine Beschreibung, op. cit., II, p. 116.

45. Jean Potocki, Voyage..., op. cit., II, p. 259.

46. Friedrich Bodenstedt, Erinnerungen..., op. cit., p. 351.

47. Id., Die Völker des Kaukasus, op. cit., p. 63. 
Gengis-khan et Tamerlan inondèrent et soumirent les régions du Caucase représentent encore la plus grande partie de la population et cela explique que leur langue qu'ils désignent eux-mêmes comme la langue turque (turkidsche dil) soit restée dominante. La langue que nous avons l'habitude de désigner comme le véritable turc, s'appelle chez les Turcs la langue ottomane (osmanli dil) et a la même origine que la langue dite tatare ${ }^{48}$. " Alors que les Arméniens sous domination persane ont conservé strictement les coutumes et usages traditionnels, les Arméniens sous domination tatare se sont très largement assimilés ${ }^{49}$. La superposition des références tatares et persanes dans la population du Caucase occupe beaucoup les voyageurs allemands: « Dans la province persane d'Azerbaïdjan (Pays du feu), dont la capitale est Tabriz, les deux langues se mêlent comme le russe et le polonais en Ukraine, et la plupart des chants populaires que me chantait mon Mirza pour en faire l'objet d'une explication trouvaient leur origine en Azerbaïdjan ${ }^{50}$. " Les poètes persans sont pour les poètes tatars un modèle aussi fort que les Grecs pour les Romains ${ }^{51}$. Bodenstedt rappelle au demeurant que le turco-tatar véhicule des moments essentiels de la culture arabe, et que parmi les régions occupées par les Tatars du Terek on rencontre des villages arméniens tandis que le Karabagh est occupé selon lui par deux tiers de Tatars et un tiers d'Arméniens. Les Tatars représentent dans l'histoire culturelle du Caucase une strate globale liée aux invasions gengiskanides ou timourides et c'est par différence par rapport à cette strate qu'on distingue l'identité d'autres groupes, de même que le Caucase dans son ensemble est perçu par opposition aux implantations et aux témoignages gréco-latins.

\section{Des strates religieuses}

$\mathrm{Au}$ moins aussi importantes que les strates linguistiques ou ethniques sont dans le Caucase, tel qu'essaient de le comprendre

48. Friedrich Bodenstedt, Erinnerungen..., op. cit., p. 291.

49. Ibid., p. 313.

50. Ibid., 331.

51. Ibid., p. 31. 
les voyageurs allemands, les strates religieuses. Les religions sont venues d'ailleurs: quand le roi géorgien Mirian se convertit, il fait venir avec le soutien de l'empereur Constantin un évêque qui serait Eustathe d'Antioche ${ }^{52}$. La Géorgie devient chrétienne en 320; l'Arménie sous le roi Tiridates dès 302. Une religion originale se constitue par rapport à ces importations. Par exemple, les Arméniens se séparent de l'Église grecque en 451 au concile de Chalcédoine $^{53}$. La religion chrétienne dans le Caucase accorde notamment une importance centrale au prophète Élie, auquel sont dédiés des lieux de culte. Souvent les appartenances religieuses se modifient au cours du temps. Güldenstädt observe que les tsars russes ont obtenu la conversion des Tcherkesses à l'orthodoxie et qu'il existe sur leur territoire des églises et des croix. Si l'orthodoxie a disparu chez eux, ce n'est pas vraiment pour céder la place à une autre religion: "Actuellement la plupart des nobles sont musulmans, mais ils n’ont ni prêtres, ni mosquées, ni écoles coraniques et ils sont donc très ignorants. Le peuple vit sans religion ${ }^{54}$. " L'islam, lui, n'est pas venu seulement avec Gengis Khan au XIII ${ }^{\mathrm{e}}$ siècle ni avec Tamerlan au XIv siècle, mais beaucoup plus tôt: «Murwan Agarian, le général d'Omar, successeur de Mahomet traversa avec le glorieux drapeau du prophète de La Mecque les ravins du Caucase ${ }^{55}$. " Mais ce qui est beaucoup plus frappant au début du xix ${ }^{\mathrm{e}}$ siècle, c'est la persistance de croyances païennes sous les religions monothéistes: "Comme singulier exemple de la manière dont ces petits peuples sont farouchement attachés à leur ancienne foi païenne on peut citer le fait que les Ingouches, quand en 1810 ils se soumirent au sceptre russe, prêtèrent serment de fidélité à leur idole Galjerd ${ }^{56}$." En dehors de ce Galjerd ils auraient d'autres idoles comme Daïlé, en l'honneur duquel ils célèbrent des fêtes au printemps et en automne ${ }^{57}$. Plus que les Géorgiens, les Arméniens auraient conservé

52. Julius Klaproth, Reise in den Kaukasus, op. cit., p. 160.

53. Friedrich Bodenstedt, Die Völker des Kaukasus, op. cit., p. 151.

54. Johann Anton Güldenstädt, Beschreibung..., op. cit., p. 136.

55. Friedrich Bodenstedt, Die Völker des Kaukasus, op. cit., p. 48.

56. Ibid., p. 88.

57. Ibid., p. 89. 
les restes d'une religion populaire qui aurait été un mélange de zoroastrisme et de mythologie grecque ${ }^{58}$. En divers lieux du Caucase, la rencontre du culte du feu avec le christianisme et le judaïsme aurait suscité des syncrétismes comme le manichéisme ou la secte de Mazdak le long de la mer Caspienne ${ }^{59}$.

La présence dominante au moins du point de vue militaire est, dès le début du XIX ${ }^{\mathrm{e}}$ siècle, la présence russe. Mais les Allemands qui étudient l'espace du Caucase n'insistent pas sur le fait que les Russes sont des étrangers. Ils tentent au contraire de voir en eux le résultat de métissages profonds qui rendraient leur présence au Caucase plus naturelle. Les Russes, ce sont notamment les Cosaques. Or, Bodenstedt rapproche les Cosaques des Khazars. L'Empire des Khazars qui allait des côtes de la Caspienne jusqu'aux steppes du sud de la Russie était un creuset de peuples. Le terme de cosaque désigne-t-il d'ailleurs autre chose qu'un guerrier errant, libre et indépendant ${ }^{60}$ ? Peuple métissé dès l'origine, le peuple des Cosaques, comme représentant de la Russie dans le Caucase, prolongerait ce métissage jusqu'à l'époque contemporaine pour Bodenstedt: «En partie du fait des fréquents métissages avec des femmes tcherkesses enlevées, en partie du fait de leur costume et de leur mode de vie caucasiens ils sont devenus si semblables aux peuples montagnards qu'un œil non averti ne peut pas les en distinguer ${ }^{61}$. "Certes, on peut parler d'une expansion russe en Asie et même d'une tentative de rejoindre l'Inde ${ }^{62}$ par voie de terre. Mais la Russie est elle même le résultat d'un métissage. Bodenstedt se réfère à l'historiographie russe: « Dans un écrit sur la littérature russe du XIv siècle le célèbre philologue Buslaeff appelle la Moscou de Rurik un camp à moitié tatar à partir duquel tous les pays slaves du nord-est et notamment la puissante Novgorod auraient été combattus dans l'intérêt des

58. Ibid., p. 151.

59. Friedrich Bodenstedt, Tausend und ein Tag im Orient, op. cit., I, p. 174.

60. Id., Die Völker des Kaukasus, op. cit., p. 239-240.

61. Ibid., p. 253.

62. Friedrich Bodenstedt se réfère notamment au livre du Français, fonctionnaire de l’Empire russe, Félix Fonton, La Russie dans l'Asie mineure, 1840. 
Mongols et avec leur aide ${ }^{63}$. Un des premiers membres de l'Académie russe des sciences, Gerhard Friedrich Müller, publiait en 1749 un livre Origines gentis et nominis Russorum pour rappeler que les Moscovites n'étaient pas des Slaves, rejoint en 1791 par un autre membre de l'Académie, Johann Gotthelf von Stritter, dont le livre Populi antiquae Russiae reprenait la thèse d'une ascendance tatare. Les Russes, souvent dirigés par des Allemands de Russie comme le premier gouverneur de l'Asie centrale Kaufmann, peinent certes à traverser les déserts centrasiatiques ou les espaces sauvages du Caucase en allant vers l'Inde. Mais Bodenstedt dispose de toutes les garanties pour observer que les Russes, lorsqu'ils sont en Asie centrale et au Caucase, retournent pour ainsi dire vers un espace originel, celui des Mongols, des Tatars ou des Khazars. La conquête du Caucase n'est pas seulement une entreprise de colonisation. C'est aussi un retour à des origines refoulées de l'espace russe.

Les strates imbriquées qui caractérisent l'espace du Caucase se manifestent aussi au niveau des toponymes et ethnonymes. Il est rare qu'un peuple, une langue, un dialecte soient désignés par un seul nom. Prenons les Tcherkesses: "Les habitants s'appellent euxmêmes et appellent leur pays Adigi, les Turcs et les Tatars Tcherkas, les Géorgiens Tscerkessiani, les Russes Tcherkessy, les Allemands Tcherkassien, mais les Ossètes l'appellent Kasach, ce qui était peut-être la dénomination commune à l'époque de Constantin ${ }^{64}$." Dépassés par la multiplicité des groupes, les Russes parlent volontiers de peuples des montagnes, "Gorsky ", ce qui devient dans la bouche des Turcs "Tawli " ${ }^{65}$. Ensemble de 647 maisons où vivent des musulmans, des Arméniens, des Géorgiens et des Juifs, la ville de Derbend, qui aurait été fondée par Alexandre est aussi appelée Darband, Derre-Deri-Durrebend, des désignations qui renvoient à l'image d'une porte fermée et correspondent à l'expression " Portae Caspiae " des Anciens ${ }^{66}$. Les noms des lieux dans leur diversité sont aussi porteurs de sens. L'Elbrouz est aussi appelé Ellborus ou

63. Friedrich Bodenstedt, Erinnerungen..., op. cit., p. 251.

64. Johann Anton Güldenstädt, Beschreibung..., op. cit., p. 135.

65. Ibid. p. 135.

66. Jacob Reineggs, Allgemeine Beschreibung, op. cit., p 113. 
Elebo-rous, mais on trouve aussi El-bourugh d'après le nom du chameau sur lequel Mahomet est parti au ciel car le profil du mont Elbrouz ressemble à un dos de chameau ${ }^{67}$. Les noms de lieux, porteurs de sens sont si divers qu'ils ne permettent pas un tableau clair des différents groupes. La montagne des langues évoquée par l'historien arabe Abul-Fida (1273-1331) est aussi pour les mêmes raisons une montagne des peuples.

\section{Traduire le Caucase}

Le Caucase est pour les voyageurs allemands un lieu qu'il faut explorer, décrire comme un système cohérent, mais il s'agit aussi d'un ensemble de traditions, de textes d'où l'on peut tirer des savoirs nouveaux, transposables à d'autres contextes. C'est tout particulièrement la perspective de Bodenstedt. Installé à Tiflis au pied du Davidsberg, ce dernier est d'abord en admiration devant le cosmopolitisme de la ville: "À côté de la Géorgienne en tchador marche la femme de fonctionnaire russe. À côté du sauvage Kurde de l'Ararat chevauche le cosaque du Don. À côté des tuniques grises des Moscovites se poussent les Merschals (porteurs) en haillons venus d'Imérétie, d'Ossétie, du Leghistan ${ }^{68}$. " Contrairement aux voyageurs qui l'ont précédé, Bodenstedt se met en position non seulement d'observateur mais d'élève. Et son principal maître va être le poète Mirza Schaffy. Ses poèmes en langue tatare mais inspirés de modèles persans, Mirza Schaffy n'a pas même songé à les publier. Ils vivent dans la bouche des Géorgiens ou des Tatars sans que personne songe à les fixer par écrit. Bodenstedt se donne comme objectif d'en assurer tout à la fois la transmission et la traduction. Rappelons au demeurant que Bodenstedt est aussi connaisseur de la poésie russe et fait partie des premiers traducteurs des textes de Lermontov sur le Caucase. À Tiflis il a rencontré la veuve de Griboïedov, l'écrivain ami de Pouchkine assassiné à Téhéran et il se souvient à ce propos de la rencontre de Pouchkine avec le convoi funèbre ${ }^{69}$. Pour l'obser-

67. Ibid., p. 289.

68. Friedrich Bodenstedt, Tausend und ein Tag im Orient, op. cit., I, p. 112.

69. Id., Erinnerungen..., op. cit., p. 278. 
vateur allemand, le Caucase est évidemment un lieu privilégié de la mémoire littéraire russe. Mais Bodenstedt à Tiflis s'intéresse principalement aux poésies orientales, celles de son ami Mirza Schaffy. Au milieu du XIX ${ }^{e}$ siècle il faudrait évoquer August von Platen, Friedrich Rückert comme traducteurs de la poésie persane et turque. Mais dans le cas de Bodenstedt, il s'agit de mettre aussi en scène la relation d'un maître à son disciple qui se fait expliquer les littératures de l'Orient et crée autant qu'il transpose, en publiant en allemand les poèmes de Mirza Schaffy. Qu'il s'agisse de plaintes, de la célébration du vin ou de femmes (Zuleikha, Hafifa), de tableaux de Tiflis, les poèmes de Bodenstedt, qui ont eu en leur temps un immense succès, répondent aux règles formelles de la poésie romantique allemande. Bodenstedt apprend auprès de Mirza Schaffy à distinguer la poésie des grands maîtres de l'imitation d'imposteurs: "La séance suivante du Divan de la sagesse fut consacrée à ce que Mirza Schaffy m'explique quelques-uns des plus aimables Ghazels de Hafiz qui comme d'authentiques diamants pris à la couronne du roi des poètes persans peuvent trouver ici leur place ${ }^{70}$. " Bodenstedt rappelle volontiers une habitude orientale consistant à choisir au hasard pour l'ami que l'on va quitter un passage de Saadi ou de Hafiz destiné à l'accompagner dans son voyage ${ }^{71}$. La relation au sage de Gandja ne se limite pas à publier en traduction allemande ses œuvres, mais Bodenstedt veut, dans une sorte d'échange, lui faire connaître la poésie allemande ou anglaise et s'efforce par exemple de traduire en tatar des poèmes de Heinrich Heine ${ }^{72}$. Et Mirza Schaffy prenait un plaisir particulier à la lecture des poèmes de Goethe (Connais-tu le pays où fleurissent les citronniers...) ou de Heine (Chant du pêcheur...). Et lorsque des difficultés linguistiques se présentent, Bodenstedt et Mirza Schaffy ont recours à l'aide du professeur de persan au lycée de Tiflis, un certain Budakoff, lui-même au demeurant Arménien. De façon générale, il est souvent question de traduction dans les écrits de Bodenstedt sur le Caucase. Il mentionne par exemple la traduction du Shah nameh de Firdousi parue

70. Friedrich Bodenstedt, Tausend und ein Tag im Orient, op. cit., II, p. 70.

71. Ibid., I, p. 127.

72. Ibid., II, p. 75. 
chez Cotta alors qu'il s'efforce, avec l'aide de Mirza Schaffy, de lire le texte original ${ }^{73}$. Il s'intéresse à la traduction par Georg Rosen (18201891), orientaliste de passage à Tiflis, de Dshalal-ed-din Rumi ${ }^{74}$. Auprès d'un inspecteur ukrainien du lycée de Tiflis, il a rencontré l'historien tatar originaire de Bakou Abbas Kuli-Chan qui selon le modèle des rois de Géorgie a écrit des contributions à l'histoire des peuples du Caucase et en assure la publication en russe ${ }^{75}$. Le modèle en question est certainement la grande chronique rédigée à Moscou au XviII ${ }^{\mathrm{e}}$ siècle par le roi de Géorgie Wachtang, dont Bodenstedt souligne que les auteurs allemands qui ont présenté l'histoire et les cultures du Caucase comme Güldenstädt et Klaproth se sont largement inspirés ${ }^{76}$.

\section{L'orientalisme et le Caucase}

Apprendre du Caucase c'est écouter les conseils prodigués par Mirza Schaffy, mais c'est aussi suivre les progrès d'une science qui se développe radicalement durant la première moitié du XIX ${ }^{\mathrm{e}}$ siècle, l'orientalisme. La plupart des récits rédigés par les voyageurs allemands sont des contributions à l'orientalisme sous ses diverses formes puisqu'ils donnent un aperçu des mœurs, de l'histoire des peuples et vont souvent jusqu'à proposer des listes de mots dans les différentes langues entendues. Mais Bodenstedt recense des contributions plus savantes. Il évoque le travail de Marie Félicité Brosset (1802-1880) qui a écrit sur la littérature géorgienne, est un des fondateurs des études géorgiennes et a publié en français un premier catalogue de la bibliothèque d'Etchmiadzin ${ }^{77}$. Bodenstedt croise l'orientaliste danois Westergaardt rentrant de Perse chargé de livres que Bodenstedt lira en partie avec l'aide de Mirza Schaffy ${ }^{78}$. Il rencontre l'orientaliste britannique Henry Danby Seymour et se lie à

73. Friedrich Bodenstedt, Erinnerungen..., op. cit., p. 331.

74. Ibid., p. 303.

75. Ibid., p. 313.

76. Friedrich Bodenstedt, Die Völker des Kaukasus, op. cit., p. 44.

77. Id., Tausend und ein Tag im Orient, op. cit., I, p. 186.

78. Ibid., II, p. 130. 
lui ${ }^{79}$. Parfois, les travaux orientalistes reposent sur une collaboration affichée entre un Européen et un érudit caucasien comme lorsque s'élabore, grâce au Français de Saint-Pétersbourg Charmoi et au prince kabarde Murzin Nogma, une grammaire du kabarde ${ }^{80}$. Mais les orientalistes rencontrés sont surtout Allemands, et Bodenstedt se lie en particulier avec Georg Rosen venu d'Istanbul et qui incarne le mieux l'orientalisme allemand: "Georg Rosen a étudié à Berlin en 1839 le sanskrit avec Bopp, avec Rückert le persan, avec Petermann l'arménien ${ }^{81}$, puis à Leipzig l'arabe avec Fleischer. Il fit paraître en 1843 comme premier fruit de ses études ses Rudimenta persica et reçut par la suite de l'Académie des sciences les moyens d'un voyage de recherche dans le Caucase ${ }^{82}$. "Étudiant le géorgien à Tiflis, analysant les fonds de la bibliothèque d'Etchmiadzin, il publie aussi un ouvrage sur la langue des Lazes. À partir notamment du vocabulaire constitué par Klaproth, il a aussi écrit une grammaire ossète ${ }^{83}$.

Rosen avait été prié par le propriétaire du principal journal allemand de l'époque de publier des articles sur son séjour, mais la rédaction de sa grammaire ossète l'empêchant d'écrire ces articles, alors qu'il fournissait des matériaux à Franz Bopp, le père de la grammaire comparée, pour étudier la partie indo-européenne des langues du Caucase, il se fit pour ainsi dire remplacer par Bodenstedt. Les premiers poèmes de ce dernier sur le Caucase sont également publiés par ce biais orientaliste: "Les poèmes devaient sur le conseil de ses amis poètes Gustav Schwab et Gustav Pfizer, qui en avaient parlé de façon très positive, paraître dans le Morgenblatt de Cotta, qui était alors le meilleur journal littéraire d'Allemagne ${ }^{84}$. » Un Allemand de Tiflis, Arthur Leist (1852-1927) ${ }^{85}$, a traduit des chants géorgiens alors

79. Friedrich Bodenstedt, Erinnerungen..., op. cit., p. 321.

80. Id., Die Völker des Kaukasus, op. cit., p. 230.

81. Julius Heinrich Petermann (1801-1876) enseignait la philologie orientale à Berlin.

82. Friedrich Bodenstedt, Erinnerungen..., op. cit., p. 292.

83. Id., Die Völker des Kaukasus, op. cit., p. 236.

84. Id., Erinnerungen, op. cit., p. 302.

85. Arthur Leist était rédacteur de la Kaukasische Post, mensuel des Allemands du Caucase; le périodique cessa d'exister en 1922. 
que la connaissance de la littérature arménienne en Europe provient de traductions faites par les makhitaristes de San Lazzaro degli Armeni à Venise ${ }^{86}$. Les visiteurs du Caucase rencontrés à Tiflis sont parfois des spécialistes de botanique comme Karl Koch (1809-1879) de Iéna ou de minéralogie comme Hermann von Abich (1806-1886) de Dorpat, qui outre leur domaine de spécialité s’intéressent également à la culture des populations rencontrées ${ }^{87}$. Le mouvement initié par Catherine II a porté ses fruits et le Caucase est devenu au fil des contributions savantes de voyageurs, notamment de voyageurs allemands, l'objet d'une intense curiosité. Alors que l'Asie centrale est encore inaccessible, on va chercher au Caucase un nouveau savoir susceptible de transformer la perception des littératures, des langues, de l'histoire des peuples.

La découverte du Caucase est contemporaine d'un modèle épistémologique lié au comparatisme entre les langues indo-européennes. Les langues et cultures caucasiennes, à l'exception des Ossètes et des Arméniens, n'entrent pas dans ce vaste tableau. Elles invitent à établir des typologies alternatives et surtout à porter l'attention moins sur les classements que sur les articulations entre les innombrables parties de cet ensemble complexe. Comme le Caucase dispose d'une profondeur historique qui remonte au mythe de Prométhée ou à l'épisode de la Toison d'or, les transferts diachroniques complètent les imbrications synchroniques dans les tentatives d'explication de la complexité de cet espace. Mais le Caucase est pour les Allemands qui le décrivent un lieu d'apprentissage: on y observe des langues difficilement classables, une histoire religieuse spécifique, des coutumes renvoyant à des temps très anciens. C'est aussi un lieu de découverte de ces poésies orientales qui ont fait la célébrité de Friedrich Bodenstedt, traducteur de Mirza Schaffy. La Russie n'est pas seulement en position de conquête de ces espaces souvent héritiers de cultures plus anciennes, elle aussi devient caucasienne.

86. Friedrich Bodenstedt, Erinnerungen..., op. cit., p. 298-299.

87. Ibid., p. 303. 

8

\title{
L'histoire singulière de la communauté grecque pontique
}

\author{
L’hellénisme russe, du Pont au Caucase \\ Servanne Jollivet
}

" J'ai déploré ma race éternellement

crucifiée, de nouveau mise en péril sur le mont prométhéen du Caucase. Ce n'était pas Prométhée, c'était la Grèce du Caucase, clouée par l'État et la Violence - telle était sa croix et on entendait son cri. Elle criait aux gens, à ses enfants de la sauver. "

Nikos Kazantzakis, Lettre au Greco, "Caucase »

L’expédition "la Toison d'or " (Xryssomallo Deras), organisée in extremis par l'État grec le 16 août 1993 s’inscrit dans la mémoire des exodes successifs d'une communauté longtemps diasporique. Ce rapatriement, qui permit à près de 15000 Grecs pris en étau dans la guerre qui déchirait alors la Géorgie, dans la région caucasienne de Soukhoumi, de rejoindre la Grèce, liait ainsi l'époque la plus récente à l'histoire mythologique de l'hellénisme, faisant des derniers membres survivants de cette vaste communauté les "nouveaux argonautes" contraints à l'exil. En lien avec les noms de Prométhée, et des Argonautes, la mythologie grecque regorge en effet de héros provenant de ces régions, attestant très clairement l'appartenance du Caucase à la cartographie de l'hellénisme le plus ancien. Originaires des rivages et vallées montagneuses du pourtour oriental de la mer Noire, les Grecs originaires du Pont-Euxin, dits Pontioi - parfois qualifiés de Romaioi, Rum, Urum, Ellinopontioi, 
Kafkasioi ou Mikrasiates - forment à cet égard une communauté singulière, qui se trouva, à mesure des exodes et déplacements, en première ligne des multiples bouleversements qui secouèrent la région du Caucase, zone charnière comme fut celle du Pont durant les deux derniers siècles. Son récit est celui de l'histoire extrêmement mouvementée et complexe, souvent tragique - liée aux exodes, persécutions et déportations - d'une population dont l'identité s'est constituée dans l'adversité, mais également celui d'une diaspora qui n'a eu de cesse, même ultérieurement dispersée dans le monde entier, de réaffirmer sa provenance et son appartenance dans la vaste histoire de l'hellénisme ${ }^{1}$.

\section{De l'origine pontique au Caucase}

La situation charnière du Caucase en fait assurément une des régions les plus composites sur le plan ethnique, aussi bien que confessionnel. Territoire qui s'étend du sud de l'actuelle Russie à la Turquie, de la Géorgie au Daghestan, jusqu'à l'Arménie, le Caucase rassemble en effet une extrême diversité de populations, des Géorgiens aux Tchétchènes, en passant par les Abkhazes, Ingouches, Tcherkesses, les peuples du Daghestan (Avars, Lezghiens...), les Arméniens, les Russes, les Juifs, les peuples d'origine iranienne (Kurdes, Ossètes), mais également venus d'Asie centrale (Azéris, Koumyks, Karatchaïs, Balkars...). On y recense plus d'une centaine de langues, principalement caucasiennes, mais également sémitiques, indo-européennes et turco-mongoles, hétérogénéité qui se

1. Cette synthèse s’appuie sur les travaux qui ont déjà été menés, du côté français notamment par Michel Bruneau, Hervé Georgelin, du côté grec par Vlassis Agtsidis, Konstantinos Fotiadis, également Anthony Bryer. Le volume collectif édité par Michel Bruneau constitue à cet égard le travail le plus abouti en langue française: Les Grecs pontiques. Diaspora, identité, territoires, CNRS Histoire, Paris, CNRS Éditions, 1998. Nous nous référons également à Michel Bruneau, "Territoires de la diaspora grecque pontique ", in Espace géographique, 1994, volume 23, n 3, p. 203216; Vlassis Agtsidis, Pontiakos Ellenismos [L’hellénisme pontique], Thessalonique,

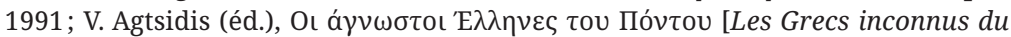
Pont], Athènes, Société d'études sur l'histoire grecque, 1995; Konstantinos Fotiadis, Iakovos Michelidis (éd.), Pontos: O Pontiakos ellinismos Athènes, Demokratia, 2011. Nous souhaitons ici tout particulièrement remercier Hervé Georgelin pour les indications de lecture qui ont guidé ce travail. 
traduit par une véritable mosaïque confessionnelle, avec coexistence des religions juive, chrétienne sous diverses variantes (Russes, Géorgiens, Arméniens), musulmane chiite (Azerbaïdjan), sunnite et même dans le passé bouddhiste.

Dans ce creuset montagneux, qui s'étend au carrefour des mondes turc, iranien et russe, dans un environnement ethnique extrêmement complexe, la population grecque, originairement installée sur le pourtour de la mer Noire, constitue, avec les communautés juive et arménienne, une des communautés " autochtones " les plus anciennes. L'installation des Grecs dans cette région, principalement concentrés autour du Pont, constitue en effet un phénomène qui remonte à l'Antiquité. Atteint par les navigateurs grecs de Milet, au viII ${ }^{\mathrm{e}}$ siècle avant notre ère, le pourtour de la mer Noire est jalonné de nombreuses colonies issues de la cité ionienne (Sinope, Irakleia, Amisos, Kerasous, Trébizonde...) $)^{2}$. Suite aux conquêtes menées par Mithridate au $\mathrm{II}^{\mathrm{e}}$ siècle avant notre ère, la présence grecque s'étend ensuite plus largement dans les deux principales régions que sont le "Pont micrasiatique ", dit PontEuxin, et la presqu'île de Crimée, ensemble régional où la présence grecque est attestée depuis près de trois millénaires. Elle a été favorisée par la succession des grands empires, byzantin jusqu'à la chute de Constantinople - à travers l'ancien royaume de Trabzon (Trébizonde), lié aux Comnènes, dernier État grec-orthodoxe conquis par les Ottomans en 1461 -, l'Empire ottoman, pendant près de quatre siècles, l'Empire tsariste, puis l'État soviétique, avant de tomber sous la coupe du nouvel État kémaliste au sortir de la Première Guerre mondiale.

De par sa situation géographique frontalière, passage et carrefour entre Orient et Occident, voie commerciale majeure en mer Noire, la région du Pont se situe au carrefour des zones d'influence des grands empires, sise sur la ligne de front entre de grands espaces culturels, parfois antagonistes, au croisement du monde slave oriental, de la péninsule anatolienne et du Caucase. Peuple des mon-

2. Patrick Counillon, « Les Grecs du Pont dans le royaume de Mithridate. Le témoignage des géographes antiques ", in M. Bruneau, Les Grecs pontiques..., op. cit., p. 41-50. 
tagnes, la communauté grecque pontique doit ainsi sa spécificité à son caractère initialement " acritique ${ }^{3}$ " qui en font un véritable "peuple des frontières ${ }^{4}$ ». C'est cette position " acritique », qui scelle la particularité de cette communauté traditionnellement prise en étau entre différents empires, et qui n'a cessé de subir, en sa longue histoire, les conquêtes et offensives, de part et d'autre d'une ligne de frontière qui n’a cessé de se déplacer, exacerbée par les revendications nationalistes durant les deux derniers siècles, du Pont au Caucase et, plus récemment, aux territoires méridionaux de l'exUnion soviétique.

Hormis l'ancienne communauté grecque cosmopolite " phanariote " installée en Crimée ou à Odessa, et les migrants métallurgistes venus de Chaldia, de la région d'Argyroupoli et de Theodosioupoli (Erzerum) en Géorgie au XviII ${ }^{\mathrm{e}}$ siècle après le déclin économique des installations minières du Pont, la quasi-totalité de la population grecque installée dans la région pontique et plus particulièrement dans le Caucase est originaire des zones montagneuses et du littoral de la mer Noire. Son installation dans le Caucase proprement dit est relativement tardif, épousant les flux et reflux, avancées et reculs de l'armée russe contre les Ottomans dans une zone charnière où l'enjeu était alors d'attirer les populations chrétiennes, grecques, mais également arméniennes pour repeupler des espaces quasiment déserts, notamment au sud de Tbilissi et dans la région de Kars-Ardahan. Sous la pression des Ottomans, très vite, le Caucase tend ainsi à devenir un espace de repli vers la Russie, entraînant les mouvements migratoires inverses des populations musulmanes (Circassiens, partiellement Abkhazes, Tchétchènes...). Lors de l'avancée russe dans la région au XIX ${ }^{\mathrm{e}}$ siècle, des centaines de milliers de musulmans sont ainsi contraints à l'exode, repoussés à leur tour

3. On nommait alors " acritiques " - de akra qui renvoie à la notion de frontière - les soldats installés par les Romains, puis Byzantins pour défendre la frontière orientale de l'empire. Le poème épique de Diogenis Akritas, dont un manuscrit datant du XvI ${ }^{\mathrm{e}}$ siècle aurait été découvert dans le monastère de Panagia Soumela dans la région de Trébizonde, et édité à la fin du XIX ${ }^{\mathrm{e}}$ siècle, en chante les exploits.

4. Michel Bruneau, « Les Grecs pontiques, du Pont au Caucase, à la Grèce et à la diaspora ", in Revue de géographie alpine, 101-2, 2013, p. 2. 
vers le nord de la Turquie et les montagnes du Caucase septentrional. Entamée au XviI ${ }^{e}$ siècle, l'avancée russe dans le Caucase est très tôt marquée par l'annexion de la Géorgie orthodoxe en 1801, suite à sa demande de protection face l'avancée ottomane. Il faut néanmoins attendre le début du XIX ${ }^{\mathrm{e}}$ siècle et la succession des guerres russo-turques pour expliquer l'installation massive des populations grecques dans la région du Caucase, jusqu'à l'installation définitive des Russes dans la région à partir de 1864. Après la première guerre russo-turque en 1828-29, la région passe en effet sous la tutelle russe, entraînant le premier exil des Grecs de Trébizonde qui dans le sillage de l'armée russe s'installent dans les territoires arméniens, mais également dans la région de Kars et celle de Tsalka dans l'actuelle Géorgie ${ }^{5}$. Durant tout le Xix ${ }^{\mathrm{e}}$ siècle, l'Empire russe, soucieux de repeupler des zones montagneuses et peu accessibles, fut ainsi à même d'offrir à la communauté grecque pontique des conditions de vie favorables dans un contexte particulièrement troublé, entraînant progressivement le déplacement massif d'une grande partie de la communauté du Pont dans le Caucase. Le cas de la famille Gurdzieff est ainsi emblématique de ces exils successifs, une famille qui quitte en 1874 la ville d'Argyropoli située dans la région du Pont pour Alexandroupoli, en Arménie, avant de rejoindre la ville de Kars, située dans le sud du Caucase et l'est de la Turquie actuelle. Comme Georges Gurdzieff le rappelle dans ses mémoires:

Mon père était d'origine grecque. Ses ancêtres avaient vécu dans l'Empire byzantin, qu'ils quittèrent après la prise de Constantinople par les Turcs pour échapper aux poursuites... Ils s'installèrent ensuite sur les côtes orientales de la mer Noire, dans la région d'Argyroupoli. Plus tard, avant la dernière guerre russo-turque, ils migrèrent en Géorgie chassés par les Turcs 6 .

Suite à la première guerre russo-turque et pendant les décennies suivantes, un grand nombre de familles grecques du Pont se réfugient ainsi dans le Caucase, à mesure que les conditions de vie

5. Sur l'installation des Grecs dans la région du Kars, voir Elefterios Charatsidis, "Les Grecs d'Arménie et de Kars aux XIx ${ }^{\mathrm{e}}$ et Xx ${ }^{\mathrm{e}}$ siècles », in M. Bruneau, Les Grecs pontiques..., op. cit., p. 143-156.

6. Georges Gurdzieff, Rencontres avec des hommes remarquables, Paris, "J'ai lu », 2008, p. 62. 
des non musulmans se détériorent. On constate ainsi le déplacement de villages entiers du Pont, scandé par les différentes guerres russoturques. Sont ainsi fondés 43 villages au sud de Tiflida en 1828, 77 villages dans la région du Kars et de l'Abkhazie, en Géorgie. Une première vague de migrants s'installe dans les vallées montagneuses de Tsalkas et de Tetri-Tskaro au sud de Tbilissi après la guerre russoturque de 1828-29. Une seconde vague, suite à la guerre de Crimée (1853-56), entraîne l'installation de 60000 Grecs du Pont dans les régions de Kouban et de Stavroupoli. Pendant la guerre russo-turque de 1876-78, on assiste à une fuite massive du Pont de Grecs en provenance des régions nord et est d'Argyroupoli et de Chaldia, qui débouche sur la création de 50 villages supplémentaires à Tiflida. Durant le XIX ${ }^{e}$ siècle, ce sont ainsi des centaines de milliers de Grecs qui s'établissent dans les régions de Terek, Stavroupoli, Sosoumi, Batoumi (villages d'Achalsion, de Koronistav, Askova, Takova, Kvirikas). En 1880, près de 100000 Grecs s'étaient déjà implantés en Crimée et dans le Caucase. Cette installation fut favorisée dans les vallées du Caucase au sud de Tbilissi et dans la région steppique de Kars-Ardahan, sur le plateau arménien de l'Anti-Caucase, annexé par la Russie entre 1878 et 1918 . Le seul XIX ${ }^{\mathrm{e}}$ siècle est ainsi marqué par l'arrivée de 300000 Grecs venus du Pont, dont 15000 à Bakou en Azerbaïdjan, 20000 à Stavroupoli ou encore 40000 en Crimée.

S'élevant à 150000 personnes au début du $\mathrm{Xx}^{\mathrm{e}}$ siècle, la population grecque installée dans le Caucase constitue une communauté extrêmement soudée et relativement homogène. Si la première vague de Grecs qui arrivent dès la fin du $\mathrm{xvIII}^{\mathrm{e}}$ dans les régions minières du Caucase sont principalement des métallurgistes issus de la région montagneuse d'Argyropoli, mettant à profit leur savoirfaire dans le travail artisanal des métaux et dans la sidérurgie - notamment dans leur contribution à la construction du chemin de fer transsibérien - , les deux tiers sont des agriculteurs et viticulteurs, spécialisés dans la polyculture et l'arboriculture fruitière, ainsi que dans la culture du tabac, dans les régions de Kars, Sourangkel, Soganlouk, Olti et de Kagisman, ou éleveurs dans les régions montagneuses d'Ardachan et de Kiolas. Le dernier tiers est principalement composé de commerçants, artisans et marins, fait dû à l'important réseau grec de navigation et de commerce, de blé et autres produits 
agricoles, dans la région du Pont et dans les ports russes de la mer Noire (Odessa, Kertch, Rostov, Novorossiisk, Batoumi).

Comme pour les diasporas juive, arménienne ou assyro-chaldéenne, la langue et la religion constituent sans conteste les éléments d'identification déterminants pour la population grecque de la région. Le maintien de la langue grecque, dite " pontique " a en effet été facilité dans l'Empire byzantin, puis dans les empires tsariste et ottoman, notamment en raison de la structuration de ce dernier en milleti. La relative autonomie des communautés a ainsi permis, pendant des siècles, la préservation de la langue grecque, à travers le dialecte vernaculaire pontique, conservé au sein des familles, et un enseignement en langue démotique à travers l'école et la religion. Le maintien de la langue, ou des langues du Pont, ce qu'on appelle le pontiaka, transmis de manière orale, constitue ainsi le principal ciment de cette communauté soumise à un exil permanent; il est pour une grande part le phénomène explicatif de la continuité multimillénaire de la langue grecque dans la région du Pont, puis dans les régions reculées du Caucase ou de Russie ${ }^{7}$. Quant au réseau d'enseignement local en langue grecque, par des professeurs formés au lycée de Trébizonde (Frontistirio), il assurait à la population grecque un niveau d'alphabétisation ( $80 \%$ des hommes) nettement supérieur au taux moyen du reste de la Russie; une éducation qui sera systématiquement étendue aux femmes après 1900.

Soudée également par une forte empreinte religieuse, la communauté pontique dispose d'un dense réseau ecclésiastique, avec un clergé formé à Trébizonde et dans les nombreux monastères fortifiés construits dans la région du Pont, puis dans les différentes régions du Caucase. Transmis de génération en génération, de nombreux rites, religieux et autres, viennent également resouder périodiquement la communauté. Le culte de la Vierge Soumela (Panagia Soumela) constitue, notamment, l'un des cultes fondateurs de l'imaginaire pontique: il s'est transmis de génération en génération, avec ceci d’intéressant qu'il s'est lui-même « déplacé » à mesure des exils successifs de la population. Initialement localisé dans la région

7. Voir Georges Drettas, « La langue pontique comme objet identitaire. Questions de représentations ", in M. Bruneau, Les Grecs pontiques... op. cit., p. 71-88. 
pontique de Trabzon, où une icône de la vierge aurait été trouvée à flanc de falaise, lieu d'édification de l'impressionnant monastère de Sumela au viII ${ }^{\mathrm{e}}$ siècle, ce culte, avec cérémonies et pèlerinages, se perpétue ensuite dans les régions de pérégrination des Pontiques, dans les monastères du Caucase et de Russie, dont le très célèbre monastère Athona situé dans la région abkhaze de Géorgie; on le retrouve ensuite implanté dans le cadre du centre religieux pontique de Panagia Sumela en Macédoine, faisant ainsi de Kastania où il est installé une nouvelle Soukhoumi, dans la continuité directe du culte initié à Trébizonde pendant la période byzantine ${ }^{8}$.

De la fin du XIX ${ }^{\mathrm{e}}$ siècle jusqu'en 1918, le mouvement migratoire se poursuit, marqué par l'arrivée de 70000 Grecs et la création de 74 villages dans la région de Kars-Ardahan dans l'Anti-Caucase. Mais, suite au « traité d'amitié et de fraternité » signé en 1921 entre les bolchéviques et le nouvel État kémaliste, la rétrocession de la région de Kars à la Turquie est marquée par un nouvel exode face à l'avancée des troupes ottomanes. La population grecque se réfugie alors autour de Tbilissi et dans le nord du Caucase, puis à Batoumi où des navires envoyés par le gouvernement grec les rapatrient en 19201921: ces réfugiés s'installent principalement au nord de la Grèce, en Macédoine et en Thrace, plus particulièrement à Kilkis, Florina, Drama, Imathia, Serres, dans une région balkanique montagneuse aux frontières de la Yougoslavie: encore une fois donc, en position charnière et « acritique ${ }^{9}$.

Les migrations sont motivées par les nombreuses persécutions subies de la part des Jeunes-Turcs, mais également par le désir d'éviter les contraintes du service militaire dans l'armée turque. Pour

8. Pour un approfondissement, voir Michel Bruneau, « Lieux de mémoire, hauts lieux et diaspora: Sanda et Soumela dans la diaspora grecque pontique », in L'Espace Géographique, 2, 1995, p. 124-134; Maria Vergeti, "L’identité pontique en Grèce. Le lien des générations avec leurs territoires de référence », in M. Bruneau, Les Grecs pontiques..., op. cit., p. 201-212.

9. Sur l'installation des Pontiques en Macédoine, voir Artémis XanthopoulouKyriakou, « Émigration d'émigrants. Du Caucase russe à la Macédoine ", in M. Bruneau, Les Grecs pontiques..., op. cit., p. 179-188; Pery Lafazani, Myron Myridis, "L'installation des Grecs du Pont en Macédoine. Le cas du département de Kilkis ", in M. Bruneau, op. cit., p. 189-200; Gerassimos Notaras, "État et société helléniques face au problème pontique », in M. Bruneau, op. cit., p. 229-240. 
la seule année 1913, le nombre de Grecs trouvant refuge dans le Caucase avait dépassé les 150000 individus. La communauté grecque dut à cette époque faire face, en contrepartie, au risque accru d'assimilation forcée du côté russe: en cause la montée en puissance du mouvement panslaviste qui tentait d'imposer uniformément dans l'ensemble du territoire impérial l'apprentissage de la langue russe comme langue d'enseignement obligatoire, et la mise sous tutelle de l'enseignement et des églises grecques, jusqu'ici relativement autonomes. La période qui suit la chute de l'Empire russe est en revanche marquée, jusqu'à la fin des années 1930, par un regain d'autonomie et une reviviscence des communautés dites "minoritaires", notamment à travers la réouverture des écoles, la multiplication des associations culturelles, organes de presse et fêtes collectives. La communauté grecque se trouve ainsi dans une situation quelque peu paradoxale, se revendiquant localement comme "grecque ", mais sans obtenir encore de reconnaissance de la part du nouvel et jeune État grec: l'hellénisme russe ne s'inscrivait pas encore, de par l'éloignement géographique, dans le projet expansionniste hellénique, jusque là entièrement concentré sur le Pont et la côte micrasiatique.

$\mathrm{Au}$ sortir de la guerre, la révolution russe et la chute de l'Empire tsariste offrent aux territoires caucasiens l'occasion de revendiquer leur indépendance, avec la République démocratique de Géorgie, suivie des républiques démocratiques d'Arménie et d'Azerbaïdjan, qui formeront l'éphémère République démocratique fédérative de Transcaucasie, membre de l'Union soviétique. Sur ce modèle, la question de la fondation d'une république grecque du Pont ne manqua pas de se poser, après l'effondrement de l'Empire ottoman. Mais le contexte n'était pas favorable, marqué par la défaite de l'armée grecque en Asie mineure et la concession de la région par le pouvoir soviétique au nouvel État kémaliste. Un premier congrès panpontique eut néanmoins lieu en 1918 à Bakou puis, l'année suivante, un second eut lieu à Thessalonique en présence des autorités grecques. Dès 1913-14, un vaste programme de rapatriement des Grecs originaires du Caucase et du Pont avait été mis en place par le gouvernement, marquant ainsi le début de l'ingérence de l'État grec en faveur de ces populations. Sur les 230000 réfugiés du Pont et d'Asie Mineure, au fil des délocalisations, 130000 s'installèrent ainsi en 
Thrace et en Macédoine, notamment dans la région de Kilkis, principalement des commerçants et agriculteurs, parmi lesquels 36000 venus de Bulgarie, 70000 de Thrace orientale, 20000 d'Asie mineure, et $4000 \mathrm{du}$ Caucase, soit quelques 853 familles, selon les chiffres avancés par le comité d'installation des réfugiés ${ }^{10}$. Dix ans plus tard, ce mouvement de "rapatriement " s'intensifia suite au traité de Lausanne (1923) qui stipulait, suite à la défaite grecque, l'échange de populations avec l'arrivée massive de populations grecques en provenance d'Asie Mineure et du Pont. Sur un total de 1200000 réfugiés enregistré alors, plus de 200000 étaient originaires du Pont, et environ 30000 du Caucase. Ces rapatriements furent extrêmement bien organisés, du côté grec, avec l'envoi de nombreux bateaux, accompagnés par la mise en place d'une politique systématique de repeuplement de la zone frontalière balkanique, en grande partie vidée de ses populations musulmanes ou chrétiennes slavophones.

Il faut rappeler un élément important de ce contexte: alors que la Russie occupait depuis près de cinquante ans la moitié orientale du Pont, ainsi que la région de Trébizonde, le retrait des troupes russes en 1917, décidé par les bolchéviques, entraîna une vague migratoire, formée par une grande partie de la population grecque de la région, soit près de 85000 personnes. Comme le rappelle Michel Bruneau, 60000 Grecs de Kars-Andachan se réfugièrent alors dans les villes portuaires de Batoumi (Batoum) et de Novorossiisk. La répression de la population arménienne et grecque demeurée dans cette région, comme celle d'Asie Mineure, déboucha sur les massacres que l'on sait, perpétrés par les Jeunes-Turcs puis par l'État kémaliste, qui se soldèrent par l'extermination de la moitié de cette population entre 1919-23. Sur quelque 600000 personnes, plus de la moitié furent anéanties, déportées ou emprisonnées, ce qui autorise à parler d'un véritable génocide, "génocide de l'hellénisme pontique " - qui ne sera reconnu que tardivement par l'État grec, en février 1994, sous la pression des associations pontiques ${ }^{11}$.

10. IAM, Г $\Delta \mathrm{M}$, dossier 64, bulletin du 12 juillet 1914.

11. Sur la "question pontique ", voir notamment les travaux de Konstantinos Fotiadis; voir également M. Charalampidis, To Pontiako Zitima simera, Athènes, Idrima Mesogiakon Meleton, 1992. 


\section{Du Caucase à la Sibérie: un peuple en exil permanent}

La période charnière des $\mathrm{XIX}^{\mathrm{e}}$-Xx $\mathrm{X}^{\mathrm{e}}$ siècles a été marquée par les revendications nationalistes qui rompent l'équilibre précaire des anciens Empires; elle constitue une période d'instabilité extrême, qui se traduit dans le Caucase et les Balkans par des échanges et exodes permanents de populations, des nettoyages ethniques de part et autre, du génocide de la population grecque et arménienne du Pont par les kémalistes aux déportations dans les goulags de Sibérie. Principalement marquée par les trois grandes vagues que sont l'échange de population après 1923-24, l'exil suite aux purges staliniennes des années 1930 et 1940 et la dissolution de l'Union soviétique après 1991, l'arrivée en Grèce des réfugiés pontiques fait ainsi figure de véritable exode massif.

La période stalinienne dans l'ex-URSS marque un nouveau tournant pour les populations installées dans le Caucase et dans le sud de la Russie. Suite aux tentatives d'insurrection fomentées par les Allemands pour soulever les populations du Caucase et s'emparer des réserves pétrolifères, Staline s'engage dans une vaste opération de déportation des populations non « russes » dans les steppes d'Asie centrale $^{12}$. La volonté d'éradiquer toute velléité nationaliste et séparatiste entraîne des persécutions, assassinats et déportations massives de nombre de populations, dont les Grecs. À partir de 1936 et jusqu'à la fin de Seconde Guerre mondiale, la majeure partie de la population grecque, désormais officiellement stigmatisée comme « ennemis du peuple ", ennemis de l'intérieur, est ainsi mise au ban de l'Union soviétique, les personnalités politiques exécutées sans aucune forme de procès, les hommes d'âge adulte arrêtés et l'ensemble de la population déporté. Dès 1938, la fermeture définitive des écoles grecques, l'interdiction de toute association et rassemblement collectif, jointe à l'imposition obligatoire de la langue russe en vue de "soviétiser " la population, rendent les conditions particulièrement difficiles pour les communautés minoritaires implantées dans le Caucase. Ce mou-

12. Sur cette période, voir Vlassis Agtsidis, « Les déplacements forcés: Asie centrale et Sibérie; territoires de la déportation ", in M. Bruneau, Les Grecs pontiques..., op. cit., p. 157-175. 
vement trouve son acmé dans les années 1937-1938, puis reprend en intensité à la fin de la guerre, entre 1944 et 1949, années au terme desquelles la quasi-totalité de la population grecque d'Union soviétique, soit près de 200000 personnes aura été chassée, déportée vers les camps sibériens et les kolkhozes d'Asie centrale. Les Grecs de Crimée furent principalement dispersés dans les régions d'Ouzbékistan et du Kazakhstan, tandis que ceux de Géorgie, soit plus de 40000, sont envoyés principalement en Asie centrale et dans le Sud de la Sibérie. Selon les chiffres avancés par la communauté pontique, ce seraient près de 47000 Grecs qui disparurent pendant cette période, exécutés ou victimes de mauvais traitements durant leur déportation. Les Grecs qui en réchappent, soit par assimilation tardive ou qui ne disposaient pas alors de passeport grec ou non répertoriés, se retrouvent une nouvelle fois contraints de fuir.

Si le processus se poursuit au début des années 1950, il faut attendre la mort de Staline en 1954, et notamment la période de "dégel " amorcée sous Khrouchtchev, pour que les populations déportées aient l'autorisation de rentrer au pays et soient réhabilitées, avec reconnaissance des massacres perpétrés, comme dans le cas du village grec de Kouma (Abkhazie), où la totalité des hommes, soit une centaine furent massacrés. Le contexte turc n'étant pas favorable, marqué par les pogroms anti-grecs et anti-chrétiens de 1955, le retour dans la région du Pont restait impossible: beaucoup de Grecs se réinstallèrent dans le Caucase. Toutefois, 20000 Grecs de Géorgie parvinrent à rejoindre la Grèce, malgré les difficultés imposées par la guerre froide, les rapports de force politiques, et également la non reconnaissance par l'État grec des populations russophones se réclamant de l'hellénisme. C'est seulement après 1985, avec l'arrivée au pouvoir de Gorbatchev et la période de la Perestroïka, puis, après 1991, que la situation commence à se détendre, avec le rapatriement d'une grande partie des Grecs vers la Grèce.

L'effondrement du bloc soviétique et la remise en cause de la domination russe dans la région qui s'ensuit, marquent en effet un nouveau tournant pour la communauté grecque ${ }^{13}$. Le recensement

13. Plus spécifiquement sur les Grecs de Russie, nous renvoyons aux travaux de Konstantinos Fotiadis, notamment $O$ Pontiakos Ellenismos tis Sovietikis Enosis, Thes- 
de 1989 indiquait encore la présence de près d'un demi-million de Grecs en Union soviétique, entre 358000 et 600000 , citoyens soviétiques pour la plupart selon les chiffres cités par Michel Bruneau, un million si l'on prend en compte les mariages mixtes ${ }^{14}$, population principalement localisée sur les bords de la mer Noire, en Russie du sud et dans le nord du Caucase, en Moldavie (Chisinau), en Ukraine (Odessa, Mariupol, Crimée) et en Géorgie (Abkhazie, Adjarie, Tbilissi). Près de 100000 Grecs étaient ainsi recensés en Géorgie, 90000 dans le nord du Caucase, 60000 au sud du Kazakhstan (Tchimkent, Kentaou) et en Ouzbékistan (Tachkent). En 1989, ils représentaient encore trois pour cent de la population totale de l'Abkhazie, région qu'ils seront néanmoins amenés à quitter quelques années plus tard pendant la guerre civile.

L’instabilité dans la région, alimentée par les revendications séparatistes, notamment pendant la guerre en Ossétie du Nord en 1992, les deux guerres de Tchétchénie en 1994-1995 et 19992000, puis en Ossétie du Sud en 2008, ajoutée à l'antagonisme russo-ukrainien, en font une zone de conflits qui contraignent de nouveau la population grecque à fuir, entraînant la fermeture des écoles grecques, les violences et bombardements, un climat général d'insécurité et une forte crise économique. C'est dans ce contexte d'instabilité extrême, alimenté par les velléités séparatistes qui suivent l'effondrement du bloc soviétique que l'État grec prend la décision d'aider à rapatrier les derniers Grecs présents dans le Caucase. Plus de la moitié de la population grecque choisit alors de s'exiler. La région de Tsalkas, en Géorgie centrale, et ses trente villages grecs furent ainsi quasiment vidés de leur population, seules

salonique, 1991; O ellinismos tis Rôsias ke tis Sovietikis Evôsis Athènes, Herodote, 1999. Voir également Spyros Kofidis, «E metanastevsis tôn Ellinopontiôn is Rôssian kata ton 19on aiôna ", in Pontiaki Estia, vol. 34, juillet-août 1980, p. 267-271; " Les Grecs de l'ex-URSS, genèse d'une diaspora ", in M. Bruneau, Les Grecs pontiques. Diaspora, identité, territoires, op. cit., p. 51-70; Vladimir Kolossov, Tamara Galkina, Alexei Krindatch, « Les Grecs du sud de la Russie et du Caucase. Peuplement, répartition, territorialité ", in M. Bruneau, Les Grecs pontiques..., op. cit., p. 91-112; Vitaly Belozorov, Tamara Galkina, Vladimir Kolossov, Pavel Touroun, "Les diasporas arménienne et grecque dans la mosaïque ethnique du Caucase du Nord », Revue européenne des migrations Internationales, vol. 14, n 3, 1998, p. 103-125.

14. Cf. M. Bruneau, « Territoires de la diaspora grecque pontique », op. cit., p. 204. 
20000 personnes firent le choix de rester. Sous la pression de manifestations à Athènes, une opération de grande envergure mise en place en 1993 par l'État grec permit ainsi de rapatrier 15000 concitoyens; l'opération "Toison d'or " (Xryssomallo Deras) reste emblématique. Le 16 août 1993, un bateau affrété par la Grèce put ainsi rapatrier près d'un millier de Grecs de Soukhoumi pris en étau dans la guerre entre Abkhazes et Géorgiens. La population grecque de Sotchi fut quant à elle rapatriée par bus, celle de Tiflida par avion. Sous le feu des projecteurs et suivies par les médias grecs, ces opérations de sauvetage ont indéniablement servi la cause pontique et favorisé la reconnaissance par l'opinion publique de l'hellénisme "russe " en provenance des régions éloignées du Caucase. Prise en charge par les autorités grecques à leur arrivée et bénéficiant des réseaux pontiques préexistants, l'installation des réfugiés a ainsi pu être grandement facilitée par la promulgation d'une «loi du retour " favorables aux " Russo-Pontiques " (Russopontioi), par les programmes de rapatriement mis en place par les pouvoirs publics, et notamment par la fondation d'un " centre d'implantation et d'installation territoriale " (ethniko Idrima Ipodokis kai apokatastasis) qui voit le jour en 1990 pour organiser le peuplement des zones marginalisées du nord de la Grèce.

$\mathrm{Au}$ total, ce sont 170000 nouveaux réfugiés qui s'installèrent en Grèce, principalement dans la banlieue athénienne, en Thrace et en Macédoine, où les réseaux pontiques étaient déjà particulièrement denses. Ce mouvement migratoire s'accélère après 1992 avec l'arrivée de 30000 à 40000 nouveaux réfugiés en provenance du Caucase. Rejoignant les vagues de migration précédentes, la population d'origine pontique s'élevait alors à 850000 personnes installées en Grèce, principalement dans la banlieue athénienne, 600000 en Macédoine, 50000 en Thrace, et 30000 à Chypre. Pour beaucoup, l'arrivée en Grèce ne marqua néanmoins pas une installation définitive. Un grand nombre de ces réfugiés pontiques firent ensuite partie des grandes vagues migratoires, à destination, dès le milieu des années 1950 et jusqu'aux années 1970, de l'Australie puis de l'Allemagne, principalement pour des raisons économiques. Quelque 55000 migrants d'origine pontique s'installèrent durant cette période en Australie, principalement à Melbourne, et quelque 90000 
en Allemagne, principalement dans le Bade-Wurtemberg, où réside près d'un tiers de la population grecque émigrée dans ce pays.

\section{Le « retour " en Grèce de la communauté pontique}

Pour la communauté grecque pontique en provenance du Caucase, qui rejoint les réfugiés du Pont arrivés après 1923, le rapatriement en Grèce, toujours contraint et imposé, est moins vécu comme un "retour ", que comme un véritable exil et arrachement. Tout comme pour les micrasiatiques, c'est avant tout la perte du territoire d'origine, et l'exode permanent qui s'en est suivi, qui soudent cette communauté qui, si elle est socialement relativement homogène, dut apprendre à s'adapter et à s'intégrer dans des régions culturellement et linguistiquement très variées. Les expériences collectives traumatisantes que furent les persécutions, déportations et massacres subis sous le régime stalinien, mais également dans l'Empire ottoman et sous le régime kémaliste constituèrent à cet égard un important élément de cohésion pour une communauté qui n’aurait pu survivre sans un ciment social et culturel extrêmement fort, souvent rendu possible et facilité par la densité des réseaux grecs, familiaux et plus élargis, à travers le maintien de voisinages souvent reproduits à mesure des déplacements et ré-enracinements. Force est de constater pourtant que ce ne sont pas tant les persécutions ni l'ostracisation dont cette communauté a été victime que la référence commune à l'hellénicité profonde qui est le plus souvent mise en avant. S'ils rencontrent de réelles difficultés d'adaptation et d'intégration à leur arrivée en Grèce, les Grecs " caucasiens " (Kavkasioi), comme les nomme parfois la population locale, sont en effet loin de se considérer comme de simples réfugiés ou migrants. Se qualifiant eux-mêmes parfois de trandellines (« trente fois plus grecs »), ils se réclament eux-mêmes d'une hellénicité ancestrale héritée en droite ligne de l'Antiquité, qui leur permet d'inscrire leur histoire singulière dans le grand roman national et de réclamer une place privilégiée dans l'histoire plus vaste de l'hellénisme. La dynamique identitaire est ainsi davantage fondée sur un processus de revendication que sur la victimisation de cette communauté, comme le souligne de manière fort juste Hervé Georgelin: 
Les Pontiques ont été pris dans une dynamique d'affirmation de soi dans le système symbolique politique grec. Ils ne sont pas passifs dans cette dynamique [...] Être Pontique, s'affirmer descendant de Grecs qui peuvent, pour la plupart, revendiquer, selon les schèmes classiques du nationalisme, une continuité d'hellénophonie avec l'Antiquité, une pérennité étatique plus longue que celle de Byzance, le vrai point de fuite de l'histoire grecque précédent juste la Renaissance et les Temps modernes occidentaux, une pugnacité contre l'Empire ottoman puis la nouvelle Turquie kémaliste, voilà qui pose un groupe venu d'ailleurs au beau milieu du récit national grec moderne ${ }^{15}$.

C'est initialement sur cet élément territorial premier, à travers la référence au Pont comme terre d'origine ancestrale, référence commune à une population désormais installée aux quatre coins du monde, que se sont cristallisées les revendications de la communauté pontique, notamment à travers le projet de création d'un territoire autonome grec sur les bords de la mer Noire, en référence explicite à l'ancien Empire de Trébizonde (1204-1461), périodiquement revendiqué après la Conférence de la paix de 1919, à l'issue de la Première Guerre mondiale et reprise après la chute de l'Union soviétique. Défendu par les représentants des Grecs d’URSS, Union fédérant les associations grecques alors présidée par Gavriil Popov, Grec pontique devenu maire de Moscou en 1990-1992, et proche collaborateur d'Eltsine, le projet d'établir une " République du Pont " est ainsi présenté au Congrès de Moscou en 1989.

Si les initiatives pour constituer un État autonome débouchent sur un échec, les efforts de la communauté vont désormais se tourner vers des revendications, non plus tant territoriales que mémorielles, dont l'une des conquêtes sera la récente reconnaissance par l'État grec, en février 1994, du "génocide des Grecs pontiques par les néoturcs et kémalistes, rendus responsables des crimes commis pendant la période 1916-1923 ». L’affirmation iden-

15. Hervé Georgelin, présentation dans le cadre du séminaire de Méropi Anastassiadou, Département d'études turques et ottomanes, École des hautes études en sciences sociales: « Le Pont, sujet de l'historiographie et élément de perception de soi dans la Grèce contemporaine. Le Pont et les Pontiques: altérité grecque-orthodoxe en Grèce contemporaine », Paris, 12 mai 2010. Nous remercions vivement l'auteur de nous avoir permis de prendre connaissance de cette présentation. 
titaire se nourrit désormais de la reconnaissance d'une histoire singulière, transformant ainsi le territoire perdu en un territoire de la mémoire dont les frontières ne sont plus territoriales, mais désormais élargies aux lieux de passage de cette communauté diasporique et à ses lieux de mémoire. L'identité pontique elle-même s'enracine, ce faisant, dans la seule capacité qu'a eue cette communauté de garder vivante la mémoire de sa patrie d'origine. L'extrême dynamisme des organisations associatives, en Grèce et à l'étranger, l'organisation de réunions et de fêtes collectives, la multiplication des études et recherches consacrées aux Pontiques, la restauration de monuments et les pèlerinages collectifs attestent de la force et de la reviviscence d'une communauté qui constitue une composante bien vivante de la diaspora hellénique ${ }^{16}$.

Se nourrissant de l'imaginaire hellénique le plus ancien, n’hésitant pas à puiser dans la mythologie et l'héritage antique, puis byzantin, la communauté "pontique " ou d'origine pontique a ainsi pu se maintenir, même en sa forme diasporique, grâce à un capital symbolique plurimillénaire qui lui offre une place, sinon mythifiée, au moins de premier rang dans l'histoire grecque. La communauté pontique constitue ainsi ce faisant une des diasporas les plus anciennes de l'hellénisme, dont la particularité est d'avoir vécu plusieurs déracinements, du Pont au Caucase, en passant par les steppes sibériennes puis, le "retour » en Grèce, en Macédoine et, pour un grand nombre, l'exil en l'Allemagne ou en Australie. Si la référence au territoire est constante, la dimension diasporique est ici constitutive d'une identité qui s'est à mesure construite, au fil des derniers siècles, sur d'incessantes vagues de migrations, succession de déracinements et de ré-enracinements successifs, de persécutions et d'assimilation. Constituée de près de deux millions de personnes

16. Sur cette reviviscence, voir A.M. Bryer, «The Pontic revival and the new Greece ", in A. Bryer (éd.), The Empire of Trebizond and the Pontos, Londres, Variorum Reprints, 1980, p. 171-190; P. Fann, « The Pontic myth of homeland: cultural expressions of nationalism and ethnicism in Pontos and Greece, 1870-1990 ", in Journal of Refugee Studies 4, 1991, p. 340-355. 
diversement répartis, la diaspora pontique incarne bien le phénomène d'une communauté "transnationale ", proche en cela de la communauté kurde ou arménienne, qui a su relier diverses communautés de réfugiés et migrants originaires du Pont, dans le Caucase et en Russie, puis en Grèce, et désormais dans le monde entier. 
9

\section{Les cultures du nord du Caucase et leurs mutations au tournant du $\mathrm{XX}^{\mathrm{e}}$ siècle}

Le cas du peuple ingouche Boris Kharsiev

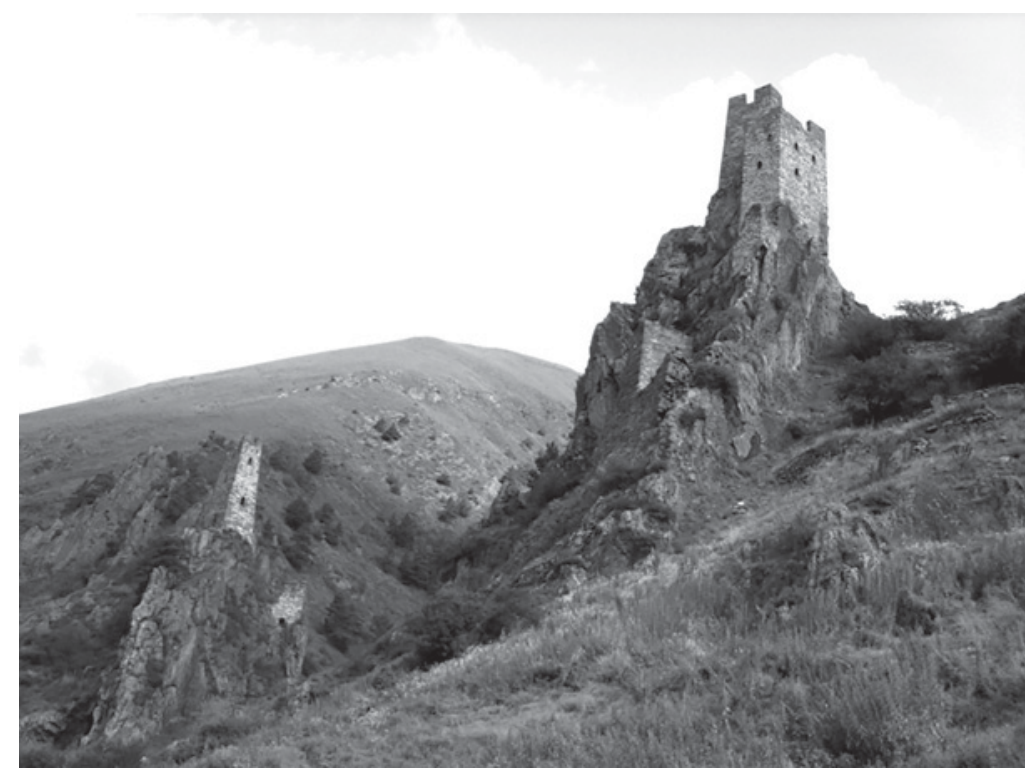

ILL. 1. Tour de clan. Le peuple ingouche est le peuple des tours, ainsi qu'il se dénomme lui-même (halghaï, de ghal: forteresse et ghaï - habitants). Ces tours forteresses, servant d'habitation, de refuge, de lieu de défense et de surveillance, ont été érigées par les divers clans (d'où leur nom de " tours de clan »). Il en subsiste plusieurs centaines. (Photo (c) CC by 3.0/Timur Ziev) 
Une ethnie ne peut généralement faire évoluer sa culture propre qu'au prix de transformations profondes et parfois contradictoires. Le processus soulève un certain nombre de questions: "Comment développer une culture qui combine des éléments universels et des éléments locaux? Comment réaliser en pratique le principe théorique du dialogue des cultures? Où situer la limite au-delà de laquelle l'interaction entre cultures conduit à la perte de leur identité originelle? Comment distinguer entre influence culturelle et expansionnisme culturel? Comment préserver les particularismes culturels tout en se montrant ouvert à la société d'information moderne? Peut-on envisager le progrès technologique comme un progrès culturel? Les moyens modernes de communication ontils un impact sur la façon de réfléchir et de percevoir, et si oui, lequel ${ }^{1}$ ?"

Les universitaires comme les acteurs culturels s'intéressent depuis longtemps aux aspects ethniques et territoriaux du phénomène culturel. En effet, on a aujourd'hui largement pris conscience de l'existence d'ethnies différenciées. Par ailleurs, on voit de plus en plus souvent se manifester une résistance à l'uniformisation des modes de vie qui accompagne l'universalisation et la simplification générale de la culture et de ses institutions.

Notre propos est de mettre au jour la chronologie des événements historiques qui sont à l'origine de tendances, socialement régressives ou progressistes, qui obéissent consciemment à des schémas d'intégration ou de dégradation culturelle. Il s'agira également de proposer une généralisation empirique à partir des sources primaires dont nous disposons, ce qui aidera à traiter objectivement de phénomènes similaires dans le futur.

La culture Nakh est née dans le Caucase au moment où apparaissait l'ethnie proto-ingouche; ses particularismes ont pu traverser les siècles. Les Ingouches (Glalgay), en tant que sujets socio-historiques, ont, à certaines époques, poursuivi des buts spécifiques liés à la mise en œuvre de leur culture et de leur société; et, comme tout groupe ethnique, ils ont subi l'influence des bouleversements historiques.

1. A.V. Kostina, Nacional'naja kul'tura - etničeskaja kul'tura - massovaja kul'tura, Moskva, Librokom Publ., 2009. p. 3. 
Les normes culturelles sont, pour une large part, issues de la morphogenèse, c'est-à-dire du processus par lequel des formes d'interaction nouvelles sont intégrées dans la pratique sociale. Certaines de ces formes finissent par acquérir le statut de nouvelles normes qui régissent l'activité et les interactions au sein du groupe ethnique. Il peut s'agit de normes institutionnelles, avec une fonction fortement prescriptive; de normes conventionnelles, de caractère plus permissif; ou de normes statistiques, dont le pouvoir régulateur est moins systématique. Certaines formes, augmentées de nouveaux éléments, sont intégrées au système de construction identitaire, en particulier au niveau de microgroupes sociaux, comme la famille élargie.

En tant que premier microgroupe social, la famille, chez les Ingouches, a joué un rôle majeur dans la formation des clans (teip), puis des communautés (shahra), et enfin de l'ethnie (kham). Les relations sociales se sont structurées suivant le même modèle: d'abord au niveau de la famille, puis au niveau de la communauté, enfin au niveau de l'État. À certaines époques, chaque communauté ingouche, dans tout le défilé montagneux, était une petite cité démocratique, laquelle avait délibérément intégré un ensemble plus large, partageant les responsabilités et les profits d'une fédération où chaque membre jouissait des mêmes droits. La structure sociale et politique de cette fédération était gouvernée avant tout par un principe de réciprocité dans les interactions sociales.

Jusqu'au début du XIX ${ }^{\mathrm{e}}$ siècle, le Mekhk-Khel ("Conseil du pays ") a joué un rôle important ${ }^{2}$. L'ensemble de la société était soumis aux décisions de cette institution civique, y compris à celles concernant l'appel des volontaires dans les corps d'armée populaires. Ces corps militaires étaient appelés au sein d'une communauté donnée et ceux qui refusaient de se rendre au rassemblement étaient sanctionnés. Dans quelques cas exceptionnels, il y a eu des corps de volontaires dans tout le pays.

Le Mekhk-Khel réunissait les pouvoirs législatif ${ }^{3}$, judiciaire et exécutif ${ }^{4}$. Au moins deux fois par an, les représentants de diverses

2. Istorija Čečeno-Ingušetii, Grozny, 1992, p. 76.

3. I. Popov, Sbornik statej Terskogo okruga, Vladikavkaz, 1878, vol. I., p. 262-263.

4. Central'nij gosudarstvennij arhiv Respubliki Dagestan, fonds 1406, f. 294, 1. 4-8 
sociétés se retrouvaient en forum sous la direction du bachcha ("président "). Au sein du Mekhk-Khel, les Sages ingouches établissaient les lois concernant la propriété foncière et le fermage ${ }^{6}$; ils s'accordaient sur les lois régissant le comportement de chacun dans la société, et sur les sanctions réservées à ceux qui les enfreignaient. Ils prenaient la décision d'entrer en guerre ou de faire la paix; ils régulaient le commerce extérieur ${ }^{7}$ et intérieur (par exemple en décidant des étalons de mesure, en fixant le prix du bétail, etc.), ils prenaient les dispositions nécessaires à la défense militaire, réquisitionnaient les biens matériels pour couvrir les besoins publics, et collectaient les impôts et les taxes ${ }^{8}$. Une phrase résume le pouvoir que détenait autrefois le Mekhk-Khel: «C'était un pays dont nul n'avait à se venger, mais qui ne laissait jamais impunie une attaque à son endroit ${ }^{9}$. "

L’ethnie ingouche s'est installée sur une aire géographique spécifique du Caucase, et se caractérisait par un mode de reproduction simplement biologique. Par ailleurs, ses valeurs culturelles fondamentales se trouvaient exprimées dans l'unité externe de ses formes culturelles, dans les champs sémantiques unifiés utilisés pour communiquer et interagir, et dans les contacts symboliques et sémantiques visant à identifier et constituer le groupe ethnique en tant que tel ${ }^{10}$.

La culture ingouche dans son ensemble touchait à tous les domaines de l'activité humaine, qu'il s'agisse de savoirs acquis, d'autoreprésentation, ou de représentations symboliques du monde

5. I.M. Saidov, Obščestvenniy byt vajnahov XIX I načala XX vv, Makhatchkala, Avtoreferat kand. Dissertacii, Tbilisskij Gosudarstvennyj Universitet 1972, p. 202.

6. V. Laudajev, Čečenskoje plemja, in Sbornik svedenij o kavkazskih gorcah, $\mathrm{n}^{\circ} 4$, Tbilissi, Tipografija Glavnogo Upravlenija Namestnika Kavkazskogo, 1878.

7. Akty Kavkazskoj Arheologičeskoj Komissii, vol. VII, p. 917-918; Tsentral'nij gosudarstvennyj vojenno-istoričeskij arhiv, fonds 26, p. 152, f. 514, l. 126-127; Raport generala Rtiščeva vojennomu ministru Barklaju de Tolli ot 6 oktjabrja 1811 , $\mathrm{n}^{0} 1858$.

8. I. M. Saidov, op. cit., p. 202.

9. B. M. Kharsiyev, Ingušskiye adaty kak fenomen pravovoj kul'tury, thèse de doctorat, Rostov na Donu, izdatel'stvo Artem, 2003, p. 71.

10. F.Y. Albakova, Sovremennije problemy nacional'no-etničeskogo soznanija na Severnom Kavkaze, http://miris.eurac.edu/mugs2. 
extérieur. Elle structurait le groupe ethnique pour garantir son intégrité et favoriser le développement d'une organisation sociale autonome et capable de survivre à des situations diverses dans l'histoire. Les réalisations architecturales en pierre, que l'on peut encore observer aujourd'hui, nous permettent d'entrevoir certains traits de l'ancienne culture ingouche. En effet, parmi les artefacts notables de la culture matérielle ingouche, on trouve notamment des tours de pierre, des terrasses, des systèmes hydrauliques et d'autres structures, présentes dans les régions montagneuses de l'Ingouchie. Ces artefacts en pierre témoignent d'une technique architecturale très avancée. De toute évidence, ce sont bien les ancêtres des Ingouches qui ont construit ces tours, ces routes de montagne, ces terrasses très particulières servant à la culture de certaines céréales, ces moulins à eau et toutes ces réalisations, que ce soit pour protéger leurs territoires des hordes guerrières venant du nord ou du sud pour attaquer le Caucase, ou pour nourrir la population, y compris dans les zones montagneuses arides:

La production artisanale, en particulier la poterie et la métallurgie, tenait une place importante dans l'économie. On a trouvé de nombreuses poteries dans les monuments funéraires et dans les maisons, et on a découvert un certain nombre de fours à poterie. [...] La métallurgie aussi a joué un rôle important. On fabriquait des armes, des outils et des ornements en métal. Les artisans locaux maîtrisaient plusieurs techniques de métallurgie: le moulage, le forgeage, le repoussé, la gravure, l'impression, l'incrustation, le tréfilage ${ }^{11}$.

$\mathrm{Au}$ début du Moyen Âge, le récit épique traditionnel des Ingouches, l'épopée narte, a pris sa forme définitive au moment même où les Ingouches étaient chassés de leur territoire par les nations voisines.

La culture matérielle et spirituelle des Ingouches est une manifestation de leur identité nationale, laquelle relève d'une axiologie des valeurs. Il nous faut étudier ces valeurs pour comprendre les évolutions historiques et culturelles observées chez les Ingouches, ainsi que toute leur philosophie sociale.

11. G.Z. Anchabadze, "Vajnahi ", in N.V. Gelašvili (éd.), http:// docplayer. ru/32612080-G-z-anchabadze-v-a-y-n-a-h-i-redaktor-n-v-gelashvili-tekst-kartoshemy-g-z-anchabadze.html, 2001, p. 26. 
À partir du milieu du Xvi ${ }^{\mathrm{e}}$ siècle, le nord du Caucase s'est vu intégrer dans l'orbite de Moscou, dont les aspirations géopolitiques s'étendaient. Depuis cette époque, la Russie n’a pas ménagé ses efforts pour s'adjoindre les États du Caucase.

La politique menée par les autorités tsaristes dans le Caucase, et les efforts des représentants des communautés ingouches fédérées, ont finalement abouti en 1770 (le 17 mars dans le calendrier grégorien) à une pétition de nobles ingouches demandant l'intégration de l'Ingouchie à l'Empire russe ${ }^{12}$.

Les montagnards du Caucase étaient disposés à subir patiemment le joug russe, tant qu'ils avaient la garantie de pouvoir conserver leur religion, leurs coutumes et leur mode de vie; en d'autres termes, leurs traditions culturelles et spirituelles ${ }^{13}$. Ils exigeaient aussi, en retour, que l'État russe protège leurs intérêts matériels et moraux. C'est exactement en ces termes que la population ingouche du Caucase entendait, et acceptait, la citoyenneté russe. Les différentes parties qui signèrent ce traité historique avaient donc une compréhension différente de ce que devaient être les relations entre la Russie et le Caucase.

Dans la deuxième moitié $d u$ XvIII $^{\mathrm{e}}$ siècle, l'Empire russe avait besoin de forger des alliances avec les montagnards du nord du Caucase pour consolider sa position politique en Transcaucasie (sud de la région). Une fois sa domination fermement établie en Transcaucasie, la Russie ne pouvait plus revenir en arrière sur son " influence " sur les autres peuples du Caucase, dont les territoires la séparaient des terres nouvellement conquises au sud. Ainsi que le fait remarquer I. Y. Kutsenko, « il nous était indispensable de maintenir la domination russe dans le Caucase à tout prix, pour préserver notre seule voie de passage à travers les montagnes ${ }^{14}$ ".

Les caractéristiques culturelles d'un peuple ou d'une ethnie sont directement liées à ses conditions de vie. Quand celles-ci sont

12. AVPRI DID (Archives des Affaires étrangères de l'Empire russe), L. 4180.

13. S. V. Kulešov, D.A. Amanžolova, P.V. Volobujev, Nacional'naja politika Rossii, Moskva, Russkij mir, 1997, p. 92.

14. I.Y. Kutsenko, « Kavkazskaja vojna i problema preemstvennosti politiki na Severnom Kavkaze, " Actes du colloque Kavkazskaya voyna: uroki istorii i sovremennost', 16-18 maja, 1994 g., Krasnodar, Rossijskij institut kul'turologii 1995, p. 55. 
modifiées, les règles qui régissent les relations entre les différentes communautés ethniques et peuples changent également. Ainsi, quand deux cultures ethniques changent leurs modes d'interaction, il leur faut trouver un nouveau compromis pour assurer le développement et la modernisation des espaces qu'elles partagent. C'est cette recherche d'interrelations positives, ainsi que des intérêts communs quant à leur autoconservation, qui amènent les différents groupes ethniques à travailler de conserve. Cependant, l'État russe s'est montré incapable d'établir une base de dialogue avec les différents peuples du Caucase, ce qui aurait permis de favoriser la paix et l'entente mutuelle entre la métropole et les régions plus éloignées.

Dans ses relations avec de petites nations, la Russie peut adopter n'importe quelle politique d'intégration ou d'assimilation, tant que cela sert ses intérêts. En ce qui concerne les peuples du Caucase, l'Empire russe a choisi l'assimilation. Ceux qui résistaient à la russification étaient durement réprimés.

Dès les premières années où le Caucase a été « propriété » russe, des malentendus sont apparus entre les autorités russes et les montagnards. La puissance russe, habituée, du fait des traditions, au servage, ne pouvait pas comprendre et encore moins accepter la libre disposition de soi-même dans la société ingouche. En effet, les Ingouches refusaient de laisser implicitement leurs propriétés, leur fourrage et leurs bêtes à la disposition de l'armée, de rendre leurs armes personnelles ou d'obéir inconditionnellement aux ordres des nouvelles autorités russes. « Ceux qui ont mené la conquête du nord du Caucase et ont, les premiers, colonisé les territoires nouvellement occupés, n’avaient pas une idée très claire de leurs motivations ni des actions à mener pendant leur présence sur les territoires conquis. C'est là une donnée essentielle: la Russie ne s'est jamais dotée d'une doctrine coloniale claire (comme l'Angleterre l'avait fait, par exemple). On ne peut suffisamment insister sur le fait que la conscience nationale est, finalement, intimement liée à cette politique de domination par le haut ${ }^{15}$. "

15. S. Lurie, « Rossijskaja imperija kak etnokul’turnij fenomen », in Obščestvennije nauki i sovremennost'1994, $\mathrm{n}^{\circ} 1$, p. 57. 
La Russie se comportait avec les nations nouvellement conquises (ou celles qui avaient librement rejoint l'Empire) très différemment d'autres empires à la même époque (par exemple l'Angleterre et la France). Le colonialisme russe était assez spécifique. On peut dire que le colonialisme européen était de nature économique, tandis que le colonialisme russe serait d'avantage d'ordre socioculturel.

Les métropoles européennes considéraient leurs colonies avant tout comme devant servir à la qualité de vie des résidents métropolitains et favoriser le progrès de l'économie nationale. En cette époque où les États-nations se constituaient et où s'établissaient leurs fondements historiques et culturels, la Russie, qui ne connaissait pas les frontières "étroites " de l'Europe, ne percevait pas non plus les territoires colonisés comme étant géographiquement isolés.

Les colons n'ont donc pas reproduit dans un ailleurs lointain leurs traits ethnoculturels: ils les ont simplement étendus, principalement à l'est et à l'ouest de leur berceau historique, dans un continuum spatial. En perdant son territoire, un peuple perd sa culture: ce truisme est particulièrement valide dans le cas des Ingouches. Les terres, les tombes des ancêtres, les richesses minières furent confisquées et brandies comme des trophées par les occupants et, des générations après, ces trésors sont maintenant considérés comme faisant partie de l'héritage national des anciens envahisseurs. Le processus de formation d'une entité russe supraethnique, qui a absorbé beaucoup d'ethnies d'origine non slave, permet de bien comprendre la nature extensive du colonialisme russe. Appliquer le terme "extensif " au phénomène colonial est sujet à caution, cependant, dans la mesure où l'on peut se demander si l'expansionnisme ethnique russe et les tendances assimilationnistes à l'œuvre dans la construction d'une entité supra-ethnique sont légitimes. En d'autres termes, du point de vue européen, c'est l'aspect financier qui compte le plus dans le colonialisme, tandis que du point de vue russe, c'est le territoire, l'espace ${ }^{16}$.

C'est en réprimant les nations tombées en disgrâce (destruction de colonies, évictions de certains groupes ethniques des terres

16. V.G. Schneider, Rossija i Severnij Kavkaz v dorevoljucionnij period: Osobennosti integracionnyh protsessov, Moskva, Sojuz, 2005, p. 97. 
inhabitées, promotion d'une structure de classe et de groupe dans l'ethnosphère), que les autorités tsaristes ont mené leur politique d'expansion dans le Caucase.

" La culture ne peut pas être assimilée aux événements historiques eux-mêmes (phénomènes, événements, effets...), mais renvoie aux formes culturelles spécifiques qui leur sont liées ${ }^{17}$."

Dans le Caucase, les valeurs étaient si différentes de celles de la métropole que les Ingouches n'avaient aucune raison de connaître une acculturation. La "culture ", comme la "société ", sont des concepts élastiques, à multiples facettes. La vie publique, c'est avant tout la vie intellectuelle, morale, économique, religieuse. Elle recouvre tous les aspects de la vie commune ${ }^{18}$.

L'ensemble des valeurs, croyances, traditions et coutumes qui régissait la société ingouche et formait sa culture dominante ou prédominante, était complètement inacceptable pour le pouvoir colonial. La culture dominante peut être soit d'ordre national, soit d'ordre ethnique, selon le degré de complexité de l'organisation sociale du pays et le nombre d'habitants.

La société ingouche, qui n'avait par exemple jamais connu l'esclavage, n'était tout simplement pas prête à accepter la domination d'un pouvoir autocratique. Les Ingouches, dans leur quasi-totalité, ne reconnaissaient au-dessus d'eux que la seule autorité divine, et considéraient que seul celui qui avait créé toute vie sur terre avait pu donner au peuple ingouche sa terre, ses lois et, à chaque homme, un cœur vaillant pour protéger le monde sacré des valeurs de l'ethnie. La mentalité des montagnards était caractérisée par une soif de liberté, soumise seulement à la foi. C'est cet ensemble de valeurs distinctives qui définissait le mode de pensée de l'ethnie ingouche.

Les valeurs sont souvent considérées comme les éléments les plus structurants parmi tous les composants d'une culture; ce sont "des idéaux abstraits [...] qui ne sont pas liés à un objet ou à une situation en particulier, mais constituent une sorte de représen-

17. A. Flier, Kul'turogenez, Moskva, Rossijskij institut kul'turologija, 1995, p. 137.

18. Z. A. Tabliašvili, V.E. Gorozia, "Čelovek: sootnošenije nacional'nogo i obščečelovečeskogo ", in V.V. Partsvania (ed.), Sbornik materialov meždunarodnogo simpozjuma, 19-20 maja 2004, volume 2, Sankt-Peterburg, Société philosophique de Saint-Pétersbourg, 2004, p. 243. 
tation humaine des modèles idéaux de comportement et des fins dernières ${ }^{19}$."

Le patriotisme anthropologique, ou génétique, est fondé sur la valorisation de la proximité biologique et géographique des membres d'une famille, d'une génération, d'une communauté, d'une ethnie, d'un berceau territorial. Ce patriotisme se forme à un niveau inconscient, sous la pression de traditions culturelles, et se traduit ensuite dans les valeurs, qui sont des constructions idéologiques. Pendant des siècles, les valeurs les plus hautes du peuple ingouche ont été l'amour du berceau territorial, le respect des coutumes et des traditions, la volonté et la liberté.

Dans le Caucase, les autorités coloniales n'avaient pas besoin de rechercher un consensus; la force brute n'est pas en mesure de produire des structures axiologiques viables.

C'est l'Empire russe, et la politique qu'il mène depuis le début du $\mathrm{XIX}^{\mathrm{e}}$ siècle, qui est à l'origine des problèmes actuels des peuples du Caucase. Le népotisme idéologique auquel les peuples du Caucase ont été soumis a largement démontré depuis deux siècles son incapacité à promouvoir un dialogue constructif. Pourtant, il a continué d'être traditionnellement perçu comme une méthode de gouvernance fiable, et continue d'être à l'origine d'injustices criantes.

Plusieurs publications se sont étendues sur le caractère prétendument "progressiste » de l'influence russe sur les cultures du Caucase, y compris la culture ingouche. Mais on ne peut souscrire à tous les arguments brandis par les tenants de cette thèse. Si cette politique d'humiliation, d'oppression et d'expulsion menée à l'encontre des Ingouches peut être qualifiée de "progrès ", alors on peut tout à fait parler du rôle progressiste de la Russie dans le développement de la culture et de l'ethnie ingouches. Sinon, on est bien obligé de dire la vérité, et cela pour s'opposer à la politique de destruction à l'œuvre, pour favoriser le dialogue et pour finalement dépasser les problèmes les plus brûlants de la relation entre Ingouches et Russes.

En même temps que les Ingouches apprenaient la langue russe, ils accédaient à un trésor littéraire mondial et à toute une culture

19. W.F. Stone, P.E. Schaffner, The Psychology of Politics, New York, Springer, 1988, p. 63. 
technique. Le russe est devenu la langue de communication interethnique pour ceux qui vivent en Russie, et la langue officielle principale dans le système éducatif. Une ethnie est tout à fait capable de renouveler ses stratégies d'adaptation, ce qui génère de nouvelles formes culturelles et permet ainsi de résoudre les problèmes les plus urgents.

La répression politique et militaire des Ingouches n'a pas été sans effet sur leur système de valeurs. Devant lutter constamment pour leur survie, ils ont vécu une crise de conscience. De plus en plus, des échecs dans la transmission de valeurs spirituelles, au profit de valeurs matérielles, se sont manifestés. Cela a eu un impact sur les niveaux de priorités dans le système de valeurs morales.

On observe aujourd'hui des phénomènes nouveaux de désorientation au sein des familles, un affaiblissement de cette structure primaire et notamment de ses fondations qui, historiquement, étaient basées sur un système patriarcal. Ce qui est en cause, c'est la schizophrénie consistant à vouloir à la fois les valeurs spirituelles nationales traditionnelles, et le mode de vie moderne:

L'ancien système de valeur est soumis à une grande pression qui conduit à sa destruction. Les cadres intermédiaires d'adaptation ne permettent pas aux nouvelles générations de s'adapter aux valeurs traditionnelles. Les systèmes axiologiques et les traditions qui ont prévalu pendant des siècles sont aujourd'hui niés. Les nouvelles valeurs en cours diffèrent trop radicalement des valeurs traditionnelles pour que leur signification culturelle soit toujours évidente ${ }^{20}$.

Pour résumer, aux XIX et $\mathrm{Xx}^{\mathrm{e}}$ siècles, les Ingouches ont connu une période d'instabilité politique et économique, une période de catastrophes et de chocs.

Les premiers symptômes de cette crise générale sont les violations de la sphère d'identification. Lorsqu'une crise devient aiguë, des mécanismes de dégradation culturelle et de divisions intraethniques se mettent en place. Les seuls éléments structurants susceptibles d'apparaître demeurent temporaires; ils ne peuvent pas assurer leur propre continuité dans le temps, et ne proposent aucun

20. V.V. Mironov, « Transformacija kul'tury v prostranstve global'noy kommunikacii », in Gumanitarij Yuga Rossii, 2012, p. 104. 
stéréotype culturel ou ethnique stable pouvant guider les comportements. Les conditions d'un conflit durable sont donc réunies, sapant les bases morales et spirituelles de l'ethnie en question, c'est-à-dire tout ce qui fait sa spécificité culturelle. Dans un tel système social, incapable de pourvoir aux besoins primaires, les individus vont se tourner vers d'autres valeurs susceptibles de répondre à leurs besoins.

Le nouveau système moral tel qu'il est promu par les médias et la société d'information à travers le monde a bouleversé l'éthique. Tout ce qui permet de tirer profit de quoi que ce soit sans violer les lois nationales (c'est-à-dire les lois inventées par l'homme pour réguler ses activités créatrices) devient moralement acceptable. L'éthique se voit séparée à dessein de ses fondements religieux et moraux; elle perd sa base sacrée et, donc, sa capacité à susciter une angoisse morale et spirituelle, essentielle au monde duel de tout individu.

En négligeant des problèmes vitaux, on finit par perdre la foi dans l'homme. Celui-ci est alors confronté à sa propre insignifiance face aux grandes réalisations de la civilisation:

L'abondance de biens matériels et d'informations agit comme un encouragement à répondre aux besoins primaires des populations. Mais contrairement à ce qu'affirment les idéologues du libéralisme, elle ne conduit pas à une personnalisation accrue de la prise en charge des individus, mais à un renversement des bases sociales, à l'indifférence et à l'apathie. On observe une véritable désintégration sociale, qui touche au désir même de mener des activités productives, et qui ne laisse subsister que les formes les plus simples d'échanges matériels ${ }^{21}$.

L'Ingouchie traverse en ce moment une nouvelle phase de développement culturel. Il est capital de préserver les traditions ancrées dans la culture nationale pour permettre à la famille, à la société et, finalement, à cette nation faiblement peuplée de continuer dans son entier à progresser.

(Traduit de l'anglais par Chloé Thomas)

21. V.V. Čigareva, Krizis rossijskogo obščestva i rol' civilizacionno-kul'turnoj identičnosti $v$ ego preodolenii (Avtoreferat dissertacii na soiskanije učenoj stepeni kandidata filosofskih nauk), Irkutsk, 2003, p. 4. 


\section{L'imam Chamil, un Caucasien héroïque vu du Daghestan

\author{
Haji Murad Donogo
}

Le premier jour du mois de mouharram de l'an 1212 de l'Hégire (1797), un garçon naît à Guimry, village avar du Daghestan. C'est d'habitude avec cet événement que commencent les récits élogieux de la vie de l'imam Chamil ${ }^{1}$. D'autres biographies s'ouvrent comme suit, captivant le lecteur dès les premières lignes: "Ainsi est né Chamil - pauvre montagnard dont le nom est aujourd'hui connu dans le monde entier et dont le destin était de remplir plus d'une page dans l'histoire de la Russie ${ }^{2} \ldots$ ».

Son enfance est marquée par des maladies chroniques et des circonstances particulières, et il change son nom d'Ali pour celui de Chamil, ou plus exactement "Shamuil ", pratique très rare à l'époque: tous ces éléments ont contribué à entourer d'un certain mystère le futur imam. Il faut bien reconnaître, même si l'on met de côté tous les aspects mystiques entourant sa naissance, que l'année 1797 marque le début d'un destin extraordinaire. Cette année est aussi celle de la naissance du compositeur autrichien Franz Schubert, de Guillaume II, futur roi de Prusse et empereur d'Alle-

1. Voir par ex. Muhammad Tahir al-Karahi, « Hronika Muhammada Tahira o dagestanskih vojnah v period Šamilja ", Moskva/Leningrad, 1941; S. K. Bušuyev, " Bor'ba gortsev za nezavisimost' pod rukovodstvom Šamilja », Leningrad, 1939; A.Y. Halilov, « Nacional'no-osvoboditel'noje dviženije gortsev Severnogo Kavkaza pod predvoditel'stvom Šamilja », Makhatchkala, 1991.

2. Voir par ex. Gadž i-Ali, "Skazanije očevidtsa o Šamile », in Sbornik svedenij o kavkazskih gortsah, vol. VII, Tiflis, 1873; M.N. Šišagova, Šamil’na Kavkaze i v Rossii, Saint-Pétersbourg, 1889; V.V. Bartol'd, "Šamil'», in Sobranije sočinenij v 9 tomah, vol. II, part I, Moskva, Izdatel’stvo vostočnoj literatury, 1963. 
magne, de Ferdinand von Wrangel, navigateur russe et explorateur des régions polaires, d'Alexandre Bestoujev, écrivain, critique et décabriste russe exilé au Caucase où il participe aux batailles contre le premier imam du Daghestan, Mohammed Ghazi. Il est probable que le décabriste et Chamil se sont rencontrés sur le champ de bataille, car ce dernier était un fidèle compagnon de Mohammed Ghazi. Bestoujev trouve la mort au Caucase occidental en 1837 alors que Chamil, devenu imam du Daghestan, est déjà bien installé au pouvoir. Face à lui, l'administration tsariste est de plus en plus mal à l'aise et, la même année, elle veut l'obliger à faire allégeance à l'empereur Nicolas $\mathrm{I}^{\mathrm{er}}$ durant la visite du souverain au Caucase.

1797 est par ailleurs une année riche en événements politiques majeurs. En Europe, Bonaparte est particulièrement heureux: cinq divisions autrichiennes prennent le chemin des hauteurs de Rivoli en plein hiver et perdent la bataille qui donne aux troupes françaises le contrôle du nord de l'Italie. Le futur empereur accumule les succès militaires dans toute l'Europe et au-delà.

Cette même année, de nouveaux monarques, présidents ou encore ministres font également leur entrée sur la scène politique: Frédéric-Guillaume III, alors âgé de 27 ans, s'installe sur le trône de Prusse; John Adams succède à George Washington et devient le deuxième président des États-Unis; le 16 juillet, Talleyrand est nommé ministre des Affaires étrangères de la France; Paul $\mathrm{I}^{\mathrm{er}}$ est couronné à Moscou. Ce dernier rédige la loi de succession au trône de Russie tandis que, à Saint-Pétersbourg, débute la construction du palais Saint-Michel (ou château des Ingénieurs), que Chamil visitera soixante-deux ans plus tard.

Cette année-là, que se passe-t-il dans le Caucase, et au Daghestan en particulier? Avec la mort de Catherine II, Paul I ${ }^{\mathrm{er}}$, son successeur, adopte une nouvelle politique vis-à-vis de la région en mettant fin aux campagnes menées par Zoubov et en en retirant les troupes russes. Profitant de cette occasion, Agha Mohammad Shah envahit le Caucase et occupe Chouchi. Mais très vite, il est victime d'une conspiration et assassiné. Les troupes iraniennes se retirent à leur tour. En janvier 1797, Saint-Pétersbourg décide de créer une co-alliance sous protectorat russe réunissant le Daghestan et l'Azerbaïdjan, la politique de l'empire en Transcaucasie reposant désormais 
sur cette fédération de territoires tournés vers la Russie ${ }^{3}$. Ainsi, le 2 mai 1797, les lettres de créance du tsar sont remises au souverain tabasaran Rustam-Kadiy pour le remercier de sa loyauté envers l'empire durant l'invasion du Caucase par Agha Mohammad Shah. Par ailleurs, Mehti-bek de Tarki reçoit le titre de chamkhal ${ }^{4}$. L'été de cette même année, celui-ci prête allégeance à la Russie, jurant « de la servir et de lui obéir toujours fidèlement et unilatéralement ${ }^{5}$ ". Cependant, cela ne fonctionne pas au niveau de la fédération: «Dans ces conditions historiques particulières, les forces politiques du Caucase oriental n’étaient pas en mesure de réagir collectivement et étaient tiraillées par des contradictions internes. ${ }^{6}$ "

Le siècle touche à sa fin. Le suivant débute en Russie par un régicide et l'avènement d'Alexandre $\mathrm{I}^{\mathrm{er}}$. L'ère napoléonienne s'achève moins glorieusement qu'elle n'avait commencé. Les décabristes connaissent quelques succès avant de voir la flamme de l'insurrection s'éteindre.

Pendant ce temps, le Caucase occupe de plus en plus de place dans la réalité et la pensée politiques russes: en 1801, Alexandre ${ }^{\mathrm{er}}$ signe un manifeste en faveur du rattachement de la Géorgie à l'Empire. L’année suivante, à la Monnaie de Saint-Pétersbourg, on frappe une médaille pour les membres de l'expédition menée par le comte Moussine-Pouchkine, qui avait pour mission de repérer des " minerais d'or dans les montagnes du Caucase et de l'Ararat ${ }^{7}$ ". En février 1804, une unité des troupes tsaristes ravage une douzaine de villages (aouls) dans la région de Piatigorsk et réprime les insurrections locales, l'événement étant lui aussi célébré par la frappe d'une médaille d'argent. En 1816 commencent les exactions du « proconsul » (ainsi que se désignait lui-même le général Alexis Iermolov),

3. Istorija Dagestana s drevnejših vremen do našihx dnej, t. 1, Moskva, Nauka, 2004, p. 453.

4. Archives de la politique étrangère de l'Empire russe [Arhiv vnešnej politiki Rossijskoj imperii], F. 77. Op. 77/6. 1791-1800 gg. D. 472. L. 195.

5. "Šamhaly Tarkovskije ", in Sbornik svedenij o kavkazskih gortsah, vol. I, Tiflis, 1868, p. 62

6. V.G. Gadžijev, Rol'Rossii v istorii Dagestana, Moskva, 1965, p. 173.

7. A. Berže (ed.), Acty Sobrannye Kavkazskoi Arheografičeskoi Komissiei, vol. I, Tiflis, Typografia Glavnogo Upravlenija Namestnika Kavkazskogo, 1866, p. 313. 
qu’on appelait alors aussi le " conquérant du Caucase ». Malgré les esprits anéantis et les campements dévastés que Iermolov laisse sur son passage, il ne parvient pas à éteindre le feu qui couve et qui sera ravivé lors de la longue lutte pour la libération nationale.

Après son voyage dans le Caucase en 1820, Alexandre Pouchkine compose "Le prisonnier du Caucase ", un poème tout empreint de sa passion pour la région et que les officiers du corps des cadets envoyés au Caucase lisent en cachette. Au même moment, la jeunesse s'enflamme pour Ammalat-Bek, Mulla Nur ou encore les Lettres du Daghestan du décabriste Bestoujev-Marlinski. La région montagneuse est au centre de toutes les attentions.

Mais, comme le souligne justement Kasbek Sultanov, « l'intérêt immense, durable et toujours renouvelé pour le Caucase pénétra la culture russe précisément sous le règne de Chamil, dont le combat, selon une perspective historique et culturelle, était perçu comme un message à l'humanité, une étape véritablement cruciale, un indicateur précis des problèmes vitaux des nations mineures. L'idée de liberté qui se répandit alors dans les consciences russe et européenne prit des accents de plus en plus caucasiens ${ }^{8}$ ».

En 1834, Chamil se voit offrir l'occasion de devenir commandant en chef, mais il refuse face à une responsabilité qu'il juge trop grande. Mais le destin s'obstine et, après plusieurs refus, il accepte de devenir imam. Alors débute la grande épopée du Caucase.

Pendant longtemps, chercheurs, écrivains et poètes se sont intéressés de très près à cette période. Un grand nombre de documents provenant d'archives et de collections privées témoignent ainsi de la lutte héroïque des peuples du Caucase et des changements majeurs qui affectèrent ces sociétés.

La vie de Chamil se divise en deux parties. La première s'achève en août 1859 et correspond à son ascension en tant que guerrier, leader et figure publique. Chamil est véritablement l'incarnation de cette époque tragique et héroïque à la fois. La seconde, qui commence à Gounib et se termine en Arabie, est plus personnelle: elle est pour lui l'occasion de réfléchir au passé, à l'avenir de sa famille et à la perte de ses proches, d'entretenir des relations " diplomatiques "

8. K. Sultanov, «Čelovek-legenda », in Novoje delo, 48, 1997, p. 8. 
avec Saint-Pétersbourg et, surtout, de viser son objectif principal, faire le pèlerinage (haji). C'est la période de sa vie où Chamil effectue en quelque sorte un retour sur lui-même, alors que son nom est depuis longtemps déjà entré dans l'histoire.

Si l'on connaît bien la première partie de sa vie, la seconde est quant à elle souvent délaissée. Ses contemporains l'ont évoquée dans leurs mémoires; mais dans la littérature scientifique, elle se trouve réduite à une peau de chagrin. Comment expliquer cette absence d'intérêt pour la période russe de la vie de Chamil, qui ne dura pas moins de onze ans?

L'historiographie daghestanaise, en particulier, accorde peu de place à cette période de la vie de l'imam. En outre, les historiens amateurs locaux sont rarement prêts à admettre l'épisode de la capture de Chamil. Ils qualifient sa rencontre avec le général Bariatinsky sur les hauteurs de Gounib le 25 août 1859 de « conclusion d'accord » et son séjour à Kalouga de simple « contrainte ».

On pourrait ainsi avoir l'impression que sa captivité, son exil forcé et le serment d'allégeance que l'imam prêta volontairement à la Russie ne sont qu'une simple série d'événements dans la vie de Chamil. On pourrait ainsi en rester là et ne pas s'interroger davantage sur la portée politique de ces épisodes, qui eurent pourtant un impact décisif sur le destin des peuples du Daghestan et sur la construction de l'État du Daghestan.

Les partisans obsessionnels d'une vision simpliste de la vie de Chamil n'ont cessé de suggérer que l'imam aurait dû mourir à Gounib, ce qui aurait été une solution facile. Mais l'imam, y compris dans ces moments dramatiques, pense à son peuple, à son destin et prend alors une décision: céder devant le cours du monde et sauver le Daghestan!

On s'accorde alors aisément avec Rasul Magomedov lorsqu'il affirme que: « Dire la vérité historique, quand bien même elle serait amère, permet de libérer les tensions et d'apaiser les souffrances. La vérité doit nous servir, afin que nous apprenions ces leçons par nous-mêmes ${ }^{9}$."

9. R. M. Magomedov, Dva stoletija s Šamilem, Makhatchkala, 1997, p. 3. 
Cependant, quiconque penserait que la période russe du prisonnier Chamil masquerait un épisode honteux ou indigne de la vie de l'imam se tromperait grossièrement. Chamil traversa bien des situations délicates et en apparence désespérées, mais jamais il ne discrédita son nom. Au contraire, il fit face aux épreuves de la guerre et de la captivité. Il perdit beaucoup en chemin, fut témoin de nombreuses injustices et, dans le même temps, ne cessa de fasciner compagnons et partisans, opposants et rivaux, par la sagesse profonde de ses décisions.

Après le mois d'août 1859, Chamil traverse une profonde crise psychologique et fait l'expérience du passage à un monde radicalement différent, celui des machines à vapeur et des fonderies, des grandes villes et des palais resplendissants, des étendues illimitées, sur terre et sur mer. Tout cela incite le montagnard de Guimry à changer sa vision du monde. Face au constat que le bonheur ne peut résulter de la guerre, l'imam tente à plusieurs reprises de trouver des accords pacifiques mais n'est pas écouté par l'autocratie. Il serait donc absolument faux de dire que Chamil n'aspirait qu'au combat armé.

En Russie, nombreux furent ceux qui, dans l'entourage de l'imam, cherchèrent à déceler sur son visage des expressions de surprise et d'admiration pour tout ce qui s'offrait à son regard. Mais l'imam savait masquer ses émotions, son excitation et ses sentiments. Si on pouvait avoir accès à ses sentiments, nul doute qu'ils nous en diraient long.

Certains font de Chamil le sujet de panégyriques affectueux, d'autres de diffamations soi-disant objectives. C'est là le propre des personnages historiques importants: ils suscitent des perceptions extrêmement variées, et leurs actes sont difficiles à expliquer car ils ne correspondent pas aux sentiments éthiques ordinaires. Un individu mérite le qualificatif d' " historique " à partir du moment où il refait surface à chaque nouvelle génération, non pas comme un invité venant de loin, mais directement comme un maître de vie.

Dans tous les cas, la dignité et les faiblesses de cette personnalité brillante ne peuvent se mesurer que d'un point de vue historique global. 
Chamil ne s'est pas seulement imposé en étant placé sur un haut piédestal. Le meilleur monument qu'on puisse lui consacrer serait d'adhérer à ses enseignements et à ses engagements. " Il reflétait, tel un verre convexe, les vertus et les défauts des transformations du monde tel qu'il était tout particulièrement appelé à se former dans le Caucase ${ }^{10}$."

Pathos et drame de la guerre du Caucase... Triomphe et tragédie de Chamil...

(Traduit de l'anglais par Camille Joseph)

10. H. M. Donogo, Imam Shamil’. Poslednij put', Makhatchkala, 2016, p. 5. 



\title{
Structure et dynamique sociale de la culture tchétchène
}

\author{
Said Mushajiyev
}

La compréhension que l'on a d'une culture peut être aussi diverse que les façons dont celle-ci se manifeste; elle dépend de l'étendue des connaissances accumulées sur la culture en question, et de la perception propre à chaque communauté. L'approche consistant à étudier une culture nationale sous différents aspects et différents angles augmente les chances d'aboutir à une vision holistique permettant de comprendre plus finement les fondations sous-jacentes de cette culture.

La culture tchétchène dans son ensemble n'a jamais fait l'objet d'une étude universitaire. Nous l'envisagerons ici aux périodes clés de son histoire, considérées non pas comme des fragments isolés, mais dans une relation holistique au destin du peuple tchétchène, à travers le prisme du temps et du changement.

Nous n'envisagerons pas la structure de la culture comme un ensemble de sphères (matérielle, spirituelle...), mais comme des couches culturelles et historiques variées, formant une symbiose complexe qui en quelque sorte mena le peuple tchétchène, à la veille du troisième millénaire, vers une quête douloureuse de son identité culturelle nationale.

La formation de la structure d'une culture ne peut être dissociée de sa dynamique sociale, c'est-à-dire du processus de développement d'une culture ethnique singulière dans le temps et dans l'espace et en interrelation avec la structure et les transformations sociales.

La culture est inextricablement liée "à l'histoire, implique toujours une continuité dans la vie morale, intellectuelle et spiri- 
tuelle de l'homme, de la société et de l'humanité. Par conséquent, quand nous évoquons notre culture moderne, nous évoquons peutêtre, sans en avoir conscience, la formidable façon dont elle a été transmise ${ }^{1}$."

Nous avons l'habitude de parler de culture spirituelle ou matérielle, de culture antique ou moderne, sans même songer au fait qu'elle ne se compose pas seulement de différents domaines de réalité, mais constitue la réalité à laquelle est confronté l'homme dans ces domaines.

Chaque peuple, au cours des siècles, façonne non seulement sa propre culture, mais aussi la compréhension qu'il en a. La spécificité de la culture d'une nation dépend de nombreux facteurs: conditions géographiques, développement historique, attitudes mentales et ethniques.

La culture tchétchène s'articule autour de deux lexèmes, de deux mots: gillakh et ozdangalla. Traditionnellement, la notion de gillakh ("politesse, affabilité, savoir-vivre ») contient pour les Tchétchènes toute une éthique de la communication, du comportement à adopter dans les relations entre individus, entre groupes et entre peuples ${ }^{2}$. En un mot, il s'agit du pan externe de la culture, dirigé de l'individu vers la société et le monde qui l'entoure. C'est du terme ozda que vient celui d'ozdangalla (" noble, éduqué, cultivé »). Le vocable ozdangalla fait à parts égales référence à la pureté du corps, du cœur et des pensées - pureté indissociablement liée à la foi en Dieu et au monde extérieur. La culture ne se manifeste donc pas uniquement à travers le comportement et le caractère d'une personne; elle doit avant tout résider dans l'âme et dans la conscience.

Ce concept met en avant la dimension intérieure de la culture à l'échelle de l'individu, ainsi que sa manifestation spirituelle et morale. Si l'on prend tous ces éléments en considération, le sens de l'expression suivante devient clair: "La culture de la bonne conduite (gillakh) vient du paradis. » Ce qui signifie que les normes d'une conduite noble entre individus ont une dimension sacrée.

1. Yu.M. Lotman, Besedy o russkoj kul'ture, Sankt-Peterburg, 1994, p. 8.

2. D.D. Mežidov, I.Y. Alirojev, Čečency: obyčai, tradicii, nravy. Social'no-filosofskij aspekt, Grozny, 1992, p. 196. 
Cette idée s'exprime de façon plus détaillée dans le proverbe tchétchène suivant: " La culture de la bonne conduite vient du paradis, et elle y retournera, portée par ceux qui la perpétuent. » Cette phrase révèle la grande importance accordée par les Tchétchènes à l'éthique et à la culture. Le lien entre raison et normes éthiques est mis en avant dans une chanson religieuse tchétchène (nazma):

On sait bien que la pomme tombe sous le pommier,

Mais y aurait-il une pomme sans pommier?

Gillakh est un arbre qui a pour fruit un état d'esprit;

La connaissance est-elle possible là où le gillakh n'est pas?

L'esprit se conforme à des normes éthiques - ce qui est toujours le cas lorsque l'on a affaire à un esprit bienveillant.

Chaque individu, quels que soient ses capacités, ses talents ou sa force, a les mêmes responsabilités morales que ses semblables.

Les deux concepts de gillakh et d'ozdangalla renferment la quintessence de la notion tchétchène de culture. L'« univers intérieur " et les " manifestations extérieures » sont interdépendants et complémentaires, reliés par des milliers de fils. Pour le peuple tchétchène, la culture n'est pas fondamentalement un phénomène collectif, public et impersonnel, ni même un ensemble d'accomplissements. Chez ce peuple qui tient pour valeurs supérieures la dignité, l'honneur, la conscience et la liberté, le concept de culture a et a toujours eu une dimension personnelle et individuelle concrète.

La philosophie tchétchène de la culture apparaît comme un modèle, un code individuel régissant les rapports de chacun à la société, une sorte de norme à laquelle chaque Tchétchène doit se conformer pour être un véritable ambassadeur de la culture de son peuple.

La culture est ainsi interprétée comme ce qui caractérise les aptitudes d'une personne dans la sphère du comportement individuel et social, y compris le tact, la dignité, le respect d'autrui, la délicatesse, la capacité à agir de façon mesurée. Il s'agit donc d'une forme de régulation des actes porteurs de sens aux niveaux personnel et social.

La culture tchétchène, agrégation de multiples couches culturelles et historiques, est structurellement symbiotique. La première couche, archaïque et autochtone, est la culture nakh (nokhchalla), 
noyau fondateur de la culture tchétchène. Le deuxième composant est religieux: il s'agit de la foi islamique. Enfin, le troisième élément, l'influence russe, résulte du processus d'occidentalisation et de conquête coloniale de la Tchétchénie et du peuple tchétchène par l’Empire russe, qui a débuté au XviII siècle.

Cette synthèse culturelle à plusieurs niveaux témoigne du processus historique complexe réalisé par le peuple tchétchène. Chacune des strates historico-culturelles ou civilisationnelles a de surcroît sa propre structure hétérogène. Chacune est un amalgame de composants culturels variés.

La strate la plus ancienne de la culture tchétchène est donc la culture nakh du Caucase du Nord. Les peuples tchétchène et ingouche constituent la culture vainakh (qui signifie " peuple " ou " notre peuple »). On situe l'antiquité nakh dans la deuxième moitié du III ${ }^{\mathrm{e}}$ millénaire avant notre ère c'est-à-dire à l'âge du bronze ancien; parmi les monuments rescapés de cette époque, on peut citer les sites de peuplement se trouvant près du village de SergenYurt dans le raïon de Chalinski en Tchétchénie, ou encore les tumulus (" kourganes ») à proximité du village de Bamut.

Les grandes similitudes entre les artefacts du bronze ancien du nord et du sud du Caucase s'expliquent par l'existence d'un milieu ethnique unique et commun à l'ensemble de la région caucasienne au III millénaire avant notre ère. La culture archéologique kouroaraxienne et celle de Maïkop nous renseignent sur la plus ancienne communauté ethnoculturelle caucasienne au moment de sa désintégration, ainsi que sur la proximité entre les différents peuples autochtones, tous locuteurs de langues nord-caucasiennes. C'est précisément au cours de l'âge de bronze ancien que les langues nakhs ont commencé à se dissocier des autres langues de la région ${ }^{3}$.

Les artefacts archéologiques permettent d'étudier les conceptions religieuses des Nakhs de l'Antiquité. Les cultes solaires étaient associés à une cosmologie archaïque, comme l'indiquent les anneaux en pierre qui se trouvent autour des tombes des tumulus de Bamut, certains ornements en relief en forme de spirales ou encore les cercles concentriques figurant sur certaines céramiques.

3. Očerki istorii Čečeno-Ingušskoj ASSR, t. 1, Grozny, 1967, p. 12. 
Le panthéon nakh antique était assez conséquent. Dela en était le dieu suprême, saint patron du Soleil et du Ciel. Ce théonyme est composé de $D e$ (« le jour, la lumière ») et d'Ela (« le seigneur, le maître »). On trouve également dans les croyances vainakhs le culte de Hal, dieu du ciel semblable au dieu hourro-urartéen Khald, vénéré en Urartu et dans d'autres régions de l'Orient antique.

Comme c'est le cas de nombreuses cultures archaïques, les croyances païennes des Vainakhs renfermaient l'idée d'une dualité du monde; le monde terrestre, appelé Dela Malche («lumière divine du Soleil ») s'opposait au monde souterrain, ou royaume des morts, Dela Late (« monde souterrain divin »). L'Au-delà, selon les croyances nakhs, était gouverné par une divinité nommée Elda, $E l$ faisant référence au royaume souterrain des morts, et $D a$ désignant le père, le maître.

Les ancêtres des Nakhs, dans un processus d'élargissement de leur horizon et d'approfondissement de leur connaissance du monde environnant et du cosmos, opérèrent peu à peu un transfert de leurs divinités vers le ciel; celles-ci se confondirent avec le soleil, la lune, les étoiles, le tonnerre ou encore les éclairs. Les ancêtres des Nakhs avaient compris que le soleil représentait la vie. Son lever correspond à l'éveil de la nature, à l'apparition de la vie et à la floraison. L'astre est un symbole de pureté et de beauté. Cela suffit peut-être à expliquer que la légendaire Malkh-Azni ("Soleil-beauté ») soit l'une des principales héroïnes des mythes et des légendes nakhs. L'histoire a même préservé le nom antique de la tribu ou du clan (taïp) des Nakhs, qui vénéraient le soleil avant tout: Malkhistoy («les Melchistins »). Et les cimetières, où les morts sont aujourd'hui encore enterrés dans des cryptes en pierre, sont appelés Malkhan keshnash — « tombes solaires " ${ }^{4}$.

Notons que la croissance et le développement des taïps - ou clans - tchétchènes, ainsi que l'essor des régions de plaines et de contreforts renforcèrent la cohésion des tribus vainakhs, ce que n'avaient pas pu réaliser des croyances mythologiques ou religieuses disparates. Celles-ci retardèrent en revanche certains processus ethnogénétiques et socio-culturels.

4. Istorija Čečni s drevnejših vremën do naših dnej, t. 1, Grozny, 2008, p. 68. 
La structure sociale patriarcale du peuple nakh des montagnes, divisé en dizaines de taïps indépendants, rendait nécessaire l'intervention d'une force de rassemblement, d'un système de valeurs supérieur capable d'achever le long processus de consolidation politique des groupes vainakhs en un seul peuple. C'est l'islam qui joua ce rôle. Il fallut plusieurs siècles aux tribus nakhs pour se convertir à cette religion, qu'elles découvrirent entre le VIII ${ }^{\mathrm{e}}$ et le $\mathrm{IX}^{\mathrm{e}}$ siècles, pour l'adopter définitivement entre le $\mathrm{XVI}^{\mathrm{e}}$ et le $\mathrm{XVII}^{\mathrm{e}}$ siècles. Ce délai s'explique par l'absence de contrainte interne ou externe. Les missionnaires arabes n'ont pas sillonné le territoire tchétchène. Les principaux acteurs de l'islamisation furent des prosélytes locaux, qui avaient découvert l'islam grâce à des marchands, des bergers ou des mollahs du Daghestan voisin.

Selon l'archéologue M.B. Muzhukhoev, les monuments musulmans de la région d'Auch (la nécropole de Gachalk) remontent au début $d u x I^{e}$ siècle et les cimetières musulmans anciens de la Tchétchénie orientale (Nakhch-Mokhk) aux XVII ${ }^{\mathrm{e}}$ et XVIII ${ }^{\mathrm{e}}$ siècles. Les premiers enterrements musulmans de la région montagneuse de Cheberloi (vallée de Makazhoy), non loin de la frontière avec le Daghestan, eurent lieu dès le XviI ${ }^{\mathrm{e}}$ siècle. Muzhukhoev situe la victoire de l'islam dans les gorges de l'Argoun au XviII siècle et dans les gorges de Galanchozhsky (sur les rives de la Fortang) au début du $\mathrm{XIX}^{\mathrm{e}}$ siècle; dans les montagnes de l'Ingouchie, l'islam s'est d'après lui peu à peu affirmé au cours du XIX ${ }^{\mathrm{e}}$ siècle $\mathrm{e}^{5}$.

Cette description correspond dans l'ensemble aux informations fournies par les sources écrites, en tenant compte, comme mentionné ci-dessus, du "retard " habituel des artefacts sur les transformations spirituelles et idéologiques des sociétés.

C'est ainsi qu'entre le $\mathrm{XVI}^{\mathrm{e}}$ et le $\mathrm{XVIII}{ }^{\mathrm{e}}$ siècles, l'islam s'est répandu dans les plaines, les contreforts et la majeure partie des zones montagneuses de Tchétchénie, jusqu'à devenir l'idéologie dominante de la société tchétchène, affectant tous les aspects de la vie des montagnards et déclenchant une uniformisation sans précédent d'anciennes communautés « libres ", précédemment isolées

5. M. B. Mužuhojev, Srednevekovie kul'tovie pamjatniki Central'nogo Kavkaza. (K istorii religioznyh verovanij v X-XIX vekah), Grozny, 1989, p. 165-169. 
et autosuffisantes. Le grand mouvement de libération nationale, à dimension religieuse, qui fut dirigé par le cheikh et imam Mansour entre 1785 et 1791 a exercé sans aucun doute une grande influence sur ce processus.

On ne peut envisager ce mouvement sans le mettre en lien avec les modifications sociales, économiques et politiques en cours dans la société tchétchène, qui cherchait non sans mal une réponse à la menace de l'Empire russe, lequel avait repoussé ses frontières jusqu'aux rives du Terek et du Kouban. Cette réponse se présenta avec la tentative de créer un État tchétchène qui trouverait son fondement idéologique dans la religion musulmane.

Le développement d'une nouvelle conscience religieuse chez les Nakhs dans la Tchétchénie des $\mathrm{XVI}^{\mathrm{e}}$ et XVII ${ }^{\mathrm{e}}$ siècles est lié à leur conversion à l'islam et à l'émergence de buts communs à tous les auls (villages) et à toutes les communautés; il correspond à la genèse politique d'un nouvel État. Les transformations qui se produisirent à cette époque dans la société nakh (ou tchétchène) étaient certes le fruit d'une évolution naturelle, mais également une réaction aux défis lancés depuis trois siècles par de grandes puissances comme la Russie, l'Iran ou l'Empire ottoman ${ }^{6}$.

L'islam dicta un système de valeurs spirituelles commun à l'ensemble de la société tchétchène, dont les principes fondamentaux étaient le monothéisme, la foi et la fraternité. L'islam s’installa peu à peu dans toutes les régions de Tchétchénie et absorba les coutumes et traditions populaires précédemment établies, sans pour autant devenir un mode de vie pour les individus.

L'islamisation de la société tchétchène atteignit son apogée aux $\mathrm{XVIII}^{\mathrm{e}}$ et XIX ${ }^{\mathrm{e}}$ siècles, lorsque les efforts titanesques de Mansour (fin $\mathrm{XVIII}^{\mathrm{e}}$ ), d'Udi-Mollah et de Tachav-Khadji (années 1820-1830), de l'imam Chamil et du cheikh Kunta Haji (années 1840-1860) fournirent une base musulmane solide à la structure sociale et à la vie des Tchétchènes.

L'expansion russe dans le Caucase du Nord, qui progressa inexorablement dans la seconde moitié du XviII ${ }^{\mathrm{e}}$ siècle, encouragea dans

6. Y. Z Ahmadov., Očerk istoričeskoj geografii i etnopolitičeskogo razvitija Čečni v XVI-XVIII vekah, Moskva, 2009, p. 240-256. 
une certaine mesure l’islamisation de la région, et de la Tchétchénie en particulier.

La création d'un État musulman sur le territoire de l'imamat du Haut-Daghestan et de Tchétchénie marqua en quelque sorte l'institutionnalisation du mouvement de libération antirusse, qui embrassait la religion musulmane. Malgré l'échec final, cette tentative resta un repère historique majeur dans la mémoire collective tchétchène. La conquête de la Tchétchénie par l'Empire russe en 1859 fut suivie d'un durcissement progressif de la politique d'occidentalisation sur le " modèle russe ». À de nombreuses occasions, cette politique, d'économique, citoyenne et éducative - en d'autres termes, pacifique -, est devenue militaire, coloniale et agressive, allant parfois jusqu'au génocide.

Après avoir survécu à deux campagnes militaires des plus rudes, le peuple tchétchène est confronté aujourd'hui à la tâche difficile de préserver une culture nationale unique, façonnée au cours de milliers d'années au gré d'influences culturelles diverses qu'il a tantôt assimilées, tantôt rejetées. Le développement futur de la culture tchétchène dépendra du degré de réalisation et de spontanéité du compromis entre tous les composants des strates civilisationnelles qui constituent cet univers ethnoculturel unique.

(Traduit de l'anglais par Pauline Tardieu-Collinet) 


\section{TROISIÈME PARTIE}

\section{MOSAIIOUE DES MÉTROPOLES ET DES PAYSAGES}





\title{
Les premières photographies comme transfert culturel en Russie impériale
}

\author{
Technique visuelle, mobilité et modernité \\ dans le Caucase et en Asie centrale
}

Svetlana Gorshenina, Heather S. Sonntag

Cet article présente un panorama de la photographie comme mode de transfert culturel entre l'Europe et l'Asie, plus spécifiquement entre la Russie, d'une part, et le Caucase et l'Asie centrale, d'autre part, dans le contexte impérial du XIX ${ }^{\mathrm{e}}$ siècle. Il s'agit d'interroger les conséquences sociales et politiques de ces transferts, qu'on mettra en parallèle avec d'autres échanges impliquant le nouveau médium à l'échelle mondiale à la même époque. Le cas évoqué ici s'appuie sur un très grand nombre d'études consacrées à l'histoire mondiale de la photographie, dont la dimension russe constitue l'un des champs en plein développement, ainsi que sur les recherches menées dans des fonds d'archives en Ouzbékistan, Géorgie, Russie, France et Suisse.

La méthode ici choisie est celle des transferts culturels ${ }^{1}$. C'est l'une des nombreuses approches permettant de décrire la circulation des idées, des techniques, des biens matériels et des individus,

1. Michel Espagne et Michael Werner (éds.), Transferts. Les Relations interculturelles dans l'espace franco-allemand (XVIII ${ }^{e}-X I X^{e}$ siècles), Paris, Éditions Recherche sur les civilisations, 1988; Michel Espagne, Les Transferts culturels franco-allemands, Paris, PUF, 1999; Michel Espagne, "La notion de transfert culturel ", in Revue Sciences/Lettres 1, 2013 URL: http://rsl.revues.org/219; DOI: 10.4000/rsl.219. 
ainsi que les interactions historiques entre des cultures différentes, qu'elles soient mondiales, transnationales, comparatives, connectées, partagées ou croisées ${ }^{2}$. À l'opposé d'une vision eurocentrée de l'histoire, qui présuppose un déploiement unilatéral de la " civilisation " et de ses " bienfaits " depuis un " centre créatif " vers une "périphérie passive ", la théorie des transferts culturels offre une perspective plus nuancée en insistant sur l'interdépendance des contacts entre cultures.

La théorie des transferts culturels repose notamment sur l'idée, présentée de manière succincte ici, qu'une "culture-inventeur" (identifiée dans la suite comme culture A) ne peut imposer des idées ou des techniques à une autre culture (culture B) qui accepterait l'innovation de manière passive. Au contraire, les échanges culturels sont multidirectionnels, puisque toute culture B, ici envisagée comme agent récepteur, prend à son tour un rôle actif en sélectionnant les innovations qui viennent compléter ou s'ajouter aux conditions de vie et aux traditions locales. C'est ainsi que sont sélectionnées des idées ou des techniques, alors que d'autres sont rejetées. Selon ce processus, les transferts culturels empruntent des voies institutionnelles ou bien sont portés par des individus. Il s'agit donc d'une relation plus complexe qui, en l'occurrence, a permis à la technique photographique d'être adoptée, adaptée et assimilée en vue de diverses applications sociales, politiques et économiques.

C'est la perspective que nous choisirons pour étudier les débuts de la photographie en Russie impériale. Nous examinerons ainsi les agents et les processus de transferts qui se sont dans un premier temps déployés depuis l'Europe occidentale jusqu'en Russie et, ensuite, de la Russie jusqu'en Asie. Nous commencerons par un bref rappel de l'histoire de l'invention photographique et de son impact à l'échelle mondiale, avant d'aborder plus en détail la diffusion de la technique à partir de la France, de l'Angleterre et de l'Allemagne vers la Russie, où la photographie circule depuis Saint-Pétersbourg et

2. Parmi les nombreuses études consacrées à cette question (par exemple A. Stanziani, K. Raj, R. Bertrand, S. Gruzinski, Y. Cohen), voir notamment Michael Werner et Bénédicte Zimmermann (éd.), De la comparaison à l'histoire croisée, Paris, Seuil, 2004, et, des mêmes auteurs, "Penser l'histoire croisée: entre empire et réflexivité », in Annales. Histoire, sciences sociales 1, 2003, p. 7-36. 
Moscou, centres de l'Empire, vers le Caucase et la ville d'Orenbourg, bâtie à la lisière de la Grande Steppe, avant d'atteindre finalement l'Asie centrale. Notre étude s'inscrit dans le cadre de recherches récentes qui abordent les transferts culturels selon une perspective géographique large: d'abord élaborée dans un contexte exclusivement européen, la théorie des transferts culturels s'est dernièrement ouverte à la Russie ${ }^{3}$, à l'Asie centrale ${ }^{4}$ et l'Altaï ${ }^{5}$, ainsi qu'à la Chine ${ }^{6}$.

La photographie, médium visuel fondé sur une série de procédés chimiques impliquant l'action de la lumière fut, comme on le sait, développée par deux nations impériales selon deux approches distinctes. En France, Louis Jacques Mandé Daguerre (1787-1851) inventa le daguerréotype, une image-miroir produite sur une plaque de cuivre recouverte d'une couche d'argent, dont la découverte fut officiellement présentée en août 1839. Au même moment, en Angleterre, William Henry Fox Talbot (1800-1877) était en train de perfectionner ce qu'il appelait des "dessins photogéniques », qui allaient ensuite devenir des calotypes. Ces images réalisées sur support papier, dont il annonça l'invention en 1841, permettaient la reproduction de négatifs, élément fondamental de la photographie moderne ${ }^{7}$. Ces deux inventions connurent une diffusion rapide et large. Quelques semaines seulement après avoir exposé sa découverte à Paris,

3. Katia Dmitrieva et Michel Espagne (éds.), Transferts culturels triangulaires. France-Allemagne-Russie, Paris, Éditions de la MSH, 1996.

4. Michel Espagne, Svetlana Gorshenina, Frantz Grenet, Shahin Mustafayev et Claude Rapin (éds.), Asie centrale: transferts culturels le long de la Route de la soie, Paris, Vendémiaire, 2016.

5. Voir le colloque "Transferts culturels dans l'Altaï », 12-17 juin 2017 : http:// transfers.ens.fr/transferts-culturels-dans-l-altai-707. — Pavel Alexeiev, Ekaterina Dmitrieva et Michel Espagne (éd.), La Sibérie comme champ de transferts culturels. De l'Altaï à la Iakoutie, Paris, Demopolis, 2018.

6. Jin Siyan et Raymond Ledru (éd.), Transfert culturel: les premiers missionnaires en Chine, Paris, Éditions You Feng, 2016. Voir aussi le projet de recherche " Les transferts culturels entre la Chine et l'Europe (XVII ${ }^{\mathrm{e}}$-XVIII ${ }^{\mathrm{e}}$ siècles): échanges, esthétiques de la chinoiserie et constructions identitaires " : http://www.agence-nationale-recherche.fr/projet-anr/?tx_lwmsuivibilan_pi2 \% 5BCODE \% 5D = ANR-12JSH3-0002.

7. Christian Sixou, Les Grandes dates de la photographie, Paris, Éditions V.M., 2000; Roger Watson and Helen Rappaport, Capturing the Light: the Birth of Photography, a True Story of Genius and Rivalry, New York, St Martin's Press, 2013. 
Daguerre publia un court volume rapidement traduit en anglais et en allemand ${ }^{8}$. Sans tarder, on se mit à réaliser des daguerréotypes à travers toute l'Europe et sur trois autres parties du globe au moins: autour de la Méditerranée et au Moyen-Orient, des explorateurs fortunés emportèrent avec eux appareils photographiques, produits chimiques et instruments nécessaires pour documenter les cultures de la Grèce antique et de l'Égypte ancienne, ainsi que les sites de Terre sainte $^{9}$. À cet engouement rapide et international pour le daguerréotype vint s'ajouter une commercialisation mondiale des appareils: on pouvait en acheter jusqu'à Calcutta, où ils furent commercialisés dès janvier $1840^{10}$. En mars de cette même année, on montrait déjà des images lors d'une réunion de la Société asiatique (Asiatic Society) de la ville ${ }^{11}$. Chahryar Adle rapporte que l'officier britannique Arthur Conolly (1807-1842) avait emporté avec lui un appareil lors de son second voyage au Turkestan (1841-1842). Mais cette technologie exotique, présentée à l'émir, n'eut pas les effets escomptés et ce dernier, peu impressionné, fit exécuter Conolly en $1842^{12}$.

Dans la décennie qui suivit les découvertes de Daguerre et Talbot, un procédé bien plus révolutionnaire encore allait avoir de profondes conséquences sur les phénomènes de transferts culturels impliquant la photographie, tant au niveau local qu'au sein des empires. Inventé en 1852 par Frederick Scott Archer, le procédé du collodion humide associait le niveau de détails du daguerréotype et la reproductibilité illimitée du calotype. En Europe, toutes ces amé-

8. Roger Watson and Helen Rappaport, Capturing the Light, op. cit., p. 157.

9. Carmen Pérez González, "A Mirror with Memory: the Daguerreotype Camera Heads East, 1839-1860 ", in Carmen Pérez González (ed.), From Istanbul to Yokohama: The Camera Meets Asia, 1839-1900, Cologne, Museum für Ostasiatische Kunst, 2014; James Ryan, Photography and Exploration, Londres, Reaktion Books, 2013; Sylvie Aubenas, Les Photographes en Orient, in Sylvie Aubenas et Jacques Lacarrière, Voyage en Orient, Paris, BNF/Hazan, 2001.

10. Vidja Dehejia, " Fixing a shadow ", in Vidja Dehejia (ed.), India through the lens: Photography, 1840-1911, Catalogue, Munich, Prestel, 2000, p. 14.

11. Christopher Pinney, The Coming of Photography in India, Londres, British Library, 2008, p. 9. Voir aussi John Falconer, " Photography in Nineteenth Century India ", in Chris Bayly (ed.), The Raj: India and the British, 1600-1947, Londres, Thames and Hudson/National Portrait Gallery Publication, 1990.

12. Communication orale personnelle de Chahryar Adle. 
liorations de la technique - qui était déjà plus simple à utiliser et moins coûteuse - firent de la photographie un procédé fascinant et très apprécié des classes moyennes. Nombreux furent ceux qui s'aventurèrent dans des pays étrangers à la recherche d'impressions nouvelles; le "Grand Tour " devint aussi populaire qu'exotique pour les voyageurs qui voulaient " découvrir » les cités légendaires d'Europe, d'Afrique du Nord (d'Égypte surtout), du Moyen-Orient (Terre sainte, Syrie, Turquie, Iran et Irak) ou encore d'Amérique du Nord. Cependant, les premières "découvertes " photographiques du Caucase et du Turkestan ne furent pas tant le fait des classes moyennes européennes que celui des militaires russes et membres de l'administration coloniale qui explorèrent ces régions et s'y installèrent avec leurs appareils photographiques.

En Russie, ce moment de développement des procédés et des transferts photographiques correspond à une époque de grande expansion impériale. Au milieu du xviII ${ }^{\mathrm{e}}$ siècle, les trois hordes nomades kazakhes qui formaient alors la partie nord de la Tartarie indépendante furent peu à peu soumises et ces territoires réorganisés en différents districts réunis dans les limites du gouvernement d'Orenbourg. Administrée depuis la capitale régionale du même nom, cette province devint le principal point de départ des conquêtes russes en Asie du Sud et de l'Est. À partir du début du XIX siècle, un même mouvement se déploya dans le Caucase, où la Russie s'empara progressivement des territoires de l'Empire ottoman. En 1844, les territoires ainsi conquis formèrent une viceroyauté du Caucase (Kavkazskoe namestničestvo), plus tard divisée en gouvernements et districts régionaux. La défaite subie lors de la guerre de Crimée en 1856 déclencha par contrecoup une série de campagnes militaires visant d'autres directions qui, sous Alexandre II surtout, permirent de soumettre le nord du Caucase et tous les khanats d'Asie centrale. Après cette période, les transferts photographiques entre la Russie, le Caucase et l'Asie centrale se produisirent avant tout dans un contexte colonialiste ${ }^{13}$ et furent le fait tant des institutions de l'Empire russe que de porteurs individuels, dans

13. Georges Balandier, "La situation coloniale: approche théorique ", in Cahiers internationaux de sociologie 110/1, 1951, p. 9-29. 
leur grande majorité des officiers et des administrateurs russes. En d'autres termes, la relation entre la Culture A et la Culture B n'était pas équilibrée. De manière générale, les transferts de technologie s'effectuèrent sans l'accord des "récepteurs ». Dans le cas qui nous occupe ici, la photographie apparaît comme un instrument de pouvoir dans un contexte de conquête et de soumission, ce médium moderne ayant dans un premier temps été transféré selon un processus strictement unilatéral, du « colonisateur » au « colonisé ».

\section{Transferts photographiques vers et de la Russie dans les années 1840}

La diffusion rapide de la nouvelle invention s'accompagna partout du mythe de la précision photographique et de la capacité du médium à produire sur papier une image réelle du monde. Très enthousiasmées, les élites sociales et impériales cherchèrent à mettre la main sur la technique, les Romanov ne faisant pas exception. On rapporte que Nicolas $\mathrm{I}^{\mathrm{er}}$ (1796-1855) aurait offert 500000 francs à Daguerre pour que ce dernier lui révèle son secret avant de l'annoncer officiellement (ce qui fut fait en janvier 1839). Daguerre refusa mais, quelques mois plus tard, il fit envoyer en cadeau au souverain trois daguerréotypes ${ }^{14}$. En dehors des transferts diplomatiques, les premiers échanges photographiques au sein de la Russie impériale relevèrent en grande partie de l'initiative de l'élite cultivée, de commerçants et de membres du gouvernement. Six mois après l'annonce publique de l'invention du daguerréotype, I. Kh. Hammel (1788-1862), membre de l'Académie des sciences de Russie rattaché au Département de la chimie et de la technique, fut envoyé à Londres et à Paris pour prendre davantage d'informations sur le calotype et le daguerréotype et rapporter à Saint-Pétersbourg des clichés et des instruments ${ }^{15}$. Plusieurs membres de l'Académie, parmi lesquels Karl von Baer (voir infra), s'intéressaient de près à

14. R. Watson \& H. Rappaport, Capturing the Light..., op.cit., p. 153, 169, 270.

15. David Elliot, « The photography in Russia: Icon of a New Age ", in David Elliot (ed.), Photography in Russia, 1840-1940, Londres, Thames and Hudson, 1992, p. 11, 26-27. 
la photographie et à ses applications dans le domaine de l'histoire naturelle ${ }^{16}$. À l'automne 1839, la daguerréotypomanie avait atteint Moscou: on pouvait désormais acheter le premier appareil à daguerréotype dans les boutiques de Charles Bekkers et Michael Smirdin; le caricaturiste Nikolaï Stepanov avait déjà écrit une brochure sur l'" utilisation pratique " de ces images-miroirs; et il était même possible de commander des daguerréotypes à des photographes professionnels ${ }^{17}$. L'année suivante, le photographe Alexeї Grekov, qui avait réussi à améliorer la technique, ouvrit son premier studio à Moscou ${ }^{18}$.

Très vite, la Russie ne se contenta plus seulement de s'approprier la nouvelle technologie: elle devint un agent actif dans la diffusion de la photographie vers les pays " orientaux ". Dès lors, le pays commença à organiser ses propres transferts diplomatiques. Le souverain persan Mohammad Shah (1810-1848), par exemple, contacta à la fois la mission russe à Téhéran et le Département asiatique du ministère des Affaires étrangères pour obtenir un appareil à daguerréotype destiné à son usage personnel. À l'automne 1842, la Russie fit livrer l'appareil avec toute sorte de matériel, et l'antenne moscovite du ministère des Affaires étrangères dépêcha un officier du Département asiatique spécialement « formé à la photographie » au palais du Golestan à Téhéran ${ }^{19}$.

16. Elena Barkhatova, « The first Photographs in Russia », in David Elliot (ed.), Photography in Russia, op. cit., p. 26.

17. Georgij Abramov, Etapy razvitija otečestvennogo fotoapparatostroenija (Les étapes du développement de la fabrication nationale d'appareils photographiques), s.d., http://www.photohistory.ru/1207248166951435.html; D. Bunimovič, Sovetskie fotoapparaty (Les appareils photographiques soviétiques), Moskva, Iskusstvo, 1950, p. 5-6.

18. David Elliot (ed.), Photography in Russia, op. cit., p. 15.

19. Reza Sheikh and Carmen Pérez González, "Editorial ", History of Photography 37/1, 2013, p. 1; Mohammad Reza Tahmasbpour, " Photography in Iran: a Chronology », in History of Photography 37/1, 2013, p. 7. Citant Yahya Zoka, Ali Behdad précise que des appareils photographiques furent offerts au shah entre 1839 et 1842, à peu près à la même période, par Nicolas $\mathrm{I}^{\mathrm{er}}$ et par la reine Victoria (voir Ali Behdad, " The Powerful Art of Qajar Photography: Orientalism and (Self-) Orientalizing in Nineteenth-Century Iran ", in Layla Diba (ed.), Qajar Art and Society, Iranian Studies 34/1, p. 144). 
La Russie mit également le daguerréotype au service d'expéditions géographiques dans le Caucase. En 1843, bien avant de devenir photographe à la cour des Romanov, Sergej Levickij (1819-1898), qui était alors employé du ministère des Affaires intérieures, fut envoyé dans le nord de la région pour y répertorier les sources d'eau locales. Engagé dans le cadre d'une commission spéciale, il avait pour mission d'accompagner des membres de l'état-major général et des savants de l'Académie impériale des sciences ${ }^{20}$ et de réaliser des vues de paysage destinées à planifier le développement futur de la région. Les daguerréotypes de Levickij (qui sont parmi les premières photographies de paysage prises en Russie ${ }^{21}$ ) ont ainsi joué un rôle fondamental de promotion de la photographie comme technique de transfert culturel: ils représentaient en effet un nouveau modèle pour les opérations sur le terrain, les photographes étant désormais envoyés aux quatre coins de l'Empire pour accompagner des expéditions militaires financées par le gouvernement central. Les vues réalisées par Leviskij furent récompensées par plusieurs médailles d'or lors de l'exposition de la Société française de photographie organisée à Paris en 1849, révélant de façon spectaculaire que la maîtrise de la technique par les Russes pouvait parfaitement s'exporter sur la scène mondiale ${ }^{22}$. Ce transfert actif de la photographie, utilisée à la fois pour les expéditions et les expositions, s'accéléra de manière significative après la guerre de Crimée, alors que l’Empire s'étendait de plus en plus vers l'Asie centrale et que le gouvernement perfectionnait la technique à des fins militaires. Cela allait profondément marquer les débuts de l'histoire de la photographie russe à l'ère de la modernité.

20. Heather S. Sonntag, Genesis of The Turkestan Album 1871-1872: The Role of Russian Military Photography, Mapping, Albums \& Exhibitions on Central Asia, thèse de doctorat, University of Wisconsin-Madison, 2011, p. 128; id., " Technology, Photography and Mapping Eurasian Territories: Genesis of the Turkestan Album and Its Antecedents, 1855-1875 ", in Conference Paper; Association of Slavic, East European and Eurasian Studies, 2012, p. 9.

21. Alexei Loginov, « Levitsky, Sergei Lvovich », in John Hannavy (ed.), Encyclopedia of Nineteenth-Century Photography, vol. 2, New York, Routledge, 2008, p. 853.

22. H. S. Sonntag, Genesis of The Turkestan Album, op. cit., p. 128. 


\section{Les transferts européens et la première institution photographique impériale russe}

$\mathrm{Au}$ milieu du siècle, la photographie était devenue une priorité étatique. Si Nicolas $\mathrm{I}^{\mathrm{er}}$ avait toujours été un partisan enthousiaste de la photographie en raison de son caractère mystérieux et novateur, il comprit rapidement également son importance et les applications nouvelles qu'elle offrait dans le domaine de la stratégie militaire et du renseignement. Le caractère stratégique de la photographie se manifesta notamment lors de la guerre de Crimée, au cours de laquelle les images de la Russie faisaient pâle figure à côté de celles des deux nations pionnières de la photographie, la France et la Grande-Bretagne ${ }^{23}$. Les archives montrent que très peu de photographes russes ou alliés produisirent des documents visuels défendant les intérêts russes entre le début de la guerre en 1853 et la défaite de 1856. Chez les photographes, on peut toutefois noter quelques exceptions, certains étant très célèbres, d'autres de complets inconnus: le célèbre photographe hongrois Carol Szathmari (1812-1887), admiré tant par la famille impériale russe que par la famille royale britannique, réalisa des albums de près de deux cents tirages illustrant les deux côtés de la guerre, parmi lesquels des portraits des généraux russes Gorčakov et Soïmonov; Vassiliï Timm (1820-1898), rédacteur en chef de la revue Russkï khudožestvennyj listok ("Gazette russe des arts ») publia une reproduction lithographique d'un portrait d'infirmières qu'il avait pris pendant la guerre $^{24}$; et après la guerre, en 1856, Fedor Orlov (1844-1909) photographia des scènes de villes détruites, notamment Sébastopol, Inkerman et Balaklava, comme le montre un petit album où ont été conservés trente-trois clichés ${ }^{25}$. Ces quelques exemples (dont le petit nombre s'explique par la censure russe) sont sans commune mesure avec la production des nombreux photographes alliés qui, grâce aux dernières évolutions de la technique du collodion humide, réali-

23. Sur la représentation visuelle de la guerre, voir Ulrich Keller, The Ultimate Spectacle: A Visual History of the Crimean War, Londres, Taylor \& Francis, 2013.

24. Paul Kerr, The Crimean War, Londres, Boxtree, 1997, p. 23, 70, 84.

25. H.S. Sonntag, « Technology, Photography and Mapping Eurasian Territories... », art. cit., p. 4-7. 
sèrent des milliers de négatifs représentant les héros, la vie de camp, les lignes d'approvisionnement et les effets du conflit. En 1854, conscient que la Russie était mal équipée pour rattraper son retard dans le domaine visuel, Nicolas $I^{\mathrm{er}}$ ordonna à l'état-major général du Département de topographie militaire (Voenno-topografičeskij otdel, désormais VTO) d'entamer sans tarder des recherches et des expériences avec le procédé du collodion ${ }^{26}$. Cela allait déclencher une nouvelle vague de transferts photographiques entre la Russie et l'Europe.

En réaction aux conséquences désastreuses et au coût exorbitant de la défaite, le tsar s'engagea à promouvoir la photographie pour une raison principale: moderniser la cartographie du territoire ${ }^{27}$ et, du même coup, moderniser l'empire. Les chercheurs ont pour habitude d'expliquer la défaite dans la guerre de Crimée par le "retard» militaire russe, qui se traduisait notamment par des armes vétustes et l'absence de réseau ferroviaire. Mais étant donné la supériorité technique du procédé au collodion, nous pouvons évoquer un troisième handicap technologique ${ }^{28}$ : la Russie, à la différence de ses adversaires, ne possédait tout simplement pas de moyen mécanique rapide de reproduction de copies des cartes sur lesquelles figuraient des renseignements géographiques stratégiques. Nicolas $\mathrm{I}^{\mathrm{er}}$ accepta dès lors ce qu'avaient déjà compris depuis longtemps d'autres armées dans le monde: la photographie, en tant que technique visuelle innovante, pouvait améliorer et accélérer les procédés d'impression et de reproduction cartographiques. En outre, ce médium pouvait être adapté et perfectionné à des fins militaires. Grâce au soutien du souverain fut alors créé à Saint-Pétersbourg, au quartier général de l'état-major des armées, un établissement photographique destiné à fournir aux photographes une solide formation.

À la mort de son père, Alexandre II (1818-1881) voulut continuer à moderniser la cartographie; à l'automne 1855, il ordonna l'ouverture de la première institution impériale dédiée à la photographie

26. Ibid., p. 3.

27. Ibid., p. 4.

28. H.S. Sonntag, Genesis of The Turkestan Album, op. cit., p. 32. 
(fotozavedenie), hébergée au sein du VTO, près du palais d'Hiver ${ }^{29}$. Cet établissement, ou plutôt ce "pavillon ", qui comportait un laboratoire et un studio (fotografičeskiï pavil'ion) installés tout en haut du bâtiment avec des plafonds de verre orientés vers le sud pour laisser pénétrer la lumière naturelle, allait être placé sous la responsabilité du capitaine Pisarevskij entre 1856 et 1861, puis du lieutenant d'artillerie Nikolaï A. Sytenko entre 1862 et $1867^{30}$. Durant leur mandat respectif, Pisarevskiï et Sytenko firent équiper l'atelier et le laboratoire de manière à pouvoir y mener un grand nombre d'expériences visant à augmenter la précision et la vitesse des appareils. Tout le matériel ainsi que les instructions et les procédés d'application étaient d'origine européenne.

Chaque officier était envoyé à l'étranger pour se documenter sur les institutions photographiques militaires créées dans les pays occidentaux et collecter du matériel. D’Allemagne, Pisarevskij rapporta des lentilles, des plaques de verre pour négatifs, des solutions chimiques et autres fournitures; il revint de France avec le plan de construction de l'atelier photographique de la marine ${ }^{31}$. Cette première mission permit de doter l'établissement du VTO d'un laboratoire fonctionnel, d'espaces de stockage, de treize ateliers et deux grands studios équipés de cinq appareils photographiques ${ }^{32}$. Pisarevskij fut en outre chargé de concevoir des cours de chimie pour le VTO sur le modèle des méthodes pédagogiques développées au sein des différentes institutions photographiques qu'il avait visitées en Europe, en particulier les cours dispensés au corps des ingénieurs royaux britanniques (British Royal Engineers) ${ }^{33}$. À ces enseignements techniques furent associés des cours de composition et d'esquisse dispensés par le professeur I. A. Bogdan de l'Académie impériale des beaux-arts.

29. Id., " Technology, Photography and Mapping Eurasian Territories... ", art. cit., p. 4; Polnoe sobranie zakonov rossijskoj imperii, $\mathrm{n}^{0} 29663$ (21 septembre 1855), Petrograd, Gosudarstvennaja Tipografija, 1856, p. 596-599.

30. H.S. Sonntag, Genesis of The Turkestan Album, op. cit., p. 128.

31. Id., " Technology, Photography and Mapping Eurasian Territories... ", art. cit., p. 4. 32. "Peterburgskaja letopis " (Chronique de Saint-Pétersbourg), in Sankt-Peterburgskie vedomosti (Bulletins de Saint-Pétersbourg), $\mathrm{n}^{\circ}$ 117, 31 mai 1859, cité dans Barkhatova, 2009, n. 64, p. 72.

33. H.S. Sonntag, Genesis of The Turkestan Album, op. cit., p. 36-37. 
Sytenko poursuivit la ligne choisie par Pisarevskij pour diriger le pavillon de photographie, mais il intensifia les transferts de techniques et d'informations par le biais d'échanges plus fréquents avec ses collègues européens. Après plusieurs voyages en Angleterre, en France, en Belgique et en Autriche, il revint avec les derniers équipements et instructions techniques ${ }^{34}$ et ce qui allait être sa contribution la plus importante: un plan pour la rénovation du pavillon, fondé sur celui des ingénieurs royaux britanniques ${ }^{35}$. En résumé, il s'agissait d'un établissement russe utilisant les meilleurs équipements photographiques d'Europe: les instruments optiques et matériaux allemands et français étaient combinés à des techniques d'impression, des instructions et des modèles architecturaux inspirés par les studios britanniques.

Une fois opérationnelle, l'institution put très vite réaliser des cartes vouées à rationaliser les opérations militaires sur le terrain. Mais cette spécialisation en "photographie militaire " (voennaja fotografija) ne se limitait pas à ce type de production: des photographies plus conventionnelles - paysages ou portraits - étaient utilisées à des fins militaires (par exemple pour explorer les territoires en vue de planifier les infrastructures, exploiter les ressources naturelles, placer les postes de renseignement ou encore classifier les groupes ethniques). Auparavant, les représentations des lieux et des individus étaient réalisées à la main par des dessinateurs militaires, qui proposaient des "vues " et des "types " entièrement imaginaires et pittoresques. La photographie mit cette méthode au rebut: selon l'idée de l'époque, elle permettait en effet de capter des détails avec une netteté parfaite, une exactitude immédiate et incontestable, et, bien entendu, une indéniable authenticité. Les photographes militaires du VTO, qui avaient reçu une formation de haut niveau, étaient dans leur grande majorité issus des unités du génie et d'artillerie de l'armée. Leurs compétences techniques devinrent vite indispensables ${ }^{36}$ : les représentants de l'Académie militaire de l'état-major général, de la Société impériale géographique de Russie,

34. Ibid., p. 35-36.

35. Ibid., p. 102.

36. Ibid., p. 38. 
de l'Académie des sciences ou encore du ministère de la Marine eurent maintes fois recours à ces nouveaux experts russes de la photographie.

Comme l'ont montré de nombreux chercheurs, la technique photographique fut utilisée par les principales disciplines scientifiques comme outil visuel pour traduire, promouvoir et diffuser des données et des théories dans le but de participer à l'élaboration des politiques étatiques et du projet impérial. L'ère du collodion succéda immédiatement en Europe à l'ère "de l'engouement statistique " (1830-1848 $)^{37}$; en Russie, celui-ci vint dynamiser le champ dominant de la géographie, donnant naissance au domaine des «statistiques militaires ", dont la paternité est attribuée à un fervent partisan de la photographie, Dmitriï A. Milioutine (1816-1912), qui devint ministre de la Guerre et l'acteur principal de la conquête de l'Asie centrale.

De la même manière, la photographie allait profondément transformer l'ethnologie et l'anthropologie, deux champs alors en plein développement en Russie à la suite de différents transferts scientifiques. À Saint-Pétersbourg, le cofondateur de la Société de géographie et éminent naturaliste allemand Karl Ernst von Baer (1792-1876) notait l'« utilité réelle [de la photographie] pour l'étude ethnologique »: pour lui, la photographie était un outil technique très performant pour classer les divers peuples de l'Empire russe ${ }^{38}$. Il s'inspira tout particulièrement des instructions établies par Paul Broca (1824-1880), président de la Société française d'anthropologie, pour la réalisation de portraits ethniques. Broca avait proposé une série de conventions visuelles rapidement adoptées à travers toute la Russie pour inventorier les "types " en utilisant des prises de vue de face et de profil. Cette méthode développée par les anthropologues français exigeait que les sujets soient photographiés nus, mais les photographes russes (militaires, scientifiques et professionnels) rejetèrent catégoriquement cette pratique au profit de clichés mon-

37. Peter Holquist, « To count, to extract, and to exterminate: population statistics and population politics in late imperial and Soviet Russia ", in Ronald Grigor Suny and Terry Martin (eds.), A State of Nations: Empire and Nation-Making in the Age of Lenin and Stalin, Oxford, Oxford University Press, 2001, p. 112-114.

38. H.S. Sonntag, Genesis of The Turkestan Album, op. cit., p. 47-49. 
trant les différentes nationalités avec leurs habits, leurs coiffures et même leurs objets quotidiens traditionnels.

Le transfert de ces idées atteignit les cercles intellectuels russes les plus importants dans les années 1860 et 1870. En 1866, par exemple, Alexeï P. Fedčenko (1844-1873), alors à la tête du comité photographique et du pavillon du Turkestan lors de l'Exposition ethnographique qui se tint à Moscou en 1867 (supervisée par l'anthropologue Anatoliï P. Bogdanov [1834-1896]), se procura une traduction des Instructions générales de Broca (Obščie instrukcii Broka). Le document servit de directive pour les photographies ethnographiques rassemblées depuis les différentes provinces et présentées à l'exposition ${ }^{39}$. Alors que la photographie devenait partie intégrante de la pratique scientifique, la Société impériale de géographie de Russie publia en 1872 une version de ces « instructions » dans sa revue ${ }^{40}$.

Après avoir perfectionné la technique et reconnu l'étendue de ses applications, les photographes du VTO utilisèrent le médium comme un moyen moderne de cartographier des informations stratégiques et de fournir au gouvernement des renseignements fiables et complets sur les territoires et les populations. Par conséquent, le pouvoir central s'empressa de déployer ces photographes aux confins de l'Empire, en particulier aux frontières du Caucase et de l'Asie centrale. Un des résultats décisifs de ce transfert interne, qui alliait culture militaire et culture savante, fut une prolifération d'albums, notamment sous le règne d'Alexandre II, l'engouement pour ce type de publication perdurant des années 1850 aux années $1880^{41}$. Les albums - objets photographiques uniques bientôt couramment utilisés comme galeries portables d'images et inventaires des nouvelles possessions asiatiques sous contrôle russe - symbolisent ce transfert culturel des techniques et des idées à travers tout l'Empire, jusque dans les minis-

39. Ibid., p. 50.

40. Ibid., p. 49. À propos de ces instructions et de leurs variantes, voir anonyme, « Nastavlenija dlja želajuščih izgotovljat' fotografičeskie snimki na pol'zu antropologii » (Instructions pour ceux qui souhaitent réaliser des photographies au profit de l'anthropologie), in Izvestija imperatorskogo russkogo geografičeskogo obščestva, vol. VIII, $\mathrm{n}^{\circ} 2$ 2, 1872, p. 86-88.

41. H.S. Sonntag, Genesis of The Turkestan Album, op. cit., p. 8, 51. 
tères, les institutions savantes et les bibliothèques, et même jusqu'à l'étranger, où ils étaient présentés dans des expositions.

\section{Les photographes et les studios du VTO aux marges asiatiques de l'empire}

\section{Transferts vers le Caucase}

Les premiers transferts photographiques et activités de terrain menées par les membres du VTO eurent lieu au Caucase avant d'atteindre l'Asie centrale. Si Sergeï Levickij fut le premier à importer les techniques photographiques dans le nord du Caucase lors de missions menées pour le compte de l'État, c'est au colonel Alexandre Ivanickij (1811-1872) qu'on doit leur première utilisation dans le sud de la région. En tant qu'ingénieur en chef d'une unité de haute montagne, il réalisa, en réalité, bien plus que les premières photographies de la région: il fut à l'origine de l'installation d'un studio permanent à l'usage de l'administration régionale russe, placé sous la direction d'un personnel particulièrement compétent, le Corps militaire des photographes du Caucase.

Pendant que Pisarevskij sillonnait l'Europe pour acheter du matériel destiné à l'établissement photographique du VTO à SaintPétersbourg, son homologue à Tbilissi, Ivanickij, réalisait en 1857 une acquisition importante auprès de Charles Chevalier, à Paris ${ }^{42}$. Il avait été chargé par le " commandant-en-chef de l'armée du Caucase ", le maréchal Alexandre I. Barjatinskij (1855-1881), d’équiper « un établissement photographique " d'une chambre noire, d'un laboratoire et d'un studio. Deux ans plus tard arrivèrent plusieurs malles contenant quelque 119 articles: produits chimiques, lampes pour chambre noire; plaques de verre; boîte de rangement; cartons; papier " positif " anglais et français; lentilles pour paysages et portraits, etc. En 1862, l'établissement employait des officiers et des topographes envoyés par l'armée du Caucase, qui avaient été formés à SaintPétersbourg "à l'art photographique " (fotografičeskoe iskusstvo)

42. H.S. Sonntag, « Technology, Photography and Mapping Eurasian Territories... ", art. cit., p. 9. Nous remercions ici Gia Gersamia pour cette information (communication personnelle, 8 juin 2012). 
pour « copier, agrandir et réduire cartes et plans, ainsi que réaliser des vues photographiques et stéréographiques naturelles ${ }^{43}$. Servant à bien des égards de pavillon satellite à celui de la capitale, cet établissement ouvrit en janvier 1863 sous le nom d'« établissement photographique de l'état-major général de l'armée du Caucase ».

Avant que Ivanickij ne se retire de l'armée en 1866 avec le grade de général de division du génie de haute montagne du Caucase, il avait réussi à mettre en place un formidable transfert de technologies d'une région à une autre, qui donna naissance à une nouvelle unité d'officiers ultra spécialisés et très productifs connue, on l'a mentionné ci-dessus, sous le nom de Corps des photographes militaires du Caucase. Certains de ces photographes ouvrirent des studios très florissants après leur départ de l'armée; citons Vladimir V. Barkanov, Dmitrij Ermakov et Dmitrij Nikitin. Les officiers du Corps des photographes militaires du Caucase utilisèrent les techniques photographiques lors d'innombrables missions pour cartographier et collecter des données statistiques sur la géologie, l'hydrologie et les routes de communication, ainsi que sur l'héritage culturel matériel (tel que les monuments anciens ou les églises) et l'ethnographie des populations rencontrées. Sous l'autorité des districts locaux, ils explorèrent le territoire caucasien pour documenter le Kouban, le Tersk, le Daghestan, les gouvernements de Koutaïssi et d'Erevan (ces territoires s'étendent aujourd'hui à cheval sur la Tchétchénie, le Daghestan, la Géorgie, l'Ossétie et l'Arménie) ${ }^{44}$. De plus, comme Levickij, ils accompagnèrent les savants de la capitale et des branches locales de la Société de géographie et de la Commission archéologique, ainsi que des membres du Comité statistique du Caucase ${ }^{45}$. Tous ces chercheurs partageaient un même intérêt pour la capacité de la photographie à transmettre le savoir et à le diffuser.

Une fois revenus du terrain, les membres du corps des photographes militaires imprimaient des cartes géographiques et des

43. Ibid., p. 9-10; H.S. Sonntag, Genesis of The Turkestan Album, op. cit., p. 126.

44. H.S. Sonntag, « Technology, Photography and Mapping Eurasian Territories... », art. cit., p. 11-12.

45. Ibid., p. 11; H.S. Sonntag, Genesis of The Turkestan Album, op. cit., p. 132. 
" images situationnelles " (situacionnye snimki) décisives sur le plan militaire ${ }^{46}$. Ils choisissaient en effet des lieux présentant un intérêt stratégique spécifique ou un patrimoine local particulièrement important, ces clichés correspondant par ailleurs aux catégories plus générales de "vues, types et sujets archéologiques ". Ils compilaient ensuite des albums à partir de centaines de négatifs et de vues panoramiques (s'emočnye listy) ${ }^{47}$. En 1866, par exemple, le corps des photographes se rendit dans la province de Koutaïssi pour mettre à jour des cartes et prendre près de 1300 clichés, dont seule une soixantaine de négatifs fut imprimée pour être classée dans un unique album ${ }^{48}$. Prises dans un contexte impérial, ces images devaient répondre aux intérêts de la Russie; à l'arrière-plan et au premier plan de nombre de ces clichés, on notera la présence immanquable de l'administration russe sous la forme d'infrastructures flambant neuves (forts, routes, ponts, hôpitaux, postes de douanes ou de police, bureaux de postes, lampadaires le long des boulevards, églises orthodoxes, etc.). Dans les années 1870, un grand nombre de photographies, par exemple celles qui représentent l'avancement des travaux de construction bordant la route militaire géorgienne, montraient très clairement des poteaux télégraphiques et des rails de chemin de fer. Ces symboles de la civilisation européenne moderne contrastaient avec le mode de vie traditionnel d'un bon nombre de communautés locales ${ }^{49}$.

Si le corps des photographes militaires avait au départ été créé dans une optique topographique, il était également impliqué dans une vaste entreprise orientaliste. Cette perspective dictait la pratique sur le terrain des photographes: les populations locales étaient documentées en fonction des types nationaux, des coutumes et de l'architecture ancienne locale. Dans ce contexte, la photographie militaire produite par le VTO peut être envisagée comme une technologie de pouvoir. En mettant en scène des femmes à la beauté

46. H.S. Sonntag, Genesis of The Turkestan Album, op. cit., p. 135.

47. Ibid., p. 130.

48. Idem.

49. H. S. Sonntag, "Technology, Photography and Mapping Eurasian Territories...", art. cit., p. 10. 
exotique ou des guerriers des montagnes à la figure menaçante, ces images ne faisaient que reprendre des représentations littéraires russes du "noble sauvage " circassien, par exemple, et proposer une version visuelle et visible de l' " Autre ", géorgien cette fois. Ces perceptions finirent par mêler ensemble toutes les cultures « caucasiennes " en un seul et unique trope. Là où la violence et la peur servaient d'instruments de domination militaire, la photographie était quant à elle utilisée pour représenter la légitimité du pouvoir russe dans une région d'une grande richesse culturelle, multiethnique et orientalisée.

Plusieurs albums produits par le corps des photographes militaires du Caucase circulèrent dans le pays et à l'étranger par le biais d'expositions, accédant ainsi à une certaine renommée internationale. On les regardait de Saint-Pétersbourg à Moscou, de Berlin en 1865 à Paris en $1867^{50}$. Comme nous l'avons dit plus haut, ces albums offraient une synthèse des différents transferts photographiques, leurs modes de présentation et leur richesse visuelle symbolisant par ailleurs la compétence des photographes russes. À partir du moment où le VTO se mit à mobiliser des photographes en Asie centrale, ce transfert allait s'inscrire dans un contexte technique et politique mouvementé, mais il allait déboucher sur ce qui allait être perçu comme le triomphe de la Russie impériale.

\section{Transferts vers l'Asie centrale}

En 1857, l'établissement photographique dirigé par Ivanickij au Caucase était en plein développement. Il n'existait alors encore aucun équivalent en Asie centrale ou dans les régions proches. Cette région était si reculée et aride qu'il était extrêmement difficile de pratiquer la photographie au collodion humide. Mais le problème était avant tout politique: la Russie n'avait pas encore assuré sa domination complète sur un territoire qui restait formellement aux mains de souverains centrasiatiques. Il fallut donc attendre plus longtemps que dans le Caucase pour établir un service photographique du VTO dans la région. Le pavillon de Tbilissi servit

50. Id., Genesis of The Turkestan Album, op. cit., p. 121-155; id., « Technology, Photography and Mapping Eurasian Territories... ", art. cit., p. 12-13. 
néanmoins de modèle et sa production eut un impact direct sur les gouverneurs des provinces orientales de l'Empire russe: finalement, deux établissements photographiques furent créés dans le but de documenter l'immense région d'Asie centrale.

En 1861, au moment où le VTO de Saint-Pétersbourg commençait officiellement à transférer des photographes militaires vers le pavillon caucasien, l'état-major général se mit à s'intéresser en même temps à l'Asie centrale. Comme dans le Caucase, un studio photographique y joua un rôle central pour le renseignement militaire, et les premiers officiers formés à la photographie (fotografičeskoe delo) furent envoyés de la capitale vers le nouvel établissement d'Orenbourg pour renouveler les techniques d'impression cartographique $^{51}$. Cette importante ville provinciale était stratégique pour le VTO: c'était là en effet qu'étaient planifiées les expéditions militaires et scientifiques vers le sud, dans les steppes kazakhes et dans les oasis des khanats d'Asie centrale. Mais en 1863, suite à des campagnes expansionnistes très agressives, le pavillon interrompit temporairement toute activité de terrain et d'impression de cartes. En 1865, enfin, le nouveau gouverneur-général d’Orenbourg, le général-adjudant Nikolaï A. Kryžanovskij (1818-1888) demanda à Sytenko quelles étaient ses instructions pour que ses officiers subordonnés puissent développer la photographie et, en 1866, le VTO d'Orenbourg commença son travail de renseignement dans les territoires nouvellement conquis et réalisa les premières cartes modernes de la région ${ }^{52}$.

Ces cartes étaient une première étape dans le travail de délimitation de la puissance territoriale grandissante de l'Empire russe en Asie. Elles montraient comment les troupes tsaristes avaient « fermé les lignes » des territoires des steppes: les villes oasis étaient rapidement tombées les unes après les autres entre 1863 et 1867, amputant le territoire du khanat de Kokand. Par la suite, ces villes rejoignirent le kraï (région) d'Orenbourg tout en étant regroupées au sein de l'oblast' du Turkestan, une nouvelle province impériale officielle-

51. Id., Genesis of The Turkestan Album, op. cit., p. 164-165.

52. Id., " Technology, Photography and Mapping Eurasian Territories... ", art. cit., p. 13-14. 
ment créée en 1865 entre la mer d'Aral et l'Issyk Koul. Cet oblast' était à l'origine gouverné depuis Tachkent par Mikhail G. Černjaev (1828-1898), puis par Dmitrij I. Romanovskij (1825-1881) et enfin par Kryžanovskij jusqu'en 1867. À partir de cette date, l'oblast' intégra le kraï du Turkestan dirigé par Konstantin P. von Kaufman (1818-1882). Ce dernier, qui était un fervent partisan de la photographie et avait lui-même assisté à son développement dans la capitale impériale alors qu'il y occupait diverses hautes fonctions au sein du gouvernement, participa à la création d'un établissement photographique du VTO à Tachkent en 1869. Comme ses contemporains et collègues de l'administration tsariste, Kaufman avait bien saisi le pouvoir de la photographie pour cartographier, classer et inventorier. Il commanda un grand nombre de projets photographiques ambitieux destinés à promouvoir l'unique colonie russe et la plus grande province de l'Empire, par exemple le Turkestanskij Albom (" Album du Turkestan ») [1871-1872 $]^{53}$.

Les tensions politiques, à la fois locales et étatiques, qui se manifestaient dans la création de ce vaste territoire frontalier allaient ressurgir dans les activités des photographes du VTO puisque, comme leurs homologues au Caucase, ils servaient d'intermédiaires et avaient pour ordre de fournir des cartes et des images de la région. Les albums photographiques et l'histoire de leur production révèlent que le transfert de la technique visuelle vers les khanats rencontra d'abord un certain nombre d'obstacles avant d'être couronné de succès.

\section{Deux albums photographiques du VTO dans un contexte de tension}

En 1857, le ministre de la Guerre Nikolaï O. Soukhozanet (17941871) recommanda aux officiers chargés d'organiser la mission diplomatique qui devait se rendre à Khiva et Boukhara d'emporter

53. Svetlana Gorshenina, "Krupnejšie proekty kolonial'nyh arhivov Rossii: utopičnost' total'noj Turkestaniki general-gubernatora K. P. fon Kaufmana » (Les plus grands projets d'archives coloniales de la Russie: l'utopie de Turkestanica exhaustifs de K. P. von Kaufmann), in Ab-Imperio 3, p. 291-354; H.S. Sonntag, Genesis of The Turkestan Album, op. cit. 
avec eux « des instruments photographiques lors de l'expédition vers le khanat ${ }^{54}$ ». L'absence de pavillon dans la région n’empêcha pas les membres de l'expédition de transporter jusqu'au désert, sur des charrettes tirées par des chameaux, puis sur le bateau traversant la mer d'Aral, tout l'équipement et les accessoires nécessaires. Le photographe de l'expédition, le lieutenant d'artillerie Anton S. Murenko (1837-1875) ne fut pas davantage troublé par l'éventualité de tensions avec les populations locales vivant sur le plateau d'Oust-Ourt, à Khiva ou à Boukhara. Le seul à critiquer l'usage de la photographie au cours de cette mission extrêmement importante fut le commandant de la campagne, Nikolaï P. Ignatiev (1832-1908), qui semblait tout simplement ignorer les avantages de la nouvelle technique et se méfiait de cette présente encombrante.

Ignatiev avait été chargé par le ministre des Affaires étrangères et le département des Affaires asiatiques, ainsi que par les ministres de la Guerre et de la Marine de mener ce qui devait être une mission diplomatique de six mois destinée à consolider les relations commerciales et politiques avec les États indépendants d'Asie centrale. La mission avait également pour objectif d'évaluer et éventuellement contrer l'influence britannique dans la région. Dans ce climat d'espionnage, Ignatiev avait exprimé ses frustrations à l'égard de Murenko, embauché pour accompagner les deux topographes dans leur travail de collecte de données visuelles et pour tester la technique photographique dans les climats désertiques de Khiva et de Boukhara ${ }^{55}$. Pour le jeune commandant, la présence d'un photographe était hautement indésirable et gênante: selon Ignatiev, Murenko représentait un risque pour la sécurité de la mission, éveillant immédiatement des soupçons inutiles par la présence de ses caméras (Ignatiev avait en tête le destin tragique des agents britanniques Charles Stoddart et Arthur Conolly exécutés en 1842 par l'émir de Boukhara Nasrullah Khan). Le mécontentement d'Ignatiev s'explique aussi d'un point de vue logistique: l'un des chariots transportant l'équipement du photographe était à l'origine destiné à des obus d'artillerie qui devaient servir à sonder la mer d'Aral.

54. H.S. Sonntag, Genesis of The Turkestan Album, op. cit., p. 62.

55. Ibid., p. 53-56. 
L’album qui résulta de l'expédition contient vingt-huit épreuves sur papier salé, publiées sous le titre Ot Orenburga čerez Khivu do Bukhary. Svetopis' artillerii podporučika Murenko («D’Orenbourg à Boukhara en passant par Khiva, dessins photographiques du lieutenant d'artillerie Murenko » ${ }^{56}$. Il représente une vaste enquête que l'on peut diviser en six étapes successives en suivant l'itinéraire de la mission: Orenbourg, le plateau d'Oust-Ourt, la mer d'Aral et l'Amou-Daria, Khiva, Boukhara et le fort $\mathrm{n}^{0} 1$ (Kazalinsk) sur le SyrDaria $^{57}$. Les images de Murenko, qui combinent des techniques développées par Archer et Talbot, déçoivent par leur manque de netteté, qui rendit indispensables des retouches qui les font davantage ressembler à des aquarelles qu'à des photographies. Mais elles remplirent leurs objectifs, et ce pour différentes raisons.

Tout d'abord, Murenko fut le premier à documenter l'expédition navale effectuée sur la mer d'Aral, spécialement commandée par l'amiral de la flotte impériale, le grand-duc Konstantin Nikolaevič (1827-1892), en commémoration de la toute première expédition dirigée par Alekseï I. Boutakov (1816-1869). Cette campagne s'était déroulée en 1848 et avait été illustrée dans un " album de dessins " par le poète et peintre Taras G. Ševčenko (1814-1861) ${ }^{58}$. Deuxièmement, l'album de Murenko témoigne de la réaction des populations locales à la photographie. Pendant les trois premières

56. S. Morozov, Russkie putešestvenniki fotografy (Les photographes voyageurs russes), Moscou, Gosudarstvennoe izdatel'stvo geografičeskoj literatury, 1953, p. 14; T. M. Devel'« Al'bom fotografij missij polkovnika N.P. Ignat'eva v Khivu i v Bukharu " (L'album de photographies de la mission du colonel N.P. Ignatiev à Khiva et à Boukhara), in Strany i narody Vostoka (geografija, ètnografija, istorija, kul'tura) (Pays et peuples de l'Orient [géographie, ethnographie, histoire, culture]), vol. XXVIII, Sankt-Peterburg, Peterburgskoe vostokovedenie, 1994, p. 259-271; Galina V. Dlužnevskaja, Arheologičeskie issledovanija v Central'noj Azii i Sibiri v 1859-1959 godah (po dokumentam Naučnogo arhiva Instituta istorii material'noj kul'tury RAN) (Études archéologiques en Asie centrale et en Sibérie en 1859-1959 [selon les documents de l'archive scientifique de l'Institut de la culture matérielle), Saint-Pétersbourg, ElekSIS, 2011, p. 282-291; H.S. Sonntag, Genesis of The Turkestan Album, op. cit., p. 32-34. Le nombre initial des photographies a été de 29; actuellement, la copie de l'album conservée à l'Institut de l'histoire de la culture matérielle (FA, op. Q211) ne contient que 24 photographies.

57. H. S. Sonntag, Genesis of The Turkestan Album, op. cit., p. 54-89.

58. Ibid., p. 66. 
semaines qui suivirent son arrivée à Khiva, la mission d'Ignatiev avait été assignée à résidence dans la cour du palais où les membres de l'expédition étaient surveillés jour et nuit par des gardes armés partout présents, y compris sur les toits. Ce sont dans ces conditions que Murenko prit ses portraits de Khiviens. Les individus qu'il sollicita avaient d'abord cru que l'appareil photographique était une arme et se montrèrent dès lors hésitants à poser, ce qui explique peut-être pourquoi on trouve parmi les " types " le jardinier et le drogman. À partir du moment où il s'avéra que la magie de l'image était bénigne, Murenko put photographier les fils du khan avec leurs lévriers préférés ainsi que d'autres résidents du palais royal.

Enfin, l'album permit à Murenko d'obtenir une médaille d'argent lors de la réunion de la Société géographique de Russie, créant ainsi un précédent qui allait permettre à l'État d'imposer la photographie parmi les instruments d'enquête lors de futures campagnes en Asie centrale. En outre, cet album procura à Murenko une renommée qui rejaillit sur l'établissement photographique du VTO. Le capitaine Mikhail K. Priorov, ingénieur et sapeur du VTO originaire d'Orenbourg, n'allait pas bénéficier de la même reconnaissance publique pour les photographies qu'il réalisa à la demande de la Commission des steppes en 1865 et qui furent compilées dans un second album consacré à la région, Iz Srednej Azii (« De l'Asie centrale ») [1867].

Commandé par le gouverneur-général d'Orenbourg lui-même, Kryžanovskiï, cet album de trente-neuf photographies représente l'une des plus importantes campagnes menées dans la région après la conquête. Il documente les travaux de la Commission des steppes en 1865 et 1866. Dirigée par Fedor K. Giers (1824-1891), celle-ci avait pour objectif de collecter des renseignements sur les institutions économiques, sociales, juridiques et politiques des populations kazakhes. En 1866, Kryžanovskiï chargea Priorov d'accompagner les membres de la Commission lors de leur tournée de visite des régions du sud de la province d'Orenbourg et, plus particulièrement des nouvelles possessions coloniales d'Asie centrale. Il est intéressant de noter que cette Commission comprenait également une mission archéologique dirigée par Petr I. Lerch (1828-1884), le même orientaliste qui avait participé à la mission de 1858 d'Ignatiev à Khiva et Boukhara. Une des tâches de Priorov était de suivre Lerch pendant 
cinq mois et de produire des plans, des croquis, ainsi que des photographies $^{59}$. En dépit de quelques portraits des élites locales, l'album contient principalement des images de l'expédition et des observations scientifiques réalisées aux forts $\mathrm{n}^{0} 1$ à Kazalinsk et à Perovskij, ainsi que dans les villes de Chimkent, Turkestan, Tachkent, Khodjent et Oura-Tubé (aujourd'hui Istaravchan, dans le Tadjikistan) ${ }^{60}$.

On peut distinguer plusieurs raisons pour lesquelles Kryžanovskiï jugea que la Commission devait s'adjoindre les services de Priorov. Tout d'abord, il est possible que cette décision de Kryžanovskiï ait été une réaction à la tenue de l'Exposition universelle de Paris de 1867 et, la même année, de l'Exposition ethnographique de Moscou: étant donné l'introduction très récente de la photographie en Asie centrale, il savait que la région y allait être mal représentée ${ }^{61}$. Deuxièmement, étant donné son investissement dans l'organisation du pavillon d'Orenbourg, Kryžanovskiï était impatient de connaître les potentialités du nouveau médium. Troisièmement, la présence de Lerch dans la mission géographique était pour le gouverneurgénéral une manière de répondre à la Commission archéologique impériale, qui avait insisté sur la nécessité d'engager des fouilles sur le site de Djankent. Enfin, en tant que membre spécial de la Commission des steppes avec Fedor Giers, Kryžanovskij avait mon-

59. Petr Lerkh, Arkheologičeskaja poezdka v Turkestanskij kraj v 1867 g. (Izvlečenie iz otčeta, predstavlennogo Imperatorskoï Arheologičeskoj kommissiej), SanktPeterburg, Tipografija Imperatorskoj Akademii Nauk, in Turkestanskij Sbornik 24, Sankt-Peterburg, 1869, p. 321-372.

60. H.S. Sonntag, Genesis of The Turkestan Album, op. cit., p. 175-188.

61. À l'Exposition de Paris, Kryžanovskij ne put envoyer qu'une maigre collection d'instruments agricoles appartenant au khwaja Yusupov de Tachkent. À Moscou, l'Asie centrale était représentée par des dessins de Kirghizes " primitifs " (dikokamennye) et de la grande horde de Kazakhs faits par P.M. Košarov, plusieurs mannequins vêtus de costumes traditionnels et divers objets collectés par le capitaine A. A. Kušakevič, gouverneur militaire du district de Khodjent, ainsi que, vraisemblablement, quelques photographies de Priorov. Voir Svetlana Gorshenina, " La construction d'une image "savante" du Turkestan russe lors des premières expositions "coloniales" dans l'empire: analyse d'une technologie culturelle du pouvoir ", in S. Gorshenina et Sergej Abashin (éd.), Le Turkestan russe: une colonie comme les autres ?, Paris, Collection de l'IFEAC, "Cahiers d'Asie centrale ", vol. 17/18, 2009, p. 136-137; H.S. Sonntag, Genesis of The Turkestan Album, op. cit., p. 159, p. 184-185. 
tré un intérêt tant personnel que politique pour la réorganisation de l'Asie centrale. Mais malgré les dépenses engagées et le rôle important que joua la photographie dans le contrôle de la région à l'époque, les contributions visuelles de Priorov (à la différence de celles de Murenko) furent vraisemblablement ignorées.

Pour reprendre la terminologie actuellement utilisée pour parler de cette époque, on peut dire que l' "impact médiatique » de l'album Iz Srednej Azii ( "De l'Asie centrale ») fut immense, même si le nom de Priorov ne fut que très rarement cité: Lerch utilisa en effet ces photographies lors d'un exposé à la Société géographique russe en 1867, mais il passa sous silence le nom du photographe, avec lequel les rapports étaient alors tendus. L’année suivante, on manqua une nouvelle fois de mentionner Priorov lorsque certaines de ses photographies furent publiées par Pietr. I. Pašino dans le récit de son voyage en Asie centrale intitulé Turkestanskï kraï v 1866 godu. Putevye zametki P.I. Pašino ("Le kraï du Turkestan en 1866. Notes du voyage de P. I. Pašino ») ${ }^{62}$. En 1869 encore, plusieurs clichés représentant des sites archéologiques furent exposés sans mention de son nom dans une exposition organisée par le ministère de la Cour impériale et des Domaines de l'État (Ministerstvo imperatorskogo dvora $i$ udelov) ${ }^{63}$. Que l'oubli ait été volontaire ou non, l'exposition était le fruit des efforts de Vassiliï V. Vereščaguine et de Konstantin von Kaufman ${ }^{64}$. En effet, ce dernier allait devenir dans les quinze années qui suivirent l'incarnation vivante du Turkestan russe, créé, rappelons-le, en 1867 par la Commission des steppes. Par le biais de deux statuts proposant une gestion administrative distincte du kraï des steppes et des nouveaux territoires de l'oblast' du Turkestan, cette décision était radicalement opposée à la vision de Kryžanovskiï et annulait tous les espoirs de ce dernier de gouverner les khanats du sud de l'Asie

62. Petr Pašino, Turkestanskij kraj v 1866 godu. Putevye zametki (Le Kraï du Turkestan en 1866. Notes de voyage de P.I. Pašino), Sankt-Peterburg, Tipografija Tiblen i $\mathrm{K}^{0}$ (Nekljudova), 1868, figures 5-8.

63. H.S. Sonntag, Genesis of The Turkestan Album, op. cit., p. 164-175; H.S. Sonntag, "Technology, Photography and Mapping Eurasian Territories... ", art. cit., p. 14-15.

64. S. Gorshenina, « La construction d'une image "savante” du Turkestan russe... », art. cit., p. 136-147. 
centrale. Tous les territoires s'étendant le long du Syr-Daria qui faisaient alors partie de l'oblast' du Turkestan - et que Priorov avait illustrés dans son album - furent réorganisés pour former le nouveau gouvernement du Turkestan. Sur les recommandations de son ami Dmitrii Milioutine, ministre de la Guerre, Kaufman fut nommé premier gouverneur-général du nouveau kraï du Turkestan.

\section{Transferts photographiques chez les populations asiatiques locales}

Durant la période coloniale, les transferts de la photographie vers l'Asie centrale furent en majorité portés par les responsables de l'administration militaire russe. À la fois clients et promoteurs tant de la Culture A (inventeurs culturels) que de la Culture B (adaptateurs de transferts), ils utilisèrent leur influence politique pour promouvoir la photographie comme nouvelle technologie dans la région et empruntèrent aux Européens un ensemble de théories, d'applications, mais aussi de thèmes et de sujets photographiques. Dans ce processus, les populations rencontrées sur le terrain, qui auraient pu être des agents récepteurs, capables de participer activement au transfert en sélectionnant les innovations particulièrement bien adaptées à leurs conditions de vie ou complémentaires de leurs traditions locales, jouèrent un rôle négligeable, voire nul.

Il va sans dire que la première réaction à ce transfert culturel fut celle d'un rejet. La photographie ne parvint pas à se faire une place à la cour des émirs de Boukhara ni à celle des khans de Khiva. À l'exception de Murenko, qui fut libéré après avoir été quelques temps astreint à résidence dans un palais khivien lors de la mission Ignatiev en 1857, les Européens qui tentèrent d'importer la nouvelle technologie auprès des population d'Asie centrale connurent un sort tragique: après les officiers britanniques Stoddard et Conolly décapités en 1842 par l'émir de Boukhara, le Français Henri de Coulibœuf de Blocqueville fut emprisonné à Khiva en $1860^{65}$; quant à eux, les

65. Henri de Coulibœuf de Blocqueville, «Quatorze mois de captivité chez les Turcomans (frontières du Turkestan et de la Perse), 1860-1861 ", in Le Tour du Monde, 1886, p. 225-272; M. R. Tahmasbpour, « Photography in Iran », art.cit. 
explorateurs italiens Modesto Miro Gavazzi, le comte Pompeo Litta Biumi Resta et Ferdinando Meazza furent emprisonnés à Boukhara en $1863^{66}$. Tous tentèrent en vain de démontrer la magie et l'utilité de la photographie. Même à la fin des années 1860 et au début des années 1870, quand les khanats d'Asie centrale furent officiellement transformés en protectorats russes, toutes les tentatives d'y introduire la photographie échouèrent.

À la différence des rois perses Mohammad Shah (reg. 1834-1848) et Nasreddin Shah (reg. 1848-1896) qui participèrent pendant de longues décennies à des échanges photographiques très riches ${ }^{67}$, les souverains du Turkestan ne purent pas s'entourer d'instructeurs ou d'officiers occidentaux formés à la photographie. Ils ne furent pas non plus en mesure d'ouvrir leurs propres ateliers royaux, comme ceux qui furent créés à Téhéran dès 1848 , pas plus qu'ils ne purent mettre en place des formations spécialisées, à l'image des cours dispensés à l'université Dar-ol Fonoun de Téhéran, où la photographie et la chimie furent ajoutés au cursus obligatoire en 1851. Les khans et les émirs ne pouvaient pas envoyer leurs sujets étudier la photographie en Europe, alors qu'un premier groupe d'étudiants iraniens de Téhéran séjourna à Paris dès $1858^{68}$.

La situation en Asie centrale contraste également avec celle qui prévalait dans l'Empire ottoman. À partir de 1863, les frères Abdullah d'Arménie y avaient établi un atelier qui servait aussi de studio photographique pour la cour du sultan. Ils produisaient des images officielles, sous autorisation de la Porte ottomane, ainsi que des clichés touristiques à caractère orientalisant destinés aux voyageurs européens. Fasciné par cet art, le sultan Abdülhamid II (reg. 1876-1909) fit plus tard installer une chambre noire dans son palais de Tildiz et, en 1892, fit paraître un décret réglementant le type de

66. Svetlana Gorshenina, Explorateurs en Asie centrale. Voyageurs et aventuriers de Marco Polo à Ella Maillart, Genève, Olizane, 2003, p. 348; Gerolamo Gavazzi, The Gavazzis Silk and Mettle. History of a Lombard Family, Milan, Caproncino, 2007, p. 64-97; Alice Britto, «I prionieri italiani a Bukara. Lettere del conte Pompeo Litta Biumi Resta ", in Miscellanea di storia delle esplorazioni 39, Gênes, 2014, p. 161173.

67. A. Behdad, « The powerful art of Qajar photography », art.cit., p. 145.

68. M. R. Tahmasbpour, « Photography in Iran », art.cit., p. 7. 
clichés de ses sujets que les voyageurs européens étaient autorisés à prendre $^{69}$. En outre, Abdülhamid II fut manifestement très attentif, dans ses propres représentations photographiques, à donner l'image d'un Empire ottoman aussi moderne que les puissances européennes de l'époque. Ses photographies témoignent d'une volonté d'apparaître sur la scène mondiale comme le monarque d'un grand pays s'étendant à la fois en Europe et en Asie. Le sultan avait en effet entrepris de développer les techniques contemporaines et le système éducatif de son pays dans le vaste mouvement de modernisation caractéristique de la fin du XIX ${ }^{\mathrm{e}}$ siècle. Son "autoportrait impérial " n'était en ce sens pas l'image d'un pouvoir exotique extravagant, mais plutôt celle d'un souverain puissant entouré des symboles de sa richesse et de son succès personnels, par exemple ses collections de yachts et de chevaux (que l'on trouvait aussi souvent représentés chez les monarques européens) $)^{70}$.

À la différence des chahs perses ou afghans ${ }^{71}$, des sultans ottomans ou encore des souverains éthiopiens ${ }^{72}$, les émirs de Boukhara

69. E. S. Gavin Carney, Şinasi Tekin, Gonul Alpay Tekin, Imperial Self-Portrait. The Ottoman Empire as Revealed in Sultan Abdul Hamid's Photographic Albums presented as gifts to the Library of Congress (1893) and the British Museum (1894): a pictorial selection with catalogue, concordance, indices, and brief essays, Cambridge, Mass., Harvard University, Office of the University Publisher (special edition of volume 12 of the Journal of Turkish Studies, 1988; Catherine Pinguet et Pierre de Gigord, Istanbul, photographes et sultans. 1840-1900, Paris, CNRS Éditions, 2011; Mary Roberts, "The limits of circumscription ", in Ali Behdad and Luke Gartlan (eds.), Photography's Orientalism: New Essays on Colonial Representation, Los Angeles, Getty Research Institute, 2013, p. 53 (citation), p. 54-74; Mary Roberts, Istanbul Exchanges: Ottomans, Orientalists, and Nineteenth-Century Visual Culture, Oakland, University of California Press, 2015; Selim Deringil, The Well-Protected Domains: Ideology and the Legitimation of Power in the Ottoman Empire, 18761909, Londres/New York, IB Tauris, 1999, p. 152.

70. S. Deringil, The Well-Protected Domains, op. cit., p. 152.

71. Khalilullah Enayat Seraj and Nancy Hatch Dupree, The KES Collection of Vintage Photographs: Summary Catalogue, New York, Afghanistan Council/Asia Society, 1979; Shah Mahmoud Hanifi, « Afghanistan's Photographic Heritage: The Khalilullah Enayat Seraj Collection and Transcending the Visual Limits of a National Imagery ", communication lors du colloque Photography in/of Iran, Afghanistan and Pakistan: Historical and Contemporary Perspectives, Royal Anthropological Institute Anthropology and Photography Conference, British Museum, 2014.

72. Estelle Sohier, Le Roi des rois et la photographie. Politique de l'image et pouvoir royal en Éthiopie sous le règne de Ménélik II, Paris, Publications de la Sorbonne, 2012. 
et les khans de Khiva ne prirent jamais l'initiative personnelle de créer une documentation visuelle de leurs possessions pour consolider leur statut. Étant donné qu'ils ne parvinrent pas à maintenir une diplomatie indépendante, ils ne furent pas non plus capables de contrôler et d'exporter une image respectable vers la Russie ou l'Europe (même si les émirs de Boukhara participèrent très activement aux expositions universelles en y présentant leurs propres collections ethnographiques). Ils furent entièrement dépendants des images produites et fournies par les photographes russes. Ainsi, par exemple, l'émir de Boukhara Muzaffar (1834-1885) négocia pendant des mois, de février à juin 1884, avec l'administration coloniale et des ministres pour obtenir vingt-cinq portraits de lui-même réalisés par un certain Savenkov lors d'une expédition qui avait traversé l'émirat ${ }^{73}$.

Cependant, on ne peut pas parler d'une absence totale de la photographie dans la région. Valerija Priščepova a montré que, en 1872, le souverain de Kokand, Khudoyar Khan (1845-1875) et son fils Nasreddin Bek (gouverneur d'Andijan) avaient déjà développé un intérêt pour la photographie depuis leur rencontre avec le lieutenant G.E. Krivcov, qui avaient pris des portraits du khan et de son palais pour le Turkestanskij Albom (Album du Turkestan) ${ }^{74}$. Peu de temps après, le khan avait demandé à ce que Krivcov fasse parvenir à Kokand et à Andijan des appareils photographiques, divers instruments et des instructions détaillées (auxquelles Krivcov ajouta des instructions qu'il transmit oralement à l'émissaire du khan appelé "kokandi Berdykul » [kokandec Berdikul]). Malheureusement, ces premières expériences indépendantes furent un échec. Et, en 1876, la conquête russe du khanat de Kokand repoussa à plus tard la possibilité de nouvelles découvertes en chambre noire.

$* * *$

73. Central'nyj Gosudarstvennyj Arhiv Respubliki Uzbekistan (CGA RUz), F. I-5, op. 1, d. 1378.

74. Valerija Priščepova, Illjustrativnye kollekcii po narodam Central'noj Azii vtorö̈ poloviny XIX-načala XX veka v sobranijah Kunstkamery, Sankt-Peterburg, Nauka, 2011, p. 21-22. 
Comme le met en lumière le cas d'étude présenté ici, les premiers transferts culturels photographiques en Russie impériale, ne permettent que difficilement de parler de transferts réussis et équilibrés dans la périphérie sud de l’Empire russe.

(Traduit de l'anglais par Camille Joseph) 


\title{
La Géorgie entre la France, la Russie et la Perse, vue par les diplomates français
}

\author{
Irina Natchkebia
}

\section{Les renseignements des diplomates français sur la Géorgie}

Après de longues négociations qui prirent la tournure d'un bras de fer entre les deux pays, un traité d'alliance fut conclu le 4 mai 1807 entre la France d'un côté, représentée par le secrétaire d'État Hugues-Bernard Maret, et la Perse de l'autre, représentée par le plénipotentiaire Mirza Mohammad Reza Khan Qazvini, au camp impérial de Finkenstein en Prusse orientale. Le document se composait d'un préambule et de seize articles. Les articles 3 et 4 traitaient de la question de la Géorgie orientale.

De quelles informations disposait l'empereur des Français concernant la Géorgie, qu'il avait promise au shah?

Avant 1805, date à laquelle Napoléon envoya des émissaires français en Perse, la Géorgie ne faisait pas partie de la sphère des intérêts politiques français, mais le gouvernement disposait déjà d'un certain nombre de renseignements à son sujet. Nous avons retrouvé des documents datés de 1795-1796 à 1804 dans les archives diplomatiques du ministère des Affaires étrangères français, rédigés par Jean-François Rousseau, consul général de France à Bassora, Guillaume-Antoine Olivier, envoyé par le Directoire auprès d'Agha Mohammad Khan en 1796, et Pascal Fourcade, consul français à Sinop. 
On apprend dans ces documents que les Français voyaient la Géorgie comme " un beau pays sauvage " sous domination russe, dirigé par la Perse jusqu'en 1783 et encore fortement influencé par cet empire. Furieux d'apprendre que Héraclius II et ses descendants avaient reconnu le pouvoir suprême de la Russie, le shah de Perse Agha Mohammad Khan avait en 1795 ravagé la capitale de la Géorgie, Tiflis (Tbilissi). Ses soldats commirent des actes d'une cruauté et d'une barbarie sans limites ${ }^{1}$. Les Russes n'avaient pas pris part à cette guerre, continuant plutôt à commercer, via la mer Caspienne, d'Astrakhan vers Rasht, Derbent et Bakou. La politique russe à cette occasion fut considérée comme cruelle, la Russie ayant laissé Agha Mohammad Khan piller et dévaster la Géorgie afin de conquérir plus tard cette région grâce à ses propres forces armées et l'annexer de façon permanente au territoire russe. Cette impression fut renforcée par la fuite en Perse du prince Alexandre, provoquée par l'incorporation du royaume de Kartli-Kakhétie à l'Empire russe à la mort de Héraclius II en 1798. Il est intéressant de noter que les rapports de Fourcade, Rousseau et Olivier soulignent tous l'aspiration de la Russie, à partir de 1783, à s'établir sur les territoires s'étendant du port de Trabzon, situé sur la mer Noire, dans l'Empire ottoman, au port de Gorgan, sur la mer Caspienne, en Perse, en raison de leur position avantageuse sur les plans militaire et commercial ${ }^{2}$.

1. Tiflis a toujours suscité l'intérêt des descendants d'Agha Muhammad Khan. L'unique illustration de l'ouvrage Les Rois oubliés de Soltan Ali Mirza Qadjar, feu le chef de la dynastie Qadjar, représente justement Agha Muhammad Khan lors de la prise de la capitale géorgienne. L'auteur écrit dans le prologue: « Dans la maison que nous habitions à Saint-Cloud, dans les années trente, ma grand mère, la reine de Perse Malekeye Djahan, épouse de Mohammad-Ali Shah Qadjar, avait fait peindre par un artiste iranien un immense tableau représentant le premier grand souverain de notre dynastie, Agha Mohammad Khan, à la prise de Tiflis, capitale du royaume de Géorgie. Cette peinture ne nous a jamais quittés. Je l'ai fait transporter dans ma résidence actuelle. Agha Mohammad Khan tourne la tête vers le spectateur du tableau et tous ceux qui le contemplent éprouvent l'impression que j'éprouvais moi-même dans mon enfance. " Prince Ali Kadjar, Les Rois oubliés, l'épopée de la dynastie Kadjare, Paris, Kian, 1992, p. 7. La geste de l'eunuque à cheval tendant la main vers Tiflis rappelle la célèbre posture de Bonaparte sur le tableau de David.

2. Archives du ministère des Affaires étrangères, mémoires et documents, Perse, vol. 2, doc. 29, fol. 141r-147v; correspondances politiques, Perse, vol. 8, doc. 156, fol. $384 \mathrm{r}-384 \mathrm{v}$; doc. 157 , fol. $385 \mathrm{r}-385 \mathrm{v}$; doc. 158 , fol. $386 \mathrm{r}$. 
La lettre d'Alexandre Romieu et les rapports d'Amédée Jaubert confirment cette information. Romieu exprime sa surprise devant la faiblesse de l'armée persane. Il insiste sur le fait que l'armée russe, bien que n'ayant guère plus de 10000 ou 12000 soldats en Géorgie, avait résisté avec succès à l'armée persane constituée de 40000 à 80000 hommes $^{3}$. D'après les informations de Jaubert, la Russie conservait les territoires qu'elle occupait entre l'Araxe et la Koura. En hiver, l'armée russe stationnait à Tiflis. Les Géorgiens étaient extrêmement mécontents de la domination russe; les Russes, en raison de la "dissolution de mœurs » et du « honteux libertinage » de leur armée, avaient perdu la sympathie d'une grande partie de la population géorgienne ${ }^{4}$.

Le manuscrit du Tableau Général de la Perse moderne écrit à la demande de Napoléon par Joseph Rousseau (fils de Jean-François Rousseau, commissaire des relations commerciales de France à Bagdad) se trouvait déjà entre les mains de Talleyrand en août $1806^{5}$. Dans ce document, Rousseau décrit les frontières de la Géorgie, son climat, son territoire fertile et sa population. Il évoque l'invasion d'Agha Mohammad Khan et conclut la sous-partie consacrée à la Géorgie par ces mots: "Les Géorgiens commencent à se désabuser de l'idée qu'ils s'étaient formée d'abord de la modération du gouvernement russe. Ils se plaignent déjà de leur dureté, et attendent impatiemment l'occasion de secouer un joug, non moins pénible que celui des Persans, qu'ils se sont imposé eux-mêmes ${ }^{6}$. " Le fait d'avoir placé dans la même sous-partie la Géorgie et le royaume de Kandahar et du Zaboulistan, qui tenait une place stratégique dans l'itinéraire de l'expédition vers l'Inde ${ }^{7}$, souligne à nouveau l'importance géopolitique de la Géorgie occidentale, désormais rattachée à la Russie.

Le troisième volume du Voyage dans l'Empire Ottoman, l'Égypte et la Perse de G.-A. Olivier, que Napoléon réclamait avec insis-

3. AMAE, CP/Perse, vol. 9, doc. 27, fol. 58v, 59v-60v.

4. AMAE, CP/Perse, vol. 8 doc. 133, fol. 334r-334v; AN, AF IV, 1686, doc. 16, fol. 5-7, 15.

5. AMAE, CP/Perse, vol. 9, doc. 41, fol. 83r-83v.

6. AMAE, MD/Perse, vol. 6, doc. 19, fol. 167r-168r.

7. AMAE, CP/Perse, vol. 8, doc. 165, fol. 399r. 
tance ${ }^{8}$, fut disponible en 1807, au moment de la signature du traité de Finkenstein. Le chapitre xx aborde les relations entre la Perse et la Géorgie. Olivier écrit qu'après la conquête des provinces méridionales de cette dernière, Agha Mohammad Khan «ne pouvait sans se déshonorer et sans se rendre indigne de la couronne qu'il avait usurpée, renoncer aux droits que la Perse avait sur la Géorgie ". Cette remarque d'Olivier révèle l'importance pour la nouvelle dynastie Qadjar de l'intégration de la Géorgie à la Perse, d'un point de vue tant moral que politique. L'auteur français appelle le royaume de Kartli-Kakhétie « la Géorgie de la Perse ${ }^{9}$ " ce qui renforça aux yeux des Européens l'idée que la Géorgie appartenait à la Perse et lui avait été arrachée de force par la Russie.

\section{La Géorgie dans la presse française}

En réponse aux missions envoyées en Perse par Napoléon, l'ambassadeur de Fath Ali Chah, Mirza Mohammad Reza Khan Qazvini, arriva à Varsovie en mars 1807; Napoléon décida alors de conclure une alliance avec la Perse. Les journaux français avaient commencé dès janvier 1807 à publier des séries d'articles sur la Perse, qu'ils présentaient sous un jour extrêmement favorable et comme un allié potentiel de la France ${ }^{10}$. Trois numéros du Journal de l'Empire parus en mars et en avril traitèrent également de la Géorgie, ce qui n'est pas anodin. Dans ces longs articles, le célèbre savant Conrad Malte-Brun offrait aux lecteurs une présentation assez complète de l'histoire, de la religion, de la culture et de la civilisation géorgiennes. Ces nombreuses parutions, qui servaient les intérêts du gouvernement, n'étaient probablement pas dues au hasard. Dans l'introduction de sa première lettre, datée du 10 mars 1807, Malte-Brun précise que des communications officielles du gouvernement français mentionnent

8. Paul Gaffarel, La politique coloniale en France de 1789 à 1830, Paris, Félix Alcan, 1908, p. 391.

9. Guillaume-Antoine Olivier, Voyage dans l'Empire Othoman, l'Égypte et la Perse, fait par ordre du Gouvernement, pendant les six premières années de la République, Paris, H. Agasse, 1807, III, 404, 409, 420.

10. Le Moniteur, 1807, 13 janvier; 27 janvier; 22 février; 23 mars; 2 avril; 19 avril; 19 avril ; 31, 1807, 26 février; 22 mars; 27 mars; 16 avril; 20 avril; 27 avril. 
l'expansion de la Russie en direction du Caucase. Attirer l'attention sur cette région était une façon de présenter la Géorgie comme une province russe récemment conquise et de montrer les peuples rebelles du Caucase encerclés de toutes parts par « les armées moscovites ». La Perse et la Turquie asiatique n'avaient donc plus de frontière naturelle avec la Géorgie. Malte-Brun présente la Géorgie comme un superbe pays sous domination russe, susceptible d'intéresser « le géographe, le naturaliste, l'historien et le littérateur » en raison de ses nombreux objets d'intérêt: «Une nature grande et singulière, des peuples antiques, des langues peu connues. Enfin, une vaste carrière à des recherches savantes. "L'auteur conclut sur des informations d'ordre général au sujet du Caucase ${ }^{11}$.

Ainsi, la presse française s'employa à présenter la Perse, allié potentiel de la France, sous un jour extrêmement positif, tout en publiant plusieurs articles conséquents sur la Géorgie, méconnue en Europe. Ces textes contribuèrent à l'établissement d'un lien, dans l'esprit des Français, entre, d'une part, la Géorgie et, d'autre part, non seulement la Perse, l'Empire ottoman et la Russie, mais aussi l'Inde. Le fait que Malte-Brun en ait été l'auteur laisse à penser que la parution de ces nombreux articles sur la Géorgie peu de temps avant la conclusion du traité franco-persan a servi les intérêts du gouvernement français. C'est un bon exemple de l'influence de la propagande sur l'opinion publique; Napoléon en était parfaitement conscient, et n'hésitait pas si nécessaire à employer cette arme puissante $^{12}$. Mais l'empereur des Français devait être persuadé de sa propre invincibilité pour ne pas craindre de provoquer la colère de l'Angleterre ou de la Russie en publiant de telles informations.

\section{La question de la Géorgie dans le projet de traité et dans le traité franco-persan}

Avant l'élaboration du texte final du traité de Finkenstein à Varsovie en avril 1807 (le jour exact n'est pas mentionné), le gouvernement français proposa le Projet du Traité entre S. M. l'Empereur

11. Journal de l'Empire, 1807, vendredi 10/03; samedi 18/03; samedi 6/04.

12. Jean Tulard, Napoléon ou le mythe du sauveur, Fayard, 1995, p. 35. 
des Français, Roi d'Italie et S. M. l'Empereur de Perse, daté lui aussi d'avril 1807. Ce projet comportait déjà 16 articles, et le troisième et le quatrième concernaient déjà la Géorgie: «Article 3. Dans le cas où les armées persanes reprendraient sur les Russes la Géorgie et se rendraient maîtresses de Tiflis, S. M. l'Empereur des Français, roi d'Italie, s'engage à employer ses bons offices, pour que dans ce traité à intervenir la souveraineté pleine et entière de cette province soit assurée à S. M. l'Empereur de Perse. Article 4. Dans ce même cas S. M. l'Empereur de Perse consent à envoyer annuellement à S. M. l'Empereur des Français le nombre de mameloucks géorgiens nécessaires pour tenir au compte le corps de mameloucks attaché à sa $\operatorname{garde}^{13}$. » En mentionnant Tiflis dans l'article 3, les auteurs du projet de traité ont probablement pris en compte le fait que la ville avait été ravagée par Agha Mohammad Khan; pour les Français, c'était une ville dévastée qui serait facile à conquérir. Mais l'on peut penser que Napoléon, au moment de l'élaboration du traité définitif, a pris en considération le fait mentionné par Amédée Jaubert que l'armée russe, dans le cadre de la guerre russo-persane (1804-1813), prenait ses quartiers d'hiver à Tiflis ${ }^{14}$, qui serait donc correctement défendue.

L'article $4 \mathrm{du}$ projet montre que Napoléon tenait à disposer de soldats géorgiens appelés « mamelouks » dans sa garde personnelle. Il semble que Bonaparte ait été convaincu dès la campagne d’Égypte de la valeur militaire de ces mamelouks, achetés dans le Caucase notamment en Géorgie - et qu'il qualifia d' " esclaves ". Jaubert, qui avait accompagné Napoléon en Égypte, décrit les mamelouks comme des guerriers célèbres pour leur courage ${ }^{15}$, et Joseph Rousseau insiste sur le fait que les Perses appréciaient la bravoure et la fidélité des Géorgiens ${ }^{16}$. Ainsi, l'opinion de Napoléon selon laquelle les soldats géorgiens feraient en Inde de bien meilleurs combattants que les soldats européens n'était pas sans fondement.

13. AMAE, CP/Perse, vol. 9, doc. 94, fol. 161r-163v.

14. AN, AF IV, 1686, doc. 16, fol. 5.

15. Pierre-Amédée Jaubert, Voyage en Arménie et en Perse, fait dans les années 1805-1806, Paris, Pélicier, 1821, p. 179.

16. AMAE, MD/Perse, vol. 6, doc. 19, fol. 98v-99r. 
Le traité franco-persan prévoyait " paix, amitié et alliance » entre la France et la Perse (art. 1). Napoléon garantissait au shah "l'intégrité de son territoire actuel " (art. 2), reconnaissait la Géorgie " comme appartenant légitimement " au shah (art. 3) et s'engageait lui-même à " contraindre la Russie à l'évacuation de la Géorgie et du territoire persan " (art. 4). Par conséquent, les articles 3 et 4 définitifs visaient encore la Géorgie.

L'article 2 du traité ne définit que de vagues obligations vis-à-vis de la Perse. Napoléon garantit au shah l'inviolabilité de son territoire, ce qui sous-entend logiquement le territoire tel qu'il était au moment de l'élaboration du traité, sans les acquisitions postérieures. Le territoire de la Géorgie n'est pas précisément défini dans le traité, car il n'existait aucune carte ni aucun document déterminant les frontières entre la Perse et la Géorgie. Les Persans ont très probablement entendu par "Géorgie " le royaume de KartliKakhétie, c'est-à-dire la Géorgie orientale qui, depuis 1801, faisait partie de la Russie. Les articles 3 et 4 du traité ${ }^{17}$, destinés à appâter la Perse, entraient dans une stratégie à long terme de la part de la France; quant à l'article 2, il donnait à la France la possibilité d'agir en accord avec ses propres intérêts selon la direction prise par les événements politiques à l'échelle internationale, et tout se passa exactement comme la France l'avait prévu.

Napoléon semble avoir élaboré les articles 3 et 4 du traité sans prendre en considération les projets de la Russie en Transcaucasie (Caucase du Sud) et dans le bassin caspien, tels que les avaient rapportés les émissaires français. Apparemment, il était si pressé d'intervenir en Inde qu'il répondit en priorité au message de Fath Ali Chah que lui avait communiqué Jaubert, l'informant que si, après avoir chassé les Russes, Napoléon décidait de traver-

17. «Article 3: S. M. l’Empereur des Français, roi d'Italie, reconnaît la Géorgie comme appartenant légitimement à S. M. l'Empereur de Perse. Article 4: Il s'engage à faire tous ses efforts pour contraindre la Russie à l'évacuation de la Géorgie et du territoire persan, et pour l'obtenir par le traité de paix à intervenir. Cette évacuation sera constamment l'objet de sa politique et de toute sa sollicitude " (AMAE, CP/Perse, vol. 9, doc. 95, fol. 164R; Jacob Coleman Hurewitz, The Middle East and North Africa in World Politics: A Documentary Record, Second Edition, Revised and Enlarged, New Haven et Londres, Yale University Press, 1975, vol. I, p. 184. 
ser la Perse avec son armée, le shah lui prouverait son amitié et sa loyauté en prenant part à l'expédition ${ }^{18}$. Il n'est pas anodin que l'unique opposant à Jean-François Rousseau (qui avait suggéré à Napoléon la stratégie à suivre pour chasser les Anglais de l'Inde ${ }^{19}$ ), l'adjudant-général Alexandre Romieu, était alors décédé; le projet de campagne de l'Inde de J.-F. Rousseau était alors la priorité. Jaubert, émissaire de Napoléon, rapporta de Perse des informations qu'il avait lui-même recueillies; il avait eu plusieurs entretiens avec deux soutiens de la France: le prince héritier Abbas Mirza, grand ennemi de la Russie, et le premier vizir de Fath Ali Chah, Mirza Chafi. Le principal sujet de leurs discussions avait été la guerre russo-persane. Les inquiétudes exprimées par Fath Ali Khan, le naib ( " tenant lieu ») du beglarbegi (gouverneur-général) d’Azerbaïdjan, au cours d'une conversation avec Jaubert en mai 1806 sont caractéristiques de la position des hauts dignitaires persans vis-à-vis de la Géorgie: « Notre souverain actuel [Fath Ali Chah], en saisissant les rênes du gouvernement, a su tout réunir dans ses mains puissantes. Si l'on excepte la Géorgie, province qui depuis longtemps ne fait plus en réalité partie de l'empire, toute la Perse lui est soumise ${ }^{20}$." L'empereur avait une entière confiance en Jaubert, qui avait déjà accompli pour lui de nombreuses missions diplomatiques dans diverses régions de l'Empire ottoman après son retour d'Égypte. C'est d'ailleurs au chevalier Jaubert que la copie du traité francopersan fut confiée ${ }^{21}$.

Ainsi, en mettant la question géorgienne au premier plan du traité d'alliance, Napoléon suggéra en perspective de résoudre le principal problème qui se posait à la Perse, à savoir libérer la Géorgie de la domination russe pour la rendre à l'Empire persan, et il fonda ses relations avec ce dernier sur cette promesse.

18. AN, AF IV, 1686, doc. 16, fol. 8, p. 21-24.

19. AMAE, CP/Perse, vol. 8, doc. 64 , fol. $182 \mathrm{r}-189 \mathrm{v}$.

20. Jaubert, Voyage, p. 163, p. 225.

21. AMAE, CP/Perse, vol. 9, doc. 97, fol. 166r-167v. 


\section{La question géorgienne dans les négociations diplomatiques du général Gardane (1807-1809)}

Quelques jours après la conclusion du traité de Finkenstein, le 10 mai 1807, Napoléon remit au général Gardane des instructions précises sur sa mission en Perse. Gardane fut chargé d'obtenir des informations détaillées au sujet de la Perse et des itinéraires vers l'Inde, d'organiser une vigoureuse diversion à la frontière russe au moment opportun, et de fournir à la Perse une occasion de récupérer les provinces géorgiennes que leur avaient enlevées les Russes "par leurs armes, par leurs intrigues", que les Russes " [s'étaient] fait céder par le dernier prince de ce pays [la Géorgie] ». La Perse était considérée à la fois comme un ennemi de la Russie et comme le moyen de lancer une expédition vers l'Inde ${ }^{22}$.

Et pourtant, le 7 juillet 1807, soit 65 jours après la conclusion du traité de Finkenstein entre la France et la Perse, un traité de paix fut signé à Tilsit ${ }^{23}$ entre Napoléon et le tsar Alexandre ${ }^{\mathrm{er}}$. Le document, qui ne comportait aucune mention de la Perse, annulait le traité franco-persan. Napoléon avait donc ignoré la volonté de Fath Ali Chah: "Je lui demanderai [à Napoléon] de former une alliance conforme à nos intérêts, avec pour condition qu'aucune négociation de paix entre le roi de Perse et la Russie n'aura lieu sans que l'Empereur des Français y participe. En contrepartie, Napoléon ne négociera pas avec l'État russe sans prendre en considération les intérêts de la Perse ${ }^{24}$. »

Malgré la conclusion de ces deux traités contradictoires, la mission française arriva à Téhéran le 4 décembre 1807. Les instructions concernant l'expédition vers l'Inde restaient inchangées, mais le général Gardane était désormais chargé de régler la paix entre la Russie et la Perse ${ }^{25}$. L'échange suivant eut lieu le 20 février $1808 \mathrm{au}$ cours des négociations entre le ministre plénipotentiaire français

22. AMAE, Protocoles, Copie des instructions pour M. le général Gardane, camp impérial de Finkenstein, 10 mai 1807, fol. 2-3.

23. Albert Vandal, Napoléon et Alexandre $I^{\text {er }}$, l'alliance russe sous le Premier Empire, De Tilsit à Erfurt, Paris, Plon, Nourrit et Cie 1891 , vol. I, p. 499-504.

24. Archives Nationales, France, AF IV, 1686, doc. 16, fol. 22.

25. AMAE, MD/Perse, vol. 8, doc. 2, fol. 50v. 
et le premier vizir Mirza Chafi. À la question du général: «Que sait Sa Majesté de la sympathie que lui portent les Géorgiens? ", le vizir répondit: "Comme un grand nombre des enfants du roi Héraclius II et la plupart des nobles géorgiens se trouvent à la cour d'Abbas Mirza, nombreuses sont les familles qui ont rejoint notre camp, mais la majorité de la population se range du côté de la Russie, uniquement en raison de la religion, qu'ils ont en commun avec les Russes. " Mirza Chafi exagère le nombre des fils de Héraclius présents à la cour du prince héritier, car seuls les princes Alexandre et Teimouraz s'y trouvaient; mais le vizir ne cache pas la raison principale qui poussait les Géorgiens de l'Est à prendre le parti de la Russie, à savoir la religion. En réponse à la question suivante du général français: "Quel était le dessein de Sa Majesté Fath Ali Chah lorsqu'il confia ses intérêts à Sa Majesté Impériale l'empereur Napoléon? ", Mirza Chafi déclara: « Notre souverain ayant remis son destin entre les mains de son frère l'empereur Napoléon, notre vœu le plus cher est que la Géorgie, le Daghestan et Erevan reviennent à la Perse de la façon la plus satisfaisante possible, et d'empêcher que les Russes ne nous accablent de réparations à leur verser suite à la guerre menée contre eux. Nous refusons d'être traités ainsi. Nous avons toute confiance en la justice, la sincérité et l'obligeance de notre frère. » La réponse du premier vizir du shah confirme que le principal intérêt que trouvaient les Perses à l'alliance avec la France était la possibilité de récupérer la Géorgie et les territoires conquis par la Russie pendant la guerre, et non la perspective de participer à l'expédition vers l'Inde.

$\mathrm{Au}$ cours des mêmes négociations, il fut question de l'adoption par l'armée persane d'un système militaire européen - français, plus exactement; le vizir objecta l'exemple du sultan ottoman Selim III qui, ayant fait adopter le système militaire européen à son armée, s'était vu détrôner par ses propres soldats, révoltés contre les innovations qui leur étaient imposées. Les Persans se montraient donc très prudents. Fath Ali Chah prit la décision de ne faire appliquer cette réforme qu'en Azerbaïdjan dans un premier temps, par Abbas Mirza, dans l'idée que « lorsque les Persans seraient convaincus du bénéfice apporté par cette réforme et habitués à ce nouveau commandement ", le shah l'appliquerait à tout l'em- 
pire $^{26}$. L'exemple ottoman n'était pas l'unique cause de la prudence de Fath Ali Chah. D'après les informations obtenues par James Morier, secrétaire à l'ambassade d'Angleterre en Perse de 1807 à 1811, "les Français à l'époque étaient impatients de se rendre à Chiraz afin d'entraîner les troupes nouvellement levées; mais le roi, qui les avait déjà empêchés lors d'une occasion précédente d'envoyer un résident à Buchehr de peur qu'il ne découvre qu'il y avait toujours un comptoir anglais en Perse, les empêcha cette foisci d'avancer vers Chiraz, de peur que les Anglais ne découvrent l'arrivée de leurs concurrents ${ }^{27}$ ». Ainsi, Fath Ali Chah n'attendait pas seulement que les Persans s'habituent au style européen pour " appliquer ces réformes "; il cherchait aussi à éviter de contrarier ses voisins du sud, les dirigeants de la Compagnie britannique des Indes orientales. En décidant de limiter l'application des nouvelles règles militaires à l'Azerbaïdjan, le shah fit preuve de pragmatisme. Il espérait libérer les territoires occupés par la Russie et " reprendre le contrôle » de la Géorgie.

Grâce au traité de Tilsit, les Russes se retrouvèrent libres d'agir comme ils l'entendaient vis-à-vis de la Perse. En mai 1808, le maréchal Goudovitch demanda à la cour de Téhéran de reconnaître les territoires déjà occupés par la Russie et proposa en échange un armistice d'un an. Le shah rejeta catégoriquement cette proposition, tandis que le gouvernement français refusait d'orienter les négociations de paix avec la Russie dans une direction favorable à la Perse ${ }^{28}$. La position de la France est exposée très clairement dans la lettre envoyée par le ministre Champagny à Gardane en juin 1808. Le ministre y soulignait le fait que le traité de Finkenstein "ne faisait que confirmer l'intégrité territoriale de la Perse telle qu'elle était alors ", et que puisqu'ils « avaient déjà perdu la Géorgie, la France ne pouvait pas après avoir signé le traité de Tilsit intercéder en faveur

26. AMAE, MD/Perse, vol. 6, doc. 25, fol. 177r-178r.

27. James Morier, A Journey Through Persia, Armenia, and Asia Minor, to Constantinople, in the Years 1808 and 1809, Londres, Longman, Hurst, Rees, Orme, and Brown, 1812, p. 30.

28. AMAE, MD/Perse, vol. 8, doc. 25, fol. 245v-246r. 
de la restitution des territoires occupés par les Russes ${ }^{29}$. " Le général Gardane avertit Champagny que la Perse n'engagerait aucune action contre l'Inde tant que rien ne serait fait pour régler son différend avec la Russie ${ }^{30}$.

Le peu de cas fait par la France de la question russo-persane rendait délicate la position du ministre plénipotentiaire français. Le 20 août 1808, au cours d'une audience, le shah exigea du général Gardane que Napoléon adopte une position claire quant à son intention de chasser les Russes de Géorgie ${ }^{31}$. Le 26 août, Gardane écrivit donc à Champagny que " tant que le territoire persan serait à la merci de la Russie, le chah ne ferait rien contre l'Hindoustan, et qu'il n'agirait en aucune façon tant que la Géorgie serait entre les mains de la Russie ». Aux yeux des Persans, la Russie bafouait l'intégrité de leur territoire en établissant ses frontières aux environs de la Koura, de l'Araxe et de l'Akhourian, malgré la garantie par Napoléon de l'intégrité territoriale de leur pays dans l'article $2 \mathrm{du}$ traité franco-persan ${ }^{32}$. Par ailleurs, le shah exigeait l'exécution des articles 3 et 4, le départ des Russes de Géorgie et la restitution «sans un coup de feu " des territoires occupés ${ }^{33}$. Le général Gardane se trouvait confronté à une situation extrêmement compliquée à gérer.

Le 14 septembre 1808, le maréchal Goudovitch envoya un ultimatum à Abbas Mirza, en lui conseillant urgemment de ratifier le traité qu'il lui avait proposé et en l'avertissant que rien n'arrêtait un pays tel que la Russie. C'était exiger de la Perse qu'elle renonce définitivement à la Géorgie et qu'elle cède la forteresse d'Erevan ainsi qu'Etchmiadzine ${ }^{34}$. Si Abbas Mirza acceptait cette proposition,

29. Édouard Driault, La politique orientale de Napoléon - Les missions de Sébastiani et de Gardane, 1806-1809, Paris, Félix Alcan, 1904, p. 329.

30. Alfred de Gardane, Mission du général Gardane en Perse sous le Premier Empire, Paris, librairie de Ad. Lainé, 1865, p. 182.

31. Dumas, Un fourrier de Napoléon vers l'Inde, p. 62-63.

32. Les territoires que la Russie disputait à la Perse étaient en réalité des principautés semi-indépendantes (des khanats) peuplées de différentes ethnies musulmanes et catholiques et gouvernées par des dynasties turques (azéries) locales.

33. Gardane, Mission, p. 182-184, 186-187, 192-194.

34. Erevan était la capitale politique du khanat d’Erevan, que gouvernait une branche locale de la dynastie Qadjar. À l'époque de l'expansion russe, la majorité 
les liens commerciaux qui s'établiraient entre la Perse et la Russie seraient plus bénéfiques au prince qu'une guerre; la Russie reconnaîtrait Bâbâ Khan (Fath Ali Chah) comme shah de Perse et Abbas Mirza comme héritier du trône. Goudovitch promit d'aider la Perse à conquérir Bagdad et les provinces de Bassora et Bayazed, et fit remarquer à son interlocuteur que cette offre lui rendrait un grand service étant donné que sa légitimité au trône de Perse était contestée par son frère aîné Mohammad Ali Mirza Dolatshah ${ }^{3536}$. Abbas Mirza refusa. Au même moment, à la fin du mois de septembre 1808, Napoléon négociait avec d'autres dirigeants européens contre l'Angleterre à Erfurt. En octobre 1808, le détail de cette entrevue fut publié dans le Journal de l'Empire, qui insista particulièrement sur les relations amicales qu'entretenaient la France et la Russie ${ }^{37}$.

Par conséquent, le maréchal Goudovitch installa son camp près d'Erevan et lança les opérations militaires le 25 septembre. Suite au début du siège de la forteresse d'Erevan, les Anglais demandèrent au shah de recevoir l'émissaire britannique, sir Harford Jones Brydges, dans le but de nouer des relations avec l'Angleterre. L'émissaire promit l'assistance de son pays et la restitution des territoires occupés par les Russes, y compris la Géorgie ${ }^{38}$. En cas d'échec, ils s'engageaient à soutenir les prétentions de la dynastie Zand au trône de Perse et de partir en guerre contre Fath Ali $\mathrm{Chah}^{39}$.

de la population du khanat (80\%) était musulmane (composée de Turcs azéris, de Kurdes et de Perses), tandis que les chrétiens (principalement des Arméniens) formaient une minorité. Cf. Erich Kettenhofen, George A. Bournoutian et Robert H. Hewsen, « Erevan », in Encyclopedia Iranica, vol. VIII, fasc. 5, p. 542-551. (http:// www.iranicaonline.org/articles/erevan-1\#ii).

35. Mohammad Ali Mirza Dolatshah (1789-1821), gouverneur des régions montagneuses du Kurdistan, du Khouzistan et du Lorestan de 1806 à sa mort en 1821, était le premier-né de Fath Ali Chah. Sa mère Zibachehr Khanum était une esclave géorgienne de la famille Tsikarishvili. Zurab Sharashenidze, Iranis shinapolitikuri vitareba da sagareo urtiertobani XIX saukunis dasackisshi, Tbilissi, Mecniereba, 1984, p. 36.

36. Actes, vol. III, doc. 836, p. 464-465; doc. 849, p. 475-476.

37. Journal de l'Empire, 1808, lundi 07/10; lundi 10/10; mardi 11/10 ; mercredi $12 / 10$; samedi $15 / 10$; dimanche $16 / 10$.

38. . Gardane, Mission, p. 247 - 252.

39. AMAE, CP/Perse, vol. 10, doc. 220, fol. 440r - 443v; doc. 225, fol. 450r-452r. 
Le 23 novembre, Fath Ali Chah déclara n'avoir plus aucun doute sur l'existence de relations d'amitié entre la France et la Russie; il rappela à Gardane le contenu du traité de Finkenstein, que le général en personne avait apporté à Téhéran au nom de la France et dont aucun point n'avait été respecté ${ }^{40}$. Le shah exigea de la France qu'elle lui envoie de nouvelles troupes pour libérer la Géorgie ${ }^{41}$.

Alors que le maréchal Goudovitch, qui ne parvenait pas à prendre la forteresse d'Erevan ${ }^{42}$, rendait l'action antirusse de Gardane responsable de son échec, Abbas Mirza se plaignait de ne pas recevoir d'aide du général, celui-ci n'ayant toujours pas reçu d'ordre de Napoléon allant dans ce sens ${ }^{43}$. Les deux camps accusaient donc le général Gardane, qui devait faire preuve d'une grande discrétion pour honorer deux traités contradictoires, tous deux conclus par Napoléon.

Vu les circonstances, Fath Ali Chah décida de recevoir l'émissaire britannique, sir Hartford Jones Brydges. Gardane, qui se trouvait dans une position inconfortable à tous points de vue, se sentit insulté par cette décision et quitta Téhéran pour Tabriz le 13 février 1809 .

Le 12 mars 1809, l'Angleterre et la Perse conclurent un traité qui annulait tous ceux précédemment conclus par chacune des parties avec d'autres pays ${ }^{44}$. Sir Harford Jones Brydges engagea la Perse à relancer avec vigueur l'offensive contre la Russie, assurant au shah que les innombrables trésors de l'Inde permettraient à l'armée persane de reconquérir la Géorgie sans difficultés ${ }^{45}$. L'émissaire britannique employa donc la même stratégie que la France en faisant miroiter à la Perse la possibilité de reprendre la Géorgie à la Russie. Ainsi, pendant cette courte période de l'histoire, l'Inde — « le joyau de la Couronne britannique »- fut protégée d'une éventuelle expédition menée par Napoléon via la Perse grâce à la Géorgie orientale, l'ancien royaume de Kartli-Kakhétie qui appartenait alors à la Russie

40. Gardane, Mission, p. 230-248.

41. AMAE, CP/Perse, vol. 11, doc. 65, fol. 110r-112r.

42. Actes, vol. III, doc. 895, p. 508-510.

43. AMAE, CP/Perse, vol. 10, doc. 279, fol. 470r.

44. AMAE, MD/Perse, vol. 6, doc. 40, fol. 221r.

45. AMAE, CP/Perse, vol. 14, doc. 289, fol. 294r-297r. 
et fut qualifié d' « ornement " par Mirza Bozorg ${ }^{46}$, premier vizir d’Abbas Mirza.

En avril 1817, le général Gardane prit la décision de quitter la Perse pour l'Europe, via Erevan et Tiflis, avec tous les membres de sa mission ${ }^{47}$. Le ville de Tiflis était alors un point de passage important entre la Perse et l'Europe - conséquence du traité franco-russe de Tilsit.

\section{La Notice sur la Géorgie du lieutenant Trézel}

Dans les archives du ministère français de la Défense est conservé un manuscrit intitulé Notice sur la Géorgie, daté du 31 mai 1809 et signé du lieutenant Camille Alphonse Trézel ${ }^{48}$, aide de camp du général Gardane. Trézel décrit en détail le trajet de la mission française d'Erevan à Mozdok via Tiflis en mai 1809. Ce document fournit de nombreux renseignements sur le paysage, les routes, la population (densité, nationalités, religions, métiers), les petites communautés, l'agriculture, les forces armées russes et les relations qu'entretenaient les Russes avec les montagnards géorgiens et caucasiens.

Le lieutenant Trézel dresse un tableau précis de la ville de Tiflis, qui adoptait de plus en plus de traits européens sous l'effet de la domination russe. Il écrit:

46. James Morier écrit: «Lors d'un entretien avec Mirza Bozurk au cours duquel nous discutions de l'utilité de la Géorgie pour la Perse, il fit une remarque typique d'un logicien asiatique. Il prit sa barbe et déclara: " La Géorgie ne sert à rien; ce n'est qu'un ornement. " " James Morier, A Second Journey Through Persia, Armenia, and Asia Minor to Constantinople, Between the Years 1810 and 1816, Londres, Longman, Hurst, Rees, Orme, and Brown, 1818, p. 217.

47. Le 17 août 1809, le général Gardane écrivit au ministre Champagny qu'il avait suivi les instructions reçues à Finkenstein, mais que n'ayant reçu aucune indication concernant l'arrivée des Anglais en Perse et leur réception à la cour de Téhéran, il n'avait plus rien à faire sur place et se trouvait dans l'incapacité de " chasser les Anglais, accueillis avec enthousiasme à la cour de Perse » (AMFAE, CP/Perse, vol. 12, doc. 81, fol. 145r). À son arrivée en France le 29 septembre, il envoya une note très succincte à Champagny dans laquelle il expliquait qu'» en quittant la Perse, [il avait] servi la dignité et les intérêts de la France qui [lui] avaient été confiés » (AN, AF, 1686 IV1, doc. 11).

48. Camille Alphonse Trézel (1780-1860) fut général de division (1837), pair de France (1846) et ministre de la Guerre (1847-1848). 
Attristés depuis deux ans par le séjour des villes silencieuses de l'Asie, [...] nous jouissions avec avidité de tout le mouvement d'une cité chrétienne et de mille choses qui échappaient à notre attention ou nous paraissaient autrefois importunes. Le roulement des chars chargés de denrées ou d'attirails et de munitions de guerre, la course rapide de quelque voiture de luxe, les sons discordants des cloches de plusieurs églises, des marchés bruyants ou se trouvent pêle-mêle des Géorgiens, des Arméniens, des Persans ${ }^{49}$ et une affluence de soldats russes, les chants, la musique des troupes, ce mélange confus d'objets nouveaux qui rappelaient vivement la patrie, tout excitait en nous une émotion indéfinissable.

Il décrit la vie quotidienne des habitants de la ville. Contrairement aux maisons asiatiques, les habitations de Tiflis ne sont pas protégées par de hauts murs, et les familles passent leurs soirées sur des terrasses découvertes et peu élevées, se voyant l'une l'autre et discutant. En sortant de l'église, les dames se rendent dans les jardins et sur les promenades qui embellissent les environs. Trézel raconte que c'était un plaisir de regarder les Géorgiennes, à la beauté naturelle, marcher sur les rives de la rivière par une belle soirée de mai. Un petit diadème blanc ceignait leur front et retenait un long voile de lin qui tombait en arrière jusqu'au sol et soulignait leurs silhouettes gracieuses et majestueuses. Cette description détaillée des dames de Tiflis fournit un exemple des mœurs européennes qui se sont répandues dans cette ville et offrent un contraste frappant avec la vie urbaine en Orient; là-bas, les femmes n'apparaissaient jamais en public parmi les hommes et sortaient toujours accompagnées et couvertes d'un tchador lorsqu'elles rendaient visite à leur famille ou allaient aux bains publics.

Alexandre $\mathrm{I}^{\mathrm{er}}$, ayant eu connaissance du projet du général Gardane de passer par Tiflis pour rentrer en France, ordonna au général Tormassov, commandant en chef de la région du Caucase

49. La population musulmane des territoires du Caucase du Sud que se disputaient la Russie et la Perse, bien que principalement turque, était souvent qualifiée de " persane ", en référence aux puissances qui s'affrontaient à l'époque dans la région, et en raison de leur identité musulmane — principalement chiite — et des liens politiques entre les dynasties au pouvoir localement et la dynastie Qadjar qui gouvernait l'Iran. À l'époque, la communauté musulmane de Tiflis était principalement composée de Turcs azéris. 
(1809-1811), de recevoir la mission française avec tout le respect qui lui était dû. Au dîner de gala organisé par Tormassov pour la mission, Trézel rencontra l'ancienne reine d'Iméréthie ${ }^{50}$, sur le point d'accompagner son fils ${ }^{51}$ qui partait le lendemain pour une université de Saint-Pétersbourg, le prince Anton ${ }^{52}$, revêtu de la dignité de catholicos, et la princesse sa sœur ${ }^{53}$ — tous deux enfants du dernier vali, Héraclius II -, le patriarche arménien ${ }^{54}$, et enfin un seigneur géorgien, frère du général-prince Bagration. Aucun des convives ne comprenait le français ni même le russe, mais le dîner se déroula sans encombre. Le but de Tormassov était de montrer aux émissaires de Napoléon la bonne entente qui régnait entre les autorités russes et l'élite géorgienne. Il tenait également à leur faire comprendre que l'orientation politique adoptée par la famille royale ne faisait pas l'unanimité. Les Russes savaient que certaines personnalités éminentes entretenaient des relations avec la Perse et que deux princes royaux géorgiens, Alexandre, fils du roi Héraclius II, et Teimouraz, fils de Georges XII, avaient émigré en Perse.

Le dernier chapitre de la Notice, intitulé "Situation des Russes en Géorgie ", mérite que l'on s'y attarde. Comme l'ont fait d'autres agents français, le lieutenant Trézel évoque le traité conclu entre la Russie et le roi Héraclius II en 1783, le saccage de Tbilissi par Agha Mohammad Khan en 1795 et le sort des jeunes Géorgiens des deux sexes emmenés en esclavage en Perse, la plupart occupant les fonctions les plus basses au sein de l'armée et du gouvernement à l'époque du séjour de Trézel en Perse.

50. Il s'agit d’Anna, fille du prince Mamuka Orbéliani et épouse du roi David II d'Iméréthie (1784-1789).

51. Le fils du couple royal, le prince Constantin, participa à la Guerre patriotique de 1812 et fut décoré de l'Ordre de Saint-Vladimir. En Russie, ses fils furent appelés « Imeretinski » ou « Bagration-Imeretinski ».

52. Anton II (1764-1827), catholicos-patriarche de Géorgie orientale, l'un des fils de Héraclius II. Son nom laïc était Teimouraz Bagration. Il fut appelé en Russie en 1811 et vécut à Nijni-Novgorod, où il est enterré.

53. Cette princesse qui n’est pas nommée est probablement la princesse Teklé, la plus jeune fille du roi Héraclius II, épouse du colonel de l'armée russe Vakhtang Orbéliani.

54. Le catholicos arménien Nersès (1760-1857). 
Trézel explique que toutes les peuplades des montagnes menaient une guerre de détail contre la Russie, qui devait installer de petites garnisons retranchées pour convoyer les marchandises depuis Tiflis et Mozdok par des chemins encore impraticables aux voitures. Les communications entre le quartier général et les divers cantonnements de l'armée ne s'effectuaient pas sans danger et occasionnaient "une consommation journalière de cosaques". Les cosaques ne pouvaient quitter leur poste par crainte d'être attaqués par des Lezghiens, des Ossètes ou des Turcs, et leurs appréhensions n'étaient pas sans fondements: peu de temps avant le passage de la mission française à Tiflis, les Lezghiens avaient volé tous les chevaux du régiment d'infanterie de Kherson, à une lieue de la ville. Les régiments de Bambak et de Gyumri, sur la route de Kars, étaient approvisionnés en vivres et en munitions depuis Tiflis; ils risquaient de se retrouver dans une situation critique, isolés du reste de l'armée, si les Persans et les Turcs d'Akhaltsikhé les attaquaient simultanément sur les deux rives du Lori. Le lieutenant était convaincu que l'union des forces persanes et turques représenterait une menace sérieuse pour les Russes, qui n'occupaient pas encore les villes d'Akhaltsikhé, Kars, Bayazed, Erevan et Nakhitchevan.

Le lieutenant note une information importante, à savoir que les généraux envoyés dans le Caucase avaient reçu l'ordre du gouvernement russe de traiter la population locale avec bienveillance et respect, afin de gagner la confiance du territoire nouvellement conquis. L'officier français ne cache pas son dégoût de voir des officiers russes expérimentés remettre toutes sortes de décorations militaires à n'importe quel " chef de horde, qui aura bien voulu accepter un rang de major ou de colonel dans l'armée ». Les officiers russes étaient contraints de quémander la coopération des chefs locaux s'ils devaient faire passer un convoi sur leur propriété, la meilleure escorte s'avérant inutile si la voiture n'était pas protégée par un chef ossète en personne ou par «quelques-uns de ses bandits », ceux-ci étant grassement payés pour leurs services.

Les informations dont disposait Camille Trézel semblent indiquer que les grandes familles géorgiennes bénéficiaient de prérogatives et de bonnes positions. De nombreux tavadi (princes) recevaient une 
pension du gouvernement russe. Un séminaire et une école militaire avaient été créés à Tbilissi - ce qu'avait également noté le général Gardane ${ }^{55}$. Le tsar consacrait de larges sommes à la construction d'une route reliant Tbilissi à Mozdok. Les troupes russes réparties sur le territoire géorgien achetaient tout à un prix exorbitant; leur nourriture était importée de Russie, mais elles laissaient toute leur solde en Géorgie. Le gouvernement ne percevait pas même un dixième du montant des dépenses nécessaires au maintien de la conquête du pays. D’après Trézel, "malgré tous ces avantages, les Géorgiens ont montré peu de zèle pour leur nouvelle patrie ». Au sein de la noblesse, seuls les Orbéliani, les Tsitsianov et les Bagration étaient favorables à la Russie; les autres sentaient bien qu'au lieu de constituer un État digne de ce nom, la Géorgie ne serait bientôt plus qu'une petite province russe, et cette humiliation blessait leur fierté. Le soutien des Géorgiens était si ténu que les Russes ne purent former qu'un bataillon de 400 à 500 hommes, n'osant peut-être pas, d'après le lieutenant, en armer davantage.

L’armée russe dispersée en Géorgie se composait de 35 bataillons d'infanterie de ligne, trois régiments de dragons et cinq régiments de cosaques du Don. Elle rassemblait au total 30000 individus. Ces unités étaient réparties entre l'Iméréthie, le Daghestan, la ville de Shirvan, l'ensemble de la Géorgie et le district de Bambak. Plusieurs unités gardaient Astara et le khan de Langheran, qui étaient sous protection russe. Trézel affirme que, les garnisons établies, on ne pouvait mettre en campagne "que 17 bataillons, deux régiments de dragons et la moitié de Cosaques, environ douze mille hommes en tout ». Ces forces avaient été suffisantes jusqu'alors pour mettre les Persans en déroute, mais il fallait prendre en compte les attentes respectives des Russes et des Persans vis-à-vis de ce conflit. Si SaintPétersbourg n'avait pas le désir de s'engager davantage, Fath Ali Chah au contraire était prêt à envoyer toutes ses forces armées sur ce terrain. Les Persans étaient encore susceptibles de reprendre la Géorgie à la Russie; il leur suffisait de garantir aux Géorgiens la restauration de l'ancien gouvernement et de leur promettre une

55. Château de Vincennes, Service historique de l'armée de terre (SHAT), Perse 1807-1857, $1 \mathrm{M} \mathrm{n}^{0} 1673$, Cracovie, non paginé, 11 août/1809, 4/52., fol. 1. 
amélioration de l'administration interne du pays, et ceux-ci seraient prêts à renouer les relations lâches qu'ils entretenaient avec l'Empire persan. Selon l'officier français, il aurait été bon pour la Russie de s'établir solidement en Géorgie et de prendre tranquillement le contrôle du Caucase ${ }^{56}$.

Ainsi, contrairement à ce qui transparaît dans les notes des consuls français de l'Empire ottoman et des émissaires de Napoléon en Perse, le lieutenant Trézel apparaît à travers son rapport favorable à la politique menée par l'Empire russe en ce qui concerne la Géorgie et le Caucase en général.

\section{Les lettres des princes royaux géorgiens à Napoléon}

Les princes royaux Alexandre et Teimouraz confièrent des lettres destinées à Napoléon au général Gardane, lors de son retour en Europe. Il ne fait aucun doute qu'en raison du traité franco-persan, les Bagration, qui s'étaient exilés en Perse, avaient espéré obtenir le soutien de l'empereur des Français. En comparant les versions persanes des lettres des princes avec la traduction française effectuée par Amédée Jaubert, on constate que celui-ci a pris des libertés. Dans la version française, les deux princes royaux qui ont fui en Perse à cause des persécutions des Russes sont qualifiés de réfugiés, et le principal propos de leurs missives est de solliciter l'appui de Napoléon pour récupérer leur royaume, « injustement conquis » par les Russes ${ }^{57}$. Le prince royal Teimouraz qualifie Napoléon de « distributeur de couronnes "; il se présente comme le potentiel roi de Géorgie et promet à Napoléon de le servir fidèlement s'il retrouve " ses anciens territoires ${ }^{58}$ ". Mais les événements politiques s'enchâ̂naient si rapidement en Europe que les princes ne disposaient pas des dernières nouvelles, et la situation des deux hommes en Perse

56. Château de Vincennes, Service historique de l'armée de terre (SHAT), Notice sur la Géorgie, $1 \mathrm{M} \mathrm{n}^{0}$ 1486, Russie jusqu'en 1811, non paginé, 31 mai/1809, doc. 13, fol. 32-76.

57. AMAE, CP/Perse, vol. 12, doc. 122, fol. 231r-231v.

58. AMAE, CP/Perse, vol. 11, doc., fol. 222v-222r. 
était si difficile qu'ils ne prirent pas toute la mesure de l'échec de la mission politique du général Gardane en Perse. Les espoirs nourris par les princes Alexandre et Teimouraz, qui pensaient que Napoléon (et l'Europe chrétienne en général) aiderait la famille royale des Bagration à recouvrer leur royaume, s'avérèrent donc vains. Le prince Alexandre resta fidèle à ses convictions, mais ne parvint jamais à atteindre son but; il mourut dans une extrême pauvreté à Téhéran en 1844. Quant au prince Teimouraz, il comprit sans aucun doute que le but de sa fuite en Perse - chasser les Russes de Géorgie afin de monter sur le trône, possiblement grâce à l'aide de Napoléon - était illusoire. Le 16 octobre 1810, Teimouraz partit pour la Russie; il s'installa à Saint-Pétersbourg le 12 janvier 1812. Le prince Teimouraz, descendant du dernier roi de Géorgie, "Teimouraz Khan, seigneur géorgien, chef d'artillerie de l'armée d'Abbas Mirza $^{59}$ ", après avoir émigré de Perse en Russie, devint célèbre en Europe en tant que savant. Il fut membre correspondant de la Société asiatique de Paris à partir de 1831 et membre honoraire de l'Académie des sciences de Russie à partir de 1837. Il mourut à SaintPétersbourg en 1846.

Le roi Salomon II d'Iméréthie (1789-1810), petit-fils du roi Héraclius II, fut emprisonné par les Russes et s'échappa en 1810. Il sollicita alors la protection de Fath Ali Chah. Celui-ci ne répondit pas favorablement à sa demande, mais lui octroya une petite pension et lui suggéra de solliciter le soutien des Ottomans. Dans ces circonstances, Salomon II envoya une lettre à Napoléon. Il avait déjà écrit à l'empereur des Français, sans obtenir de réponse. Le roi décida de faire une autre tentative. Dans cette nouvelle missive, il appelle Napoléon "l'arbitre de l'univers ", et lui demande de le délivrer de l'intolérable joug de «l'empereur de Moscou » et d'accorder sa protection au royaume d'Iméréthie ${ }^{60}$. La lettre fut remise à un diplomate français, Georges Outrey. Le combat du roi Salomon contre l'occupation russe fut sans effet. Il émigra en Turquie et mourut à Trabzon, loin de sa terre natale, le 7 (19) février 1815, à l'âge de 43 ans.

59. Joseph Michel Tancoigne, Lettres sur la Perse et la Turquie d'Asie, Paris, Nepveu, 1819, vol. II, p. 165-166.

60. AMAE, Russie, vol. 10, doc. 24, fol. 292R, doc. 26, fol. 296r-296v. 
$\mathrm{Au}$ cours de la première décennie du XIX ${ }^{\mathrm{e}}$ siècle, les intérêts des plus grandes puissances - l'Angleterre, la Russie, la France dépassèrent le cadre européen pour converger en Perse. Le traité d'alliance franco-persan, qui constituait la première alliance militaire et politique conclue entre un État européen et la Perse au début du XIX ${ }^{\mathrm{e}}$ siècle, fit de la Géorgie un enjeu international. Avec la conclusion du traité de Tilsit, la Géorgie, qui appartenait déjà à l'espace géopolitique de l'Empire russe, perdit son importance pour la France, mais pas pour la Perse. Les notes d'un membre de la mission de sir Harford Jones Brydges, datées du 28 février 1810, le prouvent. D'après cette source, lorsque le baron Wrede, lieutenantcolonel d'artillerie et émissaire russe, rappela à Mirza Bozorg que la Perse avait rompu le traité qu'elle avait conclu avec la France, le vizir rétorqua: «Ce n’est pas la Perse qui l'a rompu, mais la France, puisque l'objet principal du document était la restitution de la Géorgie à l'Iran. La France n'a pas voulu ou n'a pas pu tenir sa promesse. Nous avons alors décidé de ne pas être traités à la légère plus longtemps et de former une alliance avec l'Angleterre ${ }^{61} »$. La question de la restitution de la Géorgie à la Perse était encore d'actualité lors des négociations menées à Londres par l'ambassadeur de Fath Ali Chah, Mirza Abul Hassan Khan, en 1809-1810

Trente ans plus tard, en 1839, l'historien français Lefebvre de Becours commenta ainsi la politique de l'empereur des Français: "Le traité de Finckensteïn était dirigé à la fois contre l'Angleterre et la Russie. [...] La stipulation relative à la Géorgie était la plus précieuse pour la Perse, elle était même la seule qui lui fut utile, les autres ne lui imposant que des charges. [...] En signant le traité de Tilsit avec la Russie, Napoléon a ignoré l'article 4 du traité de
\end{abstract}

61. Sir Harford Jones Brydges, An Account of the Transactions of His Majesty's Mission to the Court of Persia, in Years 1807-1811, Londres, James Bohn, 1834, vol. I, p. xxiv-xxv.

62. Mirza Abul Hassan Khan, A Persian at the Court of King George, 1809-10, traduit et édité par Margaret Morris Cloake, introduction de Denis Wright, Londres, Barrie \& Jenkins, 1988, p. 60, 64, 69, 119, 164. 
Finkenstein qui prévoyait le retour de la Géorgie à la Perse ${ }^{63}$. » La mission du général Gardane en Perse était donc vouée à l'échec dès la signature du traité de Tilsit, en raison de la politique trompeuse menée par Napoléon. À Tilsit, les objectifs politiques de l'empereur des Français ne coïncidaient plus avec les projets de Fath Ali Chah, si bien que la Perse et la Géorgie finirent en victimes du grand jeu qui opposait les empires européens. Lorsqu'il signa le traité de Finkenstein avec la Perse, Napoléon oublia de prendre en considération le fait que ses adversaires n'abandonneraient jamais leurs positions, qu'il s'agisse de la Russie dans le Caucase et sur les rives caspiennes, ou de l'Angleterre en Inde.

(Traduit de l'anglais par Pauline Tardieu-Collinet) 



\title{
14
}

\section{Bakou à la croisée des cultures}

\author{
Du XIX $X^{e}$ siècle au début du $X X^{e}$ siècle
}

Irada Baghirova

Après l'invasion russe du début du XIx ${ }^{\mathrm{e}}$ siècle, le Caucase musulman et l'Azerbaïdjan en particulier durent faire face à l'introduction d'une civilisation porteuse de valeurs étrangères et connurent alors une période de transformations culturelles qui modifièrent profondément l'histoire de la région. Ce mouvement se prolongea tout au long du XIX ${ }^{\mathrm{e}}$ siècle et jusqu'au début du $\mathrm{Xx}^{\mathrm{e}}$ siècle, et affecta quasiment tous les aspects de la vie sociale et culturelle locale. La politique menée par le gouvernement central modifia radicalement le statut des différents groupes sociaux, comme en témoigne la diversité des origines de la population actuelle de l'Azerbaïdjan, en particulier à Bakou:

De larges zones d'échanges furent créées, parmi lesquelles les industries, qui s'étaient particulièrement développées autour de Bakou, alors un centre d'exploitation et de traitement du pétrole, tentèrent d'employer une force de travail mobile possédant une même culture et, surtout, une langue unique et standardisée. Cette nouvelle situation confronta les masses, et surtout les élites, à de nouvelles difficultés ${ }^{1}$.

En dépit des aspects négatifs de la conquête, les nations musulmanes de l'Empire russe, parmi lesquelles l'Azerbaïdjan, entrèrent en contact avec les idées culturelles et sociopolitiques alors développées en Europe. Selon le linguiste et historien Gaziz Gubaydulin

1. E-M. Auh, « Meždu prisposobleniem i samoutverždeniem. Rannij ètap poiskov nacional'noj identičnosti v srede mysul'manskoj intelligencii i voznikovenie novogo obščestva na jugo-vostočnom Kavkaze (1875-1905 ", in Azerbajdžan i Rossija: obščestvo i gosudarstva. Otv. Red. I sost. D.E. Furman. Moskva, Letnij sad 2001, p. 51. 
(1887 - 1937), tandis que la pression exercée par le capitalisme européen stimula le mouvement moderniste en Égypte, en Iran, en Turquie et en Inde, les provinces orientales de l'Empire tsariste furent quant à elles influencées par le développement du capitalisme russe ${ }^{2}$. La conquête russe n'eut pas seulement des effets politiques, législatifs, sociaux et économiques: elle introduisit également un certain nombre d'innovations dans le domaine spirituel et culturel. Les peuples musulmans de l'empire, tout d'abord, eurent accès à la culture et aux théories sociales et politiques européennes. Par ailleurs, le contact entre la civilisation européenne, incarnée par la Russie, et la civilisation musulmane traditionnelle entraîna l'apparition d'une nouvelle strate sociale, bien spécifique, l'intelligentsia azerbaïdjanaise.

\section{La russification de Bakou}

La volonté de l'Empire russe de russifier et de christianiser les populations musulmanes du Caucase, notamment dans l'actuel Azerbaïdjan, n'alla pas sans rencontrer des obstacles majeurs. Selon l'ethnologue russe S. Lourié:

Le principal défaut de cette politique était de considérer les musulmans « russes " d'un point de vue interne à l'empire: on pensait qu'ils s'habitueraient peu à peu à de nouvelles conditions, se rapprocheraient des populations russes chrétiennes et finiraient par décider de les rejoindre. On ignora complètement le fait que les musulmans faisaient partie du monde islamique, dont ils continueraient toujours de se sentir proches et avec lequel ils essaieraient de maintenir des relations ${ }^{3}$.

Cependant, les autorités durent par la suite prendre en compte ce facteur. Mise en place en 1840, la réforme administrative abolissant l'ancienne gestion militaire du Caucase établit un système de provinces éliminant les frontières ethniques et politiques traditionnelles dans la région. En outre, les représentants de l'aristocratie

2. G. Gubajdullin, « K voprosy ob ideologii Gasprinskogo », in Gasyrlar avazy (Èho vekov), Naučno dokumental'nyj žurnal 3/4, 1998, p. 7.

3. S. Lur'e, « Ot drevnego Rima do Rossii XX Veka: preemstvennost’ imperskoj politiki », in Obščesrvennye nauki i sovremennost’ 4, 1997, p. 131. 
azerbaïdjanaise locale furent éliminés du pouvoir — les beys et les aghas virent leurs terres confisquées - et remplacés par des Russes ${ }^{4}$.

La réforme imposa l'usage exclusif du russe dans l'administration, et le doublement du nombre de représentants officiels russes ${ }^{5}$. Mais les représentants de l'empire se rendirent vite compte qu'ils avaient besoin d'une base sociale plus solide pour mener à bien cette réforme administrative. Le prince Vorontsov, nommé premier gouverneur du Caucase en 1844, s'attacha à résoudre ce problème. Il rendit leurs terres à de nombreux seigneurs azerbaïdjanais, faisant ainsi d'eux une classe privilégiée, et noua des alliances ${ }^{6}$ avec eux.

Par ailleurs, en 1849, fut adoptée une loi sur « l'instruction des indigènes du Caucase et de Transcaucasie à destination des institutions d'éducation supérieure et spécialisée de l'Empire », dont la finalité était de préparer les représentants officiels de l'empire à leur mission au service de l'État ${ }^{7}$. Si elle s'appliquait avant tout aux peuples chrétiens de la région - Arméniens et Géorgiens -, elle eut un certain impact sur la noblesse azerbaïdjanaise. En conséquence de ces nouvelles dispositions, on ouvrit des écoles, des institutions culturelles et des établissements d'éducation, ainsi que des maisons d'édition. Sur le plan politique, en 1870, la douma de Bakou, dont les membres étaient élus pour quatre ans sur la base de leurs titres fonciers, commença ses activités ${ }^{8}$. Elle était constituée pour moitié de députés élus par des électeurs non chrétiens. Par conséquent, en 1877, lors de l'élection du premier parlement, 2900 Azerbaïdjanais votèrent pour élire le même nombre de députés que 499 électeurs

4. I.P. Petruševskij, «Sistema russkogo kolonial’nogo upravlenija v Azerbajdžane v perv. Polovine XIX veka ", in Kolonial'naja politika rossijskogo carizma $v$ Azerbajdžane v 20-60-x godah XIX veka, Moskva-Leningrad, Izd-vo AN SSSR, 1936, č 1 , p. 23

5. «Iz zpisok barona Korfa », in Russkaja starina 1900, Janvar’, T. 101, p. 43.

6. . S. Èsadze, Istoričeskaja zapiska ob upravlenii Kavkazom. Tiflis, 1907, t. 1, p. $80-81$.

7. Polnoe sobranie zakonov Rossijskoj imperii, Izd $2^{\mathrm{e}}$ Sankt-Peterburg, 1847, t. XXIV, Otd $1 \mathrm{n}^{0} 23307$

8. K. Odžagova, Gorodskoe samoupravlenie Baku v konce XIX-načale XXvv, Baku, 2003, p. 26. 
russes et arméniens ${ }^{9}$. La discrimination était criante, mais c'était la première fois que des musulmans avaient le droit de participer à des élections locales.

Avec la révolution industrielle du XIX ${ }^{\mathrm{e}}$ siècle, il devint nécessaire d'exploiter de nouvelles ressources d'énergie pour soutenir le développement économique. Cette période marque ainsi le début de la transformation de la ressource la plus importante, le pétrole, en une arme politique et économique, et, par suite, l'émergence de nouvelles relations interétatiques. L'Azerbaïdjan, dont l'histoire est profondément marquée par les effets socio-économiques et politiques de l'exploitation du pétrole, fut concerné au premier chef par ce processus.

L'abolition du système d'impôts agricoles en 1872 sonna le début du développement rapide de l'industrie pétrolière. Le manque de capitaux domestiques obligea le gouvernement tsariste à attirer des capitaux étrangers et, en 1872, les étrangers furent dotés des mêmes droits que les sujets russes concernant l'exploitation des hydrocarbures. Dès lors, l'industrie pétrolière de Bakou connut un afflux spectaculaire de capitaux étrangers qui transformèrent la ville en un Klondike pétrolier dont la réputation dépassa vite les frontières russes.

\section{Bakou et le pétrole}

Parmi les leaders de cette nouvelle industrie figurait la société des frères Nobel, fondée par un entrepreneur suédois, Ludwig Nobel, et le baron P. Bildering. Très vite, la compagnie exerça le monopole de la production et de l'exportation de pétrole en Russie ${ }^{10}$.

En mai 1883, l'une des plus grandes sociétés pétrolières de Bakou, la Compagnie pétrolière de la Caspienne et de la mer Noire, dirigée par de célèbres banquiers parisiens, les frères Rothschild, entama

9. GIAAR (Archives nationales de la république d'Azerbaïdjan), F. 50, L. 1, R. 4, p. 41.

10. Monopolističeskij kapital v neftjanoj promyščlennosti Rossii. 1882-1914. Dokumenty i materialy. Moskva-Leningrad, 1961, p. 689. 


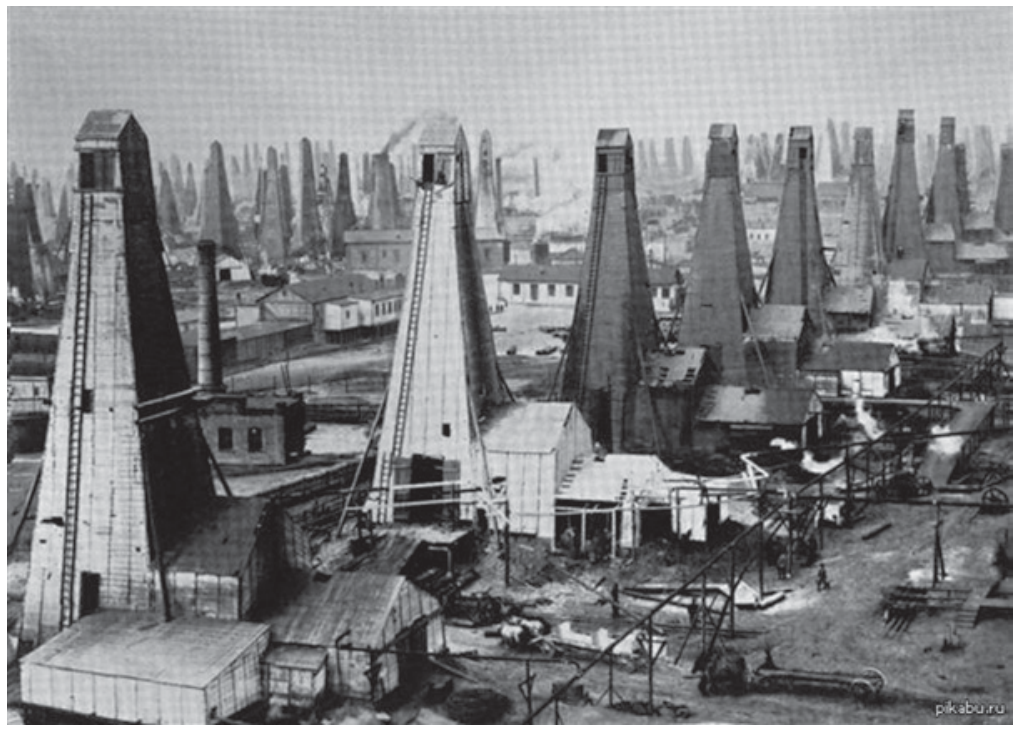

ILL. 1. Tours de forage appartenant à la famille Nobel à Bakou @ Musée national d'histoire de l'Azerbaïdjan.

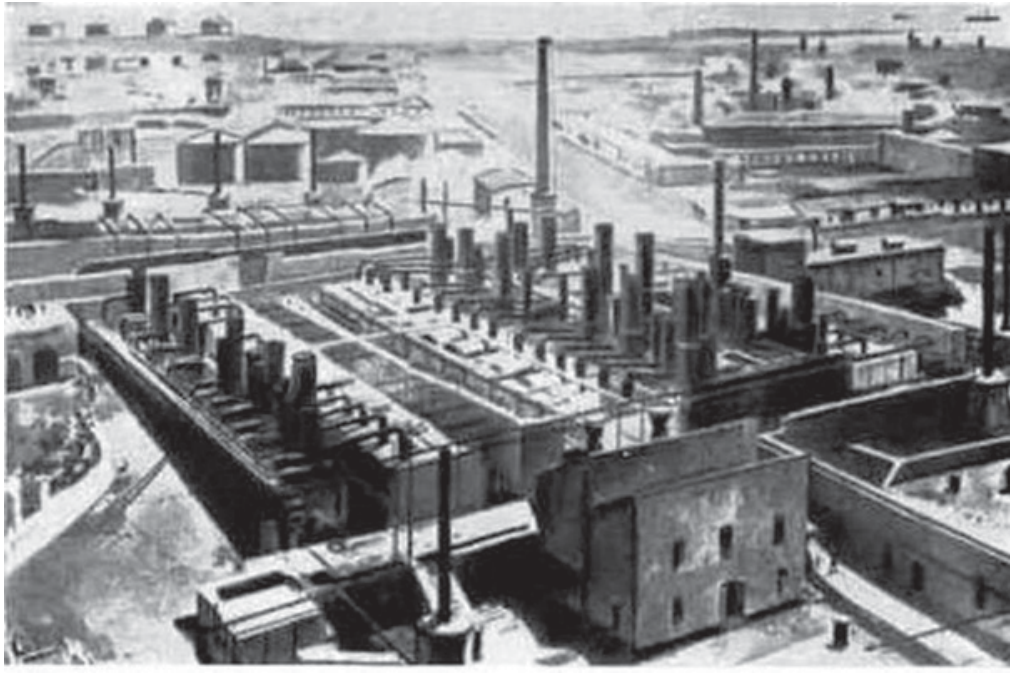

ILL. 2. Raffinerie des frères Nobel à Bakou $\odot$ Musée national d'histoire de l'Azerbaïdjan. 
ses activités dans la région ${ }^{11}$. Rapidement, elle se partagea l'exclusivité du pétrole russe avec la société des frères Nobel ${ }^{12}$.

Afin d'exporter le pétrole sur le marché international, les Rothschild financèrent la construction d'un oléoduc entre Bakou et Batoumi, dont la construction fut achevée en $1907^{13}$.

Les activités des Rothschild en Russie et dans l'actuel Azerbaïdjan cessèrent en 1912: ils cédèrent leur entreprise à la Royal Dutch Shell, compagnie néerlando-britannique. Depuis la fin du XIX ${ }^{e}$ siècle, les capitaux anglais étaient de plus en plus présents sur le marché de Bakou. En 1898, six compagnies britanniques étaient déjà installées; en 1903, elles étaient deux fois plus nombreuses, avec un capital global de 60 millions de roubles ${ }^{14}$.

La Compagnie pétrolière russe de Bakou, ou encore la Compagnie pétrolière européenne figuraient parmi les plus importantes sociétés d'exploitation. En 1897, un célèbre magnat du pétrole azéri, Haji Zeynalabdin Taghiyev (ou Taguiev), vendit sa compagnie cinq millions de roubles aux Britanniques G. Gladston et J. Moore. Cette opération donna naissance à une société par actions, Oleum ${ }^{15}$. Mais Tagiyev parvint à garder la main sur 13,7 \% des actions et devint membre du conseil d'administration de la société aux côtés de E. Gubbart, directeur de la Banque d'Angleterre ${ }^{16}$.

$\mathrm{Au}$ début de la Première Guerre mondiale, un large consortium industriel et financier, qui rassemblait toutes les entreprises pétrolières britanniques, vit le jour à Bakou et à Londres. La part commerciale des activités de la compagnie, dont le capital s'élevait à

11. M. Ju Mir-Babaev, "Transkavkazskij truboprovod i brat’ja Rotšil'd ", Azerbajdžanskoe neftjanoe hozjajstvo, 2007, $\mathrm{n}^{0} 11-12$, p. 68.

12. Il est intéressant de noter que l'ingénieur en chef de la compagnie Rothschild était David Landau, père du futur prix Nobel Lev Landau, et que l'un des directeurs de la compagnie n'était autre que le célèbre chimiste Adolf Gukhman, membre de la Société technique impériale de Russie. F. Sadıqlı, « Azərbaycan hələ XIX əsrin sonunda neft ixrac edən ölkə kimi tanınırdı ", Azərbaycan, 2013.-17. sentyabr.

13. V.A. Pritula, Transport nefti i gaza, Moskva, Gostehizdat, 1848, p. 72.

14. M.D. Ibragimov, Neftjanaja promyšlennost' Azerbajdžana v period imperializma, Baku, Elm, 1984, p. 103

15. Ibid., p. 16-17.

16. Ibid., p. 68. 
28 millions de roubles, était entièrement contrôlée par la Shell ${ }^{17}$. Dès lors, celle-ci devint le plus grand exploitant de pétrole en Russie et le deuxième à l'échelle mondiale, derrière la Standard Oil américaine. Bien évidemment, toute entreprise privée est guidée par ses propres intérêts et fonctionne sur l'exploitation maximale de la force de travail; Bakou fut elle aussi le théâtre de ces mécanismes économiques. Mais cela ne s'arrêtait pas là : les investissements et les progrès technologiques qui attirèrent les compagnies dans cette région eurent également un impact majeur sur l'économie et la vie locale.

\section{La croissance d'une ville cosmopolite}

Après le tremblement de terre qui affecta Chemakha, l'ancienne capitale historique, en 1859, Bakou devint le centre de la province. Puis, dans la seconde moitié du XIX ${ }^{\mathrm{e}}$ siècle, la croissance rapide de la ville accompagna le développement de l’industrie pétrolière. En 1826, Bakou comptait quelque 4500 habitants; on en recensait 155786 en 1903, et 214679 en $1913^{18}$. Au tout début du xx ${ }^{\mathrm{e}}$ siècle, la ville comptait 878 nouveaux bâtiments; on en dénombrait 1404 en $1910^{19}$.

Le développement des champs pétroliers, des raffineries, d'une compagnie maritime desservant la Caspienne, le changement de capitale et la construction de voies de chemin de fer vers la mer Noire, tout cela transforma le statut de Bakou. Aucune autre ville russe ne connut une évolution et une transformation si rapides. Le paysage ethno-démographique de la ville fut lui aussi bouleversé. Des milliers de travailleurs arrivèrent des quatre coins de la Russie et de l'Iran. Rapportée à la masse des ouvriers azerbaïdjanais, la proportion d'immigrés en provenance de Russie, d'Arménie et du sud de l'Azerbaïdjan passa entre 1903 et 1917 de 65,1 \% à 77,8 \% puis à $132 \%{ }^{20}$. En outre, l'ingénierie et le secteur bancaire accueillirent

17. S. M. Sadyhzade, Proniknovenie anglijskogo kapitala v neftianuju promyšlennost' Azerbajdžana (1896-1914 gg), Avtoreferat diss., d’Azeris kand. Ist. Nauk. Baku, 1967, p. 31

18. Izvestija Bakinskoj gorodskoj Dumy, 1915, nº 5-6, p. 7.

19. L. S. Bretanickij, Baku v krepostnyh stenah, Moskva-Leningrad, 1976, p. 93 et 95. 20. V.V. Pokšiševskij, Polojenie bakinskogo proletariata nakanune revolucii 1917 gg, Baku, 1927, p. 8. 
de nombreux spécialistes, anglais, français, allemands, finlandais et autres $^{21}$.

La population de Bakou resta toutefois majoritairement composée d'Azéris, présents à tous les niveaux sociaux, des ouvriers et paysans aux magnats du pétrole. Une grande partie des ouvriers employés dans les gisements de pétrole étaient originaires du sud de la région (en Iran). Venaient ensuite les Arméniens, dont certains possédaient des parts importantes dans des entreprises d'exploitation et de commercialisation. Un Arménien, M. Gukasov, fut à la tête du conseil du Congrès des industriels du pétrole. Il y avait aussi beaucoup de Russes parmi les propriétaires de gisements. On peut aussi citer les Moloques (ou Molokanes), membres d'une secte russe longtemps, persécutée installée dans la région au milieu du XIX ${ }^{\mathrm{e}}$ siècle, qui étaient ouvriers et artisans, ou encore chauffeurs.

C'est à cette époque de croissance que remonte la construction d'églises chrétiennes. Dès le début du $\mathrm{xx}^{\mathrm{e}}$ siècle, la ville, outre ses mosquées, et une synagogue, comptait six églises orthodoxes, deux églises grégoriennes arméniennes, une église catholique et deux temples luthériens ${ }^{22}$. Certains de ces édifices furent bâtis avec l'aide d'entrepreneurs azerbaïdjanais. Par exemple, la cathédrale orthodoxe des Myrrhophores fut construite en 1909 grâce au soutien du magnat et philanthrope cité plus haut, H. Z. Taghiyev, en sus des dons de fidèles ${ }^{23}$. Notons que, en 2003, la reconstruction de la cathédrale fut financée par l'entrepreneur et philanthrope azerbaïdjanais A. Kurbanov.

En vingt ans, Bakou devint un centre cosmopolite majeur, lieu d'une intense activité non seulement industrielle, mais aussi culturelle. Un nouveau mode de vie combinant de manière innovante des éléments à la fois asiatiques et européens vit le jour sous les influences conjuguées de la bourgeoisie azerbaïdjanaise, représentée entre

21. G.I. Rovtovcev, Bloeznennost'naselenija bakinskih neftjanyh promyslov (po dannym obrašaemosti naselenija v lečebnicy v 1908 i 1910 gg., Baku, Tipografija « Truenik » A. A. Kuindži, 1912, p. 16.

22. G. Tomson, Bakinskie Vospominanija 1914-1917 gg, Baku, « QNT Nəşriyyatı », 2013, p. 20.

23. A. I. Junickij, Istorija cerkvej i prohodov Bakinskoj gubernii, 1906, p. 15 http:// baku.eparhia.ru/church/cathedral/ 
autres par H.Z. Taghiyev, M. Nagiev et Sh. Asadullaev, de représentants de la bourgeoisie européenne et russe, par exemple L. et E. Nobel, S. M. Shibaev, A. Benkendorf, de la bureaucratie impériale, ainsi que d'une intelligentsia internationale composée de techniciens et d'humanistes porteurs d'idéologies réformistes, libérales et socialistes.

Avec l'augmentation de la population et des revenus pétroliers, il devint nécessaire de construire des logements et de développer toutes sortes d'activités. Grâce aux immenses capitaux disponibles, on put embaucher des architectes européens et russes pour concevoir de nouveaux bâtiments, empruntant aux styles les plus divers, classique, rococo, art nouveau, etc.

Le long des berges, là où était installée une grande société maritime (Caucase et Mercure), se trouvaient le palais du gouverneur et, à côté, le Jardin du khan. Derrière le front de mer, les rues pavées

étaient bordées de maisons de style européen. À flanc de colline s'étendait la ville asiatique aux toits plats et aux ruelles étroites. On pouvait également voir les ruines du palais du khan et sa magnifique architecture islamique du Xv $\mathrm{x}^{\mathrm{e}}$ siècle et, plus loin, la Mosquée du shah, construite en 1078. Au bord de la mer, près des fortifications de l'ancienne ville s'élevait la tour de la Vierge (ainsi dénommée d'après un thème courant dans les légendes orientales), qui servait alors de phare. La "ville noire ", où étaient installées toutes les raffineries, n’était pas éloignée de la jetée qui menait à la plage; ce quartier devait son nom à l'épaisse fumée rejetée par la combustion des déchets pétroliers.

\section{Architectures de Bakou - La contribution polonaise}

Au tournant du $\mathrm{xx}^{\mathrm{e}}$ siècle, de belles contributions à l'architecture de la ville furent le fait d'architectes polonais, dont les plus célèbres sont Goslavsky, Ploszko, Skureich et Skibitsky.

Entre 1893 et 1904, Joseph Goslavsky fut l'un des principaux architectes et ingénieurs de Bakou. On lui doit un très grand nombre de bâtiments du centre-ville. Diplômé de l'Institut du génie civil de Saint-Pétersbourg en 1891, il fut envoyé à Bakou pour y construire la cathédrale orthodoxe Alexandre-Nevski. 


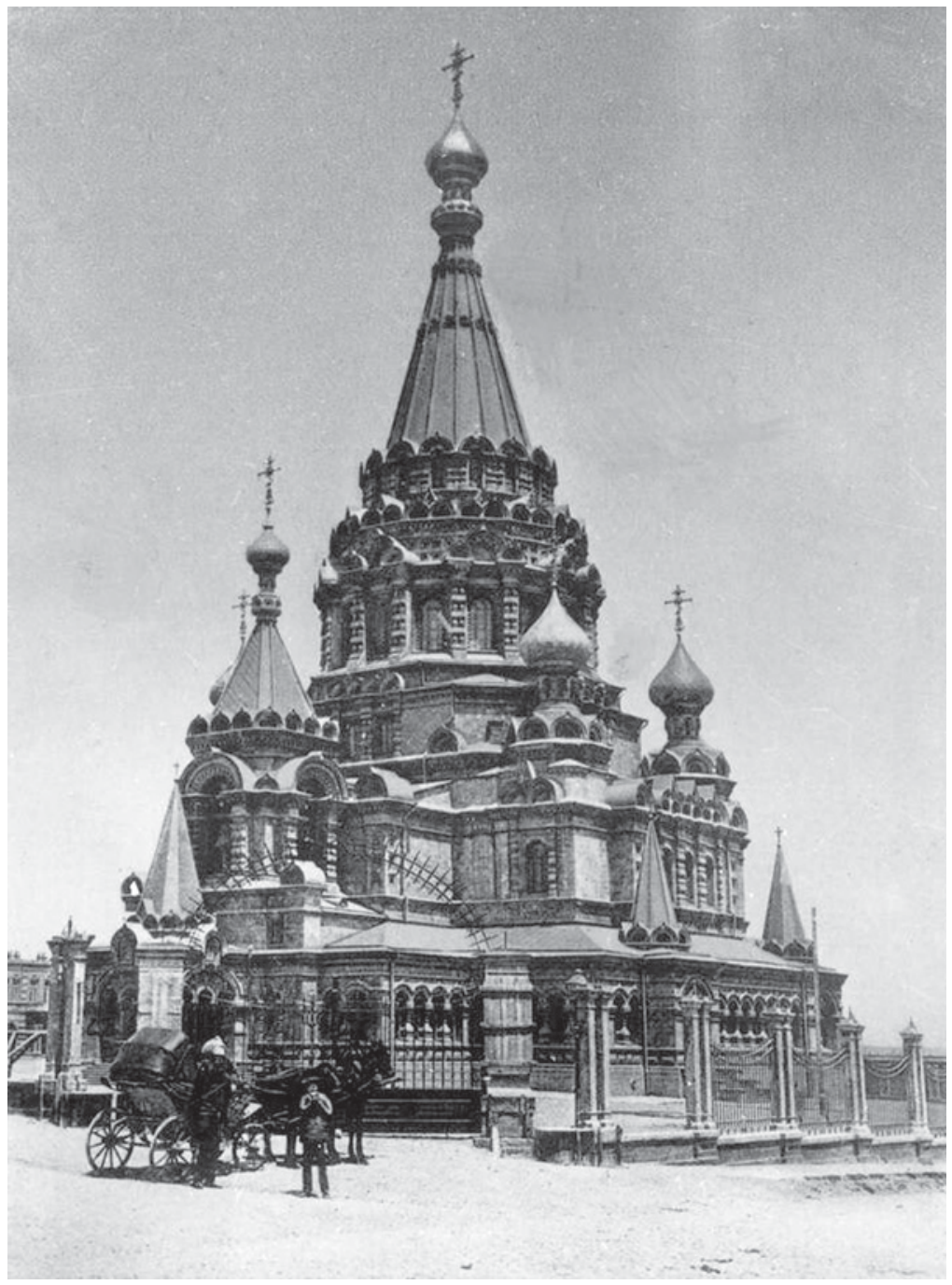

ILL. 3. Cathédrale orthodoxe Alexandre-Nevski @ Musée national d'histoire de l'Azerbaïdjan.

Cet édifice, construit en 1898, était la plus grande église orthodoxe de la ville. Elle fut démolie durant l'époque soviétique, en 1936. Grand admirateur des classiques, Goslavsky y rendait éga- 
lement hommage à d'autres styles architecturaux, comme cela se fit couramment durant la seconde moitié du XIX ${ }^{e}$ siècle. Il élabora et réalisa douze autres projets en sept ans, parmi lesquels le palais de Taghiyev rue Gorchakovskaya (aujourd'hui musée d'histoire de l'Azerbaïdjan, rue Taghiyev), un immeuble de trois étages dans la rue Nikolaevskaja (aujourd'hui au 7, rue Istiglalijat), la villa Taghiyev dans le village de Mardakian ${ }^{24}$, dans la péninsule d'Apchéron, le bâtiment de l'école polytechnique de Bakou dans la rue Stanislavsky (aujourd'hui au 20, rue Azadlig), ou encore le bâtiment de la branche locale de la Société technique impériale dans la rue Torgovi (aujourd'hui Nizami).

La fin du XIX ${ }^{\mathrm{e}}$ et le début du Xx ${ }^{\mathrm{e}}$ siècle virent également l'apparition de structures industrielles en Azerbaïdjan, par exemple une usine de textile dans la ville de Zikh près de Bakou, conçue par Goslavsky et construite sous la responsabilité de Taghiyev, qui avait décidé de créer une industrie légère en raison du coût très bas du pétrole et du coton (en Iran et en Asie centrale). Cette usine était située près de la mer, un emplacement particulièrement judicieux offrant des échanges directs avec les ports d'Iran, d'Asie centrale et de Russie ${ }^{25}$.

L’une des œuvres les plus réussies de Goslavsky est l’École musulmane pour femmes - fondation de Taghiyev — dans la rue Nikolaevskaya (aujourd'hui 8, rue Istiglaliyat). L'établissement possédait une cour fermée, côté sud, par un mur fortifié. Cette disposition était particulièrement bien adaptée aux conditions locales et au climat de la ville. En 1918-1920, le bâtiment hébergea le parlement de la République démocratique d'Azerbaïdjan et il abrite aujourd'hui l'Institut des manuscrits de l'Académie nationale des sciences.

24. . Les millionnaires de Bakou, qui avaient fréquenté toutes les stations touristiques d'Europe, décidèrent de créer chez eux des lieux de villégiature. Le village de Mardakian était tout indiqué et, très vite, de nombreux entrepreneurs y établirent leur résidence. L’un des édifices les plus intéressants est la villa Taghiyev, conçue par Goslavsky en 1893-1895.

25. Š Fatullaev-Figarov Juzef Goslavskij//http://www.polonia-baku.org/ru/goslawski.phtml 


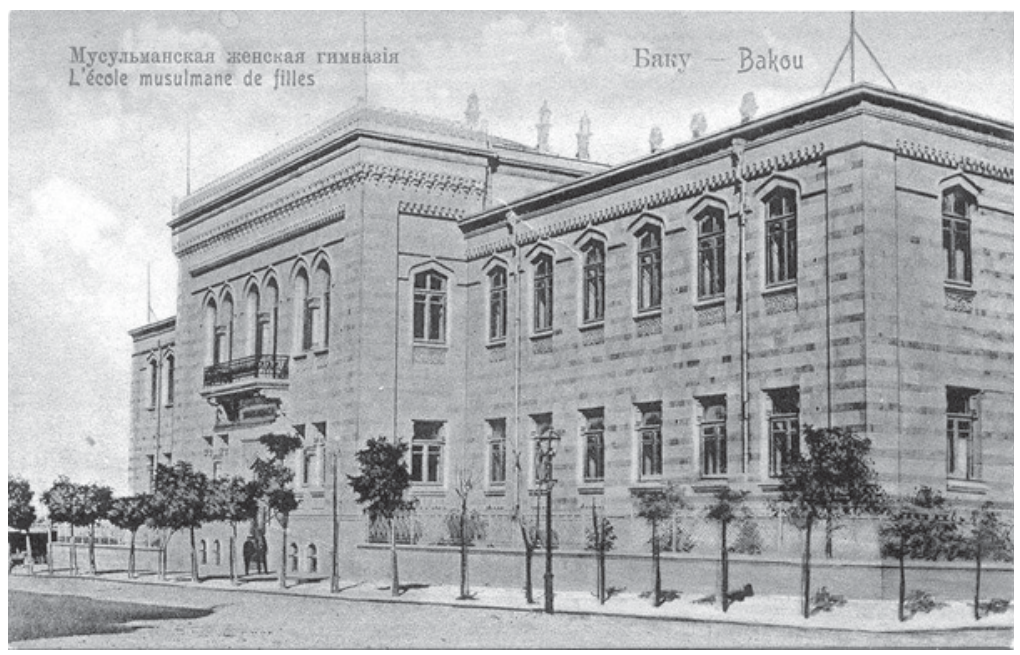

ILL. 4. L’École musulmane pour femmes (c) Archives filmiques et photographiques, Administration générale des archives de la république d’Azerbaïdjan.

Le dernier chef-d'œuvre de Goslavsky est le bâtiment de la Douma de Bakou. Son architecture est de composition classique. C'était le seul bâtiment strictement administratif de la ville à adopter ce style et à proposer une interprétation originale de motifs baroques. Aujourd'hui, il abrite les bureaux du maire de la ville. Goslavsky est mort en 1904 à l'âge de 39 ans.

En 1897, Goslavsky invita un autre architecte polonais, Joseph Ploszko, à le rejoindre à Bakou. Ce dernier a conçu les plus beaux bâtiments de la ville, dont il occupa le poste d'architecte en chef après la mort de Goslavsky. Les œuvres de Ploszko empruntent au classicisme européen, à un style gothique vénitien et français de très haute qualité, revisité dans un esprit très moderne pour ce début du $\mathrm{xx}^{\mathrm{e}}$ siècle. L'architecte trouva bientôt des clients parmi les millionnaires locaux, qui admiraient son génie créatif. Ploszko fut proche du magnat du pétrole Aga Musa Nagiyev, mais compta aussi parmi ses clients Murtuza Mukhatarov, Nuri Amiraslanov, la famille du riche Polonais Rylsky et bien d'autres encore. 
À Bakou, le premier bâtiment réalisé par Ploszko, qui est aussi le plus célèbre, est le monumental Ismaïlia. En 1907, Nagiyev avait demandé à l'architecte de créer un bâtiment destiné à héberger des œuvres de bienfaisance à la mémoire de son fils mort, Ismaill. L’œuvre conçue par Ploszko contribua véritablement à embellir la ville. Ismailia, splendide palais de style gothique vénitien très harmonieux, donne à admirer la maîtrise de l'architecte et l'art des maçons. À l'heure actuelle, le bâtiment est occupé par le conseil de l'Académie nationale des sciences d'Azerbaïdjan.

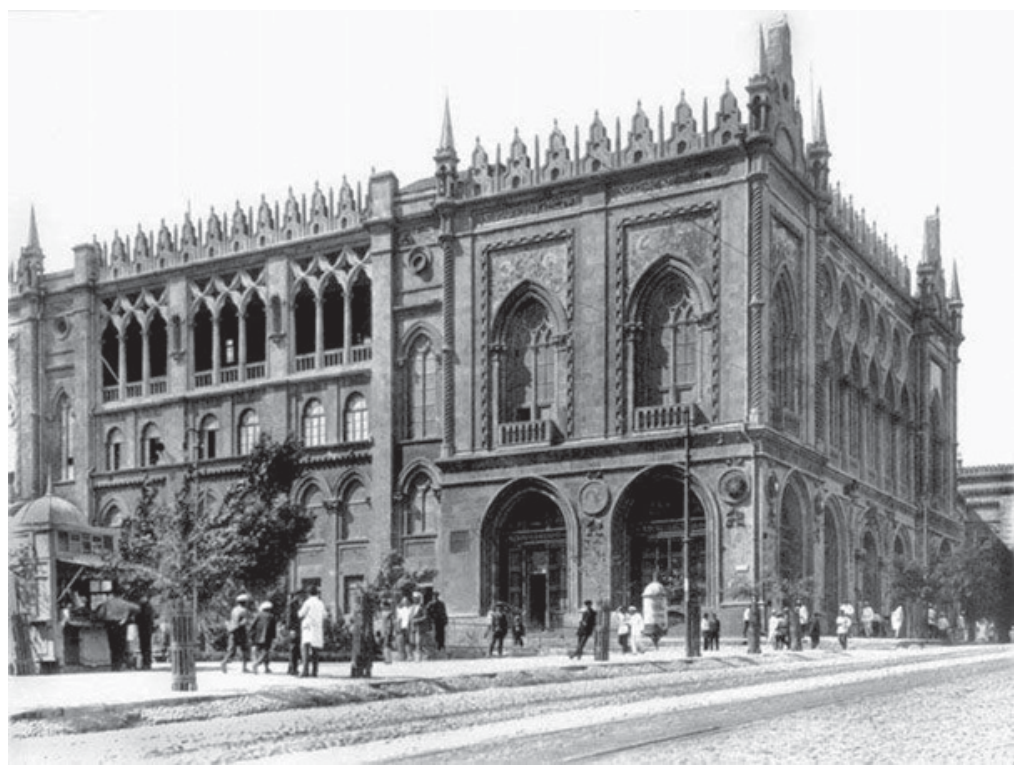

ILL. 5. L'Ismaïlia @ Archives filmiques et photographiques, Administration générale des archives de la république d'Azerbaïdjan.

Parmi les autres œuvres cultes de Joseph Ploszko figurait l'église de l'Immaculée Conception de la bienheureuse Vierge Marie, dont la construction fut achevée en 1912. Qualifié de " polonais ", l'édifice était de style gothique. Il fut principalement financé par la famille Rylsky et par Vitold Zglenitsky, les premiers à avoir foré la 
Caspienne. L'église, située dans les quartiers prestigieux de Bakou, était un des joyaux de la ville. Elle fut démolie dans les années 1930.

Les bourgeois, que le boom pétrolier enrichissait à vue d'œil, déplacèrent la compétition économique sur le champ de l'architecture en se faisant construire des villas et des palais de plus en plus majestueux. Murtuza Mukhtarov, dont il a déjà été question, demanda à Ploszko de lui construire un palais de style gothique. Mukhtarov, qui était marié à une riche héritière d'Ossétie, Elizaveta Tuganova, fille du colonel Aslan-bek Tuganov, offrit à cette dernière le palais en gage d'amour. Situé dans la rue de Perse (aujourd'hui rue Mukhtarov), le bâtiment est un mélange de différents styles architecturaux: art nouveau, baroque, classique et autres. Encore dans la deuxième moitié du $\mathrm{xx}^{\mathrm{e}}$ siècle, le palais Mukhtarov était le plus impressionnant bâtiment de la ville ${ }^{26}$.

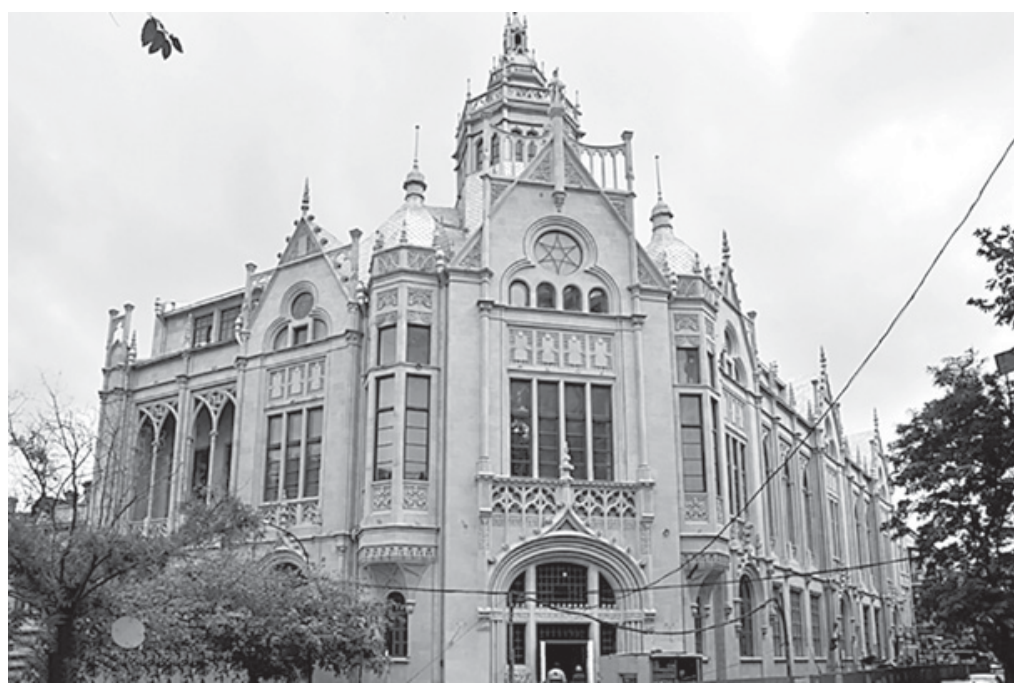

ILL. 6. Le palais Mukhtarov. Collection privée Irada Baghirova.

26. Son propriétaire connut un destin tragique. Quand Bakou fut envahie par les bolchéviques en 1920, Mukhtarov prit lui-même les armes contre les soldats de l'Armée rouge. Mais le palais tomba entre leurs mains, et il se suicida. 
Après la prise du pouvoir par les soviétiques dans les années 1920, Ploszko resta à Bakou comme ingénieur et, avec Z. Akhmedbekov, participa à l'élaboration du projet de jardins à Abchéron. En 1925, après près de trente ans passés en Azerbaïdjan, il partit pour Varsovie puis rejoignit la France ${ }^{27}$.

La gare centrale fut à l'origine conçue par l'architecte polonais Eugene Skibinsky. Le vaste et célèbre magasin d'alimentation anciennement situé passage Tagievsky est l'œuvre de Kazimierz Skurevich, à qui l'on doit aussi le projet de boulevard de Bakou.

$\mathrm{Au}$ total, ce sont près de cinq cents bâtiments qui furent construits en Azerbaïdjan par des architectes polonais. Ces derniers eurent un impact fondamental sur le paysage architectural unique de Bakou, qui devint pour eux comme une seconde patrie.

Signalons aussi qu'on doit au talentueux ingénieur d'origine polonaise Pavel Pototsky d'avoir contribué de manière décisive au développement de l'industrie pétrolière au début du $\mathrm{xx}^{\mathrm{e}}$ siècle. Installé à Saint-Pétersbourg, il avait été invité à rejoindre Bakou pour organiser les travaux de forage dans la baie de Bibi-Heybat. Une zone maritime fut délimitée et Pototsky mit en place un ingénieux système d'extraction. En 1922, alors qu'il était devenu aveugle, il imagina un remblai entourant près de cent hectares d'eau et supervisa personnellement tous les travaux, décrits avec grande précision dans son projet. Il ne vécut pas suffisamment longtemps pour voir la fin des travaux, mais il demanda à être enterré sur la côte entourant la baie de Bibi-Heybat ${ }^{28}$.

\section{Une révolution culturelle}

En plus d'être un haut lieu de production et de commerce du pétrole, Bakou, qui avait l'avantage de posséder un port et d'héberger la Compagnie maritime de la Caspienne, servit de dépôt pour les marchandises circulant du Caucase et de la Perse jusqu'aux provinces de Russie et à l'étranger, via la mer Noire ${ }^{29}$.

27. Š. Fatullaev-Figarov Josef Ploško, http://www.polonia-baku.org/ru/ploszko.phtml 28. F. Handžanbekova, Bakinskie šedevry rukami pol'skih arhitektorov http:// www.1news.az/society/20121223034936267.html

29. http://www.ourbaku.com/index. 
Parallèlement à ce développement économique, une certaine renaissance culturelle vit le jour à Bakou dans les premières décennies du $\mathrm{xx}^{\mathrm{e}}$ siècle. La société azerbaïdjanaise de l'époque connut un mouvement de modernisation typique, caractérisé par le passage d'une société traditionnelle à une société moderne, de la pré-industrie à l'industrie, de la fermeture à l'ouverture, d'un niveau faible à un haut degré de différentiation structurelle, du corporatisme à l'individualisme, du despotisme à la démocratie, etc ${ }^{30}$.

La période décrite plus haut correspond à un moment décisif de transformation d'une société orientale traditionnelle. En dépit des nombreuses conséquences négatives de la colonisation russe, qui eut notamment pour effet de briser les conditions de vie et les systèmes de valeurs traditionnels et de spolier les ressources naturelles locales, les nations musulmanes furent de plus en plus soumises à l'influence de la Russie et, à travers elle, de la civilisation occidentale. Elles intégrèrent un système de relations mondiales, prirent peu à peu le contrôle sur les institutions politiques et créèrent de nouvelles infrastructures économiques.

Cependant, la véritable révolution culturelle eut lieu à partir du moment où ce patrimoine oriental infiniment riche, qui avait produit de nouvelles formes littéraires, philosophiques et historique ainsi que des genres inédits d'art dramatique et de musique, s'ouvrit au monde. L'un des acteurs de cette ouverture fut A. O. Chernyaevsky, enseignant exceptionnel et inspecteur du Séminaire des enseignants transcaucasiens de Gori, qui contribua de manière décisive à familiariser les jeunes Azerbaïdjanais avec les cultures russe et européenne à la fin du XIX siècle. Né à Chemakha, il maîtrisait parfaitement le dialecte local et fut l'auteur de l'un des premiers livres en langue azerbaïdjanaise, Vatan Dili ( La langue de la patrie »). Avec $S$. Velibekov, il publia la deuxième partie de Vatan Dili, dans laquelle la plupart des fables et des poèmes avaient été composés par G. Karadagski. Le contenu des fables était inspiré des œuvres du grand poète russe Krylov, car ce genre n'existait pas

30. M.D. Nikitin, "Orientalizm » è Saida, teorija kolonial'nogo diskursa i vzaimodejstvie Vostoka i Zapada: $k$ vyrabotke novogo ponimanija problemy. Saratov State University: https://www.sgu.ru/archive/old.sgu.ru/files/nodes/9877/14.pdf 
dans la littérature azerbaïdjanaise. De célèbres écrivains, éducateurs et journalistes de langue azérie, parmi lesquels Firidun bey Kocharli, Rashid bey Efendiyev, Safarali bey Velibekov, Mahmoud bey Makhmudbekov, Teymur bey Bayramalibekov, Suleyman Sani Akhundov, Jalil Mammadguluzadeh, Nariman Narimanov et d'autres, furent les étudiants de Chernyaevsky au séminaire de Gori. On a donné son nom à une école du village de Maraza, dans la région de Chemakha, devant laquelle on installa son buste. Son personnage est évoqué dans un roman de I. Shikhly (Dali Kur), célèbre auteur azerbaïdjanais de la période soviétique ${ }^{31}$. Uzyir Hajibeyov, grand compositeur azerbaïdjanais et créateur du premier opéra asiatique, Leyli et Majnun, fut également étudiant du séminaire. Il est intéressant de noter qu'il fut inspiré par la production que proposa Chernyaevsky de l'opéra de Rossini, Le Barbier de Séville ${ }^{32}$. Pour la première fois, en 1908, sur la scène du théâtre de H.Z. Taghiyev, fut proposée à Bakou une synthèse de la musique symphonique européenne et de l'improvisation mugham orientale.

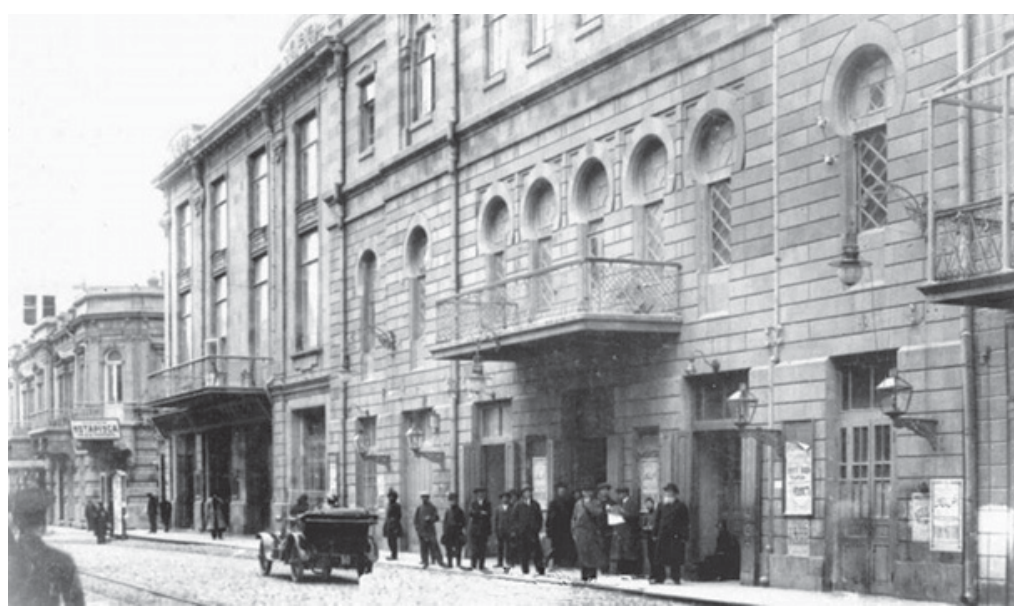

ILL. 7. Le théâtre Taghiyev (C Archives filmiques et photographiques, Administration générale des archives de la république d’Azerbaïdjan.

31. G. Zapletin, Širin-Zade, Russkie v istorii Azerbajdžana, Baku, 2008, p. 156.

32. Meline Toumani, « For the love of Layla », The New York Times, 27 février 2009. 


\title{
OIFPA HA MYGY JBMAHCROMB ЯBЫR.
}

\author{
TEATP' $\Gamma$. 3. A. TAГIEBA.
}

Въ еубботу, 12-го января 1908 года

Операнма артастамн театральяой секиіи О-да „Н К Д Ж А Т Ъ*

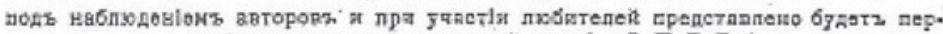

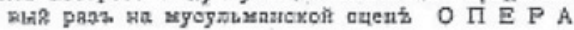
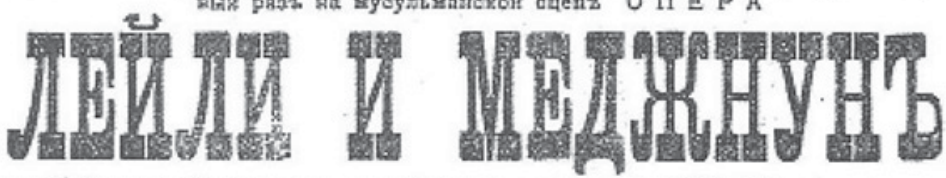

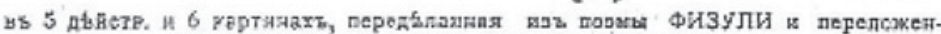

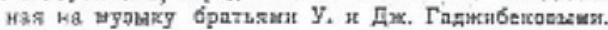

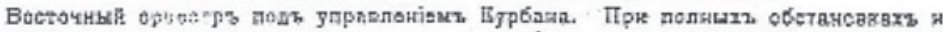

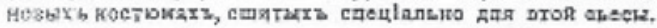

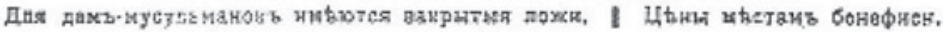
Начато ровно в'ь $81 / 2$ часонъ печеря.

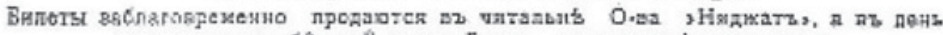

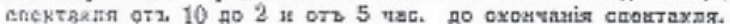

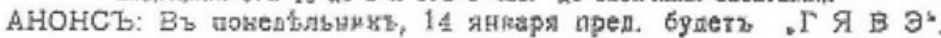

O6mit pacu. A. Bank. Режснеслрь Аряблннекія.

\section{Въ субботу, 12 ตнваря 1908 r., въ залахъ Бакинскаго Общественнаго Собранія

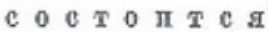

ILL. 8. Première affiche de Leyli et Majnun, dans le quotidien Kaspiy, $\mathrm{n}^{0}$ 9, 14 janvier 1908.

Étant donné que les femmes musulmanes n'avaient pas le droit de monter sur scène, le rôle de Leyli fut interprété par A. Faradzhev et celui de Majnun par un chanteur renommé, H. Sarabski ${ }^{33}$. L’opéra continue de faire aujourd'hui recette dans de nombreux pays et, en 2008, pour son centième anniversaire, il fut donné sous l'égide de l'UNESCO ${ }^{34}$.

33. È. Abasova, K. Kasimov, Uzeir Gadžibekov - muzykant-publicist - Isskustvo Azerbajdžana, Baku, 1968, t. XII, p. 17.

34. "Celebration of anniversaries with which UNESCO is associated in 20082009 ", Sector for External Relations and Cooperation (ERC), Paris, 2008. [http:// old.unesco.kz/publications/clt/Anniversaries_2008-9.pdf] 


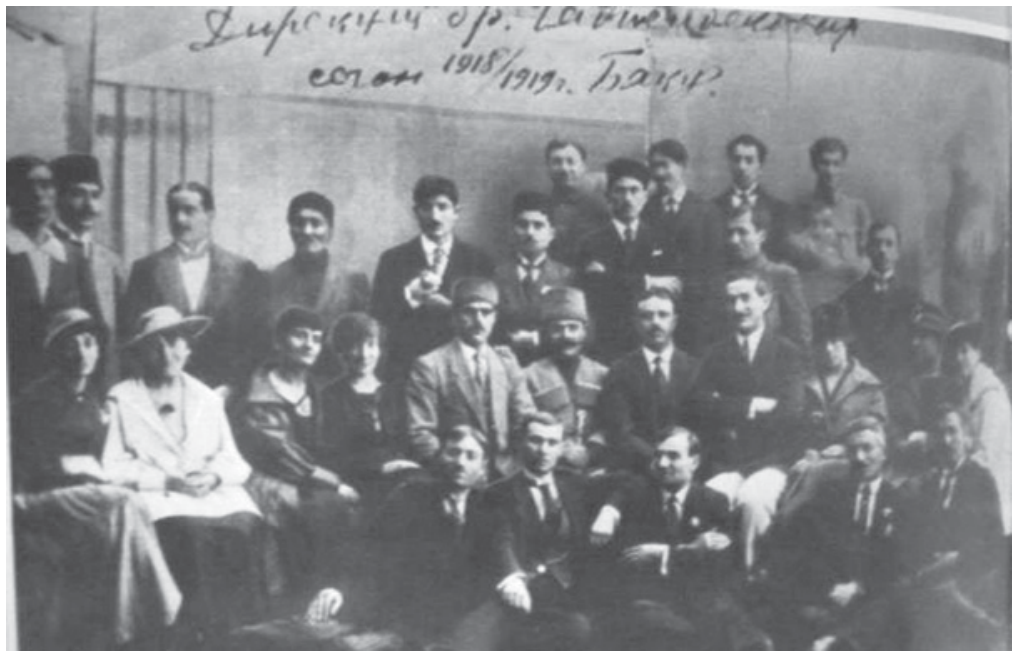

ILL. 9. La troupe de théâtre des frères Hajibeyov ( Archives filmiques et photographiques, Administration générale des archives de la république d’Azerbaïdjan.

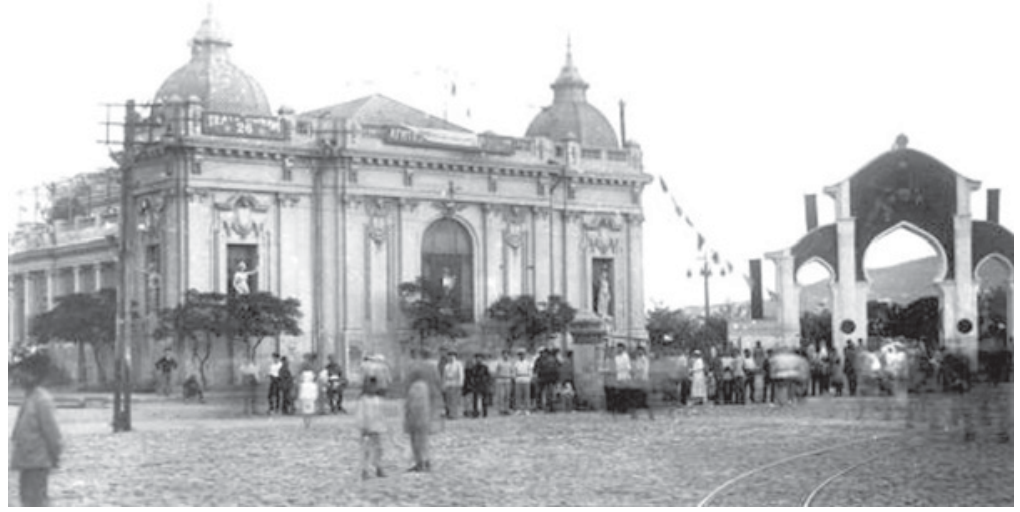

ILL. 10. Le théâtre Phénomène (aujourd'hui Théâtre de marionnettes) 〔 Archives filmiques et photographiques, Administration générale des archives de la république d'Azerbaïdjan. 
La première performance théâtrale en azéri, tirée d'une pièce de M.F. Akhundov, Le Vizir du khanat de Lankaran, fut jouée à Bakou en 1873. À Bakou et à Shusha (Karabakh), on joua de nombreuses pièces de G. Vezirov et Akhundov, dont la représentation avait jusqu'alors été empêchée par des mollahs et des croyants fanatiques qui voyaient dans le théâtre un ennemi du canon islamique et un péché importé par les Européens.

En dépit de tous ces obstacles, on continua de donner des représentations, et la première troupe professionnelle d'acteurs, "la Troupe de théâtre musulmane ", fut formée en 1897. Ils jouèrent des pièces azerbaïdjanaises, russes et des classiques européens (Shakespeare, Molière, Schiller). En 1919, sous la première république d'Azerbaïdjan, fut fondé le Théâtre national d'Azerbaïdjan ${ }^{35}$. Le théâtre Mailov était lui aussi actif, on y joua des pièces russes et arméniennes. De célèbres artistes russes et étrangers passèrent en tournée à Bakou. En 1904, par exemple, la danseuse américaine Isadora Duncan effectua une représentation dans la ville à l'occasion de sa tournée russe.

La période fut également marquée par un essor sans précédent de la presse: près de soixante journaux et périodiques en diverses langues paraissaient à Bakou. Selon l'historien A. Benningsen, entre 1875 et février 1917, 172 titres musulmans étaient imprimés et circulaient dans l'Empire russe, dont plus de $66 \%$ en langues azéri et $\operatorname{tatar}^{36}$.

Des journaux russes comme " La Caspienne " et " Bakou " ainsi que des imprimés tels que "Le Caucase " ou "La Nouvelle Revue", publiés à Tbilissi, faisaient paraître des textes de membres de l'élite progressiste locale formée en Russie, tels que A.M. Topchibashev, E. Sultanov, M.E. Rasulzade, G. Minasazov, S. Mehmandarov, F. Kocharli et autres ${ }^{37}$. Grâce à cela, un vaste lectorat russophone put prendre connaissance des difficultés rencontrées par le pays et par

35. . A. A. Alieva, Azerbajdžanskij teatr za 100 let. Azerb. Gos. Izd-vo, 1974, p. 35. 36. . A. Benningsen, Pečat'i nacional'noe dviženie russkih musul'man do 1920 goda, traduit du français par S. M. Poljakov, Bakou 1971, p. 7, p. 49-50, p. 58.

37. Zakavkaz'e, 10 avril 1907, et 16 septembre.1908. 


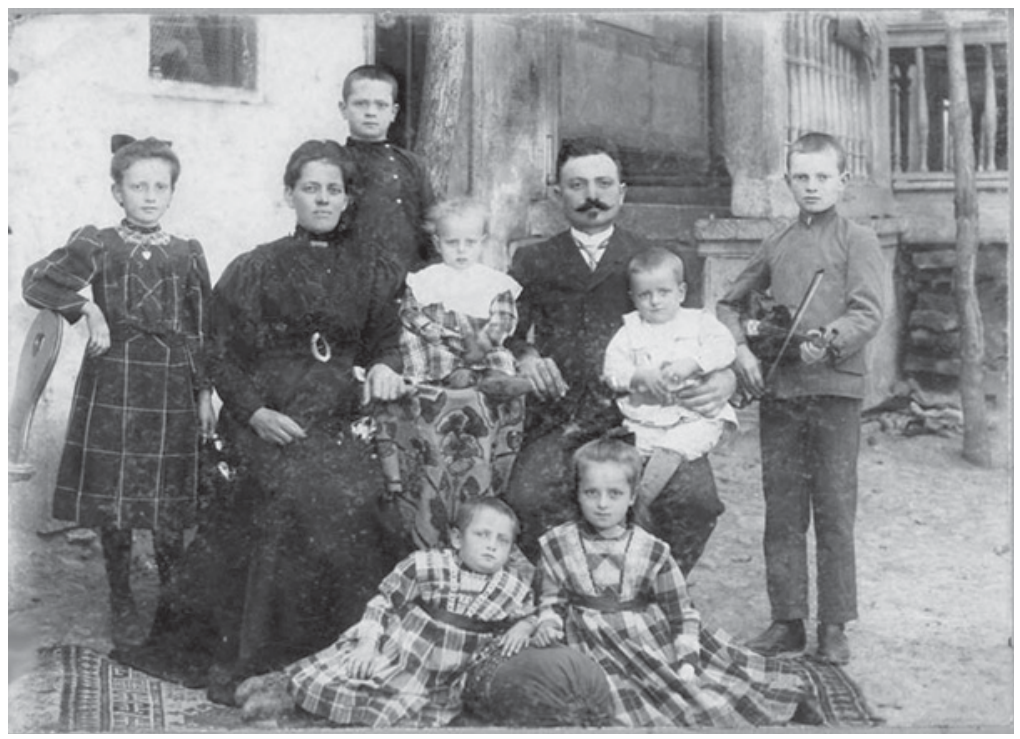

ILL. 11. Famille allemande à Elenendorf, 1910. $D R$.

les nations musulmanes en général, et eut accès à la diversité culturelle et historique du pays.

Le visage multinational de Bakou ne se limitait pas à trois groupes ethniques principaux. Allemands, Polonais, Juifs, Estoniens, Lituaniens et autres y tenaient des maisons de commerce et des œuvres de bienfaisance. Les Allemands qui s'installèrent en Azerbaïdjan au début du $\mathrm{xIx}^{\mathrm{e}}$ siècle sur ordre du tsar jouèrent notamment un rôle fondamental dans le développement de l'industrie locale. Ils se distinguèrent tout particulièrement dans les domaines du vin et des fonderies de cuivre. Les vins produits par les maisons Forer Frères et Hummel Frères remportèrent de nombreux prix lors d'expositions universelles, leurs champagnes alimentant les cours russes et européennes. À la fin du XIX siècle, le célèbre groupe électrotechnique Siemens construisit une fonderie de cuivre à Kedabek. Par ailleurs, les Allemands contribuèrent grandement au développement de la science et de la culture azerbaïdjanaises. Ils furent les premiers à se lancer dans des recherches archéologiques; le célèbre archéologue Y. Gummel publia plusieurs articles et créa 


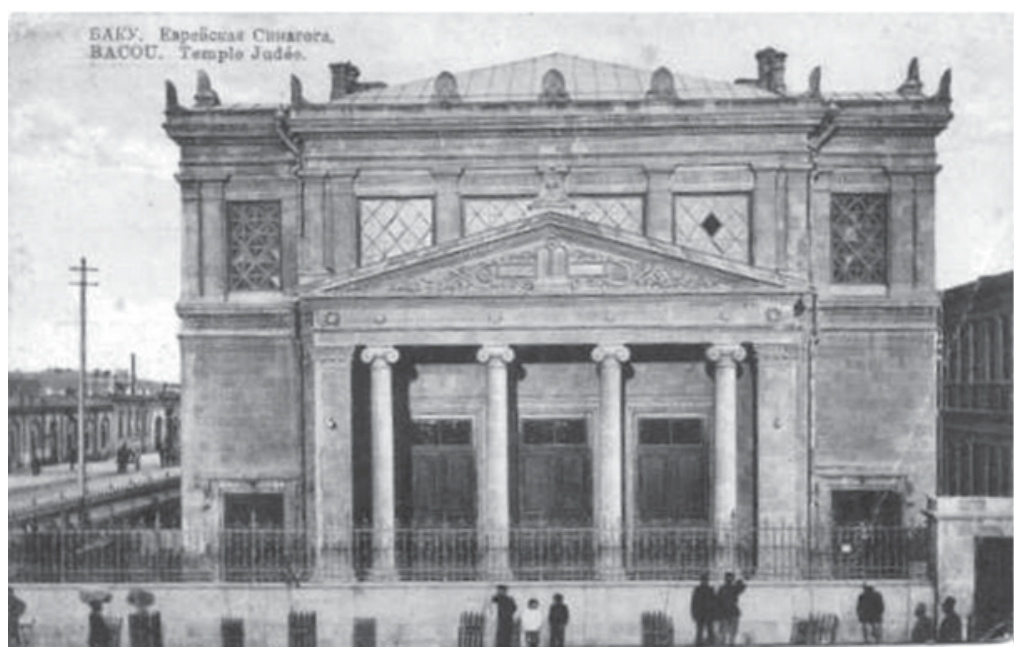

ILL. 12. Synagogue à Bakou. DR.

un musée d'histoire locale dans la colonie allemande d'Elenendorf (aujourd'hui Shamkir).

V. Abih, membre de l'Académie des sciences de Russie et Emil Lenz, un physicien qui avait étudié les causes des fluctuations du niveau de la Caspienne ${ }^{38}$, participèrent tous deux de manière décisive à importer la science géologique en Azerbaïdjan. Les Allemands apportèrent par ailleurs des contributions importantes à l'architecture de Bakou: le plus célèbre d'entre eux, N.A. von der Nonne, architecte et ingénieur militaire, fut maire de la ville entre 1889 et 1902 et dessina à cette occasion un plan de la ville. Le Centre culturel allemand joua également un rôle fondamental; on lui doit l'église luthérienne située au cœur de la ville.

$\mathrm{Au}$ début du $\mathrm{xx}^{\mathrm{e}}$ siècle, d'importantes populations juives rejoignirent le sud du Caucase après les massacres de Kichinev et de Belostok. Beaucoup s'installèrent à Bakou, centre industriel et culturel. Ils participèrent de manière active à la vie locale et créèrent des

38. S. A. Vengerov, « German Vil'gel'movič Abih », Kritiko biografičeskij slovar'russkih pisatelej i učennyh (ot načala russkoj obrazovannosti do naščih dnej). — Sankt Peterburg, Semenovskaja Tipo-Litografija (I. Efrona), 1889, p. 8-11; È. H. Lenc, Russkij biografičeskij slovar' A. A. Polovceva, Sankt Peterburg, 1896-1913, p. 192-194. 
organisations publiques et politiques, parmi lesquels le Parti travailliste social-démocrate juif de Bakou — Poalei Zion (« les Travailleurs de Sion $»)$-, le Bund ou encore l'organisation sioniste-socialiste ${ }^{39}$. Kadima, une association culturelle et d'éducation à caractère sioniste, était elle aussi active: elle visait à promouvoir l'art national auprès des autorités locales. Elle organisait aussi des conférences sur " l'histoire palestinienne et le sionisme ${ }^{40}$ ".

En 1908-1909, des œuvres de bienfaisance lituanienne et estonienne regroupant des représentants de ces pays virent aussi le jour à Bakou.

\section{Après 1917}

Après la révolution de février 1917 qui renversa la monarchie des Romanov, la vie culturelle et sociale de Bakou connut un nouvel élan.

Le 6 mars, l'un des premiers actes du nouveau gouvernement fut d'abolir toutes les restrictions religieuses et nationales pour les citoyens résidant en Russie. Cette nouvelle déclencha l'enthousiasme des citoyens non russes, qui virent là l'espoir d'obtenir la pleine reconnaissance de leurs droits civiques et politiques sous le nouveau système démocratique. À côté des autorités locales, des conseils et des comités nationaux se formèrent à Bakou et à Elisavetpol (aujourd'hui Gandja), ainsi que dans bien d'autres villes russes. Dans la deuxième moitié du mois de mars, on créa un Conseil national arménien: parmi ses cinquante membres, dix-sept étaient des représentants du parti Dashnaktsyutun ${ }^{41}$. Celui-ci eut un impact important sur la communauté arménienne: il publiait le journal Arev et possédait des représentants au gouvernement provisoire et au soviet des députés ouvriers de Bakou.

Le 21 mars fut créé le Conseil national juif, composé de plusieurs membres du Bund, de la jeunesse juive et de la communauté juive.

39. I. S. Bagirov, Političeskie partii i organizacii Azerbajdžana v načale XX veka. Baku, Èlm, 1997, p. 287.

40. Kaspij, 21 janvier et 8 septembrev1906.

41. Ibid., 18 mars 1917. 
En mars 1922, des Ukrainiens se réunirent et décidèrent de former un groupe national appelé la "Gromada ukrainienne de Bakou ». La disposition principale concernait la structure de l'Ukraine et l'établissement des principes à suivre pour favoriser le meilleur développement national, culturel et politique du pays. Il fut également décidé que le groupe harmoniserait ses activités avec la Rada centrale d'Ukraine ${ }^{42}$.

En mars 1926 se tint à Balakhani une réunion d'ouvriers tatars de Kazan, qui décidèrent de créer une organisation spéciale dont la mission serait de diffuser auprès du prolétariat tatar les idéaux démocratiques en vue des élections à l'Assemblée constituante ${ }^{43}$.

Les conseils et organisations créés à cette époque se caractérisent tous par une même loyauté envers les nouvelles autorités, leurs revendications se limitant à quelques principes fondamentaux d'autonomie culturelle et nationale. Le Comité des organisations non gouvernementales musulmanes, qui réunissait des personnalités azerbaïdjanaises ${ }^{44}$, joua un rôle important dans la société locale en tant qu'une des premières institutions du gouvernement national créé en mars.

Le gouvernement de la République démocratique d'Azerbaïdjan, formé en 1918 et renversé par les troupes soviétiques en 1920, continua de mener une politique de tolérance et de soutien inconditionnel à toutes les cultures et à toutes les ethnies. Ainsi, par exemple, en dépit des événements sanglants de mars 1918, quand les bolcheviques massacrèrent près de 10000 Azerbaïdjanais à Bakou avec le soutien de la Dachnak (Fédération révolutionnaire arménienne), toutes les nationalités vivant en Azerbaïdjan, y compris les Arméniens, étaient représentées au parlement réuni en décembre 1918.

Le roman de Kurban Saïd, Ali et Nino, qui relate les événements tragiques de la période et symbolise les échanges réciproques entre Orient et Occident, représente un phénomène culturel exceptionnel. En 1937, ce roman, qui retrace l'histoire de Bakou au début du

42. Ibid., 24 mars 1917.

43. «Baku », 29 mars 1917.

44. I. S. Baghirova, ibid., p. 317. 
siècle, fut publié en allemand en Autriche. Situé au Caucase et en Iran, il raconte une histoire d'amour entre deux jeunes gens: Ali Khan Shirvanshir, Azerbaïdjanais et musulman, et Nino Kipiani, Géorgienne et chrétienne. Le roman décrit en détails la vie des différentes nationalités à Bakou sur fond historique: la Première Guerre mondiale, la guerre civile et les événements de mars 1918, l'arrivée de l'armée britannique, la création de la République démocratique d'Azerbaïdjan, l'occupation de Bakou par les bolchéviques et l'élimination des centres de résistance nationale.

Le destin de l'auteur de ce roman qui connut plus de cent rééditions et fut traduit en trente-trois langues est encore plus intéressant. Sa véritable identité est encore un mystère, Kurban Saïd n'étant qu'un pseudonyme. Pour de nombreux chercheurs, il s'agirait de l'écrivain azerbaïdjanais et homme politique Yusif Vazir Chamanzaminli, dont la vie correspond étrangement à celle du personnage principal du roman. D'autres avancent le nom de Lev Nussimbaum, un écrivain allemand d'origine juive, fils d'un magnat du pétrole de Bakou ${ }^{45}$. Enfin, d'autres attribuent la paternité de cette œuvre à la baronne E. Erenfelds Bodmerskhof, à laquelle on trouve associé le pseudonyme de Kurban Saïd dans un catalogue d'éditeur allemand datant de 1935-193946.

Le roman prend notamment pour thème la confrontation et l'interaction, dans le Caucase, entre l'Occident et l'Orient, l'Asie et l'Europe, l'islam et la chrétienté, autant de cultures à la fois différentes et semblables.

Tous les événements et catastrophes du début du xxe siècle contribuèrent à façonner l'image multiethnique et cosmopolite de Bakou. La révolution industrielle et le boom pétrolier transformèrent la petite ville provinciale en une métropole diversifiée. Cette évolution était en grande partie liée à l'influence réciproque des cultures

45. Č. Gusejnov, Kto že avtor «Ali i Nin? Roman o nacii «Bakincev polon tajn i zagadkov ", in " Eho », 2004, 9 octobre, n 196.

46. L. Ehrenfels, « Ali \& Nino »// «Azerbaijan International ", 2004, p. 10, p. 14-15; A. Nariskaja, Roman odnogo neizvestnogo, in Kommersant $n^{\circ} 43$ (89), 2008, 07, 11. 
musulmane et chrétienne, qui participèrent à l'essor de Bakou et l'auront fait accéder à une place de choix parmi les villes les plus développées et les plus prospères tout au long des transformations politiques et socio-culturelles du $\mathrm{xx}^{\mathrm{e}}$ et du début du XxI ${ }^{\mathrm{e}}$ siècle.

(Traduit de l'anglais par Camille Joseph) 


\title{
Tbilissi, centre d'échanges interculturels
}

\author{
$D u X I X^{e}$ siècle au début du XX siècle \\ Nino Chikovani
}

Tbilissi (Tiflis jusqu'à 1935), la capitale de la Géorgie, aura été au cours de sa longue histoire un lieu privilégié de rencontres et d'échanges entre différentes cultures. Le présent article traite de l'une des périodes les plus intéressantes à ce sujet. Lorsque, au début du XIX ${ }^{\mathrm{e}}$ siècle, l'Empire russe établit sa domination sur le Caucase, Tbilissi devint un centre politique officiel au rayonnement régional. Dans la seconde moitié du $\mathrm{XIX}^{\mathrm{e}}$ siècle, des changements politiques et économiques importants s'accompagnèrent d'une modification significative de la composition ethnique et religieuse de la ville, de son activité culturelle et du mode de vie de ses habitants.

Pendant des siècles, Tbilissi fut un lieu de mélange de différents groupes ethniques et religieux (à l'instar de bien d'autres agglomérations du même type) plutôt qu'une ville véritablement géorgienne, à l'entendre d'un point de vue ethnique. Nul besoin de remonter loin dans le passé; il y a quelques dizaines d'années encore, les habitants des " cours urbaines " (souvent appelées " cours à l'italienne », elles ont aujourd'hui presque disparu du paysage urbain) parlaient plusieurs langues couramment. Les familles mixtes, d'un point de vue ethnique ou religieux, n'étaient pas rares. Ceux qui arrivent dans ce genre de villes, que certains chercheurs qualifient de " cosmopoles", sont susceptibles de s'intégrer, au moins de façon temporaire, dans un endogroupe - en l'occurrence celui des Tbilissiens. Ce phénomène se produit sans qu'aucune politique d'assi- 
milation soit nécessaire, grâce à la force d'intégration inhérente à ces villes ${ }^{1}$. Tbilissi eut ainsi la capacité de fondre les diverses influences extérieures et de les transformer en caractère propre - en d'autres termes le " mode de vie tbilissien ", la « sous-culture tbilissienne ${ }^{2}$. Elle resta en même temps une ville véritablement géorgienne, bien que le peuple géorgien ne fût pas majoritaire au sein de sa population ${ }^{3}$. Une éternité durant, jusqu'au XIX ${ }^{\mathrm{e}}$ siècle, Tbilissi apparut comme la seule ville digne de ce nom aux yeux des Géorgiens ${ }^{4}$, qui l'appelaient d'ailleurs tout simplement « la ville ${ }^{5}$.

Tbilissi était un centre politique et culturel non seulement pour les Géorgiens, mais aussi pour d'autres peuples caucasiens, comme les Azéris ou les Arméniens. Un groupe de chercheurs évoque un " cosmopolitisme multiculturel " pour décrire la réalité culturelle de cette ville ${ }^{6}$

Le but de cet article est d'étudier le processus de transformation et d'évolution de ce " cosmopolitisme multiculturel » tout au long du $\mathrm{XIX}^{\mathrm{e}}$ et jusqu'au début du Xx $\mathrm{x}^{\mathrm{e}}$ siècle.

\section{Le contexte historique}

La fin du royaume géorgien de Kartli-Kakhétie en 1801 marqua le commencement d'un processus d'annexion par l'Empire russe

1. Zaal Andronikashvili, Tbilissi cosmopolite (en géorgien), Tbilissi, Edition of the Institute of Tolerance and Diversity, 2015, p. 227.

2. R. Revaz Gachechiladze, "Tbilissi au début du $\mathrm{xx}^{\mathrm{e}}$ siècle ", in Tbilissi à l'ère des changements. Dimensions socio-culturelles de l'espace urbain et urbanisme (en géorgien), Tbilissi, Tbilissi University Press, 2010, p. 77.

3. Jozeph Salukvadze, "Tbilissi au croisement de l'histoire et des cultures ", in Tbilissi à l'ère des changements. Dimensions socio-culturelles de l'espace urbain et urbanisme (en géorgien), Tbilissi, Tbilissi University Press, 2010, p. 11.

4. Revaz Gachechiladze, "Tbilissi au début du xxe siècle ", in Tbilissi à l'ère des changements. Dimensions socio-culturelles de l'espace urbain et urbanisme (en géorgien) , op. cit., p. 10.

5. Ronald G. Suny, « Tbilissi in the Russian Empire: On the Ethnic, Social and Class Composition of the Population ", in Tbilissi in the Era of Changes. Sociocultural Dimensions of Urban Space and City Planning, Tbilissi, Tbilissi University Press, 2010, p. 43.

6. Ibid., p. 40. 
de l'ensemble des principautés et royaumes géorgiens, qui devait aboutir dans les années 1860. Au cours de cette période, la société géorgienne se modifia en profondeur. La noblesse géorgienne développa une réelle loyauté envers les nouveaux gouvernants - après une période marquée par les rébellions et les complots antitsaristes, dans les premières décennies du XIX ${ }^{\mathrm{e}}$ siècle. L'échec de la conspiration de 1832 affecta profondément leurs sentiments nationalistes. De nombreux nobles géorgiens se mirent au service de l'État ou de l'armée tsariste et « trouvèrent des accommodements confortables avec la domination russe ${ }^{7}$ ».

L'administration russe " encourageait le patriotisme aristocratique tout en limitant l'autonomie des nobles locaux ». Privés des postes qui leur étaient traditionnellement dévolus, ils étaient invités à entrer au service de l'État. Cette politique avait pour objectif, d'une part, d'accroître l'efficacité de l'administration caucasienne en recrutant des individus loyaux qui connaissaient les langues et les particularités de la région, d'autre part, de subordonner au pouvoir central, de façon directe et stricte, les anciens détenteurs de l'autorité ${ }^{8}$.

Pendant toute la première moitié du XIX ${ }^{\mathrm{e}}$ siècle, Tbilissi resta inchangée sous bien des aspects. Les commerçants et les artisans étaient organisés en corporations. Ces deux groupes, très diversifiés sur le plan ethnique et religieux, constituaient avec les citoyens (mokalakeni) et l'aristocratie de la ville les principales catégories sociales de la capitale ${ }^{9}$. L'établissement de l'armée et de l'administration russes provoqua une hausse non négligeable de la demande en certains produits, notamment agricoles et artisanaux. Le nombre d'artisans russes et européens s'accrut, répondant aux besoins d'une clientèle qui adhérait au mode de vie européen et prenait peu à peu une place prédominante dans la ville ${ }^{10}$.

7. Stephen F. Jones, Socialism in Georgian Colors. The European Road to Social Democracy, 1883-1917, Harvard University Press, 2005, p. 6.

8. Ronald G. Suny, The Making of the Georgian Nation, Indiana University Press, Hoover Institution Press, 1988, p. 68.

9. Essais sur l'histoire de la Géorgie (en géorgien), vol. 5, Tbilissi, Sabchotasakartvelo, 1970, p. 107.

10. Shota Meskhia, David Gvritishvili, Mamia Dumbadze, Akaki Surguladze, Histoire de Tbilissi (en géorgien), Tbilissi, Sakhelmcipogamomcemloba, 1958, p. 385-386, 401. 
Entre 1821 et 1865, la population de Tbilissi passa de 15374 à 67770 habitants (5,6 \% de la population totale de la Géorgie ${ }^{11}$ ). Les statistiques révèlent que cette augmentation fut principalement due à l'arrivée de paysans de Géorgie orientale, de travailleurs venus de différentes régions de Transcaucasie et de Perse, et de migrants russes originaires des provinces intérieures de l'empire ${ }^{12}$. Le territoire de Tbilissi s'étendit, incorporant les banlieues. Des constructions d'un nouveau style — logements et bâtiments administratifs — apparurent. Se posa alors concrètement la question de l'organisation du développement de la ville ${ }^{13}$ : malgré un demi-siècle d'occupation russe, la vie à Tbilissi n'avait pas encore beaucoup changé.

Le règne du vice-roi du Caucase Mikhaïl Vorontsov (1845-1854), à l'impressionnant parcours militaire et civil, marqua un tournant à cet égard. Comme l'écrit Stephen Jones, «Vorontsov, qui était un administrateur intelligent, a " européanisé » la société géorgienne. [...] L'empire promettait stabilité, protection, puissance et civilisation, que ce soit sous la forme de salles de bal ou de livres. [...] Les anciens conspirateurs qui avaient été châtiés voyaient ces avantages d'un bon œil. $»^{14}$

Vorontsov lança un plan de développement de la ville à long terme. Tbilissi devint une cité avenante dotée d'avantages manifestement européens. Les citoyens aisés se déplacèrent en calèches, les costumes nationaux s'effacèrent au profit de la mode européenne, les vieux meubles rustiques furent remplacés par d'autres plus confortables, le chuniri et la zurna (des instruments de musique traditionnels de Géorgie et d'Orient) disparurent au profit du piano, parfois du piano à queue ${ }^{15}$.

À la même époque, un système éducatif fut mis en place dans le Caucase, avec la création de nouvelles écoles, de l'élémentaire au

11. Essais sur l'histoire de la Géorgie (en géorgien), vol. 5, Tbilissi, Sabchotasakartvelo, 1970, p. 109-110.

12. Ibid., p. 112-113.

13. Shota Meskhia et al., Histoire de Tbilissi (en géorgien), op. cit., p. 396.

14. Stephen F. Jones, Socialism in Georgian Colors. The European Road to Social Democracy, 1883-1917, p. 8.

15. Shota Meskhia et al., History of Tbilissi, op. cit., p. 409. 
collège. Chaque année, à partir de 1849, 160 étudiants caucasiens se virent octroyer une bourse leur permettant d'étudier dans une université russe. Des journaux furent créés; une bibliothèque et un théâtre russe ouvrirent leurs portes. Si tous ces efforts avaient pour but de diffuser la langue russe et de renforcer l'influence de l'empire, ils contribuèrent indirectement à l'enrichissement culturel de la ville. Certains faubourgs anciens furent incorporés à Tbilissi; de nouveaux bâtiments furent construits - demeures d'aristocrates et de riches marchands ou édifices publics.

Les réformes menées au cours des années 1860, notamment les réformes agraires, bouleversèrent la vie économique de la Géorgie. Les liens économiques entre les différentes parties du pays se renforcèrent, ce qui mit fin à leur isolement et posa les fondations nécessaires à l'émergence d'une conscience nationale commune. Le tout nouveau réseau ferroviaire relia l'ouest et l'est du pays; la première ligne (Tiflis-Poti) fut achevée en 1872. Un embranchement vers Koutaïssi fut ouvert en 1877, et Batoumi fut reliée au réseau en 1883. L’apparition du chemin de fer fut un événement de première importance qui entraîna l'intensification des flux migratoires entre les différentes régions du pays. Des villages géorgiens isolés, jadis autosuffisants et n'ayant que peu de contacts avec les villes, s'ouvrirent les uns aux autres ${ }^{16}$.

Certains nobles géorgiens ne parvinrent pas à se montrer à la hauteur de ces nouveaux défis et virent leur statut économique et politique se détériorer rapidement. En quête d'une vie meilleure, ils migrèrent vers les villes, en particulier Tiflis/Tbilissi, pour devenir fonctionnaires ou entamer une carrière politique. Leurs domaines passèrent aux mains de riches marchands ou de paysans fortunés. En même temps que la noblesse, une partie de la paysannerie émancipée dans le cadre de la réforme agraire de 1864 vint s'installer en ville, à la recherche d'une solution aux problèmes économiques causés par son nouveau statut. Dans les villes, les Géorgiens issus de différentes catégories sociales se trouvèrent confrontés à une classe moyenne urbaine, bien enracinée et financièrement stable, sans homogénéité ethnique; ses membres ne parlaient pas la même

16. Ronald G. Suny, The Making of the Georgian Nation, p. 122. 
langue, appartenaient à différentes confessions, ne partageaient pas les mêmes valeurs. Les différences culturelles et linguistiques renforçaient les distinctions sociales entre classes ${ }^{17}$.

Entre 1886 et 1897, la population de Tbilissi (Tiflis) augmenta de $103 \%$. C'était alors une ville majoritairement peuplée d'immigrants: en 1897, seuls $43,7 \%$ des habitants y étaient nés et y avaient grandi ${ }^{18}$. Les pourcentages respectifs de représentation des différents groupes ethniques au sein de la population se stabilisèrent peu à peu, mais le statut économique et politique du peuple géorgien resta fragile ${ }^{19}$ : les Russes contrôlaient la sphère administrative, tandis que la bourgeoisie arménienne dominait l'économie et s'efforçait de prendre le contrôle de la gestion de la ville ${ }^{20}$.

Comme l'explique Stephen Jones, l'Empire russe, par sa volonté de modernisation, a créé des conditions plus favorables au développement de la Géorgie: l'émergence d'une élite intellectuelle locale, l'alphabétisation croissante de la population, l'urbanisation, l'amélioration des communications entre les villes et les villages et l'établissement de relations avec l'Europe ont largement contribué à ce processus ${ }^{21}$.

\section{Une histoire d'amour entre l'Asie et l'Europe}

$\mathrm{Au}$ début du XIX ${ }^{\mathrm{e}}$ siècle, la vie à Tbilissi était ponctuée de jours fériés, de fêtes et de jeux publics qui interrompaient fréquemment le rythme de la semaine de travail ${ }^{22}$; on n'y faisait guère plus que jouer aux cartes, s'affronter dans des concours de lutte et boire. En quelques décennies, "d'un coin perdu aux confins de l'Asie, [...] Tiflis devint un centre urbain où les aristocrates géorgiens

17. Ibid., p. 116.

18. Stephen F. Jones, Socialism in Georgian Colors. The European Road to Social Democracy, 1883-1917, op. cit., p. 25.

19. Ronald G. Suny, op. cit., p. 116.

20. Essays in the History of Georgia, vol. 5, p. 700.

21. Stephen F. Jones, "Georgia: The Long Battle for Independence ", in Nationalism and the Breakup of an Empire: Russia and its Periphery, éd. par M. Rezum, Westport, Praeger Press, 1992, p. 80.

22. Ronald G. Suny, op. cit., p. 90-91. 
lisaient les journaux européens, se mêlaient au monde littéraire russe et faisaient parader leurs épouses vêtues à la dernière mode française $^{23}$ ». Dès la fin des années 1850, l'âme géorgienne avait donc perdu sa coloration asiatique ${ }^{24}$.

Deux missionnaires américains qui se rendirent en Géorgie en 1830 furent impressionnés par la diversité des habitants de Tbilissi, qui parlaient des langues différentes, portaient des costumes variés et représentaient de nombreuses nationalités: Russes, Arméniens de l'Empire ottoman, religieux géorgiens et arméniens, marchands arméniens originaires de différentes villes, paysans géorgiens, Laks, Persans, Circassiens ${ }^{25}$.

Alexandre Dumas, qui visita la Géorgie à la fin des années 1850, décrit ainsi la partie asiatique de la ville

Le principal caravansérail de Tiflis a été bâti par un Arménien [...]. C'est un spectacle curieux que la vue de ce caravansérail, par toutes les portes duquel entrent [...] des députations de toutes les nations de l'Orient et de l'Europe du Nord. Turcs, Arméniens, Persans, Arabes, Hindous, Chinois, Kalmouks, Turkomans, Tatars, Tcherkesses, Géorgiens, Mingréliens, Sibériens, que sais-je, moi! Chacun avec son type, son costume, ses armes, son caractère, sa physionomie [...]. À ces bazars, se rattache le réseau des rues commerciales, complètement séparé du quartier aristocratique. Chacune de ces rues est affectée à un genre d'industrie. Je ne sais pas comment ces rues s'appellent à Tiflis, je ne sais pas même si elles ont des noms; mais, pour moi, elles n'en peuvent porter d'autres que la rue des Orfèvres, [...] la rue des Armuriers, la rue des Fruitiers, [...] la rue des Tailleurs, la rue des Cordonniers, et je dirai même la rue des Babouchiers et des Pantoufliers. [...] Rien de plus curieux qu'un voyage à travers ces rues: l'étranger ne s'en lasse pas ${ }^{26}$.

Tbilissi s'est agrandie tout au long du XIX ${ }^{e}$ siècle. Les édifices, tout en conservant une allure orientale, témoignaient d'une forte

23. Stephen F. Jones, Socialism in Georgian Colors. The European Road to Social Democracy, 1883-1917, op. cit., p. 6.

24. Ibid., p. 33.

25. Ronald G. Suny, « Tbilissi in the Russian Empire: On the Ethnic, Social and Class Composition of the Population ", p. 42.

26. Alexandre Dumas, Le Caucase (en géorgien), Tbilissi, Merani, 1988, p. 168 (Le Caucase, Paris, Librairie théâtrale, 1859). 
influence de l'architecture européenne. « Meidan — la place située dans la partie orientale de la ville - , le marché, les corporations tout cela est d'origine iranienne; en revanche, le réseau ferroviaire et les quartiers ouvriers construits récemment dans la partie occidentale évoquent une ville européenne industrielle typique ${ }^{27}$. "

Parmi ces bâtiments, qui ont disparu aujourd'hui mais ont longtemps joué un rôle essentiel dans la ville, se trouvait un pont reliant depuis le $\mathrm{Xv}^{\mathrm{e}}$ siècle les deux rives de la Koura: le pont Kakheti. Il se détériora avec le temps et ne fut reconstruit qu'en 1851 par les Russes Gagemeister et Rais. La traversée était alors soumise à une taxe. Au bout d'un an, un citoyen de Tbilissi, le commerçant Ivane Mnatsakanov, acheta l'ouvrage pour la somme de 25000 roubles et en fit cadeau à la ville. La taxe fut donc supprimée. Le pont et la rue adjacente furent rebaptisés du nom de Mnatsakanov. Trente ans plus tard, le pont en bois fut remplacé par un ouvrage en fer. Il fut finalement détruit dans les années 1950, suite à la reconstruction de l'ensemble du quartier ${ }^{28}$.

À la place de l'actuel Jardin botanique de Tbilissi, se trouvait un cimetière musulman appelé Gorkhana ( "la maison des tombes » en persan). Durant la période soviétique, il fut en grande partie nivelé par les tracteurs; la mosquée qui se trouvait à proximité fut également détruite. Seules quelques tombes de personnalités furent conservées, puis érigées en panthéon, parmi lesquelles les tombeaux de Mirza Chafi Vazekh, Mirza Fatali Akhoundov et Fatali Khan Khoisel (Khoyski), l'un des fondateurs de la République démocratique d'Azerbaïdjan dont il fut premier ministre ${ }^{29}$. En 2006, la fondation Heydar Aliyev a restauré ces pierres tombales et leur entourage, ainsi que les tombes d'autres grandes figures azéries inhumées dans le panthéon ${ }^{30}$. Le lieu est bien entretenu aujourd'hui.

27. Ronald G. Suny, « Tbilissi in the Russian Empire: On the Ethnic, Social and Class Composition of the Population ", op. cit., p. 43.

28. Alexandre Elisashvili, Comment Tbilissi s'est transformée (en géorgien), Tbilissi, Bakur Sulakauri, 2013, p. 11.

29. Ibid., p. 17.

30. Restauration des tombeaux d'Azéris éminents à Tbilissi: http://heydar-aliyevfoundation.org/en/content/view (date d'accès 24 septembre 2016). 
De la deuxième moitié du XIX ${ }^{\mathrm{e}}$ siècle aux années 1920, le cimetière catholique, accompagné d'une petite église et d'un clocher, se trouvait dans le quartier Sololaki, là où se croisent aujourd'hui la rue Chonqadze et la rue Gergeti. Le cimetière et le bâtiment dédiés à la Dormition de la Vierge - étaient au centre d'un terrain appartenant à la confrérie Notre-Dame du Rosaire, sous l'autorité de l'Église catholique romaine de Tbilissi. Les catholiques géorgiens - les familles Andronikashvili, Zubalashvili, Tumanishvili, Djakeli, Chikovani, Mizandari et bien d'autres - y possédaient des tombeaux familiaux. On trouvait aussi dans le cimetière une magnifique roseraie, composée de plantes rapportées d'Inde et de la ville de Chiraz par le lieutenant-colonel Monsini, un ingénieur militaire anglais. Le cimetière fut détruit par les bolcheviques dans les années 1920 et remplacé par des logements et des bâtiments officiels ${ }^{31}$.

Une mosquée chiite se dressait près du pont de Métékhi. Bien que bâtie par le shah de Perse Ismaill, les Tbilissiens l'appelaient la mosquée du shah Abbas ou la Mosquée bleue (en raison des incrustations qui ornaient son dôme et son minaret). Elle fut détruite en 1950-1951, sous le prétexte de la reconstruction du pont de Métékhi. Aujourd'hui, seuls quelques vestiges des incrustations de l'édifice sont conservés au Musée national des beaux-arts de Géorgie; le minbar - chaire en bois - a également survécu ${ }^{32}$. De nos jours, Tbilissi ne possède plus qu'une mosquée, sunnite, où sunnites et chiites prient ensemble.

Certains bâtiments publics furent conçus et édifiés par des architectes européens; la plupart d'entre eux restent aujourd'hui encore emblématiques de la ville. En 1835, à la demande de Jacob Zubalashvili, l'architecte suisse Bernadotte construisit le Palace Hotel dans le style néoclassique, très populaire en Russie à l'époque. Le bâtiment abrita d'abord un hôtel, puis un séminaire après avoir été racheté par l'exarchat en 1840. Ce séminaire occupa l'édifice jusqu'en 1905. En 1917, ce dernier retrouva sa fonction première et le Palace Hotel rouvrit ses portes. Il resta en service après l'établissement du pouvoir soviétique en 1921, et ce jusqu'en 1950. Le

31. Alexandre Elisashvili, Comment Tbilissi s'est transformée (en géorgien), p. 65.

32. Ibid., p. 21. 
bâtiment fut alors reconstruit pour accueillir, à partir de 1952, le Musée des beaux-arts de Géorgie, également connu sous le nom de Musée Shalva Amiranashvili ${ }^{33}$.

$\mathrm{Au}$ début du XIX ${ }^{\mathrm{e}}$ siècle, un bâtiment de deux étages destiné à accueillir le chef de la police fut construit sur la place de la Liberté, à l'emplacement de l'actuel hôtel de ville. Une tour de surveillance des incendies y fut ajoutée, puis l'édifice subit une restauration complète entre 1882 et 1886, à l'initiative du maire de l'époque, Alexandre Matinov, et sous la direction de l'architecte Alexandre Ozerov. Un étage supplémentaire fut ajouté, et la tour de guet devint le beffroi de l'hôtel de ville. Le bâtiment arbore depuis 1884 la principale horloge de la ville. Il fut reconstruit et agrandi jusqu'à revêtir son aspect actuel ${ }^{34}$.

Dans les années 1840, le vice-roi Mikhaïl Vorontsov prit la décision d'ériger un opéra italien à Tbilissi, au milieu de l'actuelle place de la Liberté. Construit sur trois niveaux sur le modèle d'un caravansérail, le bâtiment accueillerait l'opéra aux premier et deuxième étages, tandis que le rez-de-chaussée abriterait des magasins. Vorontsov sollicita les marchands tbilissiens pour le financement des travaux, mais un seul individu, du nom de Tamamshev, répondit à l'appel. Ce dernier finança intégralement la construction de l'opéra, qui fut réalisé entre 1847 et 1851 d'après les plans de l'architecte italien Giovanni Scudieri; c'est le célèbre peintre russe Gagarine qui peignit le rideau. Cet édifice impressionnant attirait le regard des passants. Les opéras italiens devinrent familiers pour le public tbilissien; on entendait les enfants chanter des mélodies italiennes dans les cours de la ville ${ }^{35}$. L'opéra devint aussi le lieu d'expression de sentiments nationalistes. En 1867, des élèves du lycée classique agitèrent le drapeau royal géorgien dans l'orchestre. L'administration russe interdit alors les opéras italiens, remplacés par des opéras russes, mais elle dut rapidement revenir sur sa décision. En octobre 1874,

33. Sur le séminaire théologique, voir le Laboratoire d'étude du passé soviétique: http://sovlab.ge/ka/node/362 (date d'accès 24 septembre 2016).

34. Alexandre Elisashvili, Comment Tbilissi s'est transformée (en géorgien), op. cit., p. 72.

35. Shota Meskhia et al., Histoire de Tbilissi (en géorgien), p. 441. 
au cours d'une représentation de la Norma, un incendie fut intentionnellement déclenché dans l'un des magasins du bâtiment, qui brûla entièrement. Aujourd'hui, les pavés de la place de la Liberté recouvrent les fondations - qui subsistent - de l'opéra ${ }^{36}$.

En 1895, l'architecte allemand Paul Stern, à la demande du prince d'Oldenbourg, construisit un palais sur le territoire occupé par les colons allemands: il s'agit de l'actuel Musée de théâtre, de musique, de cinéma et de danse.

L'architecte polonais Alexandre Shimkevich, architecte en chef de Tbilissi de 1885 à 1891 et élu au conseil de la ville à plusieurs reprises, construisit le palais de justice en 1894. En 1905-1906, il enseigna l'architecture et la peinture à l'école des beaux-arts de Tbilissi. Le palais de justice abrite aujourd'hui la Cour suprême de Géorgie.

Shimkevich a également conçu le bâtiment de la Société artistique, aidé par Korneli Tatishchev, ingénieur en chef de la province. La construction s'effectua entre 1898 et 1901, grâce au soutien financier de la maison de commerce Isaya Pitoev. Depuis l'époque de la République démocratique de Géorgie, l'édifice est occupé par le théâtre national Roustavéli ${ }^{37}$.

En 1892, on inaugura dans ce que l'on appelait alors le « Nouveau Jardin " (l'actuelle place de la Liberté) la statue d'Alexandre Pouchkine. C'est Niko Nikoladzé, un représentant de la deuxième génération du mouvement des Tergdaleuli, qui organisa une levée de fonds pour l'érection du monument et suggéra de rebaptiser du nom de l'écrivain russe la rue où il avait vécu lors de son séjour à Tbilissi. Le sculpteur polonais Felix Khodorovich réalisa la sculpture, tandis qu'un maçon italien répondant au nom de "Vinchentso Pileji », qui vivait à Tbilissi à l'époque, construisit le piédestal. Cette statue est aujourd'hui le plus ancien monument de la ville (elle a ravi ce titre à la statue de Mikhaïl Vorontsov érigée en 1867 et détruite par les bolcheviques) ${ }^{38}$.

36. Ibid., p. 77.

37. Revaz Gachechiladze, "Tbilissi au début du $\mathrm{xx}^{\mathrm{e}}$ siècle ", in Tbilissi à l'ère des changements. Dimensions socio-culturelles de l'espace urbain et urbanisme (en géorgien), p. 80.

38. Alexandre Elisashvili, Comment Tbilissi s'est transformée (en géorgien), op. cit., p. 80. 
En 1910 fut inauguré un hôpital financé par le marchand arménien Mikhail Aramyants; l'établissement s'appelle d'ailleurs toujours l'hôpital Aramyants. Le commerçant finança également la construction de l'hôtel Majestic. Celle-ci commença en 1911 d'après les plans de l'architecte russe Alexandre Ozerov, qui travaillait à Tbilissi à l'époque, et s'acheva en 1915 sous la direction de l'architecte tbilissien Gabriel Ter-Melikov. De nos jours, le bâtiment est l'hôtel Tbilissi Marriott ${ }^{39}$.

Le bâtiment de la Banque de la Noblesse fut érigé entre 1913 et 1916 d'après les plans de l'architecte Anatoly Kalgin et du peintre Hainrich Hrinevski. Le décor de la façade est l'œuvre de Neofite, Vladimer et Lavrenti Agladzé. L'édifice héberge aujourd'hui la Bibliothèque nationale parlementaire de Géorgie.

Tbilissi disposait des infrastructures les plus développées de toutes les villes du Caucase. D'après L'Agenda du Caucase ( "Kavkazskijkalendar” » de 1913, elle comptait une institution privée d'enseignement supérieur, des programmes d'études supérieures destinés aux femmes, cinq lycées pour garçons et cinq lycées pour filles. Au total, on dénombrait cent cinquante établissements d'enseignement différents. La majeure partie des journaux et des revues du nord et du sud du Caucase étaient imprimés à Tbilissi, dont dixneuf en russe, dix en arménien, six en géorgien, deux en azéri et un en allemand. On trouvait en ville cinq théâtres, huit cinémas, dix hôpitaux, environ vingt pharmacies, trente-sept hôtels et des dizaines de banques et de compagnies d'assurance. S'ajoutaient à cela dix bibliothèques publiques, des églises orthodoxes, arméniennes, catholiques et luthériennes, deux synagogues et deux mosquées. La ville était équipée d'un réseau téléphonique et, depuis 1904, desservie par un tramway ${ }^{40}$. Au début du $\mathrm{xx}^{\mathrm{e}}$ siècle, Tbilissi comptait environ six cents usines et manufactures produisant du textile, des allumettes, du tabac, de la maroquinerie ou encore de la bière.

39. Revaz Gachechiladze, "Tbilissi au début du $\mathrm{xx}^{\mathrm{e}}$ siècle ", in Tbilissi à l'ère des changements. Dimensions socio-culturelles de l'espace urbain et urbanisme (en géorgien), p. 79.

40. Ibid., p. 75. 


\section{Les Caucasiens à Tbilissi}

De nombreuses personnalités d'origines caucasiennes diverses se sont illustrées en Géorgie. En 1861, l'Histoire du peuple adyguéen de Shora Nogmov, premier historien kabarde, fut publiée à Tbilissi. Le célèbre penseur ossète Ioane Ialghuzisdze-Gabaraev (1770-1830) fut chargé d'enseignement spirituel auprès de la famille royale d'Héraclius II et de Georges XII. Professeur et missionnaire actif, il maîtrisait le géorgien, l'ossète et le russe. En 1802, il recréa un alphabet ossète en s'appuyant sur la graphie géorgienne; celui-ci fut utilisé aussi bien par les Ossètes du sud du Caucase que par ceux du nord. Ialghuzisdze traduisit des ouvrages liturgiques du géorgien à l'ossète et joua un rôle essentiel dans la christianisation des Ossètes du sud du Caucase. Quant à l'écrivain géorgien Daniel Chonqadze (1830-1860), il élabora des dictionnaires géorgien-ossète et ossètegéorgien, publiés plus tard par Shiffner.

Dans les années 1900, les Ossètes commencèrent à développer leur propre centre culturel national à Tbilissi. En 1906, des Tbilissiens ossètes fondèrent la Société d'édition ossète. Giorgi Jioti et Vaso Tsabaiti en furent des membres actifs. La maison d'édition Ir fut fondée la même année à Vladikavkaz et à Tbilissi.

La société mentionnée ci-dessus créa une troupe théâtrale ossète, qui donna des représentations jusque dans les années 1980. Les dirigeants de la société émirent plusieurs requêtes auprès du gouvernement pour créer un journal ossète; ils obtinrent finalement la permission en 1907 (le 13 février). Le 6 mars de la même année, le premier journal ossète de Tbilissi, Nog Tsard (« Nouvelle Vie) » fut publié (il s'agissait du deuxième journal en langue ossète de l'histoire, le premier, Iron Gazet (" Le journal ossète »), ayant été publié à Vladikavkaz en 1906). Avant même la publication du premier numéro, le journal géorgien Isari annonçait: « À partir de début mars, il sera possible de s'abonner à Nog Tsard, le journal ossète de Tbilissi qui paraîtra deux fois par semaine. " Le premier numéro fut tiré à 400 exemplaires; le tirage atteignit ensuite les 1800 exemplaires. Petre Tedeti en fut le premier rédacteur en chef, et Gaioz Tskhvrbat lui succéda. Les journaux et magazines publiés à Tbilissi proposaient des textes d'écrivains ossètes en version originale, 
y compris ceux qui étaient censurés ou qu'il était impossible de publier à Vladikavkaz ${ }^{41}$. En 1913, un établissement d'enseignement secondaire destiné aux jeunes Ossètes ouvrit ses portes à Tbilissi ${ }^{42}$.

$\mathrm{Au} \mathrm{XIX}^{\mathrm{e}}$ siècle, Tbilissi était un centre important de la vie culturelle et intellectuelle azérie. Le poète, calligraphe et penseur azéri Mirza Vazekh, plus connu sous le pseudonyme de Mirza Chafi (1792/96-1852), vécut et travailla dans cette ville. Il est d'ailleurs surnommé le "Sage de Tbilissi ». Il naquit et grandit à Gandja, mais passa en 1840 l'examen de tatar du lycée de Tbilissi et commença à travailler en tant que professeur de persan et d'azéri (ou de " tatar ", pour reprendre le terme de l'époque) dans une école d'enseignement secondaire locale. Il compta parmi ses élèves un célèbre journaliste, écrivain et poète géorgien, rédacteur en chef de la revue Tsiskari, du nom d'Ivane Kereselidze. En 1844, Mirza Chafi fonda un cercle littéraire et philosophique à Tbilissi, puis retourna à Gandja au bout de deux ans pour enseigner à l'école locale. Avant son départ, il dédia à la ville l'un de ses plus célèbres poèmes, "Adieu à Tbilissi ». De retour dès 1850, il donna des cours de persan et de tatar au lycée classique et au pensionnat de Raevski et Hakke. Il rédigea un Dictionnaire tatar-russe et un Livre de lecture, et créa dans le quartier de Sololaki un jardin qu'il céda à la ville. Il mourut à Tbilissi et fut enterré à l'emplacement de l'actuel Jardin botanique ${ }^{43}$.

Certains poèmes de Mirza Chafi furent traduits en allemand par l'un de ses élèves, l'écrivain et traducteur allemand Friedrich Bodenstedt. Au cours de son séjour à Tbilissi (en 1844-1845), celui-ci suivit les cours d'azéri, de géorgien, d'arménien et de persan donnés par Mirza Chafi. Les traductions en question, regroupées sous le nom de "Chants de Chafi », furent publiées par Bodenstedt en 1851

41. David Matsaberidze et Ivane Tsereteli, « Narratifs de l'identité arménienne " in Narratifs identitaires en Géorgie: aux origines de la nation géorgienne multiethnique (1860-1918) (en géorgien), Tbilissi, 2014, p. 162-163.

42. Groupes ethniques en Géorgie (en géorgien), Tbilissi, Librairie de défense publique de la Géorgie, 2008, p. 73.

43. Eka Makharashvili, Mirza Vazeh Schaffy and Mirza Fatali Akhundov - Azerbaijani writers who were in love with Georgia, in 24saati Weekend, 27 février 2010, http://www.24hours.ge/weekend/story/3791 (date d'accès: le 22 octobre 2016). 
dans l'ouvrage Mille et un jours en Orient, qui fut par la suite traduit en de nombreuses langues, y compris en géorgien ${ }^{44}$.

L'écrivain, penseur, philosophe et dramaturge azéri Mirza Fatali Akhoundov (1812-1878) fut également l'élève de Mirza Chafi. Il passa presque la moitié de sa vie à Tbilissi et y mourut. Né à Shaki (Nukha), il reçut une éducation perso-arabe traditionnelle. Il commença à travailler à Tbilissi en 1834 en tant que traducteur de langues orientales à la chancellerie du vice-roi; il enseignait en même temps le turc et le persan à l'école de Tbilissi. À la chancellerie, il se lia d'amitié avec d'éminentes personnalités géorgiennes, comme Platon Ioseliani, Dimitri Khipiani et Giorgi Eristavi. Il commença à écrire dans les années 1830. La mise en scène de sa pièce Vizir de khanat de Lencorane (1873, Bakou, en azéri) marqua la naissance d'un théâtre azéri professionnel. Akaki Tsereteli, qui avait étudié l'azéri à l'université de Saint-Pétersbourg, traduisit la pièce d'Akhoundov en géorgien (Mirza Fatali Akhoundov était l'un de ses auteurs favoris). La traduction d'Akaki Tsereteli fut publiée en 1898 dans la revue Krebuli sous le titre Vizir de khanat et jouée sur la scène géorgienne la même année. Akaki Tsereteli écrivit en 1898 dans le journal Tsnobis Purceli:

Cette pièce fut composée par l'écrivain tatar Mirza Fatali Akhoundov, dont l'œuvre est traduite en plusieurs langues. Ses écrits sont parvenus jusqu'aux écrivains russes, et le critique littéraire Apollon Grigoriev [...] l'a alors comparé à Molière. Comme nous, Géorgiens, ne connaissons ni cet auteur ni le mode de vie de nos voisins les Tatars, j'ai décidé de traduire l'une des pièces d'Akhoundov, Vizir de khanat $^{45}$.

C'est à Tbilissi que les comédies d'Akhoundov furent publiées pour la première fois, en russe et en azéri. L'homme de lettres avait pour amis proches de célèbres poètes et hommes publics géorgiens, dont Alexandre Tchavtchavadzé et Grigol Orbéliani. Ce dernier joua

44. Friedrich M. Bodenstedt, One Thousand and one Days in the East, traduction anglaise abrégée de l'allemand, lettre d'introduction d'Akaki Gelovani, Tbilissi, Sabchotasakartvelo, 1965.

45. Levan Bregadze, Mirza Schaffy Vazeh, Friedrich M. Bodenstedt, in Enlightement in Georgia. Ideas and Personalities, http://nateba.net/index.php/biographies/251 (date d'accès: le22 octobre 2016). 
un rôle crucial dans la décision d'inhumer Akhoundov à l'emplacement de l'actuel Jardin botanique, alors que les dirigeants de la ville refusaient de l'enterrer dans le cimetière musulman ou à proximité.

Le célèbre penseur, écrivain et historien azéri Abbasgoulou agha Bakikhanov passa plusieurs années à Tbilissi, où il exerça les fonctions de traducteur et d'interprète au sein de la chancellerie du général Iermolov. C'est là qu'il se lia d'amitié avec Alexandre Tchavtchavadzé, Nikoloz Baratachvili et Grigol Orbéliani, ainsi qu'avec d'autres écrivains et hommes célèbres russes et arméniens ${ }^{46}$.

Des revues azéries furent publiées à Tbilissi à partir du début du $\mathrm{xx}^{\mathrm{e}}$ siècle; il s'agissait de publications satiriques, Mulla Nasreddin (publiée à partir de 1906 par Jalil Mamed-Guli-Zadeh) et Tartan-Phartan. Le gouvernement interdit la publication de Mulla Nasreddin à plusieurs reprises, en raison de son contenu critique. L'écrivain allemand Arthur Leist, qui vivait et travaillait à Tbilissi à l'époque, s'exprima en faveur de la revue. En 1908, il rédigea une lettre ouverte dans laquelle il commenta: "Ce qui fut accepté sans contestation pendant des siècles, ce que seuls les sages comme Mirza Chafi critiquaient, ce qui était tu et caché, tout cela fut dénoncé par Mulla Nasreddin au moyen des mots et de la caricature, avec force et brio, faisant rire certains et rendant les autres fous de colère ${ }^{47}$. "

Des Arméniens célèbres résidèrent à Tbilissi, et plusieurs journaux arméniens y furent publiés, comme Mshak, Nordar et Horizon, pour n'en nommer que quelques-uns. La ville comptait également plusieurs écoles arméniennes.

Hovhannes Toumanian naquit en 1869 dans le district de Lorri et mourut le 23 mars 1923 à Moscou. Il fréquenta l'école de son village, puis se rendit à Tbilissi afin de poursuivre au séminaire de Nersès des études qu'il dut interrompre pour des raisons financières. Dès 1886, il prit part activement aux cercles littéraires de la ville, écrivant des poèmes, des contes, des récits, des allégories et des ballades. Toumanian consacra de nombreuses œuvres à la Géorgie et à ses amis géorgiens (notamment "Réconciliation ", " De la Géorgie ",

46. Shota Meskhia et al., Histoire de Tbilissi (en géorgien), p. 442.

47. Levan Bregadze, Mirza Schaffy Vazeh, Friedrich M. Bodenstedt. 
"L’âme de la Géorgie » et " Aux poètes géorgiens »). Le célèbre poète géorgien Titsian Tabidze écrivit à son sujet:

Les Géorgiens étaient convaincus de la sincérité de Hovhannes Toumanian, et les célébrations dont il fut l'objet à Tbilissi le prouvent. Son patriotisme ne l'a jamais empêché d'être Géorgien de cœur. [...] L'influence qu'avait Hovhannes Toumanian sur son peuple est comparable à celle d’Ilia Tchavtchavadzé. [...] Il entretenait des relations privilégiées avec les poètes géorgiens, assistait à leurs discours publics et faisait l'éloge de leurs œuvres. [...] Il ne manquait jamais les anniversaires et autres événements en leur honneur, auxquels il se présentait toujours avec un discours écrit d'avance. Il recevait souvent chez lui des poètes musulmans. Il était aimé de tous ${ }^{48}$.

L'écrivain arménien Gabriel Sundukyan était aussi très populaire à Tbilissi. Sa pièce Pepo, écrite en 1871, fut jouée au théâtre géorgien en 1875; l'année suivante, elle fut publiée en géorgien dans le journal Droeba (1876), puis dans un ouvrage autonome en 1880. Gabriel Sundukyan (1825-1912) passa sa vie à Tbilissi. Il étudia dans différents lycées et pensionnats, sortit diplômé de la faculté d'histoire et de philologie de l'université de Saint-Pétersbourg, puis rejoignit la chancellerie du vice-roi à Tbilissi. Il prit par la suite la direction de la division spéciale en charge des routes du Caucase et reçut le grade de colonel civil. Il fut très actif au sein du conseil municipal. Sundukyan commença sa carrière littéraire dans les années 1860 et resta très lié au théâtre arménien, dont il fut l'un des fondateurs. Il écrivit sur le dialecte géorgien de la langue arménienne, qui contenait de nombreux mots et expressions issus du géorgien. Les références au folklore géorgien sont fréquentes dans ses textes, et il traduisit ses propres œuvres du géorgien en arménien ${ }^{49}$.

Khatchatour Abovian (1805-1848), qui est considéré comme le fondateur de la littérature arménienne moderne et de la langue littéraire arménienne, a lui aussi vécu et travaillé à Tbilissi. Il étudia au séminaire de Nersès avant d'occuper un poste de responsable dans une école de 1837 à $1843^{50}$. Arfiar Arfiaryan (1852-1908), écri-

48. Titsian Tabidze, Hovhaness Tumanyan, http://litklubi.ge/biblioteka/viewnawarmoebi (accès le 22 octobre 2016).

49. Essays on the History of Georgia, vol. 5, p. 836.

50. Gevork Abov, Hačatur Abovjan: žizn’ i tvorčestvo, Erevan, 1948. 
vain et militant arménien influent, compte également parmi les résidents célèbres de la ville géorgienne; correspondant du journal Mshak à Constantinople pendant la guerre russo-turque de 1877-1878, il écrivit pendant trente ans sur l'actualité politique et culturelle des Arméniens de l'ouest. L'écrivain, professeur et homme public arménien Ghazaros Aghayan (1840-1911) naquit et mourut à Tbilissi; il enseigna à Tbilissi et en Arménie, et rédigea un manuel d'arménien. Michael Hovhannisyan, mieux connu sous le pseudonyme de Nar-Dos (1867-1933), fut un autre habitant de Tbilissi; il obtint le statut d'écrivain du peuple pendant la période soviétique ${ }^{51}$. Alexandre Movsesyan (1858-1935), connu sous le nom de plume de Shirvanzade, œuvra à Tbilissi à partir de 1883. Il vécut à Paris de 1905 à 1910, puis revint à Tbilissi de 1910 à 1919. Il émigra de nouveau par la suite, avant son retour en Arménie soviétique en 1926. Il fut nommé écrivain du peuple d'Arménie et d'Azerbaïdjan pendant la période soviétique ${ }^{52}$.

La vie et l'œuvre du penseur et essayiste arménien Grigor Artsruni (1845-1952) sont particulièrement intéressantes. Son grandpère fut déporté de Turquie en Géorgie en 1813; son père, un colonel de l'armée russe, occupa pendant deux ans (1866-1868) un poste à la tête du conseil municipal de Tbilissi. Né à Moscou et diplômé du lycée classique de Tbilissi, Grigor Artsruni fit ses études dans de prestigieuses universités européennes. En 1872, il fonda à Tbilissi le journal politique et littéraire Mshak ("Le Travailleur »), publié jusqu'en 1920. Mshak joua un rôle fondamental dans l'émergence d'une identité nationale arménienne ${ }^{53}$. Comme le remarque G. Suny, ce journal remettait sérieusement en cause le conservatisme traditionnel et religieux de la bourgeoisie arménienne ${ }^{54}$. Les opposants à Artsruni lui reprochaient son cosmopolitisme et l'accusaient de nier les spécificités de la nation arménienne. Artsruni avait pour

51. Essays in the History of Georgia, vol. 5, p. 835.

52. Hrach Tamrazyan, Shirvan-Zade, Moskva, Sovetskipisatel, 1967.

53. Pour plus de détails, voir chap. 3 de Identity Narratives in Georgia: at the Origins of Multiethnic Georgian Nation (1860-1918), Tbilissi, 2014.

54. Ronald G. Suny, Tbilissi in the Russian Empire: On the Ethnic, Social and Class Composition of the Population, p. 57. 
amis proches de célèbres Géorgiens: Ilia Tchavtchavadzé, Akaki Tsereteli, Giorgi Tsereteli, Ivane Machabeli et Alexandre Jabadari. En 1879, suite à l'appel des dirigeants du théâtre géorgien, Grigor Artsruni aménagea une partie de son caravansérail (qui se trouvait à l'emplacement actuel du théâtre Griboïedov) qu'il mit à disposition de la troupe de façon permanente. Le célèbre dramaturge Avksenti Tsagareli se souvient des importants privilèges financiers accordés par Artsruni à la troupe, et du soutien pécuniaire qu'il apportait aux $\operatorname{artistes}^{55}$.

Tbilissi faisait office de centre des recherches scientifiques menées dans le Caucase. En 1851, la branche caucasienne de la Société russe de géographie s’y établit. En 1864, fut créée une commission archéologique qui publia les Actes de la Commission archéologique caucasienne en douze volumes, rassemblant des informations d'une importance capitale sur l'histoire du Caucase ${ }^{56}$.

Le Musée du Caucase de Tbilissi ouvrit en 1862. Un Comité archéologique du Caucase fut fondé peu après, transformé en 1873 en Société des amateurs d'archéologie ${ }^{57}$. Les jeunes intellectuels géorgiens participaient activement à la vie de ces sociétés.

Il fut décidé en 1878 que le cinquième congrès archéologique russe se tiendrait dans la ville géorgienne. Le comité d'organisation fut présidé par l'historien géorgien Dimitri Bakradze, qui fit lors du congrès une intervention sur la paléographie géorgienne. Le congrès, qui s'ouvrit le 3 septembre 1883, fut un événement considérable dans la vie scientifique du Caucase ${ }^{58}$.

L'expérience de la vie urbaine contribua grandement à la compréhension des différences ethniques, religieuses et culturelles et à leur expression politique sous la forme de nationalismes. À partir de la deuxième moitié du XIX ${ }^{e}$ siècle, une nouvelle génération d'intellectuels géorgiens émergea. De retour dans leur pays natal après avoir

55. Levan Bregadze, Grigor Artsruni, in Enlightement in Georgia. Ideas and Personalities, http://nateba.net/index.php/biographies/251 (date d'accès: le 22 octobre 2016).

56. Shota Meskhia et al., Histoire de Tbilissi (en géorgien), p. 444.

57. Ibid., p. 445.

58. Ibid., p. 446. 
fréquenté les universités russes, ils introduisirent auprès du public géorgien les idées des penseurs européens et russes et participèrent à la création d'un nouveau cadre politique et culturel propice au développement de la société géorgienne.

"Selon les théoriciens modernistes du nationalisme, ce sont les intellectuels qui, en employant une rhétorique nationaliste, sont les principaux agents de sa propagation. Ils sont les créateurs non seulement de la nation, mais aussi du discours et des modes d'expression universels permettant la création de cette nation ${ }^{59}$ ". Ils jouent un rôle essentiel dans l'émergence de la conscience nationale, dans la propagation des valeurs communes, dans la création de liens entre les individus et dans la définition des caractéristiques et des frontières de la nation. Les intellectuels effectuent " un travail d'idéologie et d'imagination, qui consiste à rassembler des éléments culturels disparates, des souvenirs historiques choisis et des interprétations, tout en oblitérant ce qui gêne et ce qui manque d'héroïsme ${ }^{60}$. " "Ce sont les philologues, les historiens, les poètes, les romanciers, les professeurs et les journalistes qui sont les plus influents à cet égard ${ }^{61}$. "

Les jeunes intellectuels géorgiens des années 1860-1870 étaient appelés les Tergdaleulebi ("Ceux qui ont bu l'eau du Térek », fleuve qui marque la frontière traditionnelle entre la Géorgie et la Russie). Ils définirent les contours et les principales orientations du projet national géorgien. La première phase de formation du nationalisme telle que l'a théorisée Miroslav Hroch décrit leurs activités à la perfection: lutte pour la formation d'une identité culturelle, réforme de la langue et intérêt grandissant pour l'histoire nationale.

Le langage, la patrie et le rapport au passé et à l'histoire étaient au cœur du projet national. L'histoire était considérée comme un outil essentiel à la consolidation de la nation. Un nouveau langage public et démocratique, compréhensible par tous, se développa;

59. Michael D. Kennedy et Ronald G. Suny, Introduction, in Intellectuals and the Articulation of the Nation, éd. par Ronald Grigor Suny et Michael D. Kennedy, Ann Arbor, University of Michigan Press, 2001, p. 2-3.

60. Ibid.

61. Ronald G. Suny, The Making of the Georgian Nation, p. 123. 
il fut promu en tant que nouveau langage standard par les revues et les journaux géorgiens (Iveria, Matsne, Droeba...), les écoles publiques, les théâtres, les bibliothèques et des associations telles que la Société d'alphabétisation de Géorgie ou la Société d'histoire et d'ethnographie.

Le principal défi des fondateurs du projet national géorgien était de parvenir à s'autodéfinir en délimitant les frontières de leur endogroupe, tout en s'efforçant d'éviter la tentation du narcissisme ethnique et de gagner le respect des autres nations. Citons Vaja Pchavéla, poète et penseur renommé qui appartenait à cette génération:

Certains pensent que le véritable patriotisme exclut le cosmopolitisme. Ils se trompent. [...] En apprenant à respecter leurs propres traditions, les nations œuvrent chacune de leur côté pour la force et la beauté collectives du monde dans son ensemble. [...] Celui qui prétend ressentir un amour égal pour chaque nation est un menteur. [...] Le patriotisme naît des sentiments plutôt que de l'esprit; le cosmopolitisme, quant à lui, est une affaire intellectuelle. [...] Soyez à l'écoute des besoins de votre pays, de la sagesse de votre peuple, consacrezvous à son bien-être, n'éprouvez aucune haine pour les autres nations et n'enviez pas leur bonheur, n'empêchez pas les autres nations d'atteindre leurs buts. Euvrez pour le jour où votre nation ne pliera plus sous aucun joug, pour la faire avancer jusqu'à ce qu'elle égale celles qui dominent le monde ${ }^{62}$.

L'action des Tergdaleulebi permit de renforcer la société géorgienne. Différentes parties du pays étaient désormais réunies par l'idée d'une nation géorgienne qui, bien qu'encore divisée, formait une entité à part entière. En tant que Géorgiens, les membres des différentes catégories sociales partageaient une identité commune plus fondamentale que tout autre sentiment d'appartenance ${ }^{63}$.

62. Vaja Pshavela, "Cosmopolitisme et patriotisme ", in Euvres (en géorgien), Tbilissi, 1986, p. 41; pour la traduction anglaise, voir V. Pshavela, et R. R. Gould, "Cosmopolitanism and Patriotism ", in Asymptote, University of Bristol, oct. 2016, http://research-information.bristol.ac.uk/files/90452374/Cosmopolitanism_and_ Patriotism_Asymptote.pdf

63. Levan Gigineishvili, " Post- reform History Textbooks in Georgia: Changing Patterns and the Issue of Minorities in Georgian History ", in History Teaching in Georgia: Representation of Minorities in Georgian History Textbooks, CIMERA, Genève, 2007, p. 8. 
Un processus similaire se déroula au sein d'autres groupes ethniques. À force d'être constamment confrontés les uns aux autres, ils ressentirent le besoin de s'autodéfinir. Selon Ronald Suny, Tbilissi fut le berceau non seulement du nationalisme géorgien, mais aussi du nationalisme arménien ${ }^{64}$. Les journaux arméniens publiés à Tbilissi, en particulier le Mshak de Grigor Artsruni, jouèrent un rôle essentiel dans la définition de l'identité arménienne et dans la construction du projet national arménien. Comme pour les nationalistes géorgiens, la langue, la patrie et la religion constituaient des questions centrales pour les intellectuels arméniens qui collaboraient à $M s h a k^{65}$. Quant aux Azéris, qui ont participé activement à la vie culturelle de Tbilissi, ils ne manifestèrent aucun signe de mobilisation nationaliste, ne firent preuve d'aucun militantisme économique ou politique pendant cette période.

Dans les villes, des Caucasiens d'origines diverses étaient en contact permanent à la fois avec d'autres membres de leur peuple et avec des étrangers; c'est ainsi qu'un processus d'identification fondé sur les notions d'ethnie et de nation s'enclencha au sein des différents peuples. Leurs membres prirent toute la mesure des liens qui existaient entre eux, tout en s'éloignant de ceux qui ne partageaient ni leur langue ni leurs coutumes. L'élite intellectuelle émergente, influencée par les idées occidentales, fit sienne l'idée nouvelle de nation $^{66}$ et s'engagea dans la construction concrète de nouvelles entités nationales.

Une fois passées sous domination soviétique, en raison du caractère complexe et contradictoire de la politique soviétique à l'égard des nations, les républiques du sud du Caucase devinrent plus homogènes. Si l'on examine les récits géorgien, arménien et azéri des périodes soviétique et postsoviétique, on voit que l'histoire et la

64. Ronald G. Suny, « Tbilissi in the Russian Empire: On the Ethnic, Social and Class Composition of the Population ", p. 40.

65. Pour une analyse plus détaillée de la question, voir Marieta Bazinyan, "Constructing a Nation: Identity Markers of Armenians (According to the "Mshak" Periodical Published during 1872-1892) ", in Analytical Bulletin 8, Erevan, 2015, p. 67-80.

66. Ronald G. Suny, « Tbilissi in the Russian Empire: On the Ethnic, Social and Class Composition of the Population », p. 42. 
culture du peuple en question sont à chaque fois mises en valeur et dissociées de celles des autres peuples, au point de négliger certains éléments communs. Et pourtant, si l'on en croit Ronald Suny, même à une époque où les nationalismes triomphent, la palette colorée que composait il n'y a pas si longtemps la population cosmopolite de la ville devient source de nostalgie ${ }^{67}$.

(Traduit de l'anglais par Pauline Tardieu-Collinet)

67. Ibid., p. 71-72. 



\section{QUATRIÈME PARTIE}

ÉCHOS LITTÉRAIRES 



\title{
Les écrits de Friedrich Bodenstedt sur le Caucase
}

\author{
Un regard sur la diversité ethnique \\ et culturelle de la région
}

Hamlet Isaxanli

$\mathrm{Au}$ fil des siècles, les toponymes acquièrent une complexité qui dépasse largement leur fonction originelle d'assignation géographique. C'est le cas de "Caucase ». Au départ, les mots "Caucase » ou "Grand Caucase " désignaient simplement la chaîne de montagnes qui s'étend de la mer Noire à la Caspienne. Ensuite, ce sont les terres au nord et au sud de ces montagnes (entre les deux mers, donc) qu'on a appelées « Caucase ».

Cette région se compose, au nord des montagnes du Grand Caucase, de provinces autonomes russes (ce qu'on appelle le district fédéral du Caucase du Nord), et, au sud, de l'Azerbaïdjan, de l'Arménie et de la Géorgie, regroupés sous l'appellation "Caucase du Sud ", ou encore "Transcaucasie». Ce dernier nom est tout sauf neutre, puisqu'il reflète le point de vue russe, et est traduit du mot russe Zakafkazija. Les chaînes de montagne du Caucase du Sud sont appelées « Petit Caucase ». Certains auteurs préfèrent appeler le Caucase du Sud "Caucase central ", dans la mesure où ils estiment que l'appellation "Caucase du Sud » devrait être réservée à certaines provinces turques et iraniennes à la frontière du Caucase central. Dans cette perspective, le "Grand Caucase " inclut non seulement l'Azerbaïdjan, l'Arménie et la Géorgie mais aussi des provinces voisines russes, turques et iraniennes. 
Le Caucase est également traversé par la frontière qui sépare l'Europe et l'Asie, même si le tracé exact de celle-ci n'a jamais été clairement établi. Doit-on considérer que c'est la chaîne du Grand Caucase qui tient lieu de frontière, ou bien la dépression de KoumaManytch, au nord? La question de savoir si le sud du Caucase (Azerbaïdjan, Géorgie, Arménie) fait partie ou non de l'Europe est laissée en suspens par les accords récents. On peut penser au livre de Kurban Said, Ali et Nino, et à la comparaison qu'il effectue entre Europe et Asie. Même s'il a pu exister, à certaines époques, une fédération du Caucase, celle-ci a toujours été éphémère. En revanche, le Caucase a de tout temps été un lieu de tension où s'opposaient plusieurs puissances voisines. En particulier, ce fut le cas de l'Empire romain, puis l'Empire byzantin (à l'ouest), contre la Perse (au sud). À cette opposition succéda celle entre les Turcs (au nord) et le califat islamique (au sud). Puis, vinrent les Ottomans (à l'ouest), l'Iran (au sud) et la Russie (au nord). Beaucoup d'empires se sont efforcés de conquérir le Caucase et d'y asseoir leur domination. La région est déjà présente dans les récits mythologiques grecs, turcs et caucasiens. En réalité, on trouve des Caucasiens dans le monde entier: "Caucasien » désigne une "race ", aussi appelée " europoïde ». Le terme est apparu en allemand à la fin du XviII ${ }^{\mathrm{e}}$ siècle pour désigner un habitant du Caucase du Sud ou du Caucase en général, lequel servait d'archétype à l'Européen. Aux États-Unis, on utilise le mot " caucasien " pour parler des Blancs en général. Le Caucase est une région multiethnique, multiculturelle, plurilingue, qui est l'une des plus riches du monde en termes de diversité culturelle et naturelle. À ce titre, elle est un petit paradis pour les chercheurs qui s'intéressent aux questions culturelles. La longue histoire du Caucase inclut des périodes de coexistence harmonieuse entre des nations capables de coopérer sur les plans économique, politique, humain et culturel. Mais la région est aussi le lieu de nombreuses tensions internes qui ont conduit à des conflits et à des guerres (jusqu'aux conflits interethniques d'aujourd'hui, largement internationalisés) et, bien sûr, elle a été le théâtre de plusieurs guerres de conquête.

Ce sont d'abord des voyageurs individuels qui ont été à l'origine des contacts entre cultures. Ces voyageurs, se documentant sur ces régions, comparaient ensuite ce qu'ils avaient vu à leur propre 
culture, et compilaient leurs observations dans des récits de voyage. C'est ainsi que se diffusent des impressions sur des régions, des pays, des peuples, issues de perspectives variées et qui peuvent être très laudatrices, exprimer le choc ou la surprise, mais aussi de nombreux préjugés, et se révéler très critiques.

De nombreux Européens ont voyagé dans le Caucase et on leur doit un certain nombre de mémoires. Ils furent de plus en plus nombreux à partir du XvII ${ }^{\mathrm{e}}$ siècle, parmi lesquels beaucoup d'Allemands. Certains étaient des savants (historiens, archéologues, philologues, écrivains, traducteurs littéraires...); d'autres étaient diplomates, missionnaires, ou encore négociants et marchands. Leurs écrits permettent d'éclairer d'un jour nouveau l'histoire et la géographie du Caucase, ses peuples et leurs traditions, la langue et la littérature, la vie domestique et la culture. Ce sont des sources importantes pour toutes les études portant sur la région, et elles ont donné lieu à de nombreux travaux universitaires. De façon plus générale, le Caucase a été une source d'inspiration privilégiée pour des artistes de différents pays, ce qui a permis le développement de tout un corpus littéraire autour de la région.

Certains de ces voyageurs européens avaient pour destination l'Iran, et traversaient donc le Caucase, qu'ils évoquaient dans leurs écrits. D'autres, surtout au XIX ${ }^{\mathrm{e}}$ siècle, voulaient visiter la Russie et incluaient alors le Caucase dans leur itinéraire et leur champ d'investigation. Des savants et artistes russes se rendirent dans le Caucase non seulement pour leur travail, mais aussi parce qu'ils y étaient envoyés en exil (le Caucase était alors appelé « la Sibérie où il fait chaud »), ou parce qu'ils voulaient y vivre et y créer. En parallèle à la politique de russification du Caucase menée par les autorités gouvernementales, il y a eu aussi, dans une certaine mesure, une " caucasification" des Russes. Les Européens et les Russes qui visitaient le Caucase au XIX ${ }^{\mathrm{e}}$ siècle ont noué des liens avec des intellectuels et des artistes de la région, lesquels ont ensuite joué un rôle majeur dans les transferts culturels observés.

Friedrich von Bodenstedt (1819-1892), un jeune intellectuel allemand, fait partie de ces jeunes Européens invités en Russie pour $\mathrm{y}$ enseigner et qui, après y avoir vécu quelque temps, se sont rendus dans le Caucase. Là, il apprit le turc azéri, un peu de persan, 


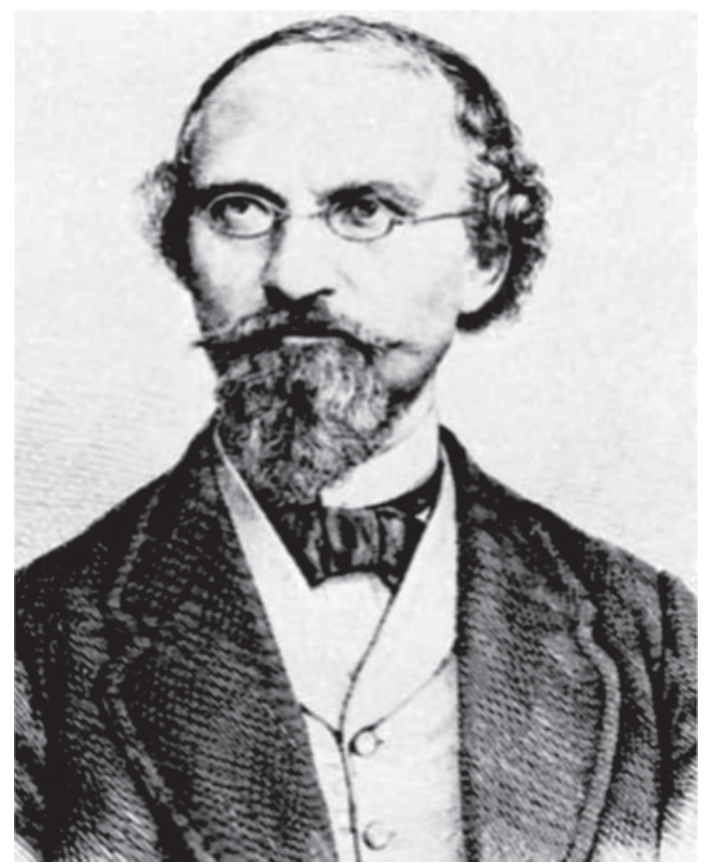

ILL. 1. Friedrich Martin von Bodenstedt. Gravure, 1876, d'après un portrait par C. Kolb (C) Archiv fur Kunst und Geschichte, Berlin

enseigna et se lança dans divers projets littéraires. À son retour en Allemagne, il écrivit de nombreux livres sur le Caucase. Une quinzaine d'années après que Bodenstedt eut quitté la région, c'est l'écrivain français Alexandre Dumas (1802-1870) qui arriva depuis la Russie, et publia ensuite ses mémoires (1858-1859), intégralement traduits en azéri en 2010.

Jusqu'ici, dans l'œuvre de Bodenstedt sur le Caucase, on s'est surtout intéressé à ce qui concernait son mentor, le poète et éducateur azéri Mirza Schaffy Vazeh (sur l'identité duquel on a beaucoup spéculé). Mais les travaux de Bodenstedt dans leur ensemble se révèlent la source la plus rigoureuse et la plus précieuse sur le Caucase, même si pour l'instant ils n'ont pas suscité suffisamment d'intérêt critique. 


\section{Friedrich Martin von Bodenstedt, une vie}

Friedrich Martin von Bodenstedt (1819-1892) est un poète, écrivain, critique littéraire, ethnographe et historien allemand ${ }^{1}$. Né à Peine, près de Hanovre, il voyagea dans de nombreux pays, mais revint toujours en Allemagne. Après avoir étudié la littérature, les langues, la philosophie et l'histoire à l'université, il se rendit en Russie à l'automne 1840 et y passa environ trois ans. Il visita d'abord Saint-Pétersbourg, puis se rendit à Moscou et plus tard dans d'autres villes russes. À Moscou, il devint précepteur auprès des deux fils du prince Mikhaill Galitzine, cousin du gouverneur général de Moscou. Il apprit le russe, fit connaissance d'Alexandre Herzen et de Lermontov. Il a laissé d'ailleurs des pages précieuses sur ses entretiens avec Lermontov ${ }^{2}$ et une correspondance avec de grands écrivains russes tels que Fiodor Tiouttchev, Léon Tolstoï, Ivan Tourgueniev et Nicolaï Nekrassov. Bodenstedt accepta une offre d'emploi à l'école normale de Tbilissi (Tifliskaja Aleksandrijskaja Gimnazija); il y fut engagé comme directeur et y enseigna également les langues et littératures occidentales. C'est entre la mi-octobre et la mi-novembre 1843 qu'il partit pour le Caucase. Il apparaît qu'au bout de quelque temps il démissionna de son poste de directeur, vraisemblablement désireux d'avoir plus de temps pour voyager, pour étudier et pour écrire. Son mentor était alors Alexandre Neidhardt, le superintendant du Caucase. On peut faire remonter leur amitié au séjour de Bodenstedt à Moscou. En tout, Bodenstedt passa environ un an et demi dans le Caucase. Il participa à la cérémonie de bienvenue du successeur de Neidhardt à Tbilissi, le vice-roi M.S. Vorontsov, en mars 1845. En avril 1845, il quitta Tbilissi (« où il

1. Ludwig Fränkel, "Bodenstedt, Friedrich », in Allgemeine Deutsche Biographie, herausgegeben von der Historischen Kommission bei der Bayerischen Akademie der Wissenschaften, vol. 47, Leipzig, 1903, p. 44 - 67, sur http://de.wikisource.org/w/ index.php?title=ADB:Bodenstedt,_Friedrich_von \& oldid = 2169072 (page consultée le 9 janvier 2015 à 14h 22 UTC); " Friedrich von Bodenstedt: Dichter, Schriftsteller und Peiner Ehenburger » ("Friedrich von Bodenstedt: poète, écrivain et citoyen d'honneur de la ville de Peine »), in Stadt Peine. Archiv Sonderblatt, $\mathrm{n}^{\circ}$ 1, 1999.

2. Sergej Romanjuk, "Poslednie pjat'moskovskih dnej poèta ", Literaturnaja gazeta, $n^{0}$ 39-6481, 8 octobre 2014. 
avait passé une période merveilleuse ${ }^{3}$ ") pour Leipzig, en longeant la côte de la mer Noire, traversant la Crimée, Istanbul (où il passa "quelques semaines agréables »), passant par la côte de la mer Égée et traversant l'Italie.

Après ce temps relativement long passé à l'étranger, Bodenstedt, de retour dans son pays natal, commença à écrire. Sa production fut prolifique et enthousiaste. Il traduisit des textes littéraires russes, anglais et persans, composa des poèmes, écrivit des nouvelles, des pièces, des études sur l'histoire et la littérature, des récits de voyage et des mémoires. Bodenstedt fut nommé représentant de l'Allemagne dans diverses réunions internationales. Au Congrès international du libre-échange, qui se tint à Paris en 1849, Victor Hugo le pria de faire un discours; Bodenstedt répondit que l'absence de drapeau allemand parmi tous ceux des pays participants l'obligeait à décliner. Hugo réfuta aussitôt l'objection: " Monsieur, vous êtes le drapeau vivant de l'Allemagne ${ }^{4}$ ! »

Bodenstedt travailla comme professeur de langues et littératures slaves, puis également de littérature anglaise, à l'université de Bavière, à Munich. Il fut également directeur de théâtre et éditeur d'un journal. D'après ses biographes, il était grand, blond, humble, un peu naïf, mais doté d'une forte confiance en lui et d'une certaine tendance à la vantardise ${ }^{5}$.

\section{Écrits de Bodenstedt sur le Caucase et les Caucasiens}

Bodenstedt se consacra d'abord à la traduction de poésie russe et ukrainienne, publiant des ouvrages en 1843 et 1845. Son premier livre consacré au Caucase, Die Völker des Kaukasus und ihre Freiheitskämpfe gegen die Russen ("Les Peuples du Caucase et leur combat pour se libérer du joug russe »), fut publié en 1848 à Francfort-sur-le-Main. C'est une œuvre ample, en deux volumes, de

3. Ludwig Fränkel, op. cit.

4. Ibid.

5. Ibid.; Friedrich von Bodenstedt: Dichter, Schriftsteller und Peiner Ehenburger, op. cit. 
572 pages, avec une introduction de seize pages incluant des informations techniques sur la publication ${ }^{6}$. Comme le titre l'indique, le livre est consacré à l'histoire, au mode de vie et à la lutte indépendantiste des peuples du Caucase; il se concentre sur le Caucase du Nord. On y trouve des informations détaillées sur Chamil (17971871), sur la première période (de 1834 à 1859) du mouvement de résistance que mena celui-ci, ainsi que sur les prémisses du mouvement avant qu'il n'en prenne la tête. Des chapitres sont également consacrés au soufisme, que Bodenstedt présente comme un mouvement de pensée humaniste. Par ailleurs, le livre contient un certain nombre de gravures intéressantes représentant des Caucasiens et divers aspects du Caucase. Des analyses qualitatives et quantitatives sont menées sur plusieurs villes et régions du Caucase. Un chapitre est intitulé " Les Tatars du Caucase, descendants de la race turque » (pages 122-147). Par " Tatar », on désignait alors les peuples de Russie qui parlaient des langues turciques: à Kazan, en Crimée, à Astrakhan, en Sibérie, etc. Dans les sources russes de l'époque, "Tatar » est également appliqué aux peuples du Caucase récemment colonisés par la Russie (les Tatars du Caucase), qu’on appelle aujourd'hui Azéris ou Turcs Azéris.

D’après le livre de Bodenstedt, une large majorité de la population de Derbend, qui s'élevait alors à vingt-huit mille habitants, était composée de Tatars chiites. La population du Karabagh s'élevait à soixante-mille habitants, dont deux tiers de Tatars et un tiers d'Arméniens. À Gandja (gouvernement d'Elisavetpol), on comptait cinquante-cinq mille habitants, dont neuf mille Arméniens.

Cette œuvre importante fut republiée dans une édition augmentée en 1855, et une traduction française parut à Paris en $1859^{7}$. En revanche, seuls quelques chapitres furent traduits en russe et, malheureusement, il n'y eut pas d'autre traduction, ni dans les langues majeures ni dans les langues du Caucase.

6. Friedrich Bodenstedt, Die Völker des Kaukasus und ihre Freiheitskämpfe gegen die Russen. Ein Beitrag zur Kenntnis des Orients, Francfort-sur-le-Main, Lizius, 1848 [deuxième édition augmentée, 1855].

7. Friedrich Bodenstedt, Les Peuples du Caucase et leurs luttes de liberté contre les Russes, traduction de M. le Prince E. de Salm-Kyrburg, Paris, E. Dentu, 1859. 


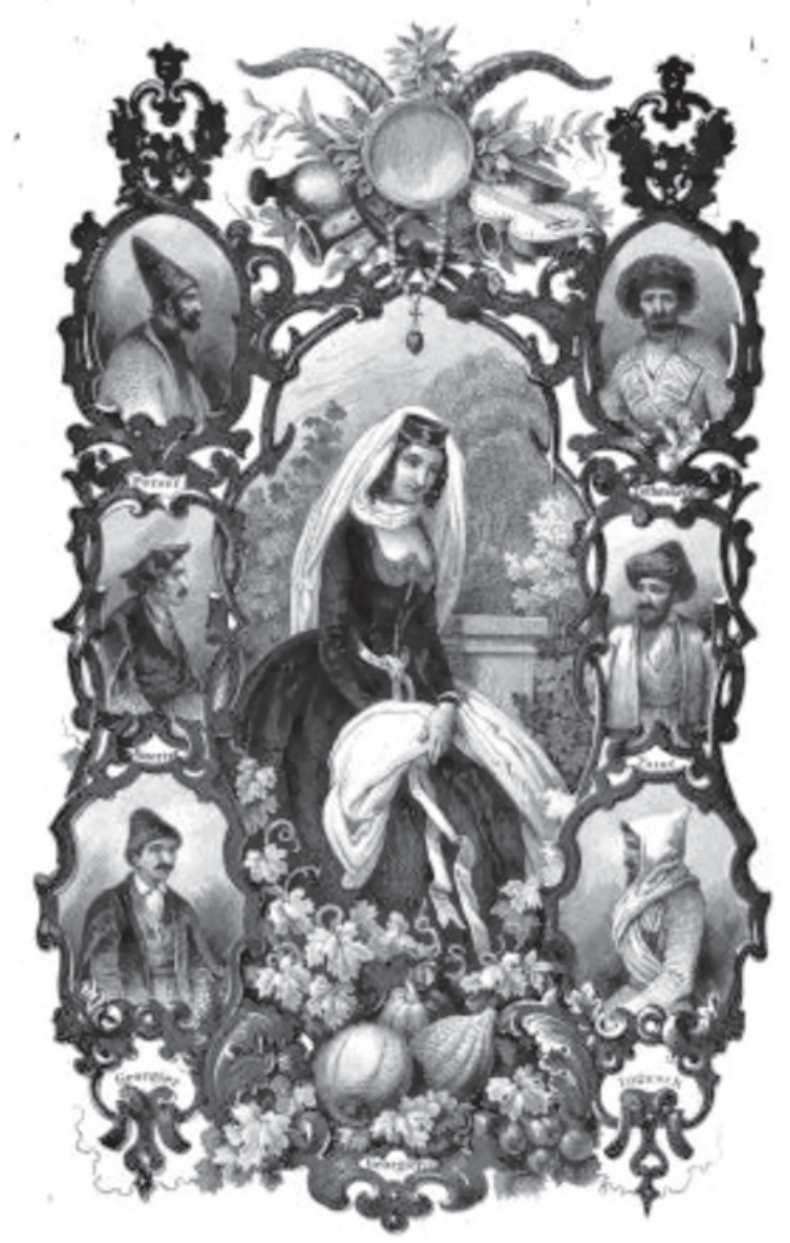

ILL. 2. Illustration de l'édition originale de Die Völker des Kaukasus und ihre Freiheitskämpfe gegen die Russen: ein Beitrag zur neuesten Geschichte des Orients.

Le deuxième livre de Bodenstedt sur le Caucase s’intitule Tausend und ein Tag im Orient ("Mille et un jours en Orient»). Il fut publié en 1850 à Berlin ${ }^{8}$. Ce livre (« son œuvre en prose la plus célèbre ${ }^{9}$ »),

8. . Id., Tausend und ein Tag im Orient (Mille et un jours en Orient), Berlin, Decker, 1850. 9. Ludwig Fränkel, « Bodenstedt, Friedrich », op. cit. 
en trois volumes et cinquante-trois chapitres, est centré sur la figure de Mirza Schaffy, poète, calligraphe et enseignant azéri. Il suscita un vif intérêt, encore plus que l'ouvrage précédent. Le personnage de Mirza Schaffy séduisit les lecteurs contemporains par son discours sincère et émouvant, par sa poésie, son sens de l'humour, son caractère, sa philosophie. Presque immédiatement, en 1851, parut à Londres une traduction en anglais ${ }^{10}$. Bodenstedt lut et corrigea lui-même les passages les plus ardus de la traduction anglaise. Ces mémoires furent aussi incorporés dans l'édition en douze volumes d'œuvres choisies de l'auteur, publiées entre 1865 et $1869^{11}$.

Rudolf von Decker, qui dirigeait la maison d'édition où Tausend und ein Tag im Orient fut publié, suggéra alors à Bodenstedt de traduire des poèmes de Mirza Schaffy; cela donna Die Lieder des Mirza Shaffy ("Les Chants de Mirza Schaffy"), en 1851"12. Bodenstedt y affirme: "J'ai traduit les chants de Mirza Schaffy en allemand sans porter atteinte aux originaux »; et encore: "Les chants que j'ai entendus, je les ai chantés à mon tour " (p. 54). Ce livre devint le plus grand succès de librairie en Allemagne à cette période (fin XIX ${ }^{\mathrm{e}}$-début $\mathrm{xx}^{\mathrm{e}}$ ). Il fut réimprimé 142 fois du vivant de Bodenstedt; en 1921 parut une nouvelle édition - la $168^{\mathrm{e}}$ ! — agrémentée de magnifiques illustrations. Des compositeurs allemands et russes adaptèrent les poèmes (les «chants ", selon la traduction de Bodenstedt) en chansons et selon d'autres genres musicaux. La traduction allemande des Chants de Mirza Schaffy, et la traduction anglaise des Rubaiyat d'Omar Khayyâm par FitzGerald en 1859, conduisirent à la très grande popularité de ces deux auteurs en Occident: on leur voua un culte proche du fanatisme ${ }^{13}$. Les Chants furent traduits dans de nombreuses autres langues européennes et extra-européennes; en 1880, Elsa d’Esterre-Keeling, écrivaine, traductrice et pédagogue, en

10. Friedrich Bodenstedt, Thousand and One Day in Orient, traduit par Richard Waddington, Londres, Richard Bantley, 1851.

11. Id., Gesammelte Schriften (Euvres choisies), 12 volumes, Berlin, Decker, 1862.

12. Id., Die Lieder des Mirza Shaffy (Les Chants de Mirza Schaffy), Berlin, Decker, 1851.

13. Hamlet Isaxanli, « History and Policy of Translating Poetry: Azerbaijan and its Neighbors ", META, Volume 59, $\mathrm{n}^{\circ}$ 2, Les Presses de l’Université de Montréal, 2014, p. 310-329, p. 316-7. 
fit une traduction anglaise. Tausend und ein Tag im Orient (« Mille et un jours en Orient ") ne connut, en revanche, " que " cinq éditions du vivant de l'auteur (en 1850, 1853, 1859, 1865 et 1891).

Après cette présentation de Bodenstedt et de ces trois ouvrages, je souhaiterais me concentrer sur Mille et un jours en Orient. Ce livre est intéressant à au moins deux titres: d'abord, grâce à la personnalité truculente de Mirza Schaffy telle que décrite et largement créée par Bodenstedt ( « le livre, mal agencé, serait tombé dans l'oubli sans Mirza Schaffy "); ensuite, dans la perspective des études caucasiennes. Il n'existe aucune traduction complète de ce livre dans une autre langue que l'allemand; la version anglaise est la plus proche de l'original. Les parties du livre qui concernent Mirza Schaffy ont été traduites en azéri dans des éditions abrégées et avec quelques erreurs $^{14}$. Mais les longues descriptions du Caucase, pourtant très intéressantes, ne l'ont jamais été.

Bodenstedt, qui parlait de "Morgenland" ("pays du matin ") pour désigner l'Orient et d' "Abendland " (" pays du soir ») pour désigner l'Occident, fait remarquer que ses livres précédents étaient de facture plus académique, et promet l'inclusion dans ce nouvel opus de petites descriptions, de résumés et de passages poétiques et vivants. De mon point de vue, ce livre est aussi important que le précédent pour les études sur le Caucase. Dans Les Peuples du Caucase et leur combat pour se libérer du joug russe, les études historiques et géographiques sont principalement tirées de sources préexistantes. Mille et un jours en Orient, en revanche, est presque entièrement fondé sur les observations directes de Bodenstedt, sur ses recherches ethnographiques consacrées aux peuples, aux nations, aux régions et aux cultures qu'il a connus pendant ses voyages. Par conséquent, il contient d'avantage de réflexions originales.

En 1861, Bodenstedt publia Aus Ost und West (« D’Orient et d'Occident »), un recueil de six conférences ${ }^{15}$. La troisième d'entre elles est intitulée "Die Stellung der Frauen im Orient und Occident " (« La situation des femmes en Orient et en Occident»). Il y cite un

14. Friedrich Bodenstedt, Mirzə Şəfi haqqında xatirələr, traduit par Akif Bayramov, Bakou, Yazıçı, 1987.

15. Id., Aus Ost und West, Sechs Vorlesungen, Berlin, Decker, 1861. 
exemple tiré de la pièce Monsieur Jordin et le derviche Masteli-chah, de M.F. Akhundov (1812-1878), où l'auteur compare les femmes d'Azerbaïdjan et de Paris. Bodenstedt traduit également des poèmes d'A. Bakikhanov, génial touche-à-tout azéri du premier XIX ${ }^{\mathrm{e}}$ siècle, en qui il voit " un grand poète ${ }^{16}$ ", et les publie sous le titre Aus dem Divan des Abbas-Kuli-Khan von Baku ("Depuis le divan du khan Abbas-Kuli de Bakou »). Un des poèmes célèbres tirés de ce recueil, "Fatma joue du tar ", n'est plus disponible que dans ses traductions en russe et en allemand, car l'original n'a pas survécu jusqu'à nous.

En 1882, Bodenstedt publie un autre livre de traductions de poèmes orientaux, Aus Morgenland und Abendland. Neue Gedichte und Sprüche (" D'Orient et d'Occident. Nouveaux poèmes et proverbes »). Le recueil contient des traductions de Saadi, Rumi, Jami, et des proverbes de Mirza Schaffy ${ }^{17}$. De manière générale, Bodenstedt fut un traducteur de littérature orientale particulièrement prolifique. Il fut " pour l'allemand ce que Vassili Joukovski fut pour le russe $^{18}$." Ses publications comprennent des extraits de classiques russes, persans et anglais (Pouchkine, Lermontov, Tourgueniev, Shakespeare, Khayyam, Saadi, Rumi, Hafiz, Jami notamment) et de la littérature azérie. Son travail de chercheur et d'enseignant s'est également concentré sur ces littératures.

En 1874, il fait paraître Aus dem Nachlasse Mirza Schaffys ("Euvres posthumes de Mirza Schaffy»), un volume beaucoup plus conséquent que les Chants de Mirza Schaffy ${ }^{19}$. Dans un long "supplément explicatif ", il révèle ou prétend révéler que Mirza Schaffy n'était en fait pas poète et que les Chants n'étaient pas traduits de Schaffy mais avaient été écrits par lui-même. L'édition suivante des Chants, parue à Berlin en 1875, porte sur la couverture le nom de Bodenstedt, qui se présente comme le véritable auteur,

16. Friedrich Bodenstedt, Aus dem Divan des Abbas-Kuli-Khan von Baku, poème, 1862, 4: 121-123.

17. Id., Aus Morgenland und Abendland. Neue Gedichte und Sprüche, Leipzig, F. A. Brockhaus, 1882.

18. " Poèt’ i professor' Fridrih' Bodenstedt 1819-1887 ", in Russkaja starina, tome 54-j, Sant-Peterburg, 1887, p. 407-503, p. 409.

19. Friedrich Bodenstedt, Aus dem Nachlasse Mirza Schaffy's, Berlin, Hofmann \& Comp, 1874. 


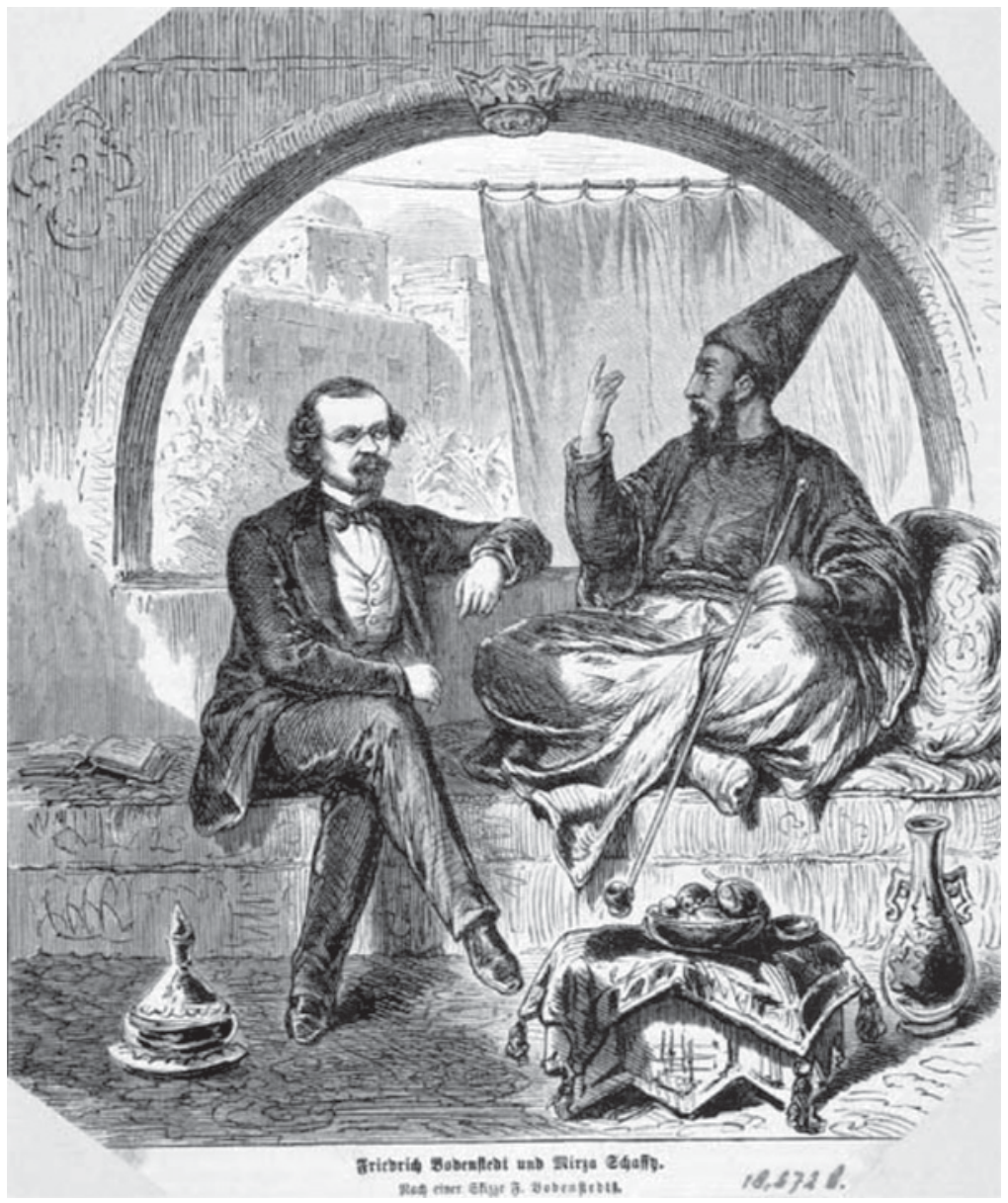

ILL. 3. Friedrich Bodenstedt et Mirza Schaffy @ Collections d'histoire théâtrale et musée Hebbel, musées du Schleswig-Holstein et de Hamburg.

ayant jusque-là pris le pseudonyme de Mirza Schaffy. En réalité, Mirza Schaffy exista bel et bien et c'était un poète. Il écrivait en persan et en azéri ${ }^{20}$; il était talentueux, mais resta largement inconnu.

20. Voir par exemple S. Mumtaz, Mirzə Şəfi Vazeh [Mirza Schaffy Vazeh], Bakou, Nurlan, 2005 [1 ${ }^{\text {re }}$ édition: 1926]); Mirza Schaffy Vazeh, Şeirlar macmuəsi [Recueil 
Avant que Bodenstedt ne fasse cette déclaration fracassante, un spécialiste du Caucase russe, Adolf Bergé (1826-1886), de père fran-

çais et de mère allemande, avait écrit un article sur Mirza Schaffy ${ }^{21}$ publié en 1870. Ce texte fut déterminant pour entériner l'idée que Bodenstedt était l'auteur des Chants. La vérité est que si Bodenstedt avait avait été reconnu lui-même comme poète, il n'aurait pas dénié à Schaffy sa paternité des poèmes. La grande amitié entre Bodenstedt et Schaffy, décrite avec enthousiasme par Bodenstedt en personne, devenait rupture. La revendication par Bodenstedt de la paternité des textes créa la confusion dans les champs littéraires tant allemand qu'azéri. Les spécialistes de littérature ont fait de ce mystère un objet d'étude et de débats. Dans le cadre de cet article, je n'aurai malheureusement pas la place de rentrer dans les détails de la relation qui unissait Bodenstedt et Schaffy; les recherches qui ont été menées à ce sujet, que ce soit en Allemagne ou en Azerbaïdjan, ne sont pas exemptes de préjugés et de points de vue orientés ${ }^{22}$.

\section{Bodenstedt à propos de la diversité ethnique et culturelle du Caucase}

Nous allons maintenant nous intéresser à Mille et un jours en Orient, qui peut être considéré comme l'une des sources les plus précieuses pour les études sur le Caucase. Ce livre, écrit au milieu du XIX ${ }^{\mathrm{e}}$ siècle, contient non seulement un compte rendu de divers événements historiques de ce siècle et des siècles précédents, mais aussi des informations complètes sur la culture et la société du Caucase, et sur un certain nombre de personnages historiques, dont les noms ne sont pas mentionnés, ou seulement en passant, dans d'autres

de poèmes], préparé par H. Mammadzadeh, édité par A. Mirahmadov, Bakou, Elm, 1987.

21. Adolph Bergé, "Mirsa Schaffi ", Zeitschrift Der Deutschen morgenländischen Gesellschaft, vol. XXIV, Leipzig, Brockhaus, 1870, p. 425-432, consulté sur ia601403. us.archive.org/24

22. Cf. Kurt Sundermeyer, Friedrich Bodenstedt und die "Lieder des Mirza-Schaffy", thèse de doctorat, Kiel, Stecker \& Company, 1930-1932; Mirza Schaffy Vazeh, Şeirlar macmuasi, op. cit.; Johannes Mundhenk, Friedrich Bodenstedt und Mirza Schaffy in der aserbeidschanischen Literaturwissenschaft, Hamburg, Helmut Buske, 1971. 
sources. Nous allons donc nous intéresser à la diversité ethnique et culturelle du Caucase telle qu'elle est décrite dans ce livre (qui n’a, jusqu'ici, pas été étudié pour cela, ainsi que nous l'avons exposé plus haut).

Plutôt que de prendre le livre dans l'ordre, nous en ferons l'analyse en considérant le point de vue de l'auteur sur un certain nombre de problèmes. Pour ne pas entraver la lecture, nous n'indiquons pas les pages de chaque citation; celles-ci peuvent être trouvées facilement dans l'original allemand ou dans sa traduction anglaise. Nous ferons ponctuellement référence à d'autres livres de Bodenstedt lorsqu'ils sont pertinents pour l'analyse.

Bodenstedt était un observateur précis et pointilleux:

J'aurais pu écrire un roman; j'aurais estompé certains détails déplaisants, comblé les trous de l'histoire avec des épisodes passionnants, inventé des protagonistes sentimentaux et vertueux, rendu les situations plus complexes, et mis dans la bouche des personnages de belles paroles. Mais moi, au contraire, je mets sous les yeux du lecteur la réalité nue; je reste sourd aux appels de l'imagination.

Quand Bodenstedt vivait à Tbilissi, où il fréquentait Mirza Schaffy et d'autres, et quand il voyageait à travers le Caucase, il prit de nombreuses notes concernant des questions diverses: l'histoire et la géographie, la mythologie et la religion, la langue, la littérature et la musique, les traditions et les modes de vie, la culture matérielle, les femmes; fréquemment, il établissait des comparaisons entre l'Europe et le Caucase.

\section{Sur les langues}

"En Géorgie, le premier soin que j'eus fut de trouver un instructeur en tartare [autre orthographe pour "tatar»] afin d'apprendre au plus vite cette langue si indispensable à la vie dans le Caucase " (1850); Bodenstedt appelle le tatar « la lingua franca de l'Est " (1874). Mirza Schaffy lui apprit également le persan. Certains auteurs, comme Kurt Sundenmeyer ${ }^{23}$, ont supposé, dans les années 1930, que Mirza Schaffy lui avait enseigné non seulement le tatar et le persan, mais aussi le géorgien et l'arménien; dès 1897, la revue

23. Kurt Sundermeyer, op. cit. 
historique Russkaja starina avait commis la même erreur ${ }^{24}$. Mais, en 1874, Bodenstedt avait précisé que Schaffy ne lui enseigna que le tatar et un peu de persan, en 1850 et en 1874. La déclaration suivante ne laisse pas de place au doute: "Sur la route [en Géorgie occidentale], j'ai rencontré un prêtre géorgien à dos d'âne (à Akhalkalaki je n'ai jamais vu de cheval; tout le monde voyage à dos d'âne) et je lui ai dit quelques mots en géorgien; mais, comme je ne parlais pas cette langue, nous avons continué en russe. » Par ailleurs, il est avéré que Mirza Schaffy ne parlait que le tatar, le persan et l'arabe.

Bodenstedt fait remarquer que les Arméniens parlent le tatar en sus de leur langue maternelle. Leurs chansons folkloriques sont en tatar; lorsqu'ils parlent, les Géorgiens comme les Arméniens utilisent de nombreuses expressions tatares. Bodenstedt note les mots tatars (azéris) suivant leur prononciation (en effet, il écrivait avant la publication des pièces d'Akhundov qui fixèrent des règles d'écriture). On trouve par exemple dans les notes de Bodenstedt axşamınız xeyir olsun (" bonsoir "), vallah, eladir (wallah, " c'est comme ça »), yaxşl yol (" bon voyage »), yaxşı oldu (" c'était bien »), çox (" beaucoup »), çörək (" pain »), atlar hazırdır/atlar haserler (" les chevaux sont prêts »), Allah verdi (" Dieu a donné », expression qui était utilisée dans le Caucase après un toast, au sens de "bon voyage »), kef elamək/keef elimäkj ( « s’amuser »), dilbilir ( " philologue »; Bodenstedt affirme que lui et Budagov inventèrent ce mot pour expliquer ce qu'est un " philologue »), eşşək [ischekj] (" âne »), çubuq ( "bâtonnet, cigarette "), qalyan (" hookah»), qalamdan (" trousse à crayons"), salam alekem - alekem salam ( " bonjour » et réponse), bülbül (« rossignol »), quzllbaşi ( "roux »; surnom donné aux partisans du shah Ismaïl ${ }^{\mathrm{er}}$, fondateur de la dynastie séfévide), Gürcüstan (Géorgie), Göyça gölü (lac de Gegham), Alagöz dağı (mont Aragats), AsslanBey, ou Arzlan-Bey (Bodenstedt note que l'orthographe correcte est "Arzlan Bey » mais que cela se prononce « Asslan Bey »).

Bodenstedt et Mirza Schaffy conversaient en tatar (en azéri). On peut l'établir par un certain nombre d'expressions apparaissant dans Mille et un jours en Orient. À cette époque, dans les salons poétiques organisés par Mirza Schaffy (les Divani-hikmet, « cercles

24. « Poèt’ i professor’ Fridrih’ Bodenstedt 1819-1887 », op. cit. 
de sagesse »), des poèmes étaient récités aussi bien en tatar qu'en persan. "Lorsque nous rencontrions des problèmes de communication, notre ami L. Budagov nous venait en aide. [Budagov, d'ethnie arménienne, était philologue]. Il enseignait le persan dans un lycée, et parlait couramment allemand, anglais et français. Il aimait particulièrement interpréter les chants de ces cultures dans un style oriental. C'est à ce moment que je réalisai comme les autres nations perdaient à ne pas connaître des hommes comme Mirza Schaffy. ”

\section{Sur la littérature, la poésie, la musique}

Bodenstedt répète en plusieurs endroits que les cours de langue qu'il prenait auprès de Mirza Schaffy étaient fondés sur la poésie. Mirza Schaffy lui récitait ses propres vers, des poèmes persans classiques et des textes de Fuzûlî, appartenant au canon turcique; puis il les analysait. Bodenstedt écrit que, quand Mirza Schaffy récitait des vers, c'était " comme s'il chantait ". Visiblement, la tradition orientale consistant à déclamer des poèmes (qu'ils soient en arabe, en persan, en langues turciques) en mettant beaucoup d'intonation et de pathos, a évoqué pour Bodenstedt l'écoute d'œuvres musicales. "Mirza Schaffy récitait avec beaucoup d'expressivité. Quand je lis platement des poèmes que j'ai traduits depuis des langues étrangères, il se fâche. "

Lorsqu'il parle de « langues étrangères ", significativement, c'est aux langues occidentales que Bodenstedt fait référence ${ }^{25}$.

25. Nous devons ici nous attarder sur quelques erreurs commises par Johann Christoph Bürgel, dans son intervention au colloque qui s'est tenu au musée de l'Ermitage à Saint-Pétersbourg en 2004, et dans l'article qui en est issu. Johann Christoph Bürgel, " Friedrich (von) Bodenstedt, a German orientalist of the $19^{\text {th }}$ century, and his Lieder des Mirza Schaffy ", communication donnée au colloque international sur l'étude de la culture persane en Occident, Musée national de l'Ermitage, Saint-Pétersbourg, 2004, p. 1-13, consulté sur archivindomed.altervista. org/bodenburgel.pdf.

De manière générale, les recherches de Bürgel sont orientées et manquent de recul critique. Finalement, il ne fait que répéter des affirmations que l'on trouve dans des publications antérieures, y compris dans le supplément publié par Bodenstedt lui-même en 1874. Par exemple, il reprend la vieille antienne selon laquelle les poèmes de Mirza Schaffy (ou de Bodenstedt, selon Bürgel) auraient été écrits en réaction à ce qui se passait en Prusse à la même époque (p. 4). Ludwig Fränkel, en revanche, s'oppose fermement, et avec des arguments solides, à 
Plus tard, en 1874, il décrit Mirza Schaffy et la littérature tatare en ces termes ${ }^{26}$ : Mirza Schaffy est né Tatar, mais a été formé en persan. Les Tatars n'ont pas la littérature riche et vive des Persans, mais leur langue est comme le français de l'Orient; par ailleurs elle a été largement influencée par le persan.

Bodenstedt ne se trompait pas quant à la richesse de la poésie persane. Dès les $\mathrm{XI}^{\mathrm{e}}$ et XII ${ }^{\mathrm{e}}$ siècles, des poètes persanophones mais aussi turcophones (et même quelques auteurs du sous-continent indien) avaient choisi d'écrire intégralement en persan. D'autres écrivaient à la fois en persan et dans leur langue maternelle; puis ils furent de plus en plus nombreux à n'écrire que dans leur langue maternelle. Mehmet Fuzûlî écrivait dans trois langues: en azéri principalement, mais aussi en persan et en arabe. Au xIX ${ }^{\mathrm{e}}$ siècle, les poètes Abbasgoulou agha Bakikhanov et Mirza Schaffy écrivaient principalement en persan, même si on leur doit quelques très belles œuvres poétiques en azéri.

Mirza Schaffy mentionna à Bodenstedt des œuvres de Hafiz et d'autres poètes persans, ainsi que de Fuzûlî, pour la littérature en langues turciques. D’autres grands poètes de langues turciques, comme Imad-ad-din Nassimi, Alicher Navoï ou Molla Panah Vagif, ne faisaient pas partie du programme d'enseignement de Mirza Schaffy et, par conséquent, Bodenstedt n'en entendit pas parler. D'autres voyageurs et artistes ayant passé du temps dans le Caucase à la même époque font état de leur même impression d'un usage assez généralisé de la langue tatare. Bodenstedt avait également raison d'affirmer

l'idée que les chants de Mirza Schaffy puissent constituer des critiques voilées de la politique prussienne. Il affirme que l'une des raisons du succès des chants est précisément que ceux-ci sont apolitiques. Ici, nous nous contenterons de pointer les imprécisions de Bürgel en ce qui concerne les langues. Visiblement, Bürgel ne connaît pas bien les langues turciques, et confond l'azéri et le turc ottoman. Il commet notamment l'erreur d'affirmer que le tatar parlé dans le Caucase était du turc ottoman, alors qu'il s'agit d'azéri. Pour étayer sa thèse, il cite l'expression axşamınız xeyir olsun (qui se prononce " achschaminiz cheir olssun ", et veut dire " bonsoir »), qu'il dit être typique du turc ottoman et ne pas exister en azéri. Mais c'est là une expression azérie typique; en turc ottoman, l'on dirait iyi akşamlar.

26. Friedrich Bodenstedt, Aus dem Nachlasse Mirza Schaffy's, Berlin, Hofmann \& Comp, 1874. 
que le tatar était influencé par le persan. Par ailleurs, les deux langues, tatar et persan, avaient auparavant été influencées par l'arabe.

Bodenstedt exprima en plusieurs endroits son admiration pour la poésie orientale, que ce soit dans Mille et un jours en Orient ou dans d'autres ouvrages. Lorsqu'il rencontra Omar Afandi, un ami de Mirza Schaffy, il lui exprima son admiration en citant Fuzûlî: "Je suis venu à vous comme un exilé affamé; comme une goutte d'eau se mêlant à l'océan. » Dans le supplément au volume d'œuvres posthumes de Mirza Schaffy, Bodenstedt discute de questions littéraires: le genre du ghazal, la forme du rubaï (quatrain), le système de rimes, les problèmes de traduction - et en donne les principaux motifs.

Bodenstedt évoque également l'attitude très négative de Mirza Schaffy envers les livres imprimés et reproduit son discours enflammé à ce sujet: "Il n'avait pas beaucoup de livres chez lui. Les livres imprimés l'irritaient, le mettaient en colère. " Ici il faut nous arrêter sur l'origine de cette aversion. Mirza Schaffy, comme d'autres mirzas ( "lettrés »), gagnait sa vie en tant que copiste, ce qui requérait une grande maîtrise de l'art calligraphique. À la fois leur statut économique et leurs œuvres étaient dépendants de ce métier. D'autres écrivains, comme Abbasgoulou agha, ne s'arrêtaient pas à ce type de question. Au contraire, Abbasgoulou agha s'efforçait de faire publier ses livres aussitôt que possible. Il était conscient de l'importance de l'imprimerie.

Bodenstedt fait aussi quelques remarques en passant sur la littérature géorgienne et arménienne. "La littérature géorgienne contient de nombreux ouvrages de théologie, d'histoire et de géographie (j'en sais peu de chose; je ne parle pas géorgien), et a une riche tradition poétique. Elle est très différente de la littérature arménienne. J'ai lu Roustavéli dans une traduction russe, mais cela ne m'a pas plu; en revanche les petites chansons géorgiennes sont très plaisantes...»

Dès ses premiers jours dans le Caucase, Bodenstedt s'émerveilla des couleurs et de la variété de la région. À propos d’une fête de bienvenue, il écrit: «Des Géorgiens, des Arméniens, des Tatars, des musiciens agiles au beau visage qui chantaient des textes de Hafiz... tout était nouveau — comme les Mille et une nuits! » C'est de là que Bodenstedt tira le titre de son livre. En visitant Erevan, il rencontra 
Khatchatour Abovian (qu'il orthographie Obowian): « Khatchatour Obowian me gratifia de chants en tatar, en kurde et en arménien. " Plus tard, Bodenstedt apporta certains de ces chants au salon littéraire de Mirza Schaffy: "Ensemble, nous apprîmes des chants tatars de l'aveugle Keshishoglu, et du combat qui l'opposa à Allahverdi (Obowian m'avait dit quelques mots de Keshishoglu)». Bodenstedt fournit aussi des informations sur des événements liés à la poésie et à la musique. Il parle du chanteur Gaytimaz, à Erevan, et de Yusif, fils d'un marchand arménien, qui, dans la demeure du marchand à Akhalkalaki, chantait de magnifiques chansons; l'un et l'autre s'accompagnaient au saz (luth à manche long) ou au tengir.

\section{Sur la vie intellectuelle, les traditions, les coutumes}

Le sujet de Bodenstedt c'est, avant tout, son maître préféré Mirza Schaffy, sa personnalité, ses réflexions, son mode de vie, son attitude envers ses collègues, envers les femmes, etc.

Mirza Schaffy disait son admiration pour Abbasgoulou Khan et Omar Afandi; il était clair qu'il n'était pas envieux d'eux. Il maintenait des relations cordiales avec les savants et les hommes en général, qu'ils soient chiites ou sunnites. Bodenstedt l'interrogea un jour sur sa tolérance; Schaffy fit une réponse brève: que chacun, dit-il, s'occupe de ses affaires. Cependant, d'après Bodenstedt, Mirza Schaffy offensa parfois les religieux, notamment quand il déclara: «Le cri d'un enfant innocent m'est plus agréable à l'oreille que l'appel à la prière d'un vieux religieux. »; et Bodenstedt ajoute: " En retour, ils dirent que Mirza était immoral. » Les paroles d'Omar Afandi, que Mirza Schaffy appelait «le plus sage des hommes, après moi », sont également éclairantes: «Il n’y a aucune intelligence dans la tête d'un idiot; un arbre ne peut pas pousser sur un rocher. Il n'y a rien de plus difficile que d'apporter l'intelligence à un idiot, ou de rendre idiot un homme intelligent. "

Bodenstedt consacre aussi certains passages à la haute société de Tbilissi, et aux événements qui l'animent: « Les fonctionnaires et les officiers russes sont en haut de la société de Tbilissi; autour d'eux, il y a les riches familles géorgiennes et arméniennes (les Eristaf, les Tourmanov, les Chavchavadze, les Karganov, les Andronikov, les Orbelian...). Daniel, le sultan de Jelussui [aujourd'hui Ilisu, en 
Azerbaïdjan], a dansé une lezginka avec la princesse Orbelian au grand palais Sardar. Toutes les femmes les regardaient, et admiraient le maintien et les gestes du sultan. Malgré la haine que lui vouaient les musulmans pieux, il fit honneur au pays et à sa couronne dans cette danse. Plus tard, j'appris que ses amis tuèrent des Russes et l'expulsèrent. Daniel se plaça sous la protection de Chamil, et devint son premier régent. " À ces mots de Bodenstedt, on peut ajouter que le nom de Daniel revient fréquemment dans une lettre de Vorontsov à Iermolov, selon laquelle le fils de Daniel était fiancé à la fille de Chamil.

Les observations de Bodenstedt concernent également les Européens et les Russes vivant à Tbilissi et dans le Caucase en général, ainsi que les populations autochtones. Il se souvient notamment de la remarque d'un officier russe cantonné à Gagra, sur la guerre, la dangerosité du Caucase, et les côtes inhospitalières de l'Abkhazie: « La Sibérie serait plus agréable. Là-bas, on peut gagner sa vie sans craindre sans cesse de la perdre; le seul danger dont il faut s'inquiéter, c'est la mort naturelle. Ici, le soleil qui se lève sur les rives de la mer Noire apporte avec lui la mort et la corruption; si le destin nous épargne et nous garde en vie, alors nous perdons un bras ou une jambe... "

Bodenstedt commente les propos du soldat russe avec un mélange d'admiration et d'ironie: "Les soldats russes apprennent vite, et s'échinent à la tâche pour obéir à n'importe quels ordres... » Il cite aussi la réponse que fit l'officier russe à un officier allemand qui prenait part à la guerre russo-turque et était convaincu de l'impossibilité d'une avancée et de l'inutilité d'une attaque: «Comment ça, impossible? Mais l'empereur nous en a donné l'ordre! »

Quant aux docteurs vivant à Tbilissi, Bodenstedt les divisait en deux catégories: les Allemands, qu'il voyait comme extraordinairement consciencieux (ce qui était aussi, de son point de vue, leur principal défaut); et les Russes et les Polonais, irresponsables et sournois. Sans citer de source, il classifie de même les différentes nationalités vivant à Tbilissi en plusieurs catégories, selon le degré de sournoiserie qu'il dit percevoir chez chacune d'entre elles. Ainsi, les Grecs seraient les plus rusés, juste devant les Juifs (curieusement, il ne mentionne pas les Tatars; peut-être étaient-ils à ses yeux inca- 
pables de ruse?) Dans son système, deux Juifs valent un Russe, deux Russes valent un Persan, deux Persans valent un Arménien, et deux Arméniens, un Grec.

Bodenstedt s'intéresse aussi aux mouvements migratoires liés aux guerres de conquête du Caucase, et à leurs effets. Par exemple, il affirme: "Après que Paskevitch eut conquis Achalzig, une majorité des Turcs aisés partit pour l'Anatolie, et beaucoup d'Arméniens de Turquie partirent pour le Caucase (ceux qui voulaient être sujets de l'Empire russe); ils remplirent plus d'espace que ce que les Turcs en partant n'avaient laissé. " Il fait aussi remarquer que "les navires grecs et turcs transportent des esclaves de la Circassie à la Turquie; ils font du commerce d'esclaves."

Bodenstedt, qui avait voyagé en Géorgie et vécu à Tbilissi, connaissait visiblement très bien la façon de vivre des Géorgiens et s'exprime très ouvertement à leur sujet: "Les Géorgiens n'ont pas l'hygiène des Européens [" avec quelques exceptions ", semble-til parfois suggérer]. Lorsqu'ils pratiquent des sports et des jeux de rue, notamment le funambulisme, les Géorgiens semblent mettre de côté leur paresse congénitale et s'y adonnent avec enthousiasme. Les danses géorgiennes ressemblent aux grecques; ils chantent en même temps qu'ils dansent. [...] La naissance d'une fille est un malheur, surtout si c'est le premier enfant, ou s'il y en a plusieurs à la suite [cela était vrai aussi d'autres peuples du Caucase] [...] En Imérétie, on vit comme on vit dans la plupart des pays d'Orient,: dans l'instant et sans souci de l'avenir. Il n'y a quasiment pas de vols ici. C'est un peuple pacifique chez lui, courageux dans la bataille. [...] Le peuple géorgien se divise en thavads (seigneurs), aznavours (nobles), vadshars (marchands), mtsshaxurs (serfs), olexis (le petit peuple) et monas (esclaves). »

Dans son premier livre, Bodenstedt s'était particulièrement intéressé aux nations vivant sur les contreforts du Grand Caucase (surtout dans la partie nord), à leur mode de vie et à leurs combats. Mille et un jours en Orient témoigne de la continuité de cet intérêt. Mais les informations qu'on y trouve semblent ne pas être issues d'observations directes, mais plutôt de ouï-dire. Voici quelques extraits de ce que Bodenstedt écrit de Derbent et de Kaytakh ou Kara-Kaytakhto au nord-ouest du Caucase: "Dans cette contrée 
sauvage du Caucase, personne n'a encore lu Werther; leur façon d'aimer n'est pas aussi sentimentale que la nôtre. » Dans ce contexte, soulignons que les stéréotypes - Orient romantique, Occident rationaliste - étaient bien ancrés dans l'imaginaire collectif à l'est comme à l'ouest. Ici, Bodenstedt inverse ces stéréotypes. Il cite également comme typiques de cette région "des intrigues imbriquées, des cycles de trahisons, des mariages et encore des mariages [...] des vendettas [...], des négociations matrimoniales. »

\section{Sur les femmes}

Les femmes en général, et celles du Caucase en particulier, sont l'un des sujets favoris de Bodenstedt. Il consacra tout un livre aux personnages féminins chez Shakespeare (1874). Dans Mille et un jours en Orient, les conversations intimes avec Mirza Schaffy sur les femmes et l'amour, et sur les aventures de Schaffy, tiennent une place importante. Il est difficile d'y démêler ce qui relève de la fiction. Nous allons nous intéresser aux histoires d'amour de Mirza Schaffy, car ses vues sur les femmes ne sont pas dénuées d'intérêt.

Alors qu'il revenait juste d'un voyage à Erevan, Bodenstedt raconte à Mirza Schaffy l'histoire suivante: "En Arménie, j'ai traversé des villages fort sales; là, les femmes arméniennes avaient les mains vraiment sales. Heureusement que le baisemain ne fait pas partie des coutumes de ce pays. " Mirza Schaffy lui fait une réponse appropriée, en vantant la dignité de ces femmes: «Honte aux hommes dont les épouses ont les mains sales! Apprends à une femme que les hommes vont désormais lui baiser la main, et elle les gardera toujours propres. Si ce sont ses pieds que tu baises, ce sont ses pieds qu'elle tiendra propres. "

Mirza Schaffy parle de la sagesse et de la force des femmes. Il démontre par analogie que les femmes méritent d'être adorées, comparant l'amour qui leur est dû à un hymne: « Les sunnites considèrent que le sultan est l'ombre de Dieu sur terre; pour les chiites, c'est le shah. En réalité, ce sont les femmes qui sont l'essence de Dieu sur terre."

Bodenstedt s'exprime peu sur la beauté féminine. Il trouve que les femmes de Novotcherkassk sont les plus belles de toute la Russie ( du bon vin, de belles femmes "; " aucune autre ville de Russie 


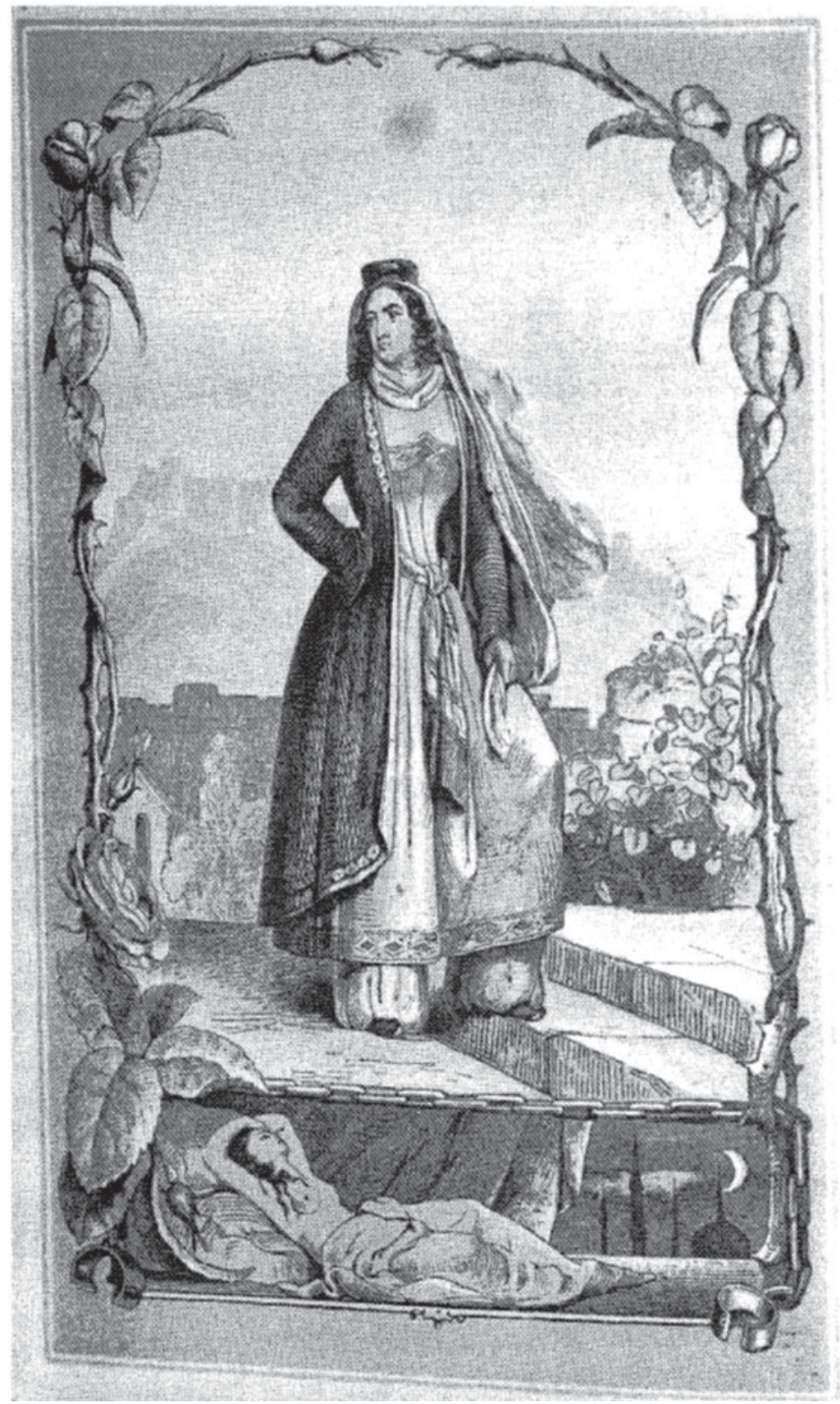

ILL. 4. Femme orientale, illustration tirée de Die Völker des Kaukasus und ihre Freiheitskämpfe gegen die Russen: ein Beitrag zur neuesten Geschichte des Orients. 
ne possède de telles femmes »). Quant aux filles et aux femmes de Géorgie, il a des idées contradictoires à leur sujet, et affirme que «les filles géorgiennes sont très belles, mais elles enlaidissent en vieillissant. " Il insiste sur la différence entre les femmes qu'il a pu voir dans l'église Saint-David, magnifiques, et celles aperçues au marché qui, géorgiennes ou arméniennes, semblent ne pas aimer les femmes de l'église. Ce sont des femmes sans enfants qui vont prier à Saint-David. Mirza Schaffy commente la chose en ces termes: "Je suis étonné que David, si longtemps après sa mort, parvienne à réunir tant de jolies femmes. Y a-t-il un autre endroit au monde où l'on puisse voir autant de jolies jambes nues?"

Bodenstedt raconte sa rencontre, à Gori, une ville de garnison russe, avec une fille issue de l'élite géorgienne, et s'interroge alors sur l'image que les Européens se font de la Géorgienne: "Je rencontrai Maria Eristaff, une jeune princesse au visage avenant et aux beaux cheveux épais, qui était le centre de toutes les conversations en Géorgie. En Europe, on s'imagine que les Géorgiennes sont grandes, élancées, ont un beau visage, des cheveux longs, un front large et noble, des yeux noirs et mystérieux. Elles apporteraient la joie et le plaisir, et laisseraient en s'en allant des regards amoureux et fascinés. Beaucoup de voyageurs d’Europe sont déçus quand ils arrivent en Géorgie; et certains trouvent même que la réalité est l'exact (et laid) contraire de ce qu'ils imaginaient. La vérité est quelque part entre les deux. Les Géorgiens dans leur ensemble constituent l'une des plus belles races du monde. Mais je préfère les hommes. Jusqu'ici, jamais je n'ai été frappé de la beauté d'un visage de femme (quand elles couvrent leur tête, on ne peut plus voir leur front étroit, et cela ne leur va pas). Mais les Géorgiennes ont du charme. Elles ont des nez très longs. " Il continue en affirmant que « les filles sont si adroites dans la manière de soulever leur voile qu'elles se laissent apercevoir [c'est le cas également en Iran aujourd'hui] ".

Dans D'Orient et d'Occident, Bodenstedt s'intéresse particulièrement aux femmes. Il prend parti dans une polémique avec le grand intellectuel et poète azéri Mirza Fatali. Akhundov, dans une de ses comédies, donnait, d'un ton mi-ironique, mi-sérieux, une image des relations entre les sexes à Paris et en Orient; Bodenstedt prend 
cela au pied de la lettre et, voulant lui répondre, il arrive à cette conclusion intéressante: «M.F. Akhundov, célèbre auteur tatar de comédies, fait dire à l'un de ses personnages [Hatamkhan agha, dans Monsieur Jordin et le derviche Masteli-chah] que « la polyandrie française n'est en rien inférieure à notre polygamie. La polygamie, cela veut dire qu'un homme ne peut se contenter d'une seule épouse; la polyandrie, qu'une femme ne peut se contenter d'un seul époux. La première est une tradition populaire ici [dans l'Orient musulman]; la seconde, à Paris. Il y a là une vérité qu'on ne peut nier, même hors de Paris. Mais on peut aussi ajouter que chez nous, la polyandrie est impossible, illégale, condamnable. La polygamie, son contraire, est fondée sur la religion de l'Orient, sur des traditions, et pour ces raisons elle continue de produire ses effets destructeurs, parce qu'aucune loi ne peut l'empêcher, et que rien ne la sanctionne. Mais cela ne veut pas dire que les femmes orientales ne rêveraient pas de s'adonner à la polyandrie! Elles en ont le désir, et ont beaucoup de talent pour la chose; il ne leur manque que l'opportunité! Même si on leur en faisait l'offre, elles pourraient difficilement en profiter. " "

\section{Sur la culture matérielle}

Pendant ses voyages dans le Caucase, Bodenstedt prit des notes sur les paysages naturels, le climat à différentes saisons, les monuments, les travaux agricoles, la vie quotidienne, le niveau de vie. Il se réfère à Marie-Félicité Brosset (1802-1880) et à Frédéric Dubois de Montpéreux (1798-1950), archéologue et ethnographe franco-suisse, pour préciser ses descriptions et leur emprunter une terminologie géographique. Brosset, artiste ayant surtout travaillé en Russie, avait voyagé dans le Caucase en 1847 et 1848, et avait écrit une Histoire de la Géorgie en sept volumes (1849-1858) ${ }^{27}$; Frédéric Dubois de Montpéreux, lui, s'était trouvé dans le Caucase et en Crimée de 1831 à 1834 et il en tira par la suite un riche ouvrage en six volumes, publié de 1839 à $1849^{28}$. Les volumes contenaient de nombreuses

27. Marie-Félicité Brosset, Histoire de la Géorgie depuis l'Antiquité jusqu'au $X I X^{e}$ siècle, 7 volumes, Saint-Pétersbourg, 1848-1858, consulté sur Google Books.

28. Frédéric Dubois de Montpéreux, Voyage autour du Caucase, chez les Tscherkesses et les Abkhases, en Colchide, en Géorgie, en Arménie et en Crimée, 6 volumes, et un atlas en annexe, librairie de Gide, Paris, 1839-1849. 
cartes, des outils, des schémas, des images, et décrivaient un grand nombre de monuments (y compris certains qui n’ont pas survécu jusqu'à nous). Les observations personnelles de Bodenstedt sont aussi d'un grand intérêt.

Il décrit les habitations partout dans le Caucase, sans craindre de multiplier les détails. De manière générale, Mille et un jours en Orient est une source ethnographique très riche. À Tbilissi, il catégorise les habitations comme suit: "De grandes maisons russes modernes, construites par le gouvernement; des maisons arméniennes confortables; des maisons géorgiennes, persanes et tatares nues et inachevées ». Il s'intéresse aussi à la célèbre Assemblée tatare (qui inclut la mosquée), et à l'ancien palais Sardar à Erevan, construit sur le point le plus élevé de la ville. Celui-ci lui fit une forte impression: " Il y avait des tableaux du shah et de ses sujets, des scènes mythologiques, Catherine II et son fils, qui sera plus tard l'empereur Paul I ${ }^{\mathrm{er}}$. À l'intérieur, on trouvait de magnifiques fontaines, des vitraux superbes. "

Bodenstedt fait des descriptions de châteaux, de mosquées, d'églises mais aussi de simples habitations, ainsi que de l'architecture d'Akhaltsikhé: «Les Turcs l'appelaient le Fort, alors que les Géorgiens l'appellent le Nouveau Fort (Akhal-Tsikhé); il présente un mélange d'architecture turque et géorgienne, et les Turcs y ont ajouté quelques ornements. " Bodenstedt s'intéresse aussi à la campagne autour de Koutaïssi et à son potentiel agricole: il note un climat agréable, de l'eau en abondance, un sol fertile, mais une agriculture peu développée et une démographie faible. Il donne des informations détaillées sur les méthodes agricoles utilisées, les fruits, les baies, l'élevage, tout en décrivant les bâtiments d'Akhalkalaki: "Comme dans les régions géorgiennes, les maisons à Akhalkalaki n'ont pas de fenêtres, leur toit est plat et troué pour laisser passer la lumière. "

Bodenstedt insiste sur le fait que, selon ce qu'il lui a été donné d'observer, les Européens se font de l'Orient une image luxuriante qui est très éloignée des réalités du Caucase. Il affirme que, dans les maisons qu'il a visitées, il n'a vu que très peu d'objets de valeur: "Je n'ai rien vu de ce « luxe oriental » dont on parle dans les livres et les récits de voyage sur les Tatars, les Perses et les Géorgiens. Ils 
vivent comme dans des étables. Les maisons des riches n’ont rien à voir avec les maisons de la classe moyenne européenne. Elles ne contiennent que trois types d'objets de valeur: des tapis, des armes, des vêtements. " Bodenstedt note aussi que "contrairement à Istanbul et à Izmir, il n’y a pas de cafés à Tbilissi. »

\section{Sur les boissons et le vin}

Lors de son trajet entre la Russie et le Caucase, Bodenstedt se passionne pour tout ce qu'il voit et entend: les femmes, les langues, l'architecture, la musique, les coutumes; mais aussi pour ce qui se goûte: le vin. De son passage dans les steppes au sud de la Russie, il conclut que les cosaques du Don s'enivrent, sont paresseux et que ce sont leurs femmes qui travaillent; que Novotcherkassk est un pays où le vin est bon et où les femmes sont belles.

Il écrit ainsi que dans les tout premiers jours de sa traversée du Caucase, en route vers Tbilissi, il avait l'impression d'être dans le pays des Mille et une nuits. On l'invite à boire du vin et à écouter de la musique dans des paysages luxuriants et avec des gens passionnants. "Le vin de Kakhétie, d'une robe couleur de sang, ne cause pas de maux de tête. " Et, à propos de Mirza Schaffy, il raconte que "quand il voulait que j'écrive [sous sa dictée] un poème ou quoi que ce soit, il commençait par se servir du vin de Kakhétie, qu'il buvait lentement, plongé dans ses pensées, puis il tirait sur une pipe bourrée de bon tabac. Ensuite, il récitait. "

Il conclut finalement que les chrétiens de Russie et du Caucase boivent trop d'alcool: "Ils boivent plus de vin qu'un chameau ne boit d'eau ". Il remarque que, tandis qu'en Europe on dit " boire du vin comme si c'était de l'eau ", on dit l'inverse en Géorgie. Il demande à son mentor Mirza Schaffy, fin connaisseur du goût et des dangers du vin, pourquoi, si le vin apporte la sagesse, les Russes et les Géorgiens sont si déraisonnables (dans une traduction soviétique en azéri de 1861, "les Russes et les Géorgiens " est traduit par «les gens de là-bas ${ }^{29}$.) Comme d'habitude, Mirza Schaffy trouva une réponse imparable: les Russes ne sont pas si bêtes car, s'ils l'étaient, ils n'auraient pas pu conquérir tant de nations et régner sur elles; et

29. Friedrich Bodenstedt, Mirza Şəfi haqqında xatiralər, op. cit. 
en ce qui concerne les Géorgiens, il existe un poème sur le vin et les sages qui en boivent [il faut avoir un certain talent pour le vin].

L'un des passages les plus intéressants des souvenirs de Bodenstedt est celui qui concerne Abbasgoulou khan (de son nom complet Abbasgoulou agha Bakikanov), fils du dernier khan de Bakou, et génial touche-à-tout azéri, à la fois poète, philologue, historien, théologien et philosophe. Il fréquentait le salon littéraire de Mirza Schaffy. Bodenstedt se souvient d'une bataille poétique (chaque participant récite un poème à son adversaire) à laquelle participait Abbasgoulou khan, qu'il décrit comme " parmi les plus érudits, passionné par la Russie, parlant couramment le russe, ayant écrit sur l'histoire du Daghestan [en réalité, l'est du Caucase; il avait écrit aussi sur l'histoire des régions orientales du Caucase azéri]". L'adversaire d'Abbasgoulou khan était Mirza Schaffy. Bodenstedt raconte qu'ils citaient le Coran, déclamaient des poèmes de Saadi, de Hafiz et de Fuzûlî, et relate sa conversation avec Abbassgoulou khan. Une fois ce dernier parti, Bodenstedt demanda à Mirza Schaffy: "Pourquoi n'avez-vous rien bu devant le khan? " Mirza Schaffy répondit simplement: "Abbasgoulou khan est un homme pieux. Il est plus âgé que moi, et plus puissant. C'est un grand homme. Parce que je devais lui témoigner mon respect, je n'ai rien bu. "

\section{Sur l'Europe comparée au Caucase}

Ainsi qu'on l'a vu plus haut, Bodenstedt recourt fréquemment à des comparaisons avec l'Europe lorsqu'il décrit le mode de vie du Caucase. C'est le cas en particulier à propos des traditions amoureuses et maritales en Géorgie et au Daghestan (puisque personne n’y avait lu Werther, la conception werthérienne de l'amour y était inconnue). Il polémique également sur les femmes, l'agriculture, le niveau de vie, le luxe et le vin. Bodenstedt demeure très eurocentré, malgré son intérêt sincère pour le Caucase, pour son histoire et pour sa culture. Il continue d'affirmer tout au long de ses écrits que l'Orient est en retard par rapport à l'Europe, une idée qui se trouve exprimée en plusieurs occasions. Lors d'un séjour à Tbilissi, à propos d'un lycée, il remarque: « Ce lycée me fait penser à un Européen parmi un peuple de troglodytes. » Dans la tradition des orientalistes européens du XIX ${ }^{e}$ siècle, Bodenstedt ne recule jamais devant 
une expression tranchée. Il affirme aussi que, comparée à l'Europe, la Russie est très arriérée, et ce malgré la vaste culture russe et les effets positifs et négatifs de l'influence russe dans le Caucase, dont il prend scrupuleusement note.

Il passe également au crible tout ce que l'Orient a assimilé de la culture occidentale (et russe): "Qu'est-ce que les Géorgiens ont appris des Russes, dont la civilisation demeure mal connue? Peu de choses: leur habillement, qui ne leur est pas propre, l'usage des couverts plutôt que des doigts, les chaises, etc. Malgré les écoles ouvertes par les Russes, il faudrait au moins un siècle pour que les Géorgiens commencent à avoir une réelle production culturelle. Les nations les moins développées sont comme des enfants: elles apprennent tout ce qu'elles savent de la nation qui les domine, que cela leur soit nécessaire ou non. "

Sur le point de retourner dans son Allemagne natale, Bodenstedt assiste à la cérémonie de bienvenue organisée pour le gouverneur du Caucase Mikhaïl Vorontsov à Tbilissi. Nommé le 27 décembre 1844, le nouveau gouverneur (namestnik) arriva à Tbilissi le 25 mars de l'année suivante, et Bodenstedt quitta la ville au mois d'avril. La cérémonie lui paraît splendide, sans comparaison avec ce qui se fait en Europe: "On avait rempli certaines fontaines de vin rouge, la ville était décorée de lumières [...] il y avait des feux de Bengale, tout semblait une mer de flammes, comme si, dans les montagnes environnantes, un volcan venait d'entrer en éruption. »

Finalement, on peut voir Bodenstedt comme l'agent d'un transfert culturel à double sens. Il diffusa des connaissances sur l'Orient en Occident (dans ses écrits, de 1848 à sa mort); mais il parla aussi de l'Occident à ses amis d'Orient et les aida à mieux comprendre l'histoire, la littérature, les principes éducatifs, la religion et la vie quotidienne de l'Occident.

Le Caucase est l'une des régions du monde qui concentre le plus de diversité, grâce à ses paysages, à ses langues, à ses religions. Au cours de l'histoire, les différentes nations du Caucase ont été en contact avec celles qui les entouraient: les Persans, les Turcs, 
les Russes; dans l'Antiquité, les Assyriens, les Grecs, les Romains; plus tard, les Arabes. Tandis que l'Europe devenait une puissance mondiale, l'intérêt manifesté par les habitants du Caucase pour la culture européenne grandit, et inversement. Après la conquête russe et la longue domination russe du Caucase, l'effondrement de l'Union soviétique aboutit à la formation de trois États indépendants dans le sud du Caucase. Ces événements géopolitiques furent des moments de bascule pour l'évolution économique, politique et culturelle du Caucase. Des contacts imprévus entre cultures, et des échanges culturels divers, furent chaque fois à l'origine de nouvelles formes culturelles et laissèrent des traces dans la culture plutôt expansive du Caucase.

Ils furent nombreux à voyager dans le Caucase, à écrire sur la région, sur leur expérience et sur leurs observations: militaires, diplomates, missionnaires, marchands, scientifiques, artistes, enseignants, voyageurs... Ils contribuèrent ainsi à l'historiographie du Caucase pour laquelle, dans bien des cas, il est difficile de trouver d'autres sources. Parmi eux, Friedrich Bodenstedt, jeune Allemand de vingt-quatre ans passionné de littérature, apprit l'azéri, qu'il appelle le tatar, et le persan, grâce à son professeur Mirza Schaffy, poète, pédagogue et calligraphe originaire de Gandja. Bodenstedt explora également bien d'autres régions du Caucase.

À son retour en Allemagne, il se mit immédiatement au travail, et son livre Les Chants de Mirza Schaffy lui valut un immense succès dès sa publication en 1851. Bodenstedt, en tant que traducteur, mais aussi Mirza Schaffy et les Chants, devinrent célèbres. Plus tard, quand l'idée se fit jour que Bodenstedt était peut-être le véritable auteur du livre, les controverses se multiplièrent.

L'héritage le plus important de Bodenstedt tient probablement dans ses ouvrages historiques, ethnographiques et littéraires sur le Caucase. Son premier livre, écrit en 1848, Les Peuples du Caucase et leur combat pour se libérer du joug russe, et le second, Mille et un jours en Orient, en 1850, constituent des contributions majeures à l'étude de la région. Le Caucase demeura l'un de ses sujets favoris et il lui consacra encore plusieurs livres.

Parce que Bodenstedt n'a, jusqu'ici, pas suscité l'intérêt des chercheurs en tant qu'expert du Caucase, il est capital aujourd'hui 
d'analyser et de classer toutes les informations qu'il fournit sur le Caucase, en particulier ce qui relève de ses observations personnelles. Parfois, il manifestait un certain recul vis-à-vis des informations qu'on lui donnait, mais, le plus souvent, il ne faisait que les répéter. C'est particulièrement visible dans les cas où son expérience personnelle ne suffisait pas à compléter ou à corroborer les choses. Il comparait systématiquement l'Orient, et surtout le Caucase, à l'Occident. Même si un transfert culturel à double sens reliait les deux régions, Bodenstedt conserva un point de vue eurocentré.

Quoique lui-même ne soit pas entièrement exempt de préjugés, il réfléchissait cependant aux clichés sur l'Orient ayant cours en Europe, et aux clichés sur l'Occident ayant cours en Orient. À partir de ses observations, il conclut que les habitants du Caucase ont à la fois une tradition de sagesse et de tolérance (incarnée par Mirza Schaffy et d'autres), et une tradition où dominent « les intrigues, les trahisons [...] dans les contrées sauvages du Caucase. »

Il ne fait aucun doute que l'œuvre de Bodenstedt est une source précieuse pour les historiens. Elle reflète toute la diversité ethnique et culturelle du Caucase: sa géographie, ses langues, sa littérature, sa musique, sa culture matérielle, ses coutumes, ses traditions, son niveau de vie, ses mythes et ses religions, ses femmes, son vin, mais aussi ses guerres, ses migrations, et bien d'autres choses encore.

(Traduit de l'anglais par Chloé Thomas) 


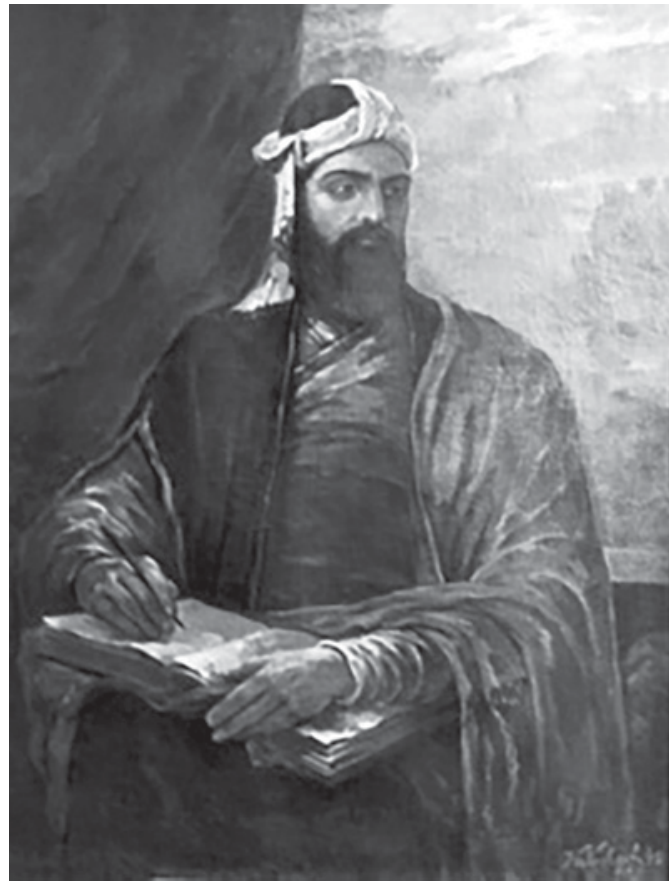

ILL. 1. Portrait de Nezâmi de Gandja, par Gazanfar Khaligov (c) Musée de la littérature azerbaïdjanaise Nizami Gandjavi (Bakou). 


\section{L'héritage de Nezâmi de Gandja, principe unificateur de la littérature orientale Rafael Huseynov}

La réputation et l'influence de Nezâmi de Gandja ${ }^{1}$, poète et philosophe azéri, dépassent largement les frontières de l'Azerbaïdjan, et son œuvre appartient au patrimoine de l'humanité.

La cité de Gandja, sur le territoire d'Arran², est aujourd'hui la deuxième ville de la république d'Azerbaïdjan. Gandja pourrait signifier, entre autres, " trésor ". Nezâmi y naquit en 1141, y mourut en 1209; si l'on en croit certaines sources médiévales, il ne quitta jamais la ville.

Lui-même pressentait que ses écrits lui survivraient longtemps; il écrivit ainsi:

$\mathrm{Si}$, dans cent ans, tu te demandes où il est,

Chacun de ses couplets te répondra: « Il est ici. » ${ }^{3}$

Or, ce n'est pas un seul siècle qui s'est écoulé depuis sa mort, mais huit. La longévité de l'œuvre de Nezâmi a largement dépassé ses propres prédictions.

1. Les translittérations françaises varient: on trouve Nezâmi chez Isabelle de Gastines, Nezâmî chez Michael Barry et, quant à la ville, respectivement Ganja, Gandja ou Gandjeh. (N. d. T.)

2. Nom qui, au Moyen Âge, désignait le territoire qui correspond à une partie de l'Azerbaïdjan et de l'Arménie actuels. (N.D.T.)

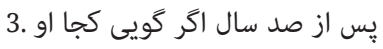

$$
\text { ز هر بيتى ندا خيزد كه ها او لونس }
$$

Kolliyyat-e Khamse-ye Nezami, Motabeq-e noskhe-ye tashihshode-ye Vahid Dastgerdi, Téhéran, Entesharat-e Rad, 1374, p. 361. Nous traduisons à partir de la traduction anglaise proposée par l'auteur (N. d. T.). 


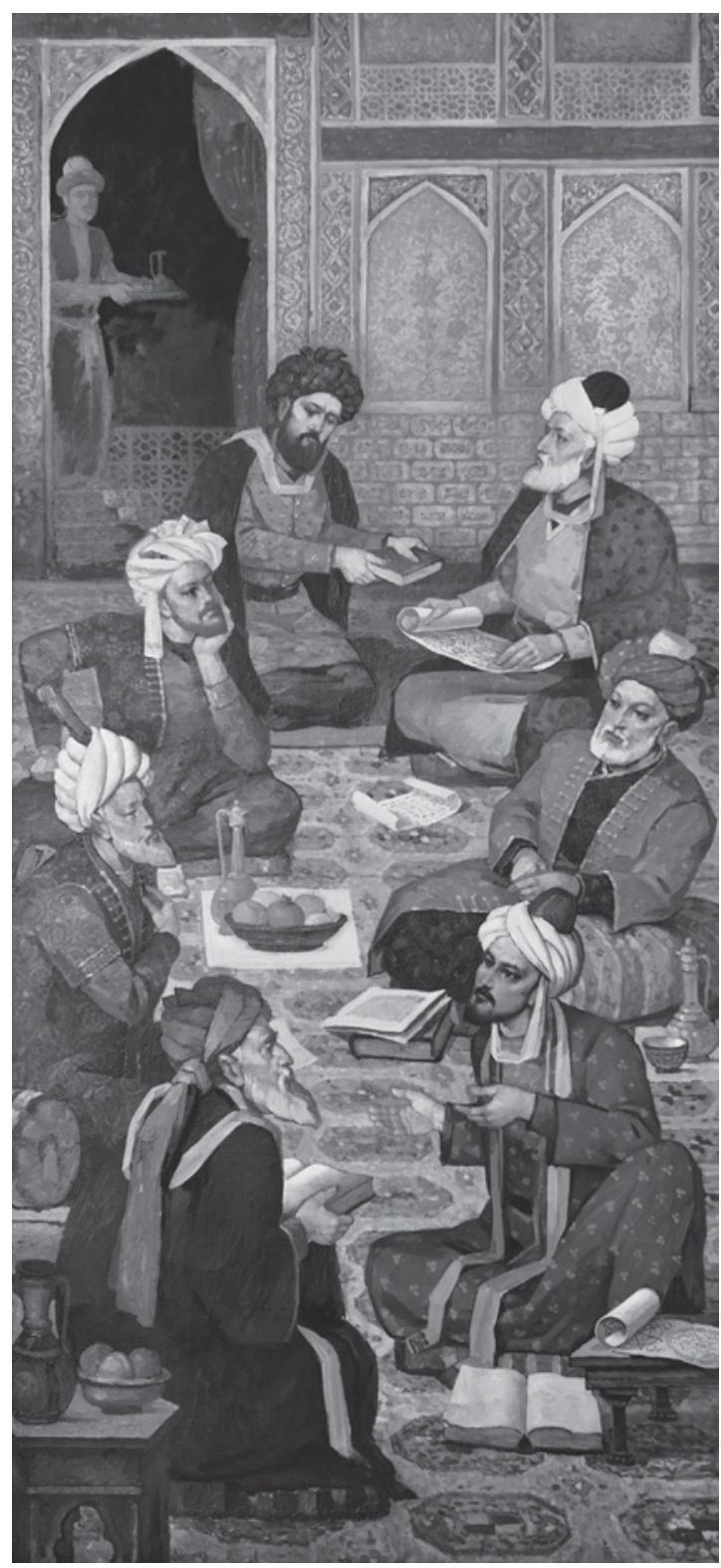

ILL. 2. Nezâmi de Gandja et ses prédécesseurs orientaux, par Oqtay Sadikhzade @ Musée de la littérature azerbaïdjanaise Nizami Gandjavi (Bakou). 
Un poète allemand de génie rendit un humble hommage à la tradition classique persanophone, laquelle distinguait seulement sept poètes parmi les plus grands: Ferdawsî, Anvari, Nezâmi, Saadi, Rûmî, Hafez et Djâmî. Il écrivit: "Si l'on ne retenait de tout l'Orient que ces sept poètes, il y en a pourtant beaucoup, parmi ceux qu'on aura laissés de côté, qui me surpasseraient ${ }^{4}$.»

Nezâmi n'était pas seulement poète: c'était aussi un scientifique accompli, en avance sur son temps. C'est pourquoi on lui octroya le titre de " hakim », c'est-à-dire " sage ». Quoique l'époque ne manquât pas de génies, seuls deux autres grands hommes eurent l'honneur d'être appelés " hakim »: Avicenne et Omar Khayyâm.

Il arrive que Nezâmi mentionne affectueusement, dans certains poèmes, son fils Mohammad, né en 1174. Aujourd'hui, nul ne sait qui composait la famille de Mohammad, ni si Nezâmi a eu, au-delà de lui, une descendance. Mais sa descendance symbolique - son œuvre littéraire - est toujours aussi vivante, aussi fameuse, aussi jeune aujourd'hui qu'il y a huit siècles. C'est là tout le pouvoir du verbe. Dans un couplet, Nezâmi adresse à son fils les conseils suivants:

Si tu prêtes attention, ô fils, à ce conseil, Du conseil d'un père tu cueilleras le fruit.

Bien que je voie ta disposition à l'excellence, Et tous les signes en toi de l'éloquence,

Ne t’astreins pas à la poésie et à son artifice:

Son mensonge en fait la séduction.

Par cet art ne cherche pas la renommée:

Sur cette voie Nezâmi est le sceau.

À la versification, bien que soit de haut rang, Préfère le savoir qui apporte profit ${ }^{5}$.

Nezâmi, dans sa grande sagesse, n'ignorait évidemment pas que la poésie lui préexistait et qu'elle allait lui survivre. Pourquoi, alors, cherchait-il ainsi à détourner son fils de l'écriture, s’il décelait chez lui un certain talent pour la poésie? Cela tient à la haute idée qu'il se faisait de la profession de poète; si son fils devait écrire, il serait

4. A. Je. Krymskij, Istorija Persii, ego literatury i derviščeskoj teosofii, Ch. 1-2, Reprintnoe izdanie 1909-1912, Sankt-Peterburg, Al'faret, 2015, p. 2.

5. Nezâmi, Layla et Majnûn, traduit du persan par Isabelle de Gastines, Paris, Fayard, 2017, p. 37-38. 
tenu d'être au moins aussi bon que son père. Or, il pressentait peutêtre qu'être le génie qu'il était n'était pas donné à tout le monde. De fait, l'existence et le destin de Nezâmi ont quelque chose de miraculeux. C'est pourquoi il encouragea son fils, qui ne semblait pas devoir le surpasser dans l'art poétique, à embrasser plutôt une autre carrière, où l'on aurait d'avantage besoin de lui. Ailleurs, Nezâmi dit peu ou prou la même chose en ces termes:

Un bourrelier en son art accompli

Vaut plus qu'un mauvais chapelier 6 .

C'est surtout au Khamseh que Nezâmi doit sa célébrité. Le Khamseh est composé de cinq masnavis (poèmes): "Makhzan alAsrar " ("Le Trésor des secrets" ${ }^{7}$ ), écrit en 1178; "Khosrow o Shirin " ("Khosrow et Shirîn ${ }^{8}$ "), écrit en 1180; "Leyli o Majnûn" ("Layla et Majnûn»), terminé en 1189; " Haft peykar » ("Les Sept Portraits" ") de 1197; et "Sekandar Nâmeh » ("La Geste d'Alexandre $\left.{ }^{10} »\right)$, terminé en 1201 et formé de deux parties intitulées "Iqual Nâmeh » et "Sharaf Nâmeh ». Nezâmi regroupa ces œuvres sous le titre Khamseh, c'est-à-dire Cinq.

Si Nezâmi avait vécu plus longtemps, il aurait certainement écrit d'avantage, et formé un ensemble non de cinq mais de sept, huit ou neuf poèmes. Mais la vie ne lui en laissa pas le temps, et il n'en termina que cinq. Après sa mort, on pressentit qu'il existait un lien organique entre ces cinq poèmes; que le poète suivait un même fil qui allait du " Trésor des secrets » à " La Geste d'Alexandre ». C'est pourquoi l'on regroupa d'abord les cinq poèmes sous le titre Panj

6. Ibid., p. 38.

7. Le Trésor des secrets, traduit par Djamchid Mortazavi, Paris, Desclée de Brouwer, 1987.

8. Le Roman de Chosroès et Chîrîn, traduit par Henri Massé, Paris, Maisonneuve \& Larose, 1970. Nous suivons ici la translittération d'Isabelle de Gastines dans l'appareil critique de Layla et Majnûn.

9. Il en existe deux traductions françaises: Les Sept Portraits, traduit par Isabelle de Gastines, Paris, Fayard, 2000; et Le Pavillon des Sept Princesses, traduit par Michael Barry, Paris, Gallimard, 2000.

10. Selon la traduction de Michael Barry proposée dans son introduction à sa traduction du Pavillon des Sept Princesses, op. cit., p. 12. 


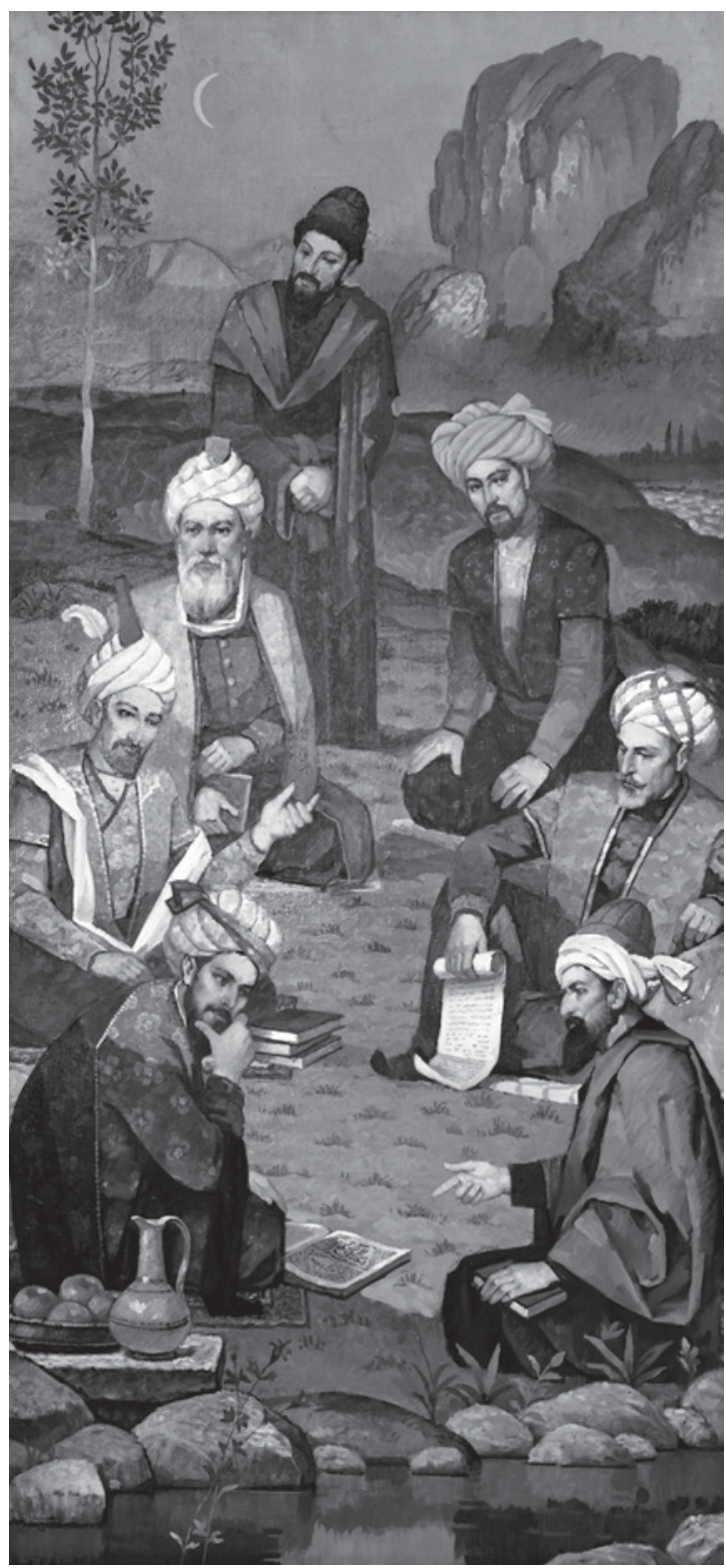

ILL. 3. Nezâmi de Gandja et ses successeurs au Proche et au Moyen-Orient, par Oqtay Sadikhzade @ Musée de la littérature azerbaïdjanaise Nizami Gandjavi (Bakou). 
La montagne des langues et des peuples

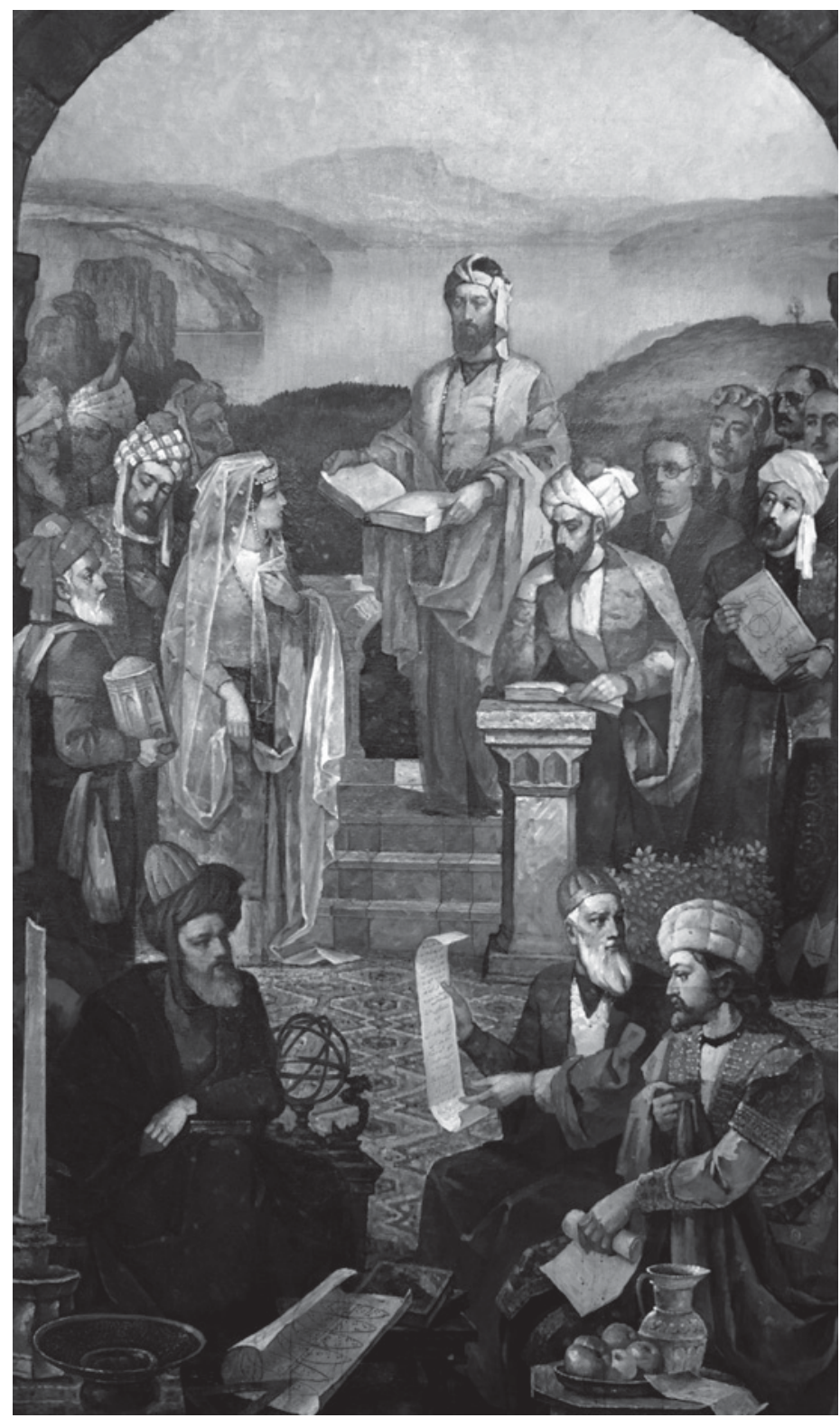

ILL. 4. Nezâmi de Gandja et la littérature azerbaïdjanaise, par Oqtay Sadikhzade @ Musée de la littérature azerbaïdjanaise Nizami Gandjavi (Bakou). 
Ganj ("Les Cinq Trésors »). Plus tard, on substitua à ce premier titre le mot arabe khamseh, qui signifie " cinq ".

L'influence de Nezâmi de Gandja a continué à s'exercer sur la littérature et la culture des siècles suivants. L'intérêt suscité par les grands thèmes qu'il évoque ne s'est pas démenti pendant huit siècles, et de nombreuses études leur ont été consacrées. Des centaines de poètes du Caucase, d'Asie centrale, du Proche et du Moyen-Orient, et même de l'Inde, adaptèrent son héritage en le transposant de plus en plus loin de son lieu de naissance, et dans plusieurs langues. Peu de poètes, dans le canon littéraire mondial, peuvent se prévaloir d'une telle influence.

Que l'œuvre de Nezâmi ait voyagé aussi loin en si peu de temps, à cette époque où les voies de communication étaient lentes, où l’imprimerie n'existait pas, voilà qui est absolument exceptionnel. On peut facilement comprendre que l'œuvre se soit rapidement diffusée dans le Caucase, en Asie centrale, en Iran et en Anatolie, compte tenu des distances assez courtes qui séparent ces territoires de la ville natale de Nezâmi. Mais, étonnamment, on trouve des imitations de la poésie de Nezâmi en Inde avant même que les terres voisines de l'Azerbaïdjan ne s'intéressent à lui. Nezâmi a donc jeté un pont entre l'Inde et l'Azerbaïdjan; c'est probablement l'un des principaux facteurs qui ont permis l'émergence d'une culture commune au Caucase et à l'Inde, que l'on retrouve aussi en Asie centrale. Nous allons maintenant brièvement montrer l'étendue de l'influence de Nezâmi dans l'Inde lointaine.

La prose et la poésie persanes sont intimement liées à la littérature indienne produite pendant plus de huit siècles dans plus de vingt autres langues vernaculaires. Parallèlement, les écrits persanophones originaires de l'Inde forment une part importante de la littérature persanophone, du $\mathrm{IX}^{\mathrm{e}} \mathrm{au} \mathrm{xx}^{\mathrm{e}}$ siècle. Celle-ci s'est développée sur un territoire gigantesque, qui va de l'Asie centrale au sud du Caucase, de l'Iran à l'Inde. À travers les siècles, la littérature persanophone a acquis un certain nombre de caractéristiques communes à tout ce territoire. Les grands bardes de chaque nation ont permis que cette littérature-monde persanophone soit intégrée aux différents canons nationaux. 
C'est aux $\mathrm{X}^{\mathrm{e}}$ et $\mathrm{XI}^{\mathrm{e}}$ siècle qu'émerge la littérature indienne de langue persane. Le sultan Mahmoud (998-1030), qui régnait sur l'empire ghaznévide, commença, à partir de l'an 1000, à mener des attaques contre l'Inde. Au terme de dix-sept assauts, il occupait une grande partie du nord de l'Inde, qu'il assimila à son vaste empire, lequel comprenait également l'Iran, l'Afghanistan et l'Asie centrale. Bien que Mahmoud fût d'origine turque, le persan était une des langues officielles du royaume ghaznévide; le sultan lui-même chérissait la littérature persane. Dès les $\mathrm{XI}^{\mathrm{e}}$ et $\mathrm{XII}^{\mathrm{e}}$ siècles, les grands poètes persanophones Abulfaj Runi Datta, Al-Hujwiri, Ata ibn Yagub et Massoud Sa'd Salman avaient acquis une solide réputation au sein de la littérature indienne.

Le premier à écrire une imitation des poèmes de Nezâmi, fondant par-là l'école littéraire qui lui est associée, fut Amîr Khosrô de Dehli (1253-1325), grand poète et musicien indien. Il écrivit un cycle de poèmes: " Matla al-anvar » ("Source de lumière »), « Shirin o Khosrow ", " Majnûn o Leyli », " Ayine-yi Iskandari » ( Le miroir d'Alexandre »), " Hasht behisht " (" Les Huit jardins du paradis »). Ces textes comptaient ensemble deux mille couplets, sous la forme de cinq naziras. Ils établirent une tradition sans équivalent dans la littérature mondiale. Amîr Khosrô de Dehli conserva du Khamseh les principales caractéristiques structurelles, les intrigues, les personnages tels que le génie de Gandja les avait posés, nonobstant quelques amendements et ajouts mineurs. Amîr Khosrô, en imitant avec autant de talent les textes de Nezâmi, qui avait pourtant mis la barre très haut, établit ainsi le standard à l'aune duquel la future littérature persanophone allait être évaluée. Dans les siècles suivants, l'exercice consistant à tenter d'égaler Nezâmi fut officieusement considéré au Proche-Orient comme l'un des passages obligés pour accéder au statut de grand poète.

Dans la littérature persane, il existe plusieurs genres qui reposent sur un rapport d'emprunt ou d'imitation entre poètes: nazira, taglid, tatabbu, istikbal, javab; et les instances en sont innombrables. Mais les réponses à Nezâmi sont, dans leur essence comme dans leur raison d'être, particulièrement originales. En premier lieu, l'imitation de Nezâmi se constitua en genre particulier, avec sa structure, ses codes propres. En second lieu, les textes issus de l'école de Nezâmi ne posent 
pas seulement des questions purement littéraires ou artistiques, mais disent quelque chose de la vision du monde, de l'idéal esthétique et de la genèse politique de la nation qui les a vus naître. Il faut donc les considérer comme le reflet de systèmes de pensée particuliers.

Le Khamseh de Nezâmi et l'école fondée par Amîr Khosrô de Dehli ont joué un rôle majeur dans la promotion d'un idéal humaniste, réunissant des hommes et des nations autour de valeurs morales supérieures, en défendant la compréhension mutuelle, la collaboration et l'amitié entre les peuples et les pays.

Après Amîr Khosrô, la première tentative de réécrire intégralement le Khamseh, dans la littérature indienne persanophone, est due à cheikh Abu al-Faiz Faizi (1547-1595), poète originaire d'Agra. Il prévoyait d'écrire cinq masnavis: "Marakiz-advar " ("Le centre du cercle »), "Salomon et Balqis ${ }^{11}$ ", " Nal et Daman », " Haft kishvar " ("Les Sept Régions du monde "), et "Akbar Nâmeh ». Mais il en termina seulement trois, les autres étant laissés inachevés ${ }^{12}$.

Muhsin Fani, poète cachemiri du milieu du XviI siècle (il mourut en 1670), parvint, lui, à terminer les quatre masnavis qu'il avait prévus en réponse au Khamseh. Dans des poèmes écrits avec beaucoup de talent, intitulés " Meykhaneh », " Masdar al-Asar » ("Source d'influence "), " Naz o niyaz " ("Coquetterie et prière »), " Haft akhtar » («Les Sept étoiles »), Fani parvint à introduire quelques innovations dans la tradition établie par le Khamseh ${ }^{13}$.

Cette tradition, y compris telle qu'elle se déployait dans la littérature indienne persanophone, laissait aux disciples de Nezâmi une certaine liberté. En particulier, ils pouvaient choisir de n'imiter que l'un ou l'autre des cinq masnavis. Par exemple, le poète pendjabi Sadig écrivit son "Shovg Nâmeh " (achevé en 1763) pour chanter l'amour de Mirza et Sahiban, dans le mode et le style de Nezâmi, comme un nazira dédié à son maître.

C'est surtout au $\mathrm{xvI}^{\mathrm{e}}$ siècle que les relations entre l'Inde et l'Azerbaïdjan se développèrent. Bairam Khan (assassiné en 1561),

11. Balqis est l'un des noms donnés à la reine de Saba. (N.D.T.)

12. G.J. Alijev, Temy $i$ čjužety Nizami v literaturah narodov Vostoka, Moskva, Nauka, 1985, p. 213-217.

13. Id., Persojazyčnaja literatura Indii, Moskva, Nauka, 1968, p. 136-139. 
originaire de la tribu azérie turcique des Baharli, était une personnalité influente de l'Empire moghol. Il faisait partie des proches de l'empereur Humayun (1530-1556), et fut le régent du futur empereur Akbar Shah. Il fut également chef des armées et grand vizir. On doit à Bairam Khan de très beaux vers en langue turcique et en persan. Il encouragea la réalisation de divers recueils littéraires et, à cette période, de nombreux poètes, artistes et savants originaires d'Iran, d'Asie centrale et du Caucase furent invités en Inde ${ }^{14}$. La tazkira (anthologie) intitulée Magalat al-shuara (La Conversation des poètes), éditée par Mir Alishir Kani (1727-1789), constitue une source précieuse d'informations sur près de sept cent poètes indiens dont la production court jusqu'au $\mathrm{XVIII}^{\mathrm{e}}$ siècle; une grande partie de leurs écrits démontrent l'influence de l'école de Nezâmi ${ }^{15}$.

Parmi tous ceux qui ont contribué à jeter des ponts entre les littératures indienne et azérie, Saeb Tabrizi (1601-1676) occupe une place particulière. Saeb fut l'un des fondateurs de ce qu'on appelle le « style indien » en littérature; il fut très populaire de son vivant en Inde, et participa énergiquement à l'adaptation et à la diffusion de la littérature indienne persanophone au Proche et au Moyen-Orient.

L'influence de Nezâmi sur la littérature indienne persanophone ne se démentit pas du XII jusqu'au Xx ${ }^{\mathrm{e}}$ siècle. Mohamed Iqbal (18471938), le fameux poète et philosophe indien, célébra ainsi la ville utopique de Maragdin, que l'on peut assimiler à la ville décrite par Nezâmi dans " Iskander Nâmeh », où régnaient la liberté, l'égalité et le bonheur.

On peut également citer Asaf Jafari (décédé en 1612), qui offrit des contributions remarquables à la littérature indienne persanophone; Malik Muhammad Kummi et Hakim Ruknaddin Masud Kashani (actifs aux XVI ${ }^{\mathrm{e}}$ et XVII ${ }^{\mathrm{e}}$ siècles); Agha Muhammad Tahir Razi Vasli, Laig Jaunpuri, Sheyda Mehdi bin Muhammad, Tabi Golkondavi et Muhammad Gulu Salim Sai au XviI ${ }^{\mathrm{e}}$ siècle; Arshi et Hajji Rabi Anjab Maghrebi au XviII ${ }^{\mathrm{e}}$ siècle; Moulavi Muhammad Abdurrauf Vahid et Abul Asim Abd al-Halim au XIX siècle; Muhammad Hadi

14. R. Gusejnov, Voznesenie slova, Bakou, Izdatel'stvo Nauka i obrazovaniye, 2014, p. 571-610.

15. G.J. Alijev, Persojazyčnaja literatura Indii, op. cit., p. 185. 
Mirza Rusva (1857-1931), qui lança en Inde la grande tradition réaliste en prose en langue ourdoue; et Kartar Singh Duggal ${ }^{16}$, dramaturge indien $\mathrm{du} \mathrm{xx}^{\mathrm{e}}$ siècle. Tous ont, avec bonheur, continué la tradition littéraire de l'école de Nezâmi, par leurs réécritures des masnavis du Khamseh.

L’héritage de Nezâmi de Gandja a joué un rôle capital dans les relations entre l'Inde et l'Azerbaïdjan, qui se développèrent grâce à un jeu d'influences régulières et mutuelles. C'est à Nezâmi que l'on doit, pour une large part, le tour positif pris par ces relations. En Inde, c'est Amîr Khosrô de Dehli qui écrivit pour la première fois cinq poèmes en réponse à ceux de Nezâmi; ce faisant, il posa les bases d'une tradition et définit les contours de l'école de Nezâmi. En d'autres termes, par son propre Khamseh, Amîr Khosrô fixa les règles de l'exercice littéraire consistant à tenter d'imiter Nezâmi: il fallait préserver l'intrigue, les personnages et les principes de base; l'auteur de la réécriture devait faire la preuve de son talent par la qualité de son expression, par son style et par la finesse de son vocabulaire.

Pour bien comprendre ce qui fait l'essence de l'école de Nezâmi, et pourquoi son influence s'est ainsi étendue sur un territoire aussi vaste, il faut nous intéresser de plus près à l'un des poèmes de Nezâmi. Toutes ses œuvres ont été admirées et chacune a fait l'objet de multiples réécritures; cependant, il en est une qui s’est révélée particulièrement attirante pour les auteurs postérieurs. Il s'agit du poème consacré à l'amour tragique de Layla et Majnûn. C'est le plus émouvant, et celui qui a fait l'objet du plus grand nombre de réécritures.

Ah, jamais il n'y eut d'histoire plus tragique

Que celle de Juliette et de son Roméo $!^{17}$

C'est en ces termes que William Shakespeare évoque la plus célèbre tragédie amoureuse d'Europe. Il avait raison: car toute histoire d'amour malheureuse est malheureuse à sa façon, et

16. I. Serebrjakov, Pendjabskaja literatura Kratkij očerk, Moskva, Nauka, 1965, p. 153.

17. William Shakespeare, Roméo et Juliette, traduit par Yves Bonnefoy, Paris, Mercure de France, 1968, p. 177. 


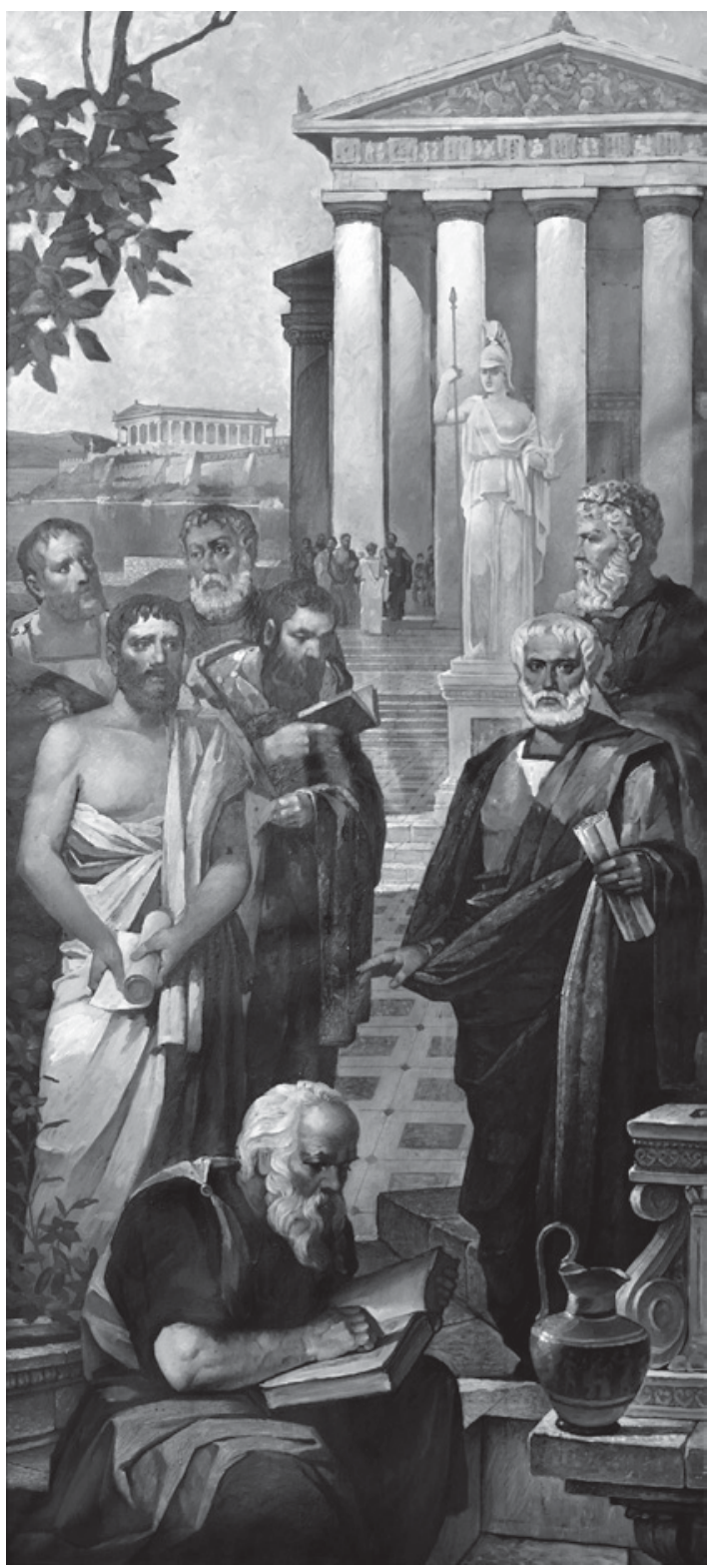

ILL. 5. Nezâmi de Gandja et ses prédécesseurs de l'Antiquité, par Oqtay Sadikhzade @ Musée de la littérature azerbaïdjanaise Nizami Gandjavi (Bakou). 
sa tragédie propre est d'une ampleur unique. Cependant, plusieurs siècles avant que Shakespeare n'écrive Roméo et Juliette vécurent deux amants dont l'existence est historiquement avérée: une fille, Layla, et un garçon, Qays, devenu "Majnûn" par l'effet de sa passion dévorante ${ }^{18}$. Plusieurs sources confirment qu'ils ont bel et bien existé19. Dès avant le XII ${ }^{\mathrm{e}}$ siècle (c'est-à-dire l'époque où vécut Nezâmi), on trouvait des contes populaires faisant le récit de l'amour tragique de Layla et Majnûn. Trois sources écrites reprenaient une partie de ce qui avait été transmis oralement dans les fables. Naturellement, Nezâmi, lorsqu'il écrivit son poème appelé à devenir très populaire, puisa à la fois dans les fables du folklore sur Layla et Majnûn, et dans les documents écrits.

La plus ancienne de ces sources est due à Ibn Qoutayba, qui avait enseigné à Bagdad et y mourut en 890. Dans son livre Kitab al-shiir va-l-shuara (Livre de la poésie et des poètes), il dit quelques mots du jeune homme appelé Qays ibn Muwallah, lesquels confirment les sources orales précédentes; il écrit que Qays avait été rendu fou par l'amour ${ }^{20}$.

D'après les fables qu'Ibn Qoutayba reprend, deux enfants faisaient paître des chamelons. Majnûn, le jeune garçon, beau, intelligent, sachant par cœur de nombreux vers, s'éprend de la fille. Son amour atteint de tels sommets qu'il fuit le monde des hommes et s'en va errer dans le désert parmi les bêtes sauvages. Quand le hasard mettait quelqu'un sur son chemin, il ne répondait pas aux paroles qu'on lui adressait: soit qu'il n'entendît pas, soit qu'il ne comprît pas. C'est seulement quand on prononçait devant lui le nom de Layla qu'il revenait à la vie, et pouvait entrer en conversation.

Dans ce livre, Ibn Qoutayba présente l'une après l'autre les diverses fables de Layla et Majnûn qu'il a tirées de sources orales

18. On peut comparer à I.J. Kračkovskij, Rannjaja istorija povesti o Mejnune i Leyle $v$ arabskoj literature. $V$ knige: Vydajuščijecia russkie učenye i pisateli o Nizami Ganjevi, Bakou, Izdatel'stvo Jazyčy, 1981, p. 183.

19. S. Asadullajev, «Leyli i Mažnun » v farsijazyčnoj poezii. Čast’ 1, Dušanbe, Izdatel'stvo Doniš, 1981, p. 16-18

20. M.J. de Goeje, Ibn Qotaiba. Liber poesis et poetarum quem edidit, Lugduni Batavorum, E. J. Brill, 1904, p. 355. 
et écrites des $\mathrm{VII}^{\mathrm{e}}$ et $\mathrm{VIII}^{\mathrm{e}}$ siècles. Il y recueille aussi les vers écrits par Majnûn, présentés comme des poèmes épars ${ }^{21}$.

Abu-al-Faraj al-Isfahani, d'une génération un peu postérieure à Qoutayba, reprend, dans son Kitab al-Aghani ("Livre des chansons ") les principales fables et poésies que l'on trouve déjà chez ce dernier, mais il va un peu plus loin, caractérisant Majnûn non seulement par son amour mais par son talent de poète, avec nombre de détails. Abu-al-Faraj avait véritablement fait des recherches sur ce point, et prend soin de citer la plupart des sources et des auteurs sur lesquels il se fonde ${ }^{22}$. Il raconte que beaucoup de jeunes filles avaient déclaré leur flamme à Majnûn, mais que celui-ci n'entretint jamais de relations avec elles et n'aima jamais que Layla. Par ailleurs, Abu-al-Faraj précise que Layla aussi était poète; il évoque la correspondance en vers des deux amants. Rien au monde, dit-il, n'était plus aimable que Layla aux yeux de Majnûn. Celui-ci réserva ensuite son affection aux gazelles du désert, parce qu'elles lui rappelaient Layla. D'après l'une des fables du Kitab al-Aghani, Majnûn rencontra un jour des chasseurs qui avaient pris des gazelles dans leurs rets. Il libéra les gazelles, après avoir donné aux giboyeurs des moutons en échange du produit de leur chasse ${ }^{23}$.

Un troisième recueil médiéval de contes et de poèmes en lien avec Majnûn s'intitule Divan-i Majnûn. Il fut composé par Abu Bakr al-Valibi au XII ${ }^{\mathrm{e}}$ siècle ${ }^{24}$. L'une des histoires les plus intéressantes que l'on trouve dans ce livre-ci concerne la rencontre entre Majnûn et le calife Abd al-Malik ibn Marwan (685-705). La fable raconte que lorsqu'il est présenté au calife, Majnûn lui récite l'une de ses célèbres odes. Le calife, séduit par le poème, veut récompenser Majnûn par des cadeaux précieux. Majnûn décline les présents, et s'en va. Quelques temps après, les messagers du calife rejoignent le

21.J.E. Bertels, Izbrannye trudy. Nizami i Fuzuli, Moskva, Vostočnaja literatura, 1962, p. 242-245.

22. Abu-al-Faraj al-Isfahani, Kniga pesen, Moskva, Vostočnaja literatura, 1980, p. 12-13.

23. Abu-al-Faraj Isfahani, Rasskazy o Kajse ibn Mulavvakhe po prozvišču Mejnun i arabojazyčnyh poetah. Filologičeskij perevod s arabskogo. Predislovie, issledovanie, kommentarii i ukazateli G.B.Bahšalievoj, Baku, Elm, 2006, p. 198.

24. I.J. Kračkovskij, op. cit., p. 188-189. 
jeune homme à cheval et lui transmettent l'ordre du calife: il ne doit pas aller à la rencontre de la tribu de Layla. Majnûn leur annonce que le calife dont l'ordre émane est déjà mort. "Comment le saistu? ", demandent les messagers. " Des oiseaux me l'ont dit ». Les messagers, cependant, n'en croient mot, et y entendent plutôt une nouvelle preuve de la folie du jeune homme. Mais à leur retour, ils apprennent, stupéfaits, la mort du calife. Pendant ce temps, Majnûn, sur la route, rencontre deux cavaliers qui lui apprennent la mort de sa bien-aimée. Il les prie de le mener à la tombe de Layla. Les cavaliers s'exécutent et, dès que Majnûn arrive sur la tombe, il se jette à terre pour embrasser le sol, et meurt ${ }^{25}$.

Dès avant Nezâmi, les noms de Layla et Majnûn sont mentionnés en passant dans les œuvres de quelques poètes azéris. $\mathrm{Au} \mathrm{XI} \mathrm{x}^{\mathrm{e}}$ siècle déjà, Baba Kuhi Bakuvi, Qatran Tabrizi et Baba Tahir Oryan chantèrent ces deux colombes et en firent l'incarnation de l'amour le plus pur. Nezâmi de Gandja, en revanche, fut le premier à choisir, parmi les diverses fables existantes, celles qui étaient les plus belles et les plus marquantes, et à les enfiler, comme des perles précieuses, sur le fil d'une seule intrigue. Cela donna naissance à une histoire d'amour parfaite, et témoigne de l'audace littéraire du poète.

Nezâmi de Gandja ne dépendait d'aucun palais; il vivait humblement, et resta libre. Cela le distingue de la plupart de ses prédécesseurs et de ses contemporains. Au contraire, ce sont les palais qui, quand le besoin s'en faisait sentir, faisaient appel à Nezâmi, lequel ne rechignait pas à accepter des commandes portant sur certains thèmes universels. "Layla et Majnûn " fut ainsi écrit, en partie, pour honorer la commande passée par le roi de Shirvân, Akhsatân ${ }^{26}$. Il faut préciser que la commande du roi de Shirvân ne portait pas simplement sur une histoire d'amour mais bien, plus spécifiquement, sur le thème des deux personnages. Il ne faut donc pas sous-estimer le rôle qu'a joué Akhsatân dans le passage de Layla et Majnûn à la grande littérature.

25. J.E. Bertels, op. cit., p. 248.

26. Kolliyyat-e Khamse-ye Nezami. Motabeq-e noskhe-ye tashihshode-ye Vahid Dastgerdi (Leyli va Majnûn), Téhéran, Entesharat-e Rad, 1374, p. 454-457. 
L’Azerbaïdjan du XII ${ }^{\mathrm{e}}$ siècle ne manquait pas de grands poètes, de prosateurs ni de savants. À Gandja vivaient également Qasym de Gandja; le frère de Nezâmi, Qivami Mutarrizi; son ami d'enfance, Abu Bakr ibn al-Ustad ${ }^{27}$; ou encore cinq femmes maîtrisant l'art du rubaï et qui formaient l'assemblée des poétesses, avec à leur tête Mahsati. Dans la province du Shirvan vivaient les poètes Abu-al-ula, Khaqani, Falaki, Qiyasaddin et Izzaddin. On peut également citer Mujiradin, qui vivait à Beylagan ou, dans la ville de Tabriz, Nizam et d'autres écrivains. Le XII ${ }^{\mathrm{e}}$ siècle fut un des âges d'or de la littérature azérie, et chacun de ces poètes aurait légitimement pu être considéré comme le plus grand de son siècle. Mais leur malheur fut qu'ils étaient les contemporains de Nezâmi.

Évoluant dans le même univers poétique que lui, ils étaient comme les planètes tournant autour du soleil. Bon gré mal gré, leurs magnifiques créations se virent privées de lumière. Néanmoins, le fait de fréquenter le cercle de Nezâmi fut déterminant pour leur production poétique, puisque cela les poussa à écrire d'avantage et à s'encourager mutuellement. Que l'on ait commandé à Nezâmi de s'attaquer à un sujet aussi monumental que l'histoire de Layla et Majnûn, qui jusque-là n'avait pas fait l'objet d'un traitement complet dans la littérature, est un signe supplémentaire du respect dont le poète était entouré.

La plume de Nezâmi a fait renaître l'histoire de Layla et Majnûn; c'est par lui que leur amour est, véritablement, devenu éternel. Aujourd'hui, plusieurs centres d'archives à travers le monde possèdent des copies du Khamseh et de "Layla et Majnûn " de Nezâmi; il n'y en a pas deux qui soient absolument identiques. Le nombre de chapitres dans « Layla et Majnûn " oscille entre 67 et 70, selon les versions. Dans les éditions imprimées, ce nombre est parfois réduit, sans que cela compromette le pouvoir évocateur de l'œuvre.

Le père de Majnûn prend une ultime mesure pour tenter de remettre son fils dans le droit chemin et lui faire oublier son amour. Il l'emmène à la Kaaba, le saint des saints musulman de La Mecque.

27. G. M. Meredith-Owens, An Early Persian Miscellany, Iran and Islam, Édimbourg, ed. C. E. Bosworth, 1971, p. 435-441. 
Là, il ordonne à Majnûn de se repentir et de prier Dieu qu'il le laisse oublier Layla, la femme qui lui a fait perdre la raison.

Mais au lieu de se repentir et d'oublier Layla, Majnûn prie Dieu qu'il fasse encore grandir son amour. De toute évidence, sa prière a été entendue: le temps passant, l'amour de Majnûn ne s'est pas émoussé et, toujours passionné, il a traversé les siècles pour édifier chaque génération et transmettre un idéal de dévotion et de fidélité.

Si l'on met de côté le poète indien du XIII ${ }^{\mathrm{e}}$ siècle Amîr Khosrô de Dehli, qui fut le premier à réécrire le "Layla et Majnûn " de Nezâmi et produisit donc le deuxième poème composé sur ce modèle, c'est le distique éponyme du poète azéri Mehmed Fuzûlî (1494-1556) qui reçut le plus d'éloges, parmi les douzaines de versions de "Layla et Majnûn " écrites en persan, en azéri, en ancien ouzbek (turc tchaghataï), en ottoman, en kurde... Ce texte de Fuzûlî dépasse toutes les autres versions de "Layla et Majnûn " par la puissance de son lyrisme. Ce n'est pas un hasard si Uzeyir Hajibeyov, fondateur de la musique savante azérie, composa un opéra intitulé Leyli et Mejdnoun à partir de ce poème de Fuzûlî; ce fut le premier opéra composé en Azerbaïdjan et dans tout l'Orient.

Mais parmi les autres distiques composés sur la même intrigue, qu'ils soient écrits en persan par Ali ibn Nasir Tabrizi, Muhammad Qasym Movji, Hossein Zamiri, Shah Jahan Hindu, Mirza Muhammad khan Kirmanshahi, ou en turc azéri par Alishir Navoï, Hamdi, Khalifa, Sevdai, Khayali ou encore Chakari, tous possèdent des qualités propres qui les distinguent des autres « Layla et Majnûn » de la poésie orientale.

Même si tous les palais ouvraient leurs portes à Nezâmi, lui préféra s'en tenir éloigné. Il goûtait plutôt une vie calme et indépendante. Mais sa porte à lui était grande ouverte, et chacun était invité à passer son seuil et à profiter de son hospitalité. Cette invitation, qu'il formula il y a huit siècles, n'a rien perdu de sa validité: quiconque passe sa porte est toujours aussi bien accueilli.

Ne ferme ma porte à personne

Car il n'est pas bon de rester porte close

Puisque l'on dit que nous sommes « une mer »

Notre porte devrait être ouverte comme la mer. 
Laissez venir à moi ceux qui me cherchent

Qu'ils voient la porte du prince des poètes ${ }^{28}$.

Alors que les splendides palais des shahs ont subi les outrages du temps, le palais du verbe construit par Nezâmi ne cesse, malgré son antiquité, de gagner en solidité, en beauté, en jeunesse.

Cela tient certainement au fait que Nezâmi écrivait au nom de toute l'humanité:

Comment celui qui fait un monument de pierre

Pourrait-il ne pas admirer les hommes ${ }^{29}$ !

C'est à lui-même que ces mots semblent être adressés. En effet, c'est bien parce que Nezâmi a toujours eu de l'admiration pour ses prochains et qu'il a voulu chanter leurs plus belles qualités qu'il a pu construire de tels « monuments " littéraires.

Toi qui es homme, va avec les hommes

Car les hommes sont faits pour se mêler ${ }^{30}$.

Cette idée, qui est au cœur de l'humanisme, est au principe de l'art de Nezâmi. Elle est présente de la première à la dernière rime de chaque texte du poète. Nezâmi fait partie des auteurs médiévaux les plus difficiles à lire et à comprendre; mais cela ne tient pas essentiellement à la complexité de son langage. En effet, bien qu'il ait écrit il y a huit siècles, sa langue diffère peu du persan moderne, à l'exception de quelques archaïsmes. Ce qui rend ses écrits d'un abord difficile,

28.

$$
\begin{aligned}
& \text { در ما به روى كسى در مبند } \\
& \text { كه در بستن در بود نايسن } \\
& \text { جو ما را سخن نام دريا نهاد } \\
& \text { در ما جو دريا ببايد كَشاد } \\
& \text { رها كن كه آيند جويندكان }
\end{aligned}
$$

Kolliyyat-e Khamse-ye Nezami (Sharaf Nâmeh), op. cit., p. 1094. Pour cette citation et les suivantes, nous traduisons à partir de la traduction anglaise proposée par l'auteur. (N. d. T.)

29.

$$
\begin{aligned}
& \text { كسى در بند مردم جون نباشد }
\end{aligned}
$$

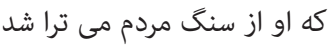

Kolliyyat-e Khamse-ye Nezami (Khosrov va Shirin), op. cit., p. 250.

30.

$$
\text { كه با مردم در آميز آر مردمى خورَ آدمى }
$$

Kolliyyat-e Khamse-ye Nezami (Sharaf Nâmeh), op. cit. p. 1032. 
c'est l'extrême précision avec laquelle il travaillait chaque couplet, donnant à un même mot plusieurs sens, multipliant les ambiguïtés au sein de chaque vers. C'est pour cela que l'on ne peut pas le lire distraitement: il faut lire et relire mot par mot, vers par vers, couplet par couplet, pour découvrir des sens cachés et repenser le sens général d'un couplet ou d'un fragment à partir de cette découverte ${ }^{31}$.

Les poèmes de Nezâmi forment une encyclopédie de son temps, le XII ${ }^{\mathrm{e}}$ siècle. Le Khamseh est sans doute l'une des sources les plus fiables pour qui s'intéresse aux mentalités de cette époque, à la vie publique et politique, à l'architecture, à l'art, à l'économie ${ }^{32}$.

Nezâmi lui-même était conscient de l'héritage qu'il allait laisser; il avertit ainsi son lecteur que les poèmes qu'il a sous les yeux n'ont pas pour seule fonction de le divertir:

J'ai parlé, et je suis parti; mais l'histoire demeure;

On ne peut pas la lire que pour le plaisiri ${ }^{33}$.

Les plus grands spécialistes de Nezâmi sont les premiers à le reconnaître: ils ne sont pas parvenus à déplier entièrement toutes les significations potentielles contenues dans les couplets du poète. La richesse sémantique des paroles de Nezâmi est infinie; une glose exhaustive couvrirait pour chaque couplet autant de pages qu'il en a fallu à Nezâmi pour le Khamseh tout entier. Nezâmi dit justement:

Le commentaire d'une parole dépasse la parole elle-même ${ }^{34}$.

Ce qui fait de Nezâmi un poète de portée internationale, ce n'est pas seulement son aptitude quasi magique à se jouer des mots, à transmuter leurs formes et leurs sens. Cela, c'est seulement l'une des

31. Cf. Johann-Christoph Burgel et Christine van Ruymbeke (éds.), A key to the treasure of the Hakim. Artistic and humanistic aspects of Nizami Ganjavi's Khamsa, Leyde, Leyden University Press, 2011.

32. Očerki istorii rasprostranenija Islamskoj civilizacii, vol. 1, Moskva, Izdatel'stvo Rosspen, 2002, p. 451, p. 454.

33.

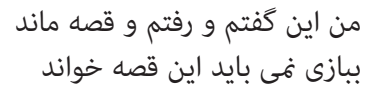

Kolliyyat-e Khamse-ye Nezami (Iqbal Nâmeh), op. cit., p. 1453.

34.

$$
\text { شرح سخن بيشتراست از سخن }
$$

Kolliyyat-e Khamse-ye Nezami (Makhzan al-asrar), op. cit., p. 19. 
nombreuses qualités qui autorisent à classer Nezâmi de Gandja parmi les génies. Nezâmi avait beaucoup lu. Il ne s'intéressait d'ailleurs pas seulement aux sources écrites en azéri-turc, en persan ou en arabe. Il disait lui-même avoir également pris connaissance d'un certain nombre de sources chrétiennes et juives. Soit il savait toutes ces langues, soit la médiation d'un tiers lui permit d'accéder au contenu de ces sources. En tous les cas, il parvint à acquérir une vaste connaissance du monde; c'est cela qui l'autorisa à créer un univers littéraire touchant toutes les cultures du monde. Nezâmi vivait à Gandja, ville de la Renaissance orientale, et il fait partie de ceux qui ont impulsé cette Renaissance, par sa vie et par ses œuvres. Le génie de Nezâmi dépassait largement les frontières, car il savait qu'il appartenait avant tout au genre humain. Le choix des personnages principaux de ses couplets en est une superbe illustration: ceux-ci peuvent être aussi bien persans ou arabes que grecs. Par ce choix, Nezâmi ne cherchait pas tant à faire de chacun d'eux l'incarnation du pays dont ils venaient; il s'agissait plutôt de représenter, dans la littérature, un idéal humaniste et universaliste. Mais ce n'est pas un hasard si les personnages principaux et secondaires de ses poèmes représentaient à eux tous des dizaines de nations différentes. C'était là tout à fait délibéré de la part de Nezâmi; c'était une façon pour lui de prouver, une nouvelle fois, qu'il écrivait sur le peuple et pour le peuple, et que ses poèmes n'étaient pas destinés à être lus par une seule nation, mais par nombre d'entre elles - ce qui, d'ailleurs, fut le cas.

En effet, Nezâmi fait partie des auteurs classiques dont les poèmes ont été traduits dans de nombreuses langues. Et à n'en pas douter, d'autres traductions viendront encore s'ajouter, dans les temps futurs, à celles qui existent déjà.

L'œuvre de Nezâmi ne propose pas seulement un modèle littéraire qui sera repris à travers les siècles; elle offre également un modèle aux idées de nation, d'État, de spiritualité, à la pensée. Les idéaux portés il y a huit siècles par Nezâmi sont encore valides. L'humanité n'a pas fini de lutter pour défendre les vertus qu'il s'efforçait de discerner dans les individus et dans les sociétés.

Dans son dernier poème (la partie de "Iskander Nâmeh " qui s'intitule "Iqual Nâmeh »), Nezâmi décrit une cité qui lui était apparue en rêve, et qu'il souhaitait voir advenir en réalité. Par la 
description de cette utopie, Nezâmi, avec d'autres grands esprits, a indéniablement contribué aux progrès de l'humanité. Dans cette ville idéale règne l'égalité entre tous; le respect des droits humains y est la norme. Quant à l'argent, il a déjà été supprimé. Il n’y a pas de police, car on n’en a plus besoin: dans une société éclairée et disciplinée, plus personne n’enfreint la loi.

Nous sommes pacifiques et pieux,

Jamais nous n’avons dévié de la vérité,

Nous ne faisons rien en nous cachant

Nous n'avons que des occupations honnêtes

Si le faible nous demande de l'aide, nous lui tendrons la main

Si nous rencontrons des difficultés, nous prendrons notre mal en patience

Aucun de nous ne possède plus que son prochain

Toutes nos possessions, nous les avons partagées équitablement

entre nous

Chacun est notre égal

Si l'un de nous est triste, nous ne pouvons être dans la joie

Nous n'avons pas peur des voleurs

Nos villes n’ont pas d'armée, ni nos rues de gardiens

Nos maisons n’ont pas de clé, pas de serrure,

Nos troupeaux n'ont pas de berger

L'or et l'argent, nous ne les comptons pas

Car personne n'en a besoin

Nous mangeons peu, comme les bœufs et les ânes,

Mais ne refusons pas la chère que nous aimons

Personne, parmi nous, ne meurt jeune

Seuls meurent ceux qui ont eu une longue vie ${ }^{35}$.

Le jour n'est pas encore arrivé où nous jouirons de ce monde, de cette vie que Nezâmi a rêvés. Mais cela fait huit siècles, cela fait des milliers d'années que l'humanité se languit d'un tel bonheur.

35.

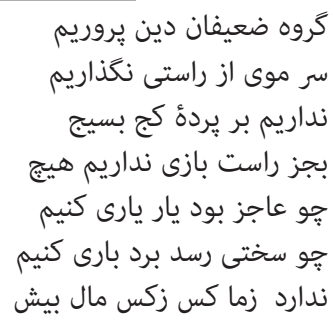


Nezâmi encouragea les générations qui lui ont succédé à tendre encore vers l'établissement d'une telle société et, en sus, il leur montra par quels moyens on pouvait y parvenir. C'est pourquoi sa lumière nous est encore indispensable aujourd'hui.

L'une des grandes qualités de Nezâmi, ce qui le rend si exceptionnel, c'est que les modèles qu'il a établis, à la fois par son mode de vie et par ses œuvres, ont contribué à rapprocher des pays et des nations. À travers son savoir, les langues qu'il maîtrisait, les livres qu'il avait lus, Nezâmi était l'héritier de toute la culture et de toute la science qui le précédaient. C'est parce que son éducation avait des fondations si solides qu'il put laisser derrière lui en héritage un trésor dont beaucoup, en Orient comme en Occident, se réclament, continuant, aujourd'hui encore, la tradition qu'il a établie.

Dans ses œuvres littéraires, on voit les cultures se mêler; le Khamseh devint, en quelque sorte, un appel aux poètes successifs de toutes les nations. Cette invitation lancée à travers les siècles, il est aujourd'hui plus urgent que jamais d'y répondre; car elle proclame que la patrie véritable de tout individu, ce sont les valeurs, la culture qui forment son monde intérieur, plutôt que les frontières imprimées arbitrairement sur le sol.

(Traduit de l'anglais par Chloé Thomas)

$$
\begin{aligned}
& \text { همه راست قسميم در مال خويش } \\
& \text { شماريم خود را همه همسران } \\
& \text { نخند يم بر كرئه ديخران } \\
& \text { ز دزدان نداريم هركز هرئ دراس درئ دران }
\end{aligned}
$$

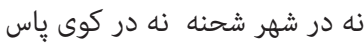

$$
\begin{aligned}
& \text { نداريم در خانها قفل و بند نه دئن } \\
& \text { نكهبان نه با كاو و با كوسفند } \\
& \text { فريب زر و سيم را در شمار } \\
& \text { نياريم و نايد كسى را بكار } \\
& \text { نه بسيار خوريم جهون كَاه و خر خر ني }
\end{aligned}
$$

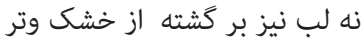

$$
\begin{aligned}
& \text { زما در جوانى نهى رد كسى ليى كيته }
\end{aligned}
$$

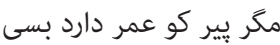

Kolliyyat-e Khamse-ye Nezami (Iqbal Nâmeh), op. cit., p. 1427. 


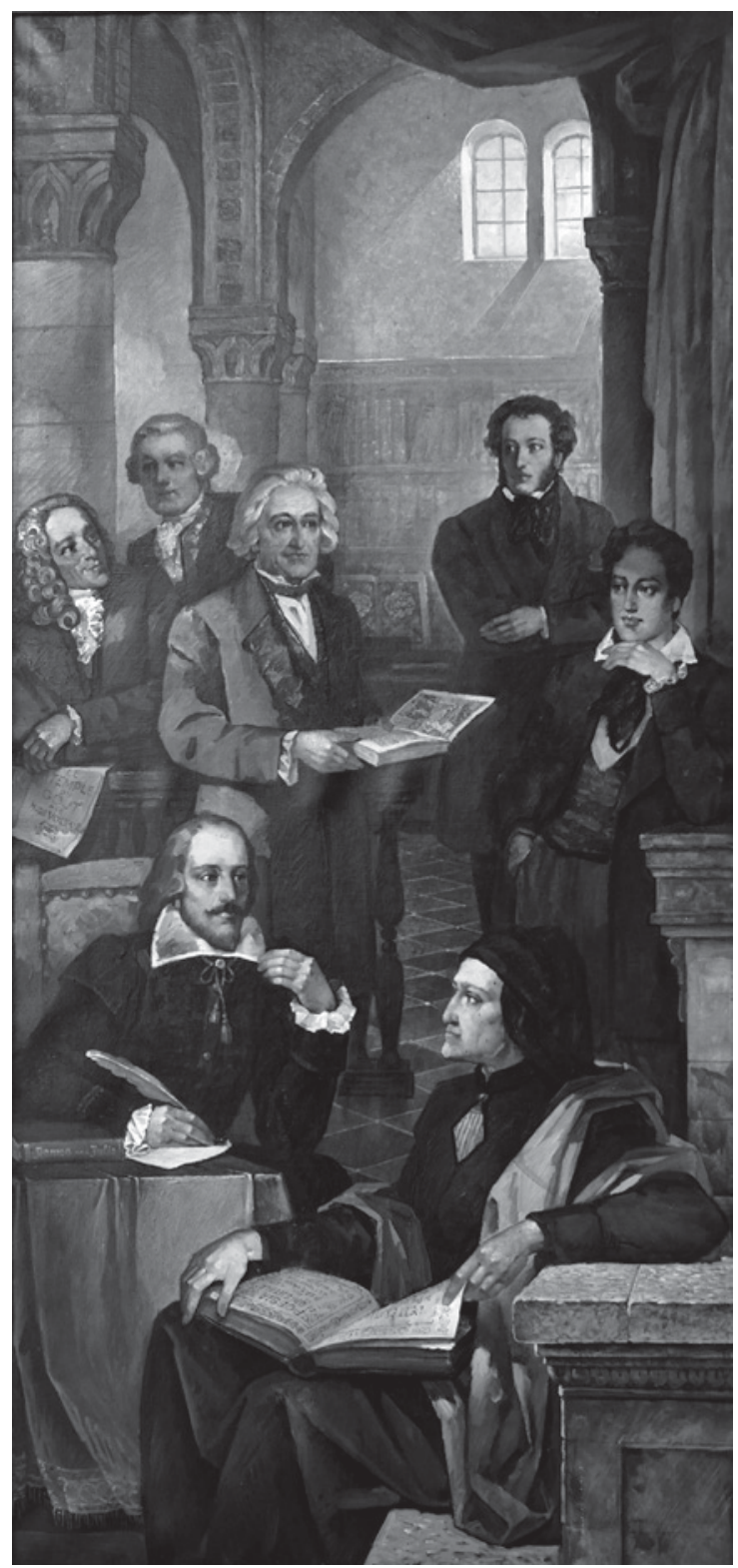

ILL. 6. Nezâmi de Gandja et la littérature européenne, par Oqtay Sadikhzade @ Musée de la littérature azerbaïdjanaise Nizami Gandjavi (Bakou). 



\title{
Le monde de la poésie de Chota Roustavéli
}

\author{
Changements de paradigme \\ dans un contexte multiculturel \\ Nino Pirtshkalava
}

Deux préalables s'imposent lorsque l'on veut considérer la poésie de Chota Roustavéli (v. 1172 - v. 1216) dans sa dimension multiculturelle. Tout d'abord, il faut mettre en lumière l'importance de l'œuvre au sein de la tradition géorgienne; ensuite, analyser le contexte transnational dans lequel l'œuvre est née. Notre travail portera principalement sur les évolutions des concepts d'amour et de liberté dans les cultures orientale et occidentale à différentes époques. En effet, chaque période historique se dote de son propre idéal amoureux, canonisé ou, pour reprendre l'expression de Niklas Luhman, possédant son propre " code symbolique » déterminant les émotions et auquel l'idéal doit être associé ${ }^{1}$. Les évolutions de cet idéal reflètent la transition d'une société traditionnelle à une société moderne. Depuis que l'amour est devenu un motif récurrent dans les productions artistiques et littéraires, la "sémantique de l'amour " a connu plusieurs stades de développement. Cette évolution-même peut d'ailleurs être prise pour sujet par des œuvres d'art. Le fondement sexuel, naturel et organique de l'amour est dissimulé et raffiné par le recours au sentiment, à l'émotion et à la passion, qui sont décrits, représentés et éprouvés dans les œuvres d'art suivant la tradition artistique et le canon littéraire de l'époque concernée.

1. Niklas Luhmann, Liebe als Passion: zur Codierung von Intimität, Francfort-surle-Main, Suhrkamp, 1994, p. 9 (non traduit en français). 
Selon la terminologie de Max Weber, l'amour courtois des chevaliers du Moyen Âge (Ritterminne), pensé comme un "service érotique de vassalité ${ }^{2}$ ", comme la sublimation de la sexualité en " érotisme ", contraste avec le "naturalisme terre à terre des paysans " et se voit élevé à une "sphère cultivée et extra-quotidienne " ${ }^{3}$. L'érotisme, en tant qu'il entretient « un rapport de vive tension avec la force irrationnelle ${ }^{4}$ ", apparaît par conséquent comme " la porte ouverte à ce qu'il y a de plus irrationnel mais aussi de plus concret dans la vie face aux dispositifs de rationalisation ${ }^{5}$ ». Cette forme de sexualité amoureuse élevée au domaine de l'irrationnel est devenue le thème central de l'amour courtois médiéval. L'Europe s'est approprié un idéal oriental: celui du chevalier faisant une cour furieuse et passionnée à sa dame. Cet idéal oriental se mue, dans la tradition européenne, en figure du "vassal érotique ", héros de l'amour courtois. Ce serviteur de l'amour, suivant le code d'honneur chevaleresque et un sens du devoir hérité de la casuistique, se met au service de l'objet de son amour sans chercher de justification rationnelle. Il n'a même pas accès aux raisons qui gouvernent les ordres en apparence irrationnels de sa maîtresse.

Que devient ce chevalier esclave de l'amour quand émerge le citoyen émancipé des Lumières? Que se passe-t-il quand le désir charnel donnant sa loi à l'esthétique amoureuse est intégré dans l'universalisme que suppose le culte de la raison? La poésie de Schiller offre une réponse à ces questions:

Devant le parc aux lions,

Attendant le prochain combat,

Le roi François était assis;

À ses côtés se tenaient les grands de la couronne,

Et tout autour, dans la haute galerie,

Les dames formaient une belle guirlande ${ }^{6}$.

2. Max Weber, "Parenthèse historique ", traduit par Philippe Fritsch, in Archives des sciences sociales des religions, $\mathrm{n}^{\circ} 61-1,1986, \mathrm{p} .23$.

3. Ibid., p. 22.

4. Ibid., p. 21.

5. Ibid., p. 22.

6. Friedrich Schiller, « Le Gant », traduit par Léon Mis, in Ballades de Goethe et de Schiller, Paris, Aubier-Montaigne, 1943, p. 233. 
Dans ces vers tirés de sa célèbre ballade "Le Gant " (Der Handschuh), Schiller, poète allemand, tenant de Kant et du classicisme de Weimar, décrit une scène d'horreur. L' " arène redoutable " résonne des cris des bêtes sauvages. L’image rappelle les comédies cruelles de la Rome antique, où des gladiateurs, esclaves formés à l'école d'une discipline stricte, devaient se battre à mort contre d'autres infortunés ou contre des bêtes sauvages. Dans la ballade de Schiller, l'esclave médiéval, le chevalier Delorges, doit obéir à l'ordre donné « d'un air railleur " par la belle dame: descendre dans l'arène et prouver héroïquement son amour en y récupérant le gant qu'elle y a laissé tomber de son balcon:

Et vers le chevalier Delorges se tourne demoiselle Cunégonde,

Et lui dit d'un air railleur:

"Sire chevalier, si votre amour est aussi ardent

Que vous me le jurez à chaque instant,

Allez donc ramasser mon gant! »

Et le chevalier s'éloigne en courant,

Et descend dans l'arène redoutable,

D'un pas ferme,

Et sa main hardie ramasse le gant

$\mathrm{Au}$ milieu des fauves.

Delorges impressionne la cour par sa bravoure, et sa facétieuse maîtresse le regarde d'un œil plein de promesse; mais Delorges lui jette le gant au visage: "Je ne veux pas, Madame, de vos remerciements ${ }^{7}$ !".

C'est là la réponse de Schiller à la question kantienne: «Que sont les Lumières? ». Pour Kant, les Lumières signifient l'arrachement de l'homme à l'immaturité qu'il s'est lui-même imposée: "Les lumières se définissent comme la sortie de l'homme hors de l'état de minorité, où il se maintient par sa propre faute. La minorité est l'incapacité de se servir de son entendement sans être dirigé par un autre. [...] Sapere aude! Aie le courage de te servir de ton propre entendement ${ }^{8}$ !

7. Ibid., p. 233-237.

8. Emmanuel Kant, « Réponse à la question: qu'est-ce que les Lumières? ", in Critique de la faculté de juger, traduit par Heinz Wismann, Paris, Gallimard, « Folio », 1985, p. 497. 
Les mots du chevalier Delorges: "Je ne veux pas, Madame, de vos remerciements! " prennent tout leur sens à la lumière de cet appel kantien. On pourrait y voir l'origine de son refus de servir sa dame. En rejetant l'irrationalité de l'amour, Schiller atteint au véritable idéal des Lumières, un idéal qui réunit l'amour et la liberté. Tout ce qui est déraisonnable, y compris l'amour irrationnel, est étranger à la liberté. Par conséquent, le modèle oriental du " fou ", meshdun (en arabe) ou midshnur (en géorgien), faisant une cour furieuse, passionnée et obsessionnelle, va disparaître de la culture occidentale à partir des Lumières.

Ce n'est pas le manque de bravoure ou de témérité en tant que tel qui est en jeu ici, mais le manque de courage intellectuel, de force morale: cette audace mentale qui permet de s'émanciper de la peur. Oser être sage, réagir avec raison aux chicaneries déraisonnables d'une maîtresse tyrannique, cela signifie, pour le " serviteur " amoureux, s'émanciper de l'esclavage auquel le soumet l'enchantement amoureux. Ce désenchantement, par lequel le medjnun revient à la raison, est la première étape d'un désenchantement général, lequel est l'idéal des Lumières européennes. Ce désenchantement préliminaire remonte au XVIII ${ }^{\mathrm{e}}$ siècle. Il a pris une forme spécifiquement bourgeoise et éclairée, caractérisée par la centralité donnée à certains thèmes comme la rationalité. Cette rationalité entrait en conflit, parfois violent, avec les traditions esthétiques qui prévalaient jusqu'alors.

Le désenchantement du monde, Adorno et Horkheimer l'ont montré, était le programme des Lumières: "Le programme de l'Aufklärung avait pour but de libérer le monde de la magie. Elle se proposait de détruire les mythes et d'apporter à l'imagination l'appui du savoir9." " La ballade de Schiller peut être lue, dans une certaine mesure, comme la mise en acte de ce programme d'émancipation individuelle, en ce qu'elle démontre la rationalisation de cette passion irrationnelle qu'est l'amour.

Cependant, le chevalier Delorges n'est pas l'élève raté d'une école de gladiateurs. C'est un noble chevalier du Moyen Âge; un esclave

9. Max Horkheimer \& Theodor W. Adorno, La Dialectique de la raison, traduit par Eliane Kaufholz, Paris, Gallimard, 1974, p. 21. 
volontaire de l'amour, ayant choisi d'obéir au code d'honneur chevaleresque européen. Ce code est un système moral, recouvrant tout à la fois une éthique guerrière de bravoure et de piété, la galanterie, et la dévotion du chevalier pour sa dame. Cette servitude volontaire de l'amour courtois trouverait sa récompense dans la promesse de "plaisirs futurs ", promesse donnée par le regard tendre que dame Cunégonde octroie à Delorges. Chez Schiller, ce qui met à bas ce système de valeur qui avait régi pendant des siècles toute la culture occidentale et avait atteint un degré de raffinement qui lui donnait une portée morale et sociale très large, c'est la rébellion surprenante de l'esclave de l'amour. Les mots du courtisan lorsqu'il jette le gant au visage de sa dame ( «Je ne veux pas, Madame, de vos remerciements! »), agissent comme une formule magique: ils ont le pouvoir de désenchanter le monde, de nier le code courtois. Ce faisant, le chevalier Delorges démolit le haut mur d'enceinte de "l'arène " médiévale, met à bas le donjon d'Aliénor d'Aquitaine: cette " grandmère de l'Europe » dont les créatures, ces premiers gentilshommes qu'elle s'appliqua à former, étaient forcées à jouer le rôle difficile et hautement codifié du chevalier courtois rendant hommage à sa dame. Aliénor, femme indépendante et intelligente, dont le nom est resté associé à la diffusion de ce bel idéal de courtoisie et de douceur, est aussi une des premières Occidentales à être entrée en contact avec la culture orientale très raffinée qui étendit son influence sur l'esprit occidental dans les siècles suivants. En effet, elle prit part à la croisade menée par son premier mari, le roi de France Louis VII.

À partir de ce premier contact, l'Europe ne cessa d'être exposée à l'influence orientale. Herder, penseur ami de Schiller, se la représentait comme une rivière: "Je vois deux courants, dont l'un venu d'Orient coule doucement à travers la Grèce et l'Italie en Europe méridionale, et a inventé en conséquence une religion méridionale douce, une poésie de l'imagination, une musique, un art, une moralité, une science du Sud-Est ${ }^{10}$. "

L’Orient, berceau de la poésie, des arts, des sciences et du mysticisme les plus anciens, a largement influencé la formation du goût

10. Johann Gottfried Herder, Journal de mon voyage (1769), traduit par Max Rouché, Paris, Aubier-Montaigne, 1942, p. 61. 
et de l'esprit en Europe du sud. La culture occidentale telle qu'on la trouve en Europe de l'Ouest résulte de ce contact entre le Sud et l'Orient, dans le monde hispano-italo-français. C'est là que se rencontrent le mysticisme oriental, relique des conquêtes sarrasines et maures, et l'âpre solennité du catholicisme. En intégrant le monde merveilleux de la poésie persane et arabe des temps anciens, les chansons de geste ou épiques (par exemple le Chant de Hildebrand, la Chanson de Roland) deviennent plus raffinées: le bruit assourdissant des sabres et les histoires de meurtre sont contrebalancés par les harmonies d'un hommage courtois hautement stylisé. Par conséquent, la Dame, dans ces histoires, prend une place plus importante.

Pour mieux comprendre les chemins tortueux de l'amour en tant que valeur symbolique servant de médiateur entre différentes cultures, nous allons nous intéresser à un ensemble de textes qui, d'un côté, mettent en avant les particularismes propres à une culture et, d'un autre côté, témoignent d'un contact avec d'autres cultures. Sans prétendre à l'exhaustivité ni à une rigueur absolue, on voit un schéma se dégager. Parmi ces textes, mentionnons d'abord, aux deux extrémités chronologiques de notre corpus, la Chanson de Roland et Orlando furioso (Roland furieux) de l'Arioste. On peut citer également les Livres des rois (Shâh Nâmeh) de Firdousi, "Vis et Ramin ", de Gorgani, "Khosrow et Shirin » et "Layla et Majnoun » de Nizami, ainsi que les œuvres de Chrétien de Troyes écrites à partir des légendes arthuriennes, le Tristan de Gottfried von Strassburg, Le Chevalier à la peau de tigre de Chota Roustavéli, "Fahrad et Shirin » et "Leily et Majnoun " de Navoï, Parzival de Wolfram von Eschenbach, et finalement Orlando innamorato (Roland amoureux) de Boiardo, précurseur d'Orlando furioso.

Ces poèmes présentent d'abord une similarité frappante de forme et de structure. Par ailleurs, ils partagent un thème commun: l'amour qui rend fou, et ses conséquences sociales souvent dramatiques, menant parfois jusqu'au chaos. Le chercheur russe Mélétinski ${ }^{11}$ propose de voir dans les correspondances évidentes entre ces chefsd’œuvre médiévaux, dans leurs différentes versions, une parenté qui

11. Eleazar Moiseevič Meletinskij, Vvednie v istoričeskuju poètiku èposa i romana, Moskva, Nauka, 1976, p. 154. 
est plus ou moins « accidentelle », ou liée à leur "structure externe »: une parenté «typologique ». Mais c'est là simplifier le problème. En fait, les correspondances entre ces œuvres peuvent être comprises à partir de l'emprunt qu'elles font à des fables persanes originelles, transmises par le truchement de sources arabes et provençales. Dans ce contexte, on comprend mieux comment, suivant l'idéal oriental, l'amant devient esclave de son amour passionné. Le héros typique de cette époque, à l'Est comme à l'Ouest, est, comme nous le rappelions d'emblée (v. supra) celui qu'on appelle en arabe medshnun, en géorgien midjnour, c'est-à-dire l'homme fou d'amour et de douleur, qui a perdu l'objet de sa passion. Roustavéli définit le personnage en ces termes:

Midjnour désigne en langue arabe l'amant dont la raison se perd, L'amant rendu fou de chagrin d'une poursuite sans espoir ${ }^{12}$.

C'est dans les modifications du type du medshnun que se manifestent les particularismes nationaux de chaque littérature et de chaque culture. Dans la poésie chrétienne orientale, qui ne semble pas avoir subi l'influence des croisades occidentales, le modèle du midjnour, toujours mobilisé à travers de prétendues références à de faux originaux persans, semble convoquer l'Orient en tant que catégorie paradigmatique, comme projet inachevé, voir irréalisable:

Cette légende d'Orient qu'en langue géorgienne je conte,

Tel un joyau de mains en mains, nos descendants se la racontent ${ }^{13}$.

Cette dimension paradigmatique, où l'Orient n'est que de façade, trahit une fidélité à la tradition narrative persane, arabe et orientale, et s'oppose à l'axe syntagmatique qui prévaut dans la culture occidentale. En d'autres termes, alors que le monde oriental et son imagerie deviennent des syntagmes, d'autres éléments de la culture

12. Chota Roustavéli, Le Chevalier à la peau de tigre, traduit par Serge Tsouladzé, Paris, Gallimard/Unesco, 1964, p. 27. Dans la traduction de Gaston Bouatchidzé: " Le mot arabe de " midjnour " désigne le "fou ", "le dément ",/ll se démène de dépit: amour entendement dément ", Le Chevalier à la peau de panthère, Paris, Publications orientalistes de France; Moscou, éditions Radouga, 1989, p. 14.

13. Chota Roustavéli, traduit par Serge Tsouladzé, op. cit., p. 26. Dans la traduction de Gaston Bouatchidzé: «La présente histoire persane en géorgien fut transposée,/Perle solitaire, avec soins de mains en mains redéposée ", op. cit., p. 12. 
orientale, grands ou petits, se voient tressés subtilement dans le réseau langagier de la poésie occidentale.

Cela se retrouve par exemple dans le Parzival de Wolfram von Eschenbach, où s'opère une synthèse utopique entre Orient et Occident. Comme Roustavéli dans Le Chevalier à la peau de tigre, Eschenbach prétend qu'il copie une source orientale, attribuée à un auteur fictif. En l'occurrence, le poète allemand a largement adapté la légende du Graal ( Perceval » de Chrétien de Troyes), et prétendu qu’un certain Kyot lui avait fourni des éléments supplémentaires tirés de sources arabes. Kyot, auteur provençal, était censé avoir découvert la première version du récit à Tolède, "dans un manuscrit arabe " (c'est-à-dire un écrit païen). La plupart des spécialistes considèrent aujourd'hui que Kyot est une invention d'Eschenbach, et fait partie de la fiction du récit. Même si l'imagerie orientale, telle qu'Eschenbach l'interprète, devient un élément fondamental du récit, on ne peut lui attribuer une fonction paradigmatique.

Encore une fois, on a un poète chrétien qui se réfère à un prétendu original oriental, mais cette référence n'est plus de l'ordre du paradigme. Dans le poème épique de Roustavéli, le texte original est comparé à une " perle précieuse ". Le pathos présent dans le poème n'a rien à voir avec l'ironie subtile de Wolfram von Eschenbach. Celui-ci, dans son jeu de cache-cache littéraire, n'a pas besoin de manifester ce niveau paradigmatique de loyauté à la tradition narrative arabe, persane et orientale. En effet, il ne s'agit pas chez lui d'une matière organique inhérente à son propos, mais seulement d'un modèle récemment découvert, et mobilisé à travers un discours à demi savant. C'est là ce qui fonde la différence entre Eschenbach et Roustavéli. Mais il reste que l'idée d'Orient est incontestablement présente dans les chefs-d'œuvre de la poésie chrétienne, en Orient comme en Occident.

Les Occidentaux, à partir de leurs premiers contacts avec l'Orient pendant les croisades, ont été amenés à remettre en cause leur sentiment initial de supériorité intellectuelle et spirituelle en découvrant les splendeurs et la magnificence de l'Orient, sa noblesse, ses trésors culturels. L'Orient devenait un possible modèle pour l'Occident. C'est à cette époque que commença une longue tradition de référence à l'Orient. On peut voir ce moment comme un seuil; à partir de là, on 
peut discerner, dans la sémantique amoureuse, un certain nombre de glissements.

La beauté sensuelle et ses fragrances capiteuses pour laquelle Kais (chez Nizami), Tariel (chez Roustavéli) ou Roland (chez l'Arioste) perdent la tête, tous plus ou moins de la même manière, fait penser aux parfums des civilisations lointaines. Mais ces différents medshnun sont radicalement éloignés culturellement. Roustavéli est absolument enchanté par la folie et l'exubérance de Tariel, son héros aux larmes amères; à l'inverse, l'Arioste jette au sien un regard en coin constamment ironique. Roustavéli se montre rarement ironique envers son héros, et prend l'idéal de l'amour chevaleresque beaucoup plus au sérieux. Entre Tariel et Roland, il n'y a pas seulement plusieurs siècles, mais tout un monde. Le sourire encore timide de l'Arioste sera bientôt noyé par le gros rire carnavalesque de Rabelais. Par le rire, c'est toute une culture qui, quand arrive la Renaissance, s'élève au scepticisme, à l'ironie, à l'autodérision.

Ce rire ce révèle en fait une reprise du moment de rire rituel par lequel l'Europe du haut Moyen Âge s'était efforcée de surmonter sa peur de la mort: le carnaval, sa joie débridée, son bruit assourdissant. Il contraste fortement avec l'Achoura, le deuil public rituel, au moment du mois de muharram, qui commémore la mort d'Hussein. D'après un proverbe populaire chiite, " une seule larme versée par Hussein peut laver des milliers de péchés ». L’Achoura est la " fête " singulière célébrant le martyre des fils de Fatima, fille de Mahomet.

Chaque année, on enterre Hussein en pleurant. C'est la mort seule qui est célébrée, et qui occupe toute la conscience. Par contraste avec cette doctrine unifiée de souffrance, le christianisme oppose la passion du Christ, sa crucifixion et sa mort, aux rires du carnaval et aux espoirs de résurrection.

Cette association antagonique du deuil rituel et du rire rituel n'est pas seulement la double face d'un théâtre cultuel, mais produit une inversion radicale de la hiérarchie sociale. Que ce soit dans les pleurs rituels, "strictement organisés " (depuis les basses couches de la société jusqu'à son chef spirituel), ou dans le rire rituel du carnaval, on observe une expérience communautaire qui unifie toutes les couches de la société. 
L’Orient a renversé le culte de la souffrance en sa célébration, produisant comme une sorte d'anticarnaval. L'Occident, en revanche, a plus ou moins consciemment ritualisé le rire et son pouvoir de réduire l'angoisse et de transcender la mort. Mais ce qui est intéressant pour nous ici, ce sont les différentes formes que prend le festif dans des cultures variées. L’opposition, en apparence irréductible, entre carnaval et anticarnaval, est abolie dans le repas collectif. À la veille de la saison du jeûne, le carnaval européen est un gigantesque banquet; l'Achoura, de son côté, culmine par le repas que les riches servent aux pauvres (Sham e ghariban, la principale soirée du mois de muharram). Dans plusieurs cultures, le pain et le vin sont enrichis d'une qualité particulière lors des banquets, dont ils tirent leur pouvoir de dissiper la peur et de libérer le monde. Seule la tradition du discours de banquet, dans la culture géorgienne, n'est vraisemblablement issue ni du carnaval européen, ni de l'anticarnaval oriental, avec leurs mises en scène sacrées, leurs éléments hautement ritualisés comme les mystères et les processions. Là, les processions où l'on pleure ou bien rit sont remplacées par la dynamique perpétuelle des convives. Le tamada, c'est-à-dire le chef de tablée, porte un toast et prononce un discours dans lequel le moment présent, toujours morne et sans espoir, est opposé au souvenir d'un passé glorieux et au rêve d'un futur tout autant idéalisé et porteur d'espoirs utopiques. L'admiration pour Tariel, qui est instillée dans la mémoire collective géorgienne par les livres et par le système scolaire, vise en lui le midjnour, l'amant fou. Le Tariel de Roustavéli est présenté comme un symbole éternel, inviolable et exemplaire. La rhétorique pathétique et terriblement sérieuse de l'œuvre n'a intégré ni l'ironie ni le scepticisme de l'Arioste, par lesquels la culture occidentale s'est progressivement distancée de l'idéal de l'amour courtois et de la souffrance exaltée de l'amoureux éconduit que toute la poésie précédemment citée portait aux nues.

Au même moment, la glorification de l'amour fou par Roustavéli se trouve légitimée par une certaine logique interne. Par le biais de très nombreux éléments métaphoriques à coloration clairement orientale (" rose qui ne fane pas", " un visage clair comme le soleil ", " des yeux comme des lacs d'encre », " un cristal aux joues roses ", " il entra, tout de rubis et de jais ", " souple comme un peu- 
plier ", " un visage lunaire »), l'amour, et la folie qu'il provoque, sont justifiés et motivés par tous ces attributs idéaux. L’idéal amoureux se donne avec la rationalité univoque d'une irrationalité cultivée. Tant que l'amour est présenté comme un idéal, il implique de pouvoir caractériser la beauté de la dame. C'est par une description hyperbolique de sa beauté que l'amour est idéalisé et que la folie amoureuse elle-même est sanctifiée. En revanche, plusieurs siècles plus tard, on trouve une inversion radicale de cet ensemble de métaphores: c'est le célèbre sonnet 130 de Shakespeare, qui renverse paradoxalement toutes les descriptions allégoriques connues et les renie:

Les yeux de ma maîtresse au soleil ne ressemblent, Le corail est plus rouge que ne le sont ses lèvres, Et si la neige est blanche, ma foi, son sein est brun; Ses cheveux sont des fils, mais fils noirs et non d'or. La rose de Damas, je l'ai vue rouge et blanche, Mais je ne vois pareilles roses sur ses joues;

Et il est des parfums bien plus délicieux Que l'haleine exhalée, impure, de ses lèvres. J'aime entendre sa voix et je sais bien pourtant Que plaisent davantage les sons de la musique. Je n'ai vu, je l'avoue, marcher une déesse; Ma maîtresse en marchant a les pieds sur le sol.

Mais, par le ciel, mon amour à mes yeux vaut bien

Toute femme affublée de fausses métaphores ${ }^{14}$.

C'est là un exemple remarquable des transformations des codes symboliques, depuis l'idéalisation de l'amour jusqu'à son renversement paradoxal, telles qu'on peut les observer à travers les siècles et les cultures. L'amour n'est plus commandé par la beauté absolue de l'être aimé. Quel chemin parcouru, du XII ${ }^{\mathrm{e}}$ au XvII ${ }^{\mathrm{e}}$ siècle, pour en arriver à cette nouvelle façon de justifier l'amour! Grâce à ce système de codification paradoxale, l'amour devient autoréférentiel. Les qualités physiques de la femme aimée, corail des lèvres, blancheur de neige des seins, rouge et blanc de la rose de Damas sur les joues, n'ont plus rien d'essentiel. Elles ne conditionnent plus l'amour. Grâce à ces déplacements sémantiques, l'amour en tant

14. William Shakespeare, "Sonnet 130 ", in Sonnets, traduit par Robert Ellrodt, Arles, Actes Sud, 2007, p. 410. 
que médiateur devient autonome et autosuffisant. Il est désormais un phénomène autotélique, ne visant que lui-même; une sorte "d'amour pour l'amour». Dans le même mouvement, l'amour perd son pouvoir de rendre fou. Il ne peut plus servir à justifier la folie. C'est pourquoi Hamlet ne peut pas devenir un medshnun furieux; l'amour ne peut être " la cause des bizarreries d'Hamlet ${ }^{15}$ ". Polonius, lorsqu'il le présente comme quelqu'un que l'amour a rendu fou, commet une absurdité:

C'est le délire même de l'amour

Qui se détruit par sa propre violence

Et voue au désespoir notre volonté

Tout autant qu'aucune passion qui soit au monde

[...]

C'est cela qui l'a rendu fou ${ }^{16}$.

Hamlet, un "Hamlet européen ", un " Hamlet intellectuel " selon les mots de Paul Valéry, a bien d'autres préoccupations que la maladie d'amour, et ce sont d'autres doutes qui l'assaillent: "Il médite sur la vie et la mort des vérités. [...] Il songe à l'ennui de recommencer le passé, à la folie de vouloir innover toujours. Il chancelle entre les deux abîmes, car deux dangers ne cessent de menacer le monde: l'ordre et le désordre ${ }^{17}$. "

Lointain ancêtre de l'intellectuel européen, Hamlet est d'avantage tourmenté par la fameuse question: "Être ou ne pas être " que par le chagrin amoureux. Mais il a, en cela, un précurseur: le Parzival de Wolfram von Eschenbach, qui est l'un des premiers à s'éloigner du modèle oriental du medshnun ou midjnour, et n'en présente aucun des traits caractéristiques. Dans le cas de ce héros, ce qui est crucial, c'est le processus de maturation, de perfectionnement individuel et spirituel, du personnage. Son immaturité première se manifeste d'abord au moment où il se sépare de la force féminine, c'est-à-dire l'amour maternel que lui porte Herzeloyde, la «noble dame " qui est « de toute noblesse la racine et de toute

15. Id., Hamlet, acte II, scène 2, traduit par Yves Bonnefoy, Paris, Mercure de France, 1962, p. 67.

16. Ibid., acte II, scène 1, p. 64.

17. Paul Valéry, La Crise de l'esprit, Paris, Gallimard, 1919, p. 328. 
humilité le tronc ${ }^{18}$. " Dès lors, ce ne sont plus l'amour courtois, la servitude amoureuse, qui vont inspirer les combats du héros mais, au contraire, la recherche de sa propre maturation, le désir d'atteindre une absolue perfection. Par conséquent, l'image iconique de la femme aimée est repoussée en arrière-plan. On observe quelque chose de similaire dans le cas d'Anfortas, « chevalier du Graal » qui, après avoir guéri de ses blessures, estime que « qui a décidé de se mettre au service du Graal doit renoncer à l'amour des femmes ${ }^{19}$ ". C'est précisément lorsque l'amour courtois et la servitude amoureuse sont dépassés, à la fin du poème, dans l'union fraternelle de Parzival et Feirefiz, que l'utopie d'une synthèse politique et religieuse entre Orient et Occident devient réalisable.

Le Parzival d'Eschenbach détruit le principe maternel et féminin. À ce titre, il devient l'archétype d’une génération de héros en quête de lumière, guidés par l'idéal de leur propre perfectionnement. Dans cette grande famille de héros, le Faust de Goethe tient une place centrale. Il évolue dans un monde où l'on passe de l'ignorance au savoir, et où le concept platonicien de paideia joue un rôle majeur.

Dans ce contexte, il est intéressant de noter que, pour Roustavéli, l'idée de lumière et de bonté est directement liée à Platon et à son " analogie du soleil ». Platon, en effet, compare le " bien " au soleil, lequel est une métaphore de la bonté. En reprenant cette analogie platonicienne, Roustavéli réalise que l'assimilation de la bonté au soleil est pleine de potentialités: le soleil est à la fois la lumière éternelle, et le moyen de défaire le mal.

Finalement, c'est le bien lui-même qui est central. Le bien, c'està-dire le soleil, est la base sur laquelle toute vérité se construit. Ainsi, Roustavéli utilise la métaphore du soleil pour approcher une définition exacte du bien:

Le soleil s'en est revenu et les ténèbres s'illuminent,

Le Bien a surpassé le Mal, car son essence est éternelle ${ }^{20}$ !

18. Wolfram von Eschenbach, Parzival, traduit par Daniel Buschinger et Jean-Marc Pastré, Paris, Honoré Champion, 2010, p. 251.

19. Ibid., p. 501.

20. Chota Roustavéli, traduit par Serge Tsouladzé, op. cit., p. 216. 
La paideia platonicienne, que l'allemand Bildung ("formation, éducation ") permet d'approcher - d'après Heidegger, cette équivalence est cependant discutable - , est souvent associée aux œuvres de Goethe et de Klopstock ${ }^{21}$. La notion d'éducation est mise en avant par la littérature allemande depuis Eschenbach et Goethe jusqu'à Thomas Mann. La célébration de l'amour courtois est remplacée par le culte de la Bildung, de l'éducation. Le motif amoureux est rejeté au second plan, servant de liant à la fable, de prétexte, mais ne pouvant plus en être le véritable argument. C'est là, précisément, que la littérature allemande s'éloigne de la poésie géorgienne. Dans cette tradition littéraire, au contraire, l'amour demeure un élément central et constitutif. Dans Le Chevalier à la peau de tigre, rien ne peut remplacer le motif de l'amour.

Il est particulièrement éclairant de relire l'œuvre de Roustavéli à l'aune du contexte littéraire international. En analysant la corrélation de différentes tendances littéraires dans le monde, on peut observer le mouvement intriqué de la littérature hors du code symbolique de la sémantique amoureuse, et construire un cadre de référence. À cette lumière, on trouve dans les manuels d'histoire littéraire un curieux paradoxe récurrent: l'association de Faust et de Don Juan comme "séducteurs". Cette association des deux personnages remonte au moins au XIX ${ }^{\mathrm{e}}$ siècle, puisque Søren Kierkegaard place côte à côte les deux « séducteurs ", pourtant fort différents, dans son essai Ou bien... ou bien. C'est là un rapprochement paradoxal, pour plusieurs raisons. Don Juan, incarnation de l'amant irrésistible, succombe à la passion destructrice de la séduction. Dès qu'il a remporté une bataille, il perd tout intérêt pour sa victime; parce qu'il est insatiable, il devient luimême la victime de sa passion et, au bout du compte, la victime du destin qui le conduit à sa triste fin. Il finit en réalité par être la victime des femmes, ses supposées victimes. Kierkegaard se demande à qui il faut attribuer « la supériorité en force ${ }^{22}$ », à Don Juan, l’homme

21. Martin Heidegger, Wegmarken, Francfort-sur-le-Main, Klostermann, 1967, p. 122-123.

22. Søren Kierkegaard, Ou bien... ou bien, traduit par F. et O. Prior et M. H. Guinot, Paris, Gallimard, 1943, p. 153. 
qui « se suffisait ${ }^{23}$ ", ou à Elvire, qui révèle que " la dialectique d'une femme est étrange ${ }^{24} »$ : est-ce vraiment lui, le plus fort? Or, on peut ici se demander s'il est légitime d'affirmer comme le fait Kierkegaard que Don Juan se suffit à lui-même. Sans une belle femme près de lui, l'existence même du personnage espagnol (dont Tirso de Molina avait probablement découvert l'archétype dans une source arabe) est menacée. Que l'amour de Don Juan trouve un écho chez son objet n'a pas d'importance pour lui. Finalement, le donjuanisme de Don Juan est conditionné par la femme: sans elle, il est annihilé. La substance du personnage est entièrement déterminée par l'aventure amoureuse. Sans figure féminine, sans " éternel féminin » (Goethe), il perd toute validité. Mais la formule goethéenne d' éternel féminin ", par laquelle se termine la longue quête de Faust vers la perfection, n'est pas elle-même déterminante pour le monde de Faust. La tragédie de Marguerite, sans doute l'une des histoires d'amour les plus tragiques de la littérature mondiale, est admirable, mais elle ne constitue qu'un épisode parmi d'autres au sein de la quête faustienne de perfection, expérience purement masculine qui traverse le monde entier, du microcosme au macrocosme. L'expérience sensuelle n'est qu'une des étapes de ce voyage. Pour Kierkegaard, Faust est " une réplique de Don Juan ${ }^{25}$ "; il est " un démon aussi bien que Don Juan, mais il est un démon supérieur ", qui recherche dans les sensations " un dérivatif plutôt qu'une jouissance ${ }^{26}$ ». L'on pourrait peut-être ajouter que le héros goethéen, contrairement à Don Juan, est réellement auto-suffisant, ce qui justifie de le classer dans un "ordre supérieur ". L'expérience amoureuse de Faust avec une jeune femme n'est qu'une des multiples possibilités qui s'offrent à lui dans la variété éblouissante du monde, et qui lui permet, à lui toujours sceptique, de s'arrêter un instant, de trouver le repos. Ainsi, Marguerite n'est qu'un élément d'une expérience globale, et il n’y a, de la part de Faust, aucune mauvaise intention à son égard. Même en son absence et sans nouvelle histoire d'amour, l'expérience qu'elle ouvre peut être

23. Ibid., p. 158 ( Il était homme, il se suffisait »).

24. Ibid., p. 155

25. Ibid., p. 160.

26. Ibid. 
continuée, ainsi que le montre l'intrigue du Faust II. Le malheur de Marguerite est presque intégralement décoratif; c'est un ornement féminin et sensuel. Il est intégré dans l'aventure purement masculine de la quête faustienne de l'idéal et de la lumière vraie. C'est l'histoire de Marguerite qui permet de donner une qualité très allemande à l'argument du pacte avec le diable. Elle donne à la pièce une élégance qui lui a valu d'être admirée dans le monde entier. Ainsi que le disait Thomas Mann à propos de Wagner, « il est propre à rendre la germanité intéressante, même pour un âne bâté d'étranger ${ }^{27}$ ".

Selon Camus, Faust "réclamait les biens de ce monde: le malheureux n'avait qu'à tendre la main. C'était déjà vendre son âme que de ne pas savoir la réjouir. La satiété, Don Juan l'ordonne au contraire. S'il quitte une femme, ce n'est pas absolument parce qu'il ne la désire plus. Une femme belle est toujours désirable. Mais c'est qu'il en désire une autre et, non, ce n'est pas la même chose ${ }^{28}$."

La quête faustienne de vérité doit se comprendre en regard de la tradition allemande de Bildung. Si l'on suit Nietzsche, les Allemands, qui échappent à toute tentative de définition et font, à ce titre, " le désespoir des Français ${ }^{29}$ ", " ressen [tent] comme " profond » l'incertain, le non-formé, ce qui se déplace, ce qui est en croissance, sous toutes ses formes. L’Allemand lui-même n'est pas; il devient, il « se développe » ». Le " développement » est donc « la trouvaille, la réussite spécifiquement allemande dans le vaste royaume des formules philosophiques. ${ }^{30}$

Mais, comme le souligne Nietzsche, l'Europe moderne a besoin d'autre chose que de "plats pimentés et épicés ", parfumés " de tous les aromates de l'Orient et de l'Occident ". Seuls des plats exotiques peuvent satisfaire le palais gâté de l'Européen cultivé et raffiné. Ainsi, pour Nietzsche, "les plus fameux de ces cuisiniers au service de ces hommes modernes [...] se trouvent, on le sait, chez les

27. Thomas Mann, Considérations d'un apolitique, traduit par Louise Servicen et Jeanne Naujac, Paris, Grasset, 2002, p. 73.

28. Albert Camus, Le Mythe de Sisyphe, Paris, Gallimard, 1985, p. 101.

29. Friedrich Nietzsche, Par-delà bien et mal, aphorisme 244, traduit par Patrick Wotling, Paris, GF Flammarion, 2000, p. 223.

30. Ibid., p. 224. 
Français, les pires, chez les Allemands ${ }^{31}$ ». Cela vient de "l'indifférence paysanne [de l'âme allemande] à l'égard du " goût ${ }^{32}$ ".

Or, c'est l'un des meilleurs " chefs cuisiniers " d'Europe, le romancier français Alexandre Dumas, qui découvrit un lieu de rencontre exceptionnel entre différents phénomènes orientaux et occidentaux: Tbilissi. La capitale géorgienne, région intermédiaire, ville multiethnique et multiconfessionnelle et à ce titre d'une importance capitale dans le Caucase, se caractérise par d'intenses échanges culturels. Dumas y trouva une ambiance intellectuelle et spirituelle inimitable.

C'est Dumas, à notre avis, qui a donné forme aux représentations occidentales de la Géorgie. Dans les deux siècles qui suivirent, ces représentations se sont ancrées dans les imaginaires européen mais aussi géorgien. En effet, les Géorgiens se sont progressivement identifiés à une culture aux marges de l'Orient et de l'Occident. Chez Dumas, c'est dans la musique que l'on voit se nouer les liens entre Est et Ouest à Tbilissi. On peut d'ailleurs mettre en rapport la polyphonie littéraire de Dumas et les poèmes persans de Saadi, qui étaient chantés dans le quartier des établissements de bains soufrés, ou encore l'opéra I Lombardi de Verdi, qui venait d'être créé. C'est donc pris entre le bel canto de l'opéra italien et la poésie chantée persane que le romancier du xix ${ }^{\mathrm{e}}$ siècle a entendu Tbilissi, ville internationale au sein de l'empire tsariste. Dans les Impressions de Voyage de Dumas, la Russie, "sombre souverain ", paraît bien morose en regard de la Géorgie, ce "joyeux esclave ${ }^{33}$ ". Dumas établit la liste des qualités géorgiennes, et cela ressemble à une liste de stéréotypes: "la parure, la guerre, le vin, la musique ${ }^{34}$ ». Plus tard, parce que les représentations de la Géorgie étaient figées, ces attributs sont devenus des clichés mobilisés dans les jeux d'alliances ou les conflits russo-géorgiens à travers les années.

31. Friedrich Nietzsche, "Schopenhauer éducateur ", in Considérations inactuelles III et IV, traduit par Henri-Alexis Baatsch, Pascal David, Cornélius Heim, Philippe Lacoue-Labarthe et Jean-Luc Nancy, Paris, Gallimard, « Folio Essais », 1990, p. 63.

32. Id., Par-delà bien et mal, op. cit., p. 224.

33. Alexandre Dumas, Impressions de voyage. $\{3\}$, Le Caucase, Paris, François Bourin, 1990, p. 347.

34. Ibid., p. 414. 
En même temps, la représentation très féminine que fait Dumas de la Géorgie, à l'opposé du canon russe impérial, a contribué à la légitimation de représentations de la Géorgie en femme orientale. Cela n'est pas sans rapport avec une certaine mythologie qui sert à justifier la domination de la Géorgie par l'Empire russe. Contrairement à la tradition russe établie par Pouchkine et Lermontov, Dumas ne fait pas de la Géorgie une "femme " orientale qui a besoin d'être dominée par un mâle russe, un fiancé ou un souverain; elle est au contraire raffinée, d'un raffinement grec, ou plutôt géorgien, ce qui, pour l'auteur français, a une grande valeur: "La Grèce, c'est Galatée encore marbre, la Géorgie, c'est Galatée animée et devenue femme ${ }^{35}$.»

Dumas trouve donc à incarner la Géorgie dans Galatée, la création de Pygmalion, symbole de la beauté féminine depuis l'Antiquité. Ce n'est d'ailleurs par un hasard si son Voyage dans le Caucase a pour sous-titre « De Prométhée au Christ ». Pour lui, «à l'horizon du monde naissant, l'homme aperçoit le gibet du premier bienfaiteur de l'humanités ${ }^{6}$. " Par conséquent, pour lui, la Géorgie fait partie intégrante du monde chrétien antique, et est un lieu unique de rencontre des cultures. À ce titre, elle joue un rôle essentiel de médiation.

C'est l'œuvre de Dumas qui a donné naissance à l'image européenne d'une Géorgie située entre Est et Ouest, à la fois limite et lieu de passage. Cet espace correspond d'avantage aux mots de Goethe dans Le Divan d'Orient et d'Occident (" À Dieu est l'Orient!/À Dieu est l'Occident!/Les contrées du Nord et du Sud/Reposent dans la paix de ses mains ${ }^{37}$ ") qu'à ceux de Kipling ("Oh, l'Est, c'est l'Est, et l'Ouest, c'est l'Ouest; onqu's ne s'mêl'ront tous deux ${ }^{38}$.") Goethe, dans le Divan, emprunte à la deuxième sourate du Coran (verset 115): «À Allah seul appartiennent l'Est et l'Ouest. » Dans ce verset, le monde

35. Ibid., p. 378.

36. Ibid., p. 12.

37. Johann Wolfgang von Goethe, Le Divan d'Orient et d'Occident, traduit par Laurent Cassagnau, Paris, Les Belles Lettres, 2012, p. 4.

38. Rudyard Kipling, « Ballade de l'Est et de l'Ouest (1889) ", in Poèmes, traduit par Jules Castier, Paris, Robert Laffont, 1949, p. 157. 
et la connaissance qu'en a Dieu sont présentés comme unis; les contraires s'annulent, les contradictions sont résolues. C'est aussi, chez Goethe, l'universalisme des Lumières qui se manifeste, lequel est quasiment contemporain du processus de mondialisation. Le Divan de Goethe manifeste une unité spatiale qui présuppose que toutes les parties du monde appartiennent au divin, au royaume de Dieu: "Car devant Dieu tout est superbe ${ }^{39}$. " Les points cardinaux sont, dans cet idéal, homogènes, et ne sont pas susceptibles de céder au mécanisme qui consiste à diviser le monde en parties qualitativement hétérogènes, soit " bonnes ", soit " mauvaises ». On a là la synthèse miraculeuse de l'éthique et de l'astronomie, réalisée par l'esthétique.

La lecture esthétique de l'astronomie est un constituant essentiel des débuts de la civilisation, et tient une place centrale dans la poésie de Roustavéli. Avec son génie poétique, son imagination, Roustavéli choisit de faire référence à la plus anciennes des sciences naturelles, celle qui s'occupe des objets célestes: les planètes, la lune, les étoiles, les galaxies.

Les étoiles sont mes témoins. Ah! toutes les sept pour moi témoignent !

Le soleil, Jupiter, Mercure et Saturne pour moi défaillent,

La belle Lune, Vénus et Mars les confirment et m'accompagnent,

Faites entendre qu'un brasier inapaisable me tenaille ${ }^{40}$ !

La cosmologie poétique de Roustavéli prête attention à tous les phénomènes astronomiques; elle est tenue par une représentation unifiée de l'univers, entité harmonieuse où tous les points cardinaux peuvent être embrassés d'un seul regard et où domine la diversité culturelle et ethnique de la " terre faite d'espèces innombrables ${ }^{41}$ ". $\mathrm{Au}$ sein de cette harmonie multiculturelle que rien ne vient troubler, du Maghreb (l'Ouest) au Mashrek (l'Est), il n'y a pas de place pour des jugements moraux qui se baseraient sur une opposition des points cardinaux:

39. Johann Wolfgang von Goethe, op. cit., p. 114.

40. Chota Roustavéli, Le Chevalier à la peau de tigre, traduit par Serge Tsouladzé, op. cit., p. 160.

41. Ibid., p. 25. 
Tous les vivants de cette terre, pour le louer se réunissent, Oiseaux du ciel, fauves des rocs, poissons de l'eau et caïmans, De Grèce, d'Arabie, des Indes, ceux d'Occident et d'Orient, Les Russes, les Persans, les Francs et les Égyptiens de Misr ${ }^{42}$.

Roustavéli, poète chrétien médiéval, choisit pour ce poème un décor fictif et exotique, situé en Inde et en Arabie. Ce déplacement lui permet de remodeler le monde à sa façon et d'impulser une dynamique au récit du Chevalier à la peau de tigre. Mais au-delà de la référence paradigmatique à un prétendu original oriental, on pourrait voir dans ce choix de décor la confirmation de la loyauté historique et culturelle de la poésie épique géorgienne vis-à-vis de sa tradition narrative arabo-perso-orientale. On reconnaît là un phénomène à la fois familier et étranger. Ce genre de références se retrouve pendant des siècles dans la culture géorgienne.

Le poème de Roustavéli, utilisant exemplairement l'idéal romantique de la chevalerie, est un poème sur la guerre, sur l'amitié et sur l'amour. Divisé en épisodes, il entremêle de nombreux thèmes, mais ce sont deux histoires d'amour qui fournissent les principaux fils conducteurs: d'un côté, celle des Arabes Thinathine et Avthandil; de l'autre, celle des Indiens Nestan'-Darédjane et Tariel (le « chevalier à la peau de tigre » du titre). Ces deux histoires sont aussi différentes que les pays qu'elles représentent. C'est dans le type de l'amoureux que se manifestent les particularités nationales: il est soit un fou, du type meshdnur (Tariel), soit un homme raisonnable (Avthandil). Avthandil, bien qu'il admette l'existence des " grands tourments » de l'amour, exige de Tariel qu'il se montre « sage » :

Si tu es sage, tous les sages sur cet avis se réunissent:

Le brave ne doit accorder aux larmes que le juste prix,

Comme le ciment, dans la peine, il faut que l'homme s'endurcisse ${ }^{43}$.

Comme de nombreux spécialistes le font remarquer, dans ce poème, les Arabes, à travers le roi Rostévann et son chevalier Avthandil, sont dotés d'un esprit rationnel. À l'inverse, les Indiens, à travers Tariel et Nestan', sont présentés comme plus émotifs et

42. Ibid., p. 161.

43. Ibid., p. 148. 
impulsifs, ce qui les conduit à provoquer des désastres inattendus ${ }^{44}$. Si l'on suit le rationalisme d'Avthandil, l'amour ne peut servir à excuser la folie, et la meilleure façon d'agir est toujours de suivre sa raison: "On peut tomber dans le malheur par la faute de trop d'esprit ${ }^{45}$. " En effet, perdre la raison, même si c'est par amour, c'est s'infliger des tourments et "tomber dans le malheur " ou, en suivant la traduction anglaise de Verena Urushadze, " sombrer dans un océan de désastre " (sink down in a sea of disaster ${ }^{46}$.)

Deux mondes s'opposent. L'Arabie représente le principe d'ordre, la stabilité, la rigueur, la cohérence. L’Inde représente le principe de désordre, l'instabilité, le chaos. Il est donc tout naturel que dans le poème de Roustavéli, l'Inde soit associée à l'élément marin, avec ce qu'il convoque de délire et de désordre. Nestan'-Darédjane est mise dans un bateau et laissée à la dérive sur la mer: ainsi se rencontrent le danger de la mer et le récit d'une catastrophe.

Ce motif narratif, l'aventure maritime terrifiante, reflète la façon dont la mythologie géorgienne s'est structurée autour d'une dichotomie mer-montagne. Cela a été le modèle suivi dans les reprises des légendes occidentales vernaculaires. Cette opposition entre terre et mer ou, plus précisément, entre montagne et mer dans la culture géorgienne permet de mettre au jour les conditions du succès ou de l'échec des mythes étrangers dans le contexte des transformations culturelles de la Géorgie et des évolutions de l'autoperception du pays dans la mémoire collective. Cela amène plusieurs questions: quel paradigme visuel a-t-il eu le plus d'impact sur la construction culturelle? Comment cette imagerie collective est-elle décrite, dans la mémoire collective, dans les perceptions culturelles, et dans les arts? Et, avant toute chose: qui est à l'origine de cette imagerie?

44. Gijs Koolemans Beynen, "Adultery and Death in Shota Rustaveli's The Man in the Panther Skin ", in Keith Busby, Christopher Kleinhenz (eds.), Courtly Arts and the Arts of Courtliness, Selected Papers from the Eleventh Triennial Congress of the International Courtly Literature Society, Madison, University of Wisconsin-Madison Press, 2004, p. 219.

45. Chota Roustavéli, Le Chevalier à la peau de tigre, traduit par Serge Tsouladzé, op. cit., p. 148.

46. Id., The Knight in the Panther's Skin, traduit en anglais par Verena Urushadze, Tbilissi, Sabchota Sakartvelo, 1986, p. 865. 
S'agit-il d'auteurs étrangers qui ont repris des images d'une autre culture pour représenter l'altérité et l'inconnu? Ou bien s'agit-il d'auteurs géorgiens, qui ont représenté leur propre culture?

À cet égard, il faut noter que les cultures du Caucase se sont diffusées depuis la périphérie lointaine jusqu'à la mémoire du vieux monde selon deux voies distinctes: soit en traversant les montagnes, soit en traversant la mer. Dans le mythe grec de Prométhée, celui-ci a été enchaîné à un rocher. On peut comparer la fortune de ce mythe-ci à celle d'un autre mythe grec, lié non plus à la montagne mais à la mer: l'histoire de Médée de Colchide. En Géorgie, le mythe de Prométhée se retrouve dans plusieurs sources poétiques et mythiques; à l'inverse, c'est plutôt dans la culture occidentale que le destin de Médée a connu une popularité artistique et théâtrale. La figure d'Amirani, dans le folklore géorgien, correspond à un Prométhée du Caucase. Mais la culture géorgienne ne porte aucune trace du mythe des Argonautes, au moins jusqu'à l'époque prémoderne. En revanche, les Argonautes, liés à la mer et à la navigation, ont inspiré de nombreux artistes européens à des époques variées. Dans la culture géorgienne, l'histoire de Médée est taboue, précisément parce que c'est une culture qui ne s'autorise pas à regarder la mer avec la moindre ironie, le moindre scepticisme. Traverser la mer, cela veut dire se couper de la mémoire: ce ne peut être que négatif. Inversement, la mer a pu transporter Médée vers d'autres rives et fait qu'on la retrouve dans des mythes étrangers et des chefs-d'œuvre artistiques.

De la sorte, c'est Prométhée et non Médée qui décrit le mieux la quête identitaire à l'œuvre dans la culture géorgienne. Depuis le romantisme nationaliste, Prométhée est souvent assimilé à des personnages mythologiques masculins de la culture géorgienne, au destin également tragique, et qui sont présentés comme les héros d'une résistance têtue et courageuse donnant à cette culture son identité propre. C'est un trait que l'on trouve par exemple dans l'image du Titan, transformé en une sorte de patriarche parti à la recherche d'une identité historique. La culture géorgienne se plaît donc à s'approprier ce héros et à en faire l'incarnation mélancolique de son propre destin tragique. Prométhée devient l'acteur principal d'un éternel théâtre de combat et de souffrance, de révolte constante 
et de vains efforts, de victimisation et d'autovictimisation: précisément ce qui, pendant des siècles, a correspondu à l'image que l'on avait du destin tragique de la Géorgie.

Contrairement à Médée, Prométhée a donc eu de nombreux admirateurs en Géorgie et son histoire y a connu plusieurs versions. Une des raisons en est que le rocher est très important dans la culture géorgienne, en tant qu'il est solidement ancré dans le sol. L'âge de pierre, dans la constante patriarchie de la vallée, a été décisif. Pendant longtemps, la mer, à l'inverse, est restée une potentialité inexplorée. On était d'avantage tenté de tourner le dos aux flots furieux pour regarder respectueusement vers les montages. La fascination pour les montagnes a été à l'origine d'un éthos complètement étranger à la folie et au désordre de la mer.

Dans ses Leçons sur la philosophie de l'Histoire, Hegel parle de la qualité liante des eaux de la mer. Selon lui, rien n'égale le pouvoir unificateur de l'eau ${ }^{47}$. À l'opposé de cet élément dangereux, qui invite à la conquête et au vol, à la victoire et au gain, « la terre, la plaine des vallées fixe l'homme au sol ${ }^{48}$ ". Hegel affirme ainsi que les États asiatiques ne disposent pas de cette «poussée de la mer hors de la limitation du continent ", et cela même s'ils " touchent eux-mêmes à la mer, comme par exemple la Chine. Pour eux, la mer, c'est simplement l'endroit où la terre cesse, ils n'ont pas avec elle de rapport positif " ${ }^{49}$. La philosophie de la géographie, depuis Hegel, envisage toujours l'eau comme un facteur structurant les différentes cultures géographiques et politiques.

La Géorgie dispose d'un paysage typique du Proche-Orient: une chaîne de montagnes, des vallées. C'est ce paysage qui fait l'identité physique et spirituelle du pays. Ce ne sont pas les mers mais les rivières qui jouent un rôle structurant dans l'organisation du territoire. Dans les Lettres d'un voyageur d'Ilia Tchavtchavadzé (1861), par exemple, la conscience spatiale de la Géorgie est subordonnée aux grands bouleversements historiques. Dans ce cas, l'opposition

47. Georg Wilhelm Friedrich Hegel, Leçons sur la philosophie de l'Histoire, traduit par J. Gibelin, Paris, Vrin, 1979, p. 73-74.

48. Ibid., p. 74.

49. Ibid. 
mise en œuvre entre le mont Kazbek (Mkinvari) et le fleuve Terek sert de modèle à un imaginaire esthétique qui place d'un côté l'univers et de l'autre des motifs géographiques spécifiques. Le Chevalier à la peau de tigre de Roustavéli pourrait être lu comme une redécouverte poétique de la géographie géorgienne. En donnant pour décors à son poème des lieux éloignés de sa patrie (l'Arabie, l'Inde, le Kathai - qui représente probablement la Chine), le grand poète de l'âge d’or géorgien touche à la variété de son univers multiculturel grâce à une perspective internationale. Cette perspective présuppose la nécessité de la traduction, ce qui peut être résumé par l'idée qu'il demeure une proximité socioculturelle réelle en dépit de la distance géographique. Cette proximité n'a rien d'illusoire. Cela est vrai aussi du rôle de médiation joué par la culture géorgienne pendant des siècles, établissant un dialogue entre des cultures très différentes.

Selon Hegel, l'Asie Mineure (dont la Géorgie fait partie), "se trouve en rapport avec l'Europe; car ce qu'elle contenait de supérieur, cette région ne l'a pas conservé, mais l'a envoyé en Europe. Elle représente tous les principes religieux et politiques à leur début, mais c'est en Europe seulement qu'ils se sont développés ${ }^{50}$ ".

Fascinée par l'atmosphère biblique, antique, de cette Géorgie prise entre Orient et Occident, "à la frontière de l'Asie et de l'Europe ", une jeune journaliste allemande pose cette belle question: "Quel est donc ce pays où les femmes s'appellent Médée et Salomé? » Et c'est chez Knut Hamsun qu'elle trouve la réponse: «le pays des Merveilles ${ }^{51}$ ".

(Traduit de l'anglais par Chloé Thomas)

50. Ibid., p. 81.

51. Hannah Lühmann, "Paradies zum Ausschneiden ", Die Welt, 15 mai 2016, https://www.welt.de/print/wams/kultur/article155359298/Paradies-zumAusschneiden.html, page consultée le 3 janvier 2018. 


\title{
Lev Nussimbaum et Banine, de Bakou à la Corne d'or
}

\author{
Sophie Basch
}

En 1905 naquirent à Bakou un homme et une femme que rien ne prédestinait à une carrière littéraire: Umm-el-Banine Assadoulaeff, plus connue sous le nom qu'elle prit plus tard à Paris, Banine; et Lev Nussimbaum, qui devint célèbre durant l'entre-deux-guerres en Allemagne et en Italie sous les pseudonymes de Essad Bey et Kurban Saïd. Née dans la communauté musulmane de Bakou pour la première, dans une famille juive de la même ville pour le second, ils eurent tous deux une enfance aisée et cosmopolite. Petite-fille de deux magnats du pétrole, Chamsy Assadoulaeff et Mirza Agha Musa Nagieff, et fille de Mirza Assadoulaeff, ministre du Commerce et de l'Industrie durant le bref interlude de la République démocratique d'Azerbaïdjan, Banine arriva à Paris en 1924. Elle laissa deux livres de mémoires écrits en français, Jours caucasiens et Jours parisiens, publiés respectivement en 1946 et 1947 aux éditions René Julliard. Il s'agit de deux récits autobiographiques, le second étant toutefois plus romancé que le premier. Aucun n'a encore été traduit en anglais, mais il existe à ma connaissance une traduction en azéri de Jours caucasiens.

Banine, qui mourut en 1992, fut son propre biographe. Son exécuteur testamentaire, un peintre allemand du nom de Rolf Stürmer, écrira peut-être un jour l'histoire de sa vie. Mais, à l'heure actuelle, on ne dispose que de ses deux livres de mémoires pour retracer ses tribulations depuis un palais de Bakou jusqu'à une chambre de bonne parisienne. Quant à Lev Nussimbaum, qui mourut en 1942 dans le sud de l'Italie, il eut la chance extraordinaire de trouver 
un biographe prodigieux en la personne du journaliste américain Tom Reiss. Celui-ci ne travailla toutefois pas à partir de rien: la formidable enquête qu'il publia en 2005 est notamment basée sur des carnets inédits que Nussimbaum rédigea à Positano sur son lit de mort et qui furent confiés à Reiss par le dernier représentant de l'éditeur de Kurban Saïd à Vienne, Therese Kirschner-Mögle. À partir de cette autobiographie posthume fragmentaire, Reiss a livré une reconstitution fascinante de la vie de Nussimbaum, qui renvoie à toute une époque et tout un milieu, dont celui des orientalistes juifs du Berlin des années 1920. Lev Nussimbaum et Banine étaient tous deux des personnages complexes. L'un comme l'autre furent fascinés par des personnalités sulfureuses: Nussimbaum par Ezra Pound dans les dernières années de sa vie, alors qu'il rédigeait une biographie de Mussolini; Banine par Ernst Jünger, figure emblématique de la révolution conservatrice.

Je n'évoquerai pas ici le célèbre roman de Kurban Saïd, Ali et Nino (1938), qui raconte l'histoire d'amour entre un Azéri musulman et une chrétienne de Géorgie, véritables Roméo et Juliette du Caucase. Le livre a connu une notoriété plus grande encore grâce à son adaptation cinématographique et, en 2011, l'excellent Azerbaijan International Magazine a consacré deux volumes à cette œuvre majeure ${ }^{1}$. Je m'intéresserai à La Fille de la Corne d'Or, publié en 1938. À la différence de Ali et Nino, cette œuvre très importante n'a pas encore fait l'objet d'études ni de commentaires détaillés.

Leur naissance à Bakou en 1905 n'est pas le seul événement qui unit Lev Nussimbaum, le juif azéri qui se faisait passer pour un prince musulman dans l'Europe des années folles, et Banine, la jeune musulmane émancipée dont les mémoires s'ouvrent sur cette phrase éloquente: «À l'encontre de certaines personnes dignes, nées dans des familles pauvres mais « bien », je suis née dans une famille pas «bien" du tout, mais très riche ${ }^{2}$. " Le lecteur est d'emblée frappé par le ton sarcastique utilisé ici par Banine, tout comme il l'est par l'insolence et la liberté manifestées par Asiadeh, l'héroïne de La Fille de la Corne d'Or. Ce n'est certainement pas un hasard si

1. Azerbaijan International, vol. 15.2-4, 2011.

2. Banine, Jours caucasiens, Paris, Julliard, 1945, p. 15. 
Kurban Saïd avait choisi pour son héroïne le nom de celle du fameux roman de Pierre Loti, Aziyadé, publié en 1879. La notoriété de cette histoire, celle de l'amour interdit entre un officier britannique et une jeune esclave circassienne dans le harem d'un vieux Turc, avait largement dépassé les frontières françaises. En 1906, Pierre Loti publia Les Désenchantées, un texte sur les harems turcs de son époque où il se faisait la voix de jeunes recluses cultivées, nourries de littérature occidentale. Son portrait de ces « Madame Bovary » du Bosphore ne manquait toutefois pas d'ambigüité. En effet, tout en reconnaissant la souffrance de ces prisonnières du harem, Loti ne pouvait s'empêcher de regretter une époque révolue. Après tout, l'éducation des femmes n'était-elle pas un des ravages de la modernité?

L'Asiadeh de Kurban Saïd est l'antithèse de l'Aziyadé de Loti. De la même manière, Banine défie les préjugés qui entourent la femme orientale. L'intérêt des mémoires de Banine, dans lesquelles elle livre un portrait d'elle-même, et le roman de Kurban Saïd, qui met en scène une figure féminine double, est de présenter au lecteur occidental une femme orientale affranchie de tous les clichés dont elle est d'ordinaire affublée. On obtient ainsi une vision inversée, opposée: la femme orientale vue du Caucase et en particulier depuis Bakou, ville mosaïque rapidement transformée par le cours de l'histoire. Banine et Asiadeh sont toutes deux le produit de cette accélération.

Le titre du roman de Kurban Saïd, La Fille de la Corne d'Or, pourrait égarer le lecteur. À première vue, en effet, il a tout du cliché exotique. Mais dans son contenu, le roman détrompe tout ce que le titre pouvait laisser entendre. Asiadeh est une jeune femme moderne qui étudie les langues orientales à l'université de Berlin avec pour ambition de se faire l'ambassadrice d'un multiculturalisme perdu. Kurban Saïd y a transposé sa propre expérience d'étudiant dans le Berlin des années 1920. Tom Reiss écrit:

Pourquoi un groupe de juifs de plus en plus en vue avait-il donc choisi le monde islamique en solution à leur dilemme [le sionisme ou les idéaux européens]? Ils se considéraient en réalité comme originaires de l'Orient, et plus particulièrement de l'Orient islamique, d'une manière séduisante et unique. Des personnages aussi divers que Disraeli ou le philosophe Martin Buber avaient contribué à re- 
placer l'esprit du judaïsme dans le monde panasiatique. Ils avaient réinventé l'Orient musulman historique pour en faire un univers où s'estompaient les démarcations ethniques et sectaires, et ou surtout l'antisémitisme avait disparu ${ }^{3}$.

Le ton caustique est donné dès les premières lignes:

«Et ce « i ", mademoiselle Anbari? "

Asiadeh leva la tête. Ses yeux gris étaient pensifs et sérieux.

"Ce « i »? " répéta-t-elle d'une vois basse et douce. Elle marqua un instant de silence avant d'affirmer d'un ton résolu et désespéré: «Ce « i » est un gérondif iakoute que l'on peut rapprocher de la forme kirghize " barisi ». "

Bang frotta son long nez busqué. Derrière la monture métallique de ses lunettes rondes, son regard avait la sagesse de celui d'une chouette. Il expira d'un air réprobateur.

" Je considère, dit-il en tapant sur la table de son doigt osseux, je considère ce « $\mathrm{i}$ » du « bari » iakoute comme un suffixe possessif. Bari signifie "la totalité " et la forme en " $\mathrm{i}$ " que nous rencontrons ici au lieu de la forme iakoute familière en « a ", provient certainement d'un palatalisation plus récente. Quel est le substantif primitif?

- Bar - ce qui existe, répondit Asiadeh.

- C'est exact, poursuivit Bang, pensif et mélancolique. Ce qui existe et, comme tout autre substantif, il se décline. Nous retrouvons la racine « bari » en Koumyk. En balkare et en karatchaï en revanche, le radical est « barasin ». J'ai pourtant quelque difficulté à m'expliquer cette absence du « a » dans la forme iakoute. "

Une odeur de vieux papier régnait dans la pièce exiguë percée d'une haute fenêtre. Bang tournait tristement les pages du dictionnaire sous les yeux du Tatare Rachmetullah, du Hongrois Szurmai et du sinologue Goetz réunis autour de la table rectangulaire. Asiadeh contemplait ses petits ongles et le sinologue Goetz suggéra d'expliquer cette forme mystérieuse par un instrumental mongol figé.

"Quand j’étais jeune, observa Bang sévèrement, j’avais moi aussi tendance à tout expliquer par un instrumental mongol figé. L'audace est un privilège de la jeunesse. "

Bang avait soixante ans. Le sinologue quarante-cinq. Asiadeh éprouva soudain un douloureux picotement au fond de la gorge. Les effluves douceâtres des dictionnaires jaunis, les fioritures sinueuses

3. Tom Reiss, L'Orientaliste: l'énigme résolue d'une vie étrange et dangereuse, Paris, Buchet-Chastel, 2005, p. 267. 
des écritures mandchoues et mongoles, les formes barbares des langues engourdies, étaient irréels, hostiles, presque glaçants. Elle poussa un profond soupir, la cloche sonna. Bang alluma sa pipe, signalant ainsi la fin du séminaire de philologie turque comparée. De son doigt maigre, il caresse tendrement la page flétrie de la grammaire ouïgoure et annonça sèchement: "La prochaine fois, nous aborderons la structure du verbe négatif à partir des hymnes manichéens. " Dans sa bouche, cette phrase tenait tout à la fois de la promesse et de la menace. La philologie avait perdu tout sens à ses yeux depuis la mort du grand Thomsen à Copenhague. La jeunesse ne comprenait rien et prétendait tout expliquer à partir d'un instrumental figé.

Les quatre auditeurs s'inclinèrent silencieusement. Asiadeh se dirigea vers le grand escalier de la faculté de langues orientales. Les salles de cours déversaient leur flot d'égyptologues barbus et de jeunes exaltés fermement décidés à consacrer leur existence à l'étude des inscriptions assyriennes en caractères cunéiformes. Derrière la porte close de l'amphithéâtre d'arabe expiraient encore les laryngales sanglotantes d'un ghazal de Lebid, et la voix du professeur concluait: «Un exemple classique d'apocope. " ${ }^{4}$

La Fille de la Corne d'Or est une sorte de fable philosophique dans laquelle Asiadeh joue le rôle d'une Uzbek moderne, à l'image du voyageur des Lettres persanes de Montesquieu.

Le roman est à la fois émouvant et extrêmement drôle. Asiadeh Abanri est la fille d'un pacha turc exilé après la chute de l'Empire ottoman. Promise en mariage à l'héritier du trône, qu'elle n'a jamais vu, Asiadeh étudie les langues orientales à Berlin. Elle tombe malade et rencontre alors le docteur Hassa, un laryngologue viennois, lointain héritier d'une famille bosniaque, les Hassanovic, dont les attentions se révèlent à la fois terrifiantes et envoûtantes. Bien qu'Asiadeh soit parfois déroutée par les manières occidentales du docteur, ils s'éprennent l'un de l'autre. Kurban Saïd parvient magistralement à saisir la fragilité de leurs différences culturelles, leur histoire d'amour s'avérant trépidante et au final décevante. Asiadeh rédige une lettre désespérée à son ancien fiancé, le prince ottoman, en lui demandant de la libérer de son engagement. Miraculeusement, la lettre parvient au prince, qui vit dans la clan-

4. Kurban Saïd, La Fille de la Corne d'Or, trad. Odile Demange, Paris, Buchet-Chastel, 2006, p. 11-13. 
destinité. Accablé par le chagrin et la perte, il lui répond et lui intime de suivre le chemin qui lui apportera la paix: le prince, noyé dans le whisky et les cocktails, est devenu scénariste et vit à New York où il est assisté par Sam Dooth, qui est en réalité un Grec phanariote, Perikles Heptomanides. Tous deux représentent l'Empire ottoman. Asiadeh et Hassa se marient, mais ni l'un ni l'autre n'est en réalité entièrement libéré du passé. Ils passent leur lune de miel à Belgrade, d'où est originaire la famille de Hassa. Mais ce dernier a le mal du pays et est désorienté. Asiadeh, quant à elle, est profondément nostalgique d'Istanbul. Ils s'installent à Vienne, mais Asiadeh semble perdre à la fois sa langue et ses repères, enfermée dans un pays froid où elle se sent continuellement et profondément incomprise. C'est alors que le prince, seul et pressé de retrouver son pays d'origine, vient réclamer sa promise. Asiadeh et Hassa divorcent. Hassa épouse une seconde fois sa première femme, Marion. Asiadeh embarque pour New York avec son prince scénariste, Sam Dooth le Phanariote, et son père.

Ce roman permet de redécouvrir de nombreux épisodes de la vie de Kurban Saïd: l'exil de la ville natale orientale et cosmopolite, les souffrances du vieux père déplacé, déclassé et ruiné, le séjour à New York dont le luxe obscène choque l'écrivain et où il suit la riche famille de sa femme, Erika Loewendahl, et enfin le divorce final. Cependant, et cela est très significatif, Asiadeh n'est pas originaire de Bakou mais d'Istanbul: c'est là en effet que Lev Nussimbaum changea de peau, où il troqua ses vieux habits de bourgeois azerbaïdjanais occidentalisé pour un vrai costume d'occidental, avant de revêtir son déguisement d'oriental. Pour Kurban Said comme pour Banine, Istanbul tient tant du lazaret que de l'incubateur. C'est dans cette ville que ces écrivains et leurs personnages sont nés, Lev en 1921 parmi les Russes de l'armée du général Wrangel, Banine en 1924 avec le mari qu'elle détestait, Balabek Gojayev (qu'elle appelle Djamil dans ses mémoires), et qu'elle abandonna, le laissant perdre le reste de sa fortune au poker tandis qu'elle montait à bord de l'Orient-Express pour rejoindre sa famille (son père, sa belle-mère et ses sœurs) déjà exilée à Paris. Dans cette perspective, qui contraste avec l'eurocentrisme habituel, Istanbul est la première étape, non pas vers l'Orient, mais vers l'Occident. Dans cette ville, l'exilé de 
Bakou se trouve dépouillé à tout point de vue: de ses illusions, de sa culture orientale et de ses économies, rapidement dilapidées dans les hôtels luxueux, les restaurants russes et les casinos. Mais au moment de quitter l'Orient, Banine s'émeut à la vue d'un dernier spectacle: les cimetières. C'est le seul passage de son autobiographie dans lequel elle renonce à son ironie corrosive:

Encouragée par notre opulence passagère et par un ciel de légende, je voulus aussi faire quelques dernières excursions; je visitais Prinkipo, Terapia, d'autres lieux de pèlerinage classique.

Mais rien ne m'émut autant que les cimetières autour de Constantinople, avec leurs cyprès droits, leurs pierres droites, elles aussi, sur les tombes. Nulle part je ne me suis sentie aussi musulmane que là: les croix, les mausolées riches et compliqués, les fleurs, me déplaisent dans un lieu dédié à la paix. J'aime la simplicité dans la mort: j’aime l'aspect ascétique d'un cimetière musulman. Le dernier que j'ai visité en terre d'Islam se trouvait sur une colline d'où l'on voyait le Bosphore. La beauté du ciel, du lieu, de la mer, se conjuguaient pour créer une beauté immense, de cette perfection qui, bien plus que du plaisir, donne de la souffrance. Mais de la souffrance d'une étrange qualité: au-delà d'elle, la joie surgit. On éprouve d'abord le sentiment de l'évanescence de la beauté, mais ensuite la certitude qu'à un certain degré la perfection rejoint l'éternité, où elle demeure, point fixe inaltérable.

[...] Instants vécus sur cette colline, jamais vous ne me quitterez; suspendus quelque part dans ma mémoire, vous mourrez avec moi. Et même, si comme je l'espère, toute beauté reflétée par nous retourne après notre mort à l'éternité, vous deviendrez immortels ${ }^{5}$.

Cette rare parenthèse dans le récit impitoyable et décapant de Banine fait écho à la fascination qu'ont pu éprouver des voyageurs occidentaux, tels Pierre Loti et Claude Farrère, pour les cimetières musulmans. La seule différence est que, chez eux, les sentiments sont intériorisés, même si les cimetières d'Istanbul, au-delà du pittoresque, ont pu eux aussi émouvoir les voyageurs.

Bien qu'il ne fût pas musulman, Lev Nussimbaum-Essad BeyKurban Said réussit à emporter sa fausse identité dans la tombe. Celle-ci domine la mer Tyrrhénienne à Positano. Tom Reiss décrit ainsi le petit cimetière italien:

5. Banine, Jours caucasiens, op. cit., p. 251-252. 
« Eccola », dit Hercule d'une voix douce et chantante. Nous nous trouvions devant une étroite pierre tombale surmontée d'un turban. "C'est dans le style turc, dit-il. [...] » On pouvait lire « Mohammed Essad Bey ${ }^{6}$.

Dans les mémoires de Banine, Istanbul est le seul endroit épargné par la dérision dont elle se sert par ailleurs pour attaquer le petit monde de Bakou et la société parisienne. Le premier est ainsi décrit comme une assemblée de fermiers " nouveaux riches ", d'arrivistes brutaux et avides, acculturés autant parce qu'ils ont perdu le sens des traditions islamiques que parce qu'ils singent avec maladresse et vulgarité les coutumes et les modes occidentales. De manière tout aussi impitoyable, Paris est dépeint comme un concentré d'hypocrisie et d'inégalités sociales.

Dans La Fille de la Corne d'Or aussi, Istanbul est la ville des origines fantasmées:

Asiadeh se taisait. Elle ne détachait pas les yeux de Rolland. Elle ne souriait pas. Il était donc là. L'exilé, celui dont on était sans nouvelles. Des pins poussaient dans son palais. Elle en connaissaient les branches et les cimes, visibles derrière les épaisses murailles. [...] Elle lui appartenait, chaque fibre de son corps lui était destinée, c'était pour lui qu'elle avait appris jadis des poésies persanes et des prières arabes, pour lui qu'elle prêtait l'oreille aux sonorités sauvages des mots barbares.

"Altesse », murmura-t-elle et sa voix s'étrangla. Le présent était confus et extravagant comme un rêve indompté. [...] La maison du Bosphore, la patrie, les couchers de soleil rouge sang sur la Corne d'or, tout lui revenait à travers cet étranger aux lèvres minces et irritées, qui la regardait fixement.

[...] Elle traversa le Ring et l'asphalte était comme un tapis moelleux. Le bonheur — l'unique, l'inconcevable —, il était là, soudain. Il avait les yeux clairs et les lèvres minces, il parlait l'onctueux dialecte d'Istanbul. Il lui appartenait soudain - aussi indissociable d'elle qu'une partie de son corps - , le bonheur ${ }^{7}$.

En dépit de son rythme enlevé et de ses multiples retournements, La Fille de la Corne d'Or est un roman mélancolique. La frénésie

6. T. Reiss, L'Orientaliste, op. cit., p. 373-374.

7. K. Saïd, La Fille de la Corne d'Or, op. cit., p. 192-193. 
linguistique d'Asiadeh rappelle l'avidité du jeune Nussimbaum traversant chaque jour Berlin à l'aube pour apprendre les langues orientales à l'université. C'était pour lui une manière, la seule, d'appréhender, de reconstruire et de préserver le passé. Derrière le Berlin multiculturel des années 1920, Babel cacophonique, se dessinait la nostalgie d'un Caucase perdu, mêlé à un touranisme ou panturquisme. À cet égard, il n'est pas surprenant qu'Istanbul, capitale de la fédération des peuples turcs, ait été identifiée comme lieu des origines, plutôt que Bakou. Pour les Occidentaux, Istanbul était le plus grand échangeur avant le grand saut dans l'inconnu. Mais vue du Caucase, la ville faisait au contraire figure de dernier repère. C'est bien ainsi qu'elle apparaissait aux yeux de Lev Nussimbaum et Banine, qui le dirent avec humour, ironie et la politesse du désespoir.

(Traduit de l'anglais par Camille Joseph) 



\section{0}

\section{L'utopie caucasienne dans la littérature et la politique russes: \\ Alexandre Griboïedov et Iouri Tynianov \\ Ekaterina Dmitrieva}

Les deux personnalités dont il est question dans cet article sont l'écrivain et diplomate russe Alexandre Griboïedov (1795-1829) et le critique littéraire Iouri Tynianov (1894-1943). Ce dernier fut l'un des principaux représentants du formalisme russe; quant à Griboïedov, il est l'auteur de la comédie Le Malheur d'avoir de l'esprit, que tous les écoliers russes connaissent par cœur. Mais il rédigea aussi un "Projet d'établissement d'une compagnie russe du Caucase ", qu'il considérait, si l'on en croit certaines sources, comme sa plus grande réussite. Et pourtant, les mentions de ce texte sont extrêmement rares. Il fut écrit en collaboration avec Piotr Demianovitch Zaveleiski, futur gouverneur de Tiflis (Tbilissi), et signé par les deux hommes dans cette même ville le 17 juillet 1828. Deux mois plus tard, Griboïedov fut envoyé en tant que ministre plénipotentiaire résident, représentant de la Russie, à Tabriz, dans l'actuel Azerbaïdjan iranien - la ville avait alors le statut de mission étrangère - , puis, de là, en Perse, où il devait périr, écharpé par une foule de fanatiques musulmans.

Un siècle après la mort de Griboïedov, Iouri Tynianov rédigea sa biographie romancée ${ }^{1}$. Le formalisme était alors très mal vu par les autorités soviétiques, et les représentants de ce mouvement cher-

1. Iurij Tynjanov, Smer’t Vazir-Muhtara, Leningrad, Priboj, 1929 (La mort du VazirMoukhtar, traduit par Lily Denis, Paris, Gallimard, 1969). 
chaient à poursuivre leurs activités professionnelles par d'autres moyens. Certains, comme Tomachevski et Eichenbaum, se concentrèrent sur leur carrière universitaire; Tynianov se tourna vers la fiction et se mit à écrire des romans biographiques. Avant de se pencher sur la carrière et la vie de Griboïedov, il écrivit une biographie de Wilhelm Küchelbecker; celui-ci, ami de lycée de Pouchkine devenu décabriste, se rendit en Allemagne au début des années 1820; il s'y consacra à la critique du romantisme allemand et plus particulièrement du roman de Novalis Heinrich von Ofterdingen. En 1826, il fut emprisonné, puis exilé en Sibérie en raison du rôle qu'il avait joué dans l'insurrection décabriste ${ }^{2}$. Tynianov travailla également jusqu'à la fin de sa vie sur une biographie romancée de Pouchkine ${ }^{3}$.

Contrairement aux deux autres romans de Tynianov qui retraçaient toute la vie de leur protagoniste, La mort du Vazir-Moukhtar, consacré à Griboïedov, se concentre sur les onze derniers mois de la vie de celui-ci, avec quelques digressions rétrospectives. Tynianov transpose même certains éléments plus anciens à l'année 1828. L’ouvrage ne comporte presque aucune mention de l'activité d'écrivain du héros, toute l'action tournant autour du « Projet » caucasien. Selon Tynianov, Griboïedov a signé avec cette proposition sa propre condamnation à mort.

D’où les interrogations suivantes: pourquoi Tynianov, contraint après la défaite du formalisme de se tourner vers la fiction et les héros littéraires, a-t-il précisément évité la question de la littérature dans son œuvre, se concentrant plutôt sur la diplomatie et la politique étrangère russes? Pourquoi le Caucase était-il un sujet central à ses yeux? Aurions-nous tort de lire dans la biographie de Griboïedov un message caché, un récit qui n'évoquerait pas tant les « légendes des temps reculés ${ }^{4}$ » que des questions contemporaines de Tynianov?

Mais cette histoire se greffe sur un autre mystère, qu'elle dissimule: quel rôle le " Projet » caucasien a-t-il véritablement joué dans le destin de Griboïedov, et quels buts ce dernier poursuivait-il à travers cette entreprise?

2. Id., Kuehla, Leningrad, Cubus, 1925.

3. Id., Puškin, $1^{\text {re }}$ partie, Hudožestvennaja Literatura, 1936.

4. Alexandre Pouchkine, « Rouslan et Lioudmila ». 


\section{Itinéraire d'une vie}

Avant de nous intéresser à ce "Projet " qui, selon Tynianov, eut des conséquences funestes pour Griboïedov, passons en revue les principaux événements de la vie de celui-ci. Né à Moscou, diplômé de la Pension noble de Moscou, il étudia à l'université de la ville de 1810 à 1812. Il assista alors à des conférences sur l'éthique et la politique, et s'intéressa tout particulièrement à l'archéologie, à l'histoire et à la littérature. Sa première comédie burlesque, Dmitri Drianskoi (le texte ne nous est pas parvenu), tournait en ridicule les querelles entre professeurs russes et allemands à l'université de Moscou. Griboïedov obtint ensuite le commandement d'un régiment de hussards. 1815 marqua le véritable lancement de sa carrière littéraire; il avait alors quitté l'armée et vivait à Saint-Pétersbourg. Il traduisit cette année-là une pièce de Creuzé de Lesser, Le Secret du ménage (1809), et publia une parodie de comédie française, Les Jeunes époux. Au printemps 1816, il fit paraître un article intitulé « Analyse d'une traduction libre de la ballade Lénore de Bürger " ${ }^{5}$. C'était à la fois une critique virulente de la traduction de Joukovski et une défense de celle de Katenine; sa prise de position plaçait Griboïedov dans le camp des « archaïstes » littéraires ${ }^{6}$. La même année, son nom rejoignit la liste des membres de la loge maçonnique Les Amis Réunis.

En 1817, il entra dans la fonction publique, au Collège des Affaires étrangères, menant alors une vie de bohème au sein d'un cercle d'écrivains et d'acteurs. La même année, il prit part à un duel à deux contre deux opposant Zavadovski et Cheremetiev, puis Griboïedov et Iakoubovitch, à propos de la danseuse Avdotia Istomina, immortalisée par Pouchkine dans Eugène Onéguine ${ }^{7}$. L'amant d'Istomina,

5. Syn otečestva, $\mathrm{n}^{0} 30,1816$.

6. Iurij Tynjanov, Arhaisty i novatory, Leningrad, Priboj, 1929.

7. Alexandre Pouchkine, Eugène Onéguine:

Блистательна, полувоздушна,

Смычку волшебному послушна,

Толпою нимф окружена,

Стоит Истомина; она,

Одной ногой касаясь пола,

Другою медленно кружит,

И вдруг прыжок, и вдруг летит, 
Cheremetiev, fut mortellement blessé au ventre. Zavadovski dut le ramener en ville sans tarder et les témoins reportèrent leur affrontement (il eut lieu l'année suivante à Tiflis, et Griboïedov fut touché à la main gauche). L'opinion publique tint Griboïedov pour responsable de l'issue tragique des événements. Il accepta alors un poste de secrétaire de mission diplomatique en Perse, qui était peut-être une sorte d'exil déguisé.

En août 1818, Griboïedov partit pour Tabriz, où se trouvait la mission diplomatique. Inquiet du sort des soldats russes retenus en captivité en Iran, il écrivit dans son journal de voyage en 1819 : "Troubles au sujet des prisonniers. Rage et tristesse... Je donnerais ma vie pour mes infortunés compatriotes. " De janvier 1820 à 1823, Griboïedov vécut entre Tiflis et la Perse. Il étudia l'arabe, le turc, le géorgien et le persan. À la même époque, il commença à travailler à sa comédie Le Malheur d'avoir de l'esprit. En février 1822, il devint secrétaire diplomatique du général A.P. Iermolov, qui se trouvait à la tête des troupes russes de Tiflis et occupait le poste de commandant en chef de la Géorgie. Griboïedov aurait travaillé la même année à une pièce intitulée 1812, apparemment destinée à célébrer le dixième anniversaire de la victoire russe sur la France napoléonienne.

Au début de l'année 1823, il prit un congé et retourna en Russie, où il resta environ deux ans. Il composa la première version de sa célèbre valse en mi mineur et acheva une traduction libre du "Prologue sur le théâtre " de Faust. Il écrivit également un opéravaudeville en collaboration avec Viazemski, Qui est le frère, qui est la sœur, ou De tromperie en tromperie. Après s'être installé à SaintPétersbourg, il termina Le Malheur d'avoir de l'esprit à l'automne 1824. Il ne parvint ni à publier ni à faire jouer sa comédie, mais le

\footnotetext{
Летит, как пух от уст Эола

Presqu'aérienne, étincelante,

Docile aux magiques archets,

Au milieu d'un essaim de nymphes,

On aperçoit Istomina.

Elle touche d'un pied le sol;

L'autre trace des cercles lents.

Elle bondit soudain, s'élance,

Vole comme un léger duvet; (traduction de Jean-Louis Backès)
} 
texte, lu dans les salons et diffusé en copies manuscrites, connut un grand succès. Il suscita d'innombrables débats au sein du monde littéraire. Pourtant, découragé par la décision de la censure d'interdire sa pièce, Griboïedov retourna dans le Caucase. Il n'assistera qu'à une seule représentation de sa comédie, mise en scène par les officiers de la garnison russe d'Erevan.

Sur le chemin de la Géorgie, à Kiev, Griboïedov retrouva ses amis M.P. Bestoujev-Rioumine, A.Z. Mouraviev, S.I. Mouraviev-Apostol et S.P. Troubetskoï, membres d'une société secrète. Cette rencontre faillit avoir des conséquences dramatiques, car au cours de l'enquête qui suivit l'insurrection décabriste, Troubetskoï et E.P. Obolensky désignèrent Griboïedov comme membre de la société secrète. Soupçonné d'être décabriste, il fut détenu à la forteresse de Grozny puis conduit à Saint-Pétersbourg, où les enquêteurs échouèrent à prouver son lien avec les insurgés. Ryleïev, l'un des meneurs de l'insurrection, prit la défense de Griboïedov en déclarant qu'il l'avait sondé mais ne l'avait pas jugé apte à les rejoindre. L'accusé lui-même nia catégoriquement toute implication dans le mouvement, arguant du fait que le quatrième acte de sa comédie présentait les conspirateurs sous un jour peu flatteur à travers le personnage de Repetilov. Griboïedov fut relâché avec un " certificat de bonne santé »; il fut reçu par Nicolas I $^{\text {er }}$ et élevé au rang de conseiller à la Cour, bien que secrètement surveillé pendant quelque temps. Il retrouva son poste diplomatique dans le Caucase au début du mois de septembre 1826, alors que la guerre entre la Russie et la Perse venait d'éclater.

Commence alors la période de sa vie qui nous intéresse tout particulièrement. Le général I.F. Paskievitch, qui avait épousé une cousine de Griboïedov, fut nommé commandant en chef de la Géorgie en remplacement de Iermolov; cela ouvrit au diplomate de nouvelles perspectives de carrière. En 1828, Griboïedov participa à l'élaboration du traité de paix de Turkmanchai ${ }^{8}$, particulièrement favorable à la Russie; lorsqu'il présenta le texte à Saint-Pétersbourg, il fut récompensé et élevé au rang de ministre plénipotentiaire

8. Ce traité entre l'Empire russe et la Perse (l'Iran) mettait fin à la guerre russopersane de 1826-1828, en des termes favorables à la Russie. Il fut signé en 1828 dans le village de Turkmanchai près de Tabriz. Il octroie à la Russie les territoires d’Erevan et de l'Arménie orientale, ainsi que le khanat de Nakhitchevan. 
résident en Perse. En juillet 1828, de retour à Tiflis, il signa donc (voir supra) ce " Projet d'établissement d'une compagnie russe du Caucase ", qui prévoyait une transformation économique radicale de la région. Le 9 septembre 1828, jour de son départ pour la Perse, Griboïedov donna à Paskievitch, pour qu'il l'examine, une note additionnelle, concernant le projet, que Zaveleiski lui avait dictée.

Il partit juste après pour la Perse - pour Téhéran plus précisément - afin de mettre à exécution les dispositions du traité de Turkmanchai, c'est-à-dire percevoir des indemnités et renvoyer au pays les sujets russes. Il se présenta également au shah, puisque le traité prévoyait que le gouvernement russe reconnaisse Abbas Mirza, qui avait signé le document, comme héritier du trône de Perse.

Les événements qui suivirent sont bien connus. Après la guerre et l'humiliation du traité de Turkmanchai, un puissant sentiment antirusse s'était développé en Perse. Peu après l'arrivée de Griboïedov à Téhéran, l'ambassade russe fut prise d'assaut par la foule. L'incident se déclencha lorsqu'un eunuque arménien s'échappa du harem du shah et que deux Arméniennes s'évadèrent de celui de son beau-fils. Tous trois sollicitèrent la protection de la légation russe, puisque le traité de Turkmanchai garantissait aux Géorgiens et aux Arméniens qui vivaient en Perse le droit de retourner en Géorgie et en Arménie orientale. Le shah demanda pourtant à Griboïedov de lui livrer les trois demandeurs d'asile. Griboïedov refusa. Sa décision provoqua un soulèvement à travers la ville, et plusieurs milliers de Perses encerclèrent l'ambassade russe en exigeant qu'on leur livre les trois Arméniens.

Le 30 janvier 1829, une foule de musulmans surgit des mosquées et envahit l'ambassade. L'eunuque qui s'était échappé et Griboïedov, qui se défendit à l'aide de son épée, furent parmi les premiers à être assassinés. Seule la cicatrice que Griboïedov avait sur la main gauche, trace de son duel contre Iakoubovitch, permit d'identifier son corps mutilé9.

9. Selon certaines sources russes, des agents britanniques craignant l'influence russe à Téhéran et des réactionnaires persans mécontents du traité de Turkmanchai auraient incité la foule au soulèvement. Des sources anglaises prétendent au contraire que l'attitude de Griboïedov en tant qu'ambassadeur était provoca- 
La vie de Griboïedov se prête parfaitement à la rédaction d'un roman ou d'une biographie romancée. Et pourtant, dans son ouvrage, Tynianov se concentre uniquement sur les deux dernières années de la vie de l'écrivain, en particulier sur son " Projet d'établissement d'une compagnie russe du Caucase ». Plusieurs raisons peuvent justifier cette décision, l'histoire du « Projet » et de la note additionnelle dont il fut assorti constituant une sorte de roman policier, plus encore que Tynianov lui-même ne pouvait l'imaginer.

\section{Projet d'établissement d'une compagnie russe du Caucase: histoire d'un quiproquo}

À en juger par ses lettres du milieu des années 1820, la popularité dont jouissait Griboïedov, les progrès de sa carrière et son mariage avec la femme qu'il aimait - la belle Nina Tchavtchavadzé, fille de son ami, l'écrivain géorgien Alexandre Tchavtchavadzé - ne suffisaient pas à apaiser le trouble de sa conscience civique et artistique. Sa comédie, malgré l'intérêt qu'elle suscitait, n’avait pas été publiée. Les décabristes, parmi lesquels Griboïedov avait de nombreux amis, avaient connu un destin tragique. L'hypothèse fut émise que « Griboïedov cherchait à lutter contre une impression de stagnation en affirmant des principes d'engagement citoyen [...], en se mettant au service d'une cause, et non pas de certains individus, et en tentant d'accomplir des réformes progressistes dans la mesure de ce qui était alors réalisable ${ }^{10} »$. Cette tentative se traduisit par son projet de création d'une compagnie russo-caucasienne.

En réalité, l'idée d'exploiter les ressources naturelles de la Transcaucasie remonte à 1823, lorsque Griboïedov, A.V. Vsevolojski

trice et insultante vis-à-vis de la Perse, et qu'il se moquait des coutumes locales. Cette dernière allégation est peu crédible, étant donné l'excellente connaissance qu'avait Griboïedov des usages de la région. En compensation de l'attaque de la légation et de l'assassinat de l'ambassadeur, et afin d'éviter une nouvelle guerre, le shah envoya son petit-fils Khosrow Mirza à Saint-Pétersbourg, pour offrir à Nicolas $I^{\text {er }}$ le diamant Shah.

10. A.L. Grišunin, V.M. Markovič, Alexandre S. Griboedov, Russkie pisateli. 18001917. Biografičeskij slovar', vol. 2, Moskva, Fianti, 1992, p. 22. 
et T. Ethier lancèrent l'idée d'une entreprise d'échange de biens avec la Perse ${ }^{11}$.

Les obligations de Griboïedov impliquaient de fréquentes visites en Géorgie et dans le Caucase. Il eut ainsi l'occasion d'explorer la région, son industrie et son agriculture, son commerce et sa culture, les mœurs et les coutumes locales. Conscient du retard de développement industriel du Caucase du Sud par rapport à l'Europe, il eut l'idée d'une grande entreprise commerciale et industrielle pour commercer avec la Perse, dans une certaine mesure sur le modèle de la Compagnie des Indes orientales et de la Compagnie russe d'Amérique.

Le " Projet d'établissement d'une compagnie russe du Caucase " fut achevé en juillet 1828. Cette entreprise avait pour buts de renforcer la position de la Russie dans le Caucase, d'intégrer le Caucase à l'ère d'influence économique, politique et culturelle de la Russie et de réunir la Russie et le Caucase en un seul et même pays. En partant pour la Perse le 9 septembre 1828, Griboïedov remit à Paskievitch, on l'a rappelé, un texte additionnel intitulé « Note sur l'établissement de la compagnie russe du Caucase ». Griboïedov n'avait plus que quatre mois à vivre et ne devait jamais connaître le destin réservé à son projet.

Après sa mort, en 1831, Zaveleiski, auteur du texte, tenta de réaliser au moins partiellement leur projet commun et de mettre en place une compagnie commerciale transcaucasienne à Tiflis. Il publia dans le journal Tiflisskie Vedomosti («Nouvelles de Tiflis») une "Introduction " au "Projet » légèrement modifiée, qui comprenait plus de la moitié du document qu'il avait rédigé avec Griboïedov ${ }^{12}$. Mais cette tentative avorta également.

Les lecteurs russes ne prirent pas connaissance du "Projet " avant la publication de son "Introduction » par I. A. Chliapkine en 1889, puis en 1891 accompagnée de la "Note » de Griboïedov dans la revue Russkij Vestnik ("Le Messager russe ") ${ }^{13}$. Cette deuxième

11. N. Calma, « Kommerčeskie zamysly Griboedova ", in Literaturnoe nasledstvo, t. 19-21, Moskva, 1935, p. 143-173.

12. Tiflisskie gubernskie vedomosti, $\mathrm{n}^{\circ} 18,19,20,1831$, p. 137-155.

13. A. Malčinski, « Neizsannaja zapiska P.D. Zavelejskogo », in Russkij vestnik, $n^{\circ}$ 9, 1891, p. 3-7. 
publication fut l'œuvre d'A. Malchinski, un individu à la réputation trouble qui exécutait des tâches pour la police secrète ${ }^{14}$. Aux fragments du texte de Griboïedov, s'ajoutait une reformulation de la partie manquante du "Projet », fondée sur une source inconnue, ainsi que des commentaires négatifs que Malchinski attribuait au colonel I.G. Bourtsov, un ancien décabriste, et à Paskievitch.

On a parfois suggéré que la mauvaise réputation de Malchinski expliquait que lors de la préparation de la première édition universitaire des œuvres de Griboïedov entre 1911 et 1916, son éditeur Nikolai Piksanov n'ait inclus ni la " Note " ni le « Projet », se contentant de les mentionner brièvement ${ }^{15}$.

Cette publication à la fiabilité douteuse dans le Russkii Vestnik tomba dans les mains de Tynianov au milieu des années 1920 et, comme nous allons le voir, détermina en grande partie l'intrigue de son roman, qui donne un rôle important à la critique négative de Bourtsov. Griboïedov voyait en Bourtsov, qui était décabriste, un homme qui partageait ses idées. Dans le recueil suivant des œuvres de Griboïedov, publié en 1940, le " Projet " et la " Note " furent inclus. Les éditeurs, dirigés par Vladimir N. Orlov, acceptaient majoritairement la version de Malchinski et expliquaient l'échec du projet par la critique acerbe de Bourtsov, qui aurait convaincu Paskevitch de le rejeter définitivement ${ }^{16}$.

Cette version influença la perception qu'eurent les chercheurs du projet de Griboïedov et les amena à s'interroger sur la noblesse de ses intentions, prétendument contraires aux « idées humanistes des décabristes ». On considéra la critique de Bourtsov comme la preuve d'un désaccord entre Griboïedov et les décabristes. Certains chercheurs virent le projet comme " une preuve manifeste de la politique [tsariste] d'exploitation menée dans la première moitié du XIX siècle ", considérant que le but de la compagnie russe du

14. A.S. Griboedov, Polnoe sobranie sočinenij (3 vol.), t. 3, édité par S. A. Fomišev, Sankt-Peterburg, 2006, p. 568.

15. Ibid.

16. A.S. Griboedov, Sočinenija, éd. par Vladimir Orlov, Leningrad, Goslitizdat, 1940, p. 585-608, 645-646. 
Caucase était « la colonisation planifiée de la région ${ }^{17}$. Une ombre tomba sur Griboïedov, qui fut étiqueté comme colonialiste impérial.

Toutefois, la tendance à opposer Griboïedov aux décabristes se dissipa avec le temps, et le " Projet », au contraire, fut de plus en plus souvent perçu comme résultant de positions décabristes. Le pathos décabriste de la proposition passa même pour la raison de son rejet: "Le gouvernement rejeta le projet de Griboïedov et de Zaveleiski car il n'y reconnut pas ses idées, ce qui est parfaitement compréhensible ", commenta l'historienne soviétique Netchkina ${ }^{18}$.

Au début des années 1950, on retrouva dans le département des manuscrits du Musée historique un autre document, qui s'intitulait « Notes de l'actuel conseiller d'État Joukovski sur la version préliminaire du projet de Griboïedov et Zaveleiski portant sur l'établissement d'une compagnie russe du Caucase. 1828. " Publié par O.P. Markova, il confirmait étrangement la version de Malchinski... tout en la contredisant ${ }^{19}$. Il comprend des notes concises rédigées par le général Joukovski lorsqu'il eut pour la première fois l'occasion d'examiner l'intégralité du " Projet d'établissement d'une compagnie russe du Caucase ». Le document comprenait également l'« Introduction " publiée pour la première fois en 1831 par Zaveleiski (voir ci-dessus), ainsi que la partie du "Projet ", que l'on croyait perdue, énonçant les conditions et les règles d'exercice de la future compagnie. Les notes de Joukovski étaient divisées en paragraphes. Les trois derniers contenaient des informations sur la critique de Bourtsov, ce qui confirma sa participation aux discussions sur le projet (le texte de Bourtsov n'a pas survécu, mais il fut ainsi résumé par Joukovski: "Après réflexion, le colonel Bourtsov donna une réponse incertaine; il était très inquiet [uzhasalsia] de l'échelle de l'entreprise, craignant des conséquences fâcheuses pour la compagnie, étant donné l'inadéquation des moyens à la nature du $\operatorname{projet}^{20} »$ ).

17. N. Calma, Kommerčeskie zamysly Griboedova, op. cit., p. 173.

18. M.V. Nečkina, Griboedov i dekabristy, Moskva, 1951, p. 522, 525. Cf. commentaires de S. A. Fomišev, Polnoe sobranie sočinenij (3 vol.), t. 3, op. cit., p. 568.

19. Istoričeskij arhiv, vol. 6, 1951, p. 324-390.

20. Ibid. 
Les notes critiques rédigées par Joukovski au sujet du projet de Griboïedov coïncidaient en partie avec celles que Malchinski avait attribuées à Bourtsov lors de la publication de 1891. Cette découverte atténua les soupçons qui pesaient sur Malchinski concernant une éventuelle falsification de documents; mais elle révéla aussi que bien qu'il eût fondé ses propos sur un document authentique, il n’avait pas hésité à les attribuer à la mauvaise personne. La principale information qu'apporta ce nouveau document était que le projet de Griboïedov avait été rejeté par Joukovski, qui l'évoque avec sévérité et sarcasme, et non pas l'ancien décabriste Bourtsov, dont la réponse n'avait été qu' incertaine ${ }^{21}$ ".

Mais le mystère entourant le projet perdu de Griboïedov ne s'arrête pas là. En 1954, l'archiviste I.K. Enikopolov publia deux autres documents, également découverts dans les archives historiques de la fondation Paskievitch et qui concernaient le projet de Griboïedov: des «Commentaires » (zamečanija) et une "Opinion sur l'établissement de la compagnie russe du Caucase " (Mnenie ob učreždenii Rossiiskoj Zakavkazskoi kompanii) ${ }^{22}$. Grâce aux remarques figurant dans la marge des "Commentaires " et qui coïncidaient avec les critiques mentionnées dans l'article de Malchinski, on put déterminer qu'il s'agissait du document utilisé par ce dernier en 1891. C'est ce document qu'il présenta comme " une critique de Bourtsov ", alors qu'il était en fait de la main du général Joukovski.

Enikopolov attribua le second document, "Opinion sur l'établissement de la compagnie russe du Caucase ", à Bourtsov. Il cita comme preuves des coïncidences entre, d'une part, les opinions économiques et politiques qui y figuraient et, d'autre part, les points de vue décabristes tels qu'ils s'exprimaient dans la charte de l'Union de la Prospérité et dans les « Principes pratiques de l'économie politique " (Praktičeskih načalah političeskoi èkonomii) compilés par P.I. Pestel. Plusieurs autres chercheurs appuyèrent l'hypothèse de l'attribution à Bourtsov. Pourtant, une comparaison textuelle des documents démontra par la suite que Joukovski, et non Bourtsov, était aussi l'auteur de l'« Opinion ", qui avait été

21. Polnoe sobranie sočinenij (3 vol.), t. 3, op. cit., p. 569-570.

22. I. K. Enikopolov, Griboedov v Gruzii, Tbilissi, 1954, p. 102-129. 
conçue comme un résumé des notes de Joukovski sur le projet de Griboïedov. Les chercheurs se retrouvaient donc avec trois documents: 1) "Commentaires sur la création de la compagnie..." ("Zamečanija na sozdanii kompanii... »), la critique de Joukovski portant sur différentes parties perdues du texte de Griboïedov, publiée par Enikopolov en 1954;2) l'« Opinion sur l'établissement de la compagnie... ", la réponse finale apportée par Joukovski à la version préliminaire du projet, qui résume une partie de ses notes et également publiée en 1954 par Enikopolov; 3) les « Notes de l'actuel conseiller d'état Joukovski » publiées en 1950 par Markova, qui est une version ultérieure des "Commentaires " préparés par le même Joukovski à la demande de G.V. Rosen, commandant en chef de la Géorgie à partir de 1831, que les idées exprimées par Griboïedov intéressaient grandement. Comme nous l'avons vu, les "Notes" comportaient également un résumé de la réponse de Bourtsov ${ }^{23}$.

\section{Le « Projet d'établissement d'une compagnie russe du Caucase »: entre philanthropie, calcul économique et ambition}

Que penser du « Projet » de Griboïedov, dont seuls des fragments nous sont parvenus, publiés en 1831 à Tiflis, en 1891 dans la revue Le Messager russe et cités dans les notes découvertes ultérieurement du général Joukovski, qui avait été chargé d'évaluer la version préliminaire du document ${ }^{24}$ ? Tout d'abord, gardons à l'esprit que le projet Griboïedov, malgré un caractère fantaisiste remarqué par ceux qui l'ont évalué (Bourtsov et Joukovski), prenait véritablement en compte l'expérience de compagnies de commerce établies de longue date. Dans le texte original de l'« Introduction » au projet, les compagnies utilisées comme références sont explicitement nommées: la Compagnie des Indes orientales et la Compagnie russe d’Amérique,

23. N. O. Tarhova, "Proekte Rossijaskoj Zakavkazskoj Kompanii (Po materialam arhiva I.F. Paskeviča) ", in Problemy tvorčestva A.S. Griboedova, éd par A.S. Fomičev, Smolensk, 1994, p. 285-295. Sur la personnalité de Bourtsov, voir V.B. Makarov, Decembrist Ivan Grigorevich Burtsev, Saratov, 1982.

24. Le texte et les notes conservés ont été récemment publiés dans A.S. Griboedov, Polnoe sobranie sočinenij (3 vol.), t. 3, op. cit., p. 325-346. 
qui profitaient de "privilèges exclusifs » (Zaveleiski avait laissé ce paragraphe de côté lors de la publication de 1831 dans les Nouvelles de Tiflis). La puissante Compagnie des Indes orientales était gérée par son propre gouverneur et disposait de représentants diplomatiques; le gouvernement britannique ne s'immisçait que très peu dans la conduite de ses affaires. La charte de la Compagnie russe d'Amérique était bien connue en Russie; par ailleurs, Griboïedov comptait parmi ses amis le dirigeant de la chancellerie de la compagnie, Ryleïev, et pouvait donc avoir connaissance du détail de ses activités.

En effet, la plupart des privilèges envisagés par Griboïedov et Zaveleiski pour la compagnie russe du Caucase rappelaient la charte de la Compagnie russe d'Amérique, notamment le droit d'attribuer des terres à la compagnie dans tous les districts des provinces transcaucasiennes, la possibilité de lui octroyer des droits sur tous les produits de ces terres, y compris les richesses souterraines, l'établissement de termes préférentiels pour le commerce des biens russes et étrangers, le droit pour la compagnie d'avoir recours à une maind'œuvre locale et enfin le monopole de la compagnie sur tous ces privilèges. Les privilèges de la Compagnie russe d'Amérique étaient renouvelés tous les vingt ans; Griboïedov souhaitait que le monopole de la compagnie du Caucase soit garanti pour cinquante $a n s^{25}$.

Mais la compagnie imaginée par Griboïedov se distinguait nettement des compagnies existantes par d'autres aspects. Le diplomate avait l'intention de favoriser le développement des forces productives et des industriels locaux, et d'établir une médiation commerciale entre la Russie et l'Europe. Le document prévoyait, parmi les avantages évoqués, la liberté diplomatique de la compagnie dans ses relations avec les neuf khanats transcaucasiens ( Entrer en relation avec les propriétaires résidant dans les provinces transcaucasiennes [...], y établir des institutions et une activité commerciale "), ce qui entrait en contradiction avec les intérêts de l'État russe, qui cherchait à recourir aux marchés caucasien et asiatique pour écouler ses propres marchandises. Il n'est donc guère surprenant que Joukovski ait critiqué le projet, puisqu’il

25. Ibid., p. 574. 
souhaitait développer les forces productives russes, et non celles du Caucase du Sud. Lorsque Zaveleiski tenta, comme mentionné ci-dessus, de créer un dépôt commercial transcaucasien en 1831, il exclut de son programme le développement de l'industrie locale.

Aujourd'hui encore, il est difficile d'analyser le projet de Griboïedov sans qu'aucune ambiguïté demeure. Certes, il était motivé par le souci de développer l'économie de ce paradis à travers notamment la création de forces productives propres, affichant ainsi des objectifs économiques, tout en prévoyant d'apporter la civilisation et la connaissance aux Caucasiens. Le but de Griboïedov à travers la compagnie était d'enrichir non seulement l'élite transcaucasienne (les propriétaires terriens et les marchands), mais aussi les gens ordinaires. En protégeant le Caucase du Sud d'éventuelles invasions turques et persanes, l'armée russe offrirait à la population locale la possibilité de mener une existence paisible; le confort et la vie des habitants seraient préservés. Leurs manières s'amélioreraient automatiquement grâce à leur implication dans la compagnie. Griboïedov décrit ces mécanismes en détail au sein des différents milieux sociaux.

La compagnie transcaucasienne était censée devoir infliger un coup sévère au commerce britannique au Moyen-Orient et affaiblir la puissance coloniale de l'Empire britannique dans cette région clé de la politique internationale. Les Britanniques étaient très probablement conscients de cette menace - d'où l'hypothèse selon laquelle ils auraient encouragé la prise d'assaut de l'ambassade russe de Téhéran, que Griboïedov en personne dirigeait. Cependant, l'aspect le plus problématique du projet était la question du statut assigné à la Russie. D’un côté, les activités de la compagnie devaient consolider la présence russe dans le Caucase, assurer l'intégration de cette région dans l'espace économique, politique et civilisationnel russe, et réunir la Russie et le Caucase en un seul et même pays. D'un autre côté, les libertés et privilèges qu'il était question d'octroyer à la compagnie témoignaient d'une intention contraire - d'un désir d'acquérir un pouvoir quasi illimité et de tenir à distance l'autocratie russe.

Un chercheur explique que « le projet Griboïedov-Zaveleiski, qui accordait au gouvernement un rôle minime dans la vie de la région, était entièrement conçu pour favoriser les initiatives et les activités 
privées; il allait à l'encontre de la politique coloniale du gouvernement et pour cette raison était voué à l'échec ${ }^{26}$ ». En revanche, bien que la version préliminaire du projet ait prévu quatre " présidents " à la tête de la compagnie, il ne fait aucun doute que si elle avait été effectivement créée, Griboïedov aurait joui d'un pouvoir presque illimité.

Et pourtant, contrairement aux compagnies existantes comme celle des Indes orientales ou la Compagnie russe d'Amérique, la compagnie du Caucase fut dès l'origine pensée comme une utopie; ce n'est donc pas un hasard si le gouvernement refusa sa création. Griboïedov et Zaveleiski voulurent créer une sorte d'État idéal à l'intérieur de l'État, et c'est précisément la nature utopique de ce projet qui étonnamment l'inscrit non pas tant dans l'histoire économique et politique que dans la perspective de l'assimilation littéraire du Caucase par la Russie. Nous devons donc momentanément laisser de côté la dimension historique du projet pour nous pencher sur ce que l'on appelle le " texte caucasien » de la littérature russe, c'est-àdire l'espace utopique que la littérature russe de l'époque attribuait au Caucase et dans lequel le projet de Griboïedov s'inscrit très harmonieusement.

\section{L'utopie caucasienne}

L'origine du thème caucasien dans la littérature russe remonte à des temps très lointains. Lorsque Moscou noua des relations diplomatiques avec la Géorgie à la fin du $\mathrm{Xv}^{\mathrm{e}}$ siècle, un cercle de copistes moscovites rédigea un texte intitulé L'histoire de la reine Dinara de Géorgie. Cent trente copies ont survécu, ce qui prouve sa grande popularité. Il s'agit d'un roman militaire qui a pour personnage principal une reine idéale et qui relate son incroyable victoire sur les Perses suite à l'intercession de la Sainte Vierge. La reine Tamar (Tamar la Grande, vers 1160-1213) servit sans doute de modèle à Dinara $^{27}$.

26. O.P. Markova, « Novye materialy », in Istoričeskij arhiv, vol. 6, 1851, p. 344.

27. N. K. Gudzij, « Povest o gruzinskoj carice Dinare », in Istorija drevnerusskoj literatury, Moskva, 1953, p. 255. 
Les pèlerinages jouaient un rôle important dans les relations entre la Russie et le Caucase, qui se trouvait sur la route de la Terre sainte. L'itinéraire maritime empruntait la Volga jusqu'à la mer Caspienne, puis la Perse, tandis que l'itinéraire terrestre passait par le Caucase du Nord, le Daghestan, Derbent, Tiflis et Trabzon, jusqu'à Jérusalem. Plusieurs textes suggèrent que les apôtres André et Simon le Cananéen auraient séjourné dans le Caucase ${ }^{28}$. Les guerres russoturques du $\mathrm{XvIII}^{\mathrm{e}}$ siècle eurent une grande importance politique, mais aussi poétique. C'est avec son « Ode sur la prise de Khotin » que Lomonosov instaura le système syllabo-tonique, qui remplaça dans la poésie russe le système syllabique, jusqu'alors largement utilisé en raison des influences polonaise et française.

La paix de Koutchouk-Kaïnardji qui mit fin à la guerre russoturque en 1774 inspira au poète Derjavine un qualificatif élogieux pour désigner Catherine II: "Félitsa, princesse des hordes de Koutchouk-Kaïnardji ${ }^{29}$ ». La Grande Catherine figura dans la poésie russe sous cette appellation jusque dans les années 1800 au moins. On peut également mentionner l'ode dans laquelle Derjavine décrit la campagne du comte Zoubov en Perse; elle contient une autre expression décrivant le Caucase de manière poétique: le «terrible pays des miracles » (Užasnyj kraj čudes) ${ }^{30}$. Cette formule fut utilisée pendant près d'un siècle ${ }^{31}$.

28. Voir I.L. Bagration-Mukhraneli, Drugaja žizn i bereg dalnij, Tver, Marina Butasova, 2016, p. 26. Voir également Harsha Ram, The Imperial Sublime: A Russian Poetics of Empire, Madison, University of Wisconsin Press, 2003; Susan Layton, Russian Literature and Empire: Conquest of the Caucasus from Pushkin to Tolstoy, Cambridge, Cambridge University Press, 2005.

29. Poème " Félitsa » (1782).

30. Poème «Le retour de Perse de Zoubov » (« На возвращение Зубова из Персии ", 1797).

О юный вождь ! Сверша походы, прошел ты с воинством Кавказ, зрел ужасы, красы природы.

Oh, jeune chef! Toi qui dans tes campagnes

As franchi le Caucase avec une armée

Toi qui as vu les horreurs et les beautés de la nature.

31. Poème de Pouchkine, "J'ai vu les confins arides de l'Asie... " (Я видел Азии бесплодные пределы, 1820). Cf.: Ужасный край чудес!... там жаркие ручьи/ 
Le premier ouvrage en prose à prendre le Caucase pour sujet fut le roman de Vassili Narejni L'Année noire, ou les Princes des montagnes (Černyj god, ili Gorskie kniaz’ia). Diplômé de l'université de Moscou, Narejni fut nommé en 1801 secrétaire du premier dirigeant russe de Géorgie, Kovalevski, dans le gouvernement géorgien qui venait d'être formé. Inspiré par sa lecture de Schiller, il entama en 1803 la rédaction d'un roman sur des brigands et des voleurs, dans l'esprit des contes allemands. Achevé en 1803, il ne fut publié qu'en 1829, alors que le thème caucasien était déjà fermement établi dans la littérature russe. La principale raison pour laquelle l'auteur n'a pas voulu le publier de son vivant serait la suivante: la vision satirique qu'il donnait de la Géorgie, sous une forme allégorique, se trouvait aux antipodes du positionnement officiel, et son allégorie, en particulier la peinture des abus de pouvoir de Kovalevski, aurait été trop facilement comprise par ses contemporains ${ }^{32}$.

On considère très souvent que le développement du romantisme a donné « une voix » au Caucase dans la littérature russe. L'attrait des splendeurs naturelles et des mœurs et coutumes pittoresques de cette région, qui était déjà considérée comme appartenant à l'Empire russe, augmenta grandement aux yeux des poètes et des romanciers russes. Le rôle du Caucase dans la vie sociale et intellectuelle russe gagna aussi en importance. Comme l'écrit l'historien russe Nathan Eidelman, "Toute la Russie allait au Caucase: les exilés comme les hommes libres, les Bestoujev comme les Pouchkine. À l'époque [les années 1820], le Caucase était l'un des centres spirituels de la Russie ${ }^{33}$."

Après la guerre de 1812 et le retour de Paris des troupes russes, une nouvelle doctrine émergea, guidée par des principes civilisateurs et humanistes, dictée par la logique selon laquelle la "lumière " de la civilisation pouvait libérer le Caucase comme la Russie s'était libérée de Napoléon. Bien sûr, il ne faut pas oublier que

Кипят в утесах раскаленных... Le terrible pays des miracles!.... Là-bas des rivières ardentes écument à travers les rochers brûlants...

32. I. L. Bagration-Mukhraneli, Drugaja žizn i bereg dalnij, op. cit., p. 43.

33. Nathan Eidelman, "Byt’ možet za hrebtom Kavkaza... » Russkaja literaturnaja I obščestevennaja mysl' pervoj poloviny XIX veka. Kavkazskij kontekst, Moskva, 1990, p. 253. 
certains libéraux et membres de l'opposition étaient eux aussi partisans du renforcement de la présence russe à l'est (ou, pour le dire plus simplement, de la conquête du Caucase). Comme l'avait déclaré le décabriste Lounine lors de la guerre russo-turque de 1828, "la prise d'Akhaltsikhé est plus importante que l'occupation de Paris. Ici, notre plus grand ennemi a été vaincu sur le front principal ${ }^{34}$ ". Rappelons-nous également les mots de Pouchkine: "Soumets-toi, Caucase, voici Iermolov! » (Smiris', Kavkaz, idet Ermolov) ${ }^{35}$.

Ce qui est paradoxal, c'est que la guerre du Caucase qui s'étendit de 1817 à 1864, la plus longue de l'histoire de la Russie, non seulement marqua l'apparition du thème caucasien dans la littérature russe, mais sembla même faire naître un certain amour pour cette région. Le Caucase était baigné dans une rivière de sang, mais la littérature russe l'évoquait avec amour. Dans "Le Prisonnier du Caucase", par exemple, Pouchkine décrit cette contrée comme un " nouveau Parnasse ». En 1827, Bestoujev-Marlinski, alors en exil en Sibérie (en Iakoutie, plus exactement), écrivit à son jeune frère Michael, exilé dans le Caucase: «Es-tu devenu poète après avoir vu le Caucase? Ne pas l'être serait presque impoli, quand on se trouve si près du ciel ${ }^{36}$."

Autre paradoxe: ce territoire conquis est souvent dépeint par les écrivains russes comme un pays de liberté. Des héros professant le culte de la liberté y sont organiquement liés. Pour les romantiques, le Caucase est devenu un Orient russe. Dans le poème de Pouchkine "Le Prisonnier du Caucase ", il joue le même rôle que la Louisiane dans Atala de Chateaubriand. Mais c'est ici que la dualité du mythe caucasien devient évidente. Dans son poème, écrit en partie sur le modèle du « Pèlerinage de Childe Harold » de Byron, en partie sur celui d'Atala, Pouchkine érige la liberté en valeur absolue. C'est l'objet de la quête du héros, « dans un monde désolé » (Svoboda, On odnoj tebja ešče iskal v pustynnom mire). Il se rend dans le Caucase, et c'est justement là, sur une terre de liberté absolue, qu'il est fait prisonnier.

34. Voir Jakov Gordin, Kavkaz: zemlja i krov'. Rossija v kavkazskoj voine XIX veka, Sankt-Peterburg., Zvezda, 2000, p. 20.

35. Alexandre Pouchkine, épilogue du Prisonnier du Caucase.

36. Russkij vestnik, n 5, 1870, p. 259. Cf. I. L. Bagration-Mukhraneli, Drugaja žizn i bereg dalnij, op. cit., p. 101. 
À vrai dire, c'est dans la littérature française, et non russe, qu'apparaît pour la première fois le thème du captif dans le Caucase; Les prisonniers du Caucase, écrit en 1815 par Xavier de Maistre, relate la captivité et l'évasion du major Kascambo, que les Tchétchènes acceptaient de libérer contre une rançon colossale de 10000 roubles $^{37}$.

Le personnage de Pouchkine est libéré par une Circassienne qui s'éprend de lui; et c'est justement elle, "une enfant des montagnes ", qui meurt lors du dénouement du poème, puisque son amour n'est pas partagé. Pouchkine associe les thèmes de la liberté et de la captivité, de la beauté de la nature caucasienne et de la mort causée par les actions d'un Européen, que subissent les peuples libres du Caucase. Plus tard, ce thème apparaîtra de nouveau avec Lermontov, dans Un héros de notre temps, l'histoire d'une vierge des montagnes qui meurt d'être tombée amoureuse d'un homme appartenant à une autre culture et une autre religion. Pourtant, étonnamment, c'est " Le prisonnier du Caucase » de Pouchkine qui ancra dans la conscience collective des Russes l'idée que les peuples caucasiens les appréciaient, voire les aimaient ${ }^{38}$.

On peut dire que le Caucase, tel qu'il apparaît dans les classiques de la littérature russe, a tous les traits d'une utopie - un territoire jouissant d'une extraordinaire liberté, l'Orient russe, un paradis terrestre et, ce qui n'est pas le moins intéressant, un lieu où l'on peut faire passer des lois spéciales, loin de toute intervention étatique. L'image du Caucase comme terre de dangers s'est effacée devant celle d'une sorte de "station thermale " où l'on soignerait le corps et l'esprit.

En fait, l'une des premières utopies politiques associées au Caucase remonte au règne de Paul $\mathrm{I}^{\mathrm{er}}$ qui, contrairement à sa mère, désirait maintenir la paix dans la région. Il aurait voulu créer une fédération des princes des montagnes afin de transformer en coopération la rivalité commerciale, économique et militaire qui existait entre la Perse, la Russie et la Turquie ${ }^{39}$.

37. M. A. Takho-Godi, Kavkaz i kavkazskie plenniki glazami putešestvennikov načala XIX veka. Disponible en ligne: http://www.darial-online.ru/2001_1/taxogo.shtml

38. I.L. Bagration-Mukhraneli, Drugaja žizn i bereg dalnij, op. cit., p. 85-152.

39. Ibid., p. 37. 
Entre 1830 et 1840, les efforts de paix menés en plein cœur de la guerre du Caucase ont aussi favorisé l'émergence d'une littérature et de projets utopiques. En collaboration avec les représentants de l'intelligentsia géorgienne A. Tchavtchavadzé et R. Eristavi, l'écrivain Vladimir Sollogoub, un aristocrate au service du gouverneur du Caucase, et le comte Vorontsov entreprirent de développer une nouvelle branche de la littérature russe, à savoir une littérature caucasienne. Vorontsov tenta de lancer une nouvelle politique éducative dans le Caucase ${ }^{40}$. Mais force est de constater qu'aucun de ces projets ne se réalisa. L'idée d'un processus de paix par le biais de la culture, mené par l'Empire russe dans le Caucase se révéla illusoire.

Léon Tolstoï fut le dernier écrivain russe majeur à écrire sur le Caucase. Dans son roman Les Cosaques, publié au début de sa carrière, il exprime l'espoir d'un Caucase terre de justice, gouverné par la communauté cosaque. Cette utopie fut réfutée par les circonstances historiques. Dans " Hadji Mourat ", texte célèbre et plus tardif, l'auteur ne fait plus preuve d'aucune pitié dans sa peinture du Caucase, espace géopolitique peuplé d'hommes forts et fiers, mais destiné à rejoindre un vaste empire. La religion, qui avait réuni la Russie et le Caucase, s'efface au second plan. Tolstoï présente Nicolas $I^{\mathrm{er}}$ et Chamil, le chef des rebelles, comme des personnages ambivalents; quant au noble héros qui représente les meilleures qualités des peuples caucasiens, il meurt.

Déjà avant Tolstoï, le décabriste Bestoujev-Marlinski, mentionné ci-dessus, refusait d'idéaliser le Caucase, ne connaissant que trop les dangers d'une telle posture: « Les poètes ont fait de ce géant couronné de glace [...] une sorte de pâtisserie aux amandes dégoulinante ${ }^{41}$. »

Ce contexte compliqué est en lien direct avec le sujet de notre article. Les notions de liberté et d'indépendance étatique s'associent dans cette région à celles d'exil et de punition, et pourtant, l'utopie reste possible. Voyons tout cela comme un cadre nous per-

40. Voir en particulier les sections "Le motif de l'utopie dans l'œuvre du comte V.A. Sollogoub » et " Le motif de la paix culturelle " dans la monographie de Bagration-Mukhraneli.

41. A. Bestužev-Marlinski, Sočinenija (2 vol.), t. 2, Moskva, GIHL, 1958, p. 201. 
mettant de mieux comprendre à la fois la dernière année de la vie de Griboïedov et le récit qu’en a fait Iouri Tynianov.

\section{Une erreur historique qui s’avéra fatale pour la littérature russe}

Je reviens pour conclure à la question posée au début de cet article: pourquoi Tynianov, qui manifesta par ailleurs un intérêt si profond pour la littérature russe, plaça-t-il au centre de son roman, écrit une centaine d'années après les événements relatés, non pas la superbe comédie de Griboïedov Le Malheur d'avoir de l'esprit, mais son projet de compagnie transcaucasienne? Pourquoi a-t-il tissé l'intrigue de son roman autour du "Projet d'établissement d'une compagnie russe du Caucase ", qu'il présenta comme un geste volontaire de la part de Griboïedov par lequel il finit par donner sa vie? La situation n'est pas sans similitudes avec, par exemple, l'acceptation par Pouchkine du duel avec d'Anthès. Ce geste volontaire, tel qu'il est décrit par Tynianov, inscrit Griboïedov dans la martyrologie de la littérature russe.

L'histoire du " Projet d'établissement d'une compagnie russe du Caucase » et de la " Note " qui l'accompagnait revêt un intérêt textologique. Pourquoi l'identité de l'auteur de la critique qui condamna le projet - l'ancien décabriste Bourtsov ou le péremptoire général Joukovski - suscita-t-elle une telle controverse? La découverte effectuée dans les années 1950 qui permit d'attribuer la critique très négative du projet à Joukovski et non à Bourtsov rendit le mystère plus facile à résoudre. Si les chercheurs qui considéraient le décabriste Bourtsov comme le principal opposant à Griboïedov devaient imaginer des raisons complexes au désaccord existant entre les deux anciens compagnons, les recherches menées entre les années 1960 et 1980 imputèrent la ruine du projet au réactionnaire Joukovski, tandis que l'opinion "incertaine » de Bourtsov semblait presque positive comparée à celle pleine de sarcasme du général. Ainsi, l'échec du projet s'expliquait par l'attitude suspicieuse et hostile des " cercles officiels » à l'égard de Griboïedov.

Certes, Iouri Tynianov, décédé en 1943, ne put avoir connaissance de ces découvertes tardives; mais c'est précisément la version 
erronée (d'un point de vue historique) présentée par Malchinski, qui rendait Bourtsov responsable de l'échec du projet, qui prit une importance centrale dans le roman, car l'intrigue est fondée sur un conflit entre d'anciens alliés décabristes séparés par la vie, qui s’affrontent autour d'un projet de transformation du Caucase. D'après Tynianov, Griboïedov espérait améliorer et mettre en œuvre les projets avortés des décabristes.

Tynianov lui-même était convaincu que " chaque période met en avant les événements passés qui lui correspondent et oublie les autres ". L'un des thèmes qui revient sans cesse dans son roman est celui de la trahison du décembrisme, qui ne se départ jamais d'un vestige de loyauté. Il décrit Griboïedov comme un radical qui a survécu à l'écrasement de la rébellion et a reconsidéré ses anciens idéaux décabristes. Il évoque ses liens avec les insurgés, mais aussi ce qui les a séparés. Il insiste sur ce qui le distingue des rebelles et expose sa vision de ce qui aurait pu se passer si l'insurrection de 1825 avait été couronnée de succès. Par le biais du personnage de Griboïedov, Tynianov prétend que la victoire des décabristes n'aurait pu mener qu'au remplacement d'une forme de tyrannie par une autre, d'un régime policier despotique par un autre.

Les héros des poèmes romantiques russes d'avant 1825 partaient vers l'est, vers le Caucase, dans l'espoir d'échapper à « l'esclavage de la ville étouffante ». Le Griboïedov de Tynianov se rend dans un État qui n'existe pas encore. Alexandre parle du Caucase comme d'une "Sibérie torride", et Nicolas $\mathrm{I}^{\mathrm{er}}$ en a fait une terre d'exil pour les décabristes. Pourtant, Tynianov compare le Caucase au Nouveau Monde, et Griboïedov s'y rend avec l'espoir de trouver un lieu où il est peut-être encore possible de réaliser quelque chose. Ces espoirs et ces pensées deviendront le Projet d'établissement d'une compagnie russe du Caucase, qu'il considérera comme l'œuvre de sa vie. Et c'est là que l'incroyable se révèle. Comme le montre Tynianov, le projet de Griboïedov, tout comme les projets des décabristes, n’offre finalement rien de nouveau, rien de meilleur. Ils ne proposent tous qu'une nouvelle forme d'asservissement.

On observe un processus similaire dans l'expérience de la Révolution française et de la dictature jacobine, et le Griboïedov de Tynianov en est conscient. En même temps, en considérant le 
"Projet d'établissement d'une compagnie russe du Caucase " de Griboïedov, Tynianov ne peut s'empêcher de penser à la révolution de 1917. Son Griboïedov a la vague intuition que la tyrannie, le despotisme, l'autocratie et l'oppression conserveront toujours leur pouvoir destructeur.

" C'est peut-être pour cette raison qu'il est vain de créer de la nouveauté dans l'espoir de faire mieux que ce qui existe déjà, et l'on pressent que la tyrannie, le despotisme, l'autocratie et l'oppression destructrice existeront toujours. " Cette conclusion fut énoncée par le biographe de Tynianov, le dissident Arkadi Belinkov, qui à son tour vit un écho à l'œuvre de Tynianov dans sa propre époque, les années $1950^{42}$. Pour ainsi dire, l'utopie caucasienne de Griboïedov déboucha sur une impasse comme l'utopie soviétique aux yeux de Tynianov cent ans plus tard, et comme la politique de « dégel » de Khrouchtchev encore trente ans plus tard.

Le " Projet d'établissement d'une compagnie russe du Caucase " de Griboïedov reste donc un test révélateur de la possibilité de construire un État parfait « dans un pays pris isolément ». Il s'inscrit en même temps dans une tradition d'utopie caucasienne prégnante dans la littérature russe.

Pour conclure, je citerai un extrait de La mort du Vazir-Moukhtar de Tynianov qui renferme l'idée d'un effondrement de l'utopie caucasienne. L'auteur décrit les membres d'une secte du Wurtemberg qui croient que la parousie est imminente et que Dieu est sur le point d'apparaître en Géorgie, en Turquie et en Perse. Ils se rendent donc en Russie et s'installent dans le Caucase. L'un d'eux rencontre Griboïedov:

Alexandre [Griboïedov] vit un homme étrange doté d'une moustache rousse à l'allemande.

- Exzellenz, commença l'Allemand, je suis un pauvre adepte d'une secte du Wurtemberg. On nous a envoyés ici et ma quarantaine s'achève aujourd'hui. Je sais que vous partez pour la Perse.

- En quoi puis-je vous aider? demanda doucement Griboïedov.

42. Arkadi Belinkov, Iurij Tynjanov, Moskva, 1961. 
- Nous croyons en la venue prochaine du Christ en Perse. Exzellenz, si vous entendez parler de lui, écrivez-moi. Mon nom est Meyer.

Alexandre regarda le pauvre homme à la moustache rousse et lui répondit en allemand d'un air grave:

- Donnez-moi votre adresse, M. Meyer, et si je rencontre den lieben Gott en Perse, je lui dirai de vous écrire. Mais connaissez-vous l'hébreu?

- Non, répondit l'Allemand dont la moustache se gonfla comme la voile d'un bateau.

- Eh bien, je serais fort étonné que der liebe Gott connaisse l'allemand, et je crains fort que vous ne parveniez pas à vous comprendre. ${ }^{43}$

Manifestement, ni Griboïedov avec son projet caucasien ni le nouvel État révolutionnaire avec son utopie communiste n'ont trouvé de langage adéquat pour communiquer avec dem lieben Gott.

(Traduit de l'anglais par Pauline Tardieu-Collinet)

43. Iurij Tynjanov, Smert' Vazir-Muhtara, op. cit., Leningrad, Priboj, 1929, p. 




\section{Table des matières}

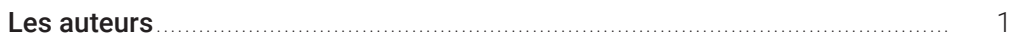

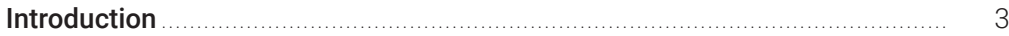

\section{PREMIÈRE PARTIE}

RENCONTRES ANCIENNES

1. Transferts culturels entre le Caucase, le Proche-Orient ancien et les steppes eurasiennes

Du Néolithique au début de l'âge du bronze

$\left(\mathrm{VI}^{\mathrm{e}}\right.$ au III ${ }^{\mathrm{e}}$ millénaire avant notre ère) - Bertille Lyonnet

Le Néolithique.

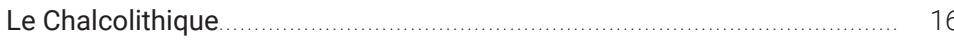

L'âge du bronze ancien .......................................................... 20

2. Galatée au pays des Amazones

Le plat d'argent doré de Yenikend (Azerbaïdjan) et les transferts entre le monde gréco-romain et le Caucase - Anca Dan

Un objet d'exception là où on ne l'attendait pas ................................... 27

Charme et mystères de la mer, des Antonins aux Sévères ........................ 38

De la mer Intérieure aux flancs du Caucase: jeux et enjeux des

contacts entre Autres ................................................................... 88

Les transferts de lieux communs ou comment le mythe fait l'histoire ....... 105

3. L'Albanie du Caucase

Une zone de contact entre une population sédentaire organisée en

États et un peuple nomade d'Eurasie ( $V^{e}$-VII ${ }^{e}$ siècle de notre ère) -

Farda Asadov

Histoire des conflits entre nomades et sédentaires ........................... 109

De longs murs

Les intérêts des États du Caucase du Sud .......................................... 113

L'Albanie caucasienne, une zone d'interaction et de commerce avec

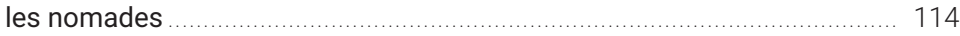

4. La monnaie dans le sud du Caucase ............................................... 119

Georges Depeyrot

Go East!

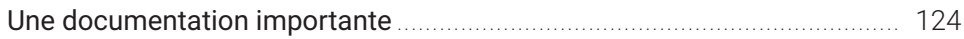




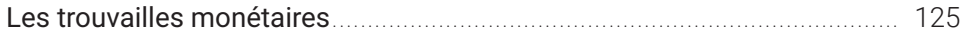

Un atelier temporaire romain en Transcaucasie? ................................ 129

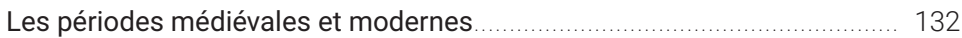

Trésors en Arménie

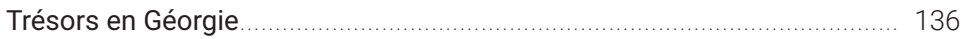

5. Les grands traits de la suprématie mongole en Azerbaïdjan et en

Transcaucasie

Shahin Mustafayev

\section{DEUXIÈME PARTIE}

CROISEMENT DES LANGUES ET NATIONS DU CAUCASE

6. Classification génétique et aréale des langues en Anatolie

et dans le Caucase

Daniel Petit

7. De Julius Klaproth à Friedrich Bodenstedt

Des savants allemands des XVIII ${ }^{\mathrm{e}}$-XIX ${ }^{\mathrm{e}}$ siècles découvrent le Caucase -

Michel Espagne

Les explorateurs allemands du Caucase ........................................ 202

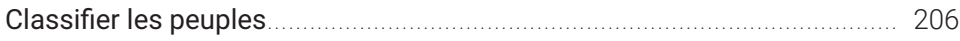

Les références antiques ................................................................. 211

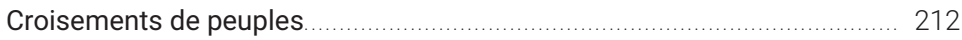

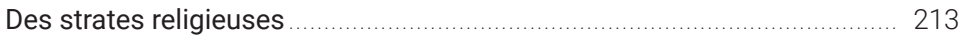

Traduire le Caucase ................................................................. 217

L'orientalisme et le Caucase............................................................ 219

8. L'histoire singulière de la communauté grecque pontique .................. 223

L'hellénisme russe, du Pont au Caucase -Servanne Jollivet

De l'origine pontique au Caucase

Du Caucase à la Sibérie: un peuple en exil permanent .......................... 233

Le « retour » en Grèce de la communauté pontique............................ 237

9. Les cultures du nord du Caucase et leurs mutations au tournant du $\mathrm{xx}^{\mathrm{e}}$ siècle

Le cas du peuple ingouche - Boris Kharsiev

10. L'imam Chamil, un Caucasien héroïque vu du Daghestan.

Haji Murad Donogo

11. Structure et dynamique sociale de la culture tchétchène Said Mushajiyev

\section{TROISIÈME PARTIE}

\section{MOSAIIQUE DES MÉTROPOLES ET DES PAYSAGES}

12. Les premières photographies comme transfert culturel en Russie impériale

Technique visuelle, mobilité et modernité dans le Caucase et en Asie centrale - Svetlana Gorshenina, Heather S. Sonntag

Transferts photographiques vers et de la Russie dans les années 1840 
Les transferts européens et la première institution photographique impériale russe

Les photographes et les studios du VTO aux marges asiatiques de l'empire

Deux albums photographiques du VTO dans un contexte de tension.

Transferts photographiques chez les populations asiatiques locales

13. La Géorgie entre la France, la Russie et la Perse, vue par les diplomates français Irina Natchkebia

Les renseignements des diplomates français sur la Géorgie

La Géorgie dans la presse française.

La question de la Géorgie dans le projet de traité et dans le traité franco-persan

La question géorgienne dans les négociations diplomatiques du général Gardane (1807-1809)

La Notice sur la Géorgie du lieutenant Trézel ................................... 315

Les lettres des princes royaux géorgiens à Napoléon .............................. 320

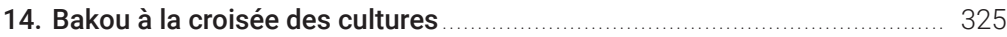

$X I X^{e}$ et début du $X X^{e}$ siècle - Irada Baghirova

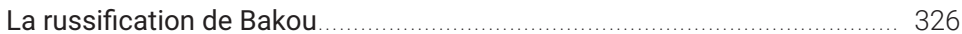

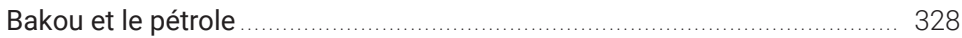

La croissance d'une ville cosmopolite .............................................. 331

Architectures de Bakou - La contribution polonaise .............................. 333

Une révolution culturelle

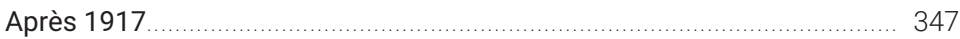

15. Tbilissi, centre d'échanges interculturels

Du $X I X^{e}$ siècle au début du $x x^{e}$ siècle -Nino Chikovani

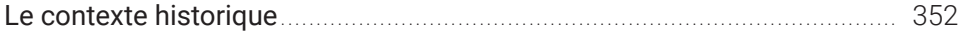

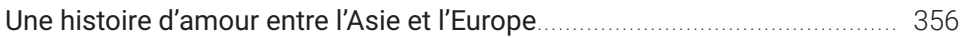

Les Caucasiens à Tbilissi ................................................................. 363

\section{QUATRIÈME PARTIE}

\section{ÉCHOS LITTÉRAIRES}

16. Les écrits de Friedrich Bodenstedt sur le Caucase

Un regard sur la diversité ethnique et culturelle de la région - Hamlet Isaxanli

Friedrich Martin von Bodenstedt, une vie ........................................ 381

Écrits de Bodenstedt sur le Caucase et les Caucasiens ........................... 382

Bodenstedt à propos de la diversité ethnique et culturelle du Caucase...... 389

17. L'héritage de Nezâmi de Gandja, principe unificateur de la littérature orientale

Rafael Huseynov

18. Le monde de la poésie de Chota Rousavéli.

Changements de paradigme dans un contexte multiculturel -

Nino Pirtshkalava 
La montagne des langues et des peuples

19. Lev Nussimbaum et Banine, de Bakou à la Corne d'or Sophie Basch

20. L'utopie caucasienne dans la littérature et la politique russes:

Alexandre Griboïedov et louri Tynianov -Ekaterina Dmitrieva

Itinéraire d'une vie

Projet d'établissement d'une compagnie russe du Caucase: histoire

d'un quiproquo.

Le «Projet d'établissement d'une compagnie russe du Caucase »:

entre philanthropie, calcul économique et ambition.

L'utopie caucasienne

Une erreur historique qui s'avéra fatale pour la littérature russe 



\section{Déjà parus aux éditions DEMOPOLIS}

$\begin{array}{ll}\text { Brossat, Alain } & \text { Durpaire, François - } \\ \text { Abécédaire Foucault } & \text { Richomme, Olivier } \\ \text { Boltanski, Luc } & \text { L'Amérique de Barack Obama } \\ \text { Rendre la réalité inacceptable } & \text { Obama face à la crise } \\ \text { Borvo Cohen-Seat, Nicole et Cohen- } & \text { Garo, Isabelle } \\ \text { Seat, Patrice } & \text { Foucault, Deleuze, Althusser et Marx } \\ \text { Réinventer la gauche } & \text { Gaulard, Mylène } \\ \text { Bourdieu, Pierre - Boltanski, Luc } & \text { Karl Max à Pékin - Les racines de la } \\ \text { La Production de l'idéologie } & \text { crise en Chine capitaliste } \\ \text { dominante } & \text { Guérin, Isabelle } \\ \text { Césaire, Aimé - Malcolm X } & \text { La microfinance et ses dérives } \\ \text { Black révolution } & \text { Hobsbawm, Éric } \\ \text { Clover, Charles } & \text { Marx et l'histoire } \\ \text { Surpêche } & \text { Hroub, Khaled } \\ \text { Cohen-Seat, Patrice } & \text { Le Hamas } \\ \text { Peuple! Les luttes de classes au } & \text { Jaurès, Jean } \\ \text { xxl siècle } & \text { Le socialisme et la Révolution } \\ \text { Chuzeville, Julien } & \text { française } \\ \text { Zimmerwald. L'internationalisme } & \text { Jennar, Raoul Marc } \\ \text { contre la première guerre mondiale } & \text { Khieu Samphan \& les Khmers rouges } \\ \text { Da Lage, Olivier (sous la dir. de) } & \text { Kautsky, Karl } \\ \text { Qatar: les nouveaux maîtres du jeu } & \text { Les luttes de classe pendant la } \\ \text { Denord, François } & \text { Révolution française } \\ \text { Néo-libéralisme, version française } & \text { Khaldi, Eddy } \\ \text { Dhume-Sonzogni, Fabrice } & \text { Abc de la laïcité } \\ \text { Communautarisme. Enquête sur une } & \text { Abc de la lä̈cité pour les jeunes } \\ \text { chimère du nationalisme français } & \text { Khaldy, Eddy - Fitoussi, Muriel } \\ \text { Duclert, Vincent } & \text { Main basse sur l'École publique } \\ \text { Occupy Gezi } & \text { La République contre son école } \\ & \text { Kalfon, Pierre } \\ & \text { Chroniques chiliennes } \\ & \\ & \end{array}$


Kamata, Satoshi,

Toyota: l'usine du désespoir

Labat, Séverine

Les islamistes tunisiens - entre l'état

et la mosquée

Landriève, Sylvie

L'immobilier. Une passion française

Latour, Bruno - Lippman, Walter

Le public fantôme

Lénine

Petit manuel pour rompre avec le

capitalisme

1914, repenser le nationalisme et la guerre

Mamdani, Mahmood

La CIA et la fabrique du terrorisme

islamique

Marx, Karl

Qu'est-ce que le capitalisme?

Les Crises du capitalisme

Le Capital financier

Mendès-France, Pierre

Liberté, liberté chérie

Mordillat, Gérard -

Prieur, Jérôme

De la crucifixion considérée

comme un accident du travail

Mussolini

Gérard Mordillat présente le fascisme de Mussolini
Nsar, Vali

Le renouveau chiite

Pivert, Marceau

L'Église et l'École

Prochasson, Christophe

L'Empire des émotions:

les historiens dans la mêlée

Rebérioux, Madeleine

Vive la République

Rodinson, Maxime

Islam et capitalisme

Sassen, Saskia

Critique de l'État

Saurin, Patrick

Les prêts toxiques: une affaire d'État

Shah, Sonia

Cobayes humains: le grand secret

des essais pharmaceutiques

Tanuro, Daniel

Le moment Trump - Une nouvelle

phase du capitalisme mondial

Uchitelle, Louis

Le salarié jetable

Wallerstein, Immanuel

L'Universalisme européen:

de la colonisation au droit d'ingérence

Wilkinson, Richard

L'égalité, c'est la santé 


\section{Collection « QUAERO »}

Cassin, Barbara et Wosny, Danièle (dir.)

Les intraduisibles du patrimoine en Afrique subsaharienne

Dawod, Hosham (dir.)

La constante "Tribu », variations arabo-musulmanes

Ehrenfreund, Christian et Schreiber, Jean-Philippe (dir.)

Les marranismes. De la religiosité cachée à la société ouverte

Espagne, Michel et Maufroy, Sandrine (dir.)

L'hellénisme de Wilhelm von Humboldt et ses prolongements Européens

Espagne, Michel et Jin Guangyao (dir.) avec la collaboration de Julie Gary

Conférences chinoises de la rue d'Ulm

Ethis, Emmanuel

Le cinéma près de la vie

Fernandez Garcia, Alicia et

Petithomme, Mathieu (dir.)

Contester en Espagne

Fontaine, Alexandre

Aux heures suisses de l'école

républicaine

Ghasarian, Christian

Rapa. Île du bout du monde, île dans le monde
Ghosn, Katia (dir.)

Rachid El-Daiif. Le roman arabe dans la tourmente de la modernisation

Gorog, Françoise et Cassin, Barbara (dir.)

Psychanalyser en langues.

Intraduisibles et langue chinoise

Lessing, Gotthold Ephraim

Adam Neuser (1774)

Marquis, Émeline et Billault, Alain (dir.)

Mixis. Le mélange des genres chez Lucien de Samosate

Mattina, Cesare; Monier, Frédéric, Dard, Olivier et Engels, Jens Ivo (dir.), Dénoncer la corruption. Chevaliers blancs, pamphlétaires et promoteurs de la transparence à l'époque contemporaine

Nguyen, Aubert, Hoai Hong et Espagne, Michel Le Vietnam, une histoire de transferts culturels

Niveleau, Charles-Édouard (dir.) Vers une philosophie scientifique. Le programme de Brentano

Oléron Evans, Émilie Nikolaus Pevsner. Arpenteur des arts Olivier, Laurent (dir.) La Mémoire et le Temps. L'œuvre transdisciplinaire d'Henri Hubert 
Rabault-Feuerhahn,

Pascale (dir.)

Théories intercontinentales.

Voyages du comparatisme

postcolonial

Richter, Jean-Paul

Vie de Maria Wutz, le joyeux

petit maître d'école d'Auenthal.

Une manière d'idylle

\section{Collection Philosophie en cours}

Cavaillé, Christian

Les jeux de langage chez

Wittgenstein

Chauve, Alain

Le Tractacus: logique et

métaphysique

Kail, Michel

Jean-Paul Sartre. Conscience et

subjectivité

\section{Collection Bande Dessinée}

En coédition avec Les Arènes

Durpaire, François \& Boudjellal, Farid La Présidente Tome 1

Totalitaire Tome 2

La Vague Tome 3
Salamagne, Michèle-H. et Thominet, Patrick (dir.), Accompagner. Trente ans de soins palliatifs en France

Xiao, Yingying Une subjectivité fluide. Modernité et perception esthétique à travers les ouvrages de Gao Xingjian

Sfez, Gérald

Machiavel et la vérité politique

Tomès, Arnaud

Castoriadis. L'imaginaire, le rationnel et le réel 
Achevé d'imprimer en France en 2019 dans les ateliers de Dupli-print à Domont (95) $\mathrm{N}^{\circ}$ d'impression: 2019020382 Dépôt légal: février 2019 
